\title{
Complex Hydride Compounds with Enhanced Hydrogen Storage Capacity
}

\section{Final Report}

Daniel A. Mosher, Susanne M. Opalka, Xia Tang, Bruce L. Laube, Ronald J. Brown, Thomas H.

Vanderspurt, Sarah Arsenault

United Technologies Research Center

Robert Wu, Jamie Strickler

Albemarle Corporation

Donald L. Anton, Ragaiy Zidan, Polly Berseth

Savannah River National Laboratory

February 14, 2008

Prepared for

Department of Energy

Office of Energy Efficiency and Renewable Energy

Hydrogen Program, Hydrogen Storage

Under Contract DE-FC36-04GO14012

Sunita Satyapal, DOE Hydrogen Program Team Leader

Carole Read, DOE Headquarters Technology Manager

Jesse Adams, DOE Field Project Officer 


\section{Table of Contents}

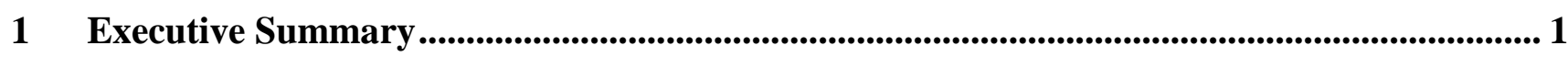

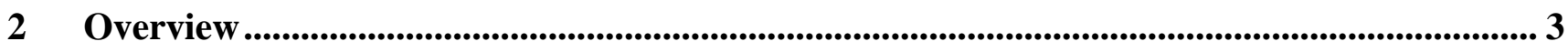

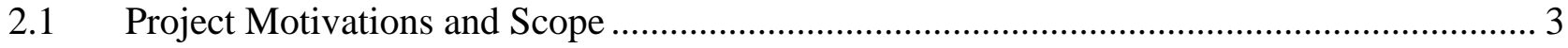

$2.2 \quad$ Statement of Project Objectives.................................................................................... 5

$3 \quad$ First Principles and Thermodynamic Modeling ............................................................................... 8

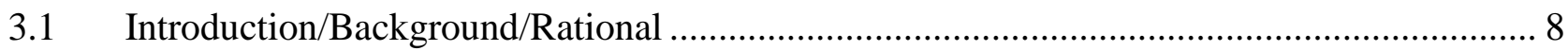

3.1.1 Quaternary Systems Encompassing Known Alanate Phases....................................... 8

3.1.2 Coupled High Hydrogen Reactions with Complex Hydrides ..................................... 10

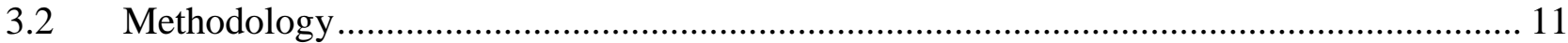

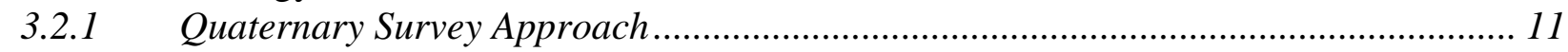

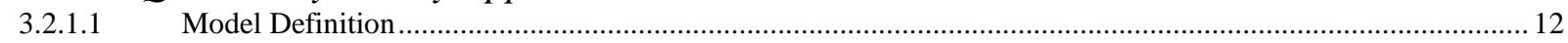

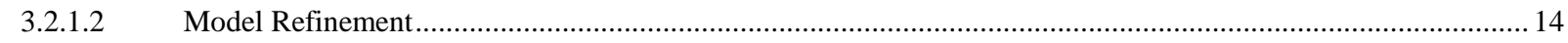

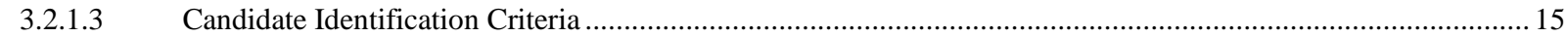

3.2.1.4 Finite Temperature Thermodynamic Property Predictions..................................................................... 15

3.2.1.5 Thermodynamic Data Assessment and Stability Predictions ......................................................................... 16

3.2.2 Refinements for High H Coupled Complex Hydride Reaction Strategy....................... 17

3.2.2.1 Improved Model Structures: Monte Carlo Simulated Annealing Methodology .............................................. 18

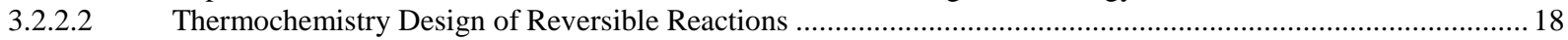

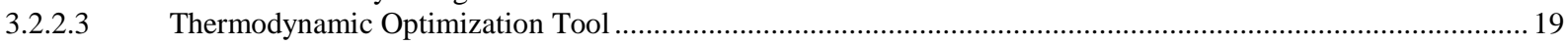

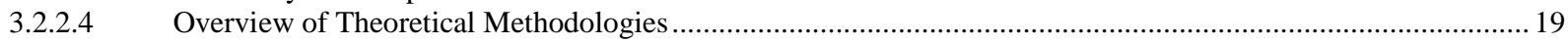

3.3 Results and Discussion ............................................................................................. 20

3.3.1 Funding Year 1 Atomic-Thermodynamic Modeling …….......................................... 20

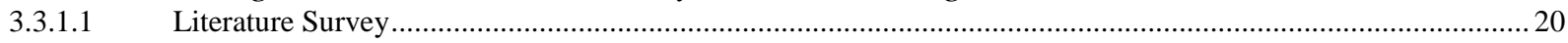

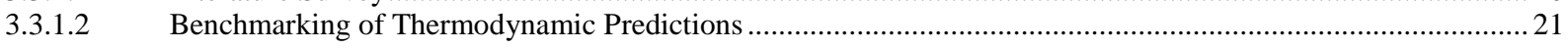

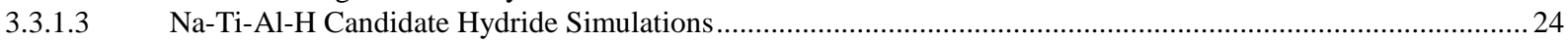

3.3.1.4 Li-Ti-Al-H and Na-Li-Al-H Candidate Hydride Simulations ................................................................. 27

3.3.1.5 Assessment of Na-Ti-Al-H, Li-Ti-Al-H and Na-Li-Al-H Candidate Hydrides ..........................................28

3.3.1.6 Thermodynamic Optimization of the Na-Li-Al-H quaternary ....................................................................29

3.3.2 Funding Year 2 Atomic-Thermodynamic Modeling ……………................................ 31

3.3.2.1 Na-Mg-Al-H and Li-Mg-Al-H Candidate Hydride Simulations ................................................................ 31

3.3.2.2 Thermodynamic Optimization of the Li-Mg-Al-H and Na-Mg-Al-H Quaternaries ...................................... 32

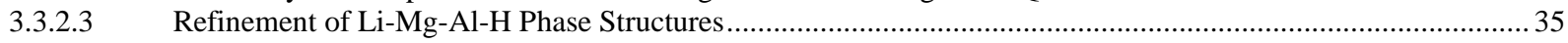

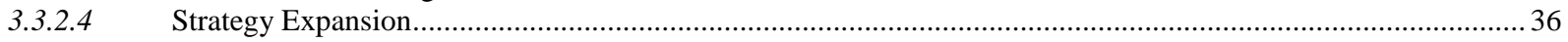

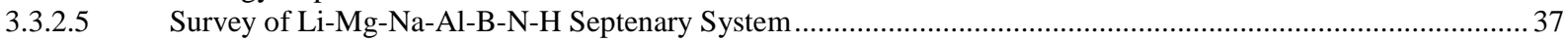

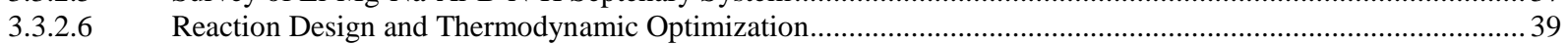

3.3.3 Funding Year 3 Atomic-Thermodynamic Modeling ...............................................41

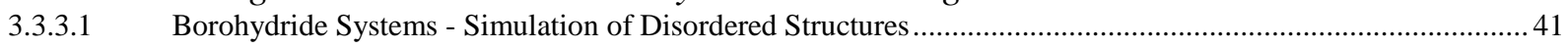

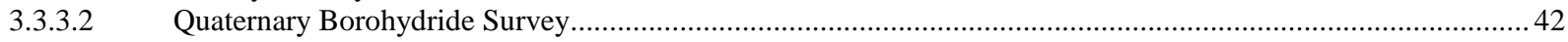

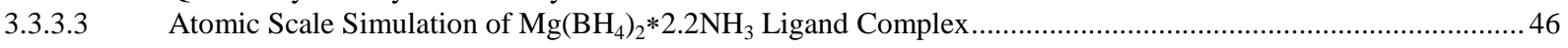

4 Solid State Processing........................................................................................................... 49

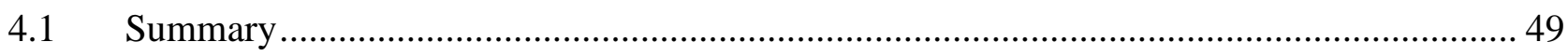

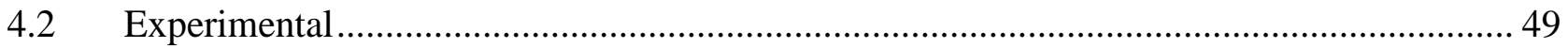

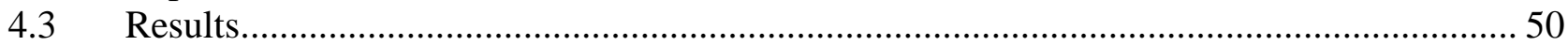

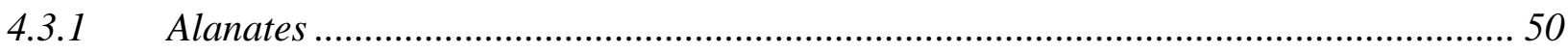

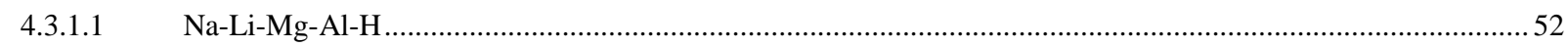

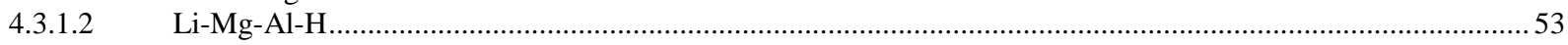

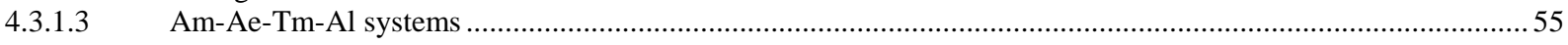

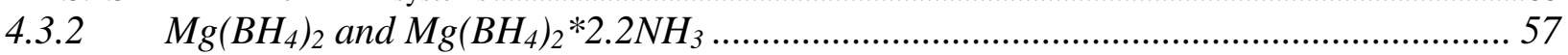

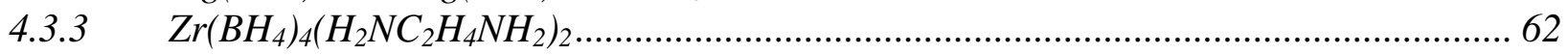

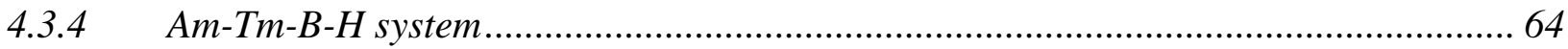




\section{Table of Contents}

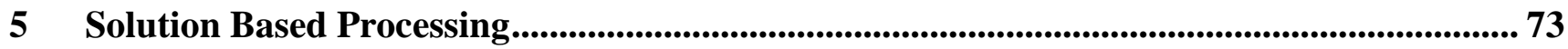

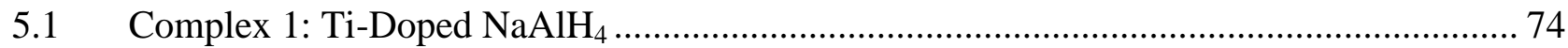

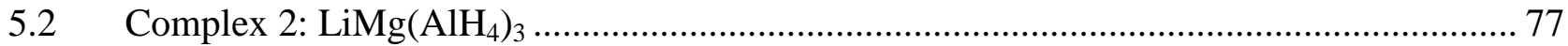

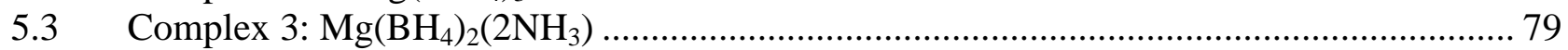

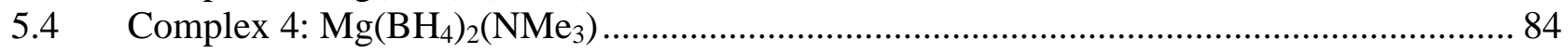

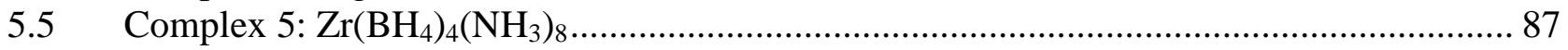

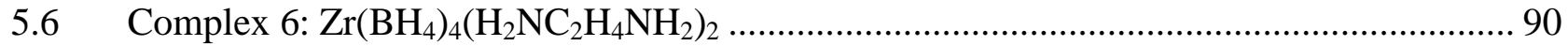

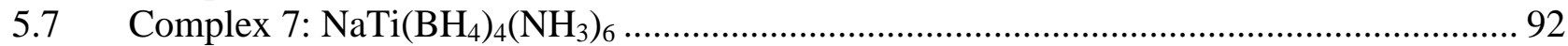

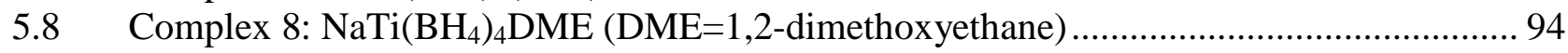

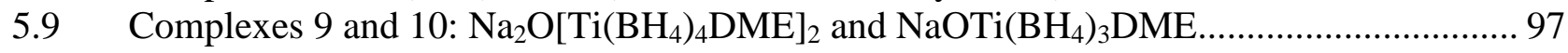

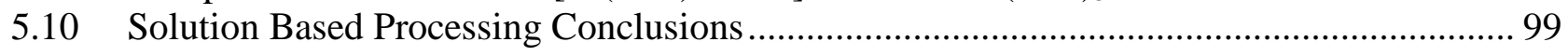

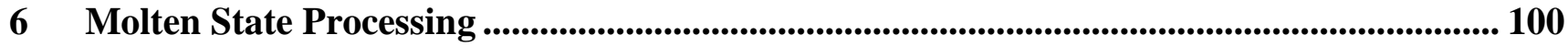

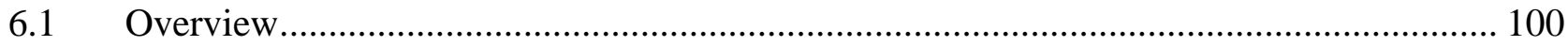

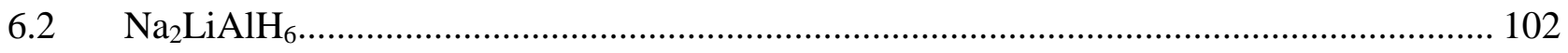

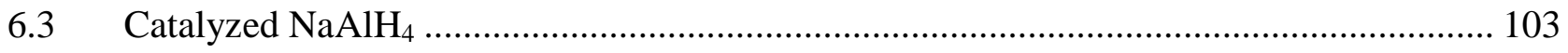

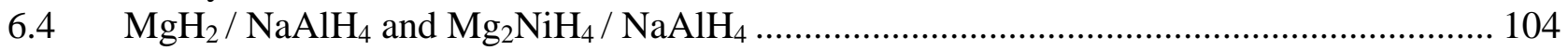

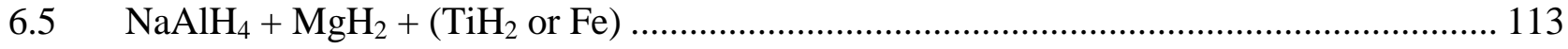

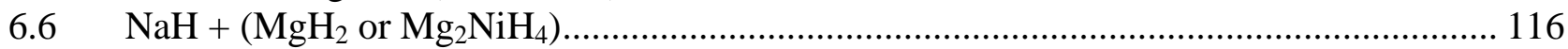

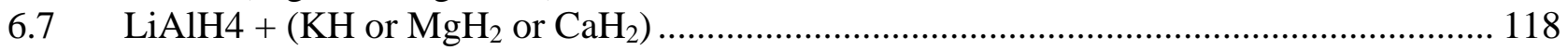

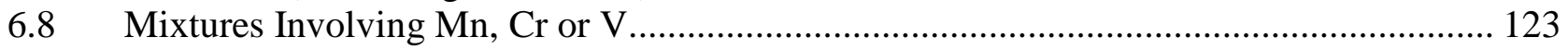

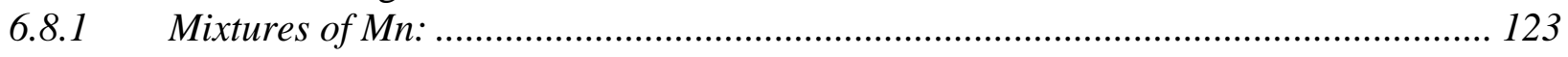

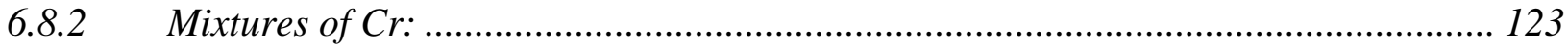

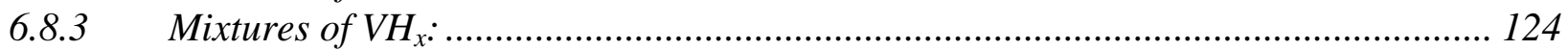

6.9 Mixed Metal Borohydrides - MSP ....................................................................... 128

6.10 Mixed Metal Borohydrides - Solvent Mixing ......................................................... 130

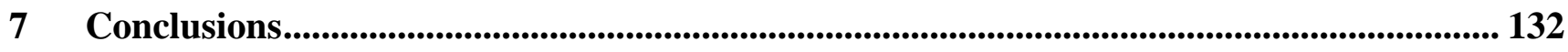

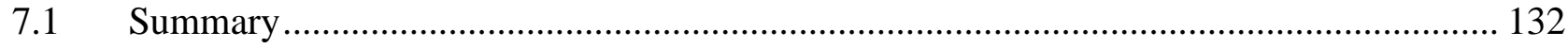

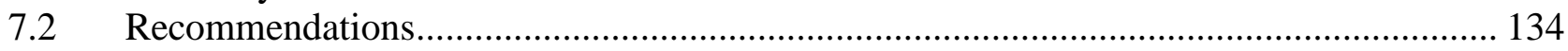

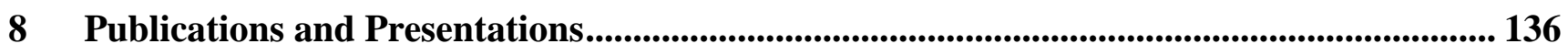

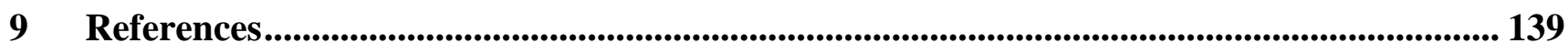

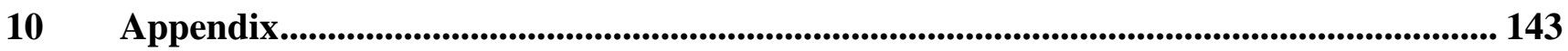

10.1 Semi-Quantitative XRD Analysis of Alanate Phases ............................................... 143 


\section{List of Tables}

Table 1: Summary of synthesized material / system performance. .............................................. 2

Table 2: DOE technical targets for on-board hydrogen storage systems. ...................................... 4

Table 3: Summary of composition systems and methods of modeling / synthesis. $\mathrm{Tm}=$ transition metal; FPM = First Principles Modeling; SSP = Solid State Processing; SBP = Solution Based Processing and MSP = Molten State Processing. ....................................................... 5

Table 4: Solid-state hydride classes and characteristics from literature review

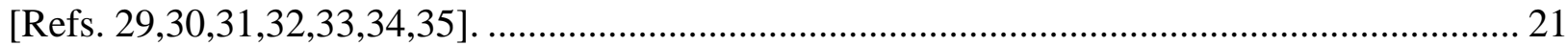

Table 5: Ground-state predictions of ternary borohydride compounds........................................ 43

Table 6: Simulated heats of formation and atomic volumes for quaternary alkali metal borohydride

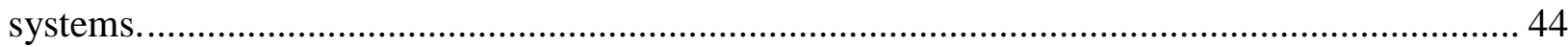

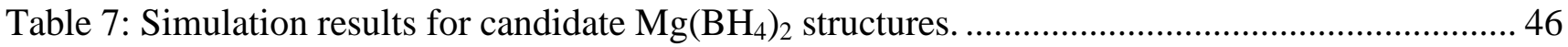

Table 8. Simulation results for proposed $\mathrm{Mg}\left(\mathrm{BH}_{4}\right)_{2} * 2 \mathrm{NH}_{3}$ complex structures............................. 47

Table 9: Predicted electronic reaction enthalpies, $\Delta \mathrm{H}_{\text {dehydrogentaion, for various decomposition }}$

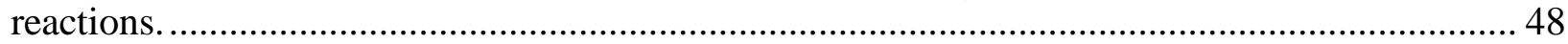

Table 10: Compositions of mixed alanates prepared by SSP ................................................ 51

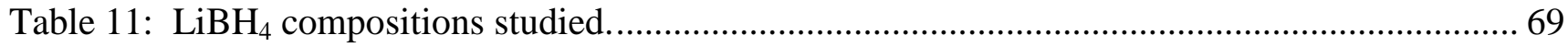

Table 12: Summary of complexes studied and their properties. ............................................... 73

Table 13: Gas evolution results of the reactions between $\mathrm{TiCl}_{3} \mathrm{THF}_{3}$ and $\mathrm{NaAlH}_{4}$ at varying $\mathrm{Ti}: \mathrm{Al}$

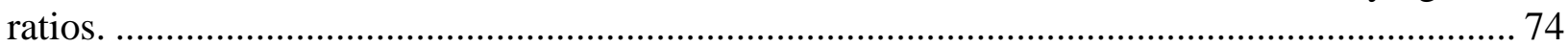

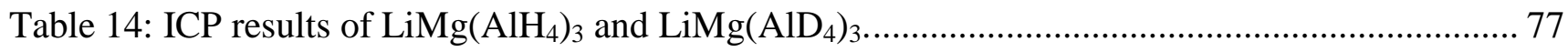

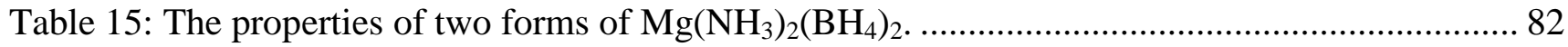

Table 16: Group 4 transition metal complexes of tetrahydroborate............................................ 87

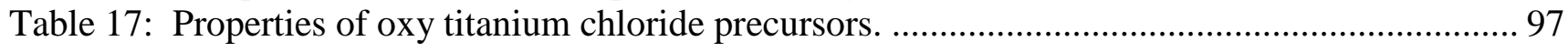

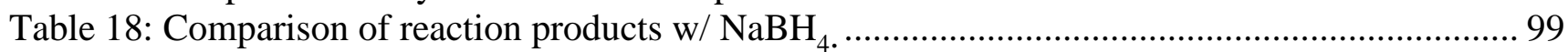

Table 19: Overview composition matrix for majority of MSP............................................... 101

Table 20: Summary of $\mathrm{MgH}_{2} / \mathrm{NaAlH}_{4}$ compositions. $\mathrm{HM}=$ Hand Mixed; $\mathrm{HS}=$ Hand Shaken; $\mathrm{BM}=$

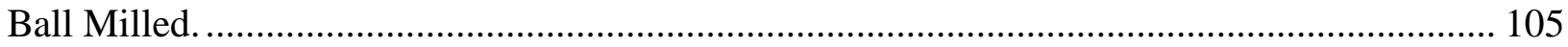

Table 21: Summary of $\mathrm{Mg}_{2} \mathrm{NiH}_{4} / \mathrm{NaAlH}_{4}$ experiments......................................................... 105

Table 22: High level conclusions for $\mathrm{Na}$ and $\mathrm{Li}$ alanate mixtures (BM = Ball Milled; MSP = Molten

State Processed; SM = Starting Materials) ................................................................ 126

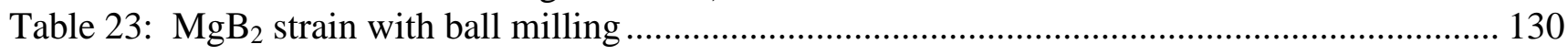




\section{List of Figures}

Figure 1: Overview of project effort material systems, modeling and synthesis. ............................ 4

Figure 2: Aerial view of Na-Ti-Al-H quaternary pyramid. ........................................................ 9

Figure 3: Aerial view of Li-Mg-Al-H quaternary pyramid. .................................................. 10

Figure 4: Shematic illustrating parallel search strategy of high $\mathrm{H}$ coupled reactions with high $\mathrm{H}$

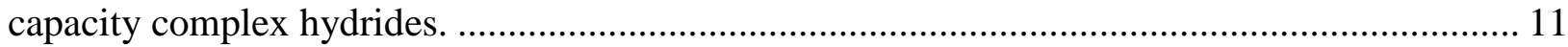

Figure 5: Schematic of model definition within the Na-Ti-Al-H quaternary system........................ 14

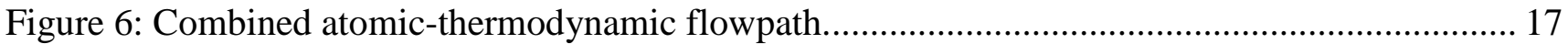

Figure 7: New combined crystallographic analyses and atomic modeling approach to accelerate refinement of crystal structures. ............................................................................. 18

Figure 8: Array of computational methodologies for virtual discovery and design of high hydrogen

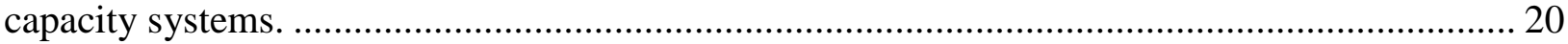

Figure 9: The comparison of $\operatorname{GHSER}_{\mathrm{NaAlH}_{4}}(\mathrm{~T})$ predicted with Phonon direct method lattice dynamics [Refs. 18,19] of the ground-state VASP minimized $\mathrm{NaAlH}_{4} \mathrm{I}_{1} / a$ phase, compared with that calculated with Thermo-Calc using assessed fits from [Ref. 5] to experimental measurements published in references [Refs. $2,36,37,38]$. ............................................................. 23

Figure 10: The comparison of predicted and measured dissociation pressures for the first $\mathrm{NaAlH}_{4}$ disproportionation reaction, $\mathrm{NaAlH}_{4}=1 /{ }_{3} \mathrm{Na}_{3} \mathrm{AlH}_{6}+{ }^{2} /{ }_{3} \mathrm{Al}+\mathrm{H}_{2}$. The dissociation pressure predictions are described in the text. The measured values are a composite fit from [Ref. 5] to the experimental data in references [Refs. 2,36,37,38]. The disproportionation enthalpies, $\Delta \mathrm{H}_{\mathrm{dis}}$, are

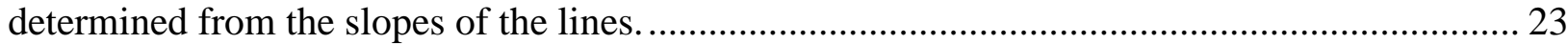

Figure 11: Ground state enthalpies of formation, $\Delta \mathrm{H}_{\text {formation }}$ gs electronic, for candidate binary $\mathrm{Ti}-\mathrm{Al}$ intermetallic structures............................................................................................ 24

Figure 12. Ground state enthalpies of formation, $\Delta \mathrm{H}_{\text {formation }}$ gs electronic, for candidate Ti-Al hydrides formed by $\mathrm{H}$ interstitial substitution in known and hypothetical Ti-Al intermetallic phases....... 25

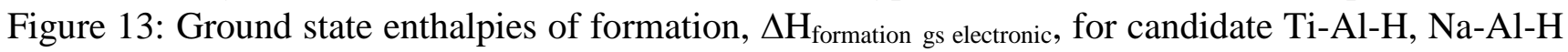

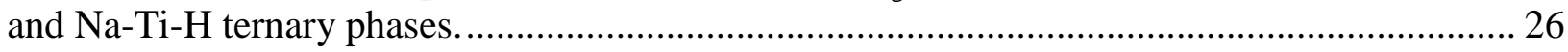

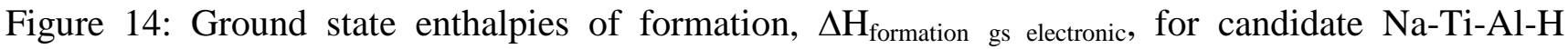

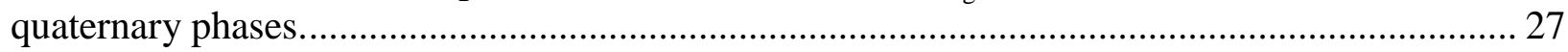

Figure 15: Ground state enthalpies of formation, $\Delta \mathrm{H}_{\text {formation }}$ gs electronic, for candidate Li-Ti-Al-H

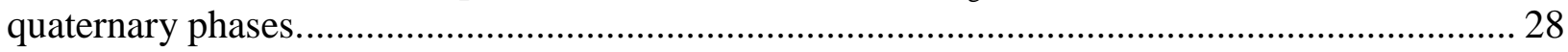

Figure 16: Na-Ti-Al-H quaternary Ti-Al isopleth comparing GHSER (298 K, 1 bar) values for newly predicted Na-Ti-Al-H complex hydride candidates with the Gibbs energy minimized phases determined with the Thermo-Calc Poly program with the combined SSUB3 [Ref. 21] and Na-Al$\mathrm{H}$ [Ref. 5] databases for the composition range in mole \%: $0.22 \mathrm{Na}, 0.66 \mathrm{H}$, with $0.12(\mathrm{Ti}+\mathrm{Al})$ and $\mathrm{Al}=0.12-\mathrm{x}(\mathrm{Ti})$.

Figure 17: The predicted van't Hoff plot showing the relationship two competing $\mathrm{Na}_{2} \mathrm{LiAlH}_{6}$

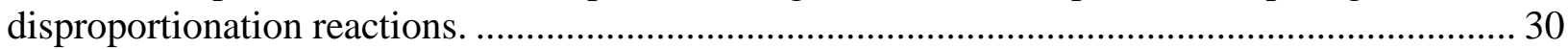

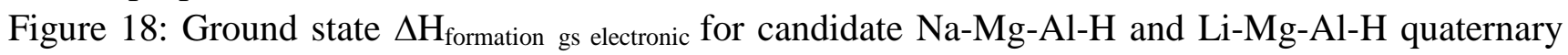
phases for the lower limit wt $\% \mathrm{H}_{\mathrm{Rev}}$ Theor. Many symbols actually consist of multiple superimposed data points for candidate phases having nearly identical enthalpies. The stoichiometries of the most favorable phases are labeled.................................................. 31

Figure 19: Ternary isopleth for Li-Mg-Al-H quaternary system at constant $3 \times 10^{-3} \mathrm{H}$ activity, $-23^{\circ} \mathrm{C}$ temperature and 100 bar pressure showing distribution of phases with varying composition..... 33

Figure 20: The mole-fraction of disproportionation phases with increasing $\mathrm{H}$ mole-fraction at $25^{\circ} \mathrm{C}$ and 100 bar with a constant stoichiometry $\{1 \mathrm{Li}: 1 \mathrm{Mg}: 1 \mathrm{Al}\}$ calculated with COST507 database [Ref. 48]...... 


\section{List of Figures}

Figure 21: $\mathrm{Na}-\mathrm{Mg}-\mathrm{Al}$ isothermal ternary section calculated at $298 \mathrm{~K}$ and 100 bar with $\mathrm{H}$ activity of

$3.9 \times 10^{-3}$ bar, showing distribution of phases with varying composition.................................. 34

Figure 22: Van't Hoff plot showing the dehydrogenation reactions predicted for the most stable

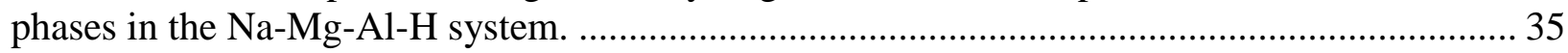

Figure 23: Schematic of high capacity septenary compositional system. .................................... 36

Figure 24: All possible permutations of multi-order systems up to and including quinaries with $\mathrm{H}$ in

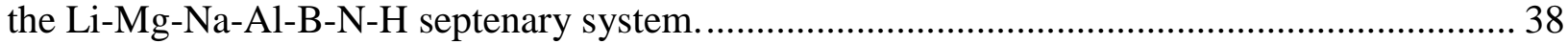

Figure 25: Benchmarking of atomic-thermodynamic predictions for the $\mathrm{Li}-\mathrm{N}-\mathrm{H}$ system. ................ 38

Figure 26: Example of thermodynamically designed and optimized reaction for $\mathrm{H}_{2}$ storage with

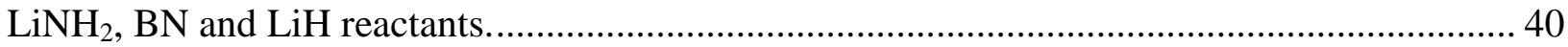

Figure 27. Schematic showing progression of modeling methodologies to design the reaction of $\mathrm{LiNH}_{2}$ with co-reactants to increase the dehydrogenation pressure closer towards 1 bar at $100^{\circ} \mathrm{C}$, including: 1) thermodynamic mapping of phase behavior for $\mathrm{Li}-\mathrm{N}-\mathrm{H}$ system and co-reactants, 2) thermochemical screening of reactions with co-reactants to search for reversible hydrogen exchange, 3) thermodynamic optimization of the best candidate compositional system, 4) prediction and evaluation of dissociation behavior.

Figure 28: Correlation plot between quaternary compound simulated $\Delta \mathrm{H}_{\text {formation gs electronic }}$ in Table 6 and the $\mathrm{M}$ substituent standard state redox potential for the most favorable M oxidation state. . 45

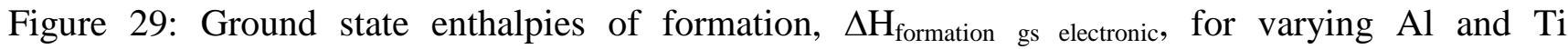

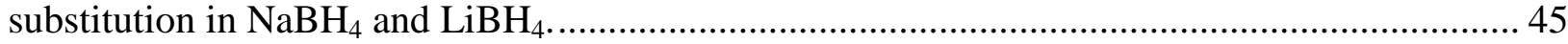

Figure 30: The $\mathrm{Mg}\left(\mathrm{BH}_{4}\right)_{2} * \mathrm{NH}_{3}$ complexes with varying $\mathrm{NH}_{3}$ in inner coordination sphere. ............ 47

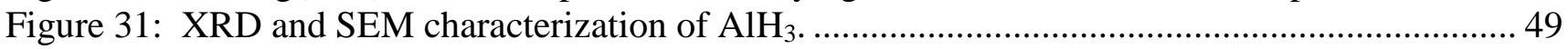

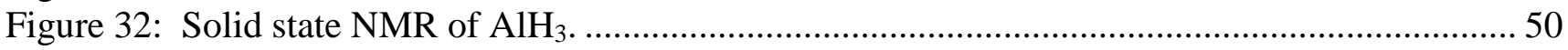

Figure 33: XRD of (a) SPEX milled for 3 hours, (b) $80^{\circ} \mathrm{C}$ and (c) $120^{\circ} \mathrm{C}$ hydriding at 195 bar

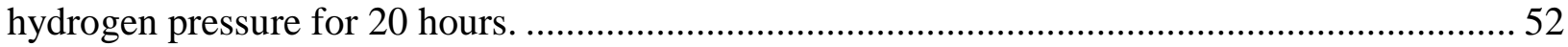

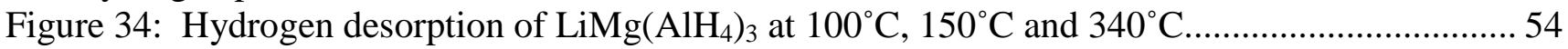

Figure 35: XRD of decomposition products of $\mathrm{LiMg}\left(\mathrm{AlH}_{4}\right)_{3}$ at $100^{\circ} \mathrm{C}, 150^{\circ} \mathrm{C}$ and $340^{\circ} \mathrm{C} \ldots \ldots \ldots \ldots . . . . .55$

Figure 36: Illustration of raw XRD data for $\mathrm{NaAlH}_{4}$ showing split peaks in the (103) and (004) peaks.

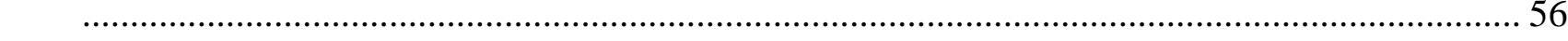

Figure 37: XRD of reaction products of $\mathrm{LiBH}_{4}$ and $\mathrm{MgH}_{2}$ at 2:1 mole ratio................................ 57

Figure 38: TGA-MS of $\mathrm{Mg}\left(\mathrm{BH}_{4}\right)_{2}$ from $\mathrm{LiBH}_{4}$ and $\mathrm{MgH}_{2}$ by SSP . ......................................... 57

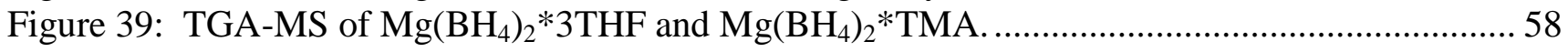

Figure 40: DSC and TGA-MS of $\mathrm{Mg}\left(\mathrm{BH}_{4}\right)_{2} * 2.2 \mathrm{NH}_{3}$ (Material A) .......................................... 58

Figure 41: DRIFT spectra of the as-synthesized $\mathrm{Mg}\left(\mathrm{BH}_{4}\right)_{2} * 2.2\left(\mathrm{NH}_{3}\right)$ (Material A) and the sample after heating at $160^{\circ} \mathrm{C}$ in vacuum for 24 hours............................................................. 59

Figure 42: TGA-MS of $\mathrm{Mg}\left(\mathrm{BH}_{4}\right)_{2} * 2.2\left(\mathrm{NH}_{3}\right)$ (Material A) after being heated at $160^{\circ} \mathrm{C}$ in vacuum for

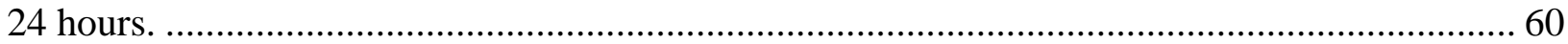

Figure 43: $\mathrm{DSC}$ analysis of $\mathrm{Mg}\left(\mathrm{BH}_{4}\right)_{2} * 2.2 \mathrm{NH}_{3}$ after heating at $160^{\circ} \mathrm{C}$ in vacuum for 24 hours...... 60

Figure 44: DSC and TGA-MS of $\mathrm{Mg}\left(\mathrm{BH}_{4}\right)_{2} * 2.2 \mathrm{NH}_{3}$ (Material A) with co-reactant. ...................... 61

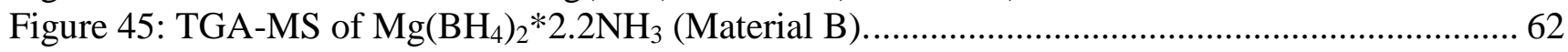

Figure 46: Hydrogen desorption of $\mathrm{Zr}\left(\mathrm{BH}_{4}\right)\left(\mathrm{H}_{2} \mathrm{NC}_{2} \mathrm{H}_{4} \mathrm{NH}_{2}\right)_{2}$ at $100^{\circ} \mathrm{C}$ and $150^{\circ} \mathrm{C} \ldots \ldots \ldots \ldots \ldots \ldots \ldots . . . \ldots . . . . . . . .62$

Figure 47: DRIFTS results for $\mathrm{Zr}\left(\mathrm{BH}_{4}\right)_{4}\left(\mathrm{H}_{2} \mathrm{NC}_{2} \mathrm{H}_{4} \mathrm{NH}_{2}\right)_{2}$ under various conditions....................... 63

Figure 48: XRD of the reaction products of $\mathrm{NaBH}_{4}$ and $\mathrm{TiCl}_{3}$ at a 4:1 mole ratio after 3 hours of

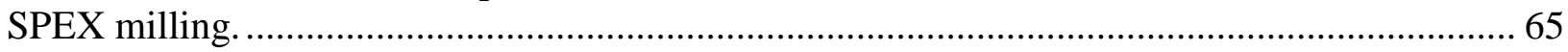

Figure 49: XRD analysis of Na-Tm-B-H materials without removal of the $\mathrm{NaCl}$ by-product. .......... 65

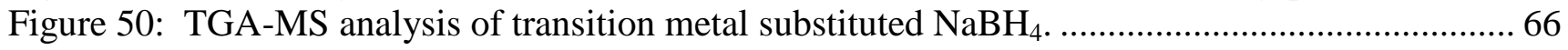




\section{List of Figures}

Figure 51: Hydrogen desorption for the Na-Tm-B-H system.

Figure 52: Hydrogen desorption of the Li-Tm-B-H system. The time to reach the peak test temperature of $400^{\circ} \mathrm{C}$ was $3.4 \mathrm{hr}$ for $\mathrm{LiBH}_{4}+\mathrm{ScCl}_{3} ; 4.5 \mathrm{hr}$ for $\mathrm{LiBH}_{4} ; 0.7 \mathrm{hr}$ for $\mathrm{LiBH}_{4}+\mathrm{TiCl}_{3} . .68$

Figure 53: TGA-MS of the reaction products of $8 \mathrm{NaBH}_{4}+\mathrm{TiCl}_{3} \mathrm{OTiCl}_{3} \cdot 2 \mathrm{DME}$. Yellow / bottom

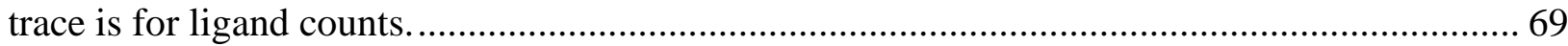

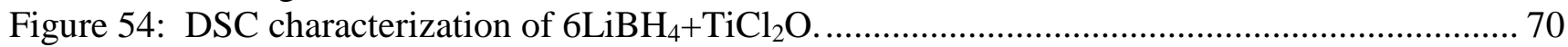

Figure 55: Sievert's apparatus / PCT desorption measurements for $6 \mathrm{LiBH}_{4}+\mathrm{TiCl}_{2} \mathrm{O} \ldots \ldots \ldots \ldots \ldots \ldots . . \ldots . \ldots$

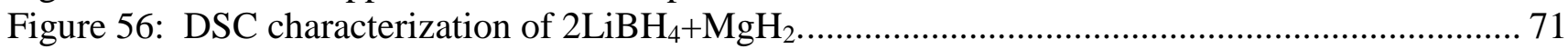

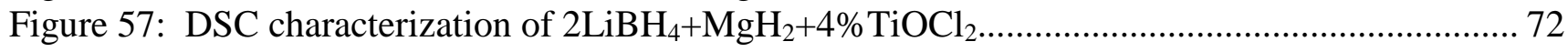

Figure 58: Sievert's apparatus / PCT desorption measurements for $2 \mathrm{LiBH}_{4}+\mathrm{MgH}_{2}+4 \% \mathrm{TiOCl}_{2} \ldots \ldots .72$

Figure 59: Hydrogen release for titanium doped $\mathrm{LiAlH}_{4}$ and $\mathrm{NaAlH}_{4}$...................................... 74

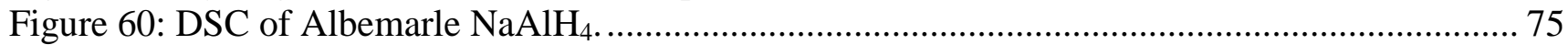

Figure 61: DSC of 4\% Ti-doped $\mathrm{NaAlH}_{4}$ via solution process................................................. 76

Figure 62: DSC of 4\% Ti-doped $\mathrm{NaAlH}_{4}$ via ball-milling...................................................... 76

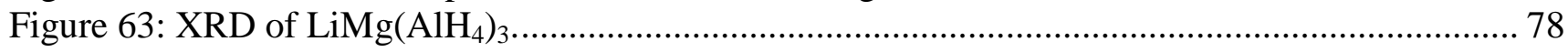

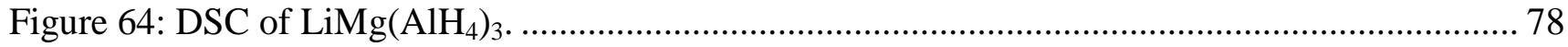

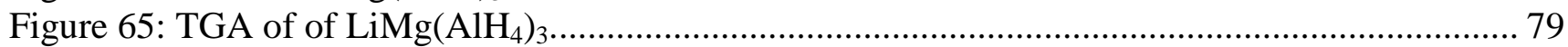

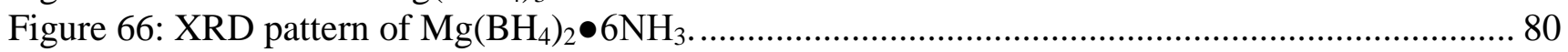

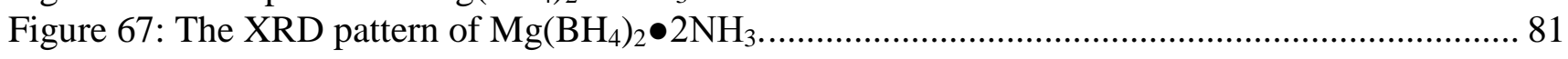

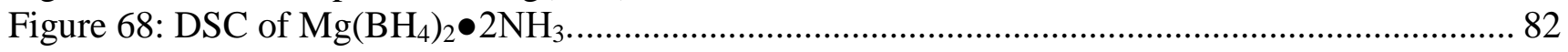

Figure 69: TGA-DTA of $\mathrm{Mg}\left(\mathrm{BH}_{4}\right)_{2} \cdot 2 \mathrm{NH}_{3}$ showing metal hydride characteristics......................... 83

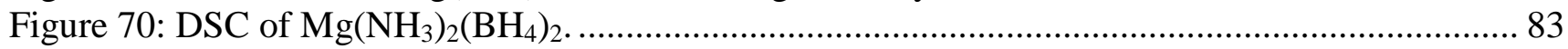

Figure 71: TGA-DSC of $\mathrm{Mg}\left(\mathrm{NH}_{3}\right)_{2}\left(\mathrm{BH}_{4}\right)_{2}$ showing $\mathrm{BH}_{3} \bullet \mathrm{NH}_{3}$-like characteristics. ....................... 84

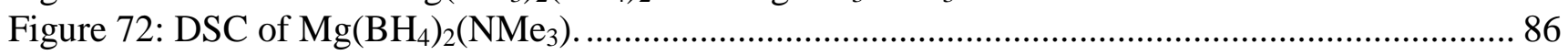

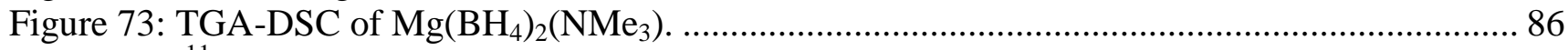

Figure 74: ${ }^{11} \mathrm{~B}$ Decoupled (red / upper) and coupled (blue / lower) spectra of $\mathrm{Zr}\left(\mathrm{BH}_{4}\right)_{4} \cdot 8 \mathrm{NH}_{3} \ldots \ldots . .88$

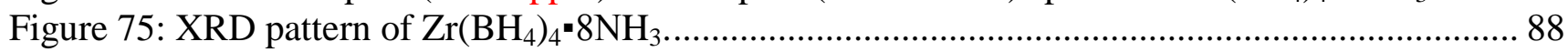

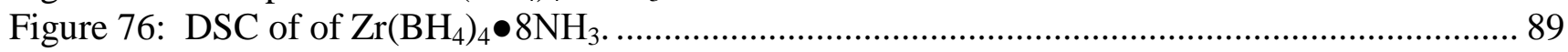

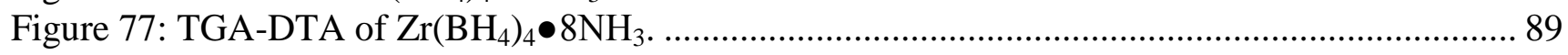

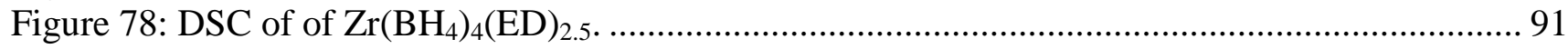

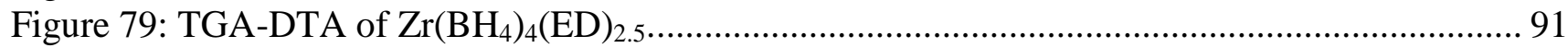

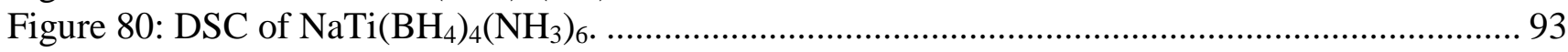

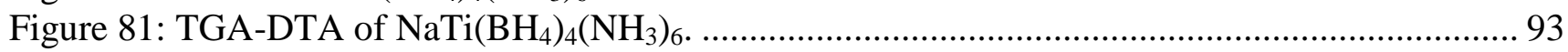

Figure 82: Overlay of DSC data for $\mathrm{Zr}\left(\mathrm{BH}_{4}\right)_{4}\left(\mathrm{NH}_{3}\right)_{8}$ (red / left peak) and $\mathrm{NaTi}\left(\mathrm{BH}_{4}\right)_{4}\left(\mathrm{NH}_{3}\right)_{6}($ blue /

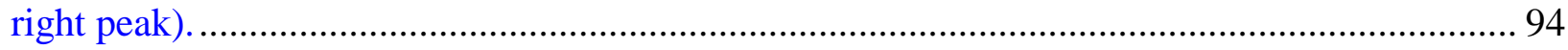

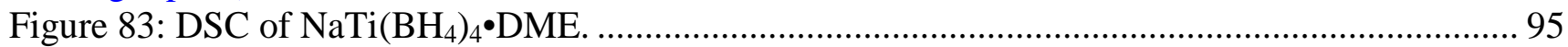

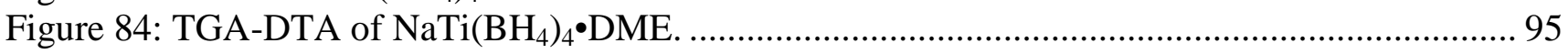

Figure 85: The overlay DRIFTS spectra of $\mathrm{NaTi}\left(\mathrm{BH}_{4}\right)_{4} \cdot \mathrm{DME}$ before and after hydrogen discharge;

Top: $\mathrm{NaTi}\left(\mathrm{BH}_{4}\right)_{4} \cdot \mathrm{DME}$ before hydrogen discharge; Middle: after $60^{\circ} \mathrm{C}$ hydrogen discharge and

$20^{\circ} \mathrm{C}$ recharge; Bottom: after $60^{\circ} \mathrm{C}$ hydrogen discharge .................................................... 96

Figure 86: SRNL Molten State Processing apparatus. .......................................................... 100

Figure 87: XRD results of MSP NaAlH $/ 4$ LiH indicating the presence of $\mathrm{Na}_{2} \mathrm{LiAlH}_{6} \ldots \ldots \ldots \ldots \ldots \ldots . . . . . . .102$

Figure 88: TPD results for $\mathrm{NaAlH}_{4} / \mathrm{LiH}$ MSP material............................................................ 103

Figure 89: XRD results following processing of $\mathrm{NaAlH} 4 / \mathrm{TiCl} 3$ at $190^{\circ} \mathrm{C} / 3 \mathrm{kpsi} / 2 \mathrm{hrs}$.................. 104

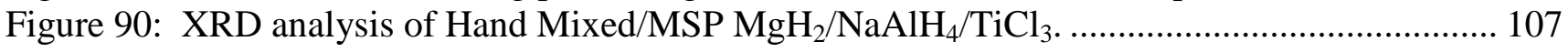

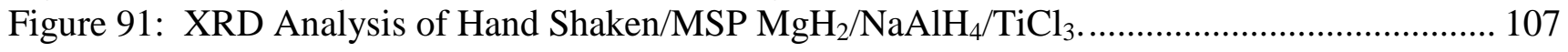




\section{List of Figures}

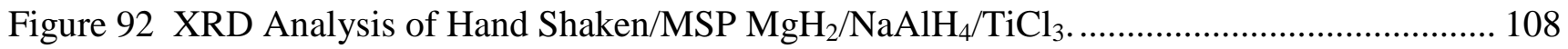

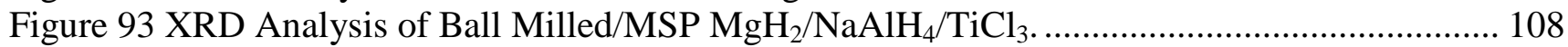

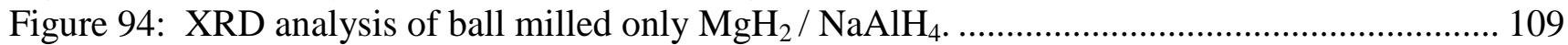

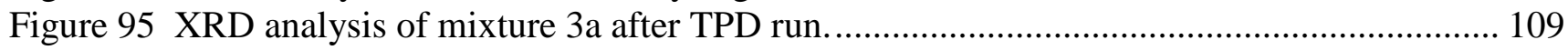

Figure 96: XRD analysis of mixture 4a after MSP, TPD and rehydrogenation.............................. 110

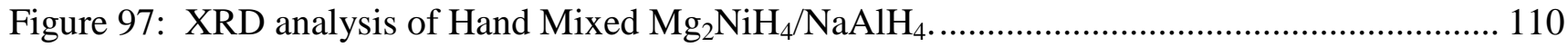

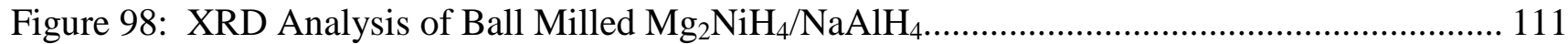

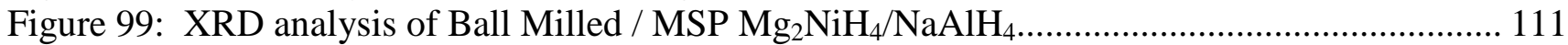

Figure 100: XRD analysis of mixture $1 \mathrm{~b}$ after two dehydride/hydride cycles................................ 112

Figure 101: analysis of mixture $2 \mathrm{~b}$ after two dehydride/hydride cycles. ........................................ 112

Figure 102: Ball milled $\mathrm{NaAlH}_{4} / \mathrm{TiCl}_{3} / \mathrm{MgH}_{2} / \mathrm{TiH}_{2}$ mixture................................................... 113

Figure 103: Melt processed $\mathrm{NaAlH}_{4} / \mathrm{TiCl}_{3} / \mathrm{MgH}_{2} / \mathrm{TiH}_{2}$ mixture............................................ 114

Figure 104: Desorbed melt processed $\mathrm{NaAlH}_{4} / \mathrm{TiCl}_{3} / \mathrm{MgH}_{2} / \mathrm{TiH}_{2}$ mixture................................. 114

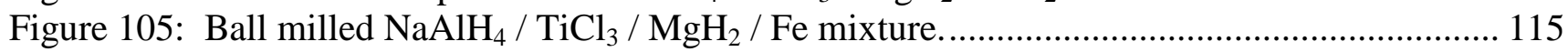

Figure 106: Melt processed $\mathrm{NaAlH}_{4} / \mathrm{TiCl}_{3} / \mathrm{MgH}_{2} / \mathrm{Fe}$ mixture. ………..................................... 115

Figure 107: Desorbed melt processed $\mathrm{NaAlH}_{4} / \mathrm{TiCl}_{3} / \mathrm{MgH}_{2} / \mathrm{Fe}$ mixture. ………......................... 116

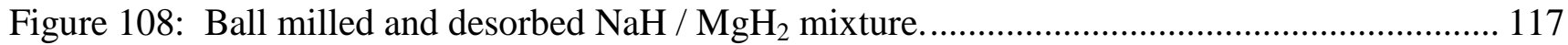

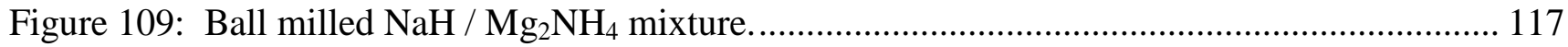

Figure 110: Desorbed $\mathrm{NaH} / \mathrm{Mg}_{2} \mathrm{NH}_{4}$ mixture. ………............................................................. 118

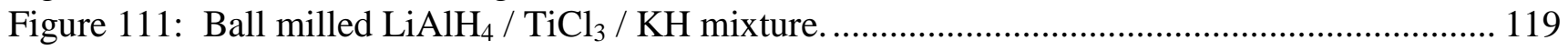

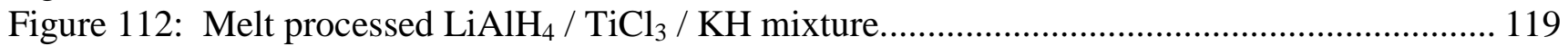

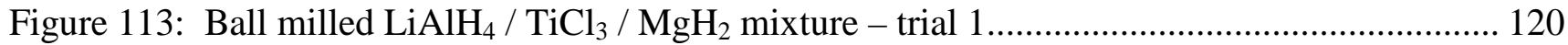

Figure 114: Melt processed $\mathrm{LiAlH}_{4} / \mathrm{TiCl}_{3} / \mathrm{MgH}_{2}$ mixture - trial 1......................................... 120

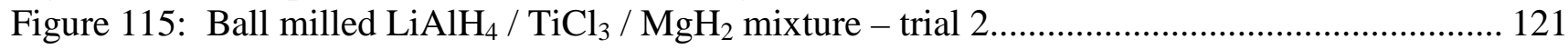

Figure 116: Melt processed $\mathrm{LiAlH}_{4} / \mathrm{TiCl}_{3} / \mathrm{MgH}_{2}$ mixture - trial 2........................................... 121

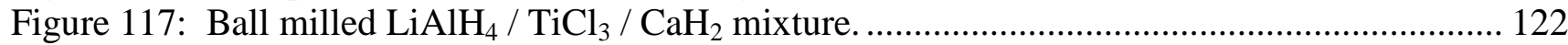

Figure 118: Melt processed $\mathrm{LiAlH}_{4} / \mathrm{TiCl}_{3} / \mathrm{CaH}_{2}$ mixture...................................................... 122

Figure 119: Ball milled $\mathrm{NaAlH}_{4}: \mathrm{LiAlH}_{4}: \mathrm{MgH}_{2}: \mathrm{Cr}$ 1:1:1:4 with cooling........................................ 124

Figure 120: XRD pattern of $\mathrm{VH}_{0.81}$ synthesized at $\mathrm{SRNL}$......................................................... 125

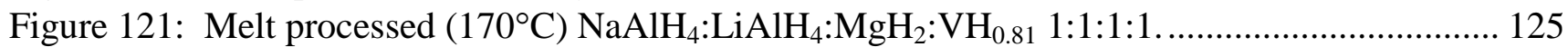

Figure 122: XRD pattern of ball milled 1:1:1:1 mol ratio $\mathrm{NaAlH}_{4}: \mathrm{LiAlH}_{4}: \mathrm{MgH}_{2}: \mathrm{Mn}$. ................... 127

Figure 123: XRD pattern of $170^{\circ} \mathrm{C}$ MSP 1:1:1:1 mol ratio $\mathrm{NaAlH}_{4}: \mathrm{LiAlH}_{4}: \mathrm{MgH}_{2}: \mathrm{Mn}$.................. 127

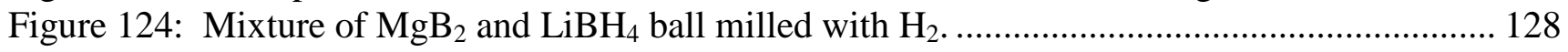

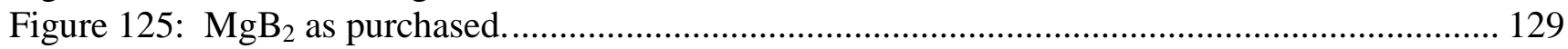

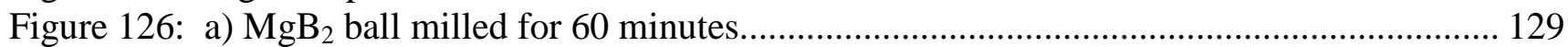

Figure 127: Mixture of $\mathrm{MgCl}_{2}$ and $\mathrm{LiBH}_{4}$ ball milled with THF................................................ 130

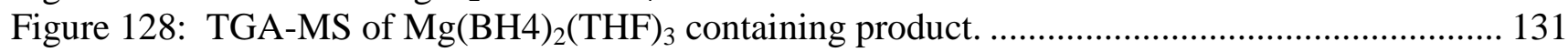

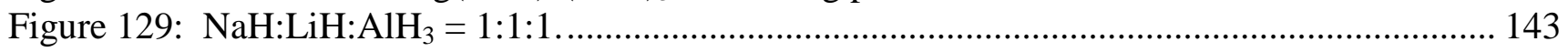

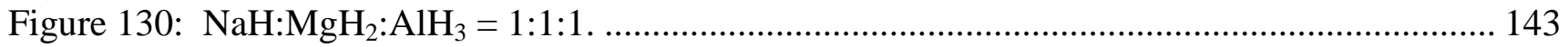

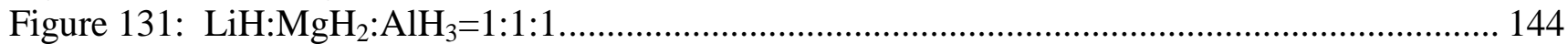

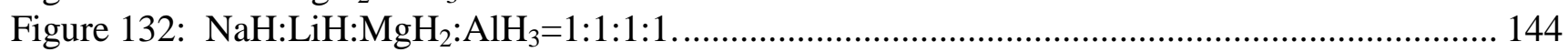

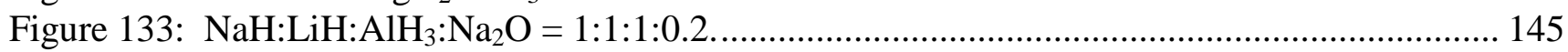

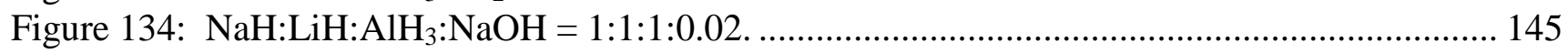

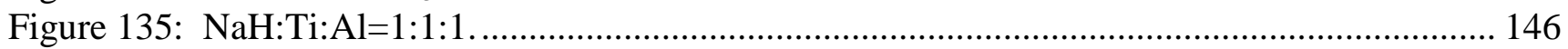

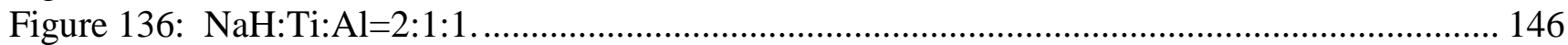

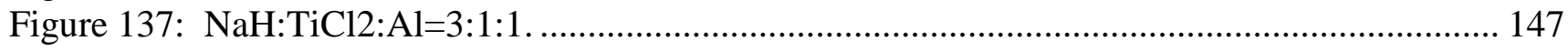




\section{List of Figures}

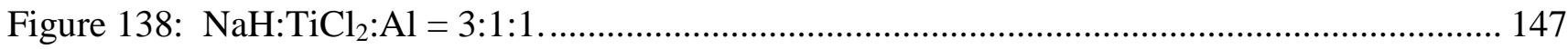

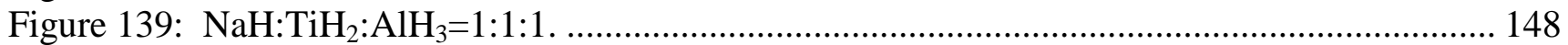

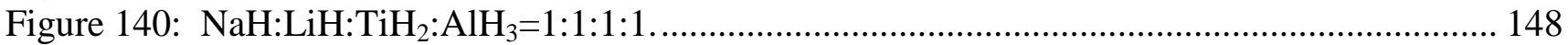

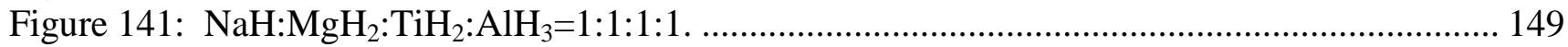

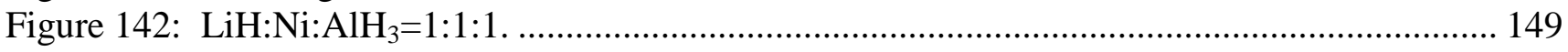

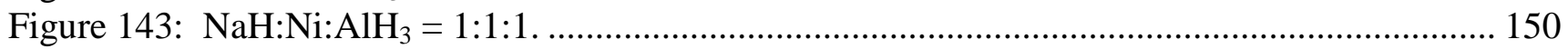

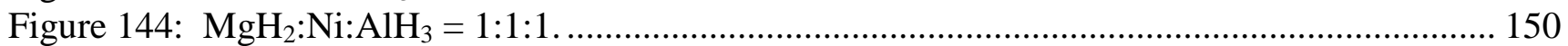

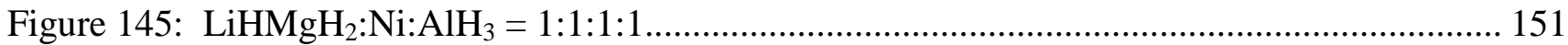

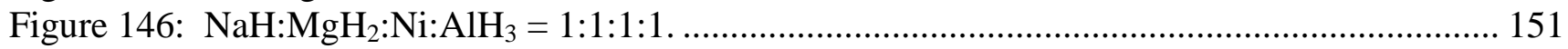

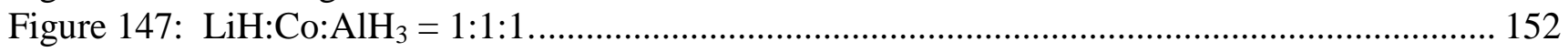

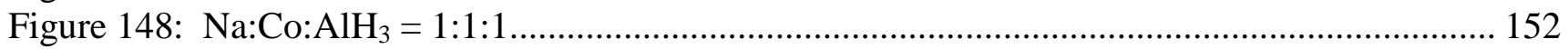

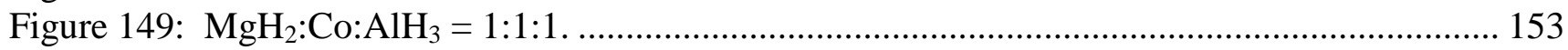

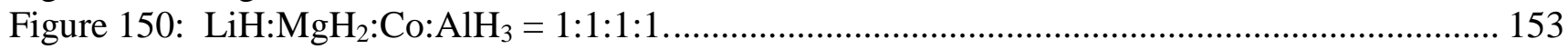

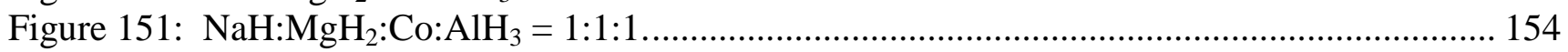

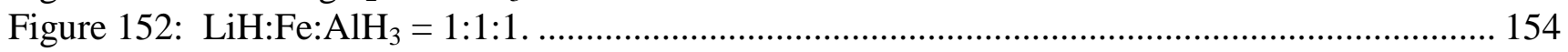

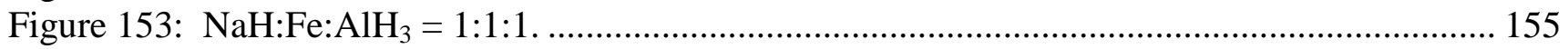

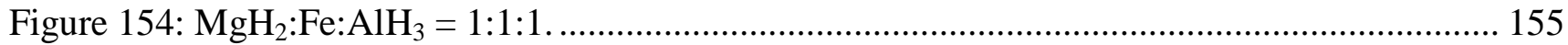

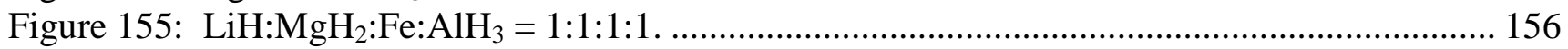

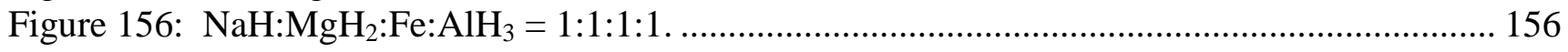

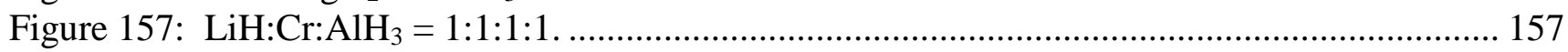

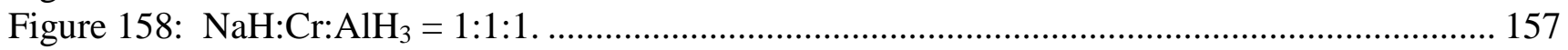

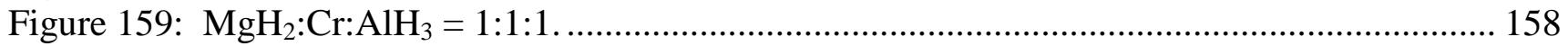




\section{Acknowledgements}

The authors would like to thank JoAnn Milliken, Sunita Satyapal, Carole Read, Jesse Adams and George Thomas of the Department of Energy (DOE) for their support and input over the course of this project. Additional thanks go to the following organizations and individuals for their contributions, advice and guidance:

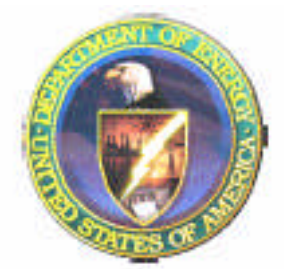

\section{Gife Institutt for $\begin{aligned} & \text { energiteknikk } \\ & \text { Bjorn C. Hauback, Hans W. Brinks, O. L. Martin }\end{aligned}$}

Norwestern University / QuesTek Innovations

Prof. Greg Olsen, W. Huang

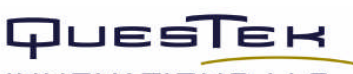

$\underline{\text { Sandia National Laboratories }}$

Ewa Rönnebro

United Technologies Corporation Power division

Francis R. Preli, Ram Ramaswamy

Michael F. Short, Dave M. Flanaghan

\section{United \\ Technologies}

Research Center
United Technologies Research Center

Craig R. Walker, Jodi A. Vecchiarelli, Susan D. Brandes

Laurence M. Pryor 


\section{Executive Summary}

\section{Executive Summary}

From 2002 to 2007, the United Technologies Research Center (UTRC), in collaboration with major partners Albemarle Corporation (Albemarle) and the Savannah River National Laboratory (SRNL), conducted research to discover new hydride materials for the storage of hydrogen having on-board reversibility and a target gravimetric capacity of $\geq 7.5$ weight percent (wt \%). When integrated into a system with a reasonable efficiency of $60 \%$ (mass of hydride / total mass), this target material would produce a system gravimetric capacity of $\geq 4.5 \mathrm{wt} \%$, consistent with the DOE 2007 target.

The approach established for the project combined first principles modeling (FPM - UTRC) with multiple synthesis methods: Solid State Processing (SSP - UTRC), Solution Based Processing (SBP Albemarle) and Molten State Processing (MSP - SRNL). In the search for novel compounds, each of these methods has advantages and disadvantages; by combining them, the potential for success was increased. During the project, UTRC refined its FPM framework which includes ground state (0 Kelvin) structural determinations, elevated temperature thermodynamic predictions and thermodynamic / phase diagram calculations. This modeling was used both to precede synthesis in a virtual search for new compounds and after initial synthesis to examine reaction details and options for modifications including co-reactant additions. The SSP synthesis method involved high energy ball milling which was simple, efficient for small batches and has proven effective for other storage material compositions. The SBP method produced very homogeneous chemical reactions, some of which cannot be performed via solid state routes, and would be the preferred approach for large scale production. The MSP technique is similar to the SSP method, but involves higher temperature and hydrogen pressure conditions to achieve greater species mobility.

During the initial phases of the project, the focus was on higher order alanate complexes in the phase space between alkaline metal hydrides $(\mathrm{AmH})$, Alkaline earth metal hydrides $\left(\mathrm{AeH}_{2}\right)$, alane $\left(\mathrm{AlH}_{3}\right)$, transition metal $(\mathrm{Tm})$ hydrides $(\mathrm{TmHz}$, where $\mathrm{z}=1-3)$ and molecular hydrogen $\left(\mathrm{H}_{2}\right)$. The effort started first with variations of known alanates and subsequently extended the search to unknown compounds. In this stage, the FPM techniques were developed and validated on known alanate materials such as $\mathrm{NaAlH}_{4}$ and $\mathrm{Na}_{2} \mathrm{LiAlH}_{6}$. The coupled predictive methodologies were used to survey over 200 proposed phases in six quaternary spaces, formed from various combinations of $\mathrm{Na}, \mathrm{Li} \mathrm{Mg}$ and/or $\mathrm{Ti}$ with $\mathrm{Al}$ and $\mathrm{H}$.

A wide range of alanate compounds was examined using SSP having additions of $\mathrm{Ti}, \mathrm{Cr}, \mathrm{Co}, \mathrm{Ni}$ and $\mathrm{Fe}$. A number of compositions and reaction paths were identified having $\mathrm{H}$ weight fractions up to $5.6 \mathrm{wt} \%$, but none meeting the $7.5 \mathrm{wt} \% \mathrm{H}$ reversible goal. Similarly, MSP of alanates produced a number of interesting compounds and general conclusions regarding reaction behavior of mixtures during processing, but no alanate based candidates meeting the $7.5 \mathrm{wt} \%$ goal. A novel alanate, $\mathrm{LiMg}\left(\mathrm{AlH}_{4}\right)_{3}$, was synthesized using SBP that demonstrated a $7.0 \mathrm{wt} \%$ capacity with a desorption temperature of $150^{\circ} \mathrm{C}$. The deuteride form was synthesized and characterized by the Institute for Energy (IFE) in Norway to determine its crystalline structure for related FPM studies. However, the reaction exhibited exothermicity and therefore was not reversible under acceptable hydrogen gas pressures for on-board recharging.

After the extensive studies of alanates, the material class of emphasis was shifted to borohydrides. Through SBP, several ligand-stabilized $\mathrm{Mg}\left(\mathrm{BH}_{4}\right)_{2}$ complexes were synthesized. The $\mathrm{Mg}\left(\mathrm{BH}_{4}\right)_{2} * 2 \mathrm{NH}_{3}$ complex was found to change behavior with slightly different synthesis conditions 


\section{Executive Summary}

and/or aging. One of the two mechanisms was an amine-borane $\left(\mathrm{NH}_{3} \mathrm{BH}_{3}\right)$ like dissociation reaction which released up to $16 \mathrm{wt} \% \mathrm{H}$ and more conservatively $9 \mathrm{wt} \% \mathrm{H}$ when not including $\mathrm{H}_{2}$ released from the $\mathrm{NH}_{3}$. From FPM, the stability of the $\mathrm{Mg}\left(\mathrm{BH}_{4}\right)_{2} * 2 \mathrm{NH}_{3}$ compound was found to increase with the inclusion of $\mathrm{NH}_{3}$ groups in the inner-Mg coordination sphere, which in turn correlated with lowering the dimensionality of the $\mathrm{Mg}\left(\mathrm{BH}_{4}\right)_{2}$ network. Development of various Ak-Tm-B-H compounds using SSP produced up to $12 \mathrm{wt} \%$ of $\mathrm{H}_{2}$ desorbed at temperatures of $400^{\circ} \mathrm{C}$. However, the most active material can only be partially recharged to $2 \mathrm{wt} \% \mathrm{H}_{2}$ at $220-300^{\circ} \mathrm{C}$ and 195 bar $\mathrm{H}_{2}$ pressure due to stable product formation. A summary of the material performance along with a conversion to system performance based on the parameters of footnote ${ }^{[1]}$ is given in Table 1 . The gravimetric \& volumetric targets are feasible, but reversibility is a persistent challenge.

Table 1: Summary of synthesized material / system performance.

\begin{tabular}{|c|c|c|c|c|}
\hline \multicolumn{5}{|c|}{ Hydrogen Storage System Targets ${ }^{[1,2]}$} \\
\hline Target & Units & $\begin{array}{l}2007 \text { System } \\
\text { Targets }\end{array}$ & $\begin{array}{c}\text { '05 to '06 } \\
\text { Best Alanate } \\
\left.\text { LiMg(AlH })_{4}\right)_{3} / \\
\text { System } \\
\end{array}$ & $\begin{array}{c}\text { '06 to '07 } \\
\text { Best Borohydride } \\
\mathrm{Mg}\left(\mathrm{BH}_{4}\right)_{2} * 2 \mathrm{NH}_{3} / \\
\text { System } \\
\end{array}$ \\
\hline $\begin{array}{l}\text { Gravimetric } \\
\text { Capacity }\end{array}$ & $\begin{array}{c}\mathrm{kWh} / \mathrm{kg} \\
(\mathrm{kg} \mathrm{H} 2 / \mathrm{kg})\end{array}$ & $\begin{array}{c}1.5 \\
(0.045)\end{array}$ & $\begin{array}{c}2.1 / 1.3 \\
(0.070 / 0.042)\end{array}$ & $\begin{array}{c}3.0 / 1.8 \\
(0.091 / 0.055)\end{array}$ \\
\hline $\begin{array}{l}\text { Volumetric } \\
\text { Capacity }\end{array}$ & $\begin{array}{c}\mathrm{kWh} / \mathrm{L} \\
(\mathrm{kg} \mathrm{H} 2 / \mathrm{L})\end{array}$ & $\begin{array}{c}1.2 \\
(0.036) \\
\end{array}$ & $\begin{array}{c}0.5 / 0.38^{[4]} \\
(0.015 / 0.011)\end{array}$ & $\begin{array}{c}1.5 / 1.1 \\
(0.044 / 0.033) \\
\end{array}$ \\
\hline $\begin{array}{l}\text { Desorption Rate } \\
\text { \& Temperature }\end{array}$ & $\begin{array}{l}\mathrm{g} / \mathrm{s} / \mathrm{kW} \\
{ }^{\circ} \mathrm{C}\end{array}$ & $\begin{array}{c}0.02 \\
(<100)\end{array}$ & $\begin{array}{c}0.019 \\
165\end{array}$ & $\begin{array}{c}0.037 \\
100-300\end{array}$ \\
\hline
\end{tabular}

${ }^{[1]}$ For a system design with the material being $60 \%$ of the system mass $\& 75 \%$ of the system volume.

${ }^{[2]}$ The materials listed are not reversible.

${ }^{[3]}$ Powders subjected to a standard vibratory densification process.

${ }^{[4]} \mathrm{LiMg}\left(\mathrm{AlH}_{4}\right)_{3}$ was in the as-received condition; ball milling could improve powder densification.

${ }^{[5]}$ Calculated results based on $5 \mathrm{~kg}$ of storage for a $75 \mathrm{~kW}$ fuel cell.

Our high level observations and recommendations are as follows:

- First Principles Modeling was productively integrated with syntheses and characterization to screen, investigate and evaluate new materials. Discovery of new materials from modeling alone is very difficult; FPM yields the greatest value when iteratively coupled with experiments.

- There were clear benefits to having multiple organizations apply their distinct synthesis methods concurrently in the same material exploration.

- Multiple organizations conducting characterization can be straightforward to execute, but care should be taken in understanding aging effects when working with potentially unstable materials.

- Based on the current studies, we concur with the trends in the community that the potential of alanates is insufficient to motivate a strong emphasis in future novel materials research.

- While no completely viable storage materials were synthesized in this effort, we feel that potential remains in developing high capacity borohydrides with tailored reactions which could result in adequate reversibility / regenerability.

In addition, 11 publications and over 13 presentations were produced as well as numerous other collaborations, reviews and meetings involving the domestic and international hydrogen storage communities during the performance of this contract. 


\section{Overview}

\section{Overview}

This final report describes the motivations, activities and results of the hydrogen storage independent project Complex Hydride Compounds with Enhanced Hydrogen Storage Capacity performed by the United Technologies Research Center (UTRC) under the Department of Energy (DOE) Hydrogen Program, contract \# DE-FC36-04GO14012. This effort officially began in April of 2002 and performed technical research through August of 2007 with subsequent concluding activities and reporting. In addition to UTRC, two organizations had central roles in the execution of this contract: Albemarle Corporation (Albemarle) and Savannah River National Laboratory (SRNL). DOE financial support to UTRC and Albemarle was $\$ 1,695 \mathrm{k}$, with these organizations contributing $\$ 785 \mathrm{k}$ (31.7\%) of cost share resources. SRNL received $\$ 450 \mathrm{k}$ of DOE funds, resulting in a total contract of $\$ 2,930 \mathrm{k}$.

\subsection{Project Motivations and Scope}

It is well recognized that storage of hydrogen in a compact and lightweight form is critical to the commercial introduction of hydrogen as an energy carrier, particularly for automotive fuel cells, with the benefits of reduced dependence on foreign oil and increased potential for utilizing renewable energy sources. According to the National Academies' February 2004 report on the DOE Hydrogen Program:

"A transition to hydrogen as a major fuel in the next 50 years could fundamentally transform the U.S. energy system, creating opportunities to increase energy security through the use of a variety of domestic energy resources for hydrogen production while reducing environmental impacts, including atmospheric $\mathrm{CO}_{2}$ emissions and criteria pollutants."

The major classes of established hydrogen storage methods are compressed gas, cryogenic liquid, metal hydrides, chemical hydrides and adsorbents, all of which have advantages and disadvantages, but none is clearly superior for automotive transportation. High pressure compressed gas systems have been certified for automotive use, but do not meet all of the desired targets. Cryogenic liquefied hydrogen has a substantial energy penalty of over $30 \%$ for production and is susceptible to boil-off issues. A disadvantage of conventional reversible metal hydrides is their low hydrogen capacities of less than $2 \mathrm{wt} \%$ for alloys with discharge temperatures for which the waste heat of a PEM fuel cell $\left(\sim 90^{\circ} \mathrm{C}\right)$ can be used to release the hydrogen.

Complex hydride materials have the potential to store higher capacities of hydrogen than conventional metal hydrides for indefinite periods of time and require only moderate hydrogen gas pressures for recharging. Associated with this are the lower energy losses compared with high pressure gas compression and liquefying processes as well as potential safety benefits. Challenges include developing novel, high hydrogen capacity storage materials which can be discharged at temperatures of PEM fuel cell waste heat $\left(100{ }^{\circ} \mathrm{C}\right.$ or below) and charged at pressures with acceptable vessel mass (nominally 100 bar).

The goal of this program is the discovery of new complex hydride compounds capable of reversibly storing hydrogen to a capacity of $\geq 7.5 \mathrm{wt} \%$ with regeneration for over 500 cycles. When integrated into a system with a gravimetric efficiency of $60 \%$, this will produce $\mathrm{a} \geq 4.5 \mathrm{wt} \%$ system. This goal for the material was driven by the emerging and revised DOE technical targets given in Table 2. 


\section{Overview}

Initially, the focus of the project was composition systems in the quaternary phase space between sodium hydride $(\mathrm{NaH})$, alane $\left(\mathrm{AlH}_{3}\right)$, transition metal or rare earth $(\mathrm{M})$ hydrides $(\mathrm{MHz}$, where $\mathrm{z}=1-3)$ and molecular hydrogen $\left(\mathrm{H}_{2}\right)$. In the latter portion of the project, the scope was extended to include other complex hydrides including borohydrides.

Table 2: DOE technical targets for on-board hydrogen storage systems.

\begin{tabular}{|c|c|c|}
\hline Storage Parameter & Units & 2007 Target \\
\hline System Gravimetric Capacity & $\mathrm{kg} \mathrm{H}_{2} / \mathrm{kg}$ system & 0.045 \\
\hline System Volumetric Capacity & $\mathrm{kg} \mathrm{H}_{2} / \mathrm{L}$ system & 0.036 \\
\hline System Fill Time & $\mathrm{min}$ & 10 \\
\hline Minimum Full Flow Rate & $(\mathrm{g} / \mathrm{s}) / \mathrm{kW}$ & 0.02 \\
\hline Storage System Cost & $\$ / \mathrm{kg} \mathrm{H}$ & 200 \\
\hline Cycle Life & Cycles & 500 \\
\hline Safety & N/A & Meets C\&S \\
\hline
\end{tabular}

The search for novel, high capacity complex hydride compounds was supported by the development and application of first principles modeling. These simulations were coupled with thermodynamic predictions and characterization experiments to develop the framework which was used both to lead synthesis efforts and to understand existing novel phases. Simultaneously, multiple synthetic methodologies were employed to enhance options for discovery of new hydrides. These methods included Solid State Processing (SSP) at UTRC, Solution Based Processing (SBP) at Albemarle and Molten State Processing (MSP) at SRNL. A high level breakdown of the project is given in Figure 1.

\begin{tabular}{|c|c|l|l|l|c|}
\hline Task & $\begin{array}{l}\text { First } \\
\text { Principles } \\
\text { Phase }\end{array}$ & $\begin{array}{l}\text { Solid- } \\
\text { State } \\
\text { Mrocessing }\end{array}$ & $\begin{array}{l}\text { Solution- } \\
\text { Based } \\
\text { Processing }\end{array}$ & $\begin{array}{l}\text { Molten- } \\
\text { State } \\
\text { Processing }\end{array}$ & $\begin{array}{l}\text { Thermo- } \\
\text { dynamic } \\
\text { Modeling }\end{array}$ \\
\hline $\begin{array}{c}\text { Known } \\
\text { Alanates }\end{array}$ & $\begin{array}{c}\text { Implement } \\
\text { finite T } \\
\text { predictions. }\end{array}$ & $\begin{array}{c}\text { Search out quaternary systems } \\
\text { encompassing known alkali alanates. } \\
\text { Validate atomic-thermodynamic modeling. }\end{array}$ & $\begin{array}{c}\text { Establish } \\
\text { thermo. } \\
\text { databases. }\end{array}$ \\
\hline $\begin{array}{c}\text { Novel } \\
\text { Nones }\end{array}$ & $\begin{array}{c}\text { Predict } \\
\text { candidate } \\
\text { properties. }\end{array}$ & $\begin{array}{c}\text { Search out high capacity alanates with } \\
\text { alkaline earth or transition metal elements. } \\
\text { Characterize properties. Test performance. }\end{array}$ & $\begin{array}{c}\text { Implement } \\
\text { reaction } \\
\text { design. }\end{array}$ \\
\hline $\begin{array}{c}2006 \\
\text { Novel } \\
\text { Boro- } \\
\text { hydrides }\end{array}$ & $\begin{array}{c}\text { Refine phase } \\
\text { structure \& } \\
\text { thermo. } \\
\text { predictions. }\end{array}$ & $\begin{array}{c}\text { Synthesize high capacity borohydrides } \\
\text { containing alkaline earths, transition metals } \\
\text { and/or stabilized with ligands. }\end{array}$ & $\begin{array}{c}\text { Design high } \\
\text { capacity } \\
\text { reactions. }\end{array}$ \\
$\begin{array}{c}\text { 2007 Final } \\
\text { Phase }\end{array}$ & $\begin{array}{c}\text { Probe } \mathrm{xx} . \\
\text { mechanisms. }\end{array}$ & $\begin{array}{c}\text { Down-select best system and synthesis } \\
\text { method. Optimize reversibility and kinetics. }\end{array}$ & $\begin{array}{c}\text { Design } \\
\text { reversibility. }\end{array}$ \\
\hline
\end{tabular}

Figure 1: Overview of project effort material systems, modeling and synthesis.

Initially, the focus of the composition systems was complex, mixed metal alanates. While novel compounds with good hydrogen capacity were developed, reversibility and discharge temperature did not meet the desired targets. To broaden the scope, high capacity borohydrides were explored in the latter portion of the project. A more detailed breakdown of the composition systems and examination methods is given in Table 3 . 


\section{Overview}

Table 3: Summary of composition systems and methods of modeling / synthesis. Tm= transition metal; FPM = First Principles Modeling; SSP = Solid State Processing; SBP = Solution Based Processing and MSP = Molten State Processing.

\begin{tabular}{|c|l|l|}
\hline \multicolumn{1}{|c|}{ System } & \multicolumn{1}{|c|}{ Compositions } & \multicolumn{1}{c|}{ Method } \\
\hline Alanates & Na-Li-Al-H & FPM, SSP, MSP \\
& Na-Tm-Al-H & FPM, SSP, SBP, MSP \\
& Li-Tm-Al-H & FPM, SSP, SBP, MSP \\
& Na-Mg-Al-H & FPM, SSP, SBP, MSP \\
& Li-Mg-Al-H & FPM, SSP, SBP \\
& Li-Na-Mg-(Ti,V,Cr,Mn,Ni,Co,Fe)-H & SSP, MSP \\
\hline Borohydrides & Tm-B-H w/ ligands & SBP \\
& Mg-B-H w/ \& w/o ligands or coreactants & FPM, SSP, SBP, MSP \\
& Ak-Tm-B-H w/ \& w/o ligands & FPM, SSP, SBP \\
\hline
\end{tabular}

This document was prepared in Microsoft Word, and if an electronic copy is available, the Document Map feature can be used to facilitate navigation from section to section. A similar structure has been produced in the PDF file conversion process. The Bookmarks tab of the Navigation Pane provides an outline of the report and a convenient method to jump from section to section. Hyperlinks are also included for in-text section numbers, figures, tables, equations and references.

\subsection{Statement of Project Objectives}

An abbreviated and reformatted version of the original Statement of Project Objectives is given below. Based on experience gained throughout the project, the detailed approach and objectives were modified while maintaining the same high level structure.

\section{First Principles Modeling}

- Evaluate theoretical phase stability

- Simulate new quaternary compositions to recommend for synthesis targets

- Predict reversible hydrogen content of the best hydride candidates

- Identify new catalyzed compositions with decreased dehydrogenation activation barriers

- Guide development of new complex hydride compound phases

- Materials:

- Known Alanate Characteristics

- Alanate Phase Predictions

- Catalyzed Complex Hydrides

\section{Synthesis}

- Synthesize materials at UTRC and Albemarle via at least one of two distinct processing routes, which both have potential for commercialization. These are solid state processing (SSP) and solute based processing (SBP).

- SRNL will perform synthesis primarily using Molten State Processing (MSP)

- Materials:

- Known Alanate Structures

- Known Alanate Catalysts I 


\section{Overview}

- Known Alanate Catalysts II

- Modeled Structures

- Catalyzed Structures

\section{Analysis}

- Primary analysis technique of x-ray diffraction

- Apply on each sample synthesized to identify the presence of new crystal structures or significantly distorted structures of existing phases.

- Once a phase has been identified as a candidate, apply more sophisticated analysis including neutron diffraction and high-resolution X-ray analyses to determine more precisely the structure of material synthesized.

\section{Performance}

- Capacity

- For the Na-Ti-Al-H quaternary phase diagram, provide predictions and theoretical calculations for hydrogen capacity and potential for reversibility.

- Complete empirical compositional section phase diagrams and pressure-compositiontemperature diagrams for evaluation of phase stability and reversible hydrogen content of Na-Ti-Al-H systems.

- Down-select of materials from Na-Ti-Al-H system that have potential for both capacity and reversibility.

- Reversibility

- Down-select of material processing routes that have the greatest potential for large-scale commercialization.

- Make predictions based on first principles modeling for high hydrogen capacity and potential reversibility based on $\mathrm{Li}-\mathrm{Mg}-\mathrm{V}, \mathrm{Cr}, \mathrm{Mn}, \mathrm{Fe}, \mathrm{Co}, \mathrm{Mo}$, Ce or other rare earth elements complex hydrides

- Down-select complex aluminum hydrides containing Li-Mg-V, Cr, Mn, Fe, Co, Mo, Ce or other rare earth elements.

\section{SRNL Objectives}

- Materials will be synthesized via Molten State Processing (MSP), utilizing their specialized equipment and technical expertise.

- Materials identical to those listed under "Synthesis" above

If mature storage material candidates are identified, perform the following development activities:

\section{Materials Stability}

- Evaluate reactivity with storage system structural materials and study safety issues.

\section{Scale Up}

- Move synthesis from the laboratory to the High Pressure Facility at the Albemarle Baton Rouge Process Development Center to evaluate $\mathrm{kg}$ scale material production.

\section{Business Analysis}

- Develop cost and performance metrics of the complex hydride compound media and the storage subsystems. 


\section{Overview}

As stated above and described in more detail below, the examinations during the first 1 to 2 years focused on alanate compositions and subsequently broadened the material types pursued to borohydrides during the remainder of the effort. While novel materials with improved performance were developed, they did not meet the maturity level required to justify pursuit of the Stability, Scale Up and Business Analysis tasks. 


\section{First Principles and Thermodynamic Modeling}

\section{First Principles and Thermodynamic Modeling}

\subsection{Introduction/Background/Rational}

\subsubsection{Quaternary Systems Encompassing Known Alanate Phases}

The motivation for this study was to overcome the existing reversible $\mathrm{H}$ capacity limitations of known hydride systems by seeking out elevated H-bearing compounds akin to the elusive reported compounds yet to be defined crystallographically, such as the titanium alanate compound, $\mathrm{Ti}\left(\mathrm{AlH}{ }_{4}\right)_{4}$, with 8 or more wt\% retrievable $\mathrm{H}$ capacity [Ref. 1]. First principles modeling was deployed to virtually explore selected multi-dimensional composition phase spaces for potential new hydride structures with high capacities of greater than $7.5 \mathrm{wt} \%$ retrievable $\mathrm{H}$ and to assess the relative stability of these structures with respect to known phases that may compete for existence. Our founding system was the Na-Ti-Al-H quaternary composition phase space bounded by the elements: $\mathrm{Na}, \mathrm{Al}, \mathrm{Ti}$, $\mathrm{H}$, that encompasses the well-known sodium alanate system and the associated phases that may form upon Ti-doping and/or dehydrogenation of the sodium alanate phases. Possible other competing phases, related lower order phases, including hypothetical end-member phases for varying substitution were also simulated.

The Na-Ti-Al-H phase space quaternary system with the known peripheral binary and ternary phases is shown schematically in Figure 2. Here, the unknown interior of the phase space was surveyed extensively for possible new stoichiometries or structures that may be stable for existence. Our motivation went beyond the reports of high capacity compounds [Ref. 1] and the well-known catalytic effects of $\mathrm{Ti}$ in sodium alanates [Refs. 2, 3 and 4], to simulate new complex hydride structures enabled by the accessible and hybridizable Ti $3 \mathrm{~d}$ electronic states. Here, a series of coupled methodologies were implemented for postulating and evaluating $\mathrm{Na}-\mathrm{Ti}-\mathrm{Al}-\mathrm{H}$ complex hydride phase structures with varying Ti coordination numbers and formal changes. Since Ti can essentially catalyze disproportionation or comproportionation reactions by thermodynamically destabilizing alkali alanate complexes [Refs. 5 and 6] and/or by forming very favorable titanium-aluminide compounds [Ref. 7], Ti incorporation also provided the means for tailoring complex hydride thermodynamic properties.

At the outset, the best available hydride system with reversible retrieval of the highest known $\mathrm{H}$ capacity under moderate temperature and pressure conditions was the $\mathrm{Na}-\mathrm{Al}-\mathrm{H}$ system with the two sodium alanate phases, $\mathrm{NaAlH}_{4}$ and $\mathrm{Na}_{3} \mathrm{AlH}_{6}$. In the first year, we progressively built upon our knowledge of the sodium alanate system to seek out and discover higher $\mathrm{H}$ capacity alanate and/or complex hydride phases. New protocols were established for model development, simulation, and analyses of phase candidates. These prediction protocols were first validated by benchmarking sodium alanate and $\mathrm{Na}-\mathrm{Al}-\mathrm{H}$ system predictions against experimental data for the Na-Al-H system. We also utilized our understanding of the sodium alanate crystal structures as a guide to systematically propose, simulate and evaluate new quaternary compounds based upon the analog structures of known ternary alkali and/or alkaline earth compounds, ternary alkali/alkaline earth and transition metal compounds, and ternary transition metal compounds.

The utility of the new prediction protocols was demonstrated by executing virtual surveys on systems encompassing some well-known sodium and lithium alanate phases: Na-Ti-Al-H, Li-Ti-Al-H, and 


\section{First Principles and Thermodynamic Modeling}

Na-Li-Al-H. The latter two quaternary systems were based on the higher potential capacity, but less reversible $\mathrm{Li}-\mathrm{Al}-\mathrm{H}$ system with the lithium alanate phases, $\mathrm{LiAlH}_{4}$ and $\mathrm{Li}_{3} \mathrm{AlH}_{6}$. The rationale for the $\mathrm{Li}-\mathrm{Ti}-\mathrm{Al}-\mathrm{H}$ system was that replacement of $\mathrm{Na}$ in the most favorable $\mathrm{Na}-\mathrm{Ti}-\mathrm{Al}-\mathrm{H}$ quaternary phases with $\mathrm{Li}$ could provide significant increases in reversible hydrogen capacity both due to the lower $\mathrm{Li}$ atomic weight and to the possible formation of $\mathrm{H}$-free $\mathrm{Li}-\mathrm{Al}$ binary phases upon disproportionation. Mixed alkali compositions also offered the prospect of tailoring both complex hydride reversibly and kinetics. This exploration of mixed alkali systems was motivated by the known existence of a number of mixed alkali complex compounds and structural analogs.

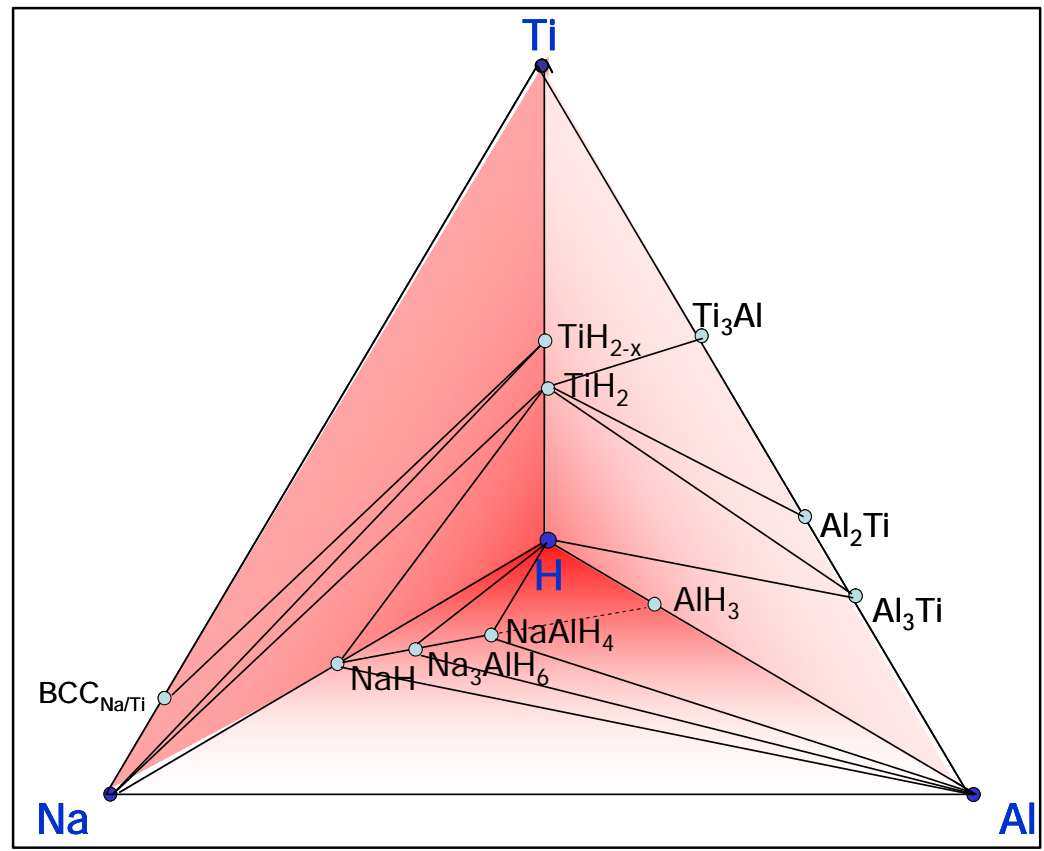

Figure 2: Aerial view of Na-Ti-Al-H quaternary pyramid.

The new simulation protocols were then utilized to explore other lesser-known compositional spaces in the remainder of the program, including the two quaternary systems: Na-Mg-Al- $\mathrm{H}$ and Li-Mg-Al$\mathrm{H}$, formed by adding the $\mathrm{Mg}$ alkaline earth to the $\mathrm{Na}-\mathrm{Al}-\mathrm{H}$ and $\mathrm{Li}-\mathrm{Al}-\mathrm{H}$ systems respectively. The Li$\mathrm{Mg}-\mathrm{Al}-\mathrm{H}$ quaternary space with known peripheral binary and ternary phases is shown schematically in Figure 3. This modeling stage broke new ground on two fronts, demonstrating the ability to: (1) survey lesser known compositional phase spaces with very limited experimental observations (or "leads") of complex hydride compound formation and (2) execute virtual surveys expediently in tandem with experimentation. These two mixed alkali/alkaline earth quaternary systems provided new opportunities for the discovery of high $\mathrm{H}$ capacity compounds by incorporating unique features of Mg-bearing phases. When the divalent $\mathrm{Mg}$ ion is replaced for two mono-valent alkali ions in known alanate structures, the $\mathrm{Mg}$ ion may effectively coordinate with a greater number of $\mathrm{Al}-\mathrm{H}$ complexes to redistribute charge balance within the structure. For sodium alanates (but not for lithium alanates), such a substitution would result in weight reduction and a marked increase in gravimetric H capacity. In many $\mathrm{Mg}$-bearing aluminum fluoride phases, the $\mathrm{Mg}$ ions form unique coordinative environments, e.g. directly bonding with fluoride anions outside of the Al complexes or coordinating as counter-ions with a very large number of neighboring fluoride anions. The Mg-bearing complex hydrides offered 


\section{First Principles and Thermodynamic Modeling}

the possible advantage of disproportionation to form binary and ternary $\mathrm{Mg}$ intermetallic compounds upon dehydrogenation. The formation of these phases in place of $\mathrm{Mg}$ hydride $\left(\mathrm{MgH}_{2}\right)$ would decrease the amount of bound hydrogen, and thus, would increase the reversible hydrogen content upon dehydrogenation.

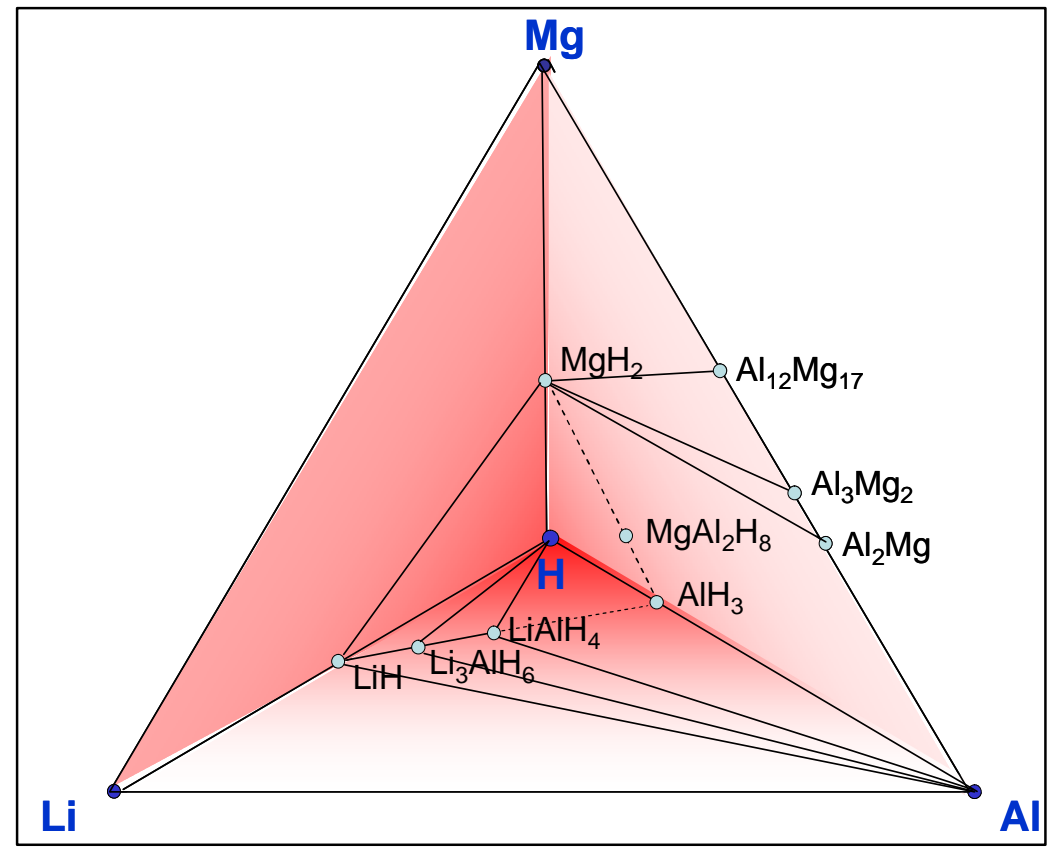

Figure 3: Aerial view of Li-Mg-Al-H quaternary pyramid.

\subsubsection{Coupled High Hydrogen Reactions with Complex Hydrides}

Following the surveys of the five quaternaries based on the $\mathrm{Na}-\mathrm{Al}-\mathrm{H}$ and $\mathrm{Li}-\mathrm{Al}-\mathrm{H}$ systems, we expanded our original strategy to search out coupled complex hydride reactions with co-reactants to enable the design of low $\mathrm{H}$ products upon disproportionation. This expanded strategy, illustrated conceptually in Figure 4, used a triad of first principles modeling, thermodynamic calculations and experimentation to identify, design and refine new reaction pathways for high $\mathrm{H}$ reversible capacity. Our atomic-thermodynamic modeling effort was expanded to encompass a larger repertoire of solidstate complex hydride chemistries and hydrogen-retrieval reactions. This expanded strategy built upon our existing capability to search out and discover new phases by comprehensively evaluating all conceivable (known and hypothetical) participating phases and their possible associated reaction pathways, within each multi-order compositional space. We updated our approach to include complex hydride mixtures and reactions with coreactants that can lead to the formation of new products upon decomposition. Such reaction scenarios enabled both the decomposition enthalpy $(\Delta H)$ per mole of $\mathrm{H}_{2}$ generated and the relative stability of reactant and product phases to be adjusted for a given set of temperature and pressure conditions. The result was an even more powerful capability to optimize the overall elemental stoichiometry of a given compositional system to stabilize the most favorable balance of phases that provide access to the largest possible retrievable hydrogen capacity. 


\section{First Principles and Thermodynamic Modeling}

The thermodynamics of hydride bearing systems were central to the new parallel search strategy, providing fertile ground for integration of our experimental and theoretical synthetic efforts. Within each compositional space, we evaluated existing experimental thermodynamic data in order to identify critical gaps and to develop formulation approaches for high capacity systems. We then applied our coupled atomic-thermodynamic methodology to simulate thermodynamic properties for uncharacterized known phases and for yet-to-be-discovered hypothetical complex hydride phase candidates. Predicted thermodynamic properties were assessed and parameterized, allowing their incorporation within our experimental thermodynamic databases. The supplemented databases were then used to identify the reaction scenarios that leveraged the most hydrogen capacity and to recommend composition targets for synthesis campaigns. Both the thermodynamic results and experimental observations were used to propose new candidate phase models for additional thermodynamic properties simulations. The result was the capability to iteratively refine high hydrogen capacity systems.

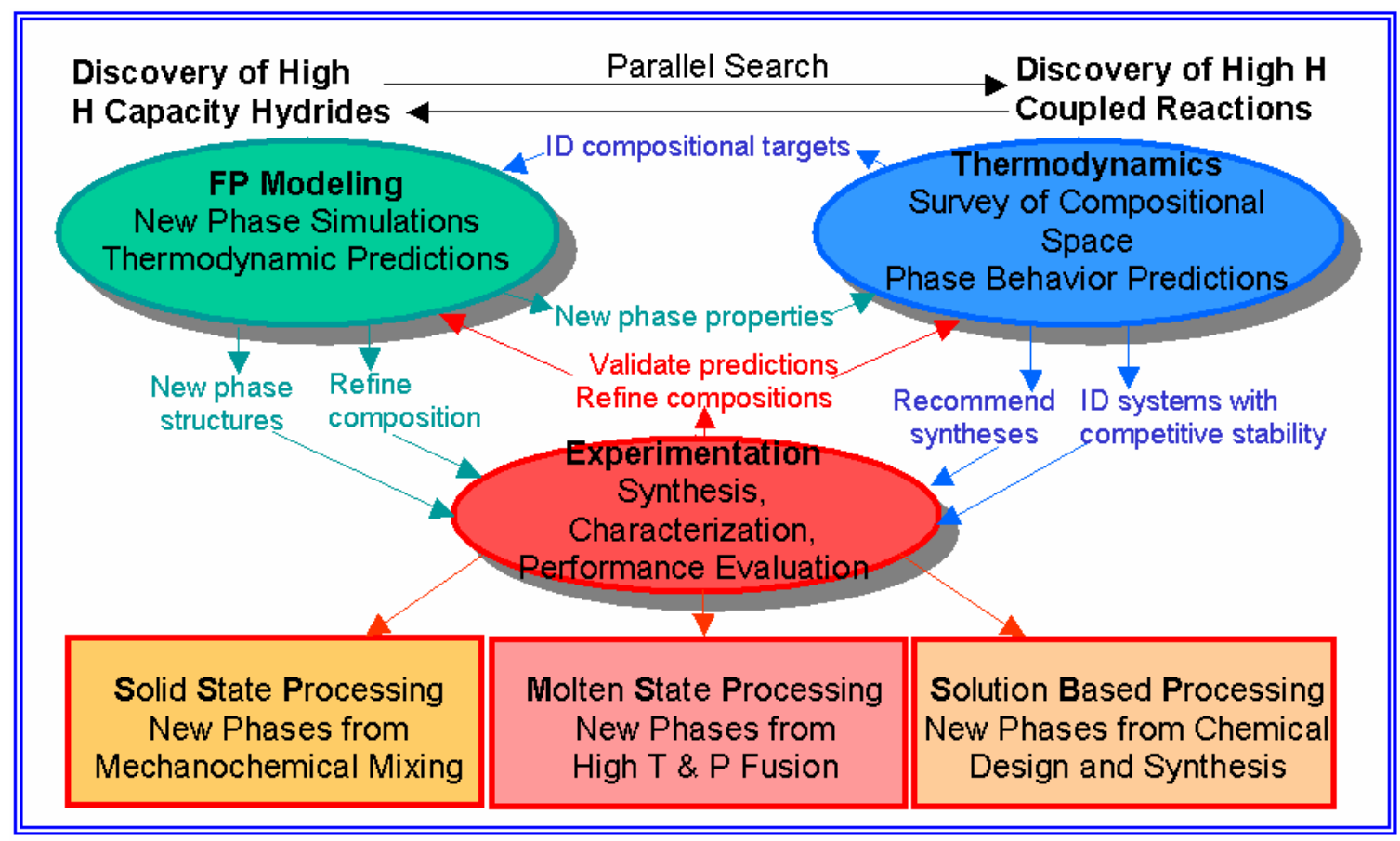

Figure 4: Shematic illustrating parallel search strategy of high $H$ coupled reactions with high $H$ capacity complex hydrides.

\subsection{Methodology}

\subsubsection{Quaternary Survey Approach}

Our strategy was to utilize combined atomistic-thermodynamic simulation methodologies to seek out high hydrogen capacity hydride compounds that could reversibly release hydrogen in a single, small reaction enthalpy disproportionation or dehydrogenation step to form predominantly non-hydrogen bearing phases. The combined atomistic-thermodynamic simulations were comprised of five stages, including: 1) model definition, 2) model refinement, 3) candidate phase identification, 4) finite 


\section{First Principles and Thermodynamic Modeling}

temperature thermodynamic property predictions and 5) thermodynamic stability predictions, which will be described in detail. Our new protocols iteratively coupled these theoretical methodologies with experimentation to establish a new paradigm for materials exploration.

Our simulations systematically screened candidate complex hydride compositions and structures in the compositional systems evaluated without reference to requisite synthesis conditions and starting reagents. The hierarchical approach used to systematically survey systems of increasing complexity within each compositional space will be described using the founding Na-Ti-Al-H system as an example. Referring to the Na-Ti-Al-H schematic in Figure 2, the trigonal pyramid representing the quaternary space is oriented so that the hydrogen-rich region of interest is closest to the viewer and is symmetrically bounded by the three important ternary surfaces. At the outset, we explored the two surfaces with the Na-Ti-H and Ti-Al-H systems with known binary phases, to complement our existing knowledge of the third $\mathrm{Na}-\mathrm{Al}-\mathrm{H}$ system. In these two systems, we proposed plausible fixed limiting ionic formulae that satisfied a preliminary (lower) minimum criterion of $6 \mathrm{wt} \%$ total $\mathrm{H}$, which were derived from substituting the quaternary elements into the stoichiometries of analogous compounds, assuming reasonable oxidation states and/or valences for the constituting elements.

We intentionally wanted to survey as many space groups as possible for each qualifying compound stoichiometry. We developed a catalog of candidate structures for the stoichiometric analogs by conducting an extensive search of crystallographic literature and databases to find complex ternary compound structures: hydrides including boronates, halides, oxides, and to a lesser extent, amides. Structural analogs of covalent oxides, sulfates and their hydrates were not considered. We created models by substituting the $\mathrm{Na}-\mathrm{Ti}-\mathrm{H}$ or $\mathrm{Ti}-\mathrm{Al}-\mathrm{H}$ compositions into the analog compound atomic positions to achieve the desired stoichiometry while maintaining the original analog space group symmetry. The most favorable ternary structures were later used as a basis for simulating quaternary compositions within the trigonal pyramid phase space. We simulated large-scale substitution of the ternary systems with the fourth remaining element, wherever possible, to achieve stoichiometries with greater than $7.5 \mathrm{wt} \%$ retrievable hydrogen. The rationale for this approach was that there are relatively few quaternary structural analogs on which to base our simulations and the alloying of line compounds with additional elements can lead compositional ranges for the existence of phases, as opposed to discrete stoichiometries in the ternary system line compounds. We then implemented methodologies to predict thermodynamic potentials and conduct preliminary thermodynamic assessments of potentials of these phases as a function of composition.

\subsubsection{Model Definition}

The multi-pronged, tiered approach employed for the simulation of more than 100 phases within the $\mathrm{Na}-\mathrm{Ti}-\mathrm{Al}-\mathrm{H}$ quaternary system $(\mathrm{Na}-\mathrm{Ti}-\mathrm{Al}-\mathrm{H})$ is shown schematically in Figure 5. In this approach, known phase structures were used as templates for the development of potential new phase models, since existing methodologies for the derivation of a wide range of solid-state structures for a given set of elements with a minimal structural basis (i.e. no assigned atomic positions) had the capability to only survey one space group at a time. As shown by the headings in Figure 5, potential candidate phases were developed in increasing order (number of elements) from known phases using three major approaches: 


\section{First Principles and Thermodynamic Modeling}

1) Isostructural hydride candidate templates -elemental, intermetallic or complex hydride structures

-higher order systems from direct cation sublattice substitution

2) Substitution in lower order mixed metal systems -derived from known low-order or intermetallic phases

-higher order systems created by interstitial substitution of $\mathrm{H}$

3) Complex analog templates -complex and mixed alkali/alkaline fluorides, boranates -direct 1:1 substitution of cations and/or anions in analogs

Known and proposed phases were theoretically evaluated in tiers of progressively increasing phase order (number of elements within phase). Only energetically favorable VASP-minimized lower order phases were used to develop higher order systems. The simulations concentrated primarily on identifying high hydrogen capacity candidate phases, and did not systematically survey lower hydrogen capacity phases, unless they were chemically related to, or, were a necessary precursor structure to derive the candidate phases.

In the first tier, known unary elemental phases were evaluated both to establish fundamental structures for the derivation of higher order phases and to determine standard state energies for thermodynamic calculations. In the higher tiers, new phases were derived either by substituting quaternary elements into known hydride or analog compound structures, or by substituting quaternary elements onto the lattice or interstitial sites of lower order known phases within the quaternary system. In a number of cases, the latter approach was used to effectively meld the ionic structures of two lower order systems to create a third higher order system. Thus, the theoretical evaluation of the proposed phases necessarily included the fundamental phases from which they were derived. The complete evaluation of the stability and reversibility of a given phase also required the simulation of lower order known phases that could form upon disproportionation and/or dehydrogenation.

In the second tier, the evaluated binary phases included: a) known elemental hydride phases (i.e. $\mathrm{TiH}_{2}$ and $\mathrm{NaH}$ ), b) known stable $\mathrm{Ti}-\mathrm{Al}$ intermetallic phases, and c) proposed metastable $\mathrm{Ti}-\mathrm{Al}$ (i.e. $\mathrm{Al}_{3} \mathrm{Ti}$ $\mathrm{D0}_{23}$ ) and $\mathrm{Ti}-\mathrm{H}\left(\right.$ i.e. $\mathrm{TiH}_{3}$ ) phases. The justification for the evaluation of low order metastable systems was their possible role as derivative structures for higher order systems. In titanium aluminides, interstitial hydrogenation has been observed to stabilize lesser known metastable systems and to shift phase boundaries to lower temperatures [Ref. 8]. The third tier focused on the Ti-Al-H and Na-Ti-H ternary phases, including: a) Ti-Al-H and $\mathrm{Na}-\mathrm{Ti}-\mathrm{H}$ phases based upon known complex and intermetallic ternary mixed alkali-alkaline earth and alkali-transition metal hydride structures, b) Ti$\mathrm{Al}-\mathrm{H}$ phases formed by interstitial hydrogenation of Ti-Al intermetallic phases, and c) $\mathrm{Ti}\left(\mathrm{AlH}_{4}\right)_{\mathrm{n}}$ $[n=1-4]$ phases formed from analog complex halide and borohydride compounds. The ternary evaluations intentionally focused on a survey of the highest possible hydrogen stoichiometries that could be used to derive high hydrogen capacity compounds. No attempts were made to determine hydrogen solubility limits in the derivative binary phases.

The fourth tier only focused on the evaluation of quaternary substituted favorable ternary phases, as no quaternary complex hydride or analog (non-oxide) compounds are known to exist. The quaternary phases evaluated primarily included favorable $\mathrm{Na}-\mathrm{Al}-\mathrm{H}$ phases highly substituted with $\mathrm{Ti}$ and favorable Na-Ti-H phases substituted with Al. 


\section{First Principles and Thermodynamic Modeling}

\begin{tabular}{|c|c|c|c|}
\hline $\begin{array}{l}\text { Unary } \\
\text { Na Ti Al H } \\
\text { first tier }\end{array}$ & $\begin{array}{l}\text { Hydride } \\
\text { Compounds }\end{array}$ & $\begin{array}{c}\text { Low Order } \\
\text { Phases }\end{array}$ & $\begin{array}{c}\text { Analog } \\
\text { Compounds }\end{array}$ \\
\hline $\begin{array}{l}\text { Binary } \\
\text { Ti-Al, Ti-H, Al-H } \\
\text { second tier }\end{array}$ & $\begin{array}{l}\text { derived from } \\
\text { binary hydrides }\end{array}$ & $\begin{array}{l}\text { derived from } \\
\text { substituted elements }\end{array}$ & $\begin{array}{l}\text { derived from binary } \\
\text { structural analogs }\end{array}$ \\
\hline $\begin{array}{l}\text { Ternary } \\
\text { Ti-Al-H, Na-Ti-H } \\
\text { third tier }\end{array}$ & $\begin{array}{l}\text { derived from complex } \\
\& \text { intermetallic hydrides }\end{array}$ & $\begin{array}{c}\text { derived from } \\
\text { substituted binaries }\end{array}$ & $\begin{array}{l}\text { derived from complex } \\
\text { structural analogs }\end{array}$ \\
\hline $\begin{array}{l}\text { Quaternary } \\
\text { Na-Ti-Al-H } \\
\text { fourth tier }\end{array}$ & & 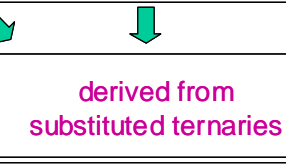 & \\
\hline
\end{tabular}

Figure 5: Schematic of model definition within the Na-Ti-Al-H quaternary system.

\subsubsection{Model Refinement}

Atomic simulations were implemented with the Vienna Ab Initio Simulation Package (VASP) code developed by Kresse and Hafner at the University of Vienna [Refs. 9,10,11], which is based upon density functional theory developments of Kohn and Sham [Ref. 12]. Crystalline and molecular atomic structures are represented as periodically repeating geometries with electronic orbitals expanded in a plane-wave basis set. In this way the number of one-electron wavefunctions is equal to the number of electrons in the crystal unit cell. The wavefunctions were described by a finite number of plane waves having wave vectors defined by the reciprocal lattice vectors of the crystal. The VASP code calculates the Kohn-Sham ground state ionic and electronic structure by an iterative band-byband matrix diagonalization scheme and by charge density mixing. The calculations employed the valence electrons and were explicitly represented with projector augmented wave (PAW) potentials [Ref. 13] using the generalized gradient approximation (GGA) of Perdew and Wang (PW 91) [Ref. 14].

For the simulation of hydride and related phase structures in the Na-Ti-Al-H system, we selected, based upon previous simulations [Refs. 5,6,15,16,17], the hard potentials for $\mathrm{Na}\left\{2 \mathrm{~s}^{2} 2 \mathrm{p}^{6} 3 \mathrm{~s}^{1}\right\}$ and $\mathrm{Ti}$ $\left\{3 s^{2} 3 p^{6} 3 d^{2} 4 s^{2}\right\}$ which include the next lower electronic level electrons in the valence shell, and the regular potentials for $\mathrm{Al}\left\{3 \mathrm{~s}^{2} 3 \mathrm{p}^{1}\right\}$ and $\mathrm{H}\left\{1 \mathrm{~s}^{1}\right\}$. Initial tests were performed on representative ternary candidate structures to optimize parameter values to within a total convergence energy of less than $1 \mathrm{meV}$ per atom. These parameters were then selected for the initial screening of all structures with the Na-Ti-Al-H system. They included a planewave cutoff energy of $780 \mathrm{eV}$ and the Gaussian smearing method energy broadening of $0.2 \mathrm{eV}$. The k-mesh of each structure was optimized individually to achieve a spacing of $0.5 /$ Angstrom or finer. The ground state geometries were determined by minimizing the Hellman-Feynman forces with the conjugate gradient algorithm, until all the ionic forces were less than $0.005 \mathrm{eV} / \AA$. In order to span as wide a range of energetically accessible crystal structures, full minimization of the cell volume, cell shape and atomic positions were made simultaneously. The structures were relaxed in this manner in a series of calculations 


\section{First Principles and Thermodynamic Modeling}

made with progressively increasing precision. A final high accuracy calculation was made to determine the ground state energy of the converged structure.

\subsubsection{Candidate Identification Criteria}

The electronic ground state (gs) heat of formation, $\Delta \mathrm{H}_{\text {formation gs electronic, was determined by referencing }}$ the ground state electronic energies of VASP-minimized complex hydride and disproportionation model phases with respect to the sum of the VASP-calculated ground state electronic energies of the respective stoichiometric equivalents of the constituent element atoms in their standard state, $\Sigma \mathrm{H}_{\text {element gs electronic }}$

Equation 1

$\Delta \mathbf{H}_{\text {formation gs electronic }}=\mathbf{H}_{\text {compound gs electronic }}-\Sigma \mathbf{H}_{\text {element gs electronic }}$

The $\Delta \mathrm{H}_{\text {formation gs electronic }}$ determined for stoichiometrically related candidate phases and known phases were systematically compared to evaluate candidate favorability. Only ternary and quaternary

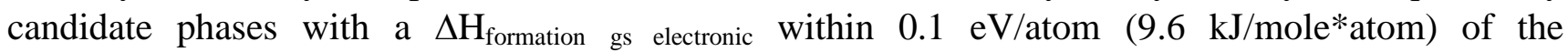
$\Delta \mathrm{H}_{\text {formation electronic }}$ of relevant known phases as well as the most favorable corresponding competing phases, or lower order disproportionation phases, were down selected for the more computationally intensive finite temperature thermodynamic property prediction by the Materials Design Phonon Module [Ref. 18]. This selection criterion was used to allow inclusion of metastable candidate phases that could possibly be stabilized by vibrational contributions at higher, more practical temperatures. Convex hull methodologies were not required with this approach to distinguish the most favorable candidate ternary and quaternary phases in the Na-Ti-Al-H and other systems.

\subsubsection{Finite Temperature Thermodynamic Property Predictions}

The atomic predictions of finite temperature thermodynamic data were obtained using the lattice dynamics direct method of Parlinski implemented in the Materials Design Phonon module interfaced with the VASP code [Refs. 18,19]. The Phonon module automates a number of steps to determine the thermodynamic functions, including: supercell formation, calculation of forces from systematic atom displacement, transformation of force constants into a dynamical matrix, matrix diagonalization to determine phonon frequencies, and integration over reciprocal space to determine phonon density of states. The vibrational thermodynamic functions as a function of temperature are derived by substituting the integrated phonon density of states into statistical mechanical functions [Ref. 20]. The finite temperature thermodynamic data are determined by summing the phase ground state structure electronic energy and the phonon-calculated zero-point energy (ZPE), with the vibrational energies as a function of temperature. Thermodynamic values are typically referenced to the elements in the standard state. This is accomplished by subtracting the sum of electronic energy, ZPE, and vibrational energy determined at $298 \mathrm{~K}$ for the stoichiometric equivalents of the respective constitutive elements of the phase. This methodology is described in detail in references [Refs. 5,16].

The phonon direct method is most suitable for predicting the thermodynamics of stable phase structures with discreet stoichiometrics that have stable (negative) $\Delta \mathrm{H}_{\text {formation gs electronic }}$ at the ground state. Since often it is found that there may be a number of energetically equivalent candidate hydride 


\section{First Principles and Thermodynamic Modeling}

structures for the same compound at the ground state, the most stable structures can be identified as those lacking imaginary (negative or soft) phonon dispersion bands. These imaginary bands indicate instabilities towards possible displacive transformations to other phase structures. Their presence confounds reliable thermodynamic predictions from lattice dynamics.

The direct approach describes finite displacements in an otherwise perfect crystal, where the displacements are approximated to be harmonic with up to quadratic order analytic terms. The chosen crystal cell has to be large enough, approaching $1000 \AA^{3}$ in size, to minimize interactions between perturbations in the translational symmetry equivalent copies. Phonon calculations were also executed on molecular structures in asymmetric periodic cells, using only the gamma point frequencies in determining thermodynamic relations. The Phonon module typically executes 10-50 calculations of displaced structures for each phase, depending on the supercell size and symmetry. The typical error in the Phonon module thermodynamic predictions was determined in initial benchmarking studies to be $5-15 \mathrm{~kJ} / \mathrm{mole}$. The vibrational contributions predicted with the Phonon module tends to be fairly accurate. The error mainly originates from the exchange-correlation approximation in the VASP ground state electronic enthalpy determination. Computationally-intense determinations of the quasiharmonic approximation for the volume-dependency of lattice phonons and of the Born effective charges to describe electric field polarization were not implemented in this study because of the limited computational facilities available. However, it has been shown that the corrections for the ZPE-induced lattice expansion and for longitudinal optical-transverse optical (LO/TO) splitting, respectively, do not make a significant impact on reducing the error of the predicted thermodynamics.

\subsubsection{Thermodynamic Data Assessment and Stability Predictions}

The thermodynamic predictions for newly identified candidate phases were first evaluated with respect to other known thermodynamic data. The candidate phases' predicted data of Gibbs free energy as a function of temperature were referenced with respect to the stoichiometric-equivalent sum of the constituent elements' standard state enthalpy values at $298.15 \mathrm{~K}$, following the GHSER referencing convention used in databases for the Thermo-Calc [Ref. 21] and HSC [Ref. 22] programs used in this study. This enabled the direct comparison of predicted data with experimentally measured and assessed thermodynamic data for known, stable phases. The Gibbs free energy as a function of temperature predicted for a given candidate phase were compared to that of the most stable assembly of phases determined by the Thermo-Calc POLY Gibbs energy minimization module to evaluate candidate stability. The Gibbs phase equilibria were calculated using experimentally-derived thermodynamic data parameters both from the previously described assessments [Refs. 5,16,23,24] and the SSUB3 database [Ref. 21]. Only phases that were shown to have lower (more favorable) GHSER (T) than that of the Gibbs energy minimized equilibrium for the equivalent stoichiometry determined for relevant temperature and pressure conditions, were down-selected as stable phases.

Rigorous thermodynamic assessments were conducted in selected cases to incorporate new experimental information and thermodynamic predictions into thermodynamic databases. Assessments involve several components: data selection, thermodynamic model selection and data fitting, and assembly of fit parameters into data files. Thermodynamic assessments involve the simultaneous optimization of empirical model fits to multiple sets of thermodynamic data, such as enthalpies of formation, heat capacities as a function of temperature, equilibria between two or more phases, etc., for stable phases within a specific compositional system. In the final stage of the 


\section{First Principles and Thermodynamic Modeling}

assessment, thermodynamic databases are constructed from the optimum parameter values that describe the system phases' referenced Gibbs free energies as a function of temperature, GHSER(T), and may include interaction parameters for varying phase compositions formed by sub-lattice or interstitial substitution. Thermodynamic parameter optimizations are an iterative process of progressive refinement. Appropriately refined databases can be used to calculate equilibria that closely match good quality measured equilibria, which were not included in the original optimization. This demonstrated capability qualifies the use of the database for predictions of thermodynamic properties for related (composition, temperature and pressure) conditions that have not yet been experimentally tested. The combined modeling approach for the progressive refinement and downselection of candidate phases is illustrated by the modeling flow path and decision criteria in Figure 6.

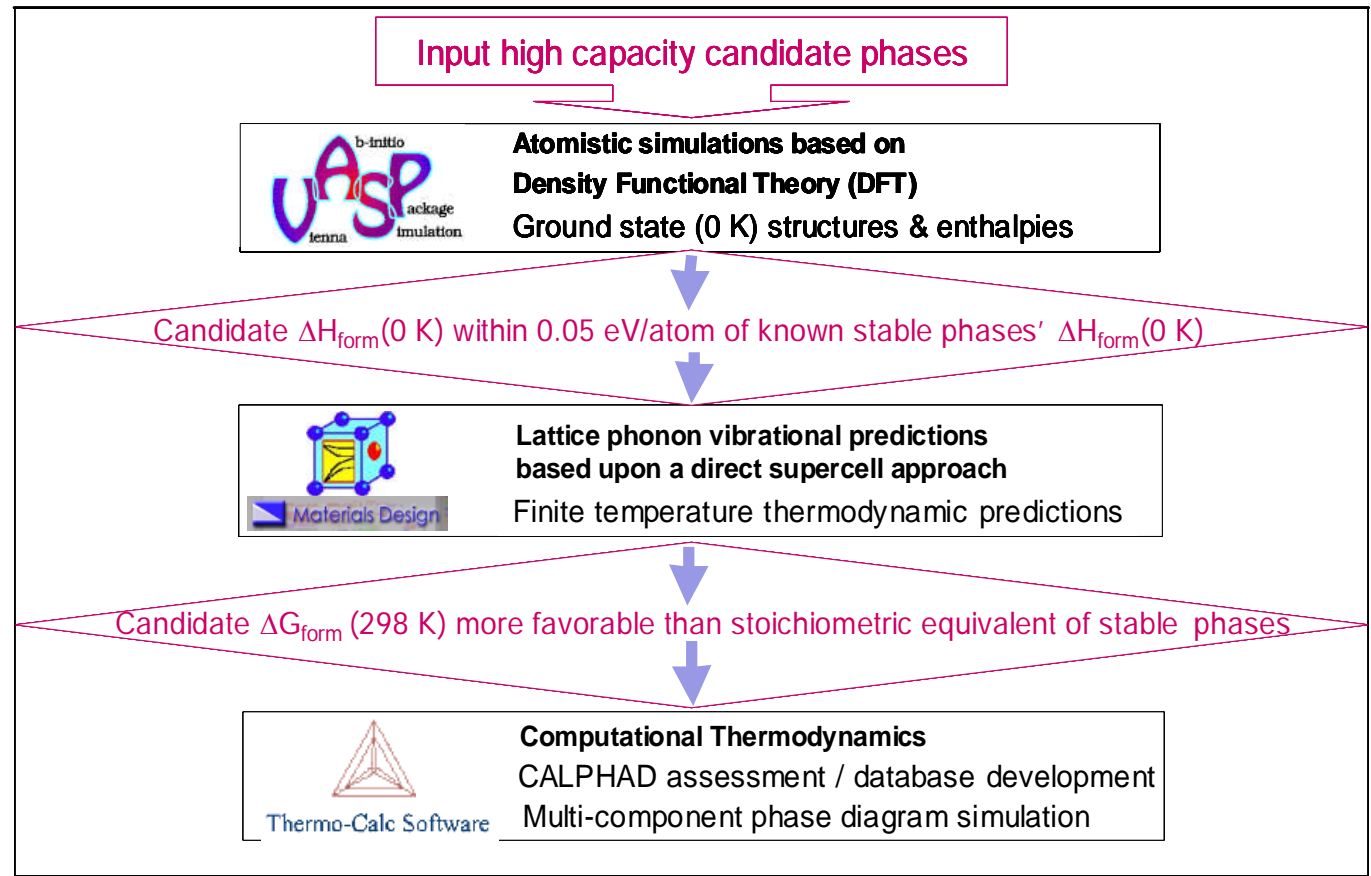

Figure 6: Combined atomic-thermodynamic flowpath.

\subsubsection{Refinements for High H Coupled Complex Hydride Reaction Strategy}

The expansion to the high $\mathrm{H}$ coupled complex reaction strategy required the implementation of additional theoretical methodologies in close integration with experimental and thermodynamic methods. First, a global optimization method was implemented for the refinement of candidate input structures, especially in conjunction with the crystallographic refinement of new phases. Second, thermochemical reaction predictions were implemented for the design of reversible high $\mathrm{H}$ capacity reactions to provide guidance for experimental formulation of new systems. Finally, a method was developed to enable thermodynamic optimization of theoretical $\mathrm{H}$ capacity within a mutlidimensional parameter space. 


\section{First Principles and Thermodynamic Modeling}

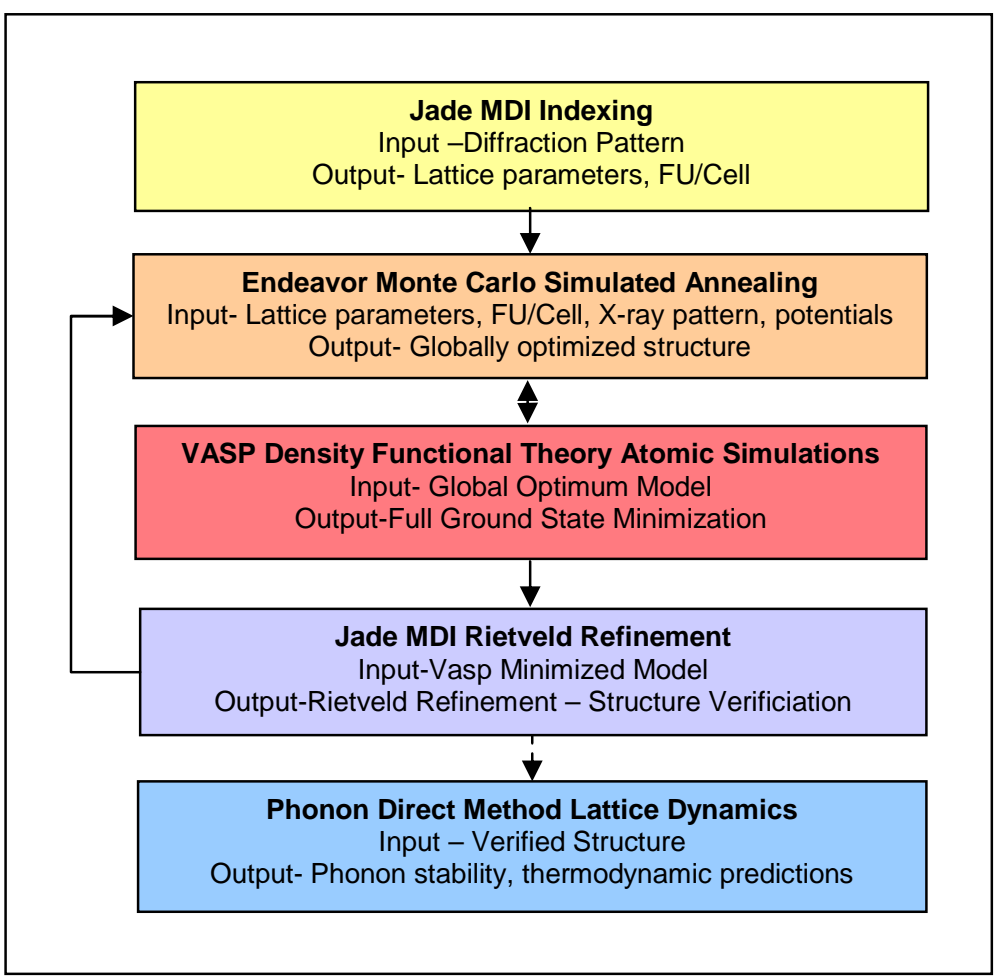

Figure 7: New combined crystallographic analyses and atomic modeling approach to accelerate refinement of crystal structures.

\subsubsection{Improved Model Structures: Monte Carlo Simulated Annealing Methodology}

A new approach has been developed to prepare new candidate input models for virtual screening studies and for crystallographic Rietveld refinements, as shown schematically in Figure 7. This approach can be used to integrate atomic simulations and experimental structural analyses to accelerate the identification and resolution of new crystallographic structures. This new linkage was first envisioned in a joint collaboration plan developed with Sandia National Laboratories to support the development of high capacity titanium borohydride compounds [Ref. 25]. The approach employs an additional methodology, Monte Carlo simulated annealing, implemented with the Endeavor code [Ref. 26]. Input models are globally optimized with this code to find the best atomic positions that (simultaneously) match given crystallographic X-ray diffraction data (and) or minimize the potential energy of the crystal structure. The simulated annealing samples both atomic displacements and exchanges over a large hypersurface with many local minima, to eventually converge on a global minimum structure [Ref. 27]. This new methodology was interfaced at the front end of our original simulation protocol shown in Figure 6, where the new methodology can be used to iteratively refine new structures to improve the reliability of thermodynamic predictions.

\subsubsection{Thermochemistry Design of Reversible Reactions}

The HSC Chemistry program [Ref. 22] was used to propose and evaluate reaction pathways for new high $\mathrm{H}$ candidate systems. First, thermodynamic data are established for candidate phases, co-reactants, and products, by supplementing with thermodynamic predictions wherever necessary. In order to identify new candidate high $\mathrm{H}$ capacity systems, new reactions are systematically evaluated in terms of reaction energetics and $\mathrm{H}$ exchange between dehydrogenation and rehydrogenation. The most 


\section{First Principles and Thermodynamic Modeling}

thermoneutral reactants with the largest $\mathrm{H}$ capacity are used to create input conditions for equilibrium survey calculations. These calculations, based on the Gibbs minimization method, are used to identify which phases will predominate in $\mathrm{H}$ exchange reactions, especially where there may be many possible competing reactions for consideration. The identification of the most stable phases is used to propose the most likely candidate reactions, which can be further evaluated. The goal is to identify reactions which have the minimum number of steps and reduce the likelihood of formation of harmful side-products.

\subsubsection{Thermodynamic Optimization Tool}

The final stage is to optimize the system composition to find the best stoichiometry that gives the highest reversible $\mathrm{H}$ capacity. A new Matlab tool was developed for the TC MATLAB Toolbox [Ref. 28] interface and Thermo-Calc thermodynamic software [Ref. 21] to calculate the equilibrium reversible hydrogen content over a selected compositional space and temperature/pressure conditions. The tool can be used with established and/or user-developed thermodynamic databases to determine the optimum elemental stoichiometry for the highest theoretical reversible hydrogen capacity. Equilibrium and phase diagram calculations can be made to determine the most stable fully hydrogenated reactant and dehydrogenated product phases that correspond to the optimum elemental stoichiometry. Thermochemical simulations can then be made to deduce the predominant reaction pathways and to project the equilibrium dehydrogenation pressure temperature dependency. This tool completes the methodology development for the virtual design of high capacity, reversible thermodynamic reactions.

\subsubsection{Overview of Theoretical Methodologies}

To summarize our progress, we have implemented a broad array of coupled theoretical methodologies that are closely integrated with experimental and thermodynamic methods, as schematically shown in Figure 8. New candidate input structures are globally optimized to match both crystallographic information and to minimize structure potential energy. Candidate structures are then minimized at the ground state with DFT. In certain cases, global optimization and minimization can be conducted iteratively to refine new crystal structures. Finite temperature thermodynamic predictions are made for stable ground state structures, enabling the inclusion of hypothetical phases in thermodynamic surveys. Assessments are conducted to validate and incorporate predicted thermodynamic data alongside experimental data in thermodynamic databases, enabling phase diagram predictions for a range of composition, temperature and pressure conditions. Thermochemistry methods are used to survey and design new coupled reactions that exchange high $\mathrm{H}$ between species. Once a target chemistry is identified, the optimum theoretical hydrogen capacity can be designed thermodynamically to guide experimental development. 


\section{First Principles and Thermodynamic Modeling}

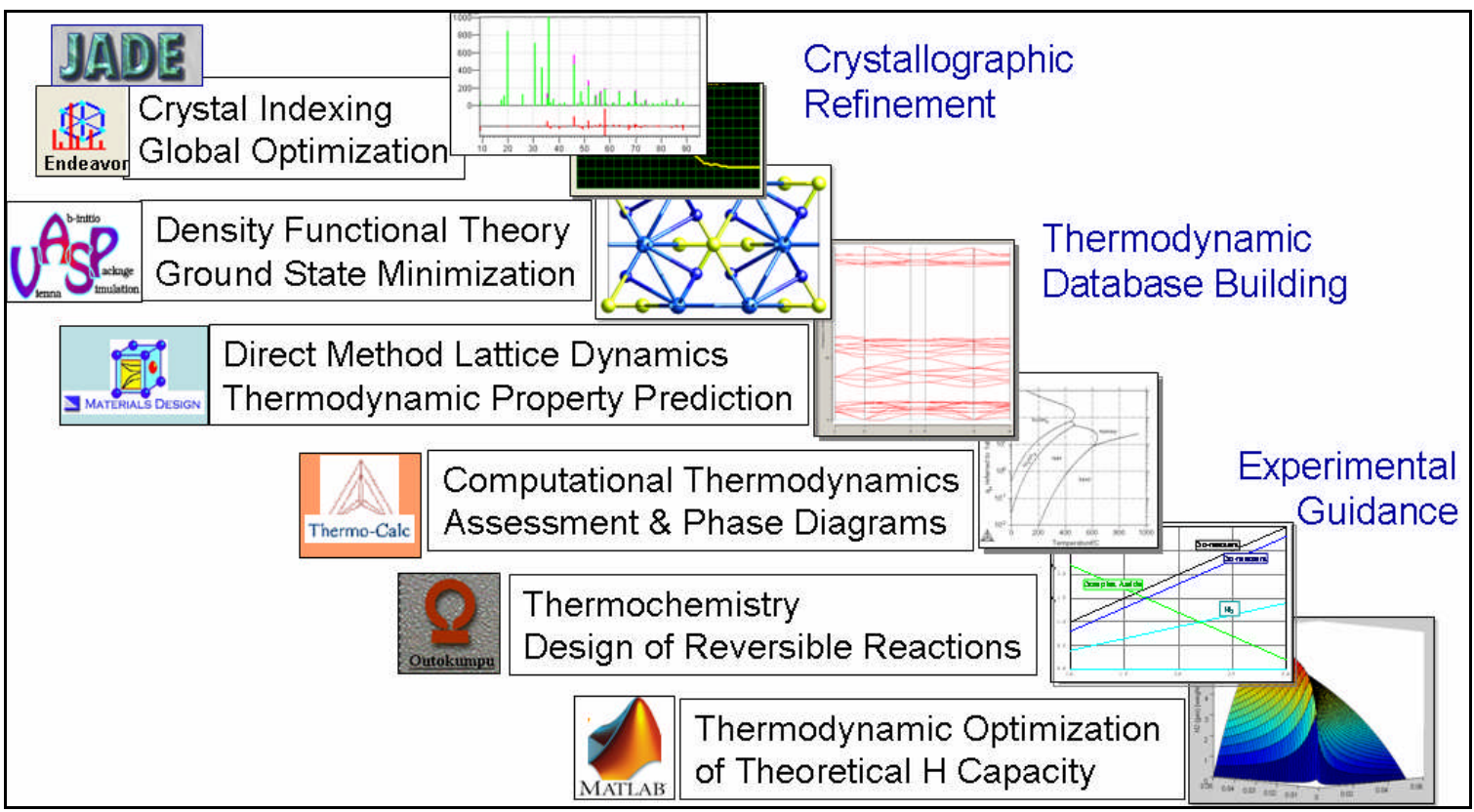

Figure 8: Array of computational methodologies for virtual discovery and design of high hydrogen capacity systems.

\subsection{Results and Discussion}

This section presents an overview of the extensive virtual survey of high capacity candidate hydrides and related phases conducted for this project, emphasizing the continuous improvement and implementation of new simulation methodologies. The approach taken and the survey scope evolved throughout the execution of the program both in response to the knowledge gained from our findings and recommendations from our reviewers and colleagues in the hydrogen storage research community. Out of necessity, many of the important findings from this project already published in the open literature are presented in brief. The reader is encouraged to consult the cited references for a more detailed presentation of results.

\subsubsection{Funding Year 1 Atomic-Thermodynamic Modeling}

\subsubsection{Literature Survey}

To prepare for our virtual surveys, we conducted extensive scientific literature surveys on binary hydrides, intermetallic and complex hydride ternary hydrides, and their respective relevant disproportionation products. From the most illuminating references [Refs. 29,30,31,32,33,34,35], we surveyed common structure-property observations and rules for their stable existence that were derived from complex hydride crystallographic, spectroscopic, and thermochemical characterizations, as summarized in Table 4. These observations include: the structural correlation of certain complex hydride stoichiometries to specific ternary halide or oxide compounds with analogous stoichiometries, typical bond distances within various types of hydride complexes, and geometrical relationships for interactions between neighboring metallic cations and between neighboring hydrogen atoms. The rules for complex hydride existence are not universal; they were developed for specific complex hydride subclasses that exhibit similar types of bonding behavior and stoichiometries. For example, 


\section{First Principles and Thermodynamic Modeling}

there are discrete stoichiometries with limiting ionic formulae observed for all complex compounds, electron rules for the formation of different covalent transition metal hydride complex geometries [Refs. 30,31], and heat of formation ranges for stable existence of complex transition metal hydrides [Ref. 29]. Since there are multiple exceptions to these established observations and rules, they were only used to guide, not to bound our search for high capacity phases with heretofore unknown characteristics.

Table 4: Solid-state hydride classes and characteristics from literature review [Refs. 29,30,31,32,33,34,35].

\begin{tabular}{|c|c|c|c|}
\hline Compound Class & Compositions & Examples & Characteristics \\
\hline $\begin{array}{c}\text { Complex Covalent Hydrides, } \\
\begin{array}{c}\mathrm{Aa}^{[+\mathrm{Z}]}\left(\mathrm{NH}_{\mathrm{x}}\right)_{\mathrm{n}}{ }^{[-\mathrm{Y}]} \text { where } \\
\mathrm{a}=\left(\mathrm{n}^{*} \mathrm{Y}\right) / \mathrm{Z}\end{array}\end{array}$ & $\begin{aligned} \mathrm{A}= & \mathrm{AK}, \mathrm{AE} \\
& \mathrm{TM}, \mathrm{NT} \\
\mathrm{N}= & \mathrm{B}, \mathrm{Al}, \mathrm{Ga}\end{aligned}$ & $\begin{array}{c}\mathrm{Mg}\left(\mathrm{AlH}_{4}\right)_{2} \\
\mathrm{Zr}\left(\mathrm{BH}_{4}\right)_{4}\end{array}$ & $\begin{array}{c}\text { Stoichiometric, covalent } \\
\text { complex of non-TM bonded } \\
\text { to } \mathrm{H} \text {, stabilized by counter } \\
\text { ions }\end{array}$ \\
\hline $\begin{array}{c}\text { Complex Ternary TM } \\
\text { Hydrides } \\
\mathrm{A}_{\mathrm{a}}^{[+1,2]}\left(\mathrm{B}_{\mathrm{m}} \mathrm{H}_{\mathrm{h}}\right)^{\left[-\mathrm{a}^{*} 1,2\right]}\end{array}$ & $\begin{aligned} \mathrm{A}= & \mathrm{AK}, \mathrm{AE}, \\
& \text { some } \mathrm{RE} \\
\mathrm{B}= & \mathrm{TM}\end{aligned}$ & $\begin{array}{c}\mathrm{K}_{3} \mathrm{PtH}_{6} \\
\mathrm{CaMgNiH}_{4}\end{array}$ & $\begin{array}{c}\text { Central complex follows } 18 \\
\text { electron rule, dehydrided } \\
\text { binary phase not stable. }\end{array}$ \\
\hline $\begin{array}{l}\text { Complex Alkali, Alkaline } \\
\text { Earth \& TM Halides } \\
\mathrm{A}_{\mathrm{a}}^{[+1,2]}\left(\mathrm{B}_{\mathrm{m}} \mathrm{X}_{\mathrm{h}}\right)^{\left[-\mathrm{a}^{*} 1,2\right]}\end{array}$ & $\begin{array}{l}\mathrm{A}=\mathrm{AK}, \mathrm{AE}, \mathrm{NT} \\
\mathrm{B}=\mathrm{A}, \mathrm{NT}, \mathrm{TM} \\
\mathrm{X}=\mathrm{F}, \mathrm{Cl}\end{array}$ & $\begin{array}{l}\mathrm{MgAl}_{2} \mathrm{Cl}_{8} \\
\mathrm{Na}_{2} \mathrm{TiH}_{6} \\
\mathrm{Na}_{3} \mathrm{AlF}_{6}\end{array}$ & $\begin{array}{c}\text { Many binary and ternary } \\
\text { hydrides are isostructural, } \\
\text { often equivalent } \\
\text { H and F ionic radii. }\end{array}$ \\
\hline $\begin{array}{l}\text { Complex Alkali/ } \\
\text { Alkaline Earth Hydrides } \\
\qquad \mathrm{A}_{\mathrm{a}} \mathrm{B}_{\mathrm{b}} \mathrm{H}_{[\mathrm{a}+2 \mathrm{~b}]}\end{array}$ & $\begin{aligned} A= & A K \\
B= & A E, \text { some } \\
& R E\end{aligned}$ & $\begin{array}{c}\mathrm{NaMgH}_{3} \\
\mathrm{SrLiH}_{3}\end{array}$ & $\begin{array}{l}\text { Ionic coordination } \\
\text { proportional to relative } \\
\text { ionic radii, binary } \\
\text { hydrides not isostructural }\end{array}$ \\
\hline $\begin{array}{l}\text { Interstitial TM \& Laves } \\
\text { Hydrides, } \mathrm{TMA}_{\mathrm{a}} \mathrm{TMB}_{\mathrm{b}} \mathrm{H}_{\mathrm{h}}\end{array}$ & $\begin{aligned} \mathrm{TMA}= & \text { some } \mathrm{TM} \\
& \text { or } \mathrm{RE} \\
\mathrm{TMB} & =\text { any } \mathrm{TM}\end{aligned}$ & $\begin{array}{l}\mathrm{LaNi}_{5} \mathrm{H}_{6} \\
\mathrm{FeTiH}_{6}\end{array}$ & $\begin{array}{l}\text { Nonstoichiometric } \mathrm{H} \\
\text { substituted in stable } \\
\text { intermetallic phases }\end{array}$ \\
\hline \multicolumn{4}{|c|}{$\begin{array}{ll}\mathrm{AK}=\text { alkali } \quad \mathrm{AE}=\text { alkaline earths } \mathrm{TM}=\text { transition metals } \\
\mathrm{RE}=\text { rare earths }\end{array}$} \\
\hline
\end{tabular}

\subsubsection{Benchmarking of Thermodynamic Predictions}

The over-riding objective of the first year was to develop theoretical and assessment methodologies for constructing thermodynamic databases jointly from both experimentally measured and predicted thermodynamic properties. This new capability would then be used as a tool to identify potential high hydrogen capacity hydride phases and to evaluate their phase stability over a wide range of temperature and pressure conditions. In this manner, the combined atomic-thermodynamic methodologies would be used to guide experimentation and to supplement thermodynamic measurements that may be difficult or impossible to execute in the laboratory. The latter includes the evaluation of candidate phases that have yet to be identified experimentally, and the prediction of pressure-composition isotherms and van't Hoff P vs. T relationships that are labor and time intensive to measure in the laboratory. In the first year, these new combined methodologies were first exercised by benchmarking predicted thermodynamic properties of known phases against those calculated using 


\section{First Principles and Thermodynamic Modeling}

experimentally-based thermodynamic data parameters [Refs. 5,16,23]. These comparisons made for known phases were then used to estimate the error of thermodynamic predictions of hypothetical candidate phases simulated within the three quaternary systems. These methodologies were then used in the remainder of the program to scout new quaternary systems that have the potential to yield high $\mathrm{H}$ complex hydrides and to develop new thermodynamic parameters for compositional phase spaces that encompass these successful new candidates. The thermodynamic parameters enable virtual evaluation of the complex hydride phase behavior over a wide range of temperature and pressure conditions.

The predicted referred Gibbs free energies of formation as a function of temperature, GHSER (T), were determined for each of the known sodium alanate complex hydrides and disproportionation products, to enable direct comparison with assessed experimental data parameterized in the ThermoCalc thermodynamic database. An example comparison is shown in Figure 9 for the predicted and experimentally measured GHSER $(\mathrm{T})$ versus temperature for sodium aluminum tetra-hydride, $\mathrm{NaAlH}_{4}$ [Ref. 5]. The predicted GHSER $\mathrm{NaAlH}_{4}(\mathrm{~T})$ values were within $9 \mathrm{~kJ} /$ Mole of the composite experimental values [Refs. 2,36,37,38] over the temperature range of $300-450 \mathrm{~K}$. The predicted and measured dissociation pressures from the van't Hoff relationship for the first $\mathrm{NaAlH}_{4}$ disproportionation reaction:

\section{Equation 2}

are shown in Figure 10. The predicted dissociation pressures were calculated using the GHSER (T) determined from the lattice dynamics of the three solid state phases in Equation 2, and the GHSER $_{\mathrm{H} 2}(\mathrm{~T})$ in the Thermo-Calc PURE database. The agreement between the predicted and composite measured dissociation pressures is excellent, due to the cancellation of errors of the predicted GHSER $\mathrm{NaAlH}_{4}$ and GHSER $\mathrm{Na}_{\mathrm{NAlH}}$ values in the van't Hoff relationship. Additional plots comparing thermodynamic experimental data and first principles predictions in the $\mathrm{Na}-\mathrm{H}$ and $\mathrm{Na}-\mathrm{Al}-$ $\mathrm{H}$ systems can be found in [Refs. 5,16]. These references also show the extensive phase diagram predictions that are possible from the assessments of the combined experimental-first principles thermodynamic datasets. 
First Principles and Thermodynamic Modeling

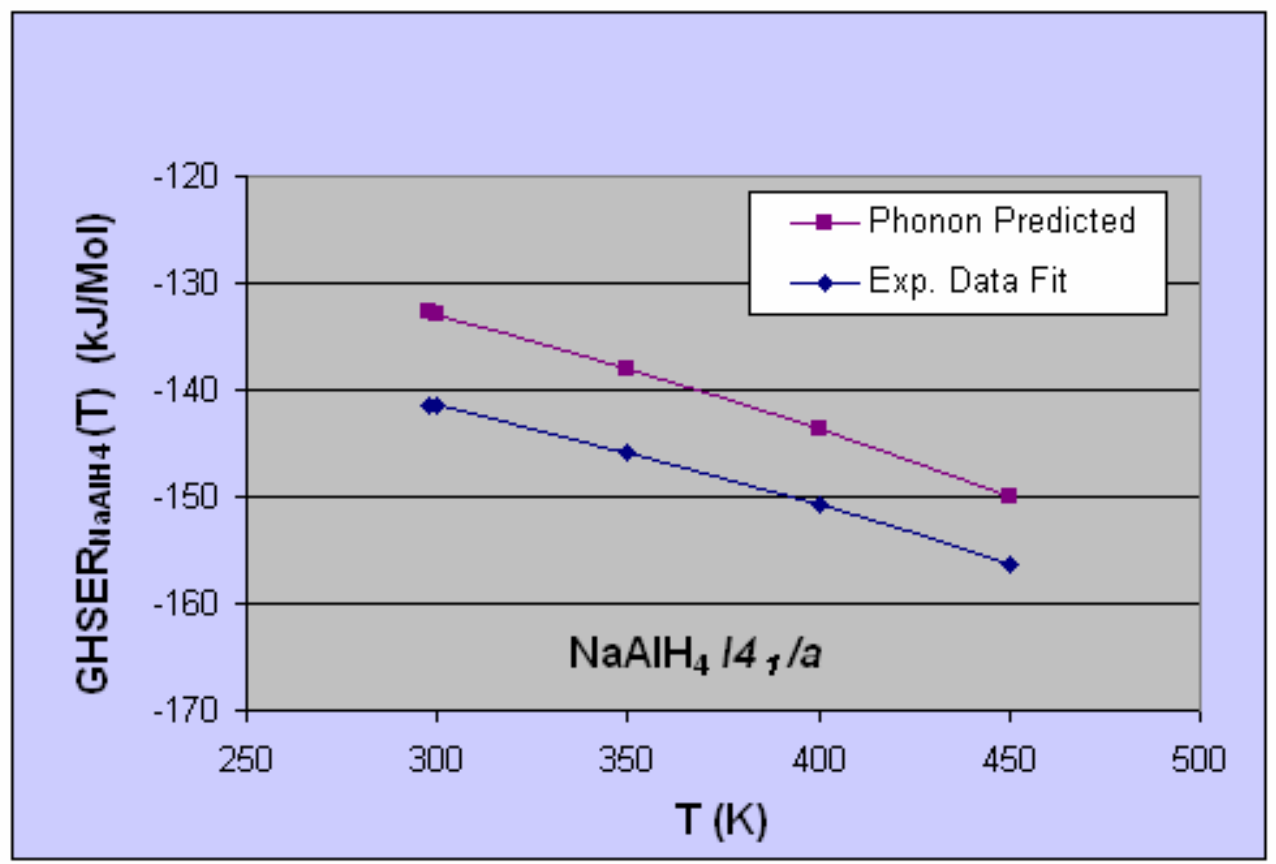

Figure 9: The comparison of GHSER $\mathrm{NaAlH}_{4}(T)$ predicted with Phonon direct method lattice dynamics [Refs. 18,19] of the ground-state VASP minimized $\mathrm{NaAlH}_{4} \mathrm{I}_{1} / a$ phase, compared with that calculated with Thermo-Calc using assessed fits from [Ref. 5] to experimental measurements published in references [Refs. 2,36,37,38].

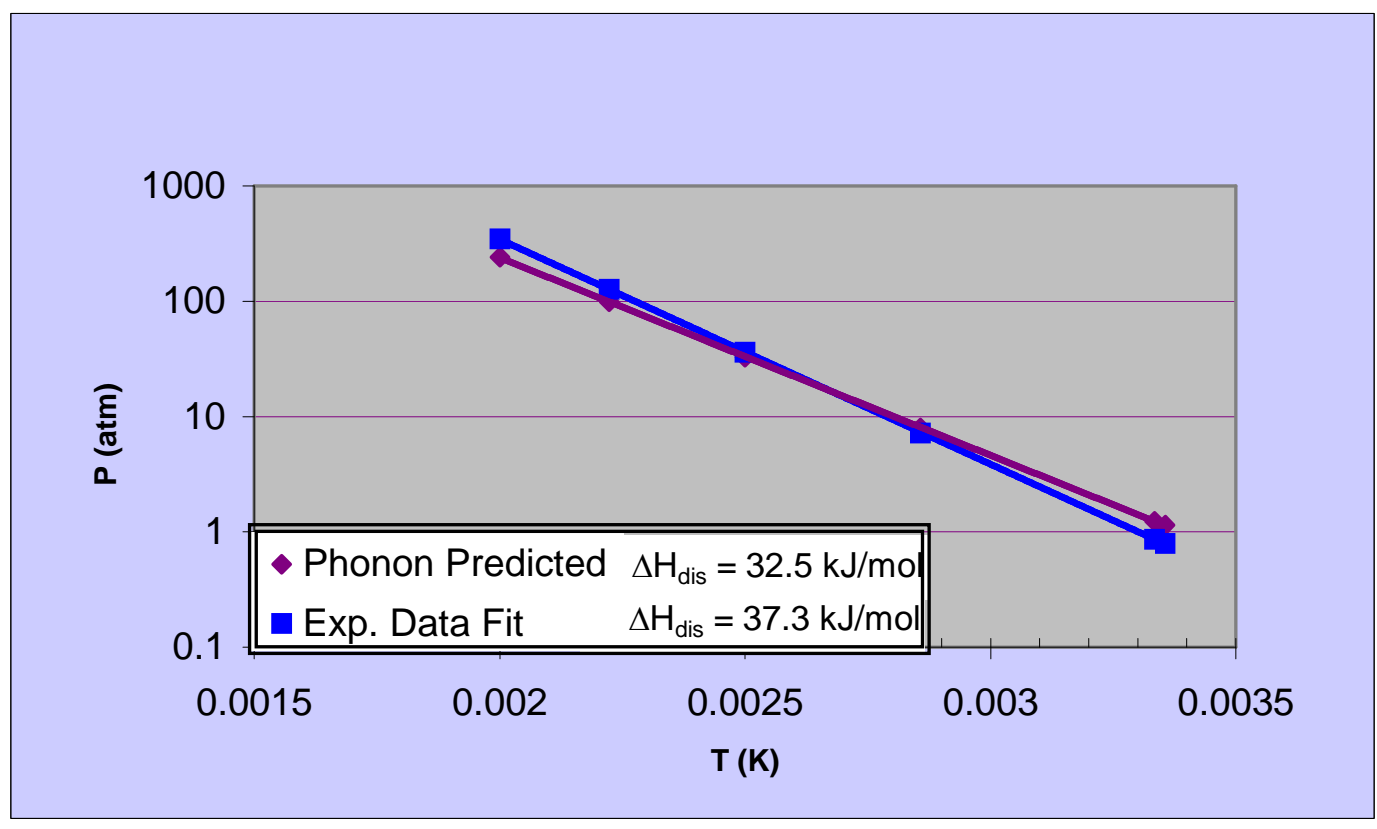

Figure 10: The comparison of predicted and measured dissociation pressures for the first $\mathrm{NaAlH}_{4}$ disproportionation reaction, $\mathrm{NaAlH}_{4}={ }_{1}^{1} \mathrm{Na}_{3} \mathrm{AlH}_{6}+{ }^{2}{ }_{3} \mathrm{Al}+\mathrm{H}_{2}$. The dissociation pressure predictions are described in the text. The measured values are a composite fit from [Ref. 5] to the experimental data in references [Refs. $2,36,37,38]$. The disproportionation enthalpies, $\Delta \mathbf{H}_{\text {dis, }}$ are determined from the slopes of the lines. 


\section{First Principles and Thermodynamic Modeling}

\subsubsection{Na-Ti-Al-H Candidate Hydride Simulations}

To build the Na-Ti-Al-H quaternary system, the candidates were refined in increasing order, yielding down-selected candidates to derive progressively higher order systems. The simulations first focused on developing precursor phases in the Ti-Al, Ti-H, Na-H, and $\mathrm{Al}-\mathrm{H}$ binaries. Unlike the other two possible $\mathrm{Na}-\mathrm{Ti}$ and $\mathrm{Na}-\mathrm{Al}$ binaries that were not evaluated, these four binaries exhibited significant co-solubilization and intermediate phase formation over their binary compositional ranges. In the TiAl binary system, a large number of stable, metastable, and hypothetical phases with varying stoichiometry in the $\leq 50 \%$ Ti binary region were evaluated to determine the relative phase stability at $0 \mathrm{~K}$. The calculated ground state heats of formation for the various Ti-Al phases are shown in Figure 11. The most stable phases were down-selected as templates for candidates in the higher order Ti-Al-H ternary, to be formed by interstitial hydrogen substitution. Simulations of the other three binaries focused primarily on simulating known phases at the ground state and hypothetical lattice stability phases to develop parameters for the further refinement of thermodynamic assessments.

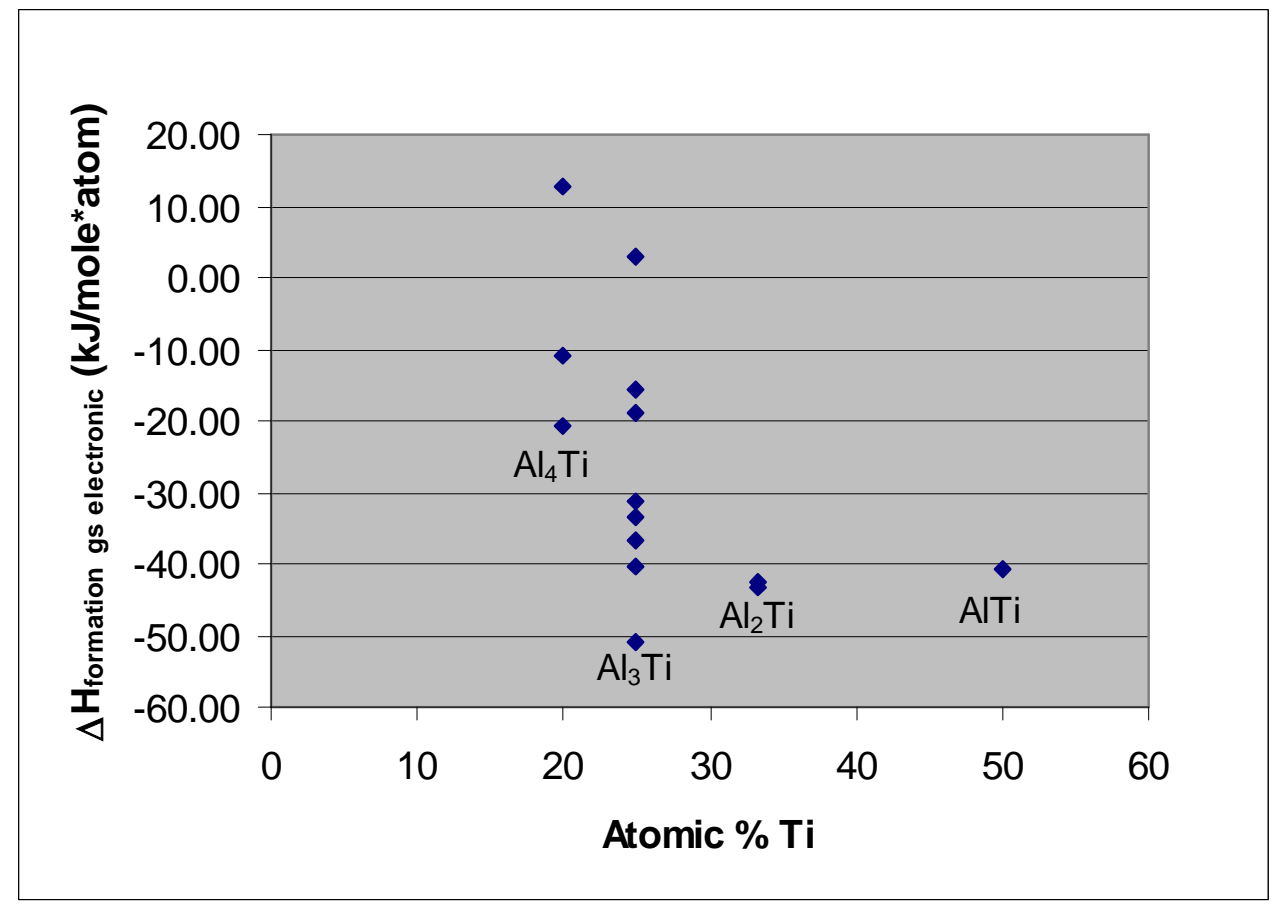

Figure 11: Ground state enthalpies of formation, $\Delta \mathbf{H}_{\text {formation gs electronic, for candidate binary }}$ Ti-Al intermetallic structures.

The next tier of simulations explored the Ti-Al-H, Na-Al-H, and Na-Ti-H ternary faces that share the common high hydrogen vertex in the Na-Ti-Al-H system. The candidates' theoretical reversible gravimetric hydrogen content was defined as:

Equation 3

wt \% $\mathbf{H}_{\text {Rev Theor }}=\left(\mathbf{N}_{\mathrm{H}}-\mathbf{N}_{\mathrm{Na}}\right) /$ Hydride Formula Weight 


\section{First Principles and Thermodynamic Modeling}

where $\mathrm{N}_{\mathrm{H}}$ and $\mathrm{N}_{\mathrm{Na}}$ were the number of $\mathrm{H}$ and $\mathrm{Na}$ atoms in the candidate hydride formula. Here, only the $\mathrm{Na}$ atoms were assumed to combine with $\mathrm{H}$ upon complete dehydrogenation and all $\mathrm{Ti}$ was assumed to be incorporated into a Ti-Al intermetallic phase ( $\mathrm{TiAl}_{3}$ is the most favorable phase) upon complete dehydrogenation and would not be available to sequester hydrogen. Candidate phases were not simulated within the basal Na-Ti-Al ternary opposite this vertex. The Ti-Al-H candidates were derived either by interstitial hydrogenation of Ti-Al intermetallic structures, or, by direct sub-lattice substitution on the complex analog templates. Both approaches offered the possibility of discovering high hydrogen capacity compounds, akin to the reported, but unsubstantiated $\operatorname{Ti}\left(\mathrm{AlH}_{4}\right)_{4}$ compound. The simulation results for a wide range of interstitially $\mathrm{H}$-substituted known and candidate $\mathrm{Ti}^{-} \mathrm{Al}_{\mathrm{x}}$ stoichiometries, where $\mathrm{x}$ ranged from 1 to 4, are shown in Figure 12, compared to predictions for the known stable sodium alanate and $\mathrm{TiH}_{2}$ phases. Most of the candidates did not have favorable (negative) $\Delta \mathrm{H}_{\text {formation gs electronic }}$ values. Interstitial hydrogenation of the Ti-Al phases exhibited a nearly linear decreasing favorability with increasing $\mathrm{wt} \% \mathrm{H}_{\mathrm{Rev}}$ Theor.

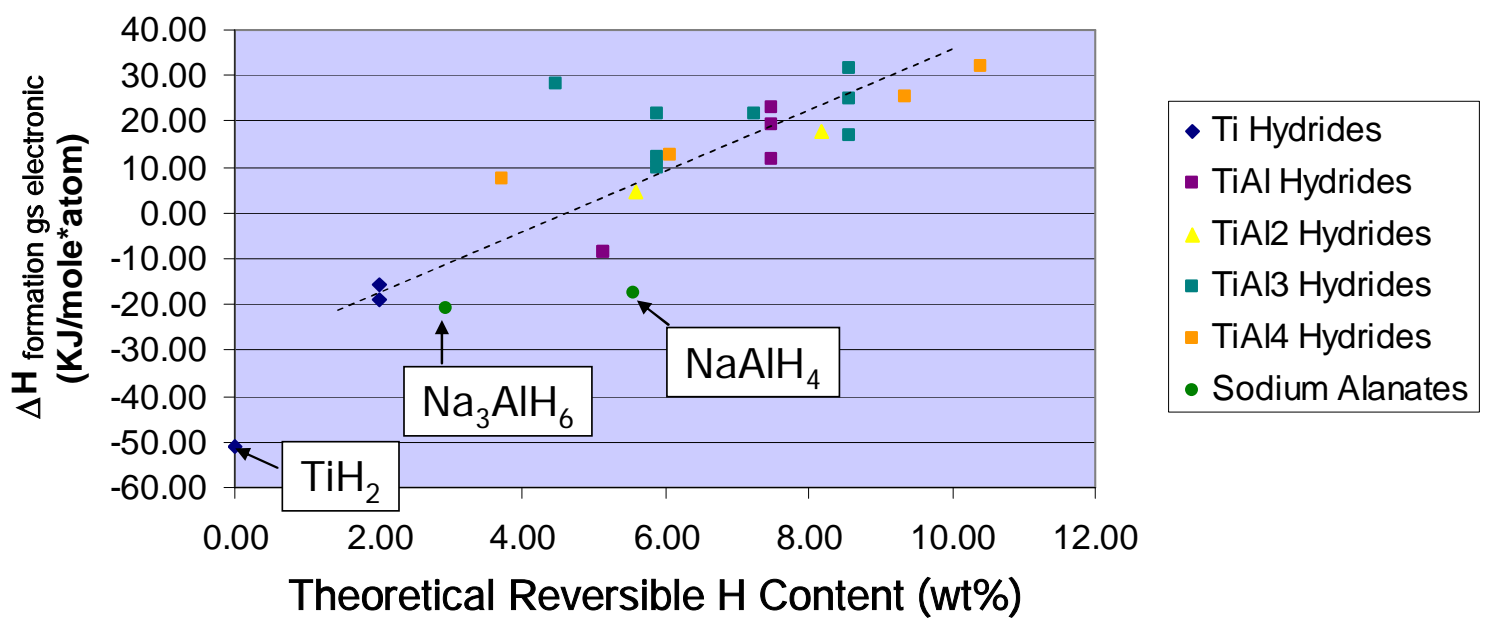

Figure 12. Ground state enthalpies of formation, $\Delta \mathbf{H}_{\text {formation gs electronic, for candidate } \mathrm{Ti}-\mathrm{Al}}$ hydrides formed by $\mathrm{H}$ interstitial substitution in known and hypothetical Ti-Al intermetallic phases.

The Ti-Al-H complex analog approach sampled a wide range of compound structures to represent the $\mathrm{Ti}\left(\mathrm{AlH}_{4}\right)_{\mathrm{x}}$ stoichiometries, where $\mathrm{x}$ ranged from 2 to 4 . These candidates corresponded to a wt $\%$ $\mathrm{H}_{\mathrm{Rev} \text { Theor }}$ range of 7.2-9.4, respectively. Figure 13 shows that a number of these later candidate phases had $\Delta \mathrm{H}_{\text {formation gs electronic }}$ in the -5 to $-10 \mathrm{~kJ} / \mathrm{mole} *$ atom range, indicative of weak favorability with a high driving force for disproportionation. None of these structures were down-selected for further refinement as a ternary phase or as templates for quaternary systems. The only new candidate phase evaluated in the Na-Al-H ternary was $\mathrm{Na}_{5} \mathrm{Al}_{3} \mathrm{H}_{14}$, derived from the fluoride analog compound. The two major approaches used to evaluate phases in the $\mathrm{Na}-\mathrm{Ti}-\mathrm{H}$ system were isostructural complex hydride and complex analog templates. Several $\mathrm{Na}-\mathrm{Ti}-\mathrm{H}$ compound $\mathrm{Na}_{2} \mathrm{TiH}_{6}$ stoichiometries were

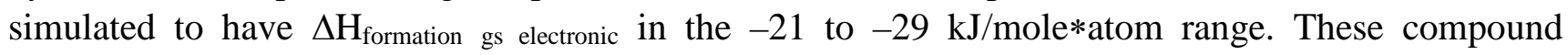
predictions are also shown in Figure 13. Although these compounds did not have potential for high 


\section{First Principles and Thermodynamic Modeling}

hydrogen capacity, they could be used as templates for higher capacity quaternary systems formed by partially substituting $\mathrm{Al}$ for Ti.

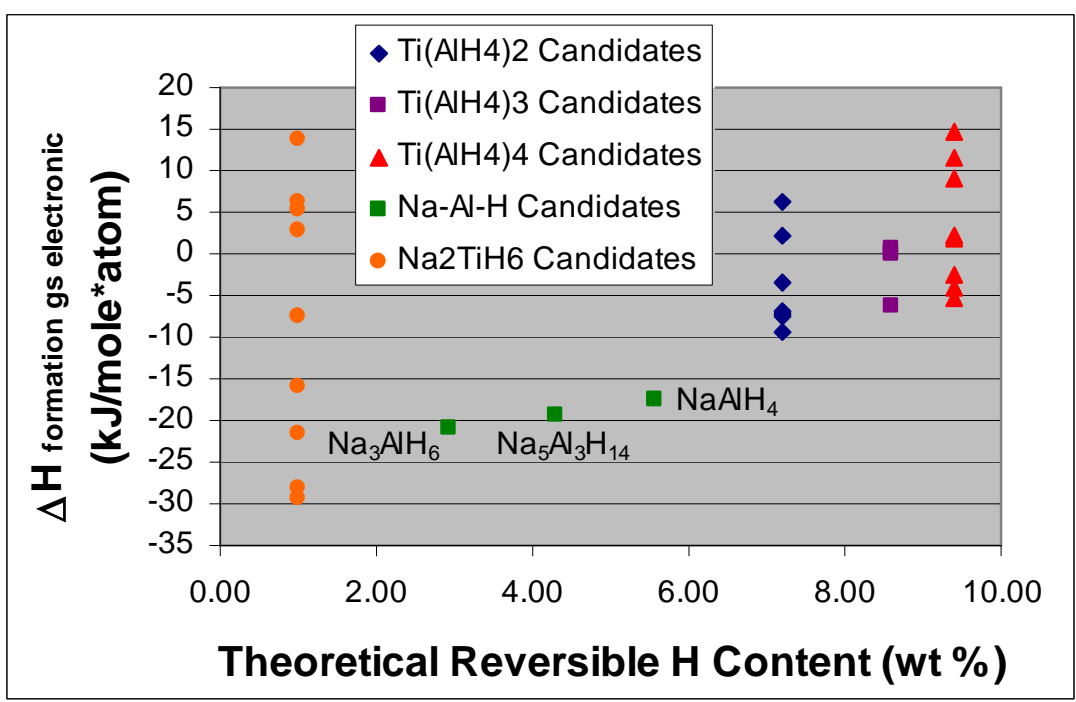

Figure 13: Ground state enthalpies of formation, $\Delta \mathbf{H}_{\text {formation gs electronic, for candidate Ti-Al-H, Na- }}$ Al-H and Na-Ti-H ternary phases.

Several approaches were also trialed for proposing new quaternary Na-Ti-Al-H candidate phase models, including candidate derivation from structures of other known complex or intermetallic hydride phases, direct or interstitial substituted lower-order phases, and non-hydride analog compounds. Since there are relatively few solved structures of complex hydride analog compounds formed from four elements in the crystallographic literature, quaternary hydride models were mainly formed by substituting a fourth element into one or more sublattices of known ternary hydride phases. The creation of ternary and quaternary complex hydrides from substitution of lower order phases only revealed stable candidates for lower $\mathrm{H}$ capacity phases that were outside of our range of interest in this contract. The most fruitful approach so far, was to utilize other analog compounds as templates for new complex phases. This approach was especially successful for virtually resolving structures of known phases [Ref. 24], and for the case of fluoride analogs, has an established solid-state basis. Many isostructural fluoride and hydride phases are known to exist, where $\mathrm{F}$ and $\mathrm{H}$ ions occupy equivalent sublattices, respectively, and the sublattice spatial arrangements are the same for each ion type. This equivalency is attributed to the similar radii of fluoride and hydride ions that are often found in corresponding local coordinative environments [Ref. 30]. An example of an iso-structural complex phase pair are the high temperature orthorhombic Immm $\beta-\mathrm{Na}_{3} \mathrm{AlF}_{6}$ cryolite and $\beta-\mathrm{Na}_{3} \mathrm{AlH}_{6}$ phases. Further justification for using fluoride analogs as templates was based directly on our synthetic observations that iso-structural fluoride/hydride mixed complex phases are formed by metathesis reactions from fluoride and hydride precursor compounds. The use of fluoride analogs to develop new hydride models essentially surveys compositional phase space by employing virtual metathetical reactions.

The best Na-Ti-Al-H quaternary candidates were derived mainly from isostructural hydrides and complex fluoride analogs. The $\mathrm{wt}_{\mathrm{t}} \% \mathrm{H}_{\mathrm{Rev}}$ Theor of the candidates ranged from 4.3 to 7.3 , encompassing a range of compositions for each of the doped candidates. Figure 14 shows that although most all 


\section{First Principles and Thermodynamic Modeling}

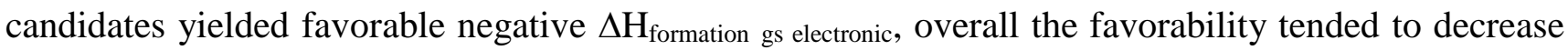
with increasing hydrogen content. The most favorable candidates with $\Delta \mathrm{H}_{\text {formation gs electronic }}$ comparable to the known sodium alanate phases had less than $5 \mathrm{wt} \% \mathrm{H}_{\mathrm{Rev}}$ Theor. Finite temperature predictions were made for several of these latter candidate phases, first to further method development for candidate stability evaluation, and, second to evaluate possible templates for other quaternary systems containing lighter elements that would have the potential to yield higher hydrogen capacity.

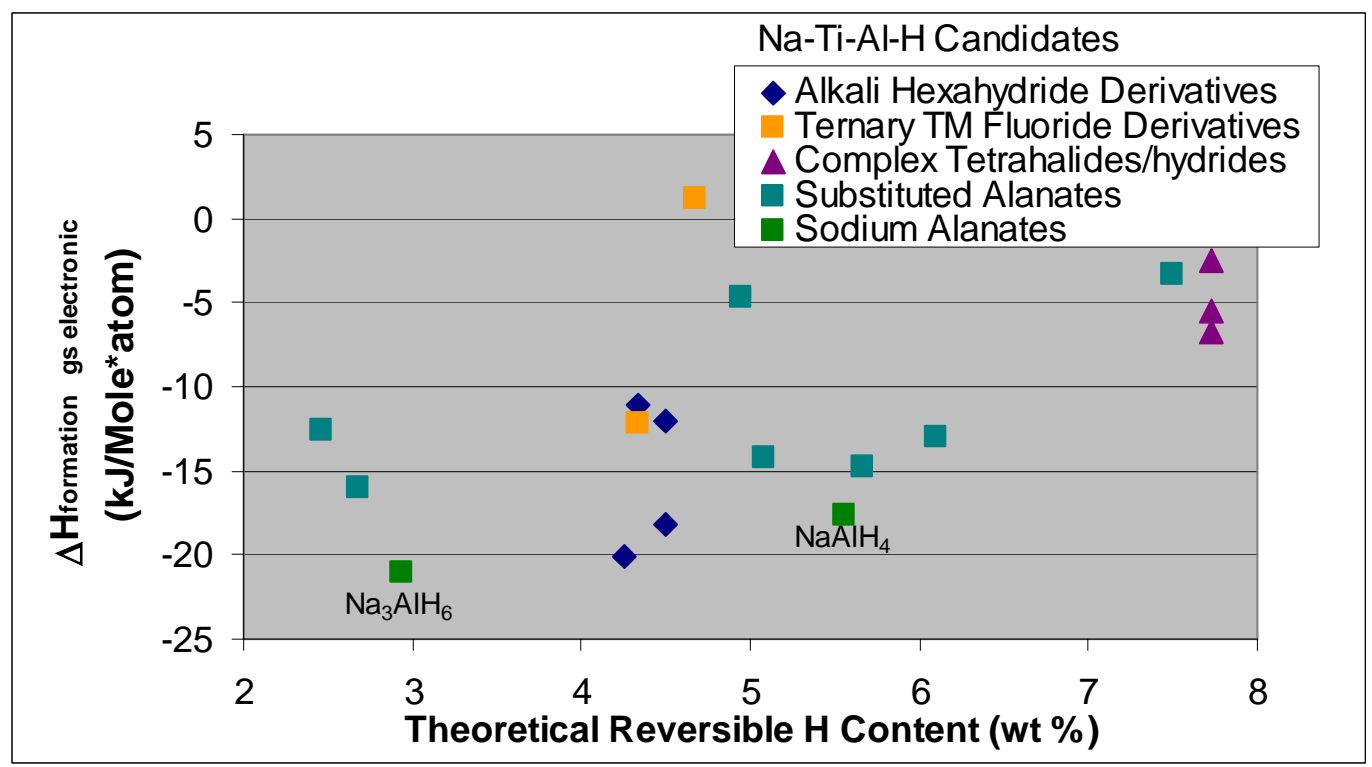

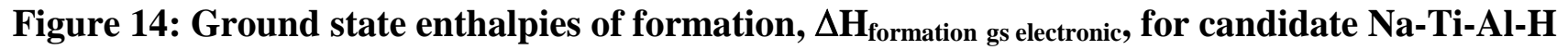
quaternary phases.

\subsubsection{Li-Ti-Al-H and Na-Li-Al-H Candidate Hydride Simulations}

The simulated quaternary phases for the Li-Ti-Al-H system built on the approaches taken and the

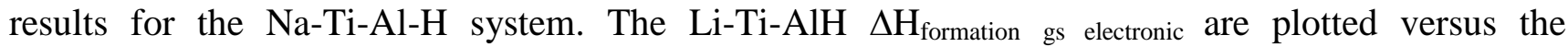
theoretical $\mathrm{H}$ content in Figure 15. Several of the quaternary Li-Ti-Al-H phases were predicted at the ground state to be more favorable, but did not offer increased capacity compared to the corresponding Li-Al-H phases. 


\section{First Principles and Thermodynamic Modeling}

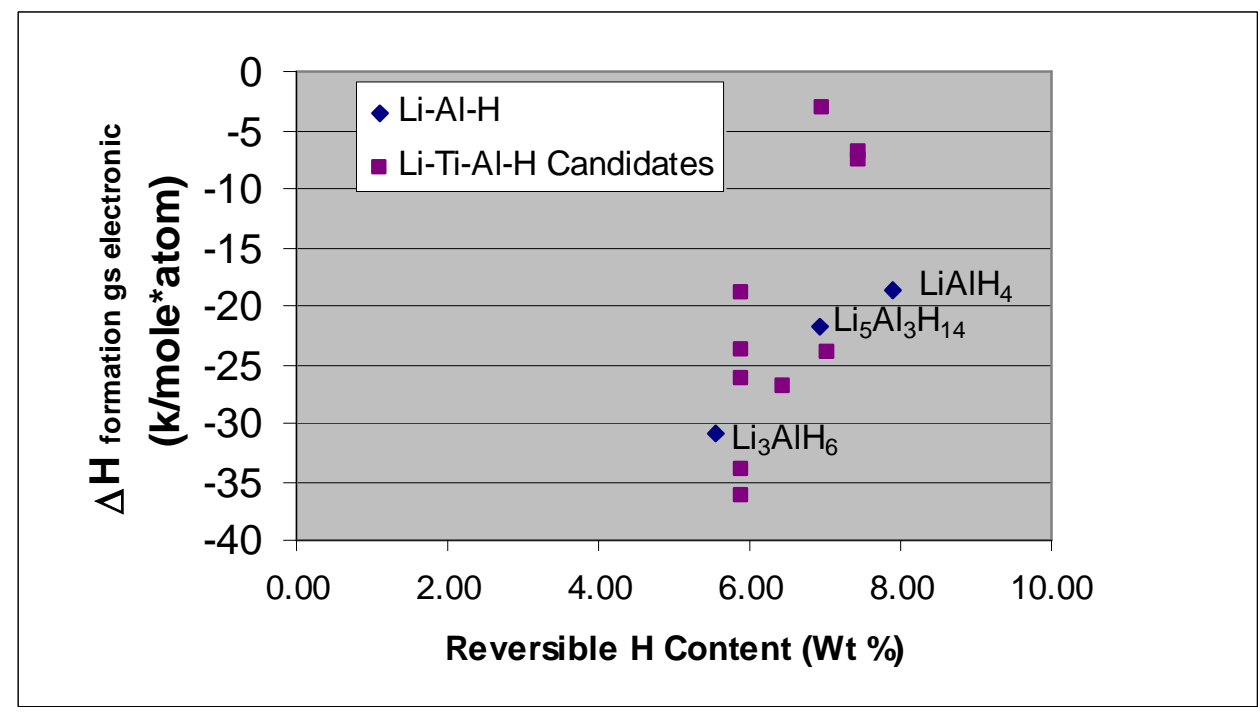

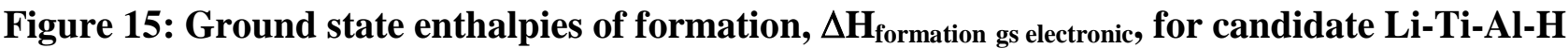
quaternary phases.

Extensive surveys were conducted on the Na-Li-Al-H and other mixed alkali quaternary systems, in collaboration with Ole M. Løvvik of the University of Olso, and the Institute for Energy, Norway. From the results summarized in Ref. 40, it was determined that no new Na-Li-Al-H candidate phases for stable existence were identified other than the known $\mathrm{Na}_{2} \mathrm{LiAlH}_{6}$ phase with $3.5 \mathrm{wt} \% \mathrm{H}_{\text {Rev Theor }}$. The comparison of the predicted thermodynamic properties for this phase with those determined from experimental measurements is made in Ref. 41. The predicted dissociation enthalpy for the first $\mathrm{Na}_{2} \mathrm{LiAlH}_{6}$ disproportionation reaction

\section{Equation 4}

$$
{ }^{2} /{ }_{3} \mathrm{Na}_{2} \mathrm{LiAlH}_{6} \rightarrow{ }^{4} / 3 \mathrm{NaH}+{ }^{2} / 3 \mathrm{LiH}+{ }^{2} / 3 \mathrm{Al}+\mathrm{H}_{2}
$$

was $6-9 \mathrm{~kJ} / \mathrm{mol}$ smaller than the measured values [Refs. 42,43].

\subsubsection{Assessment of Na-Ti-Al-H, Li-Ti-Al-H and Na-Li-Al-H Candidate Hydrides}

Complex hydride phase candidates with theoretically reversible gravimetric hydrogen capacities of $5.9 \%$ or higher, as well as associated phases, were evaluated within the three Na-Ti-Al-H, Li-Ti-Al$\mathrm{H}$, and Na-Li-Al-H systems. The predicted candidate phases' GHSER(T) values were compared to the Thermo-Calc Gibbs energy minimized equilibrium of known phases at relevant temperature and pressure conditions. One such comparison is shown in Figure 16 for the favorable complex hydrides (wt\% $\mathrm{H}_{\mathrm{Rev}}$ Theor): $\mathrm{Na}_{4} \mathrm{TiAlH}_{12}$ (4.5), $\mathrm{Na}_{6} \mathrm{Ti}_{2} \mathrm{AlH}_{18}$ (4.3), and $\mathrm{Na}_{8} \mathrm{Ti}_{3} \mathrm{AlH}_{24}$ (4.3). Although these candidates do not have significant $\mathrm{H}$ capacity, the comparison of their stability with the predicted equilibrium of phases determined with established thermodynamic databases provides a clear illustration of candidate evaluation for down-selection. In this case, the predicted equilibrium of $\mathrm{NaH}$, $\mathrm{TiH}_{2}, \mathrm{Na}_{3} \mathrm{AlH}_{6}$ and gas phases are more stable by over $10 \mathrm{~kJ} / \mathrm{mole}$ *atom over the isopleth composition range, having the $\mathrm{Na}$ and $\mathrm{H}$ mole fractions fixed at 0.22 and 0.66 , respectively, at $298 \mathrm{~K}$ and $1 \mathrm{~atm}$. None of these candidate phases were shown to have lower (more favorable) GHSER(T) than that of the Gibbs energy minimized equilibrium for the equivalent stoichiometry determined for 


\section{First Principles and Thermodynamic Modeling}

relevant conditions, the criteria for down-selection as stable phases. However, the predicted thermodynamic properties of a number of stable, uncharacterized, associated phases in these systems were successfully assessed and incorporated into the database. This latter activity signifies successful completion of the combined modeling first-year objective for database construction.

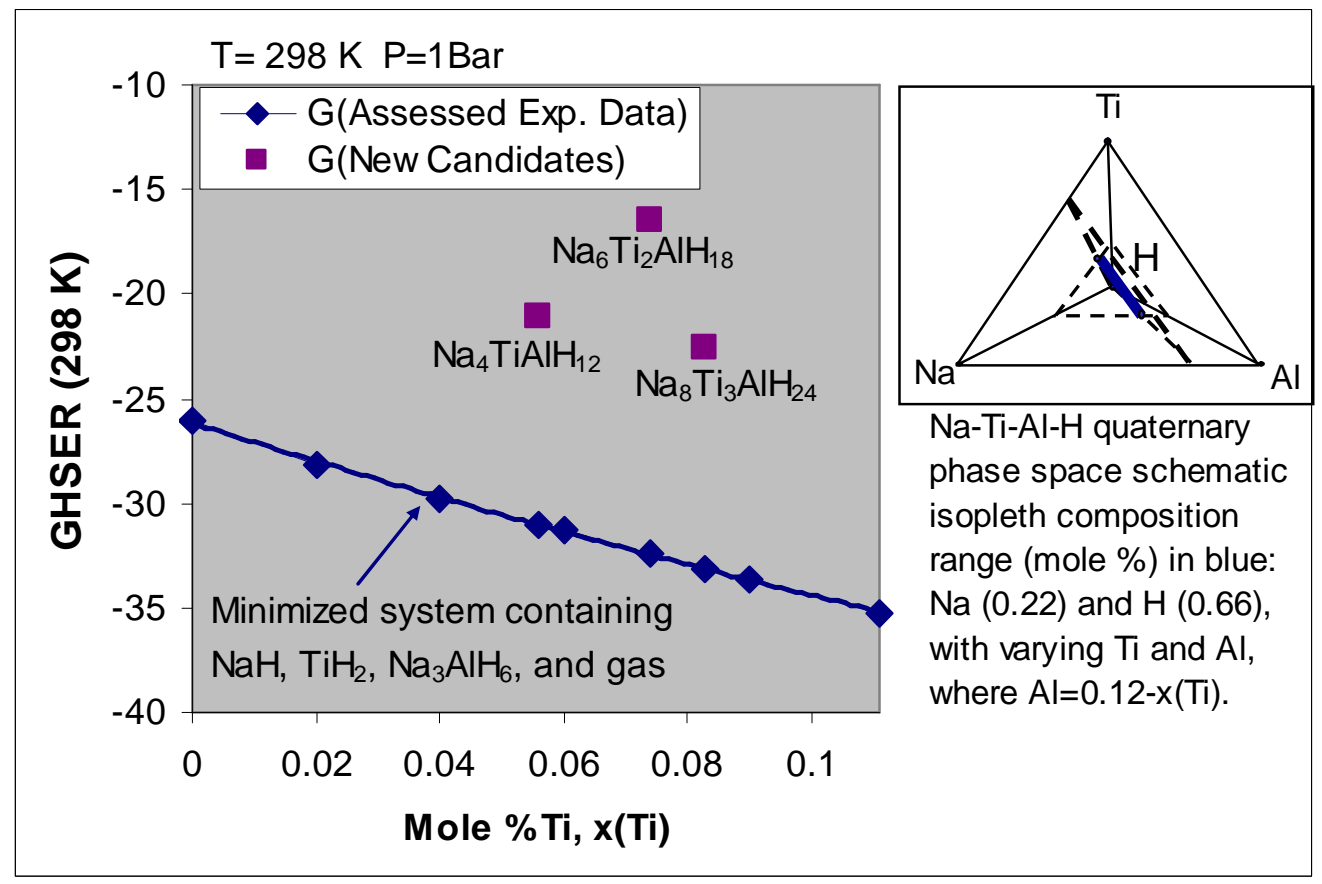

Figure 16: Na-Ti-Al-H quaternary Ti-Al isopleth comparing GHSER ( $298 \mathrm{~K}, 1$ bar) values for newly predicted Na-Ti-Al-H complex hydride candidates with the Gibbs energy minimized phases determined with the Thermo-Calc Poly program with the combined SSUB3 [Ref. 21] and Na-Al-H [Ref. 5] databases for the composition range in mole \%: $0.22 \mathrm{Na}, 0.66 \mathrm{H}$, with 0.12 $(\mathrm{Ti}+\mathrm{Al})$ and $\mathrm{Al}=\mathbf{0 . 1 2}-\mathbf{x}(\mathrm{Ti})$.

The thermodynamic assessment of selected experimentally characterized and predicted phase data within the Na-Ti-Al-H quaternary system is detailed in reference [Ref. 44]. This enabled the thermodynamic modeling of $\mathrm{Ti}$ solubility within the $\mathrm{NaAlH}_{4}, \mathrm{Na}_{3} \mathrm{AlH}_{6}$, and $\mathrm{NaH}$ phases, and the coexistence of Ti-bearing phases with the Na-Al-H system using sub-lattice models. This included the predicted thermodynamic properties of the hypothetical $\mathrm{NaTiH}_{4}$ and $\mathrm{Na}_{3} \mathrm{TiH}_{6}$ compounds, as well as their mixing properties with $\mathrm{NaAlH}_{4}$ or $\alpha-\mathrm{Na}_{3} \mathrm{AlH}_{6}$. A repulsive interaction is predicted by the first principle calculations when $\mathrm{Ti}$ is dissolved in $\mathrm{NaAlH}_{4}$ or $\alpha-\mathrm{Na}_{3} \mathrm{AlH}_{6}$ which becomes stronger when increasing the temperature. If $\mathrm{Ti}$ is present, decomposition of $\mathrm{NaAlH}_{4}$ and $\alpha-\mathrm{Na}_{3} \mathrm{AlH}_{6}$ can lead to formation of $\mathrm{TiAl}_{3}$ and/or $\mathrm{TiH}_{2}$.

\subsubsection{Thermodynamic Optimization of the Na-Li-Al-H quaternary}

An investigation was conducted on the Na-Li-Al-H system to demonstrate the utility of coupling experimental and theoretical methodologies for material optimization [Ref. 41]. Of interest was the development of mixed hydride systems that could leverage the high capacity of the lithium alanates 


\section{First Principles and Thermodynamic Modeling}

and the reversibility of the sodium alanates. A database of the predicted thermodynamic properties of all known phases in the Na-Li-Al-H quaternary system was created, including the recently evaluated $\mathrm{Na}_{2} \mathrm{LiAlH}_{6}$ phase [Refs. 42,43,45,46]. Thermodynamic calculations with this database were used to elucidate the most favorable reactions for synthesis and disproportionation of the intermediate $\mathrm{Na}_{2} \mathrm{LiAlH}_{6}$ phase. The two most favorable competing disproportionation reactions are shown in Figure 17. The disproportionation to the elemental hydrides, as given in $2 / 3 \mathrm{Na}_{2} \mathrm{LiAlH}_{6} \rightarrow{ }^{4} / 3 \mathrm{NaH}+$ $2 / 3 \mathrm{LiH}+{ }^{2} / 3 \mathrm{Al}+\mathrm{H}_{2}$ releases the most hydrogen. A less desirable $\mathrm{Na}_{2} \mathrm{LiAlH}_{6}$ disproportionation step releasing less $\mathrm{H}_{2}$ was predicted to predominate below $87^{\circ} \mathrm{C}$.

\section{Equation 5}

$$
2 /{ }_{3} \mathrm{Na}_{2} \mathrm{LiAlH}_{6}={ }^{4} / 9 \mathrm{Na}_{3} \mathrm{AlH}{ }_{6}+{ }^{2} / 3 \mathrm{LiH}+{ }^{2} / 9 \mathrm{Al}+{ }^{1 / 3} \mathrm{H}_{2}
$$

In this latter pathway, another reaction step would be required to fully release all of the hydrogen within the system. Experimental observations corroborated the occurrence of this reaction occurring at lower temperature [Ref. 41].

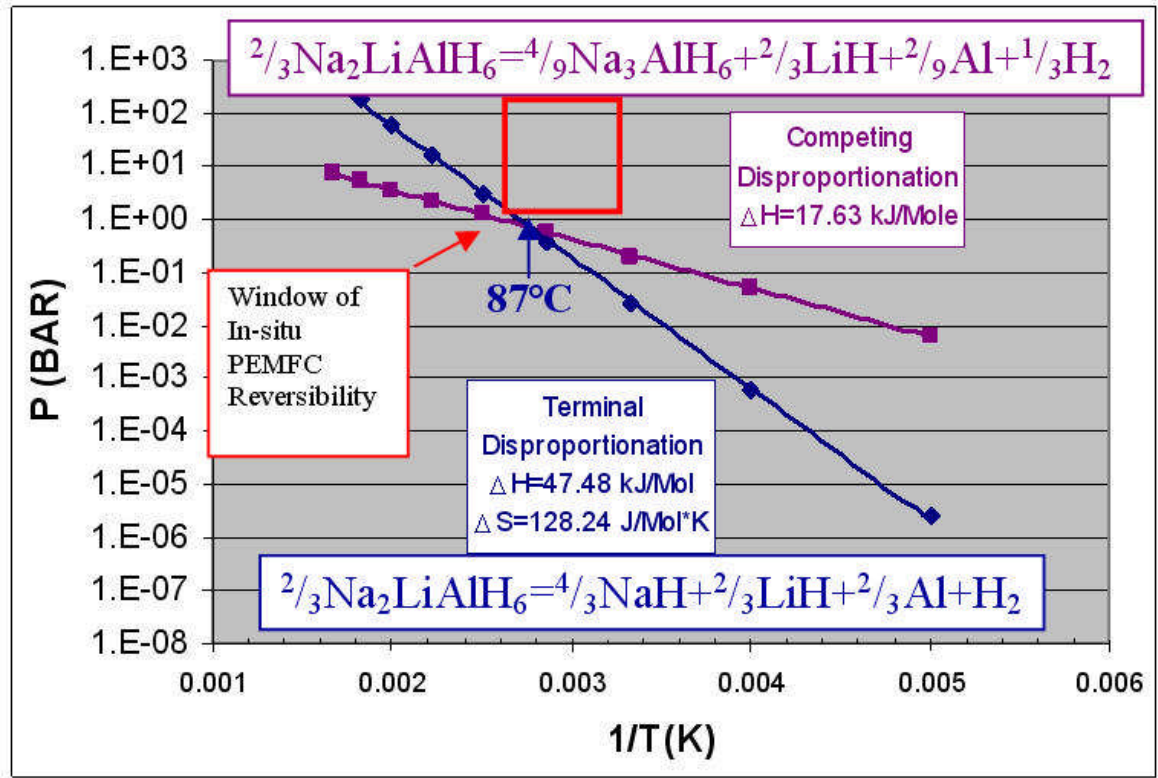

Figure 17: The predicted van't Hoff plot showing the relationship two competing $\mathrm{Na}_{2} \mathrm{LiAlH}_{6}$ disproportionation reactions.

Gibbs free energy minimization and phase diagram calculations were conducted to identify the composition, temperature and pressure conditions for optimum $\mathrm{H}$ capacity within the $\mathrm{Na}-\mathrm{Li}-\mathrm{Al}-\mathrm{H}$ system. A theoretical reversible $5.2 \mathrm{wt} \% \mathrm{H}_{\mathrm{Rev}}$ Theor was predicted for the starting stoichiometry $\{2 \mathrm{Na}$ : $1 \mathrm{Li}: 2 \mathrm{Al}: 9 \mathrm{H}\}$ corresponding to a $2 \mathrm{NaAlH}_{4}: 1 \mathrm{LiH}$ mixed hydride composition. This mixture would disproportionate at ambient temperature and pressure to release $2.6 \mathrm{wt} \% \mathrm{H}_{\mathrm{Rev}}$ Theor.

\section{Equation 6}

$$
{ }^{4} / \mathrm{NaAlH}_{4}+{ }^{2} /{ }_{3} \mathrm{LiH} \rightarrow{ }^{2} /{ }_{3} \mathrm{Na}_{2} \mathrm{LiAlH}_{6}+{ }^{2} / 3 \mathrm{Al}+\mathrm{H}_{2}
$$




\section{First Principles and Thermodynamic Modeling}

This is essentially a destabilized disproportionation reaction that has a lower $\Delta G_{\text {disproportionation }}$ below

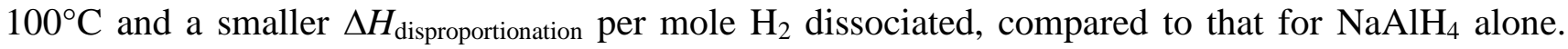
Upon heating above $100^{\circ} \mathrm{C}$, a second disproportionation is predicted to follow the reaction to release

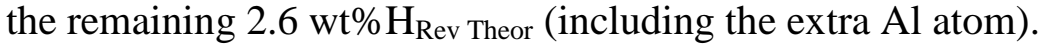

\subsubsection{Funding Year 2 Atomic-Thermodynamic Modeling}

\subsubsection{Na-Mg-Al-H and Li-Mg-Al-H Candidate Hydride Simulations}

The $\mathrm{wt}_{\mathrm{t}} \mathrm{H}_{\mathrm{Rev}}$ Theor of quaternary complex hydrides in the Na-Mg-Al-H and Li-Mg-Al-H systems will be dependent upon the change in dehydrogenation products formed with varying conditions. A lower wt $\% \mathrm{H}_{2}$ limit can be projected for the formation of both alkali and alkaline earth hydrides upon dehydrogenation at lower temperatures. A higher $\mathrm{wt}_{\mathrm{t}} \mathrm{\textrm {H } _ { 2 }}$ limit can be projected when all of the $\mathrm{Mg}$ is incorporated in intermetallic phases upon disproportionation at higher temperatures. Numerous fluoride and other complex analog models were used as templates to survey for possible existence of quaternary hydride phases in each of the $\mathrm{Na}-\mathrm{Mg}-\mathrm{Al}-\mathrm{H}$ and $\mathrm{Li}-\mathrm{Mg}-\mathrm{Al}-\mathrm{H}$ systems with atomic simulations. Thermodynamic predictions were made of quaternary complex hydride candidates, numerous binary and ternary lower order phases, including many known Al-Mg and Al-Li phases and line compounds, and lesser-known Li-Al-Mg alloys and compounds. The ternary hydride phases, both known and proposed phases for $\mathrm{Mg}\left(\mathrm{AlH}_{4}\right)_{2}, \mathrm{NaMgH}_{3}$, and $\mathrm{Li}_{\mathrm{x}} \mathrm{Mg}_{\mathrm{y}} \mathrm{H}_{\mathrm{z}}$ compositions have also been predicted, as well as the elemental hydride phases. This enabled the determination of candidate phase stability under different temperatures and pressure.

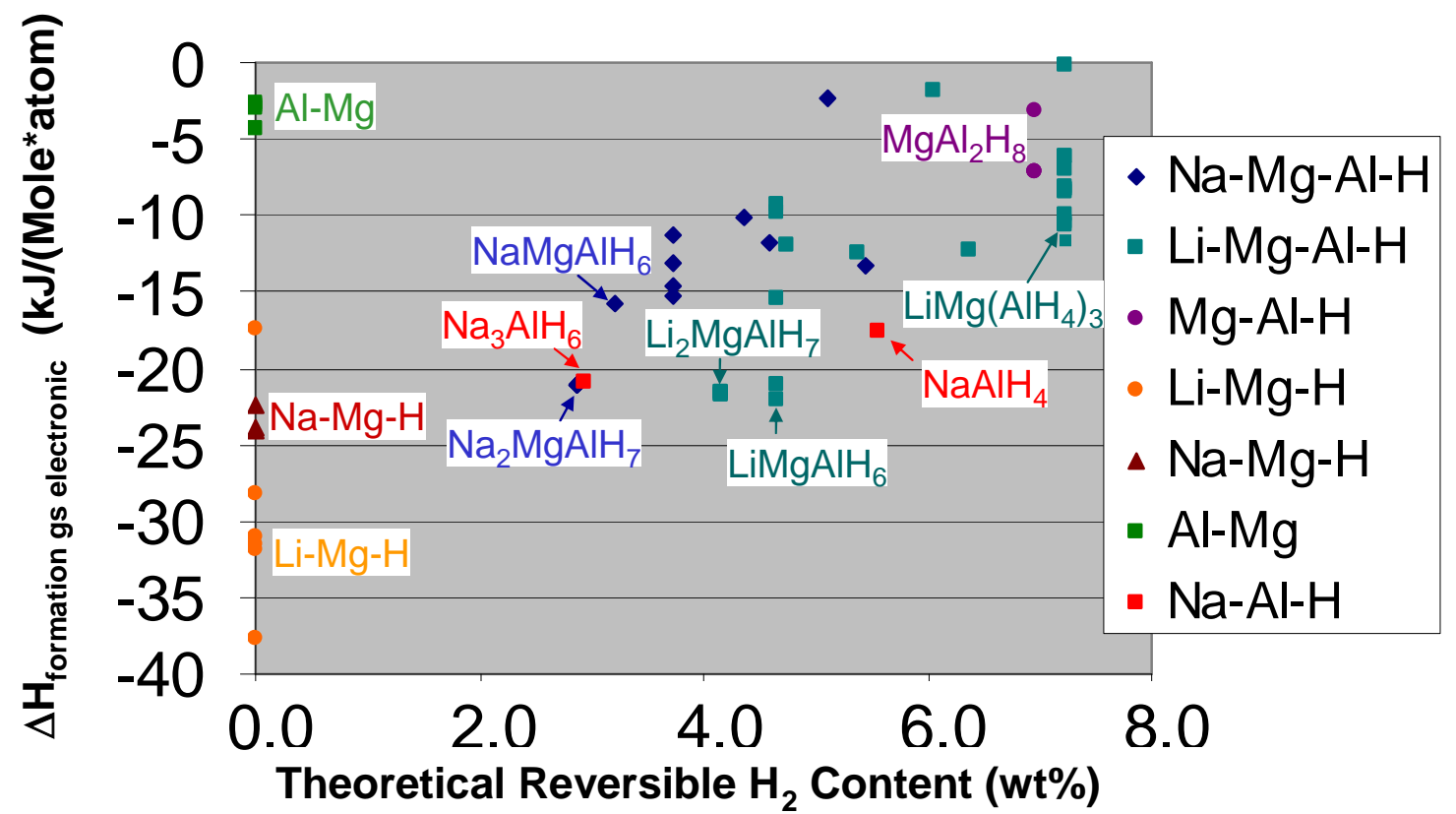

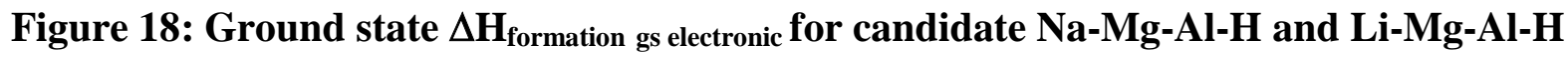
quaternary phases for the lower limit $\mathrm{wt} \% \mathrm{H}_{\mathrm{Rev}}$ Theor. Many symbols actually consist of multiple superimposed data points for candidate phases having nearly identical enthalpies. The stoichiometries of the most favorable phases are labeled. 


\section{First Principles and Thermodynamic Modeling}

The ground state electronic heat of formation, $\Delta \mathrm{H}_{\text {formation gs electronic }}$, for quaternary candidate structures in the Na-Li-Mg-Al-H quinary system are plotted versus the lower limit wt $\% \mathrm{H}_{\mathrm{Rev}}$ Theor in Figure 18. Also shown for comparison are some lower order related phases. Many of the candidates' electronic $\Delta \mathrm{H}_{\text {formation gs electronic }}$ were comparable in stability to the corresponding values determined for the sodium alanates. Despite the overall trends of decreasing stability with increasing $\mathrm{H}_{2}$ content, there were many ground state stable $\mathrm{Li}-\mathrm{Mg}-\mathrm{Al}-\mathrm{H}$ candidates with significant $\mathrm{wt} \% \mathrm{H}_{\mathrm{Rev}}$ Theor.

\subsubsection{Thermodynamic Optimization of the Li-Mg-Al-H and Na-Mg-Al-H Quaternaries}

A large number of favorable candidate phase structures were identified for the $\mathrm{AkMgAlH}_{6}$ and $\mathrm{Ak}_{2} \mathrm{MgAlH}_{7}$ stoichiometries, where $\mathrm{Ak}$ is either $\mathrm{Na}$ or $\mathrm{Li}$, that had heats of formation, $\Delta \mathrm{H}_{\text {formation gs }}$ electronic more negative than $-20 \mathrm{~kJ} / \mathrm{mole}$ *atom. Such values were competitive with those that have been determined for the well-known alkali alanate phases. The former compound has been synthesized by solution-based processing in our program and also by mechanochemical preparation in another laboratory [Ref. 47], but did not yet have a crystallographically-refined structure. For this reason, we experimentally and theoretically sought to identify the most stable $\mathrm{LiMg}\left(\mathrm{AlH}_{4}\right)_{3}$ structure, in order to enable thermodynamic predictions to be made for this phase.

Thermodynamic calculations were made in order to access the total theoretical reversible hydrogen capacity of our newly identified favorable candidate structures. Thermodynamic property predictions were made for selected $\mathrm{AkMgAlH}_{6}$ and $\mathrm{Ak}_{2} \mathrm{MgAlH}_{7}$ phases, as well as other favorable known and hypothetical lower-order phases in the Li-Mg-Al-H and Na-Mg-Al-H systems, using direct method lattice dynamics. These latter known phases included $\mathrm{Mg}\left(\mathrm{AlH}_{4}\right)_{2}, \mathrm{NaMgH}_{3}$, pure alkali alanate, elemental hydride phases, and various $\mathrm{Mg}$-Al intermetallic phases. The latter hypothetical favorable candidate phases included $\mathrm{Li}_{6} \mathrm{MgH}_{8}, \mathrm{Li}_{2} \mathrm{MgH}_{4}$, and $\mathrm{Li}-\mathrm{Mg}-\mathrm{Al}$ alloy phases. The predicted thermodynamic properties were parameterized and compiled into a thermodynamic database, and were used along with the COST507 database [Ref. 48] to identify the composition, temperature and pressure conditions for the optimum hydrogen capacity within both quaternary systems. For brevity, only the results for the Li-Mg-Al-H system, with the greater potential for high $\mathrm{H}$ capacity will be presented. Our major question was whether it would be possible to form intermetallic Al-Mg or Li$\mathrm{Mg}-\mathrm{Al}$ phases upon complete dehydrogenation of the complex quaternary $\mathrm{AkMgAlH}_{6}$ and $\mathrm{Ak}_{2} \mathrm{MgAlH}_{7}$ phases, partially or fully in place of forming the elemental hydride phases. This would result in significantly higher theoretical reversible hydrogen capacities for these hypothetical compounds. The ternary isopleth for the $\mathrm{Li}-\mathrm{Mg}-\mathrm{Al}-\mathrm{H}$ elemental stoichiometry $\{1 \mathrm{Li}: 1 \mathrm{Mg}: 1 \mathrm{Al}$ : $6 \mathrm{H}$, shown in Figure 19, predicts the stable existence of the $\mathrm{LiMgAlH}_{6}$ phase at $-23^{\circ} \mathrm{C}, 100$ bar pressure, and $3 \times 10^{-3}$ hydrogen activity over a range of compositions (higher pressures were necessary to predict stable existence at room temperature). Upon lowering the pressure to $1 \mathrm{bar}$ at $25^{\circ} \mathrm{C}$, the $\mathrm{LiMgAlH}_{6}$ phase decomposes to the elemental hydride phases to release $4.7 \mathrm{wt} \% \mathrm{H}$.

\footnotetext{
Equation $7 \quad \mathrm{LiMgAlH}_{6} \rightarrow \mathrm{LiH}+\mathrm{MgH}_{2}+\mathrm{Al}+{ }^{3} /{ }_{2} \mathrm{H}_{2}$
} 


\section{First Principles and Thermodynamic Modeling}

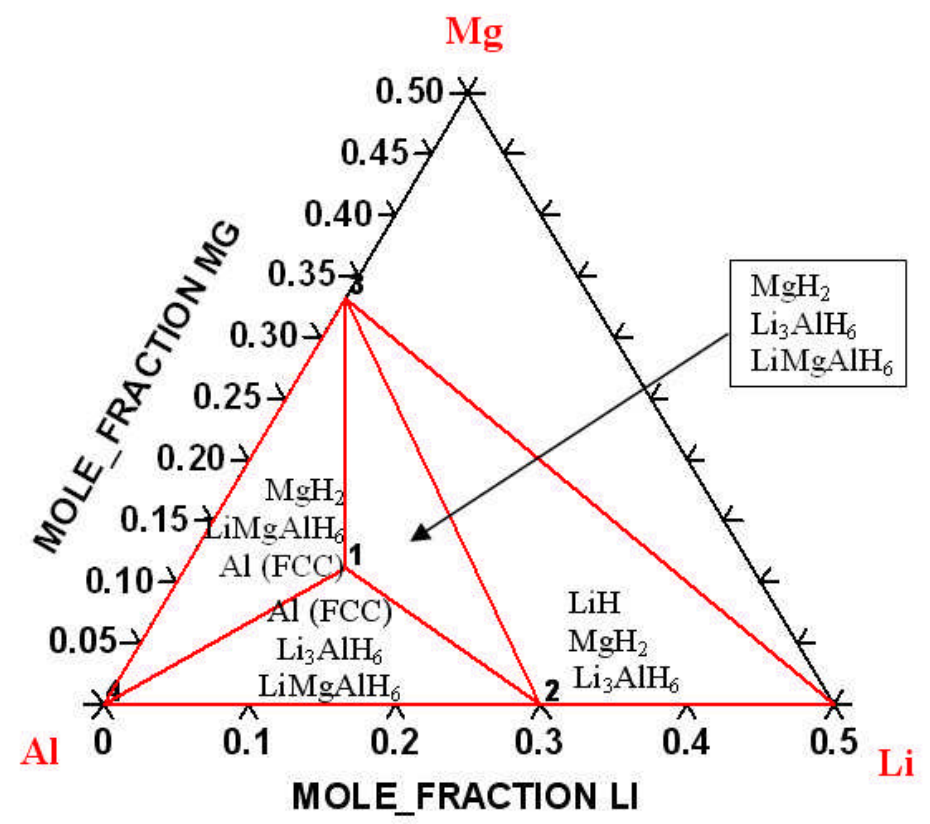

Figure 19: Ternary isopleth for Li-Mg-Al-H quaternary system at constant $3 \times 10^{-3} \mathrm{H}_{\text {activity, - }}$ $23^{\circ} \mathrm{C}$ temperature and 100 bar pressure showing distribution of phases with varying composition.

If the hydrogen activity is lowered further, akin to the evacuation of $\mathrm{H}_{2}$, various $\mathrm{Al}-\mathrm{Mg}$ and in some cases, Al-Li intermetallic phases are predicted to form, in place of the elemental hydride phases. The change in disproportionation phases with decreasing $\mathrm{H}$ mole-fraction at $25^{\circ} \mathrm{C}$ and 100 bar is shown in Figure 20. If starting from the fully hydrided $\mathrm{LiMgAlH}_{6}$ phase, the $\mathrm{H}$ mole-fraction is decreased to 0.25 under these conditions and the corresponding disproportionation reaction would be

\section{Equation $8 \quad \mathrm{LiMgAlH}_{6} \rightarrow 0.25 \mathrm{LiH}+0.04 \mathrm{Al}_{3} \mathrm{Mg}_{2}+0.01 \mathrm{Al}_{12} \mathrm{Mg}_{17}\left(+5 /{ }_{2} \mathrm{H}_{2}\right.$ evacuated $)$}

resulting in the release of $7.7 \mathrm{wt} \% \mathrm{H}$. In the $\mathrm{Mg}$-Al binary phase diagram at 1 bar pressure, $\mathrm{Al}_{3} \mathrm{Mg}_{2}$ and $\mathrm{Al}_{12} \mathrm{Mg}_{17}$ are stable over narrow composition ranges from $100^{\circ} \mathrm{C}$ up to melting at $450^{\circ} \mathrm{C}$ [Ref. 49]. The formation of an intermetallic phase similar to $\mathrm{Al}_{3} \mathrm{Mg}_{2}$ has been observed experimentally during the decomposition of $\operatorname{LiMg}\left(\mathrm{AlH}_{4}\right)_{3}$ above $250^{\circ} \mathrm{C}$ [Ref. 47], signifying the possibility of an even higher $\mathrm{H}$ capacity. Thus, these combined atomic-thermodynamic predictions have projected a theoretical upper bound for $\mathrm{Li}-\mathrm{Mg}-\mathrm{Al}-\mathrm{H}$ complex alanates to have the potential for $\mathrm{H}$ capacities that meet or exceed the project target. 
First Principles and Thermodynamic Modeling

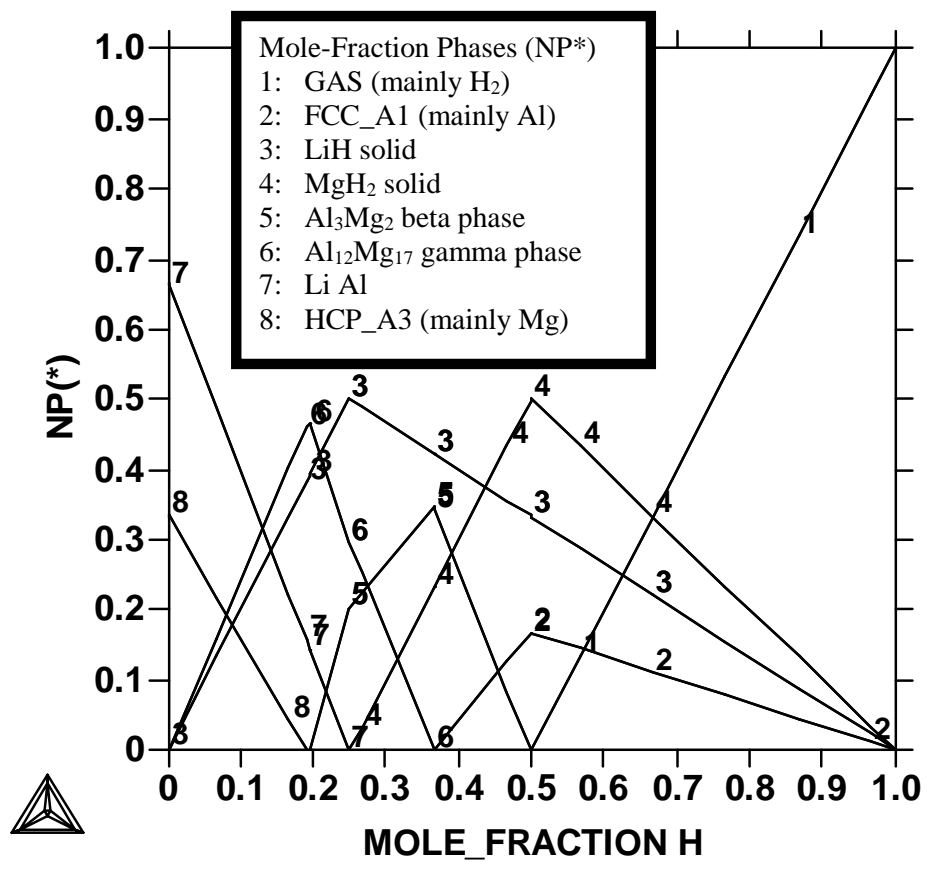

Figure 20: The mole-fraction of disproportionation phases with increasing $\mathrm{H}$ mole-fraction at $25^{\circ} \mathrm{C}$ and 100 bar with a constant stoichiometry $\{1 \mathrm{Li}: 1 \mathrm{Mg}: 1 \mathrm{Al}\}$ calculated with COST507 database [Ref. 48].

Thermodynamic modeling of the Na-Mg-Al-H system showed that the best quaternary candidate phases were not stable under reasonable temperature and pressure conditions. The phase diagram in Figure 21 shows that only the ternary $\mathrm{NaMgH}_{3}$ phase was predicted to co-exist with the sodium alanate phases at $298 \mathrm{~K}$ and 100 bar.

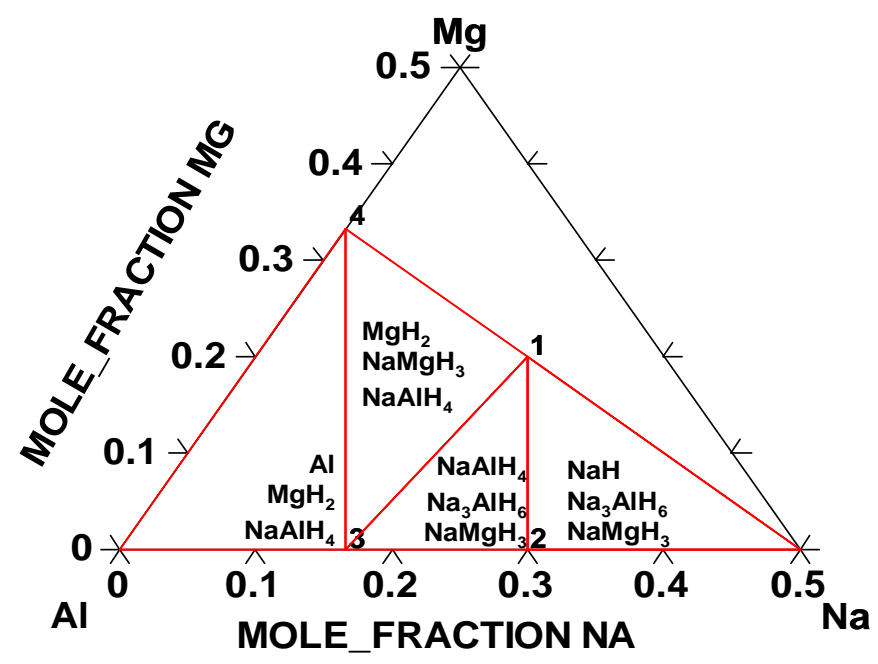

Figure 21: $\mathrm{Na}-\mathrm{Mg}-\mathrm{Al}$ isothermal ternary section calculated at $298 \mathrm{~K}$ and 100 bar with $\mathrm{H}$ activity of 3.9 $\times 10^{-3}$ bar, showing distribution of phases with varying composition. 


\section{First Principles and Thermodynamic Modeling}

Although the Na-Mg-Al-H system does not have potential for high $\mathrm{H}$ capacity, the thermodynamic modeling of reactions with the $\mathrm{NaMgH}_{3}$ phase enabled insight into the modification of $\mathrm{NaAlH}_{4}$ decomposition. A van't Hoff plot of the possible reactions in the Na-Mg-Al-H system is shown in Figure 22. The addition of $\mathrm{MgH}_{2}$ to $\mathrm{NaAlH}_{4}$ may promote the single step dehydrogenation reaction to form $\mathrm{NaMgH}_{3}$ below $52^{\circ} \mathrm{C}$.

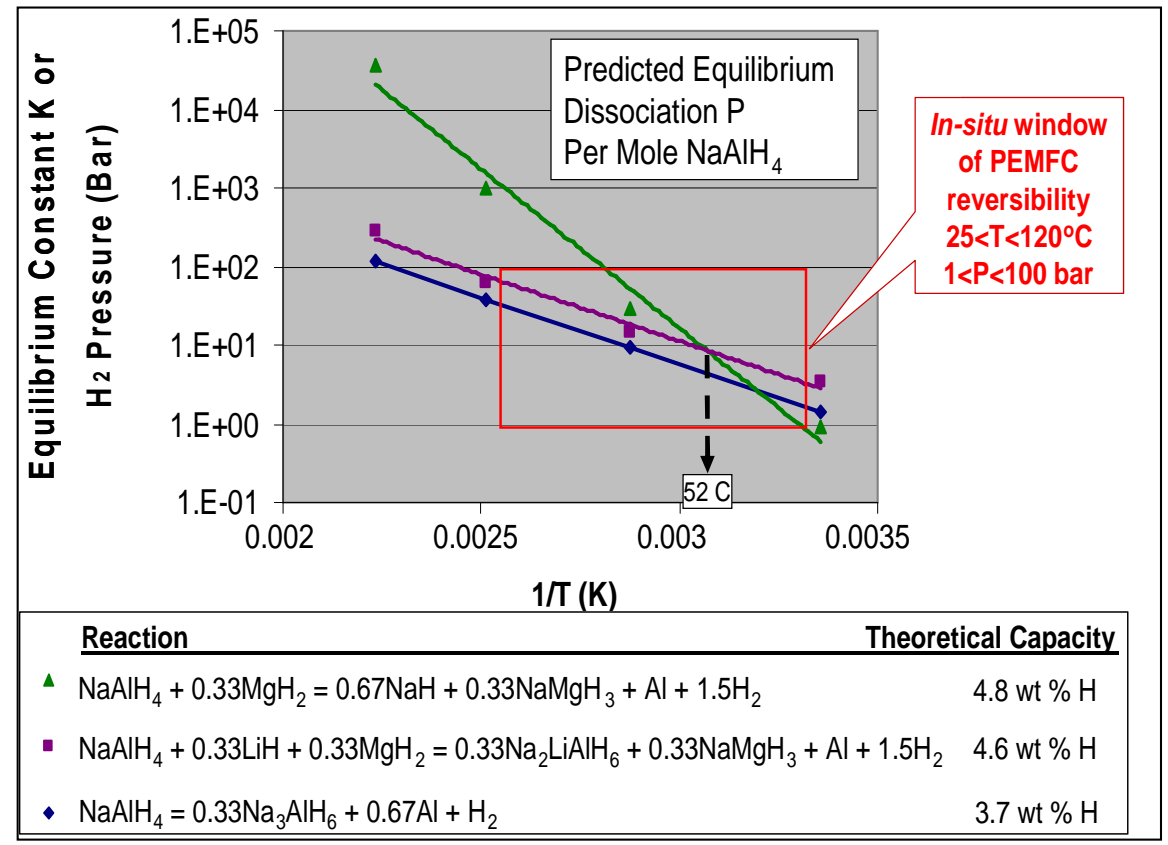

Figure 22: Van't Hoff plot showing the dehydrogenation reactions predicted for the most stable phases in the Na-Mg-Al-H system.

\subsubsection{Refinement of Li-Mg-Al-H Phase Structures}

Atomic modeling was used in conjunction with experimentation to further refine the structures and thermodynamic predictions of two unique phases in the $\mathrm{Li}-\mathrm{Mg}-\mathrm{Al}-\mathrm{H}$ system: $\mathrm{LiMg}(\mathrm{AlH})_{3}$ and $\mathrm{LiMgAlH}_{6}$ [Refs. 50,51]. The best ground state candidate structures were previously identified for $\operatorname{LiMg}\left(\mathrm{AlH}_{4}\right)_{3}$ and were used as preliminary input for the refinement of crystallographic structure. Our collaborators at the Institute for Energy (IFE) in Norway, Hendrik Brinks and Hilda Grove, refined the monoclinic structure for this compound from powder neutron diffraction and high resolution synchrotron radiation powder x-ray diffraction analytical results. We evaluated the refined structure with respect to other possible candidates simulated with the structural analog approach. There are relatively few known analog quaternary complex compounds, none of which are hydrides, which have a ratio of one or two counterions to three complex functional groups that could function as templates for the derivation of the $\operatorname{LiMg}\left(\mathrm{AlH}_{4}\right)_{3}$ structure. Therefore, additional quaternary complex halide and oxide compound structures with closely related stoichiometries were also used as templates. Additional approaches to derive candidate structures, including the substitution of $\mathrm{Li}$ in $\mathrm{Mg}\left(\mathrm{AlH}_{4}\right)_{2}$ and $\mathrm{Mg}$ in $\mathrm{LiAlH}_{4}$ were also employed, as well as the use of the Endeavor program Monte Carlo simulated annealing [Ref. 26] to globally optimize atomic positions. The refined $\operatorname{LiMg}\left(\mathrm{AlH}_{4}\right)_{3}$ structure developed in this study was predicted to have the lowest, most stable $\Delta \mathrm{H}_{\text {formation gs electronic }}$ 


\section{First Principles and Thermodynamic Modeling}

compared to the other most favorable candidate structures derived from the structural analog approach [Ref. 50].

Comparison of experimental and modeling results have confirmed the likelihood of the existence of best candidate trigonal $P 32_{1}$ structure simulated for the $\mathrm{LiMgAlH}_{6}$ intermediate phase [Ref. 51]. This structure was also identified in parallel in separate studies by our collaborators [Ref. 52]. Following desorption of the $\mathrm{LiMg}\left(\mathrm{AlH}_{4}\right)_{3}$ phase for several hours at $100{ }^{\circ} \mathrm{C}$, unidentified peaks were detected by $\mathrm{x}$-ray diffraction. The $2 \theta$ positions of many of these peaks were found to be equivalent to those in the simulated $x$-ray pattern determined for the trigonal $\mathrm{LiMgAlH}_{6}$ structure [Ref. 51]. This validation serves both to confirm the important reaction mechanism for $\operatorname{LiMg}\left(\mathrm{AlH}_{4}\right)_{3}$ and to validate the structures for generating thermodynamic predictions. First principles thermodynamic predictions were made with these refined structures to improve our thermochemical predictions.

\subsubsection{Strategy Expansion}

The newly expanded "coupled complex reaction strategy" implemented during the course of the second year, mandated the inclusion of a broader range of chemistries for the effective identification, design, and refinement of reversible high capacity complex hydrides and co-reactants, and low capacity disproportionation products, using our integrated atomic-thermodynamic-experimental approach. To accomplish this, the atomic-thermodynamic surveys were expanded to include the $\mathrm{Na}$ Li-Al-H, Na-Mg-Al-H, Li-Mg-Al-H, Li-Mg-(Na)-N-(Al)-H, Li-Mg-(Na)-B-(Al)-H, and Li-Mg-(Na)(Al)-B-N quaternary compositional systems. These systems were then merged into the higher order septenary system: Li-Mg-Na-Al-B-N-H, schematically illustrated in Figure 23. This multi-order extension in compositional space outfitted our palette for designing coupled complex reactions using a combination of established thermochemical formulation methods. In addition, a new thermodynamic methodology was developed for optimizing the $\mathrm{H}$ capacity and reversibility of newly designed coupled complex reactions. The following sections highlight our progress in the survey, reaction design, and thermodynamic optimization of coupled complex reactions within this septenary system.

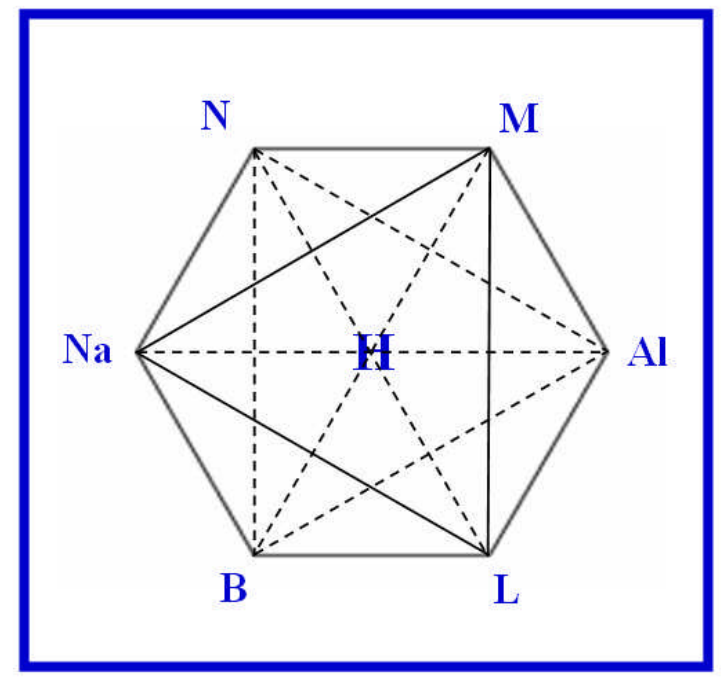

Figure 23: Schematic of high capacity septenary compositional system. 


\section{First Principles and Thermodynamic Modeling}

\subsubsection{Survey of Li-Mg-Na-Al-B-N-H Septenary System}

During the second-half of the second year, atomic-thermodynamic surveys concentrated on rapidly building a database of simulated finite thermodynamic properties for phases within the Li-Mg-(Na)$\mathrm{N}-(\mathrm{Al})-\mathrm{H}$, Li-Mg-(Na)-B-(Al)-H, and Li-Mg-(Na)-(Al)-B-N systems. These systems included both known and hypothetical amides-imides, borohydrides, and their disproportionation products, such as complex boron-nitrides, elemental borides and nitrides. These simulations first concentrated on over 40 known phases within these three systems. For structurally-defined known phases, a higher priority was given to systems which have not yet been thermodynamically characterized. For known phases with incomplete or no known structural information, analogous systems were utilized as templates to create candidate structure phases. The best candidate(s) for each phase were then input into Phonon lattice dynamics calculations for prediction of finite temperature thermodynamic values. These predicted values were integrated into thermodynamic databases to facilitate design of new high capacity coupled reactions. A tabulation of all the possible permutations of multi-order systems up to and including quinaries with $\mathrm{H}$ in the Li-Mg-Na-Al-B-N-H septenary system is shown in Figure 24, with the subsystems having known compound formation colored in red. Many subsystems shown in magenta remain to be investigation for potential hydrides, co-reactants and/or disproportionation products.

The expansion of our virtual surveys to the nitrogen- and boron-based chemistries called for additional benchmarking of our predictive accuracy. The well-known lithium amide system was selected for this validation. A ternary isothermal section for the Li-N-H system in Figure 25 shows the relative stability of the lithium amide $\left(\mathrm{LiNH}_{2}\right)$, imide $\left(\mathrm{Li}_{2} \mathrm{NH}\right)$, and hydride $(\mathrm{LiH})$ phases, as well as the gaseous decomposition products predicted at $25^{\circ} \mathrm{C}(298 \mathrm{~K})$ and 100 bar. From this diagram, it can be clearly seen how the change in composition dramatically affects the stability of the decomposition products, especially how the ammonia formation can be eliminated through the thermodynamic optimization of the elemental system stoichiometry. As a benchmark, the change in enthalpy upon dehydrogenation for the reaction: $\mathrm{LiNH}_{2}+\mathrm{LiH}=\mathrm{Li}_{2} \mathrm{NH}+\mathrm{H}_{2}$, was predicted to be $79.92 \mathrm{~kJ} / \mathrm{mol}$. This value compares well with the experimental value of $66 \mathrm{~kJ} / \mathrm{mol}$ determined by Chen et al. [Ref. 53], and the theoretical value of $73.6 \mathrm{~kJ} / \mathrm{mol}$ determined by Herbst and Hector [Ref. 54]. 
First Principles and Thermodynamic Modeling

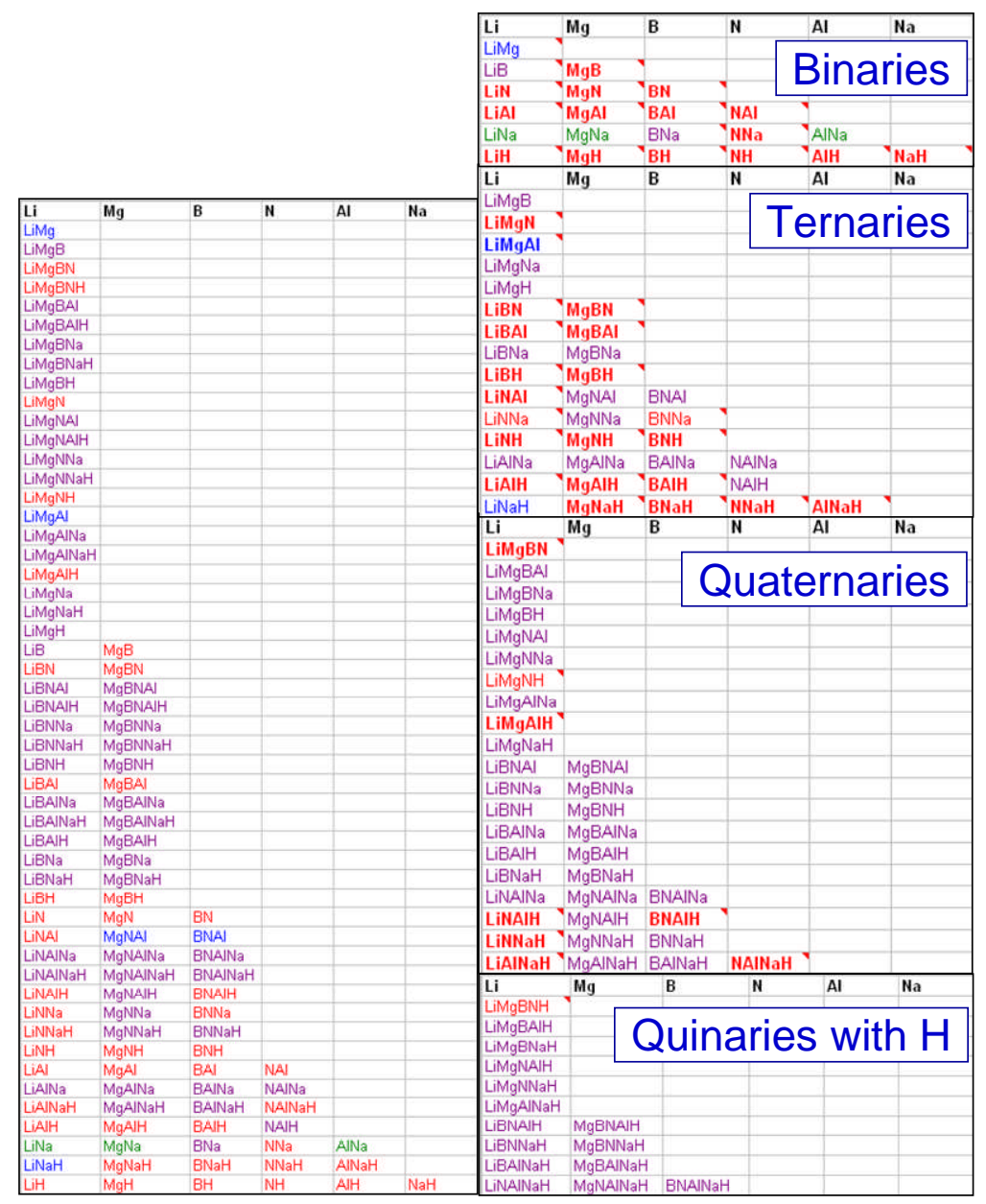

Figure 24: All possible permutations of multi-order systems up to and including quinaries with $\mathrm{H}$ in the Li-Mg-Na-Al-B-N-H septenary system.

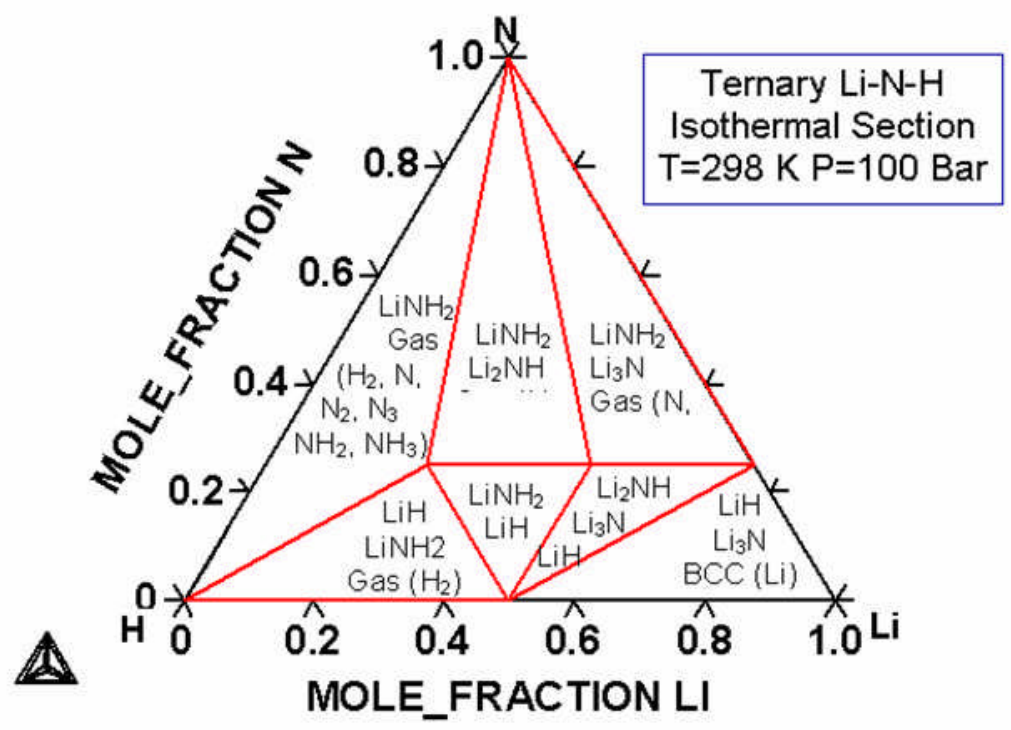

Figure 25: Benchmarking of atomic-thermodynamic predictions for the Li-N-H system. 


\section{First Principles and Thermodynamic Modeling}

\subsubsection{Reaction Design and Thermodynamic Optimization}

One high capacity strategy was to mix complex hydrides combining $\mathrm{Al}$ and $\mathrm{N}, \mathrm{Al}$ and $\mathrm{B}$, or $\mathrm{B}$ and $\mathrm{N}$ centered complexes. However, the dehydrogenation of these mixtures can lead to the very exothermic formation of favorable products of $\mathrm{AlN}$, $\mathrm{AlB}$, or $\mathrm{BN}$-bearing compounds, rendering the reverse hydrogenation reactions to be thermodynamically impractical. Alternatively, our new strategy and expanded survey enables the design of reversible high capacity coupled reactions with more stable coreactants, and less stable products, to effectively balance or tune the dehydrogenation reaction. Reaction design was accomplished by systematically examining complex hydride reactions with coreactants, iteratively utilizing both thermochemical reaction and Gibbs energy minimization equilibria calculations. The reaction $\mathrm{H}$ capacity is determined from the most favorable reaction products and the reversibility is determined from the change in free energy or enthalpy upon dehydrogenation.

Once a new potential chemistry was identified from the reaction design surveys, the composition was optimized to maximize reversibility, $\mathrm{H}$ capacity, simplify discharge/recharge reactions, and/or eliminate side-products. This was done by simulating the change in phase stability within the multidimensional space formed by varying composition, temperature, and pressure. The composition and parameters are converged to maximize the $\mathrm{H}$ reversibility within the "in-situ window of reversibility" for polymer electrolyte membrane fuel cell (PEMFC) operation $\left(25-120^{\circ} \mathrm{C}\right.$ and $1-100$ bar).

The dehydrogenation of the $\mathrm{LiNH}_{2}$ to release up the $6.5-8.7 \mathrm{wt} \% \mathrm{H}_{\mathrm{Rev}}$ Theor by forming the $\mathrm{Li}_{2} \mathrm{NH}$ or $\mathrm{Li}_{3} \mathrm{~N}$ products, respectively, presents a challenge because the decomposition reactions are endothermic and accessible only at high temperatures. In addition, these reactions involve multiple possible intermediates, are kinetically impeded, and are subject to forming $\mathrm{NH}_{3}$ and other sideproducts. A new reversible dehydrogenation reaction that was optimized for $\mathrm{LiNH}_{2}$ using our thermochemical reaction design approach is illustrated in Figure 26. An isobaric temperature thermochemical survey shown on the left hand side revealed a significant change in $\mathrm{H}$ content for reactions of $\mathrm{LiNH}_{2}$ with the $\mathrm{BN}$ and $\mathrm{LiH}$ co-reactants to form the $\mathrm{Li}_{3} \mathrm{BN}_{2}$. Thermodynamic optimization was conducted to find the best stoichiometry that would generate the largest $\mathrm{wt} \% \mathrm{H}_{\mathrm{Rev} \text { Theor }}$ at the temperature and pressure conditions closest to PEMFC operation. The van't Hoff plot of reaction with the optimized $3 \mathrm{Li}: 1 \mathrm{~B}: 2 \mathrm{~N}: 4 \mathrm{H}$ stoichiometry with $6.3 \mathrm{wt} \% \mathrm{H}_{\text {Rev Theor }}$

\section{Equation 9}

is shown on the right hand side of Figure 26. Here, the co-reactants effectively shifted the dehydrogenation reaction to just below the "in-situ window of reversibility", yielding a predicted single step $\mathrm{H}_{2}$ dissociation with an 1 bar equilibrium pressure at $135^{\circ} \mathrm{C}$, with minimal formation of ammonia. It is important to remember that this prediction is an upper bound for what thermodynamically could be possible in the absence of kinetic limitations. 


\section{First Principles and Thermodynamic Modeling}

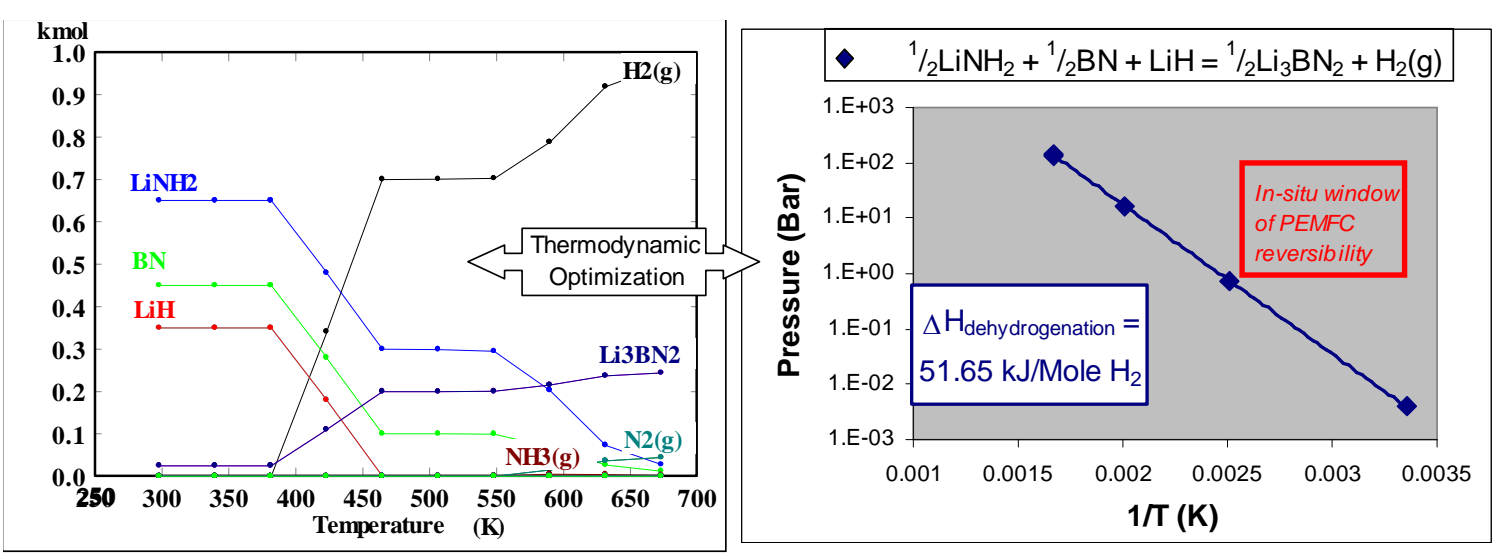

Figure 26: Example of thermodynamically designed and optimized reaction for $\mathrm{H}_{2}$ storage with $\mathrm{LiNH}_{2}, \mathrm{BN}$ and $\mathrm{LiH}$ reactants.

The example above gives evidence for implementation of the thermodynamic optimization tool. An expanded schematic for the virtual design of reversible, high capacity reactions is shown in Figure 27 based on this lithium amide reaction. Our approach to designing balanced reactions is through thermodynamic predictions, equilibrium studies, and optimization. We start with establishing thermodynamic data for candidate phases, co-reactants, and products, supplementing with firstprinciples finite $\mathrm{T}$ thermodynamic predictions wherever necessary. In order to identify new candidate systems, we employ an iterative approach of proposing reactions, then evaluating the reaction thermodynamics and hydrogen exchange for the reaction. For interesting reactions, we then employ equilibrium survey calculations, to determine for the many possible competing reactions which phases will predominate in hydrogen exchange reactions. We look for conditions, whereby changing composition, $\mathrm{T}$ or $\mathrm{P}, \mathrm{H}$ evolves from being entrained in a solid phase to gaseous state. Once we find such an exchange, we extract the best possible reaction scenario, and scope out a candidate composition range for thermodynamic optimization. We also seek reactions that have a minimum number of steps and which minimize the formation of harmful side-products. Finally, we thermodynamically optimize the composition of our system to find the best stoichiometry that gives the highest hydrogen capacity. Shown in Figure 27 is a surface formed over a compositional range for a model system from the difference in $\mathrm{H}$ pressure between relevant high $\mathrm{T}$, low $\mathrm{P}$ conditions and low $\mathrm{T}$, high $\mathrm{P}$ conditions. We are able to predict phase diagrams and predict the equilibrium of phases for the thermodynamically optimized stoichiometry. From there we can back out the reaction, and determine the dissociation pressure. Shown in the van't Hoff plot on the right is a designed reaction for $\mathrm{LiNH}_{2}$ with co-reactants that is predicted to exhibit intermediate dehydrogenation behavior, falling just below the window for PEMFC desorption. 
First Principles and Thermodynamic Modeling

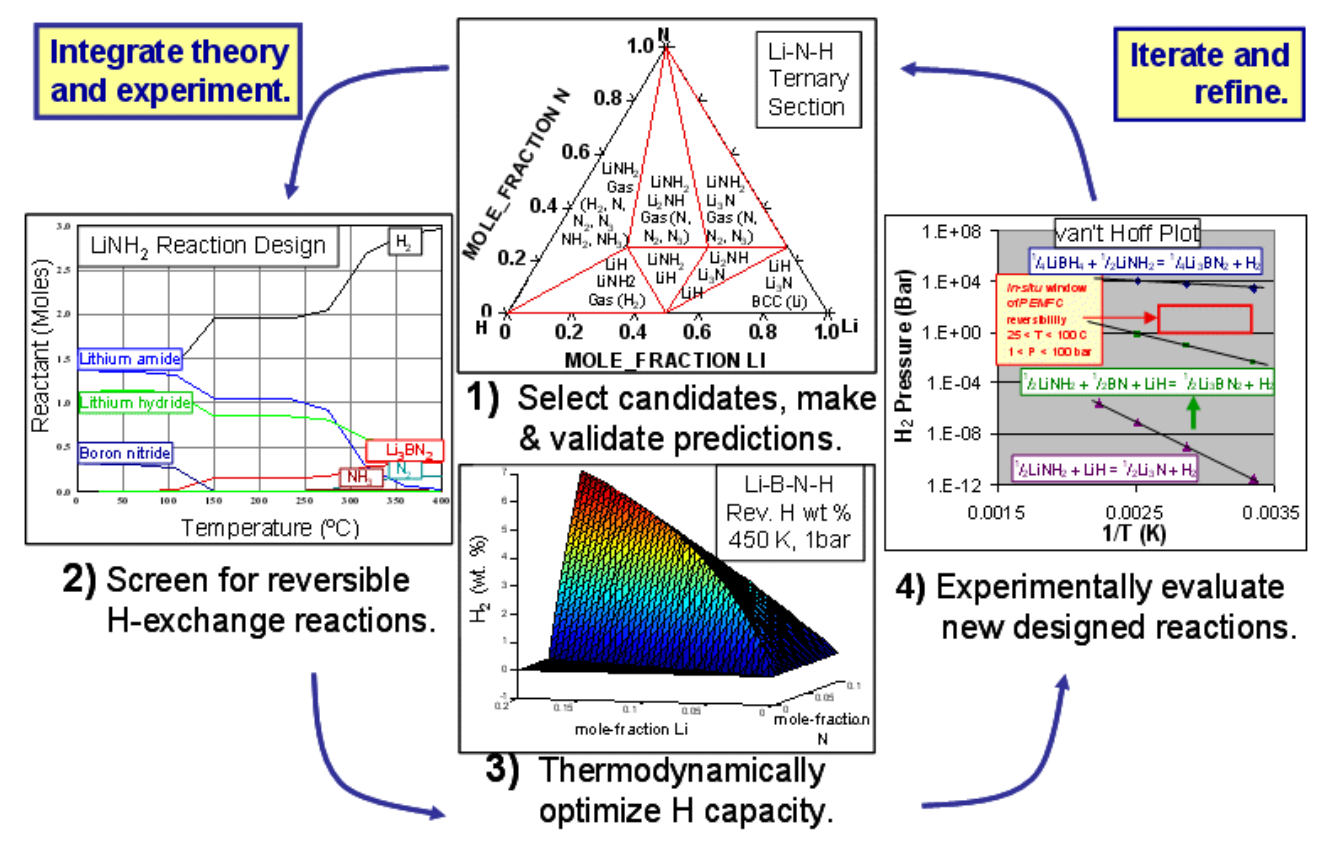

Figure 27. Schematic showing progression of modeling methodologies to design the reaction of $\mathrm{LiNH}_{2}$ with co-reactants to increase the dehydrogenation pressure closer towards 1 bar at $1^{\circ} 0^{\circ} \mathrm{C}$, including: 1 ) thermodynamic mapping of phase behavior for $\mathrm{Li}-\mathrm{N}-\mathrm{H}$ system and coreactants, 2) thermochemical screening of reactions with co-reactants to search for reversible hydrogen exchange, 3 ) thermodynamic optimization of the best candidate compositional system, 4) prediction and evaluation of dissociation behavior.

\subsubsection{Funding Year 3 Atomic-Thermodynamic Modeling}

\subsubsection{Borohydride Systems - Simulation of Disordered Structures}

The decision to selectively focus on borohydride systems was prompted by the challenges identified in the $\mathrm{H}$ storage community with the reversibility and side-products of amide-based systems. Our first principles atomic modeling of the borohydride systems followed several parallel paths. First, baseline finite temperature thermodynamic property predictions were established for the known structures of $\mathrm{LiBH}_{4}$ and $\mathrm{NaBH}_{4}$ compounds and for the candidate structures for the lesser known compounds $\mathrm{Mg}\left(\mathrm{BH}_{4}\right)_{2}, \mathrm{Al}\left(\mathrm{BH}_{4}\right)_{3}$ and $\mathrm{Ti}\left(\mathrm{BH}_{4}\right)_{4}$. These thermodynamic property predictions enabled a preliminary assessment of designed borohydride reactions with other co-reactants (at that time, this was more of an approximation for the lesser known borohydrides) that served to guide experimental efforts. In a second path, modeling was used in an attempt to identify the structures of the newly synthesized $\mathrm{Mg}$ and $\mathrm{Zr}$ borohydride complexes with organic ligands. The structures of these complexes could not be obtained from the multiple overlapping peaks in the x-ray pattern indicative of an amorphous structure. Since there are very few known quaternary crystal structures to serve as templates for input models, especially for quaternary complexes with ligand adducts, and there was limited structural experimental information available for verification of modeling results, these systems were difficult to model with our established methodology for crystallographic simulations. This inspired us to turn 


\section{First Principles and Thermodynamic Modeling}

to molecular dynamic simulated anneals for the refinement of amorphous or locally ordered hydride phases. It made sense to implement this methodology in a third path, a new initiative to integrate simulations with solid-state (UTRC) and solution-based (Albemarle) syntheses to explore alkali borohydride destabilization through metal dopant substitution. This new approach showed great utility for screening doped compositions, elucidating doping mechanisms, and providing insights into experimental results. The following sections will highlight our approach and results for this third path.

The newly implemented atomic scale modeling approach combined VASP density functional theory elevated temperature molecular dynamics (MD) simulations with ground state minimizations to search out and refine low symmetry doped alkali borohydride structures. The MD served to impart kinetic energy to the structures that enabled: 1) energy barriers for crystallographic rearrangement to be overcome at moderate temperatures, sampling a larger configurational space for the development of input models for ground state minimization, and 2) the melting (amorphitization) of structures and progressive annealing into lower energy (more stable) configurations by slowly decreasing the simulation temperature. In the first phase, we used the former MD approach coupled with ground state minimizations to quickly screen dopant element substitution in the alkali or boron sublattices in the $\mathrm{LiBH}_{4}$ and $\mathrm{NaBH}_{4}$ crystals, using a doped stoichiometry for a charge-neutral structure with the dopant atom formal charge in the most stable oxidation state (for example: if $\mathrm{Ti}^{+3}$ was substituted for $\mathrm{Li}^{+1}$ in $4 \mathrm{LiBH}_{4}$, then altogether $3 \mathrm{Li}^{+1}$ ions were removed from the input model). Initial ground state minimizations were conducted to identify the most favorable of all possible configurations. The best configuration was then annealed in a MD run for several picoseconds ( $10^{-12}$ seconds), where each step was $\sim$ a fentosecond $\left(1 \times 10^{-15}\right.$ seconds) in duration, at an intermediate temperature near the melting point until an equilibrium energy oscillation was achieved. In some cases, less stable structures actually fell apart and/or became less favorable in the MD run. In other cases, significantly lower energy structures were formed, where the additional kinetic energy enabled local energy barriers to be overcome. Thus, the MD was used to quickly evaluate the stability of a doped structure with respect to decomposition. The MD output structures were fully minimized to determine the ground state

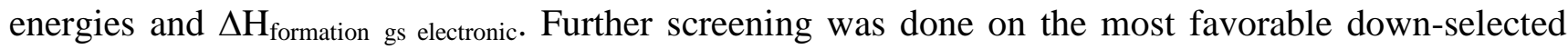
dopant/substitution site combinations to evaluate variation of dopant oxidation state/stoichiometry (only for TM dopants) and variation of dopant loading level to identify maximum solubility in the lattice. The best candidate structures were selected for experimental evaluation. For the most promising amorphous experimental systems, the second MD approach described above was appropriate. The melting and simulating annealing runs typically were 20 picoseconds or longer in total duration, and were conducted for systematically varying volumes. These rigorously refined structures could be directly compared with experimental results.

\subsubsection{Quaternary Borohydride Survey}

Our first principles atomic modeling survey assessed the stabilities and structures of the high $\mathrm{H}$ discharging quaternary alkali metal borohydride systems newly discovered by solution-based processing and solid-state processing, and the candidacy of hypothetical compositions for future experimental evaluation. The thermodynamic properties of known and lesser-known ternary borohydride systems were benchmarked to set the stage for the survey. The alkali borohydride $\mathrm{NaBH}_{4}$

$F \overline{4} 3 m$ and $\mathrm{LiBH}_{4}$ Pmna structures were substituted with an additional element to survey a wide range of quaternary compositions. These included the substitution of 25 mole\% metal (M): alkali ( $\mathrm{Na}$ or $\mathrm{Li}$ ), $\mathrm{Mg}, \mathrm{Al}, \mathrm{Sc}$ and $\mathrm{Ti}$ on the $\mathrm{Li}$ or $\mathrm{Na}$ sublattices (introducing alkali vacancies as necessary to maintain 


\section{First Principles and Thermodynamic Modeling}

compound charge neutrality), and of $\mathrm{Al}$ and $\mathrm{Ti}$ on the $\mathrm{B}$ sublattices. These quaternary systems have a theoretical maximum $\mathrm{H}$ capacity of $4.9-12.3 \mathrm{wt} \% \mathrm{H}_{\mathrm{Rev}}$ Theor, assuming their full decomposition to binary hydrides and elements, such as: $\mathrm{LiH}, \mathrm{NaH}, \mathrm{MgH}_{2}$, the most stable transition metal hydrides, $\mathrm{Al}$ and/or B upon dehydrogenation.

The ternary borohydride stability predictions set the foundation for assessing the relative stability of the quaternary phases. The benchmarking of the ternary alkali borohydride predictions, given in Table 5, gave us confidence to use the well-known $\mathrm{NaBH}_{4}$ and $\mathrm{LiBH}_{4}$ structures as the basis for our quaternary borohydride survey. The other ternary compounds: $\mathrm{Mg}\left(\mathrm{BH}_{4}\right)_{2}, \mathrm{Al}\left(\mathrm{BH}_{4}\right)_{3}$, and $\mathrm{Ti}\left(\mathrm{BH}_{4}\right)_{4}$, had been synthetically reported in the literature, but were not structurally known at that time. The values given for these latter compounds are for the most stable structures identified from ground state surveys of possible candidate structures. These predictions essentially bound the lower limit for ternary hydride stability.

Table 5: Ground-state predictions of ternary borohydride compounds.

\begin{tabular}{|c|c|c|c|}
\hline $\begin{array}{c}\text { Metal } \\
\text { Borohydrides }\end{array}$ & $\begin{array}{c}\text { Space } \\
\text { Group }\end{array}$ & $\begin{array}{c}\text { Predicted } \\
\Delta \mathbf{H}_{\text {formation gs electronic }} \\
\mathrm{kJ} / \mathrm{Mol}^{*} \text { atom }\end{array}$ & $\begin{array}{c}\text { Calculated } \\
\text { Volume } \\
\AA^{3} / \text { atom }\end{array}$ \\
\hline $\mathrm{NaBH}_{4}$ & $P 4_{2} / n m c$ & -33.88 & 9.33 \\
$\mathrm{LiBH}_{4}$ & $P n m a$ & -34.69 & 8.91 \\
$\mathrm{Mg}\left(\mathrm{BH}_{4}\right)_{2}$ & $P c$ & -22.94 & 9.38 \\
$\mathrm{Al}\left(\mathrm{BH}_{4}\right)_{3}$ & $P 3_{1} 1_{2}$ & -11.98 & 10.68 \\
$\mathrm{Ti}\left(\mathrm{BH}_{4}\right)_{4}$ & $P 4_{2} / n m c$ & -14.46 & 12.04 \\
\hline
\end{tabular}

The metal quaternary constituents have a dramatic impact on quaternary alkali borohydride stability, as shown in Table 6 for a wide range of compound stoichiometries. Overall, the quaternary lithium borohydrides were more stable than the quaternary sodium borohydrides. The most stable compositions were substituted with other alkali (25 mole\% $\mathrm{Na}$ in $\mathrm{LiBH}_{4}$ and 25 mole\% $\mathrm{Li}$ in $\mathrm{NaBH}_{4}$ ), and were very close in stability to the corresponding ternary phases. The other most stable phases included the substitution of $\mathrm{Mg}$ on the $\mathrm{LiBH}_{4} \mathrm{Li}$ sublattice with the requisite additional vacancy formation, and the substitution of $\mathrm{Al}$ on the $\mathrm{B}$ sublattices of $\mathrm{LiBH}_{4}$ and $\mathrm{NaBH}_{4}$. The substitutions of 25 mole\% $\mathrm{Ti}$ or $\mathrm{Sc}$ on the Li sublattice (with the concomitant formation of two vacancies to simulate a +3 transition metal charge) or $\mathrm{Ti}$ on the B sublattice were of similar magnitude in stability. The 25 mole\% substitution level selected for the preliminary screening is rather high, and all heats of substitution are endothermic, indicating that the substituent solubility limits were exceeded. The relaxations were limited by the relatively few degrees of freedom for the doped high symmetry structure based on the $F \overline{4} 3 m \mathrm{NaBH}_{4}$ isomorph (this structure was selected for convenience; it is slightly less stable than the $\mathrm{P}_{2} \mathrm{nmc}$ structure). Although the $700 \mathrm{~K} \mathrm{MD}$ temperature was below that of the $\mathrm{NaBH}_{4}$ melting point, all of the doped compositions became less stable from the MD anneals. 
First Principles and Thermodynamic Modeling

Table 6: Simulated heats of formation and atomic volumes for quaternary alkali metal borohydride systems.

\begin{tabular}{|c|c|c|c|c|}
\hline $\begin{array}{c}\text { Quaternary } \\
\text { Compound } \\
\text { Formula } \\
\end{array}$ & $\begin{array}{c}\mathbf{A k} \\
\begin{array}{c}\Delta \mathbf{H}_{\mathbf{f o r m a t i o n ~ g s ~}} \\
\text { electronic }\end{array} \\
\mathrm{kJ} / \mathrm{Mol}^{*} \text { atom } \\
\end{array}$ & $\begin{array}{l}\text { Volume } \\
\AA^{3} \text { /atom }\end{array}$ & $\begin{array}{r}\mathbf{A k} \\
\Delta \mathbf{H}_{\text {formation gs }} \\
\text { electronic } \\
\mathrm{kJ} / \mathrm{Mol} \text { *atom } \\
\end{array}$ & $\begin{array}{l}\text { Volume } \\
\AA^{3} / \text { atom }\end{array}$ \\
\hline$(\mathrm{Ak}) \mathrm{Al}\left(\mathrm{BH}_{4}\right)_{4}$ & -15.45 & 9.87 & 3.03 & 7.73 \\
\hline$(\mathrm{Ak}) \mathrm{Ti}\left(\mathrm{BH}_{4}\right)_{4}$ & -14.03 & 10.78 & -2.21 & 7.69 \\
\hline$(\mathrm{Ak}) \mathrm{Sc}\left(\mathrm{BH}_{4}\right)_{4}$ & -23.34 & 12.19 & -16.95 & 8.06 \\
\hline$(\mathrm{Ak})_{2} \mathrm{Mg}\left(\mathrm{BH}_{4}\right)_{4}$ & -28.05 & 11.00 & -22.07 & 8.68 \\
\hline$(\mathrm{Ak})_{3} \mathrm{Li} / \mathrm{Na}\left(\mathrm{BH}_{4}\right)_{4}$ & -34.17 & 9.95 & -30.72 & 9.26 \\
\hline$(\mathrm{Ak})_{4} \mathrm{AlH}{ }_{4}\left(\mathrm{BH}_{4}\right)_{3}$ & -28.07 & 10.82 & -24.80 & 10.94 \\
\hline$(\mathrm{Ak})_{4} \mathrm{TiH}_{4}\left(\mathrm{BH}_{4}\right)_{3}$ & -21.48 & 9.16 & -10.88 & 11.46 \\
\hline
\end{tabular}

The resulting ionic and electronic structures were analyzed, and excellent correlations were found between stability and electronic properties, which were used as the basis for further formulation development. For example, the correlation between the quaternary compound heats of formation and the metal substituent redox potential for the most favorable metal oxidation state is shown in Figure 28. In general, it may be concluded that the lower the redox potential for the metal substituent, the more stable the substituted quaternary alkali metal borohydride. 
First Principles and Thermodynamic Modeling

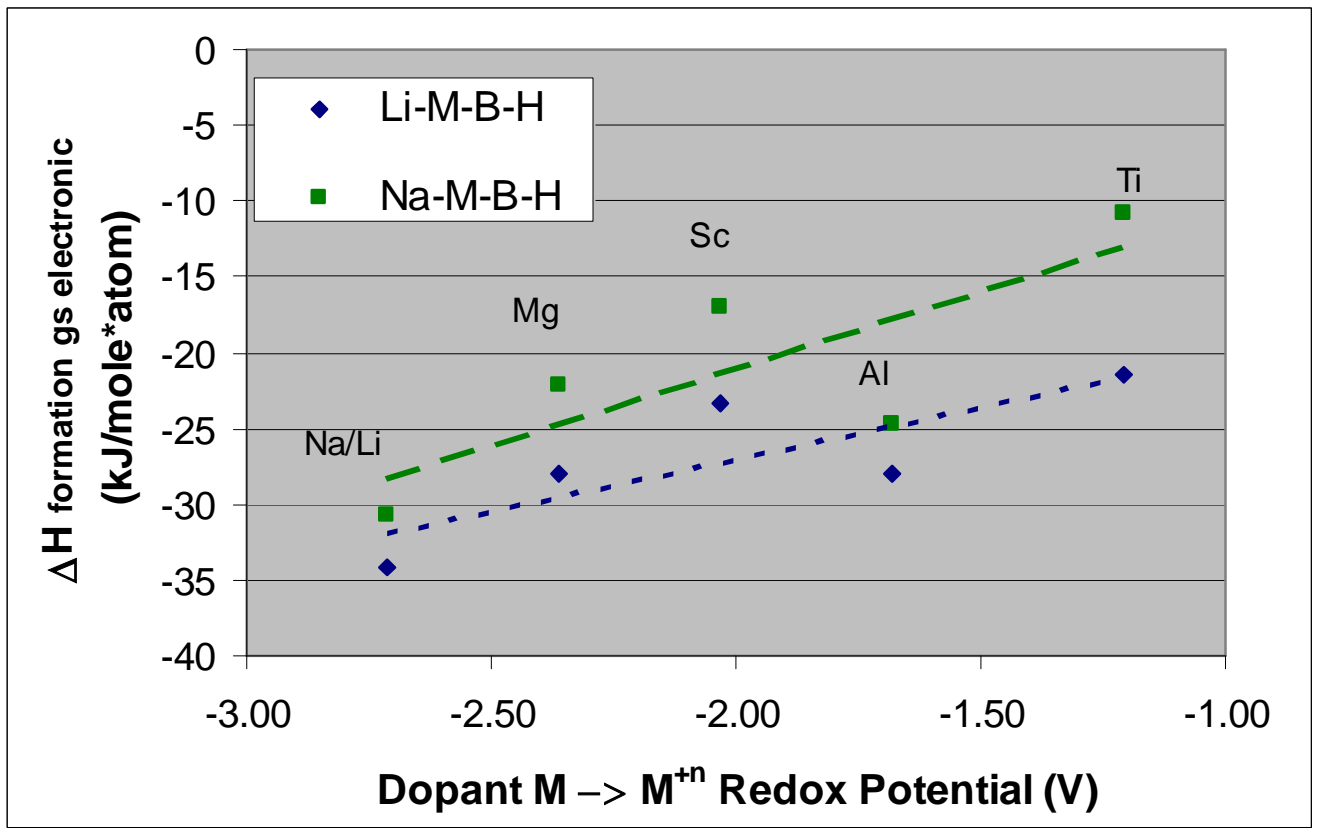

Figure 28: Correlation plot between quaternary compound simulated $\Delta \mathbf{H}_{\text {formation gs electronic in }}$

Table 6 and the $M$ substituent standard state redox potential for the most favorable $M$ oxidation state.

For the quaternary systems formed with $\mathrm{Al}$ and $\mathrm{Ti}$ substituents on the alkali B sublattices, varying compositions were simulated to determine if there was a possible compositional range where quaternary compositions would be more stable than corresponding ternary alkali borohydrides. The heats of formation for varying $\mathrm{Al}$ and Ti substitution in $\mathrm{NaBH}_{4}$ and $\mathrm{LiBH}_{4}$ are plotted in Figure 29. The substitution of low concentrations of $\mathrm{Al}$ in $\mathrm{LiBH}_{4}$ is predicted to be more stable than $\mathrm{LiBH}_{4}$.

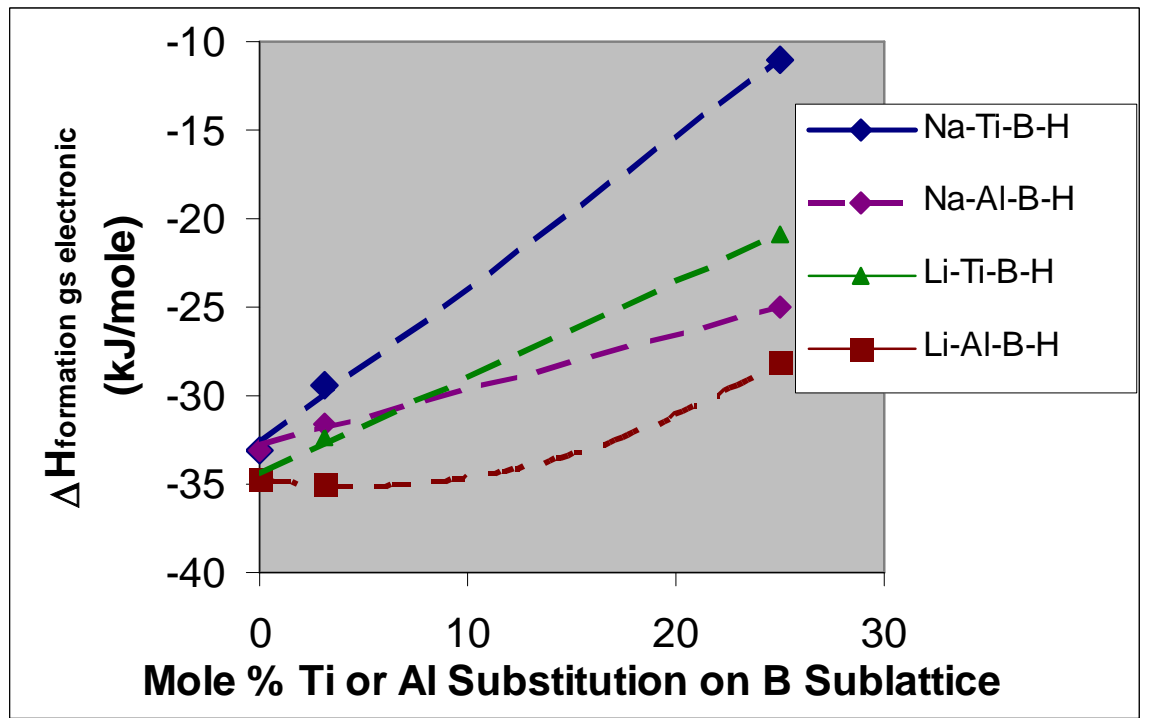

Figure 29: Ground state enthalpies of formation, $\Delta \mathbf{H}_{\text {formation gs electronic, for varying } \mathrm{Al} \text { and } \mathrm{Ti}}$ substitution in $\mathrm{NaBH}_{4}$ and $\mathrm{LiBH}_{4}$. 


\section{First Principles and Thermodynamic Modeling}

\subsubsection{Atomic Scale Simulation of $\mathrm{Mg}\left(\mathrm{BH}_{4}\right)_{2} * 2.2 \mathrm{NH}_{3}$ Ligand Complex}

Atomic modeling was used to investigate the range of possible structures that could be formed with the $\mathrm{Mg}\left(\mathrm{BH}_{4}\right)_{2} * 2.2 \mathrm{NH}_{3}$ complex synthesized by Albemarle (Section 5.3) and the change in possible decomposition reaction mechanisms with structure. Although synthesis of the complex $\operatorname{Mg}\left(\mathrm{BH}_{4}\right)_{2}$ without ligands has been reported, its stability and structure had not yet been substantiated. A recent atomic modeling study surveyed possible $\mathrm{Mg}\left(\mathrm{BH}_{4}\right)_{2}$ crystal structures and found the most favorable structure to be that derived from the substitution of $\mathrm{Mg}\left(\mathrm{BH}_{4}\right)_{2}$ stoichiometry on the $\mathrm{CdAl}_{2} \mathrm{Cl}_{8} P m c 2_{1}$ structural analog lattice sites [Ref. 57]. We surveyed a number of candidate structure types for this compound, including several structures not covered by Ref. 57. We found a number of structures that were very similar in stability, but none as stable as that derived from $\mathrm{CdAl}_{2} \mathrm{Cl}_{8}$. However, we found that the input and minimized symmetry for this structure was $P c$, not $P m c 2_{1}$ as was stated in Ref. 57. The calculation results are shown in Table 7.

\section{Table 7: Simulation results for candidate $\mathrm{Mg}\left(\mathrm{BH}_{4}\right)_{2}$ structures.}

\begin{tabular}{|c|c|c|c|}
\hline $\begin{array}{c}\mathbf{M g B}_{2} \mathbf{H}_{8} \\
\text { Structural } \\
\text { Analog }\end{array}$ & Reference & Space group / Pearson & $\begin{array}{c}\text { electronic } \\
\left(\mathrm{kJ} / \mathrm{mole}^{*} \text { atom) }\right.\end{array}$ \\
\hline $\mathrm{CdAl}_{2} \mathrm{Cl}_{8}$ & 62037 & $\mathrm{mP} 22$ & -23.68 \\
\hline $\mathrm{MgAl}_{2} \mathrm{Cl}_{8}$ & 62046 & $\mathrm{mS} 44$ & -22.94 \\
\hline $\mathrm{MgAu}_{2} \mathrm{~F}_{8}$ & 65287 & $P_{1} 2_{1 /} C_{1} \mathrm{mP} 22$ & -21.76 \\
\hline $\mathrm{UPbSe}_{2} \mathrm{O}_{8}$ & 280839 & $\mathrm{mP} 44$ & -21.75 \\
\hline $\mathrm{BaMn}_{2} \mathrm{O}_{8}$ & 27087 & $F d d d$ & -21.43 \\
\hline $\mathrm{BeB}_{2} \mathrm{H}_{8}$ & 10315 & $I 4{ }_{1} C D \quad \mathrm{tI} 176$ & -21.20 \\
\hline
\end{tabular}

This most favorable $\mathrm{Mg}\left(\mathrm{BH}_{4}\right)_{2} P c$ model was used as the starting point for developing models for the $\mathrm{Mg}\left(\mathrm{BH}_{4}\right)_{2} * 2 \mathrm{NH}_{3}$ complex $\left(2 \mathrm{NH}_{3}\right.$ groups were used instead of 2.2 , because fractional numbers are atomically difficult to represent). Several approaches were used to simulate varying possible $\mathrm{NH}_{3}$ complexing interactions. First, $\mathrm{NH}_{3}$ groups were added to obtain the $\mathrm{Mg}\left(\mathrm{BH}_{4}\right)_{2} * 2 \mathrm{NH}_{3}$ stoichiometry, and the structure was minimized while maintaining the $P c$ symmetry. The $\mathrm{NH}_{3}$ groups in this structure were in the outer coordination sphere and were not directly associated with the $\mathrm{Mg}$ ion. The $\mathrm{Mg}\left(\mathrm{BH}_{4}\right)_{2}$ formed 2-dimensional staggered layers, where each $\mathrm{Mg}$ was tetrahedrally bonded to $4 \mathrm{BH}_{4}{ }^{-}$ groups and each $\mathrm{BH}_{4}{ }^{-}$complex was associated with $2 \mathrm{Mg}$ ions. The $\mathrm{Mg}\left(\mathrm{BH}_{4}\right)_{2}$ layers were intercalated with the $\mathrm{NH}_{3}$ molecules. Next, in order to explore other possible interactions of $\mathrm{NH}_{3}$ with $\mathrm{Mg}$, the symmetry was "broken" by displacing one of the atoms slightly. Molecular dynamics was conducted, thermalizing the model at $400 \mathrm{~K}$ for 1.3 picoseconds (1000 steps). The model was then minimized, with the result that one of the two $\mathrm{NH}_{3}$ groups became directly bonded to $\mathrm{Mg}$. Here, the $\mathrm{Mg}\left(\mathrm{BH}_{4}\right)_{2}$ sheets were broken up into chains and each $\mathrm{Mg}$ was bonded to $3 \mathrm{BH}_{4}{ }^{-}$groups and $1 \mathrm{NH}_{3}$ group. There were two types of $\mathrm{BH}_{4}{ }^{-}$groups in this structure, one shared between two $\mathrm{Mg}$ ions and one bonded as a pendant group to one $\mathrm{Mg}$. Two pendant $\mathrm{BH}_{4}{ }^{-}$and $\mathrm{NH}_{3}$ groups, and two shared $\mathrm{BH}_{4}$ groups were arranged tetrahedrally around each $\mathrm{Mg}$ ion. Finally, to simulate the possible direct bonding of two $\mathrm{NH}_{3}$ to each $\mathrm{Mg}$, the second $\mathrm{NH}_{3}$ was moved closer to each $\mathrm{Mg}$. Molecular dynamics and minimizations were conducted as before. The result was a crystal structure containing distinct 


\section{First Principles and Thermodynamic Modeling}

tetrahedral $\mathrm{Mg}\left(\mathrm{BH}_{4}\right)_{2}\left(\mathrm{NH}_{3}\right)_{2}$ complexes that were not bridge-bonded to other complexes. The complexes are shown in Figure 30, and the $\Delta \mathrm{H}_{\text {formation gs electronic }}$ are given in Table 8 . The stability of the $\mathrm{Mg}\left(\mathrm{BH}_{4}\right)_{2} * 2 \mathrm{NH}_{3}$ compound was found to increase with the lowering of the dimensionality of $\mathrm{Mg}\left(\mathrm{BH}_{4}\right)_{2}$ network bonding and with the increasing inclusion of the $\mathrm{NH}_{3}$ group in the innercoordination sphere.

Table 8. Simulation results for proposed $\mathrm{Mg}\left(\mathrm{BH}_{4}\right)_{2} * 2 \mathrm{NH}_{3}$ complex structures.

\section{$\mathrm{Mg}\left(\mathrm{BH}_{4}\right)_{2} * 2 \mathrm{NH}_{3}$

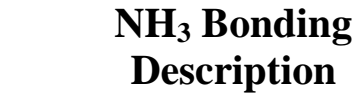

$2 \mathrm{NH}_{3}$ bonded to $\mathrm{Mg}$

$1 \mathrm{NH}_{3}$ bonded to $\mathrm{Mg}$

$\mathrm{No} \mathrm{NH}_{3}$ directly bonded

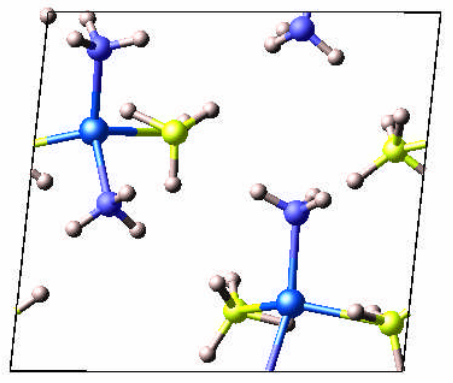

$2 \mathrm{NH}_{3}$ bonded to $\mathrm{Mg}$

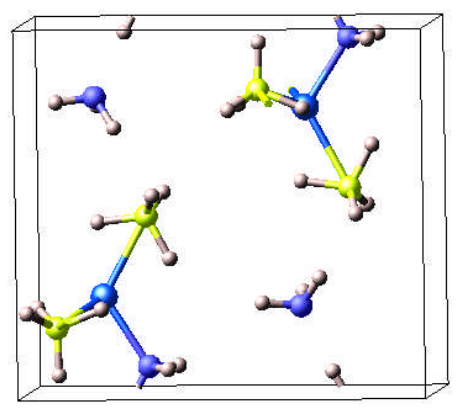

$1 \mathrm{NH}_{3}$ bonded to $\mathrm{Mg}$
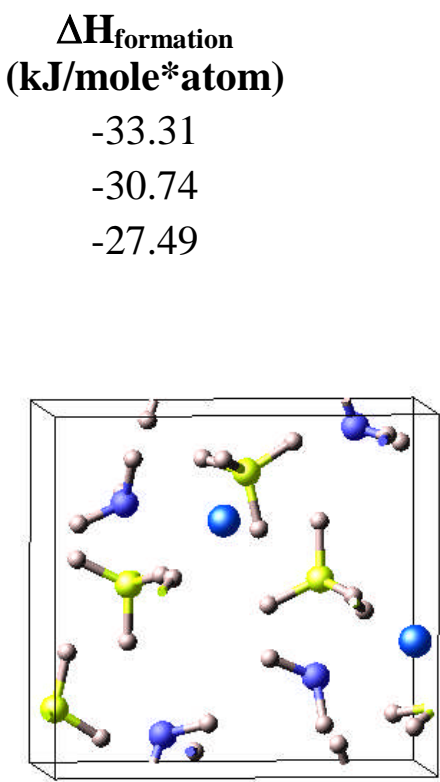

$0 \mathrm{NH}_{3}$ bonded to $\mathrm{Mg}$

Figure 30: The $\mathrm{Mg}\left(\mathrm{BH}_{4}\right)_{2} * \mathrm{NH}_{3}$ complexes with varying $\mathrm{NH}_{3}$ in inner coordination sphere.

The predictions provided insight into $\mathrm{Mg}\left(\mathrm{BH}_{4}\right)_{2}$ stabilization by complexation with $\mathrm{NH}_{3}$. The proposed disruption of the $\mathrm{Mg}\left(\mathrm{BH}_{4}\right)_{2}$ inter-complex bonding by $\mathrm{NH}_{3}$ may also provide an explanation for the kinetic enhancement of decomposition that was observed experimentally. The predicted

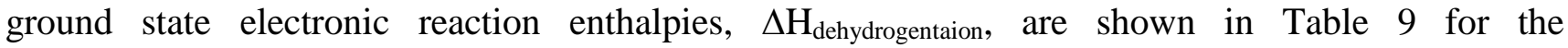
decomposition of $\mathrm{Mg}\left(\mathrm{BH}_{4}\right)_{2}$ and $\mathrm{Mg}\left(\mathrm{BH}_{4}\right)_{2} * 2 \mathrm{NH}_{3}$ complexes. These give an indication of relative reaction trends, but are not corrected for vibrational contributions. The ground state predictions show that the $\mathrm{Mg}\left(\mathrm{BH}_{4}\right)_{2}$ decomposition reactions to $\mathrm{MgH}_{2}$ or $\mathrm{Mg}$ have similar enthalpies per $\mathrm{H}_{2}$ molecule generated. The ground state decomposition enthalpies for the $\mathrm{Mg}\left(\mathrm{BH}_{4}\right)_{2} * 2 \mathrm{NH}_{3}$ complex varied with the incorporation of $\mathrm{NH}_{3}$ into the complex. The first reaction for $\mathrm{Mg}\left(\mathrm{BH}_{4}\right)_{2} * 2 \mathrm{NH}_{3}$ "hydridemechanism" decomposition to form $\mathrm{MgH}_{2}$ is more endothermic than the $\mathrm{Mg}\left(\mathrm{BH}_{4}\right)_{2}$ reaction, and becomes decreasingly endothermic with the decrease in stability of the complex $\left(2 \rightarrow 0 \mathrm{NH}_{3}\right.$ directly bonded). On the other hand, the second reaction "amine-borane mechanism" for $\mathrm{Mg}\left(\mathrm{BH}_{4}\right)_{2} * 2 \mathrm{NH}_{3}$ decomposition, is predicted to be only slightly endothermic at the ground state and becomes almost thermally neutral with decreasing $\mathrm{NH}_{3}$ bonding to $\mathrm{Mg}$. 
First Principles and Thermodynamic Modeling

Table 9: Predicted electronic reaction enthalpies, $\Delta \mathbf{H}_{\text {dehydrogentaion, for various decomposition }}$ reactions.

\begin{tabular}{|c|c|c|c|}
\hline \multirow[t]{3}{*}{ Ground State Reactions } & \multicolumn{3}{|c|}{ No. $\mathrm{NH}_{3}$ Groups Bonded to $\mathrm{Mg}$} \\
\hline & 2 & 1 & $\mathbf{0}$ \\
\hline & \multicolumn{3}{|c|}{$\Delta \mathbf{H}_{\text {decomposition }}\left(\mathrm{kJ} / \mathrm{mole}^{*} \mathbf{H}_{2}\right)$} \\
\hline $\mathrm{Mg}\left(\mathrm{BH}_{4}\right)_{2}-->\mathrm{MgH}_{2}+2 \mathrm{~B}+3 \mathrm{H}_{2}$ & 64.35 & - & - \\
\hline $\mathrm{Mg}\left(\mathrm{BH}_{4}\right)_{2}-->\mathrm{Mg}+2 \mathrm{~B}+4 \mathrm{H}_{2}$ & 65.13 & - & - \\
\hline $\mathrm{Mg}\left(\mathrm{BH}_{4}\right)_{2} * 2 \mathrm{NH}_{3}->\mathrm{MgH}_{2}+2 \mathrm{~B}+2 \mathrm{NH}_{3}+3 \mathrm{H}_{2}$ & 115.06 & 98.81 & 78.18 \\
\hline $\mathrm{Mg}\left(\mathrm{BH}_{4}\right)_{2} * 2 \mathrm{NH}_{3}-->1 / 3 \mathrm{Mg}_{3} \mathrm{BN}_{3}+\mathrm{BN}+2 / 3 \mathrm{~B}+7 \mathrm{H}_{2}$ & 25.16 & 18.20 & 9.36 \\
\hline
\end{tabular}




\section{Solid State Processing}

\section{Solid State Processing}

\subsection{Summary}

Solid state processing has been used to investigate the high hydrogen capacity alanate and borohydride classes of materials described above. The primary composition systems are listed in Table 3 along with the other methods which have been applied for those systems. A total of nine compositional systems were studied in the search for high capacity materials. The project started with the investigation of mixed Am (alkaline metal) and Ae (alkaline earth metal) alanates with and without transition metals. The research focus was later shifted to borohydrides for their potential of higher storage capacity. In this section, the techniques and results for solid state synthesis are presented.

\subsection{Experimental}

The starting materials, $\mathrm{NaH}(95 \%), \mathrm{LiH}(95 \%) \mathrm{MgH}_{2}(90 \%), \mathrm{LiBH}_{4}(>90 \%)$, transitional metals and hydrides were purchased from the Aldrich Co. and other commercial sources. $\mathrm{AlH}_{3}$ was obtained utilizing a proprietary method. Detailed characterization of this aluminum hydride is described in Ref. 58. The X-ray diffraction pattern of this material shows only $\mathrm{AlH}_{3}$, with no detectable impurities (Figure 31). Solid state NMR (by the California Institute of Technology) confirms that the material does not contain trapped $\mathrm{H}_{2}$ gas and only a trace amount of elemental $\mathrm{Al}$ is present in the sample (Figure 32). Commercial grade $\mathrm{NaAlH}_{4}(98 \%)$ was obtained from Albemarle having only $\mathrm{Na}_{3} \mathrm{AlH}_{6}$ and Al, products of dehydrogenation, as "impurities" detected by XRD examination. All solid materials were used in the as-received condition without further purification. The chemicals were stored, measured and transferred under high purity $\mathrm{N}_{2}$ environment inside a glove box with oxygen content $<25$ ppm.
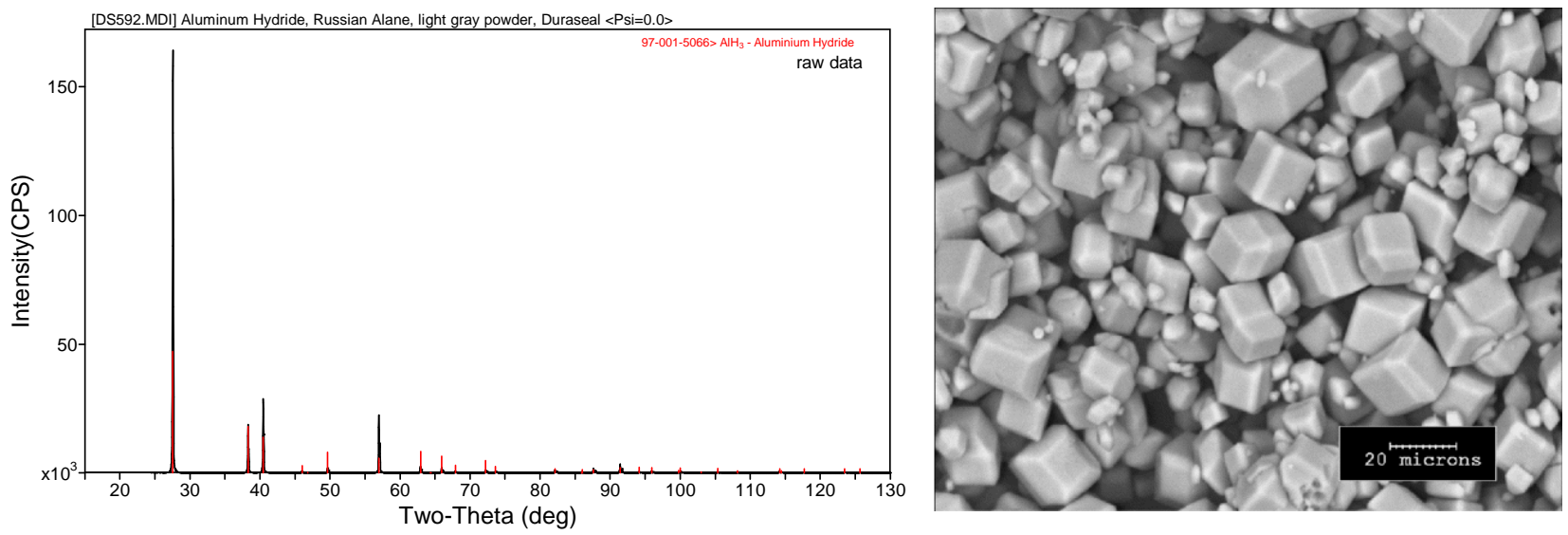

Figure 31: XRD and SEM characterization of $\mathrm{AlH}_{3}$. 


\section{Solid State Processing}
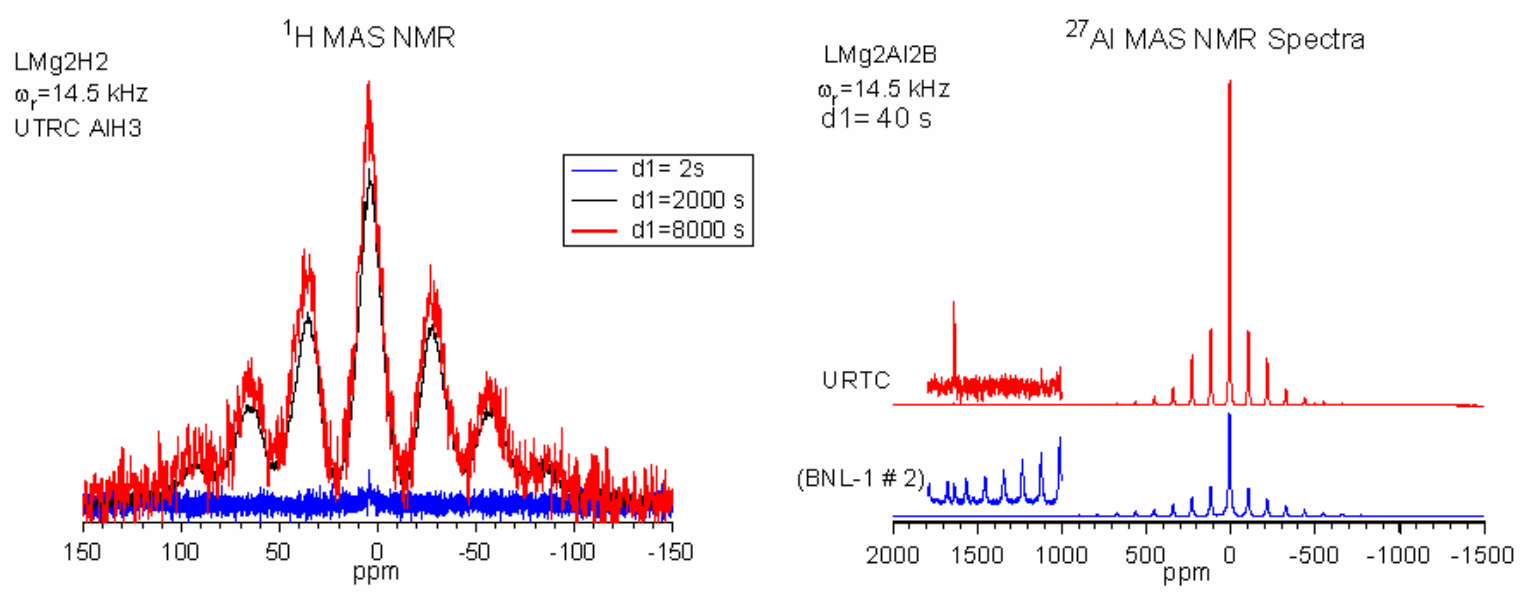

Figure 32: Solid state NMR of $\mathrm{AlH}_{3}$.

The new complex alanate materials were synthesized by mixing simple hydrides, such as $\mathrm{NaH}, \mathrm{LiH}$, $\mathrm{MgH}_{2}, \mathrm{AlH}_{3}$ and transition metals or metal hydrides in a mortar and pestle for 15 min at various molar ratios. Approximately $10 \mathrm{~g}$ of the mixtures were ball milled in a high energy SPEX mill in an $\mathrm{N}_{2}$ environment for 3 hours. Immediately after ball milling, approximately $1 \mathrm{~g}$ of the samples were transferred into a sample holder of a modified Sievert's apparatus (Advanced Materials Co.). The samples were hydrided under 190-195 bar hydrogen for 20 hours each at 60, 80, 100 and $120^{\circ} \mathrm{C}$ respectively and followed by XRD analysis.

XRD analyses were performed on a Rigaku D/Max-b, Model RU-200B diffractometer equipped with a rotating $\mathrm{Cu}$ anode, or a Scintag X1 Advanced Diffraction System equipped with a $\mathrm{Cu}$ anode housed in a glove box. Samples for the Rigaku were mounted on a glass sample holder and covered with a layer of DuraSeal ${ }^{\mathrm{TM}}$ sealed with a ring of silicone grease in the glove box. Differential Scanning Calorimetry (DSC) measurements were conducted on TA Instruments 2910 (Albemarle) or 2920 (UTRC). The sample pans were made of gold plated stainless steel (Swiss Institute for Safety and Security) or $\mathrm{Al}$, and the sample heating rate was $10^{\circ} \mathrm{C} / \mathrm{min}$. Thermal Gravimetric Analysis - Mass Spectrometry (TGA-MS) was conducted using a TA 2950, coupled with Pfeiffer Omnistar Mass Spectrometer GSD 300 through heated capillary tubing.

\subsection{Results}

\subsubsection{Alanates}

The syntheses of mixed alkaline and alkaline earth salts of aluminum hydride from simple hydrides were attempted by the solid synthesis method described in the experimental section. This method of synthesis was chosen due to its high energy mechanical alloying effect. In addition, this method is simple to implement, and therefore it can serve as a screening method for a large collection of compositions. Table 10 lists alanate compositions studied using this method, including key reactions derived based on XRD analysis. A few examples are reported in the following sections in detail. The appendix of Section 10.1 provides additional composition evolution results for a larger set of materials. 


\section{Solid State Processing}

Table 10: Compositions of mixed alanates prepared by SSP.

\begin{tabular}{|c|c|c|c|}
\hline \multicolumn{2}{|r|}{ Compositions } & Mole ratio & Main Reactions \\
\hline \multicolumn{4}{|c|}{ Basic Alanates } \\
\hline \multirow{2}{*}{1} & \multirow{2}{*}{$\mathrm{NaH}: \mathrm{LiH}: \mathrm{AlH}_{3}$} & \multirow{2}{*}{$1: 1: 1$} & $\mathrm{NaH}+\mathrm{LiH}+\mathrm{AlH}_{3} \Rightarrow \mathrm{LiH}+\mathrm{NaAlH}_{4}$ \\
\hline & & & $2 \mathrm{NaAlH}_{4}+\mathrm{LiH} \Rightarrow \mathrm{Na}_{2} \mathrm{LiAlH}_{6}+\mathrm{Al}+3 / 2 \mathrm{H}_{2}$ \\
\hline \multirow{2}{*}{2} & \multirow{2}{*}{$\mathrm{NaH}: \mathrm{MgH}_{2}: \mathrm{AlH}_{3}$} & \multirow{2}{*}{$1: 1: 1$} & $\mathrm{NaH}+\mathrm{MgH}_{2}+\mathrm{AlH}_{3} \rightarrow \mathrm{MgH}_{2}+\mathrm{NaAlH}_{4}$ \\
\hline & & & $\mathrm{MgH}_{2}+\mathrm{NaAlH}_{4} \Leftrightarrow \mathrm{NaMgH}_{3}+\mathrm{Al}+3 / 2 \mathrm{H}_{2}$ \\
\hline \multirow[b]{2}{*}{3} & \multirow[b]{2}{*}{$\mathrm{LiH}: \mathrm{MgH}_{2}: \mathrm{AlH}_{3}$} & \multirow[b]{2}{*}{$1: 1: 1$} & $\mathrm{LiH}+\mathrm{MgH}_{2}+\mathrm{AlH}_{3} \Rightarrow \mathrm{MgH}_{2}+\mathrm{LiAlH}_{4}$ \\
\hline & & & $\begin{array}{l}\mathrm{LiAlH}_{4} \Rightarrow 1 / 3 \mathrm{Li}_{3} \mathrm{AlH}_{6}+2 / 3 \mathrm{Al}+\mathrm{H}_{2} \Rightarrow>\mathrm{LiH}+\mathrm{Al} \\
+3 / 2 \mathrm{H}_{2}\end{array}$ \\
\hline \multirow[b]{2}{*}{4} & \multirow[b]{2}{*}{$\mathrm{NaH}: \mathrm{LiH}: \mathrm{MgH}_{2}: \mathrm{AlH}_{3}$} & \multirow[b]{2}{*}{$1: 1: 1: 1$} & $\begin{array}{l}\mathrm{NaH}+\mathrm{LiH}+\mathrm{AlH}_{3}=>1 / 3 \mathrm{Na}_{2} \mathrm{LiAlH}_{6}+1 / 3 \mathrm{NaAlH}_{4}+ \\
1 / 3 \mathrm{Al}+2 / 3 \mathrm{LiH}+1 / 2 \mathrm{H}_{2}\end{array}$ \\
\hline & & & $\begin{array}{l}\mathrm{NaH}+\mathrm{MgH}_{2}+\mathrm{LiH}+\mathrm{AlH}_{3}=>1 / 2 \mathrm{MgH}_{2}+1 / 4 \mathrm{Na}_{2} \mathrm{LiAlH}_{6} \\
+1 / 2 \mathrm{NaMgH}_{3}+3 / 4 \mathrm{Al}+3 / 4 \mathrm{LiH}+9 / 8 \mathrm{H}_{2}\end{array}$ \\
\hline 5 & $\mathrm{NaH}: \mathrm{LiH}: \mathrm{AlH}_{3}: \mathrm{Na}_{2} \mathrm{O}$ & $1: 1: 1: 0.2$ & $\mathrm{NaH}+\mathrm{LiH}+\mathrm{AlH}_{3} \rightarrow \mathrm{NaAlH}_{4}+\mathrm{Na}_{2} \mathrm{LiAlH}_{6}+\mathrm{Al}+\mathrm{H}_{2}$ \\
\hline 6 & $\mathrm{NaH}: \mathrm{LiH}: \mathrm{AlH}_{3}: \mathrm{NaOH}$ & $1: 1: 1: 0.2$ & $\mathrm{NaH}+\mathrm{LiH}+\mathrm{AlH}_{3} \rightarrow \mathrm{NaAlH}_{4}+\mathrm{Na}_{2} \mathrm{LiAlH}_{6}+\mathrm{Al}+\mathrm{H}_{2}$ \\
\hline \multicolumn{2}{|r|}{ Ti Addition } & & \\
\hline 7 & $\mathrm{NaH}: \mathrm{Ti}: \mathrm{Al}$ & $1: 1: 1$ & $\begin{array}{l}\mathrm{NaH}+\mathrm{Ti}+\mathrm{A} l+3 / 2 \mathrm{H}_{2}->1 / 3 \mathrm{TiH}_{1.5}+2 / 3 \mathrm{TiH}_{2}+ \\
\mathrm{NaAlH}_{4}\end{array}$ \\
\hline 8 & $\mathrm{NaH}: \mathrm{Ti}: \mathrm{Al}$ & $2: 1: 1$ & $\mathrm{NaH}+\mathrm{Ti}+\mathrm{Al}+3 / 2 \mathrm{H}_{2} \rightarrow 1 / 3 \mathrm{TiH}_{1.5}+2 / 3 \mathrm{TiH}_{2}+\mathrm{NaAlH}_{4}$ \\
\hline 9 & $\mathrm{NaH}: \mathrm{TiCl}_{2}: \mathrm{Al}$ & $3: 1: 1$ & $\begin{array}{l}3 \mathrm{NaH}+\mathrm{TiCl}_{2}+\mathrm{Al}+3 / 2 \mathrm{H}_{2}->2 \mathrm{NaCl}+1 / 2 \mathrm{Al}+\mathrm{NaH} \\
+\mathrm{TiH}_{2}+1 / 6 \mathrm{Al} 3 \mathrm{Ti}\end{array}$ \\
\hline 10 & $\mathrm{NaH}: \mathrm{TiCl}_{2}: \mathrm{AlH}_{3}$ & $3: 1: 1$ & $2 \mathrm{NaH}+\mathrm{TiCl}_{2}>2 \mathrm{NaCl}+\mathrm{TiH}_{2}, \mathrm{AlH}_{3} \rightarrow \mathrm{Al}+3 / 2 \mathrm{H}_{2}$ \\
\hline 11 & $\mathrm{NaH}: \mathrm{TiH}_{2}: \mathrm{AlH}_{3}$ & $1: 1: 1$ & $\mathrm{NaH}+\mathrm{TiH}_{2}+\mathrm{AlH} \mathrm{H}_{3} \rightarrow \mathrm{TiH}_{2}+\mathrm{NaAlH}_{4}$ \\
\hline \multirow[t]{2}{*}{12} & \multirow[t]{2}{*}{$\mathrm{NaH}: \mathrm{LiH}: \mathrm{TiH}_{2}: \mathrm{AlH}_{3}$} & \multirow[t]{2}{*}{$1: 1: 1: 1$} & $\begin{array}{l}\mathrm{NaH}+\mathrm{LiH}+\mathrm{AlH}_{3} \Rightarrow 1 / 3 \mathrm{NaAlH}_{4}+1 / 3 \mathrm{Al}+ \\
1 / 3 \mathrm{Na}_{2} \mathrm{LiAlH}_{6}+2 / 3 \mathrm{LiH}+1 / 2 \mathrm{H}_{2}\end{array}$ \\
\hline & & & $2 \mathrm{NaAlH}_{4}+\mathrm{LiH} \Rightarrow \mathrm{Na}_{2} \mathrm{LiAlH}_{6}+\mathrm{Al}+3 / 2 \mathrm{H}_{2}$ \\
\hline \multirow[t]{2}{*}{13} & \multirow{2}{*}{$\mathrm{NaH}: \mathrm{MgH}_{2}: \mathrm{TiH}_{2}: \mathrm{AlH}_{3}$} & \multirow[t]{2}{*}{$1: 1: 1: 1$} & $\begin{array}{l}\mathrm{NaH}+\mathrm{MgH}_{2}+\mathrm{TiH} 2+\mathrm{AlH} 3=1 / 2 \mathrm{MgH}_{2}+\mathrm{TiH}_{2} \\
+1 / 2 \mathrm{NaAlH}_{4}+1 / 2 \mathrm{NaMgH}_{3}+1 / 2 \mathrm{Al}+3 / 4 \mathrm{H}_{2}\end{array}$ \\
\hline & & & $\mathrm{NaAlH}_{4}+\mathrm{MgH}_{2} \Rightarrow \mathrm{NaMgH}_{3}+\mathrm{Al}+3 / 2 \mathrm{H}_{2}$ \\
\hline \multicolumn{4}{|c|}{ Ni Addition } \\
\hline 14 & LiH:Ni:AlH 3 & $1: 1: 1$ & $\mathrm{LiH}+\mathrm{Ni}+\mathrm{AlH}_{3} \Rightarrow 1 / 3 \mathrm{Li} 3 \mathrm{AlH}_{6}+\mathrm{Al}+\mathrm{Ni}$ \\
\hline 15 & $\mathrm{NaH}: \mathrm{Ni}: \mathrm{AlH}_{3}$ & $1: 1: 1$ & $\mathrm{NaH}+\mathrm{Ni}+\mathrm{AlH}_{3} \Rightarrow \mathrm{NaAlH}_{4}+\mathrm{Ni}$ \\
\hline 16 & $\mathrm{MgH}_{2}: \mathrm{Ni}: \mathrm{AlH}_{3}$ & $1: 1: 1$ & $\mathrm{MgH}_{2}+\mathrm{Ni}+\mathrm{AlH}_{3} \Rightarrow \mathrm{MgH}_{2}+\mathrm{Ni}+\mathrm{Al}$ \\
\hline 17 & $\mathrm{LiH}: \mathrm{MgH}_{2}: \mathrm{Ni}: \mathrm{AlH}_{3}$ & $1: 1: 1: 1$ & $\begin{array}{l}\mathrm{LiH}+\mathrm{MgH}_{2}+\mathrm{Ni}+\mathrm{AlH}_{3} \Rightarrow \mathrm{MgH}_{2}+\mathrm{Ni}+\mathrm{Al} \\
+\mathrm{Li}_{3} \mathrm{AlH}_{6}\end{array}$ \\
\hline 18 & $\mathrm{NaH}: \mathrm{MgH}_{2}: \mathrm{Ni}: \mathrm{AlH}_{3}$ & $1: 1: 1: 1$ & $\mathrm{NaH}+\mathrm{MgH}_{2}+\mathrm{Ni}+\mathrm{AlH} 3 \Rightarrow \mathrm{MgH}_{2}+\mathrm{Ni}+\mathrm{NaAlH}_{4}$ \\
\hline \multicolumn{4}{|c|}{ Co Addition } \\
\hline 19 & $\mathrm{LiH}: \mathrm{Co}: \mathrm{AlH}_{3}$ & $1: 1: 1$ & $\mathrm{LiH}+\mathrm{AlH}_{3}+\mathrm{Co}=>1 / 3 \mathrm{Li}_{3} \mathrm{AlH}_{6}+2 / 3 \mathrm{Al}+\mathrm{Co}$ \\
\hline 20 & $\mathrm{NaH}: \mathrm{Co}: \mathrm{AlH}_{3}$ & $1: 1: 1$ & $\mathrm{NaH}+\mathrm{Co}+\mathrm{AlH}_{3} \Rightarrow>\mathrm{NaAlH}_{4}+\mathrm{Co}$ \\
\hline 21 & $\mathrm{MgH}_{2}: \mathrm{Co}: \mathrm{AlH}_{3}$ & $1: 1: 1$ & $\mathrm{MgH}_{2}+\mathrm{Co}+\mathrm{AlH}_{3} \Rightarrow \mathrm{MgH}_{2}+\mathrm{Co}+\mathrm{Al}+3 / 2 \mathrm{H}_{2}$ \\
\hline 22 & $\mathrm{LiH}: \mathrm{MgH}_{2}: \mathrm{Co}: \mathrm{AlH}_{3}$ & $1: 1: 1: 1$ & $\mathrm{LiH}+\mathrm{MgH}_{2}+\mathrm{Co}+\mathrm{AlH}_{3} \Rightarrow \mathrm{MgH}_{2}+\mathrm{Co}+\mathrm{Al}$ \\
\hline 23 & $\mathrm{NaH}: \mathrm{MgH}_{2}: \mathrm{Co}: \mathrm{AlH}_{3}$ & $1: 1: 1: 1$ & $\mathrm{NaH}+\mathrm{MgH}_{2}+\mathrm{Co}+\mathrm{AlH}_{3} \Rightarrow \mathrm{MgH}_{2}+\mathrm{Co}+\mathrm{NaAlH}_{4}$ \\
\hline
\end{tabular}




\section{Solid State Processing}

\begin{tabular}{|c|c|c|c|}
\hline \multicolumn{2}{|r|}{ Fe Addition } & & \\
\hline 24 & $\mathrm{LiH}: \mathrm{Fe}: \mathrm{AlH}_{3}$ & $1: 1: 1$ & $\begin{array}{l}\mathrm{LiH}+\mathrm{Fe}+\mathrm{AlH}_{3} \Rightarrow 1 / 2 \mathrm{LiAlH}_{4}+1 / 6 \mathrm{Li}_{3} \mathrm{AlH}_{6}+1 / 3 \mathrm{Al} \\
+\mathrm{Fe}\end{array}$ \\
\hline 25 & $\mathrm{NaH}: \mathrm{Fe}: \mathrm{AlH}_{3}$ & $1: 1: 1$ & $\mathrm{NaH}+\mathrm{Fe}+\mathrm{AlH}_{3} \Rightarrow>\mathrm{NaAlH}_{4}+\mathrm{Fe}$ \\
\hline 26 & $\mathrm{MgH}_{2}: \mathrm{Fe}: \mathrm{AlH}_{3}$ & $1: 1: 1$ & $\mathrm{MgH}_{2}+\mathrm{Fe}+\mathrm{AlH}_{3} \Rightarrow \mathrm{MgH}_{2}+\mathrm{Al}+\mathrm{Fe}$ \\
\hline 27 & $\mathrm{LiH}: \mathrm{MgH}_{2}: \mathrm{Fe}: \mathrm{AlH}_{3}$ & $1: 1: 1: 1$ & $\mathrm{LiH}+\mathrm{MgH}_{2}+\mathrm{Fe}+\mathrm{AlH}_{3} \Rightarrow \mathrm{MgH}_{2}+\mathrm{Fe}+\mathrm{Al}$ \\
\hline 28 & $\mathrm{NaH}: \mathrm{MgH}_{2}: \mathrm{Fe}: \mathrm{AlH}_{3}$ & $1: 1: 1: 1$ & $\mathrm{NaH}+\mathrm{MgH}_{2}+\mathrm{Fe}+\mathrm{AlH}_{3} \Rightarrow \mathrm{MgH}_{2}+\mathrm{Fe}+\mathrm{NaAlH}_{4}$ \\
\hline \multicolumn{2}{|r|}{ Cr Addition } & & \\
\hline 29 & $\mathrm{LiH}: \mathrm{Cr}: \mathrm{AlH}_{3}$ & $1: 1: 1$ & $\mathrm{LiH}+\mathrm{Cr}+\mathrm{AlH}_{3} \Rightarrow \mathrm{LiAlH}_{4}+\mathrm{Cr}$ \\
\hline 30 & $\mathrm{NaH}: \mathrm{Cr}: \mathrm{AlH}_{3}$ & $1: 1: 1$ & $\mathrm{NaH}+\mathrm{Cr}+\mathrm{AlH}_{3} \Rightarrow>\mathrm{NaAlH}_{4}+\mathrm{Cr}$ \\
\hline 31 & $\mathrm{MgH}_{2}: \mathrm{Cr}: \mathrm{AlH}_{3}$ & $1: 1: 1$ & $\mathrm{MgH}_{2}+\mathrm{Cr}+\mathrm{AlH}_{3} \Rightarrow \mathrm{MgAlH}_{4}+\mathrm{Cr}$ \\
\hline
\end{tabular}

\subsubsection{Na-Li-Mg-Al-H}

In the Na-Li-Mg-Al-H (1:1:1:1) system (Composition \#4), XRD examination of the samples after hand mixing did not show evidence of chemical reactions, although the LiH signal was absent in mixtures containing $\mathrm{LiH}$. It is suspected that the $\mathrm{LiH}$ signal, which should not be masked by any of the other constituents, is absorbed by one or more of the other compounds present. After SPEX milling, several reaction products were detected by XRD, including $\mathrm{NaAlH}_{4}, \mathrm{LiNa}_{2} \mathrm{AlH}_{6}, \mathrm{NaMgH}_{3}$, and $\mathrm{Al}$ (Figure 33).

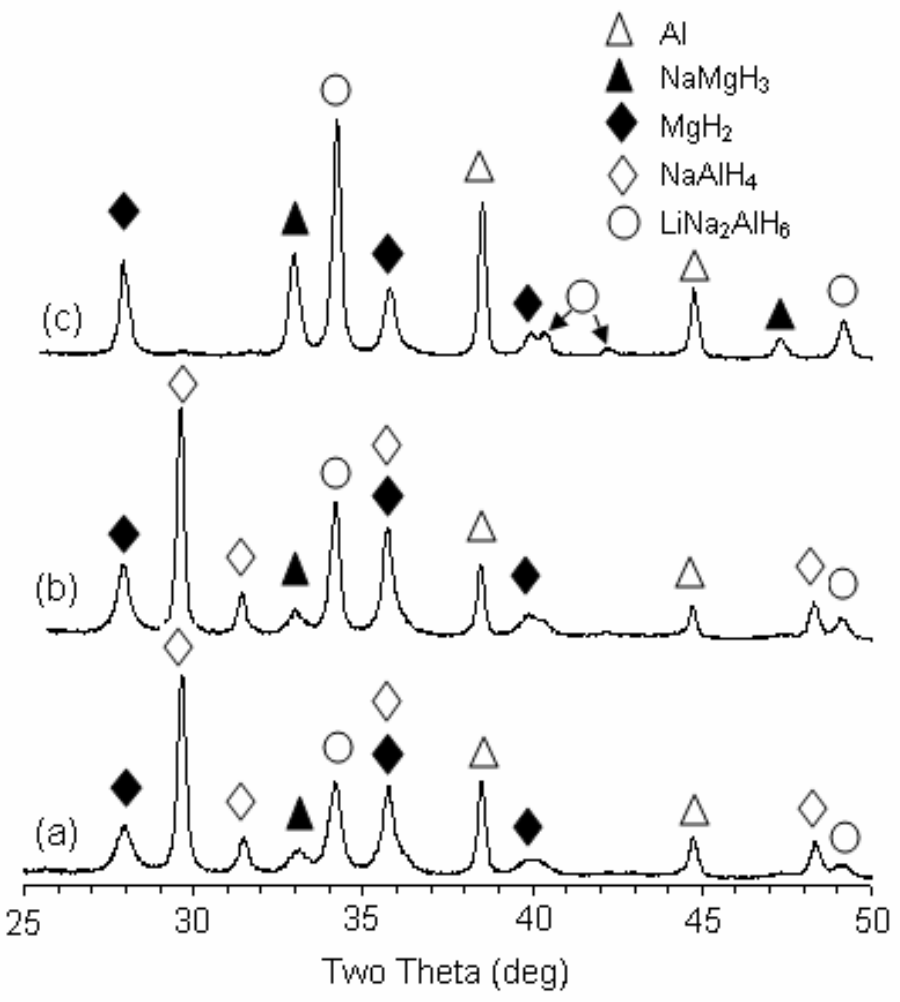

Figure 33: XRD of (a) SPEX milled for 3 hours, (b) $80^{\circ} \mathrm{C}$ and (c) $120^{\circ} \mathrm{C}$ hydriding at 195 bar hydrogen pressure for 20 hours. 


\section{Solid State Processing}

This observation suggests that the following reaction occurred during the milling process:

Equation 10:

Equation 11:

Equation 12:

Equation 13:
$2 \mathrm{AlH}_{3} \rightarrow 2 \mathrm{Al}+3 \mathrm{H}_{2}$

$\mathrm{NaH}+\mathrm{AlH}_{3} \rightarrow \mathrm{NaAlH}_{4}$

$\mathrm{LiH}+2 \mathrm{NaH}+\mathrm{AlH}_{3} \rightarrow \mathrm{LiNa}_{2} \mathrm{AlH}_{6}$

$\mathrm{NaH}+\mathrm{MgH}_{2} \rightarrow \mathrm{NaMgH}_{3}$

Upon heat-treatment, the sample composition remained unchanged below $100^{\circ} \mathrm{C}$. At temperatures greater than $100^{\circ} \mathrm{C}$, the signal of $\mathrm{NaAlH}_{4}$ decreased substantially. Signals from the $\mathrm{LiNa}_{2} \mathrm{AlH}_{6}$, $\mathrm{NaMgH}_{3}$ and $\mathrm{Al}$ phases increased, indicating Equation 14 and Equation 15 may occur at this temperature.

\section{Equation 14:}

Equation 15:
$2 \mathrm{NaAlH}_{4}+\mathrm{LiH} \rightarrow \mathrm{LiNa}_{2} \mathrm{AlH}_{6}+\mathrm{Al}+3 / 2 \mathrm{H}_{2}$

$\mathrm{NaAlH}_{4}+\mathrm{MgH}_{2} \rightarrow \mathrm{NaMgH}_{2}+\mathrm{Al}+2 \mathrm{H}_{2}$

In this system, $\mathrm{NaH}$ appears to be the most reactive among alkali and alkaline earth hydrides. It can form binary complex hydrides with $\mathrm{AlH}_{3}$ and $\mathrm{MgH}_{2}$ respectively, and ternary complexes with $\mathrm{LiH}$ plus $\mathrm{AlH}_{3}$. Among the complex hydrides formed, $\mathrm{LiNa}_{2} \mathrm{AlH}_{6}$ and $\mathrm{NaMgH}_{3}$ are the most stable. The existence of $\mathrm{LiNa}_{2} \mathrm{AlH}_{6}$ and $\mathrm{NaMgH}_{3}$ [Refs. 59,60,61] has been reported in the literature. No $\mathrm{LiAlH}_{4}$, $\mathrm{Li}_{3} \mathrm{AlH}_{6}, \mathrm{Na}_{3} \mathrm{AlH}_{6}$ and mixed lithium magnesium aluminum hydride phases were observed, indicating they were less stable than the $\mathrm{LiNa}_{2} \mathrm{AlH}_{6}$ and $\mathrm{NaMgH}_{3}$ under this reaction environment. It could also be due to their formation being kinetically impeded.

In order to further understand thermodynamic stability without the interference of varying kinetics, first principles thermodynamic property predictions were utilized to generate data for equilibrium thermochemical calculations. Below $87^{\circ} \mathrm{C}$, the $\mathrm{LiH}$ destabilization of $\mathrm{NaAlH}_{4}$ to form the $\mathrm{Na}_{2} \mathrm{LiAlH}_{6}$ intermediate phase (Equation 14) with the release of only 2.6 weight $\% \mathrm{H}_{2}$, is predicted to predominate. At higher temperatures, the $\mathrm{NaAlH}_{4}$ decomposition reaction to the intermediate phase, $\mathrm{Na}_{3} \mathrm{AlH}_{6}$, with the release of 3.7 weight $\% \mathrm{H}_{2}$ is predicted to predominate, even in the presence of $\mathrm{LiH}$. In contrast, the $\mathrm{MgH}_{2}$ destabilization of $\mathrm{NaAlH}_{4}$ to form $\mathrm{NaMgH}_{3}$ (Equation 15) is predicted to predominate above $52^{\circ} \mathrm{C}$, leading to the release of 4.8 weight $\% \mathrm{H}_{2}$. These predictions confirm the above experimental observations that $\mathrm{Na}_{2} \mathrm{LiAlH}_{6}$ and $\mathrm{NaMgH}_{3}$ are predominate phases at higher temperatures.

\subsubsection{Li-Mg-Al-H}

The initial synthesis attempts of Li-Mg-Al-H compounds were performed with solid state methods. A reaction mixture containing $\mathrm{LiH}, \mathrm{MgH}_{2}$ and $\mathrm{AlH}_{3}$ (1:1:1) (Composition \#3) was hand mixed and SPEX milled for 3 hours. The SPEX milling resulted in the formation of $\mathrm{LiAlH}_{4}$. Upon heat-treatment to $60^{\circ} \mathrm{C}$ under $190-195$ bar of hydrogen, $\mathrm{LiAlH}_{4}$ dissociated to $\mathrm{Al}$ and $\mathrm{Li}_{3} \mathrm{AlH}_{6}$. Further heating above $100^{\circ} \mathrm{C}$ in hydrogen dissociated the $\mathrm{Li}_{3} \mathrm{AlH}_{6}$ to $\mathrm{LiH}$ and $\mathrm{Al}$. The $\mathrm{MgH}_{2}$ did not react. No mixed lithium 


\section{Solid State Processing}

magnesium aluminum hydride phase formed using the solid state method with simple hydride precursors.

In this study, $\operatorname{LiMg}\left(\mathrm{AlH}_{4}\right)_{3}$ was prepared by Albemarle using the solution based method described in Section 5.2. The as-synthesized compound was tested for isothermal hydrogen desorption at 100 and $150^{\circ} \mathrm{C}$ (Figure 34). At $100^{\circ} \mathrm{C}, 4.0 \mathrm{wt} \% \mathrm{H}_{2}$ was released at a slow rate. The desorption rate increased significantly at $150^{\circ} \mathrm{C}$, with 6.9-7.0 wt $\% \mathrm{H}_{2}$ released. An additional $1.8 \mathrm{wt} \% \mathrm{H}_{2}$ was released at $340^{\circ} \mathrm{C}$, yielding a total capacity of $8.7-8.8 \mathrm{wt} \% \mathrm{H}_{2}$.

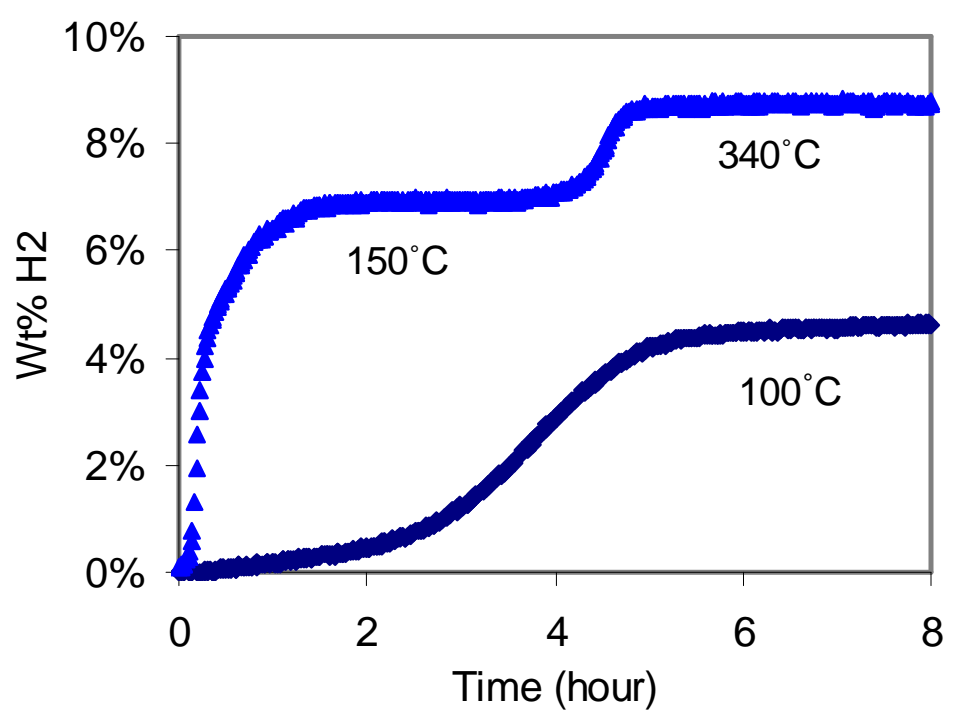

Figure 34: Hydrogen desorption of $\mathrm{LiMg}\left(\mathrm{AlH}_{4}\right)_{3}$ at $100^{\circ} \mathrm{C}, 150^{\circ} \mathrm{C}$ and $340^{\circ} \mathrm{C}$.

The XRD characterization of the dehydrogenated $\mathrm{LiMg}\left(\mathrm{AlH}_{4}\right)_{3}$ indicated that the phase composition varied with desorption temperature (Figure 35) and desorption time. After 5 hours of desorption at $100^{\circ} \mathrm{C}, \mathrm{XRD}$ showed the presence of $\mathrm{Al}$ and an unknown compound, proposed to be an intermediate $\mathrm{LiMgAlH}_{6}$ phase based on the $\mathrm{H}_{2}$ weight \% released (Equation 16). This hypothesis was corroborated by the identification of a VASP-minimized $\mathrm{LiMgAlH}_{6}$ hexagonal candidate structure whose simulated powder pattern closely matched the unknown XRD peaks. Desorption at $150^{\circ} \mathrm{C}$ for 24 hours resulted in the formation of $\mathrm{MgH}_{2}$ and additional $\mathrm{Al}$ (Equation 17). Note that small amounts of $\mathrm{LiH}$ cannot be determined by XRD in the presence of $\mathrm{Al}$. Increasing the temperature to $340^{\circ} \mathrm{C}$ caused the appearance of $\mathrm{Al}_{3} \mathrm{Mg}_{2}$ via Equation 18.

Equation 16:

Equation 17:

Equation 18: $100^{\circ} \mathrm{C}: \operatorname{LiMg}\left(\mathrm{AlH}_{4}\right)_{3} \rightarrow \mathrm{LiMgAlH}_{6}+2 \mathrm{Al}+3 \mathrm{H}_{2}$

$150^{\circ} \mathrm{C}: \mathrm{LiMgAlH}_{6} \rightarrow \mathrm{LiH}+\mathrm{MgH}_{2}+\mathrm{Al}+2 \mathrm{H}_{2}$

$340^{\circ} \mathrm{C}: 2 \mathrm{MgH}_{2}+3 \mathrm{Al} \rightarrow \mathrm{Al}_{3} \mathrm{Mg}_{2}+2 \mathrm{H}_{2}$ 


\section{Solid State Processing}

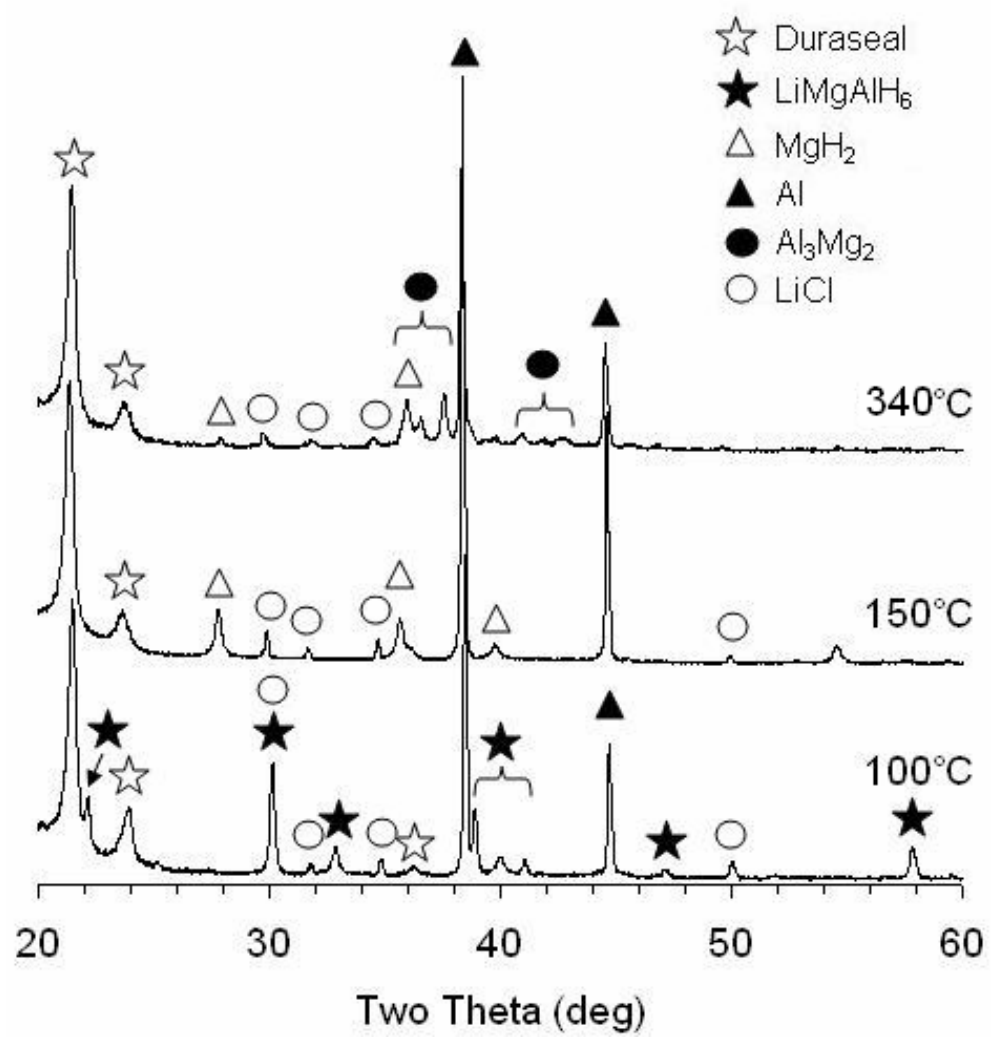

Figure 35: XRD of decomposition products of $\operatorname{LiMg}\left(\mathrm{AlH}_{4}\right)_{3}$ at $100^{\circ} \mathrm{C}, 150^{\circ} \mathrm{C}$ and $340^{\circ} \mathrm{C}$.

Thermal analyses and first principles thermodynamic predictions confirmed the likelihood of these reactions. When $\operatorname{LiMg}\left(\mathrm{AlH}_{4}\right)_{3}$ was heated at $10^{\circ} \mathrm{C} / \mathrm{min}$ in a $\mathrm{DSC}$, an exothermic reaction began at $140^{\circ} \mathrm{C}$ with a latent heat of $-5.5 \mathrm{KJ} / \mathrm{mol}-\mathrm{H}_{2}$ (Equation 16), immediately followed by an endothermic reaction with a latent heat of $13.1 \mathrm{KJ} / \mathrm{mol}-\mathrm{H}_{2}$ (Equation 17). Results from the first principles thermodynamic modeling confirmed their exothermic (Equation 16) and endothermic nature (Equation 17). The reaction heat for Equation 17 agrees with the value reported by Mamatha [Ref. 62].

The reverse hydrogen absorption of Equation 17 was experimentally tested using both undoped and $2 \% \mathrm{TiCl}_{3}$ doped $\mathrm{LiMg}\left(\mathrm{AlH}_{4}\right)_{3}$. The doping was achieved by 15 minutes of SPEX milling. After being discharged at $150^{\circ} \mathrm{C}$ for more than 5 hours, the samples were charged under 190 bar of hydrogen at 80 and $100^{\circ} \mathrm{C}$ for a total of 24 hours. No absorption was observed. The material is not rechargeable under these conditions.

\subsubsection{Am-Ae-Tm-Al systems}

Synthesizing mixed alkaline ( $\mathrm{Na}, \mathrm{Li})$ or alkaline earth $(\mathrm{Mg})$ and transition metal alanates using solid state processing method was also investigated. Transition metals investigated included $\mathrm{Ti}, \mathrm{Ni}, \mathrm{Co}, \mathrm{Fe}$ and $\mathrm{Cr}$. In the case of $\mathrm{Ti}$, various precursors: $\mathrm{Ti}$ metal, $\mathrm{TiCl}_{2}$, and $\mathrm{TiH}_{2}$, were studied in the Na-Ti-Al system. When Ti metal was used as the precursor, a 75\% decrease in observed Ti appeared to occur. It was later determined that the loss in Ti signal strength was due to absorption by the metallic aluminum. It is hypothesized that the lack of Ti signal, widely reported in the literature as occurring in catalyzed $\mathrm{NaAlH}_{4}$ samples, is due in part to absorption with elemental aluminum, which is widely 


\section{Solid State Processing}

present after reduction during the catalyzation. Furthermore, upon SPEX milling, significant amounts of elemental sodium are apparent, resulting from reduction by Ti. Thermal exposure at 200 bar $\mathrm{H}_{2}$ transforms much of the remaining $\mathrm{Ti}$ metal to $\mathrm{TiH}_{2}$. Higher temperature exposures increase both $\mathrm{TiH}_{2}$ and $\mathrm{Na}_{\mathrm{x}} \mathrm{AlH}_{\mathrm{y}}$ concentrations. It is concluded that the introduction of Ti through the elemental route is not effective to alternate phase formation.

In the case of $\mathrm{TiCl}_{2}$ as a precursor, the primary product of SPEX milling is $\mathrm{NaCl}$ with $\mathrm{Al}_{3} \mathrm{Ti}$ and $\mathrm{TiH}_{2}$. No unidentified peaks or significant shifts in peak locations were observed. It is thus concluded that the utilization of halides as cation precursor materials is inappropriate.

$\mathrm{TiH}_{2}$ was also tested for the synthesis of transition metal alanates using the SSP method. The XRD results of the $\mathrm{NaH}: \mathrm{TiH}_{2}: \mathrm{AlH}_{3}$ (1:1:1) material indicate that the primary products are $\mathrm{TiH}_{2}$ and $\mathrm{NaAlH}_{4}$ at all temperatures studied. No new phases were generated. One interesting feature resulting from this experiment is the tentative observation at $100^{\circ} \mathrm{C}$ of a second $\mathrm{NaAlH}_{4}$ phase having a higher $2 \theta$ than the JFIZ database indicates. This split is manifest in all of the $\mathrm{NaAlH}_{4}$ peaks and is consistent with a lattice dilation of $0.13 \%$ in the $a$ and $b$ directions. Figure 36 shows this split peak effect in both the (103) and (004) peaks. This is not a solitary observation, but has been observed in a number of instances in the past.

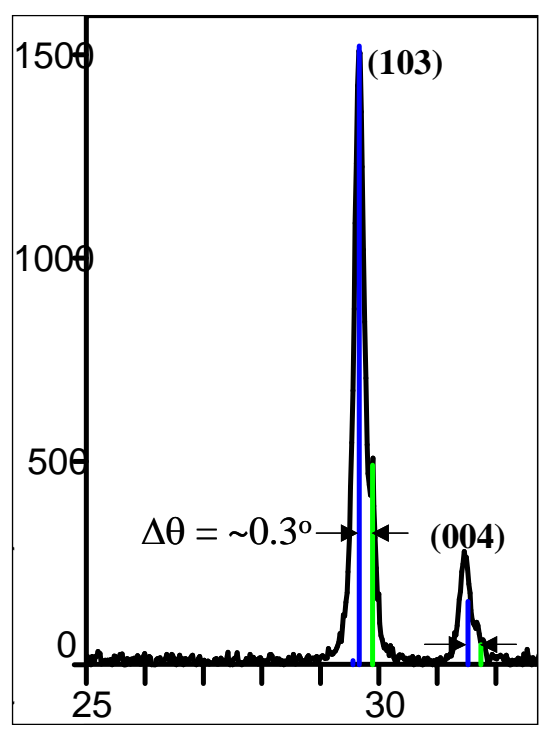

Figure 36: Illustration of raw XRD data for $\mathrm{NaAlH}_{4}$ showing split peaks in the (103) and (004) peaks.

No new phases that contain transition metals were formed with the addition of other transition metals, including $\mathrm{Ni}, \mathrm{Co}, \mathrm{Fe}$ and $\mathrm{Cr}$. Based on these results, it is concluded that SSP is not a suitable method to synthesize transition metal alanates. It was subsequently discovered by our partners at Albemarle and other researchers that transition metal alanates are thermodynamically unstable. Our attention was then transitioned to the development of borohydride based materials for their high hydrogen capacity. 


\section{Solid State Processing}

\subsection{2 $\mathrm{Mg}\left(\mathrm{BH}_{4}\right)_{2}$ and $\mathrm{Mg}\left(\mathrm{BH}_{4}\right)_{2} * 2.2 \mathrm{NH}_{3}$}

$\mathrm{Mg}\left(\mathrm{BH}_{4}\right)_{2}$ has a theoretical capacity of $14.93 \mathrm{wt} \%$ if all hydrogen is released. SSP was used to synthesis $\mathrm{Mg}\left(\mathrm{BH}_{4}\right)_{2}$ by SPEX milling $\mathrm{LiBH}_{4}$ and $\mathrm{MgCl}_{2}$ at a 2:1 mole ratio for 6 hours. The XRD characterization showed the formation of the by-product $\mathrm{LiCl}$ (Figure 37). A small amount of $\mathrm{LiBH}_{4}$ remains in the sample. Only a trace amount of crystalline $\mathrm{Mg}\left(\mathrm{BH}_{4}\right)_{2}$ was detected. TGA-MS analysis showed that the material starts to release hydrogen around $150^{\circ} \mathrm{C}$. The release of hydrogen peaks circa $300^{\circ} \mathrm{C}$ (Figure 38 ).

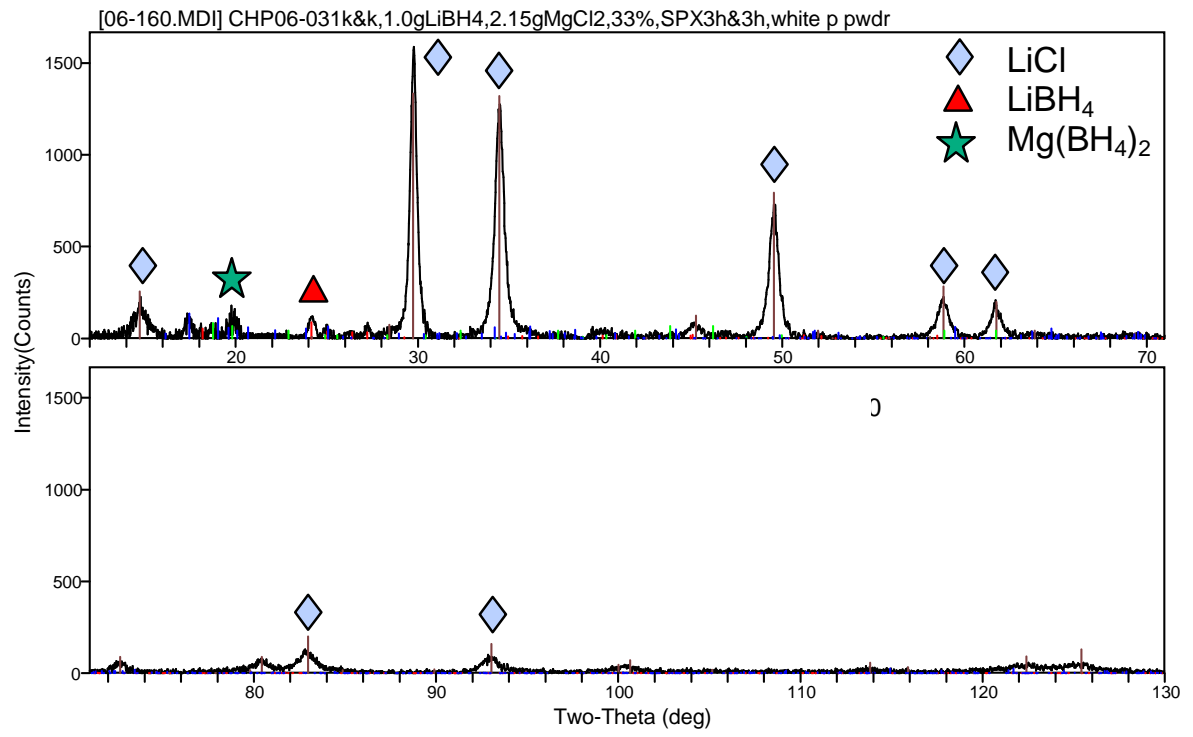

Figure 37: XRD of reaction products of $\mathrm{LiBH}_{4}$ and $\mathrm{MgH}_{2}$ at 2:1 mole ratio.

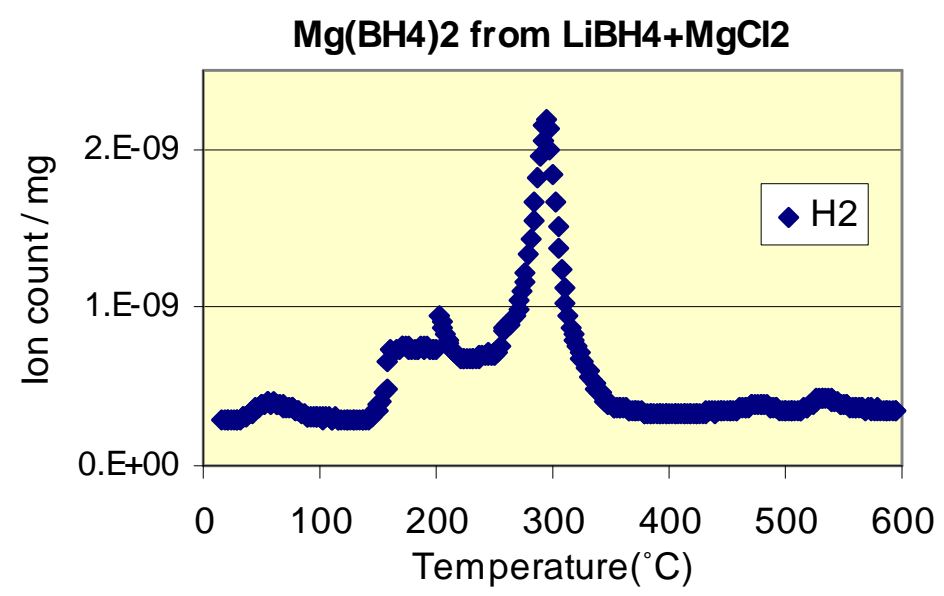

Figure 38: TGA-MS of $\mathrm{Mg}\left(\mathrm{BH}_{4}\right)_{2}$ from $\mathrm{LiBH}_{4}$ and $\mathrm{MgH}_{2}$ by SSP. 


\section{Solid State Processing}

In order to purify the reaction mixture and remove the $\mathrm{LiCl}$ by-product, a solvent is needed to dissolve $\mathrm{Mg}\left(\mathrm{BH}_{4}\right)_{2}$. It was found that $\mathrm{Mg}\left(\mathrm{BH}_{4}\right)_{2}$ easily forms adducts with organic ligands in tetrahydrofurane (THF) solution. $\mathrm{A} \mathrm{Mg}\left(\mathrm{BH}_{4}\right)_{2}$ *3THF sample was prepared by our partners at SRNL (Section 6.10). Samples were also synthesized with another aprotic ligand, trimethyl amine (TMA), to form $\mathrm{Mg}\left(\mathrm{BH}_{4}\right)_{2}$ *TMA by Albemarle using SBP. Both ligands do not contain protonic hydrogen, and therefore can not react with $\mathrm{BH}_{4}{ }^{-}$. Figure 39 shows that for both samples, the $\mathrm{H}_{2}$ started to release below $100^{\circ} \mathrm{C}$; at the same time, the ligands started to volatilize. These results indicate that the incorporation of a $\mathrm{N}$ or $\mathrm{O}$ containing ligand destabilized the magnesium borohydride structure and significantly lowered the $\mathrm{H}_{2}$ releasing temperature. $\mathrm{In} \mathrm{Mg}\left(\mathrm{BH}_{4}\right)_{2} * 3 \mathrm{THF}$, most of the THF released before $300^{\circ} \mathrm{C}$, accompanied by some $\mathrm{H}_{2}$ release. The remaining $\mathrm{Mg}\left(\mathrm{BH}_{4}\right)_{2}$ decomposed in the neighborhood of $300^{\circ} \mathrm{C}$, releasing additional $\mathrm{H}_{2} \cdot \mathrm{Mg}\left(\mathrm{BH}_{4}\right)_{2}{ }^{*} \mathrm{TMA}$, on the other hand, decomposed in two stages, each stage releasing $\mathrm{H}_{2}$ and the ligand. This can be attributed to two different types of adduct structures, one of which is much less stable than the other.
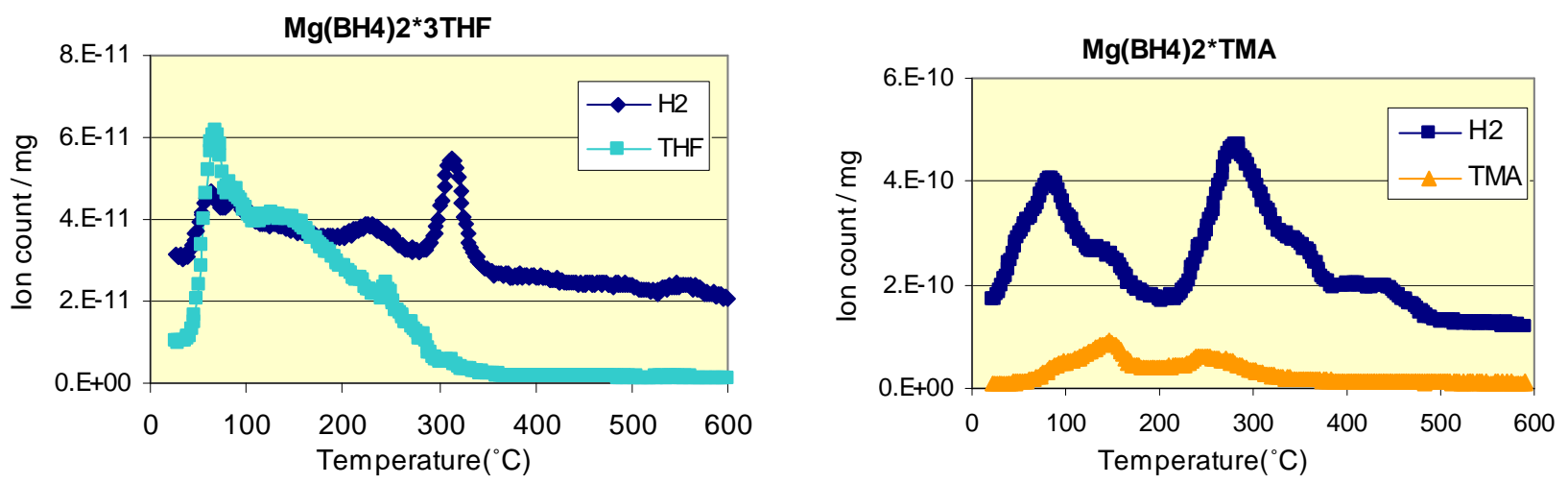

Figure 39: TGA-MS of $\mathrm{Mg}\left(\mathrm{BH}_{4}\right)_{2} * 3 \mathrm{THF}$ and $\mathrm{Mg}\left(\mathrm{BH}_{4}\right)_{2} * \mathrm{TMA}$.

$\mathrm{Mg}\left(\mathrm{BH}_{4}\right)_{2} * 2.2 \mathrm{NH}_{3}$ (Material A) was synthesized by Albemarle using solution based processing for its additional capacity from $\mathrm{NH}_{3}$ if all the hydrogen is released as $\mathrm{H}_{2}$ gas. Figure 40 shows the DSC and TGA-MS of the as-synthesized material.
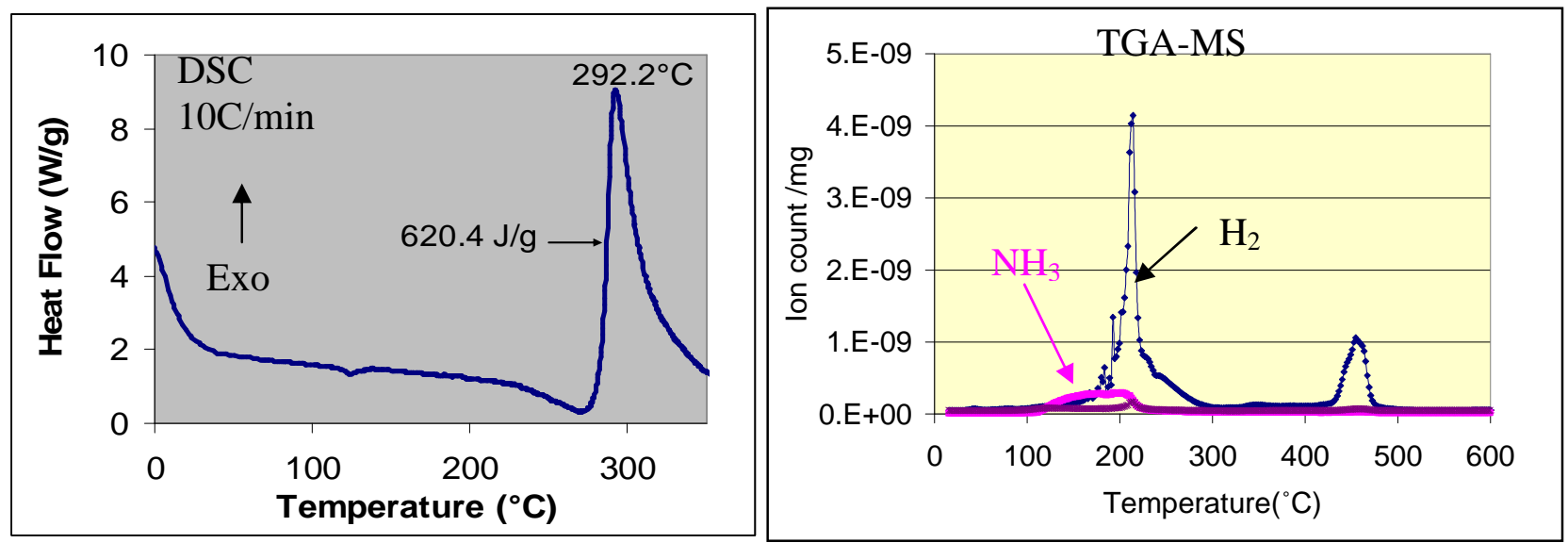

Figure 40: DSC and TGA-MS of $\mathrm{Mg}\left(\mathrm{BH}_{4}\right)_{2} * 2.2 \mathrm{NH}_{3}$ (Material A). 


\section{Solid State Processing}

DSC analysis showed an exothermic event around $292^{\circ} \mathrm{C}$, generating a significant amount of heat $(620.4 \mathrm{~J} / \mathrm{g})$. TGA-MS showed two hydrogen peaks at $214^{\circ} \mathrm{C}$ and $450^{\circ} \mathrm{C}$. In addition to hydrogen, a significant amount of ammonia was also released at temperatures between $100^{\circ} \mathrm{C}$ to $220^{\circ} \mathrm{C}$. Compared with the THF ligand, $\mathrm{NH}_{3}$ decomposes at a higher temperature; however, most ammonia is liberated before hydrogen release reaches its peak $\left(214^{\circ} \mathrm{C}\right)$.

Ammonia is an undesirable impurity for fuel cells. Two approaches were taken to reduce the generation of ammonia to acceptable levels. The first was to heat the samples at $160^{\circ} \mathrm{C}$ in vacuum for 24 hours to remove $\mathrm{NH}_{3}$ ligands. Figure 41 shows the DRIFT spectra of the as-synthesized and the heated sample. It can be seen that after heating, the peak intensity of $\mathrm{N}-\mathrm{H}$ bond decreased significantly, indicating the removal of $\mathrm{NH}_{3}$. However, the signal for the $\mathrm{B}-\mathrm{H}$ bond was reduced, suggesting that partial decomposition of $\mathrm{BH}_{4}{ }^{-}$occurred during heating. TGA-MS analysis of the heated sample (Figure 42) shows the temperature of $\mathrm{H}_{2}$ releasing peak increased from the original temperature, $214^{\circ} \mathrm{C}$ to $256^{\circ} \mathrm{C}$. However, no $\mathrm{NH}_{3}$ was detected in the gas phase. DSC analyses of the as-synthesized and vacuum heated $\mathrm{Mg}\left(\mathrm{BH}_{4}\right)_{2} * 2.2 \mathrm{NH}_{3}$ are shown in Figure 40 and Figure 43. The assynthesized material shows an exothermic event around $292^{\circ} \mathrm{C}$, generating a significant amount of heat $(620.4 \mathrm{~J} / \mathrm{g})$. The vacuum heated sample has significantly different thermal events than the assynthesized one. It shows two relative small exothermic peaks (at $135^{\circ} \mathrm{C}$ and $240^{\circ} \mathrm{C}$ ), followed by an endothermic event at $271^{\circ} \mathrm{C}$. The above characterization indicates that the low temperature $\mathrm{H}_{2}$ release in the as-synthesized material could be caused by the release of $\mathrm{NH}_{3}$ ligands. It could also be initiated by the reaction between $\mathrm{BH}_{4}{ }^{-}$and $\mathrm{NH}_{3}$. After being heated at $160^{\circ} \mathrm{C}$ in vacuum, a significant amount of the $\mathrm{NH}_{3}$ was removed. The remaining $\mathrm{NH}_{3}$ reacted with $\mathrm{BH}_{4}{ }^{-}$upon further heating during the TGA-MS analysis, forming boron nitride without releasing $\mathrm{NH}_{3}$. In the sealed pan DSC analysis for the as-synthesized $\mathrm{Mg}\left(\mathrm{BH}_{4}\right)_{2} * 2.2 \mathrm{NH}_{3}$, all the $\mathrm{NH}_{3}$ was trapped in the sealed pan, and then reacted with $\mathrm{BH}_{4}{ }^{-}$, resulting a large exothermic peak. In the vacuum heated material, a significant amount of $\mathrm{NH}_{3}$ was removed prior to the analysis in sealed pan. The DSC showed only two small exothermic peaks, resulting from the reaction of residual $\mathrm{NH}_{3}$ with $\mathrm{BH}_{4}{ }^{-}$. The endothermic peak at $271^{\circ} \mathrm{C}$ is due to the decomposition of unreacted $\mathrm{Mg}\left(\mathrm{BH}_{4}\right)_{2}$.

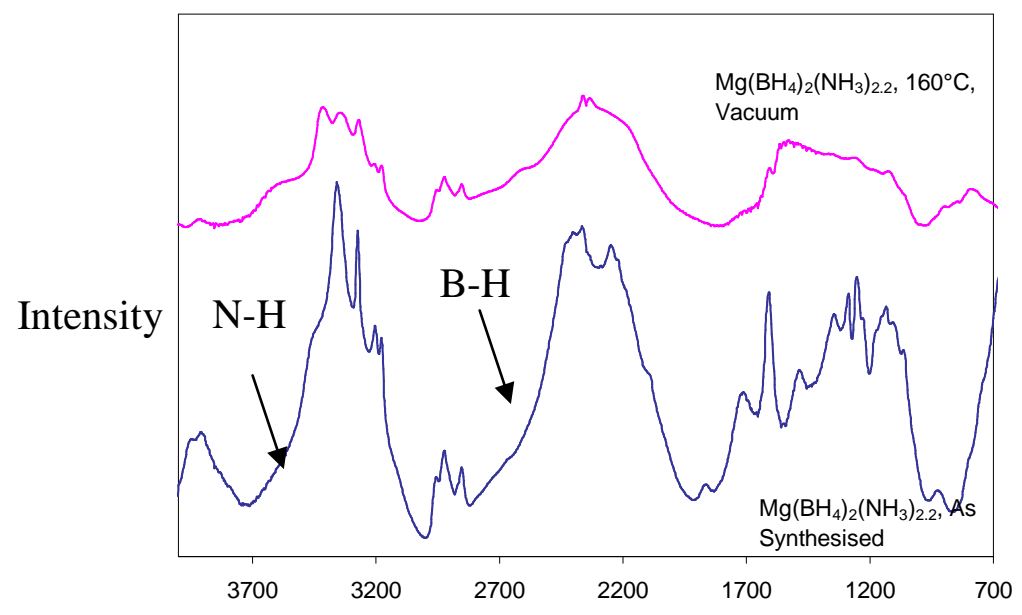

Figure 41: DRIFT spectra of the as-synthesized $\operatorname{Mg}\left(\mathrm{BH}_{4}\right)_{2} * 2.2\left(\mathrm{NH}_{3}\right)(\mathrm{Material} A)$ and the sample after heating at $160^{\circ} \mathrm{C}$ in vacuum for 24 hours. 


\section{Solid State Processing}

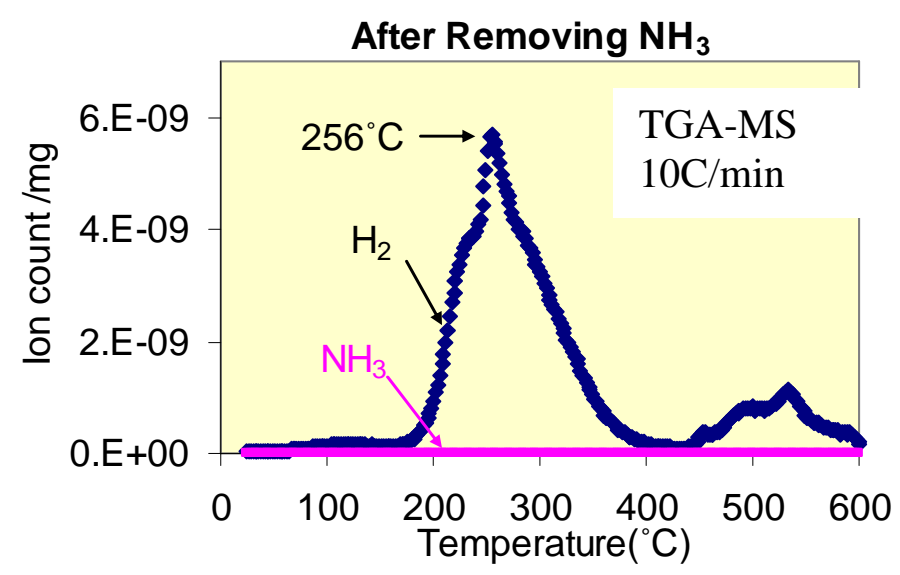

Figure 42: TGA-MS of $\mathrm{Mg}\left(\mathrm{BH}_{4}\right)_{2} * 2.2\left(\mathrm{NH}_{3}\right)$ (Material $\mathrm{A}$ ) after being heated at $160^{\circ} \mathrm{C}$ in vacuum for 24 hours.

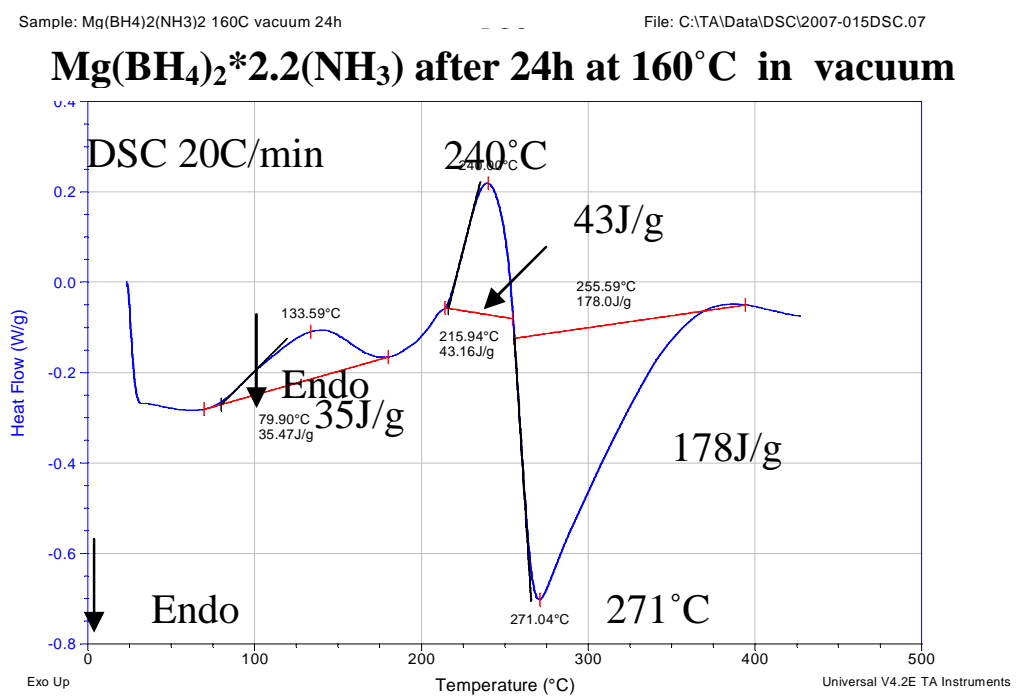

Figure 43: $\mathrm{DSC}$ analysis of $\mathrm{Mg}\left(\mathrm{BH}_{4}\right)_{2} * 2.2 \mathrm{NH}_{3}$ after heating at $160^{\circ} \mathrm{C}$ in vacuum for 24 hours.

Another approach is to mechanically mix a co-reactant with $\mathrm{Mg}\left(\mathrm{BH}_{4}\right)_{2} * 2.2 \mathrm{NH}_{3}$. This designed reaction has the potential of releasing $>8 \mathrm{wt} \% \mathrm{H}_{2}$. Figure 44 shows the DSC and TGA-MS results. Two exothermal peaks were observed at $194^{\circ} \mathrm{C}$ and $245^{\circ} \mathrm{C}$ in the DSC analysis. Compared with the as-synthesized $\mathrm{Mg}\left(\mathrm{BH}_{4}\right)_{2} * 2.2 \mathrm{NH}_{3}$, the designed reaction contains multiple reaction steps, which onset at lower temperatures than that of the original material. More importantly, the total heat of the reactions was significantly reduced, indicating a less exothermic system. The TGA-MS showed three hydrogen peaks at $128^{\circ} \mathrm{C}, 238^{\circ} \mathrm{C}$, and $444^{\circ} \mathrm{C}$. No ammonia was detected. This indicated that the introduction of a co-reactant can significantly reduce ammonia generation. For the designed reaction, isothermal desorption testing showed that $>7.5 \mathrm{wt} \%$ hydrogen was released at temperatures up to $350^{\circ} \mathrm{C}$. The dehydrided material was tested for rehydriding under 195 bar hydrogen at $100-300^{\circ} \mathrm{C}$. No hydrogen absorption was observed, indicating the system is not reversible. 


\section{Solid State Processing}
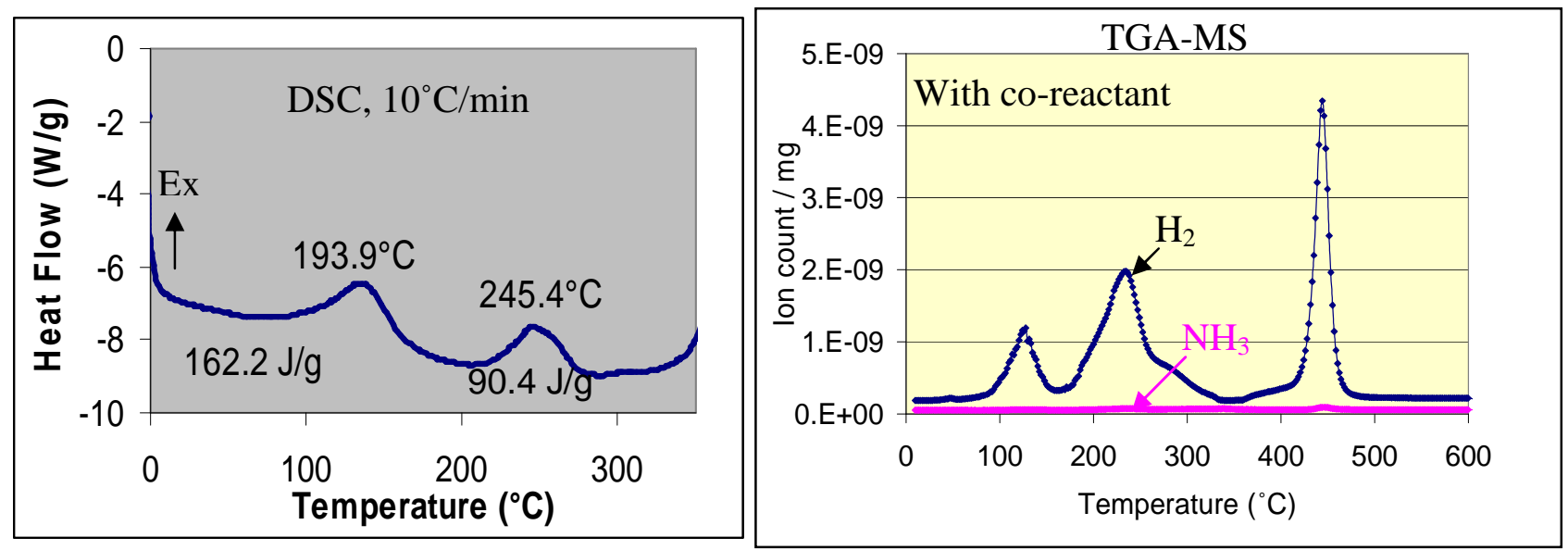

Figure 44: DSC and TGA-MS of $\operatorname{Mg}\left(\mathrm{BH}_{4}\right)_{2} * 2.2 \mathrm{NH}_{3}$ (Material A) with co-reactant.

It was later found that the nature of the $\mathrm{Mg}\left(\mathrm{BH}_{4}\right)_{2} * 2.2 \mathrm{NH}_{3}$ ligand-stabilized borohydride complex synthesized by solution based processing changed with synthesis conditions and/or with aging. Depending on the synthesis conditions, the compound could have two different dissociation mechanisms, one of which involves the release of $\mathrm{NH}_{3}$ and has a theoretical hydrogen capacity of 9 wt\% (Equation 19, Equation 20 and Equation 21). The results in Figure 40 indicate that Material A follows this decomposition mechanism.

Equation 19: $\quad 100-200^{\circ} \mathrm{C}: \operatorname{Mg}\left(\mathrm{BH}_{4}\right)_{2} * 2 \mathrm{NH}_{3}=\mathrm{Mg}\left(\mathrm{BH}_{4}\right)_{2}+2 \mathrm{NH}_{3} \uparrow($ endotherm)

Equation 20: $\quad 200-250^{\circ} \mathrm{C}: \mathrm{Mg}\left(\mathrm{BH}_{4}\right)_{2}=\mathrm{MgH}_{2}+2 \mathrm{~B}+3 \mathrm{H}_{2}(\mathrm{~g})$ (small endotherm)

Equation 21

430-470 ${ }^{\circ} \mathrm{C}: \mathrm{MgH}_{2}=\mathrm{Mg}+\mathrm{H}_{2}($ endotherm)

The second mechanism is an amine-borane $\left(\mathrm{NH}_{3}-\mathrm{BH}_{3}\right)$ like dissociation reaction, possibly forming $\mathrm{MgH}_{2}$ and $\mathrm{BN}$. This mechanism releases $16 \mathrm{wt} \% \mathrm{H}_{2}$ :

Equation 22: $\quad 150-280^{\circ} \mathrm{C}: \mathrm{Mg}\left(\mathrm{BH}_{4}\right)_{2} * 2 \mathrm{NH}_{3}=\mathrm{MgH}_{2}+2 \mathrm{BN}+6 \mathrm{H}_{2}($ exotherm)

Equation 23: $\quad 480-520^{\circ} \mathrm{C}: \mathrm{MgH}_{2}=\mathrm{Mg}+\mathrm{H}_{2}$ (endotherm)

Figure 45 shows the TGA-MS of $\mathrm{Mg}\left(\mathrm{BH}_{4}\right)_{2} * 2.2 \mathrm{NH}_{3}$ for another batch (Material B) synthesized under slightly different conditions, with minimal $\mathrm{NH}_{3}$ release, but increased $\mathrm{H}_{2}$ evolution following mainly the second mechanism. Section 3.3.3.3 describes the atomic modeling investigation of possible structures that could be formed with the $\mathrm{Mg}\left(\mathrm{BH}_{4}\right)_{2} * 2.2 \mathrm{NH}_{3}$ complex and the change in possible decomposition reaction mechanisms with structure. 


\section{Solid State Processing}

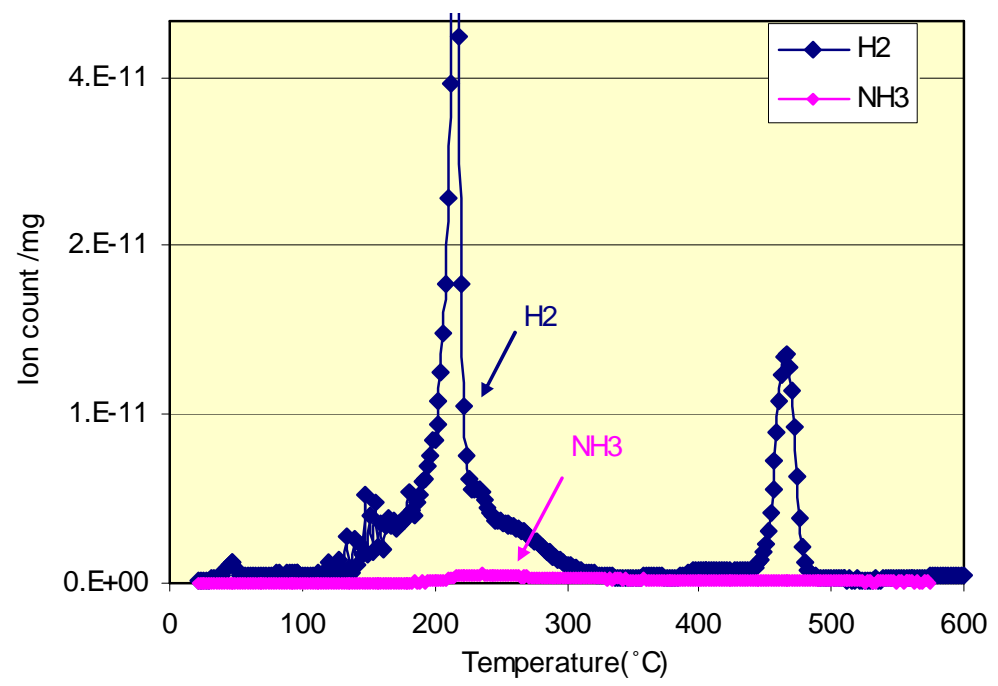

Figure 45: TGA-MS of $\mathrm{Mg}\left(\mathrm{BH}_{4}\right)_{2} * 2.2 \mathrm{NH}_{3}$ (Material B).

\subsection{3 $\mathrm{Zr}\left(\mathrm{BH}_{4}\right)_{4}\left(\mathrm{H}_{2} \mathrm{NC}_{2} \mathrm{H}_{4} \mathrm{NH}_{2}\right)_{2}$}

$\mathrm{Zr}\left(\mathrm{BH}_{4}\right)_{4}\left(\mathrm{H}_{2} \mathrm{NC}_{2} \mathrm{H}_{4} \mathrm{NH}_{2}\right)_{2}$ contains $8.8 \mathrm{wt} \% \mathrm{H}_{2}$ from combined $\mathrm{N}-\mathrm{H} / \mathrm{B}-\mathrm{H}$ hydrogen ligands. It was synthesized by Albemarle using the SBP method (Section 5.6). The material was tested for isothermal hydrogen desorption at $100^{\circ} \mathrm{C}$ and $150^{\circ} \mathrm{C}$ for 10 hours under $0-1$ bar of hydrogen at UTRC. Figure 46 shows the desorption curves of this compound. This compound showed rapid desorption kinetics at both temperatures, releasing $3.3 \mathrm{wt} \% \mathrm{H}_{2}$ at $100^{\circ} \mathrm{C}$ and $5.9 \mathrm{wt} \%$ at $150^{\circ} \mathrm{C}$. The color of the material changed from ivory to brown at $100^{\circ} \mathrm{C}$ and then to dark brown or black at $150^{\circ} \mathrm{C}$. In order to investigate the fate of the organic ligand, $\mathrm{H}_{2} \mathrm{NC}_{2} \mathrm{H}_{4} \mathrm{NH}_{2}$, the desorbed materials were analyzed for residual $-\mathrm{CH}_{2}-\mathrm{CH}_{2}$ - containing species in the solid material using DRIFTS.
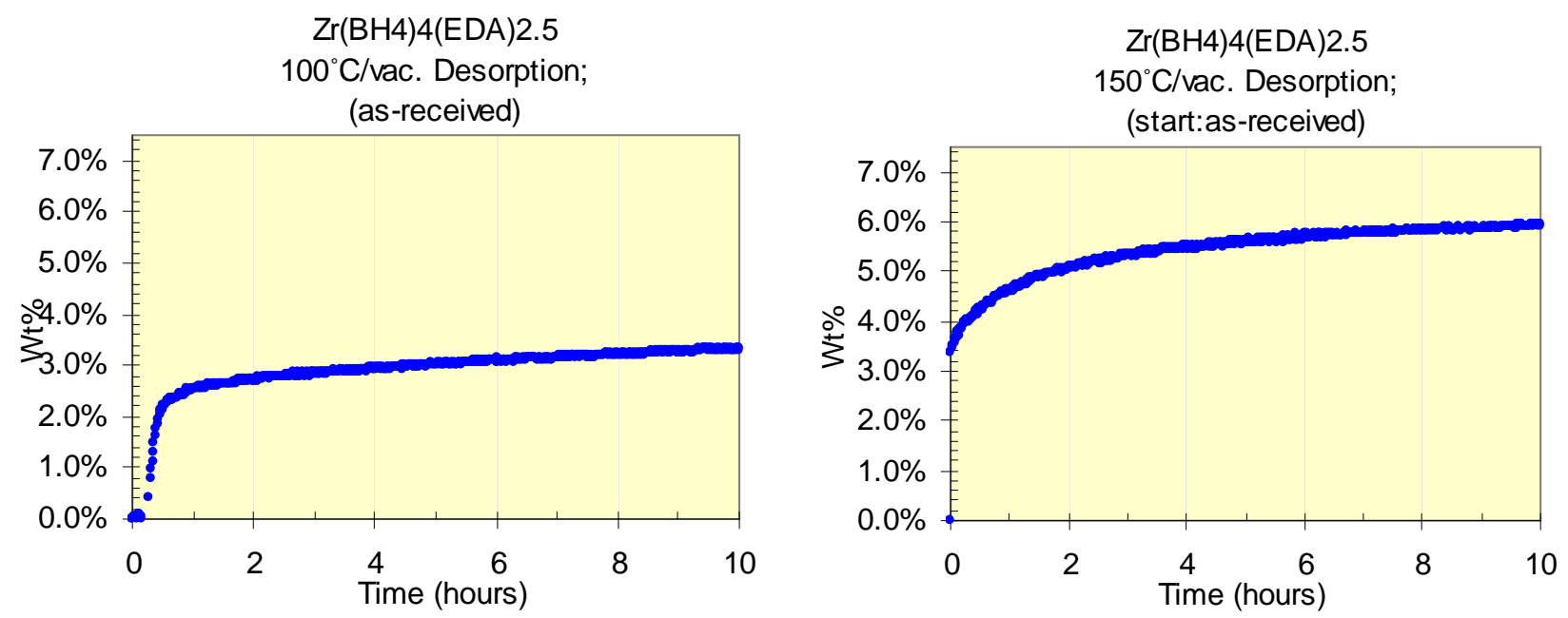

Figure 46: Hydrogen desorption of $\mathrm{Zr}\left(\mathrm{BH}_{4}\right)\left(\mathrm{H}_{2} \mathrm{NC}_{2} \mathrm{H}_{4} \mathrm{NH}_{2}\right)_{2}$ at $100^{\circ} \mathrm{C}$ and $150^{\circ} \mathrm{C}$. 


\section{Solid State Processing}

DRIFTS (Diffuse Reflectance Infrared Fourier Transform Spectroscopy) is an FTIR technique, which allows the sample to be mounted in a nitrogen-filled sealed cell. It measures the FT-IR spectra of the species on powder surfaces. This technique was developed first at Albemarle and then at UTRC to evaluate non-crystalline hydride materials that can not be characterized by XRD. The first complex examined by this technique was $\mathrm{Zr}\left(\mathrm{BH}_{4}\right)_{4}\left(\mathrm{H}_{2} \mathrm{NC}_{2} \mathrm{H}_{4} \mathrm{NH}_{2}\right)_{2}$. The DRIFTS spectra for this compound under various $\mathrm{H}_{2}$ discharge and charge conditions are shown in the Figure 47.

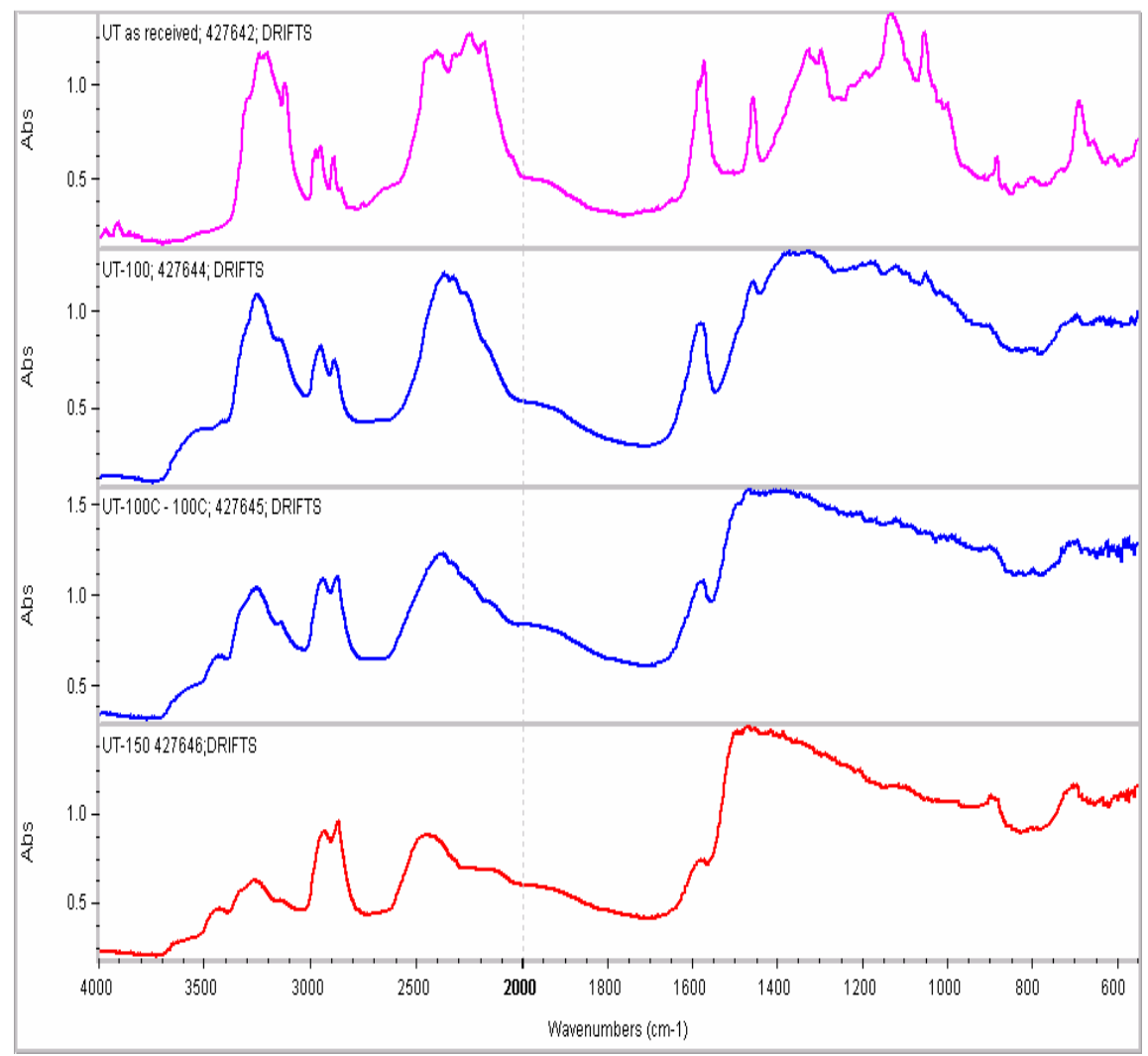

Figure 47: DRIFTS results for $\mathrm{Zr}\left(\mathrm{BH}_{4}\right)_{4}\left(\mathrm{H}_{2} \mathrm{NC}_{2} \mathrm{H}_{4} \mathrm{NH}_{2}\right)_{2}$ under various conditions.

From top to bottom:

Magenta - untreated sample

Blue - after hydrogen discharge at $100^{\circ} \mathrm{C}$

Blue - after hydrogen discharge at $100^{\circ} \mathrm{C}$ and 60 bars $\mathrm{H}_{2}$ at $100^{\circ} \mathrm{C}$

Red - after hydrogen discharge at $150^{\circ} \mathrm{C}$

While the results are semi-quantitative, the following conclusions can be drawn:

- After hydrogen discharge at $100^{\circ} \mathrm{C}$, the N-H $\left(3100-3500 \mathrm{~cm}^{-1}\right.$ or $\left.1550-1600 \mathrm{~cm}^{-1}\right)$ and $\mathrm{B}-\mathrm{H}$ $\left(2000-2500 \mathrm{~cm}^{-1}\right)$ frequencies were reduced but did not disappear completely, indicating partial dehydrogenation under these conditions. This is consistent with a weight loss of $5.9 \mathrm{wt} \%$ (full discharge: $8.8 \%)$.

- The C-H (2800-3000 $\left.\mathrm{cm}^{-1}\right)$ frequencies, on the other hand, stayed constant, indicating little or no loss of the ethylenediamine ligand throughout the processing. 


\section{Solid State Processing}

- There is no evidence of hydrogenation under the hydrogen charging conditions $\left(100^{\circ} \mathrm{C}, 68 \mathrm{bar}\right.$ $\mathrm{H}_{2}$ ).

It is clear that DRIFTS is a powerful tool for studying non-crystalline hydrogen storage materials. In combination with PCI or any other thermo-physical instrumentation, it allows the determination of the origin of weight loss. No hydrogen absorption was observed at $100^{\circ} \mathrm{C}$ and 68 bar $\mathrm{H}_{2}$ pressure; $\mathrm{Zr}\left(\mathrm{BH}_{4}\right)_{4}\left(\mathrm{H}_{2} \mathrm{NC}_{2} \mathrm{H}_{4} \mathrm{NH}_{2}\right)_{2}$ appears to be irreversible.

\subsubsection{Am-Tm-B-H system}

The mixed alkali metal and transition metal borohydride system (Am-Tm-B-H) is an extension of the Am-Tm-Al-H system in our original proposal. Alkali metal borohydrides $\left(\mathrm{LiBH}_{4}\right.$ and $\left.\mathrm{NaBH}_{4}\right)$ are very stable hydrides and require desorption temperatures higher than $500-600^{\circ} \mathrm{C}$. Transition metal borohydrides $\left(\mathrm{Ti}\left(\mathrm{BH}_{4}\right)_{3}, \mathrm{Zr}\left(\mathrm{BH}_{4}\right)_{4}, \mathrm{Sc}\left(\mathrm{BH}_{4}\right)_{3}\right)$ are unstable at room temperature. Partial substitution of transition metal in alkali metal borohydrides could potentially combine their distinctively different thermodynamic behaviors, forming new stable systems with intermediate desorption temperatures.

The syntheses of $\mathrm{NaTi}\left(\mathrm{BH}_{4}\right)_{4}, \mathrm{NaSc}\left(\mathrm{BH}_{4}\right)_{4}$ and $\mathrm{LiSc}\left(\mathrm{BH}_{4}\right)_{4}$ were attempted by ball milling of $\mathrm{NaBH}_{4}$ or $\mathrm{LiBH}_{4}$ and $\mathrm{TiCl}_{3}$ or $\mathrm{ScCl}_{3}$ at 4:1 or 5:1 mole ratios. In the case of $\mathrm{NaBH}_{4}$ reacting with $\mathrm{TiCl}_{3}$ at a 4:1 mole ratio, the following reactions may occur during milling:

\section{Equation 24:}

\section{Equation 25:}

Equation 26:

Equation 27:
$\mathrm{NaBH}_{4}+\mathrm{TiCl}_{3}=\mathrm{TiCl}_{2} \mathrm{BH}_{4}+\mathrm{NaCl}$

$$
\begin{gathered}
\mathrm{NaBH}_{4}+\mathrm{TiCl}_{2}\left(\mathrm{BH}_{4}\right)=\mathrm{TiCl}\left(\mathrm{BH}_{4}\right)_{2}+\mathrm{NaCl} \\
\mathrm{NaBH}_{4}+\mathrm{TiCl}\left(\mathrm{BH}_{4}\right)_{2}=\mathrm{Ti}\left(\mathrm{BH}_{4}\right)_{3}+\mathrm{NaCl} \\
\mathrm{NaBH}_{4}+\mathrm{Ti}\left(\mathrm{BH}_{4}\right)_{3}=\mathrm{NaTi}\left(\mathrm{BH}_{4}\right)_{4}+\mathrm{NaCl}
\end{gathered}
$$

The XRD analysis of the reaction products after 3 hours of SPEX milling (Figure 48) shows that all of the $\mathrm{NaBH}_{4}$ reacted with the $\mathrm{TiCl}_{3}$. However, $\mathrm{NaCl}$ is the only major identifiable phase as a reaction product. All the other reaction products or intermediates are amorphous. Similar amorphous products were observed by other researchers [Ref. 63]. Multiple compositions in Na-Tm-B-H and Li-Tm-B-H systems were synthesized using SSP. The Tm included Sc, Ti(III), Ti(II), and a mixture of Ti(III) and $\mathrm{Al}$ (III). Figure 49 shows the XRD of the SPEX milled Na-Tm-B-H samples without removing the reaction by-product $\mathrm{NaCl}$. It can be seen that $\mathrm{NaBH}_{4}$ partially reacted with the transition metal chloride, $\mathrm{TiCl}_{2}$ after 0.5 hours of SPEX milling, forming $\mathrm{NaCl}$. After 1 hour of milling, most of the $\mathrm{NaBH}_{4}$ has reacted with $\mathrm{TiCl}_{2}$.

In the reaction mixtures of $\mathrm{NaBH}_{4}$ with $\mathrm{TiCl}_{3}$, including $4 \mathrm{NaBH}_{4}+\mathrm{TiCl}_{3}, 5 \mathrm{NaBH}_{4}+\mathrm{TiCl}_{3}$, $6 \mathrm{NaBH}_{4}+\mathrm{TiCl}_{3} / \mathrm{AlCl}_{3}$, no $\mathrm{NaBH}_{4}$ was observed after 3 hours of SPEX milling. $\mathrm{NaCl}$ was the only product observed by XRD. This indicates that the formed Na-Ti-B-H complexes are likely to be amorphous. In the $4 \mathrm{NaBH}_{4}+\mathrm{ScCl}_{3}$ reaction mixture, there is only a small amount of $\mathrm{NaCl}$ formed. $\mathrm{A}$ set of broad peaks was observed, which was labeled as Na-Sc-B-H. These peaks are slightly shifted from the original $\mathrm{NaBH}_{4}$. This could be due to the lattice parameter change caused by the substitution of Sc. 


\section{Solid State Processing}

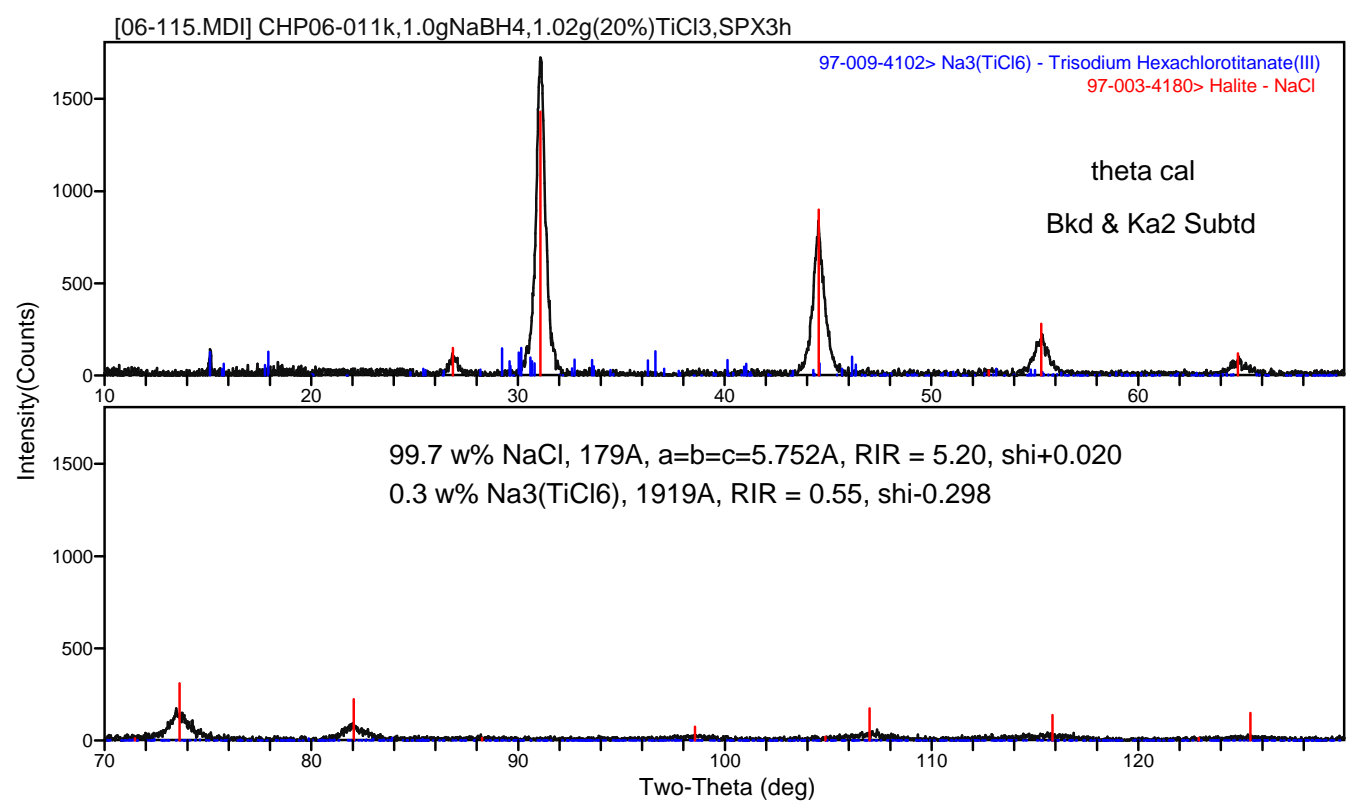

Figure 48: XRD of the reaction products of $\mathrm{NaBH}_{4}$ and $\mathrm{TiCl}_{3}$ at a 4:1 mole ratio after 3 hours of SPEX milling.

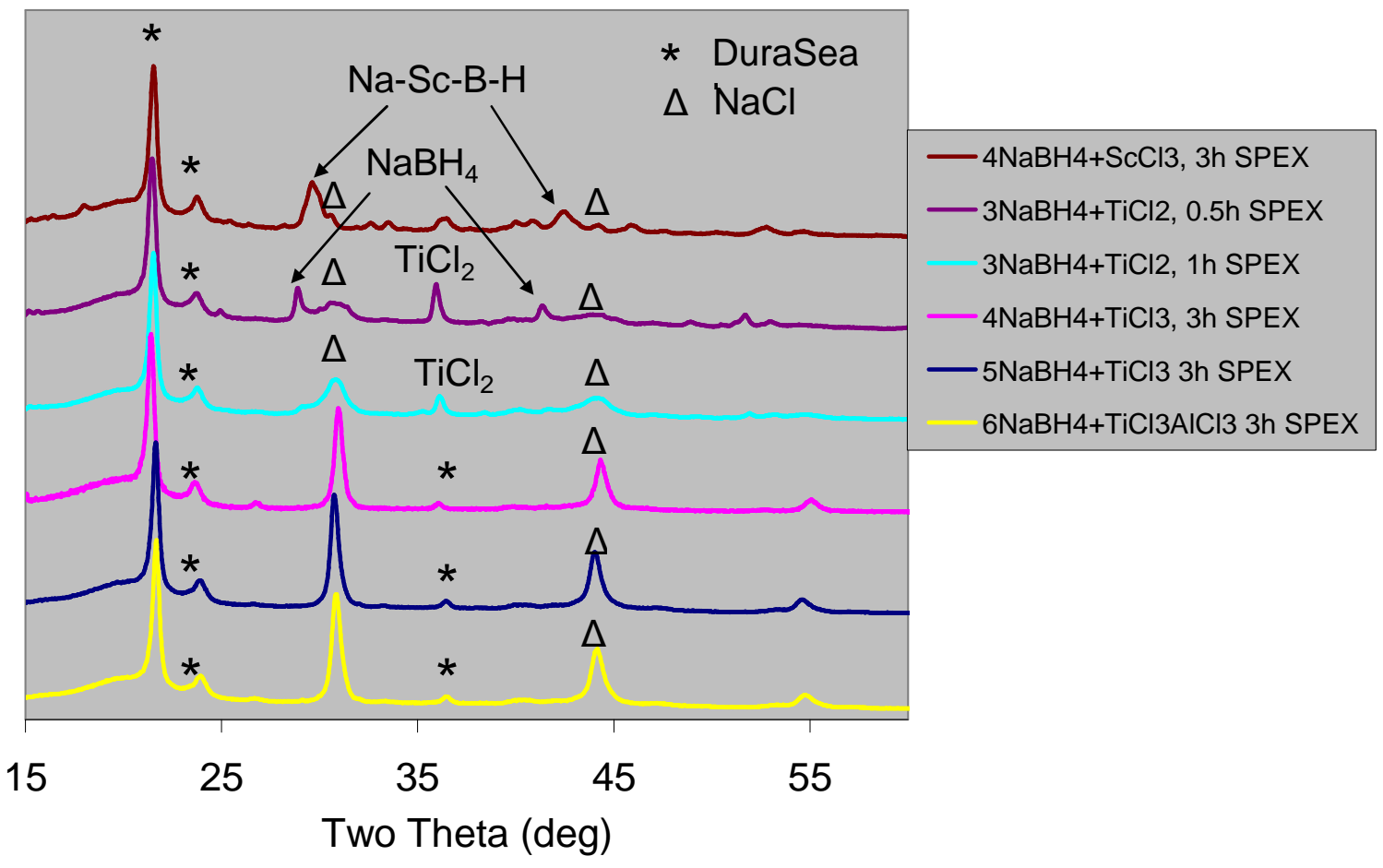

Figure 49: XRD analysis of Na-Tm-B-H materials without removal of the NaCl by-product. 


\section{Solid State Processing}

TGA-MS analysis of the reaction products after 3 hours of SPEX milling (Figure 50) shows that the hydrogen release temperature is decreased in $\mathrm{Ti}$ or $\mathrm{Sc}$ substituted $\mathrm{NaBH}_{4}$, compared with that of $\mathrm{NaBH}_{4}$. The $\mathrm{NaBH}_{4}-\mathrm{ScCl}_{3}$ system has the lowest $\mathrm{H}_{2}$ release temperature. However, it has also been observed that the total amount of $\mathrm{H}_{2}$ released is significantly lower for the Ti doped system, especially for the $4 \mathrm{NaBH}_{4}+\mathrm{TiCl}_{3}$ system. It is suspected that part of the $\mathrm{Ti}^{3+}$ might be reduced to $\mathrm{Ti}$ during ball milling. Based on observations by our collaborators at Albemarle, the freshly synthesized $\mathrm{NaTi}\left(\mathrm{BH}_{4}\right)_{4}$ (using the solution based method) has a clear blue color. It slowly turned to gray and then black at room temperature due to the reduction of Ti. Our material had black color immediately after milling, indicating partial reduction of Ti. The Ti is not detected by XRD, so it could be amorphous or nano-sized particles. The TGA-MS results also indicate that a trace amount of diborane $\left(\mathrm{B}_{2} \mathrm{H}_{6}\right)$ was released during desorption along with hydrogen.

TGA-MS

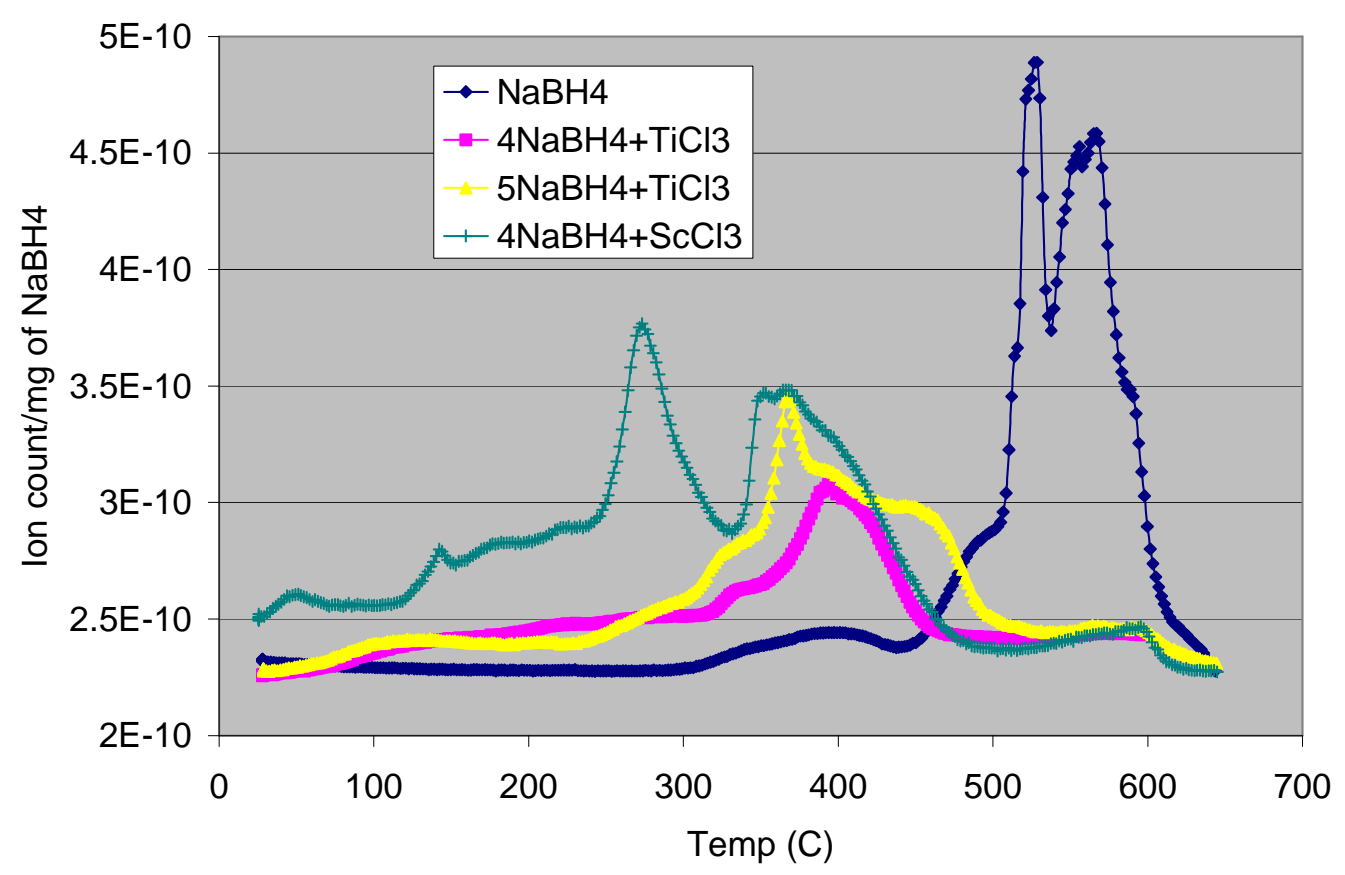

Figure 50: TGA-MS analysis of transition metal substituted $\mathrm{NaBH}_{4}$.

Hydrogen desorption tests using a PCI apparatus were performed on these transition metal substituted sodium borohydrides without removing the $\mathrm{NaCl}$. Figure 51 shows the results for the $4 \mathrm{NaBH}_{4}+\mathrm{ScCl}_{3}$, $3 \mathrm{NaBH}_{4}+\mathrm{TiCl}_{2}$ and $5 \mathrm{NaBH}_{4}+\mathrm{TiCl}_{3}$ systems at $400^{\circ} \mathrm{C}$ or $500^{\circ} \mathrm{C}$. The $4 \mathrm{NaBH}_{4}+\mathrm{ScCl}_{3}$ composition released more than $9 \mathrm{wt} \%$ of $\mathrm{H}_{2}$ at $500^{\circ} \mathrm{C}$ when not including the weight of $\mathrm{NaCl}$ by-product. 


\section{Solid State Processing}

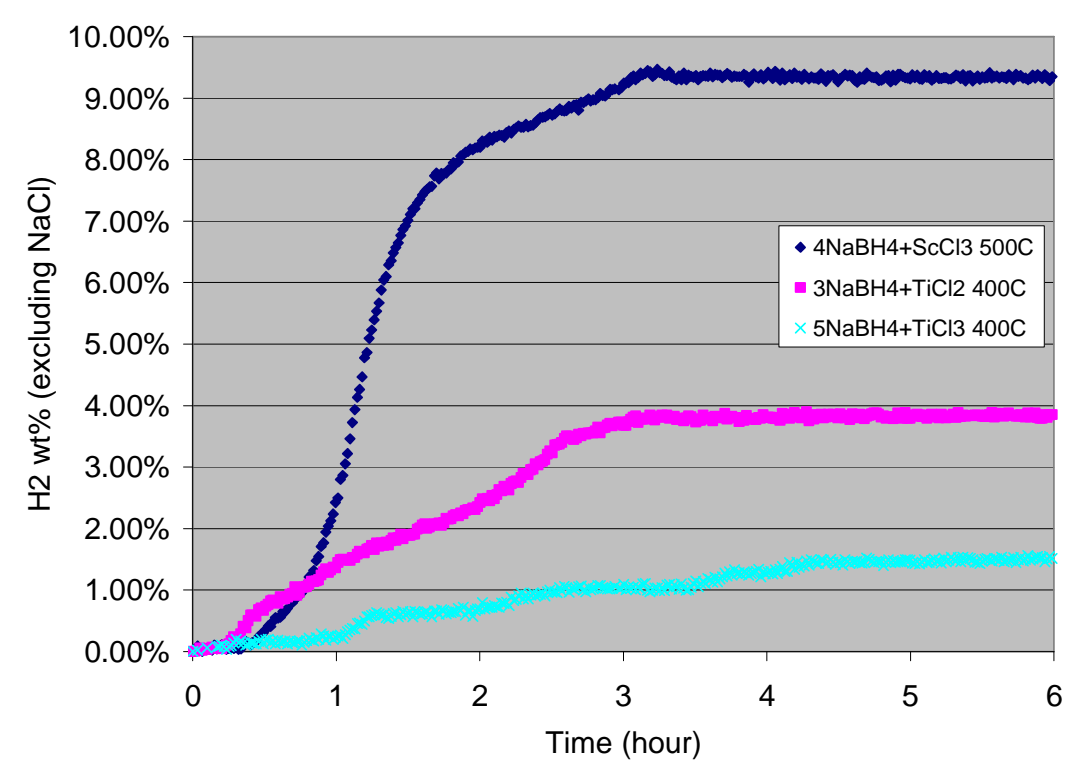

Figure 51: Hydrogen desorption for the Na-Tm-B-H system.

Several materials in the Li-Tm-B-H system were also synthesized and evaluated for their hydrogen desorption properties. Figure 52 shows the desorption curves of the Li-Tm-B-H system where the times to reach the peak test temperature of $400^{\circ} \mathrm{C}$ are given in the figure caption. The Li-Sc-B-H system released up to $12 \mathrm{wt} \%$ hydrogen when not including the weight of $\mathrm{LiCl}$. The undoped $\mathrm{LiBH}_{4}$ released less than $2 \mathrm{wt} \%$ hydrogen. Compared with $\mathrm{LiBH}_{4}$, the Sc substituted material showed greater than 6 times improvement in hydrogen releasing capacity. The Li-Ti-B-H composition, however, released less than $2 \mathrm{wt} \%$ hydrogen at $400^{\circ} \mathrm{C}$. One possible cause is kinetics. The Sc substituted borohydride has much faster kinetics than $\mathrm{LiBH}_{4}$ with or without substitution. Another possible reason is that $\mathrm{LiBH}_{4}$ or $\mathrm{NaBH}_{4}$ can reduce Ti(III) during SPEX milling, producing Ti, B and releasing hydrogen or borane. Outgas in the milling vials was observed. This reaction could significantly reduce hydrogen content stored in the material after milling. Scandium, on the other hand, could not be reduced by $\mathrm{AkBH}_{4}$. It remained as $\mathrm{Sc}$ (III) during the milling process, possibly substituted in the lattice of $\mathrm{NaBH}_{4}$ and $\mathrm{LiBH}_{4}$. This substitution significantly reduced the hydrogen releasing temperature of alkaline borohydride and enhanced kinetics.

Although the Sc containing mixed borohydrides had good kinetics in desorption, they only absorbed approximately $2 \mathrm{wt} \%$ hydrogen during recharging at $220^{\circ} \mathrm{C}$ and 195 bar. Increasing absorption temperature did not increase absorption capacity. This limited absorption capacity could be due to the formation of stable (either kinetically or thermodynamically) boron containing products or intermediates under high temperature during desorption. The possible desorption/absorption reactions in Ak-Tm-B-H system are shown in the following reactions:

Equation 28:

Equation 29:
$\operatorname{AkTm}\left(\mathrm{BH}_{4}\right)_{4}<=>A k H+T m+4 B+15 / 2 \mathrm{H}_{2}$

$\operatorname{AkTm}\left(\mathrm{BH}_{4}\right)_{4}=>\mathrm{AkH}+\mathrm{TmB}_{2}+2 \mathrm{~B}+15 / 2 \mathrm{H}_{2}$ (irreversible) 


\section{Solid State Processing}

If the system forms $\mathrm{TmB}_{2}$, the reaction will not be reversible since $\mathrm{TmB}_{2}$ is thermodynamically stable. If elemental boron is formed as a major reaction product, the reaction could be reversible with catalyzation. Due to the amorphous nature of the reaction products, we were unable to identify the reaction products in our system.

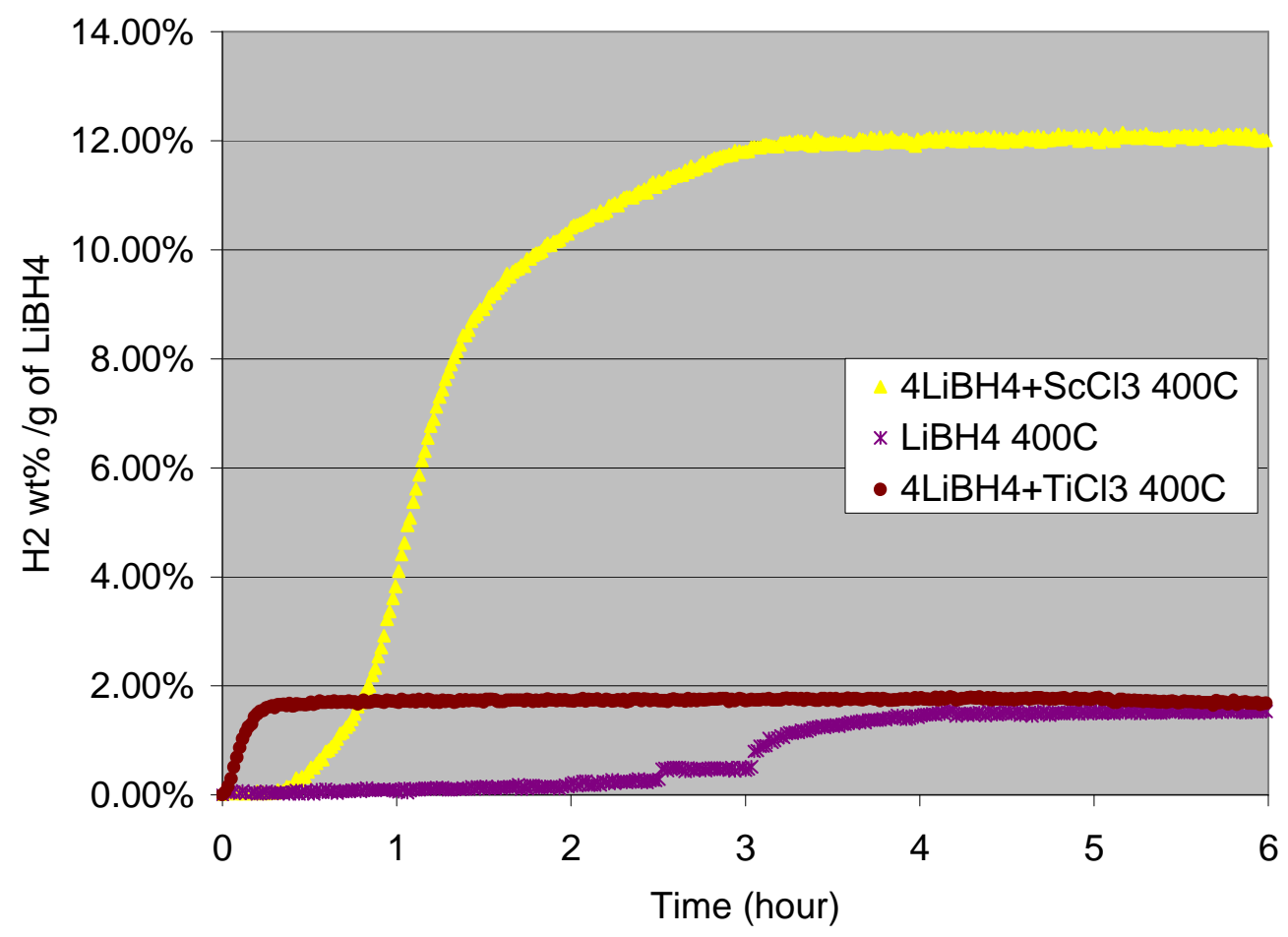

Figure 52: Hydrogen desorption of the $\mathrm{Li}-\mathrm{Tm}-\mathrm{B}-\mathrm{H}$ system. The time to reach the peak test temperature of $400^{\circ} \mathrm{C}$ was $3.4 \mathrm{hr}$ for $\mathrm{LiBH}_{4}+\mathrm{ScCl}_{3} ; 4.5 \mathrm{hr}$ for $\mathrm{LiBH}_{4} ; 0.7 \mathrm{hr}$ for $\mathrm{LiBH}_{4}+\mathrm{TiCl}_{3}$.

Attempts were also made to reduce the desorption temperature to form less stable desorption products. Studies were performed on a variety of $\mathrm{LiBH}_{4}$ based compositions detailed in Table 11 . The initial attempt was to use a titanium oxychloride complex, $\left[\mathrm{TiCl}_{3} \mathrm{OTiCl}_{3} \cdot 2 \mathrm{DME}\right]_{\mathrm{x}}$, which was synthesized by Albemarle to replace titanium chloride as a synthesis precursor. It could also assist in the formation of less stable desorption products. Since scandium is much more expensive than titanium, we focused on improving titanium containing mixed borohydrides. The $\left[\mathrm{TiCl}_{3} \mathrm{OTiCl}_{3} \cdot 2 \mathrm{DME}\right]_{\mathrm{x}}$ was milled with $\mathrm{NaBH}_{4}$ for 30 and 60 minutes to synthesize Na-Ti-B-H material. It appears that the Ti was again reduced in this case, since the color of the material changed to black, indicating the formation of metallic Ti. It could be due to the fact that the number of oxygen per titanium is not enough to prevent it from being reduced. Figure 53 shows the TGA-MS analysis of the resulting products at 30 and 60 min SPEX milling time. The dark blue and pink traces represent the $\mathrm{H}_{2}$ ion counts as function of temperature. The yellow trace is the signal from organic ligand (DME) at 30 min milling time. The results indicated that the milling process generated a new composition which has a much lower hydrogen desorption temperature than the original $\mathrm{NaBH}_{4}$. Also, the product dissociates during prolonged milling. The ligand remained in the reaction product and released upon heating in the $50^{\circ} \mathrm{C}$ to $200^{\circ} \mathrm{C}$ temperature range. 


\section{Solid State Processing}

Table 11: $\mathrm{LiBH}_{4}$ compositions studied.

\section{System}

$\mathrm{LiBH}_{4}+\mathrm{TM}$

$\mathrm{LiBH}_{4}$

$\mathrm{LiBH}_{4}+\mathrm{MgH}_{2}$

$\mathrm{LiBH}_{4}+\mathrm{Si}$

\section{Composition}

$8 \mathrm{NaBH}_{4}+\left[\mathrm{OTiCl}_{2} \cdot \mathrm{DME}_{\mathrm{x}}\right.$ $6 \mathrm{LiBH}_{4}+\mathrm{TiOCl}_{2}$

$6 \mathrm{LiBH}_{4}+\mathrm{TiCl}_{3}$

$6 \mathrm{LiBH}_{4}+\mathrm{TiCl}_{3} / \mathrm{FeCl}_{3}$

$\mathrm{LiBH}_{4}+3 \% \mathrm{TiOCl}_{2}$

$\mathrm{LiBH}_{4}+3 \% \mathrm{TiCl}_{3}$

$\mathrm{LiBH}_{4}+3 \% \mathrm{TiCl}_{3} / \mathrm{FeCl}_{3}$

$\mathrm{LiBH}_{4}+\mathrm{MgH}_{2}+4 \% \mathrm{TiOCl}_{2}$ $\mathrm{LiBH}_{4}+\mathrm{MgH}_{2}+2 \% \mathrm{TiOCl}_{2}$

$\mathrm{LiBH}_{4}+\mathrm{MgH}_{2}+3 \% \mathrm{TiCl}_{3}$

$\mathrm{LiBH}_{4}+\mathrm{MgH}_{2}+3 \% \mathrm{TiCl} 3 / \mathrm{FeCl}_{3}$

$4 \mathrm{LiBH}_{4}+\mathrm{Si}+4 \% \mathrm{TiOCl}_{2}$

\section{Testing}

TGA-MS

DSC, TGA, PCT

DSC, TGA, PCT

DSC, TGA

DSC, TGA

DSC, TGA

DSC, TGA

DSC, TGA, PCT

DSC, TGA

DSC, TGA

DSC, TGA

DSC

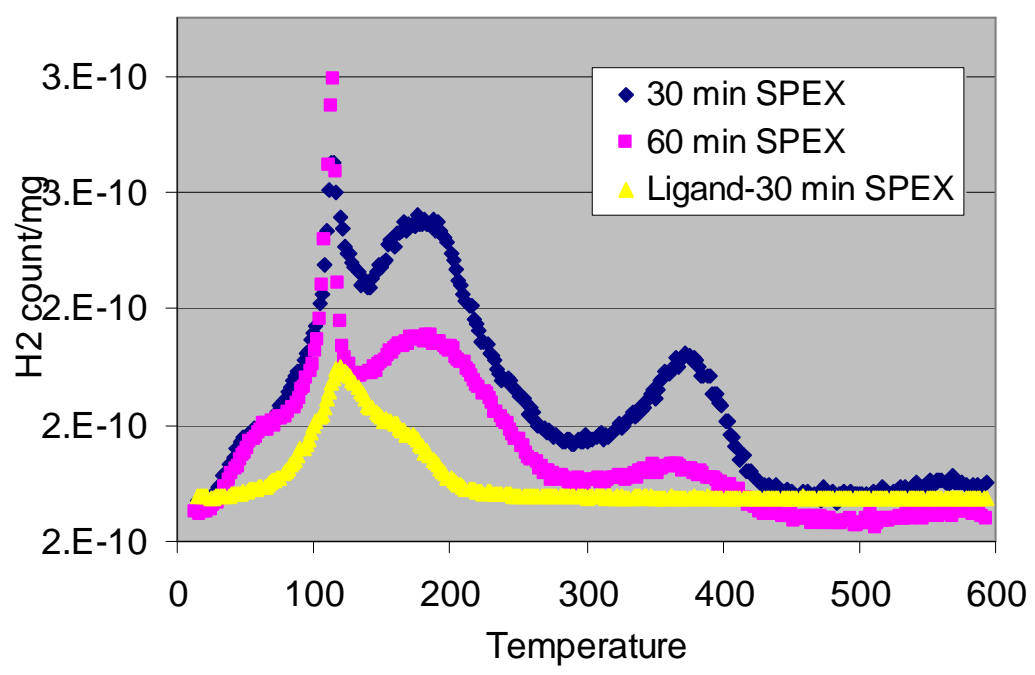

Figure 53: TGA-MS of the reaction products of $8 \mathrm{NaBH}_{4}+\mathrm{TiCl}_{3} \mathrm{OTiCl} \cdot 2 \mathrm{DME}$. Yellow / bottom trace is for ligand counts.

Subsequent examinations were conducted by reacting $\mathrm{LiBH}_{4}$ with high levels of $\mathrm{TiOCl}_{2}, \mathrm{TiCl}_{3}$ and $\mathrm{TiCl}_{3} / \mathrm{FeCl}_{3}$. TiOCl${ }_{2}$ is an improved titanium oxy-chloral complex, which does not contain organic ligands. Results for the $\mathrm{TiOCl}_{2}$ composition are given in Figure 54 and Figure 55. The DSC data shows a significant exotherm peaking at $175^{\circ} \mathrm{C}$. The desorption kinetics and capacity measurements indicate a reversible capacity for the indicated conditions of nominally $2 \mathrm{wt} \%$, far below the initial 


\section{Solid State Processing}

desorption of $7 \mathrm{wt} \%$. Desorption/absorption testing of the $6 \mathrm{LiBH}_{4}+\mathrm{TiCl}_{3}$ gave similar capacity upon cycling of approximately $2 \mathrm{wt} \%$. The evaluations indicate that the high level of these additives caused exothermic dehydrogenation and reduced reversibility.

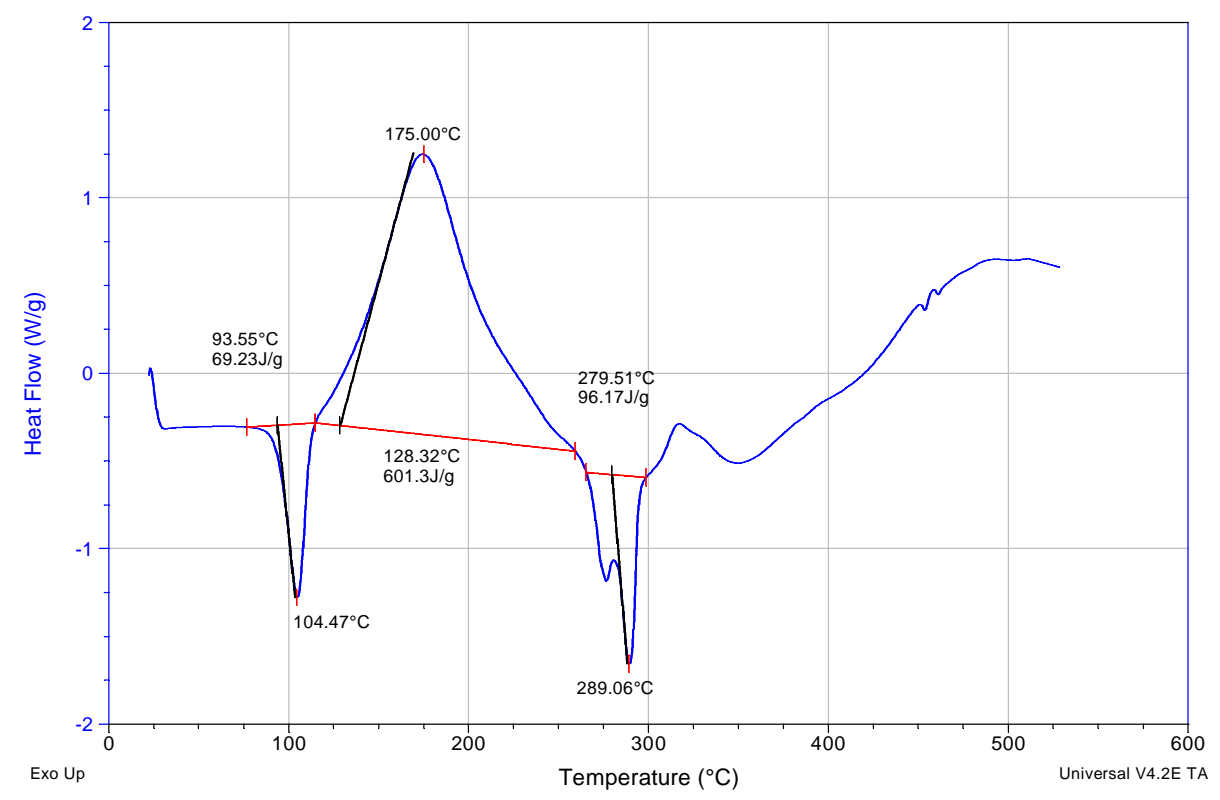

Figure 54: $\mathrm{DSC}$ characterization of $6 \mathrm{LiBH}_{4}+\mathrm{TiCl}_{2} \mathrm{O}$.

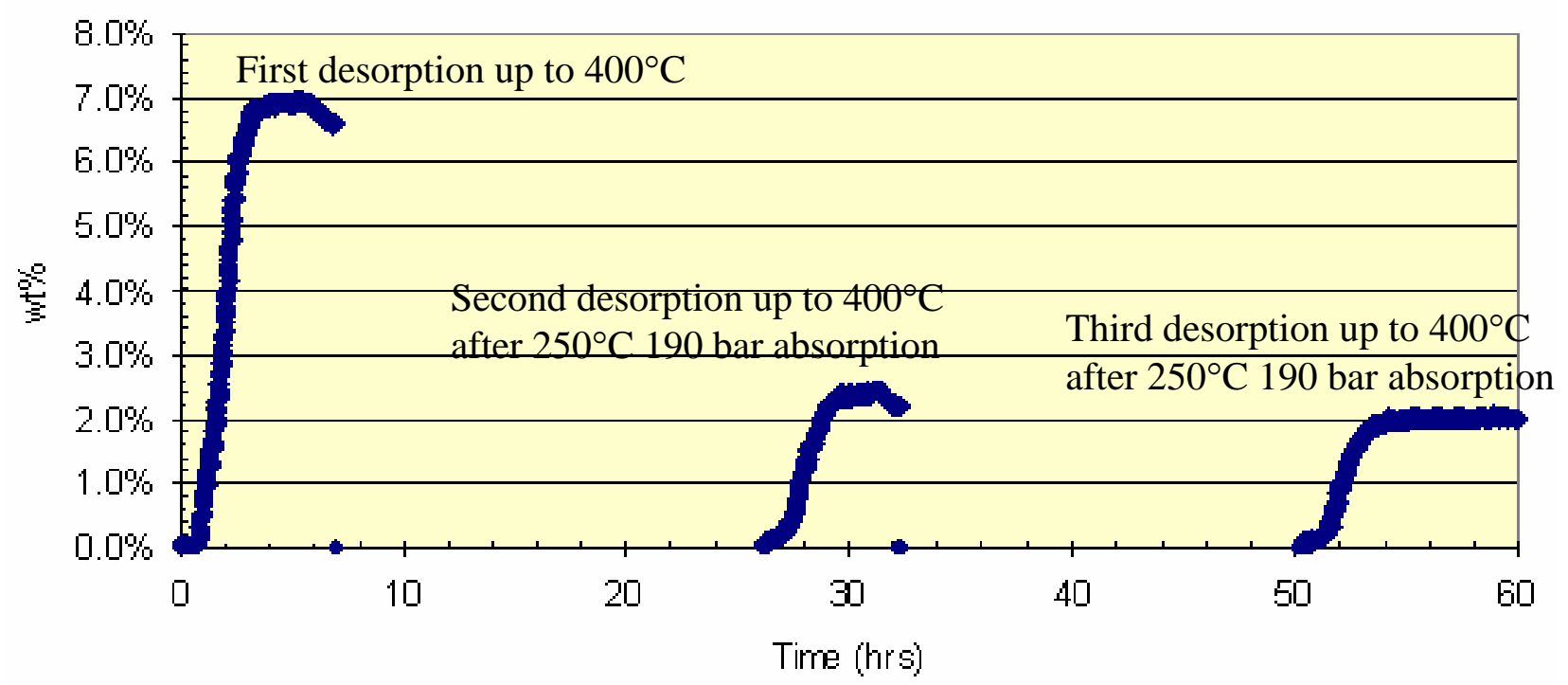

Figure 55: Sievert's apparatus / PCT desorption measurements for $6 \mathrm{LiBH}_{4}+\mathrm{TiCl}_{2} \mathrm{O}$.

The levels of the $\mathrm{TiOCl}_{2}, \mathrm{TiCl}_{3}$ and $\mathrm{TiCl}_{3} / \mathrm{FeCl}_{3}$ additions were decreased to reduce the potential / level of the exothermic reaction. DSC results of these compositions indicated that the exothermicity was reduced, but PCT testing was not conducted as these materials foamed upon desorption and clogged the PCT apparatus. The inclusion of $\mathrm{MgH}_{2}$ along with the above additives was also examined. A baseline DSC trace for $2 \mathrm{LiBH}_{4}+\mathrm{MgH}_{2}$ is shown in Figure 56. The behavior and 


\section{Solid State Processing}

performance of $2 \mathrm{LiBH}_{4}+\mathrm{MgH}_{2}+4 \% \mathrm{TiOCl}_{2}$ are plotted in Figure 57 and Figure 58. Compared with the DSC data for $2 \mathrm{LiBH}_{4}+\mathrm{MgH}_{2}$, the second primary endotherm is composed of two valleys and the temperature of the third primary endotherm has been reduced from $377^{\circ} \mathrm{C}$ to $335^{\circ} \mathrm{C}$. The capacity for temperatures up to $400^{\circ} \mathrm{C}$ is seen to be above $6 \mathrm{wt} \%$ for the second desorption cycle.

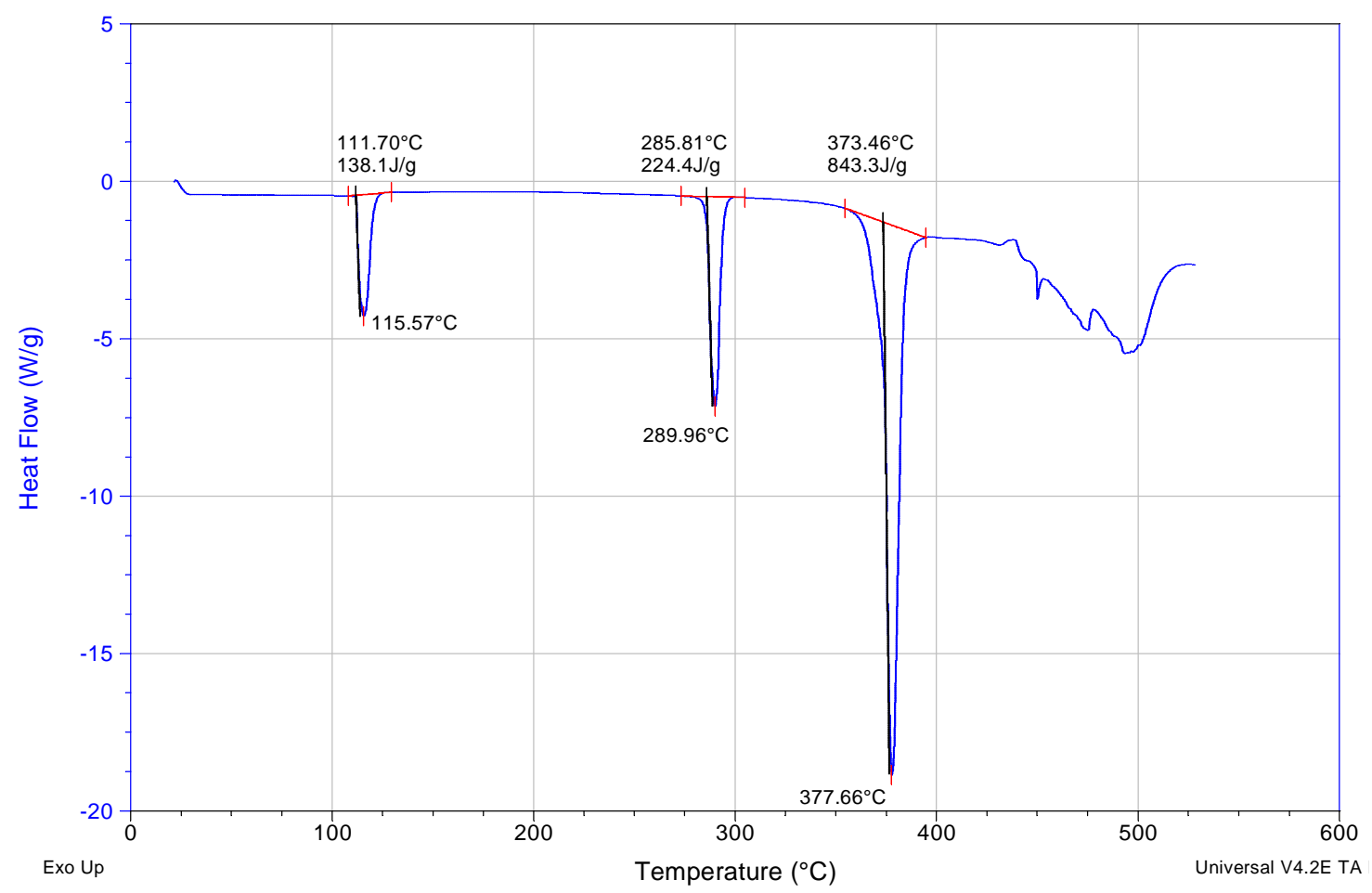

Figure 56: DSC characterization of $2 \mathrm{LiBH}_{4}+\mathrm{MgH}_{2}$.

$\mathrm{NaTi}\left(\mathrm{BH}_{4}\right)_{4}$ *DME synthesized by Albemarle using the solution based method (Section 5.8) was also tested for hydrogen desorption and absorption. When tested at $150^{\circ} \mathrm{C}$ for desorption, the compound released approximately $1.5 \mathrm{wt} \%$ hydrogen. It absorbed approximately $1 \% \mathrm{H}_{2}$ at $150^{\circ} \mathrm{C}$ and $190 \mathrm{bar}_{2}$ pressure. This result indicates that the reversibility of borohydrides can be increased if the temperature for desorption and reabsorption is low enough to prevent the formation of stable boron decomposition compounds. Currently, there are still some issues with this compound. It is not stable at room temperature, and the presence of the organic ligand, DME, decreases its $\mathrm{H}_{2}$ capacity significantly. Possibilities exist for increasing its reversibility and stability using nano-framework structures. 


\section{Solid State Processing}

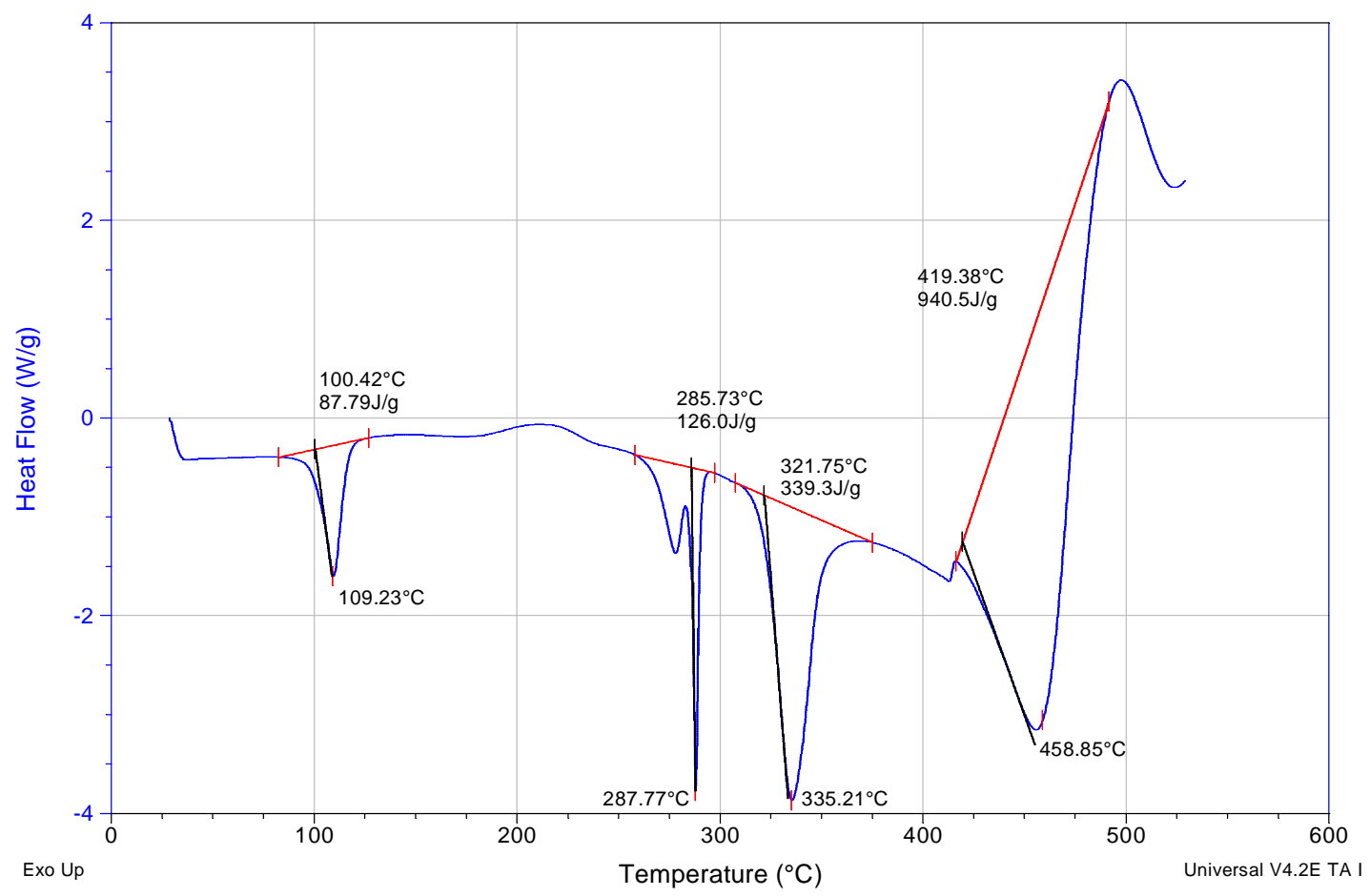

Figure 57: $\mathrm{DSC}$ characterization of $2 \mathrm{LiBH}_{4}+\mathrm{MgH}_{2}+4 \% \mathrm{TiOCl}_{2}$.

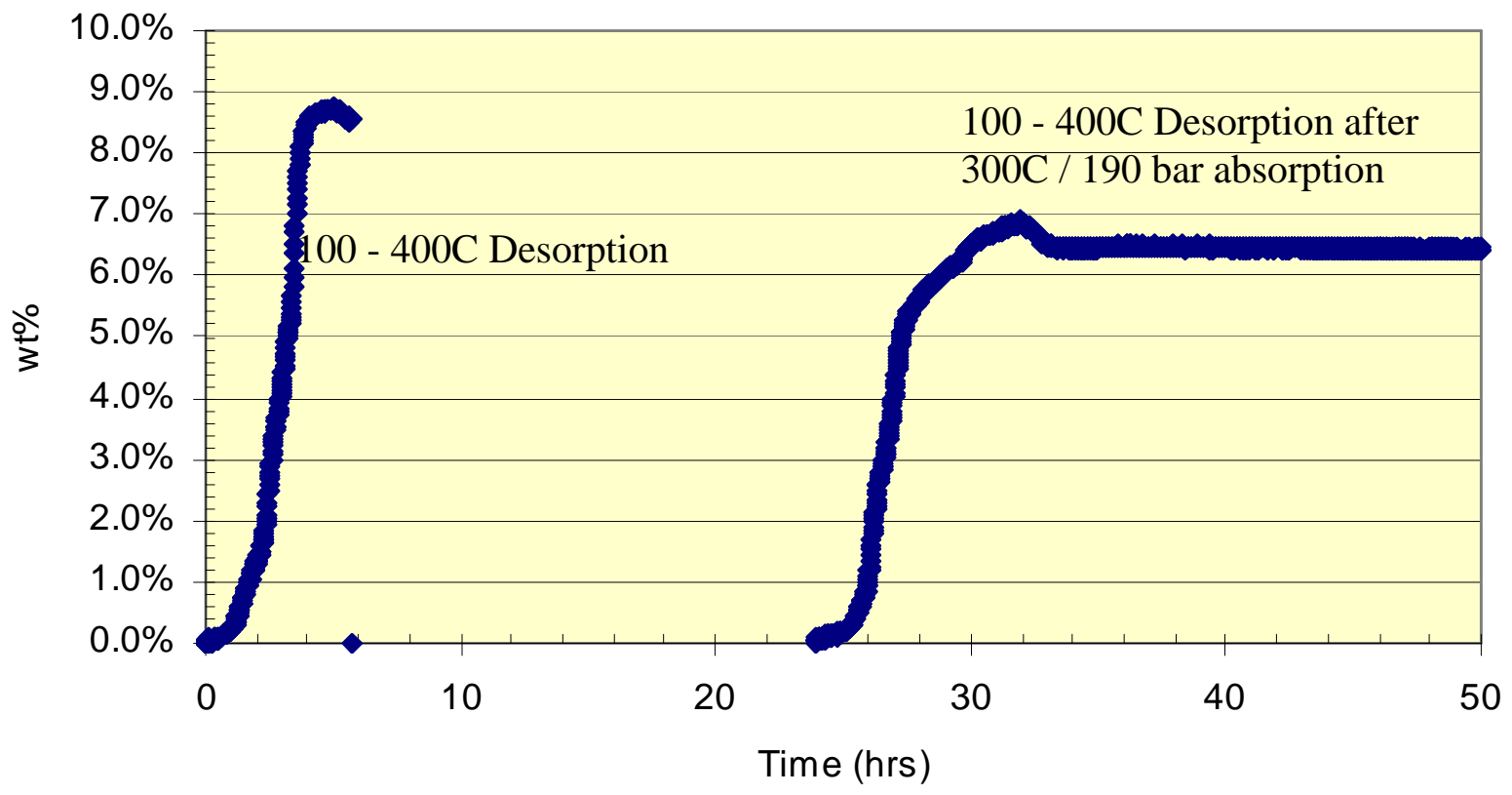

Figure 58: Sievert's apparatus / PCT desorption measurements for $2 \mathrm{LiBH}_{4}+\mathrm{MgH}_{2}+4 \% \mathrm{TiOCl}_{2}$. 


\section{Solution Based Processing}

\section{Solution Based Processing}

In this project, Albemarle Corporation has applied the approach of solution based processing (SBP) which offers potential benefits in the following areas:

- Greater control of process variables

- Homogeneity (i.e. more uniform distribution of metal dopants)

- Possible separation of reaction by-product (i.e. $\mathrm{NaCl}$...etc)

- Ease of scale up production

Table 12 summarizes the majority of the important complexes studied in the program. Complexes 4-10 are new compounds synthesized. Complexes 5-10 involve the strategy of ligand-stabilized transition metal compounds whose hydrogen discharge temperatures fall in the commercially viable range. With the exception of complex $\mathbf{1}$, complex $\mathbf{8}$ is the only one showing some limited signs of reversibility.

Table 12: Summary of complexes studied and their properties.

\begin{tabular}{|c|c|c|c|c|}
\hline & Complexes Studied & $\begin{array}{c}\text { Anticipated } \\
\text { Dehydrided Products }\end{array}$ & $\begin{array}{c}\text { Theoretical } \\
\text { Max H\% }\end{array}$ & $\begin{array}{c}\text { Observed } \\
\text { Hydrogen } \\
\text { Discharge } \\
\text { T }\left({ }^{\circ} \mathrm{C}\right)\end{array}$ \\
\hline 1 & Ti-doped $\mathrm{NaAlH}_{4}$ & $\mathrm{NaH}+\mathrm{Al}$ & $5.6 \%$ & $110^{\circ} \mathrm{C}$ \\
\hline 2 & $\operatorname{LiMg}\left(\mathrm{AlH}_{4}\right)_{3}$ & $\mathrm{LiH}+\mathrm{Mg}+3 \mathrm{Al}$ & $8.9 \%$ & $160^{\circ} \mathrm{C}$ \\
\hline 3 & $\operatorname{Mg}\left(\mathrm{BH}_{4}\right)_{2}\left(\mathrm{NH}_{3}\right)_{2}$ & $\mathrm{Mg}+2 \mathrm{BN}$ & $16.0 \%$ & $180^{\circ} \mathrm{C}$ \\
\hline 4 & $\mathrm{Mg}\left(\mathrm{BH}_{4}\right)_{2}\left(\mathrm{NMe}_{3}\right)$ & $\mathrm{Mg}+2 \mathrm{~B}+\mathrm{NMe}_{3}$ & $7.1 \%$ & $80^{\circ} \mathrm{C}$ \\
\hline 5 & $\mathrm{Zr}\left(\mathrm{BH}_{4}\right)_{4}\left(\mathrm{NH}_{3}\right)_{8}$ & $\mathrm{Zr}+4 \mathrm{BN}+4 \mathrm{NH}_{3}$ & $9.8 \%$ & $80^{\circ} \mathrm{C}$ \\
\hline 6 & $\mathrm{Zr}\left(\mathrm{BH}_{4}\right)_{4}\left(\mathrm{H}_{2} \mathrm{NC}_{2} \mathrm{H}_{4} \mathrm{NH}_{2}\right)_{2}$ & $\mathrm{Zr}\left(\mathrm{BNC}_{2} \mathrm{H}_{4} \mathrm{NB}\right)_{2}$ & $6.0 \%$ & $100^{\circ} \mathrm{C}$ \\
\hline 7 & $\mathrm{NaTi}\left(\mathrm{BH}_{4}\right)_{4}\left(\mathrm{NH}_{3}\right)_{6}$ & $\mathrm{NaH}+\mathrm{Ti}+4 \mathrm{BN}$ & $13.9 \%$ & $100^{\circ} \mathrm{C}$ \\
\hline 8 & $\operatorname{NaTi}\left(\mathrm{BH}_{4}\right)_{4} \cdot \mathrm{DME}$ & $\mathrm{NaH}+\mathrm{Ti}+4 \mathrm{~B}+\mathrm{DME}$ & $6.9 \%$ & $60^{\circ} \mathrm{C}$ \\
\hline 9 & $\mathrm{Na}_{2} \mathrm{O}\left[\mathrm{Ti}\left(\mathrm{BH}_{4}\right)_{4} \mathrm{DME}\right]_{2}$ & $\begin{array}{c}2 \mathrm{NaH}+\mathrm{OTi}_{2}+8 \mathrm{~B} \\
+2 \mathrm{DME}\end{array}$ & $6.6 \%$ & $85^{\circ} \mathrm{C}$ \\
\hline 10 & $\operatorname{NaOTi}\left(\mathrm{BH}_{4}\right)_{3} \cdot \mathrm{DME}$ & $\begin{array}{c}\mathrm{NaH}+\mathrm{OTi}+3 \mathrm{~B}+ \\
\mathrm{DME}\end{array}$ & $5.0 \%$ & $80^{\circ} \mathrm{C}$ \\
\hline
\end{tabular}

* Data were obtained from the DSC/TGA thermal analyses. They are onset temperatures for the first discharge which is followed by second or third discharges at much higher temperatures such as $\mathrm{MgH}_{2}$ at $480^{\circ} \mathrm{C}$. 


\section{Solution Based Processing}

\subsection{Complex 1: Ti-Doped NaAlH}

The Ti-doped $\mathrm{NaAlH}_{4}(\mathrm{SAH})$ samples were prepared by reacting $\mathrm{NaAlH}_{4}$ with varying mol\% of $\mathrm{TiCl}_{3} \bullet \mathrm{THF}_{3}$ in $\mathrm{THF}$ at $-5^{\circ} \mathrm{C}$. The highly pure titanium complex (Aldrich sells a $85 \%$ pure material) was freshly prepared using an Albemarle patented procedure [Ref. 64]. The reaction was monitored by gas evolution measurement. Similar reactions between $\beta-\mathrm{TiCl}_{3}$ and $\mathrm{SAH}$ in ether or toluene have been reported in Ref. 65. They found the $\mathrm{H}_{2}$ evolution to be around 1.5-2.0 $\mathrm{mol} \mathrm{H}_{2} / \mathrm{mol} \mathrm{Ti}$ and thus suggest reduction of $\operatorname{Ti}(+3)$ to $\operatorname{Ti}(0)$.

Interestingly, very different gas evolution results were obtained in our case as shown in Table 13. Much more hydrogen was evolved from our system, around $6 \mathrm{~mol} \mathrm{H}_{2} / \mathrm{mol} \mathrm{Ti}$.

Table 13: Gas evolution results of the reactions between $\mathrm{TiCl}_{3} \mathrm{THF}_{3}$ and $\mathrm{NaAlH}_{4}$ at varying $\mathrm{Ti}$ : Al ratios.

\begin{tabular}{|l|c|c|c|c|}
\hline Mole ratios of $\mathbf{T i}: \mathbf{A l}$ & $2: 100$ & $4: 100$ & $10: 100$ & $33: 100$ \\
\hline Mole $\mathbf{H}_{2}$ per mole $\mathbf{~ T i}$ & 7.7 & 6.7 & 6.4 & 5.7 \\
\hline
\end{tabular}

Figure 59 below shows the evolution of hydrogen with time during the first two hours of titanium doping reaction $(10 \mathrm{~mol} \%)$ for both $\mathrm{LiAlH}_{4}$ and $\mathrm{NaAlH}_{4}$. The reaction was carried out in THF and during those two hours the temperature increases from $-5^{\circ} \mathrm{C}$ to ambient. We found that $\mathrm{LiAlH}_{4}$ releases $\mathrm{H}_{2}$ earlier at lower temperatures than $\mathrm{NaAlH}_{4}$ but, eventually, it maintains the same pattern of releasing six mole equivalents of $\mathrm{H}_{2}$ per mole of Ti.

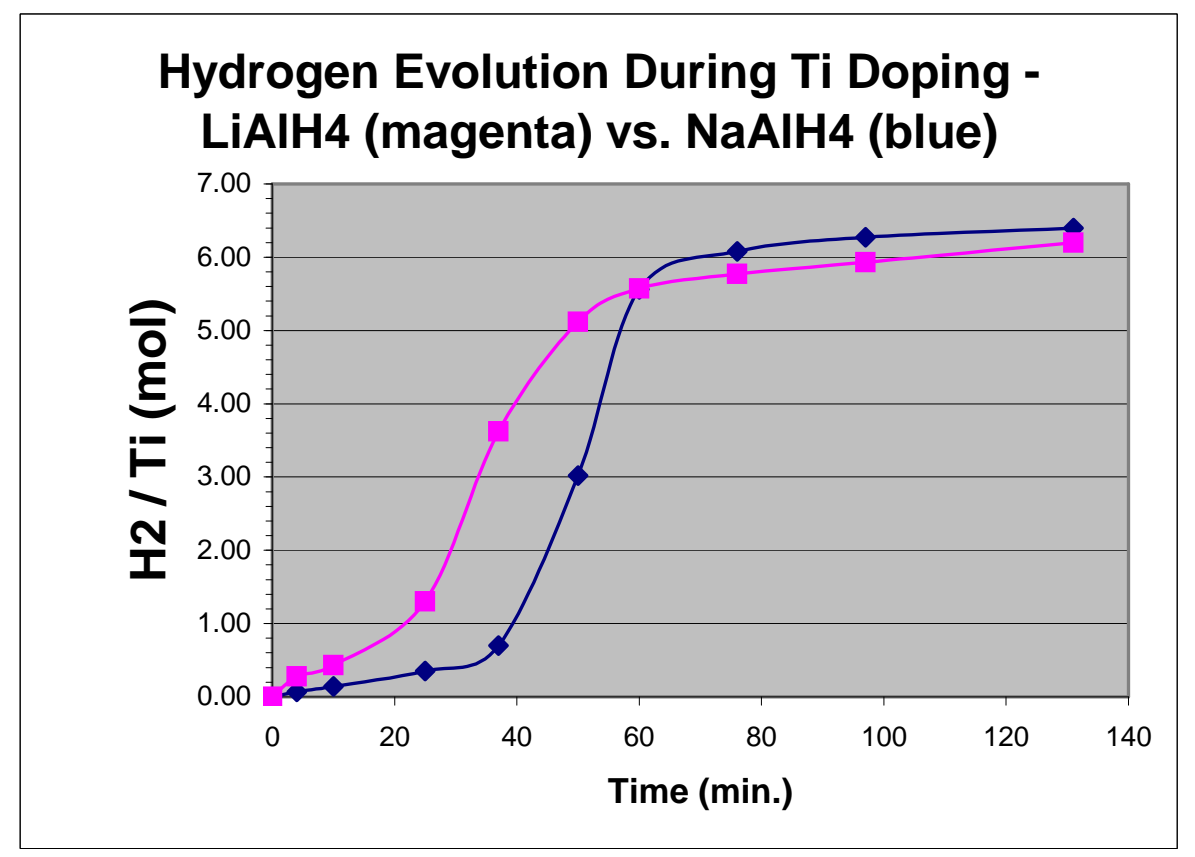

Figure 59: Hydrogen release for titanium doped $\mathrm{LiAlH}_{4}$ and $\mathrm{NaAlH}_{4}$. 


\section{Solution Based Processing}

Our gas evolution results strongly suggest the doping reaction involves a 12-electron redox reaction per mole of $\mathrm{Ti}$ ( 6 moles of $\mathrm{H}_{2}$ evolved, see Equation 30 and Equation 31 below), thus, reinforcing the $\mathrm{TiAl}_{3}$ theory proposed by Graetz et al. in Ref. 66. The results also raise a possibility that previous solution based preparations of Ti-doped SAH done by Bogdanovic and others might have been incomplete.

Equation $30 \quad \mathrm{TiCl}_{3}+3 \mathrm{NaAlH}_{4} \rightarrow \mathrm{Ti}\left(\mathrm{AlH}_{4}\right)_{3}+3 \mathrm{NaCl}$

Equation 31

$$
\operatorname{Ti}\left(\mathrm{AlH}_{4}\right)_{3} \rightarrow \mathrm{TiAl}_{3}+6 \mathrm{H}_{2}
$$

Figure 60 to Figure 62 shows the DSCs of Albemarle's commercial $\mathrm{NaAlH}_{4}$, and $4 \%$ Ti-doped $\mathrm{NaAlH}_{4}$ via the solution process and through ball milling, respectively. Interestingly, Figure 61 and Figure 62 clearly show a different product composition was formed from solution processing.

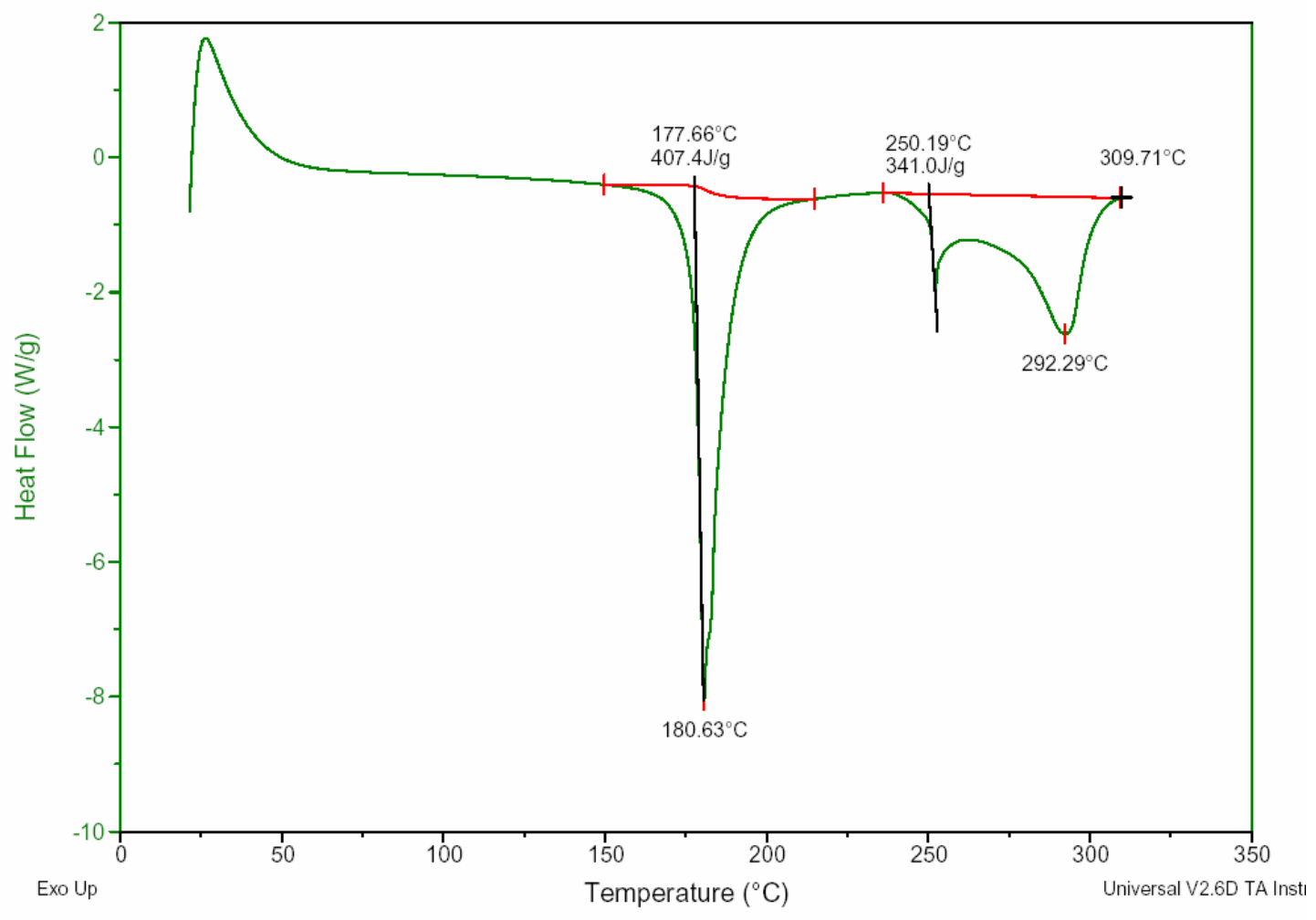

Figure 60: DSC of Albemarle $\mathrm{NaAlH}_{4}$. 


\section{Solution Based Processing}

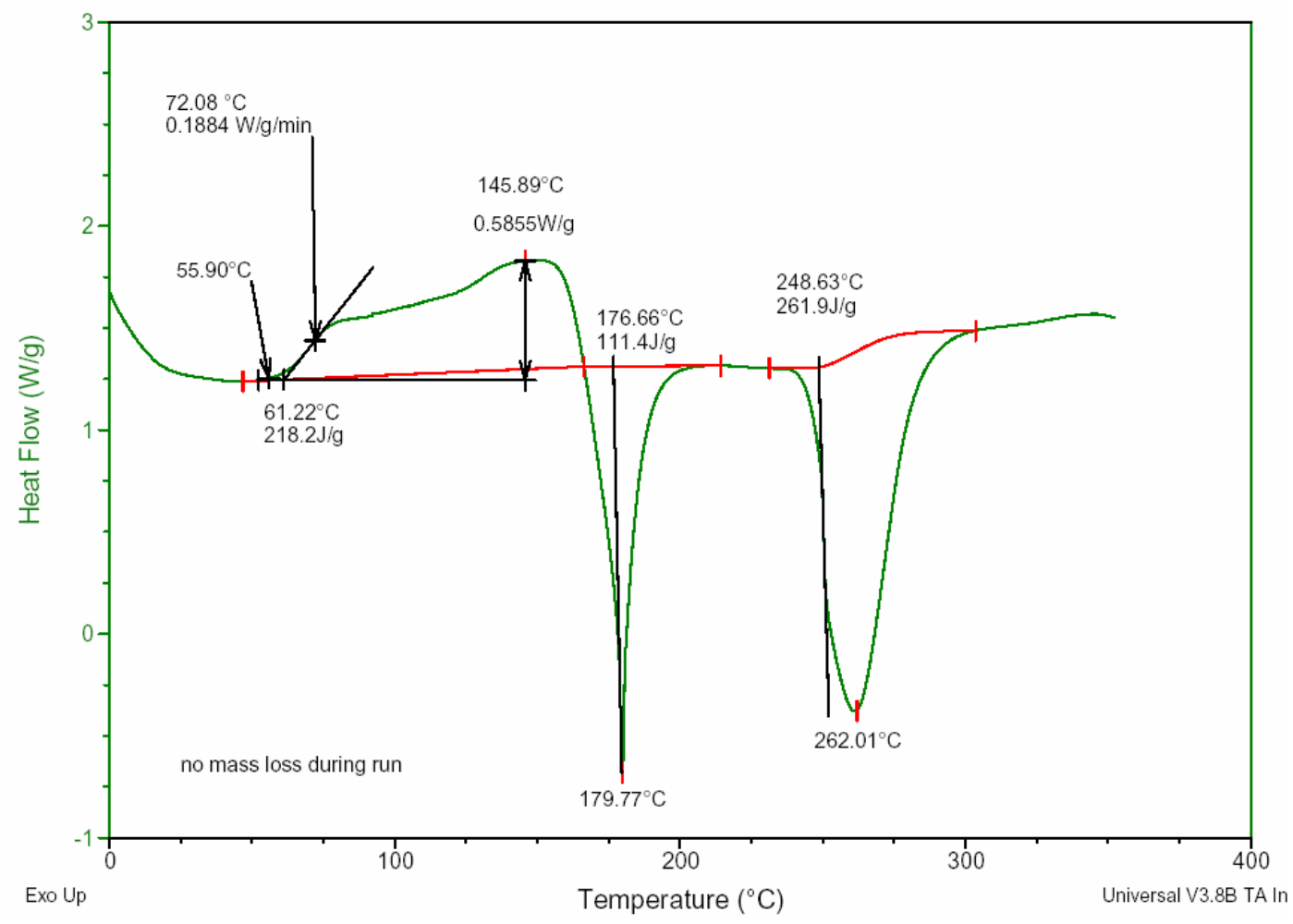

Figure 61: DSC of 4\% Ti-doped $\mathrm{NaAlH}_{4}$ via solution process.

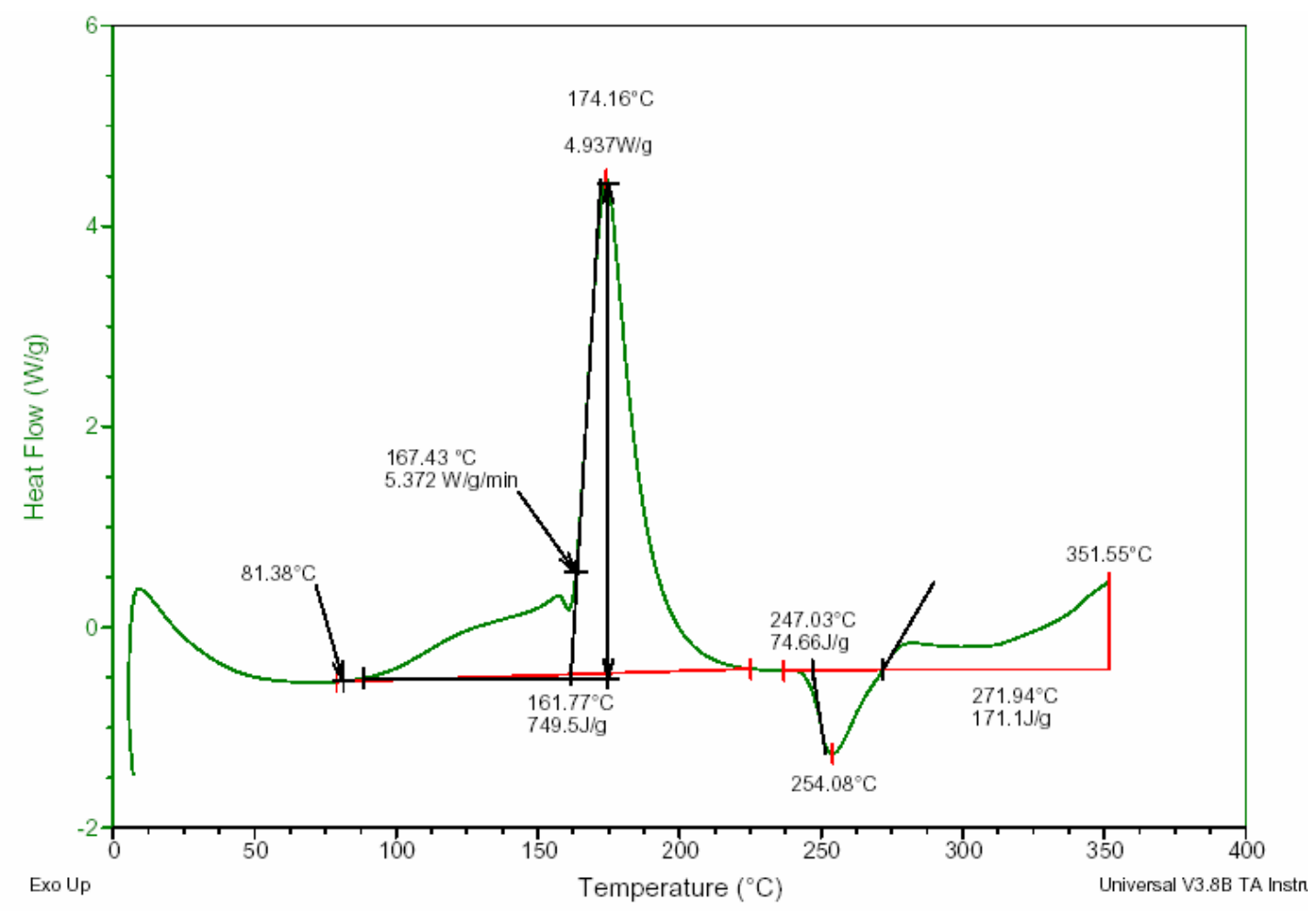

Figure 62: DSC of 4\% Ti-doped $\mathrm{NaAlH}_{4}$ via ball-milling. 


\section{Solution Based Processing}

\subsection{Complex 2: $\mathrm{LiMg}\left(\mathrm{AlH}_{4}\right)_{3}$}

This Li-Mg-Al-H quaternary compound has a theoretical maximum $\mathrm{H}$ wt $\%$ of $8.9 \%$, assuming $\mathrm{LiH}$, $\mathrm{Mg}$, and $\mathrm{Al}$ as the depleted products. This compound has been successfully synthesized by a threestep process in the literature [Ref. 67] as outlined below. Reactions of Equation 32 and Equation 33 were carried out in $\mathrm{Et}_{2} \mathrm{O}$. The reaction of Equation 34 was carried out in $\mathrm{Et}_{2} \mathrm{O} /$ toluene at $80^{\circ} \mathrm{C}$. Use of $\mathrm{NaAlH}_{4}$ in Equation 33 was critical in producing a chloride-free product.

Equation $\left.32 \quad \mathrm{MgCl}_{2}+3 \mathrm{LiAlH}_{4} \rightarrow\{\text { LiCloLiMg(AlH })_{3}\right\}+\mathrm{LiCl}$

Equation $33 \quad\left\{\mathrm{LiCl} \cdot L i M g\left(\mathrm{AlH}_{4}\right)_{3}\right\}+\mathrm{NaAlH}_{4} \rightarrow\left\{\mathrm{LiAlH}_{4} \bullet \mathrm{LiMg}(\mathrm{AlH})_{3}\right\}+\mathrm{NaCl}$

Equation 34

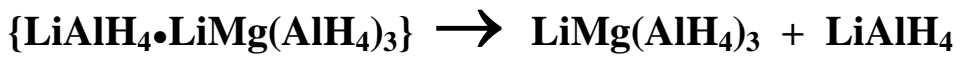

To support detailed characterization by IFE, the analogous deuterium compound, $\operatorname{LiMg}\left(\mathrm{AlD}_{4}\right)_{3}$, was successfully synthesized from $\mathrm{LiAlD}_{4}$. The elemental analyses for both of these compounds are shown in Table 14 below.

Table 14: ICP results of $\operatorname{LiMg}\left(\mathrm{AlH}_{4}\right)_{3}$ and $\operatorname{LiMg}\left(\mathrm{AlD}_{4}\right)_{3}$.

\begin{tabular}{|c|c|c|c|c|}
\hline & $\mathrm{Li} \%$ & $\mathrm{Mg \%}$ & $\mathrm{Al \%}$ & $\mathrm{Na} \%$ \\
\hline \multicolumn{5}{|l|}{$\mathrm{LiMg}_{\left(\mathrm{AlH}_{4}\right)_{3}}$} \\
\hline theory & 5.58 & 19.6 & 65.1 & 0 \\
\hline found & 5.50 & 19.1 & 63.9 & 1.12 \\
\hline \multicolumn{5}{|l|}{$\mathrm{LiMg}\left(\mathrm{AlD}_{4}\right)_{3}$} \\
\hline theory & 5.09 & 17.8 & 59.4 & 0 \\
\hline found & 5.27 & 17.4 & 58.3 & 0.60 \\
\hline
\end{tabular}

The XRD pattern for $\operatorname{LiMg}\left(\mathrm{AlH}_{4}\right)_{3}$ is shown in Figure 63. The DSC/TGA data are given in Figure 64 and Figure 65, respectively. Refer to Section 4.3.1.2 for more characterization data and discussion. 


\section{Solution Based Processing}

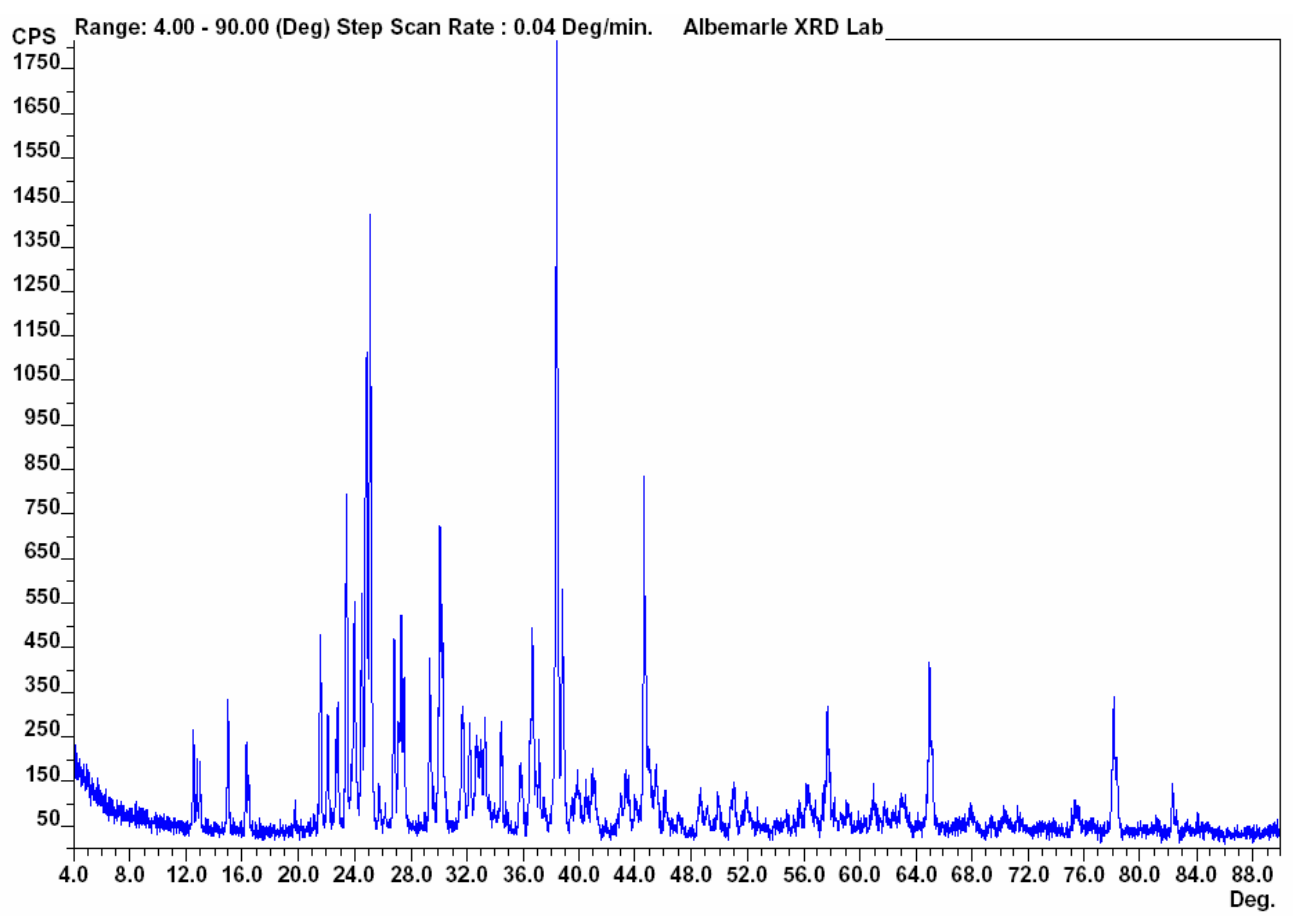

Figure 63: XRD of $\mathrm{LiMg}\left(\mathrm{AlH}_{4}\right)_{3}$.

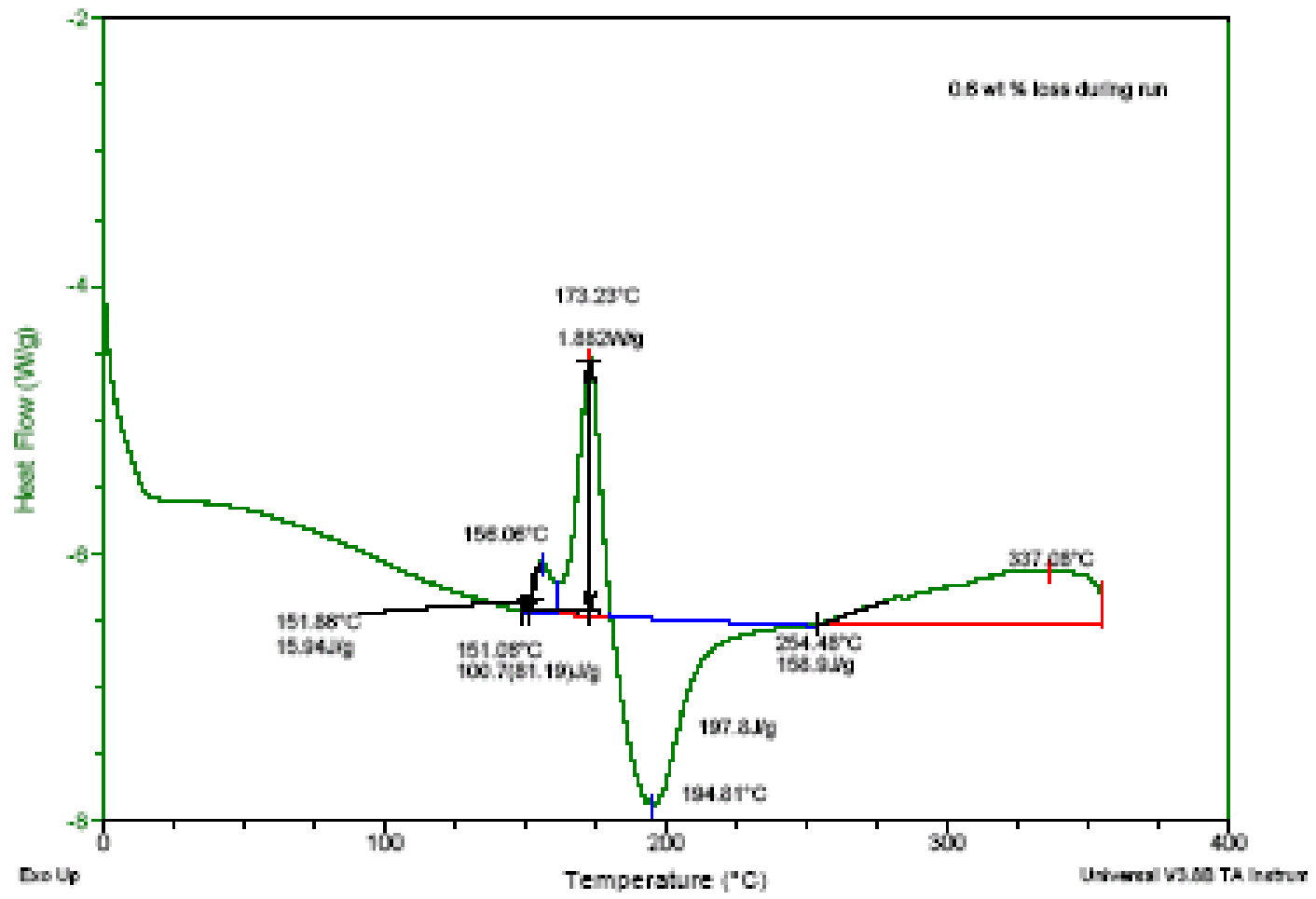

Figure 64: $\mathrm{DSC}$ of $\operatorname{LiMg}\left(\mathrm{AlH}_{4}\right)_{3}$. 


\section{Solution Based Processing}

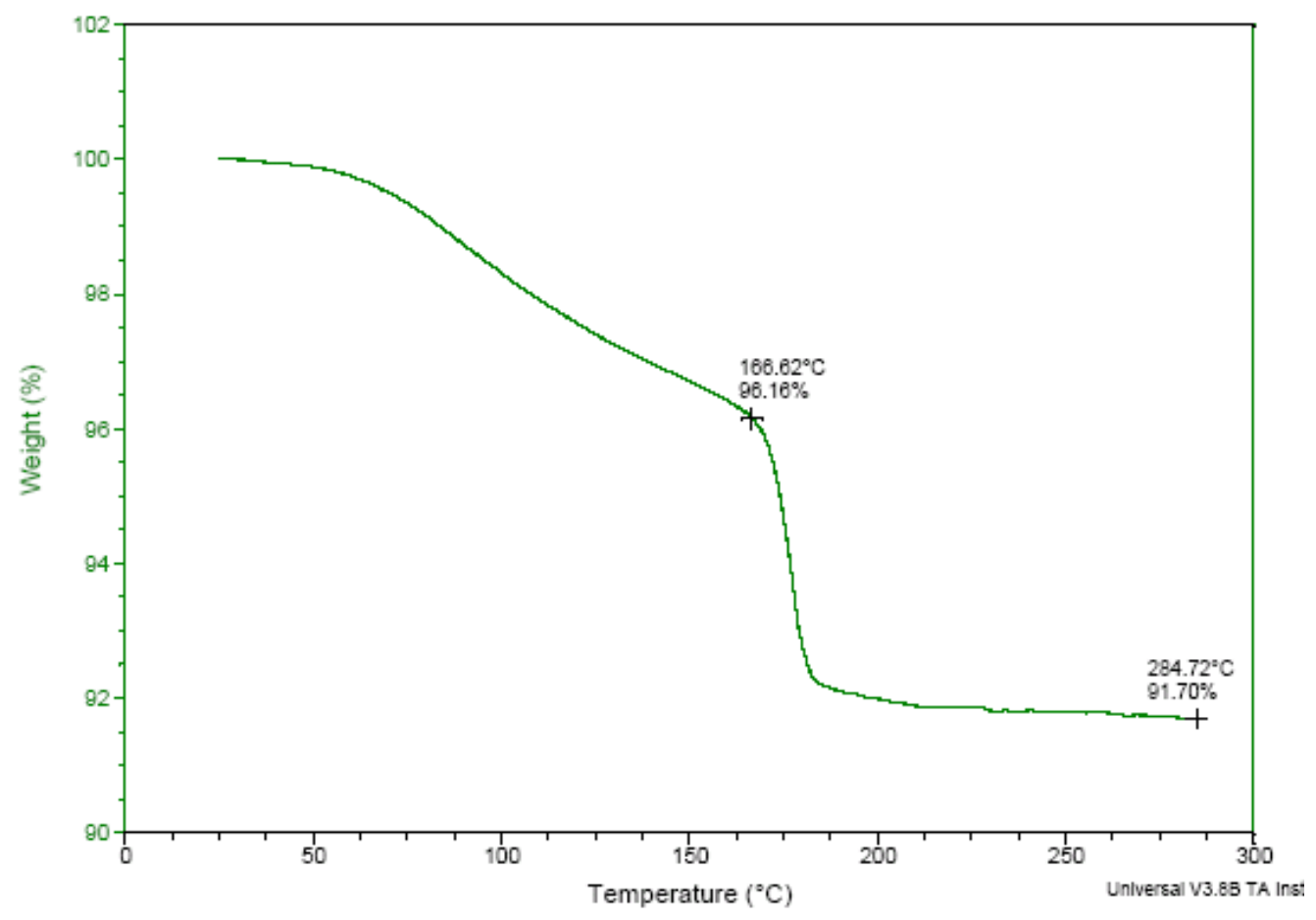

Figure 65: TGA of of $\mathrm{LiMg}\left(\mathrm{AlH}_{4}\right)_{3}$.

Bogdanovic et al. [Ref. 68] also reported the synthesis of $\operatorname{LiMg}\left(\mathrm{AlH}_{4}\right)_{3}$ by way of ball milling based on the reaction below

$$
\mathrm{MgCl}_{2}+3 \mathrm{LiAlH}_{4} \rightarrow \operatorname{LiMg}\left(\mathrm{AlH}_{4}\right)_{3}+2 \mathrm{LiCl}
$$

In this work, separation of $\mathrm{LiMg}\left(\mathrm{AlH}_{4}\right)_{3}$ from $\mathrm{LiCl}$ was accomplished using a wet chemical separation method. Dehydrogenation of the material was also reported. Interestingly, the XRD analysis suggested that the bulk of the material was mostly amorphous. It should be noted that the mixture $\mathrm{LiMg}\left(\mathrm{AlH}_{4}\right)_{3}+2 \mathrm{LiCl}$ was used in the dehydrogenation study. No reverse hydrogenation reactions were mentioned.

The synthesis of the corresponding sodium analog, $\mathrm{NaMg}\left(\mathrm{AlH}_{4}\right)_{3}$, was not successful after a few attempts. This turns out to be consistent with the calculation showing its formation being thermodynamically unfavorable according to Ref. 69.

\subsection{Complex 3: $\mathrm{Mg}\left(\mathrm{BH}_{4}\right)_{2}\left(2 \mathrm{NH}_{3}\right)$}

This magnesium borohydride ammonia complex has a theoretical maximum $\mathrm{H}$ wt $\%$ of $16.0 \%$, assuming $\mathrm{Mg}$ and $\mathrm{BN}$ as the hydride-depleted products. It represents an interesting alternative to ammonia borane, $\mathrm{BH}_{3} \bullet \mathrm{NH}_{3}$, which has received considerable interest as a hydrogen storage material. The compound can be prepared by a three-step procedure according to a literature report as outlined below [Ref. 70].

Equation $35 \quad \mathrm{MgCl}_{2}+2 \mathrm{NaBH}_{4} \rightarrow \mathrm{Mg}\left(\mathrm{BH}_{4}\right)_{2} \cdot \mathrm{Et}_{2} \mathrm{O}+2 \mathrm{NaCl}$ 


\section{Solution Based Processing}

Equation 36

$$
\mathrm{Mg}\left(\mathrm{BH}_{4}\right)_{2} \bullet \mathrm{Et}_{2} \mathrm{O}+6 \mathrm{NH}_{3} \rightarrow \mathrm{Mg}\left(\mathrm{BH}_{4}\right)_{2} \bullet 6 \mathrm{NH}_{3}+\mathrm{Et}_{2} \mathrm{O}
$$

Equation 37

$$
\mathrm{Mg}\left(\mathrm{BH}_{4}\right)_{2} \bullet 6 \mathrm{NH}_{3} \rightarrow \mathrm{Mg}\left(\mathrm{BH}_{4}\right)_{2} \bullet 2 \mathrm{NH}_{3}+4 \mathrm{NH}_{3}
$$

The reactions of Equation 35 and Equation 36 were carried out in $\mathrm{Et}_{2} \mathrm{O}$. In Equation 37, the hexaammonia complex is converted to the di-ammonia complex by heating at $100^{\circ} \mathrm{C}$ under vacuum for 7 hours.

The XRD patterns of $\mathrm{Mg}\left(\mathrm{BH}_{4}\right)_{2} \bullet 6 \mathrm{NH}_{3}$ and $\mathrm{Mg}\left(\mathrm{BH}_{4}\right)_{2} \cdot 2 \mathrm{NH}_{3}$ are shown in Figure 66 and Figure 67, respectively.

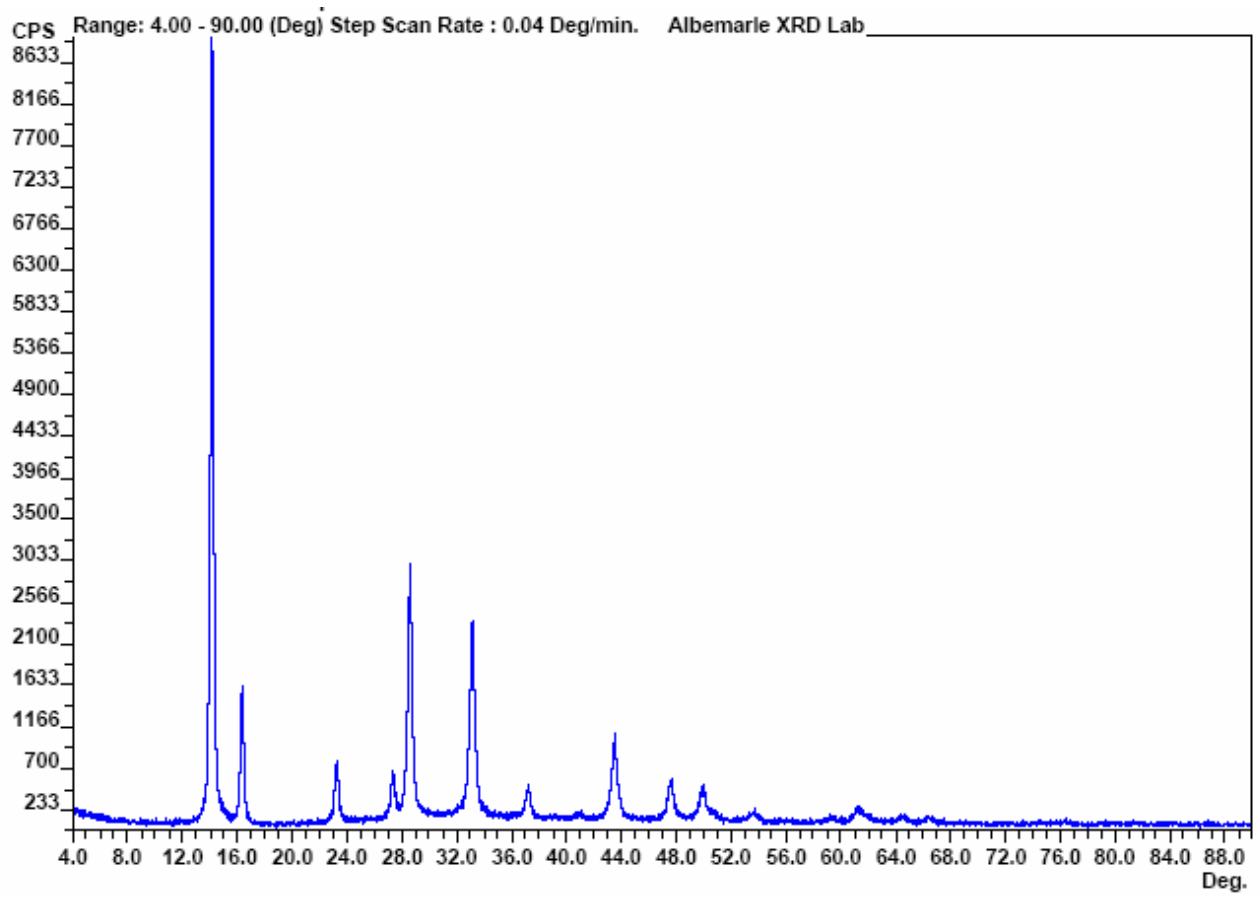

Figure 66: XRD pattern of $\mathrm{Mg}\left(\mathrm{BH}_{4}\right)_{2} \bullet 6 \mathrm{NH}_{3}$. 


\section{Solution Based Processing}

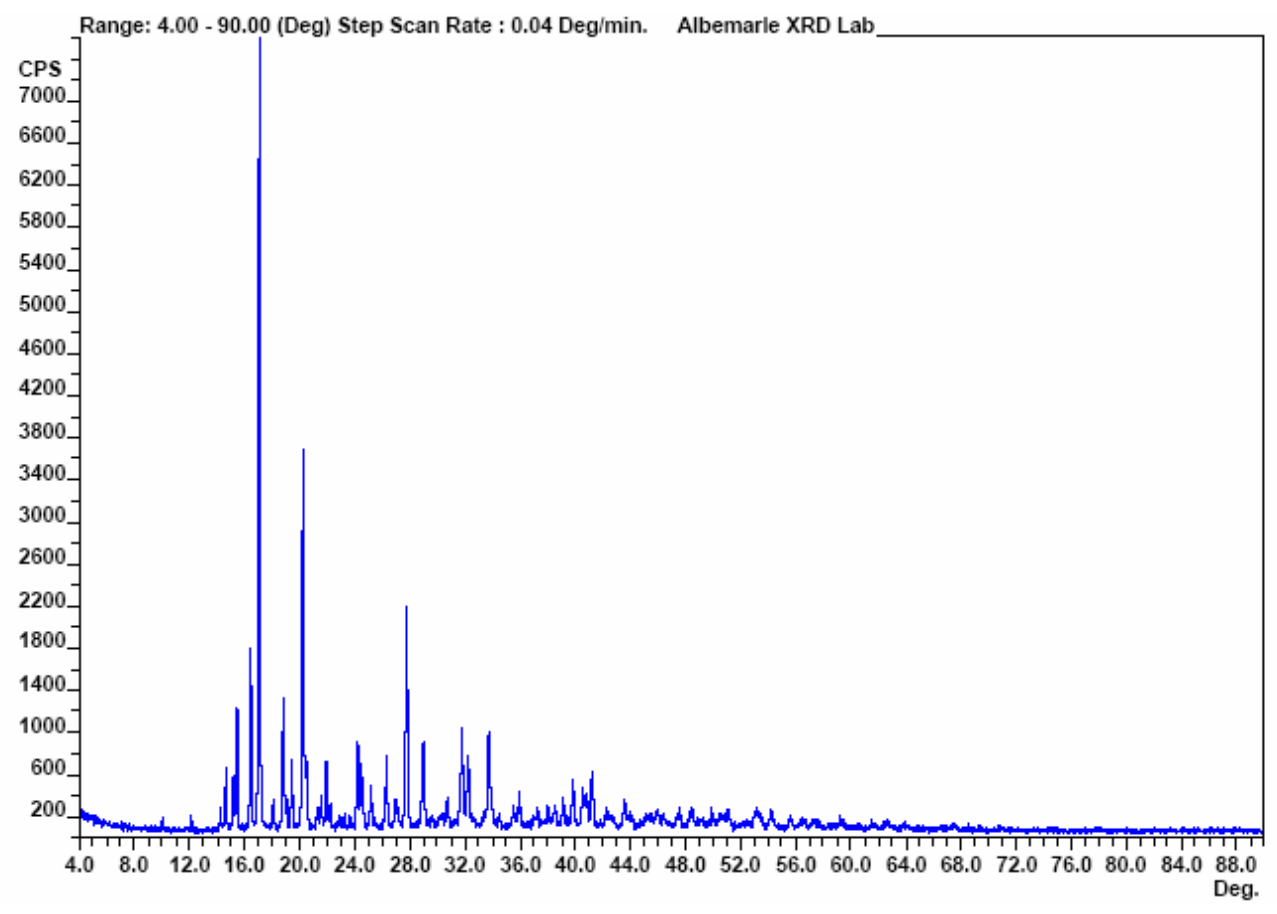

Figure 67: The XRD pattern of $\mathrm{Mg}\left(\mathrm{BH}_{4}\right)_{2} \bullet 2 \mathrm{NH}_{3}$.

Interestingly, two distinct forms of the di-ammonia complex seem to exist based on thermal analyses. One has two ammonia molecules loosely bound, consistent with the "solvate" formulation of $\mathrm{Mg}\left(\mathrm{BH}_{4}\right)_{2} \bullet 2 \mathrm{NH}_{3}$ and another has the two ammonias tightly bound, more consistent with the formulation of $\mathrm{Mg}\left(\mathrm{NH}_{3}\right)_{2}\left(\mathrm{BH}_{4}\right)_{2}$. The two forms have drastically different thermal behaviors during hydrogen discharge, as shown in Figure 68 to Figure 71.

$\operatorname{Mg}\left(\mathrm{BH}_{4}\right)_{2} \cdot 2 \mathrm{NH}_{3}($ Metal Hydride Mechanism)

$$
\begin{aligned}
& \mathrm{Mg}\left(\mathrm{BH}_{4}\right)_{2} \cdot 2 \mathrm{NH}_{3} \longrightarrow \mathrm{Mg}\left(\mathrm{BH}_{4}\right)_{2}+2 \mathrm{NH}_{3} \\
& \mathrm{Mg}\left(\mathrm{BH}_{4}\right)_{2} \longrightarrow \mathrm{MgH}_{2}+2 \mathrm{~B}+3 \mathrm{H}_{2} \\
& \mathrm{MgH}_{2} \longrightarrow \mathrm{Mg}+\mathrm{H}_{2}
\end{aligned}
$$

$\operatorname{Mg}\left(\mathrm{NH}_{3}\right)_{2}\left(\mathrm{BH}_{4}\right)_{2}\left(\mathrm{BH}_{3} \bullet \mathrm{NH}_{3}\right.$-like Mechanism)

$$
\begin{aligned}
& \mathrm{Mg}\left(\mathrm{NH}_{3}\right)_{2}\left(\mathrm{BH}_{4}\right)_{2} \longrightarrow \mathrm{MgH}_{2}+2 \mathrm{BN}+6 \mathrm{H}_{2} \\
& \mathrm{MgH}_{2} \longrightarrow \mathrm{Mg}+\mathrm{H}_{2}
\end{aligned}
$$

Table 15 summarizes the expected weight loss and thermal characteristics predicted by the two hydrogen discharge mechanisms exhibited by $\mathrm{Mg}\left(\mathrm{BH}_{4}\right)_{2}\left(\mathrm{NH}_{3}\right)_{2}$, which are in total agreement with the TGA data (Figure 69 and Figure 71, respectively). The two sets of corresponding DSC data are shown in Figure 68 and Figure 70 . Figure 70 shows an endotherm at $61^{\circ} \mathrm{C}$ likely due to melting of 


\section{Solution Based Processing}

$\mathrm{Mg}\left(\mathrm{NH}_{3}\right)_{2}\left(\mathrm{BH}_{4}\right)_{2}$, which is not seen in Figure 68 consistent with a more ionic nature of $\mathrm{Mg}\left(\mathrm{BH}_{4}\right)_{2} \cdot 2 \mathrm{NH}_{3}$. The exotherm at $232^{\circ} \mathrm{C}$ in Figure 70 corresponds to $70.3 \mathrm{~kJ} / \mathrm{mol}$.

Table 15: The properties of two forms of $\mathrm{Mg}\left(\mathrm{NH}_{3}\right)_{2}\left(\mathrm{BH}_{4}\right)_{2}$.

\begin{tabular}{|c|c|c|}
\hline & $\begin{array}{c}\text { Theoretical Total } \\
\text { Weight Loss in TGA }\end{array}$ & $\begin{array}{c}\text { Thermal Events in Open System } \\
\text { (TGA) }\end{array}$ \\
\hline $\begin{array}{c}\mathrm{Mg}\left(\mathrm{BH}_{4}\right)_{2} \bullet 2 \mathrm{NH}_{3} \\
\text { Metal hydride } \\
\text { mechanism }\end{array}$ & $52.2 \%$ & $\begin{array}{l}\text { 1. Ammonia evaporation: } \\
\text { endothermic } \\
\text { 2. Hydrogen discharge }(\mathrm{B}-\mathrm{H}) \text { : } \\
\text { endothermic } \\
\text { 3. Hydrogen discharge }(\mathrm{Mg}-\mathrm{H}) \text { : } \\
\text { endothermic }\end{array}$ \\
\hline $\begin{array}{c}\mathrm{Mg}\left(\mathrm{NH}_{3}\right)_{2}\left(\mathrm{BH}_{4}\right)_{2} \\
\mathrm{BH}_{3} \bullet \mathrm{NH}_{3} \text {-like } \\
\text { mechanism }\end{array}$ & $16.0 \%$ & $\begin{array}{l}\text { 1. Hydrogen discharge }(\mathrm{H}-\mathrm{BN}-\mathrm{H}) \text { : } \\
\text { exothermic } \\
\text { 2. Hydrogen discharge }(\mathrm{Mg}-\mathrm{H}) \text { : } \\
\text { endothermic }\end{array}$ \\
\hline
\end{tabular}

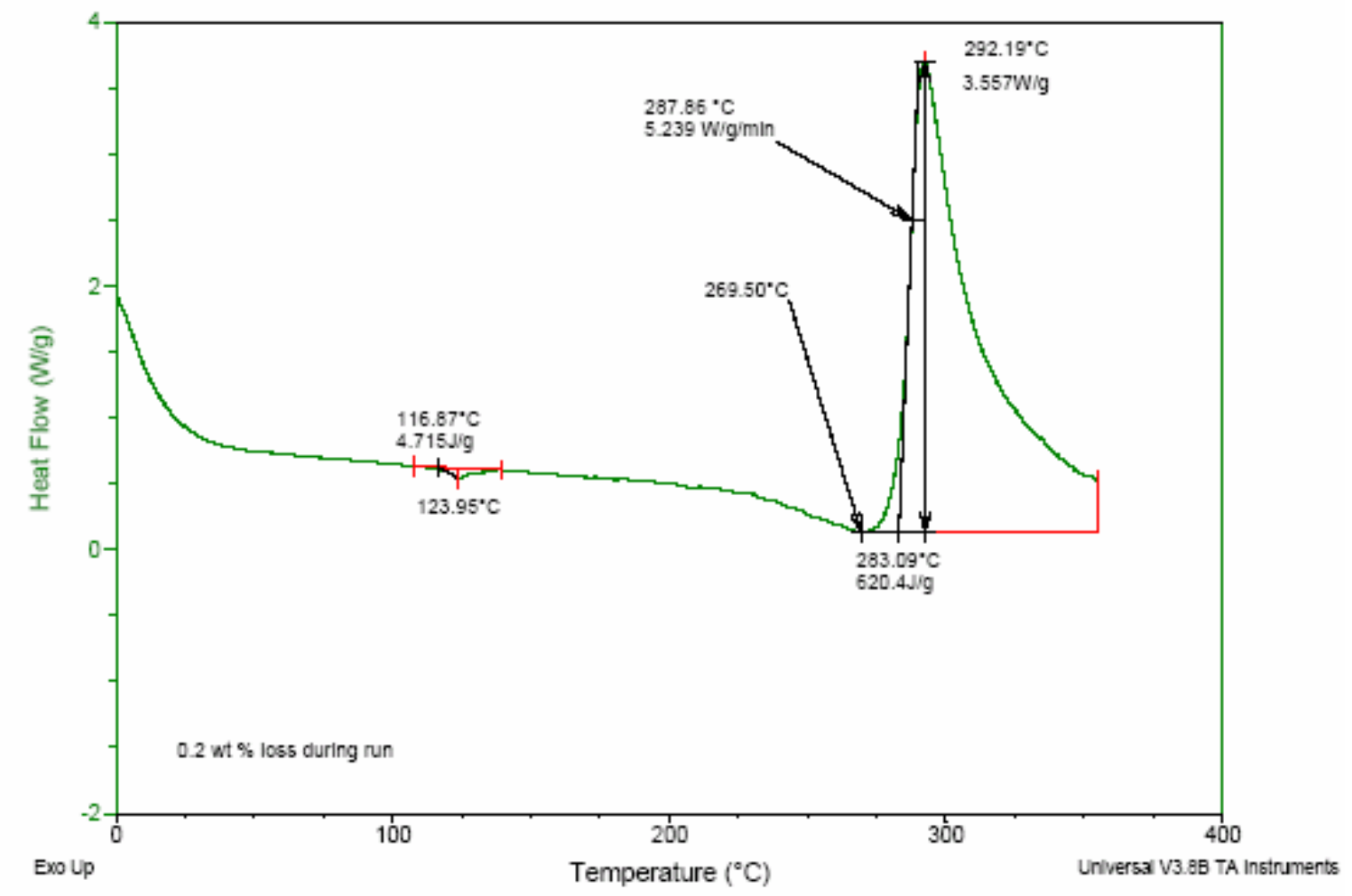

Figure 68: DSC of $\mathrm{Mg}\left(\mathrm{BH}_{4}\right)_{2} \bullet 2 \mathrm{NH}_{3}$. 


\section{Solution Based Processing}

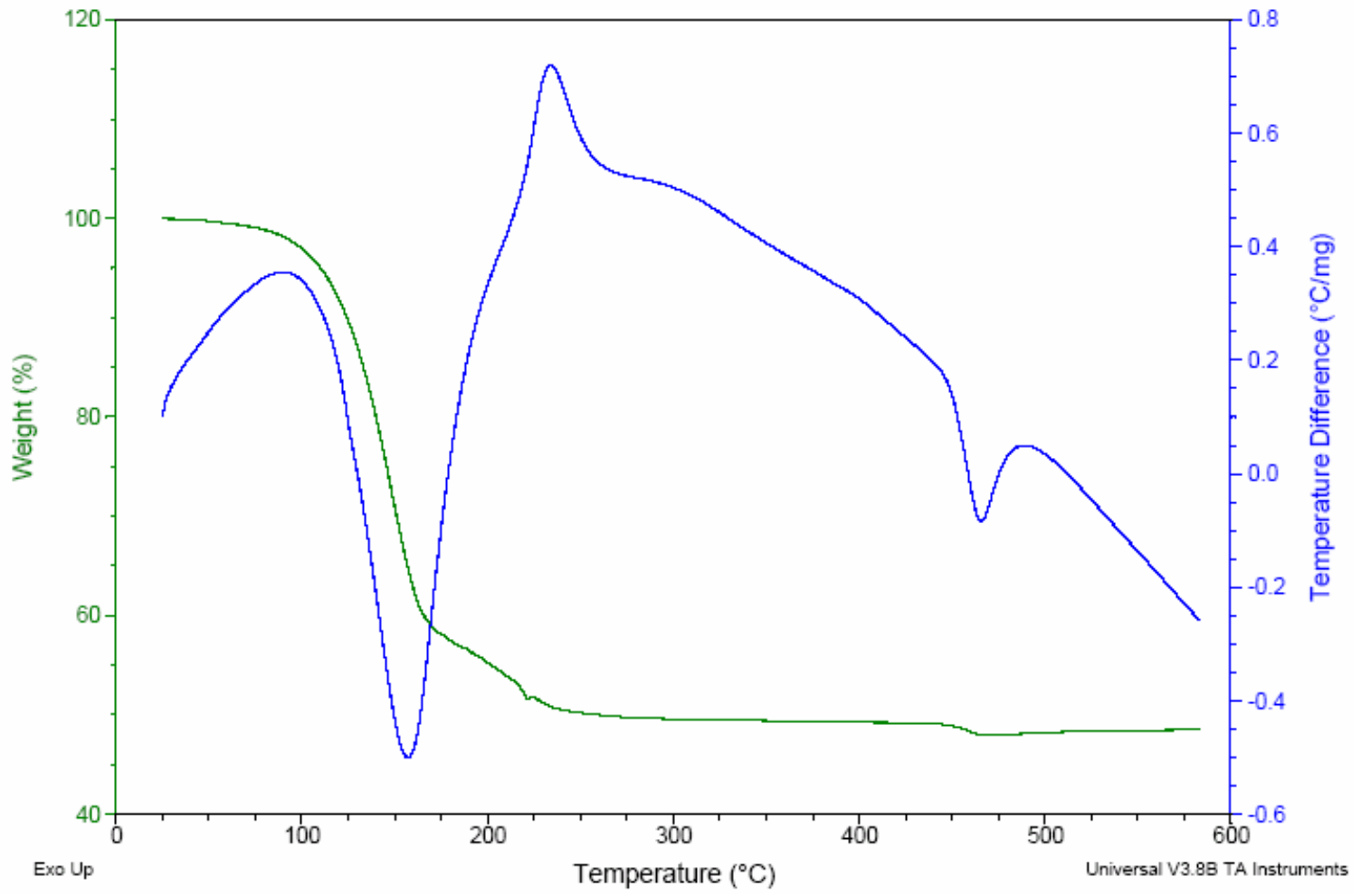

Figure 69: TGA-DTA of $\mathrm{Mg}\left(\mathrm{BH}_{4}\right)_{2}-2 \mathrm{NH}_{3}$ showing metal hydride characteristics.

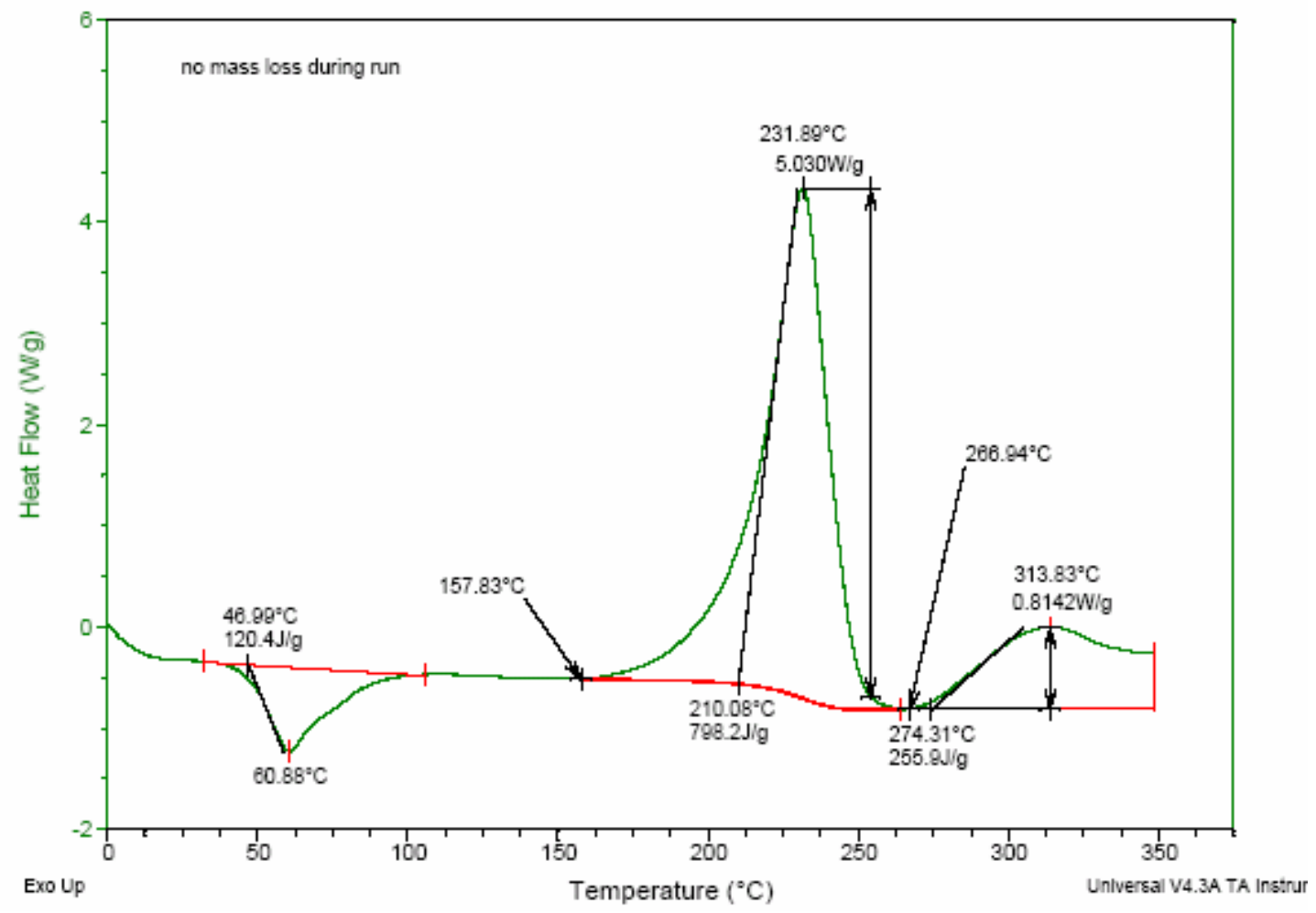

Figure 70: $\mathrm{DSC}$ of $\mathrm{Mg}\left(\mathrm{NH}_{3}\right)_{2}\left(\mathrm{BH}_{4}\right)_{2}$. 


\section{Solution Based Processing}

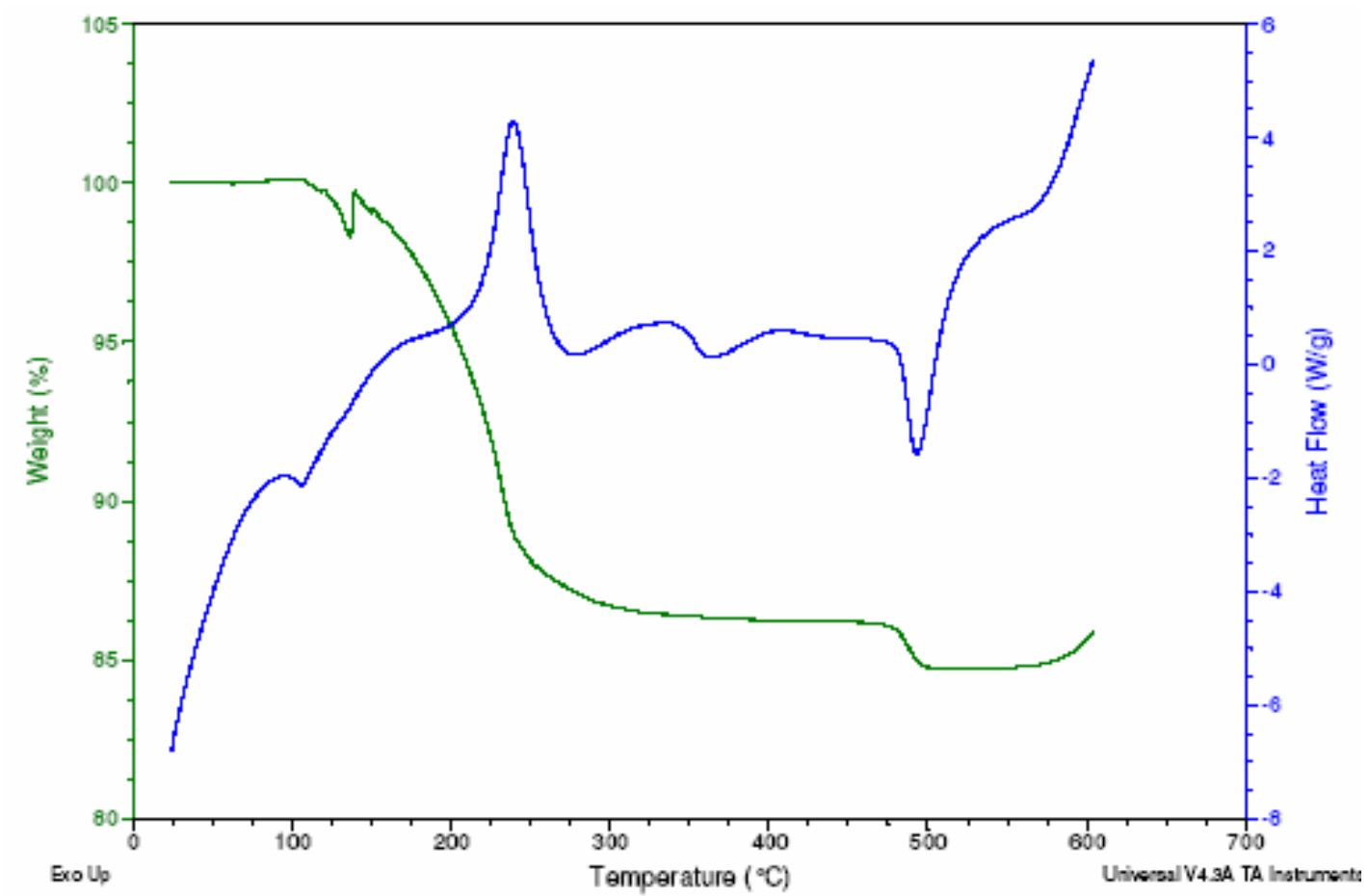

Figure 71: TGA-DSC of $\mathrm{Mg}\left(\mathrm{NH}_{3}\right)_{2}\left(\mathrm{BH}_{4}\right)_{2}$ showing $\mathrm{BH}_{3} \bullet \mathrm{NH}_{3}$-like characteristics.

It is not clear what causes these two types of the di-ammonia complexes to form. It is speculated that the likely cause is the manner in which the reaction of Equation 37 is carried out. The hexa to diammonia reaction, performed at $90-110^{\circ} \mathrm{C}$ under vacuum, is sometimes accompanied by melting of the solids but sometimes not, with no apparent pattern. Notice that in the two DSC data sets shown above, one has a melting endotherm at $60.9^{\circ} \mathrm{C}$ (Figure 70) and the other has none (Figure 68). Conceivably, factors such as the temperature profile and vacuum strength could influence the reaction.

It also should be mentioned that we have synthesized a sample of $\mathrm{Mg}\left(\mathrm{BH}_{4}\right)_{2}\left(\mathrm{NH}_{3}\right)_{2}$ that shows a weight loss of around $28 \%$, suggesting a roughly 50/50 ratio of the two forms.

In Konoplev's article [Ref. 70], the IR data of $\mathrm{BH}_{4}{ }^{-}$in both the hexa and di-ammonia complexes are reported. The results suggest the hexa-ammonia complex has the formulation of $\left[\mathrm{Mg}\left(\mathrm{NH}_{3}\right)_{6}\right]\left(\mathrm{BH}_{4}\right)_{2}$ where the $\mathrm{BH}_{4}{ }^{-}$anions are in the outer coordination sphere, whereas the di-ammonia complex has the $\mathrm{BH}_{4}{ }^{-}$anions directly coordinated to the $\mathrm{Mg}$. The transition of inner and outer sphere ligands is certainly a poorly understood process which must have a significant bearing on the observed chemistry.

\subsection{Complex 4: $\mathrm{Mg}\left(\mathrm{BH}_{4}\right)_{2}\left(\mathrm{NMe}_{3}\right)$}

The trimethylamine complexes of $\mathrm{Mg}\left(\mathrm{BH}_{4}\right)_{2}$ were synthesized specifically to rule out the possibility of the hydrogen release via a $\mathrm{BH}_{3} \bullet \mathrm{NH}_{3}$-like mechanism. The synthesis was carried out in a similar fashion as that of the ammonia complex, i.e.: 


\section{Solution Based Processing}

$$
\begin{aligned}
& \mathrm{MgCl}_{2}+2 \mathrm{NaBH}_{4}+\text { excess } \mathrm{NMe}_{3} \longrightarrow \mathrm{Mg}\left(\mathrm{BH}_{4}\right)_{2}\left(\mathrm{NMe}_{3}\right)_{2}+2 \mathrm{NaCl} \\
& \mathrm{Mg}\left(\mathrm{BH}_{4}\right)_{2}\left(\mathrm{NMe}_{3}\right)_{2} \longrightarrow \mathrm{Mg}\left(\mathrm{BH}_{4}\right)_{2}\left(\mathrm{NMe}_{3}\right)+\mathrm{NMe}_{3}
\end{aligned}
$$

The first reaction was carried out in toluene at $60^{\circ} \mathrm{C}$. Carrying out the reaction above $60^{\circ} \mathrm{C}$ resulted in production of grayish materials, likely a result of some decomposition. After filtration and removal of excess $\mathrm{NMe}_{3}$, the toluene filtrate showed by $\mathrm{H}^{1}$-NMR to contain roughly a 1:1 ratio of $\mathrm{BH}_{4}$ and $\mathrm{NMe}_{3}$, indicating the formation of a di-amine complex. In the case of $\mathrm{NH}_{3}$, the initial product was a hexa-ammonia complex, $\mathrm{Mg}\left(\mathrm{BH}_{4}\right)_{2}\left(\mathrm{NH}_{3}\right)_{6}$. One of the trimethylamine ligands in $\mathrm{Mg}\left(\mathrm{BH}_{4}\right)_{2}\left(\mathrm{NMe}_{3}\right)_{2}$ is labile at room temperature under vacuum. By contrast, four of the six ammonias in $\mathrm{Mg}\left(\mathrm{BH}_{4}\right)_{2}\left(\mathrm{NH}_{3}\right)_{6}$ are labile, but only when heated to around $100^{\circ} \mathrm{C}$ under vacuum. The monoamine complex was analyzed by ICP to contain $21.3 \% \mathrm{Mg}$ (theory: $21.5 \%$ ).

The monoamine complex indeed exhibits very different thermal properties in DSC and TGA from those of $\mathrm{Mg}\left(\mathrm{BH}_{4}\right)_{2}\left(\mathrm{NH}_{3}\right)_{2}$. The DSC of the complex (Figure 72) shows small exo- and endotherms at low temperatures $\left(101^{\circ} \mathrm{C}\right.$ and $128^{\circ} \mathrm{C}$ respectively), likely due to a partial hydrogen release and evaporation of the amine. A prolonged endotherm follows at temperatures of $>240^{\circ} \mathrm{C}$. The TGADSC (Figure 73) shows two gradual weight losses, one between $80-200^{\circ} \mathrm{C}$ and another between $200-300^{\circ} \mathrm{C}$. The total of the two weight losses was $>50 \%$ and are roughly thermally neutral as shown by the accompanying DSC. Interestingly, the TGA-MS carried out by UTRC shows the complex begins to release hydrogen at temperatures as low as $60^{\circ} \mathrm{C}$. Thus, the first weight loss in the TGA must be the combination of hydrogen discharge and $\mathrm{NMe}_{3}$ evaporation. This result indicates a dramatic reduction of the hydrogen discharge temperature from $\sim 320^{\circ} \mathrm{C}$ for $\mathrm{Mg}\left(\mathrm{BH}_{4}\right)_{2}$ to $<100^{\circ} \mathrm{C}$ in $\mathrm{Mg}\left(\mathrm{BH}_{4}\right)_{2}\left(\mathrm{NMe}_{3}\right)$. Thus, we have unambiguously demonstrated the use of simple nitrogen ligands to destabilize $\mathrm{Mg}\left(\mathrm{BH}_{4}\right)_{2}$ which otherwise would only discharge hydrogen at an impractical temperature range. 


\section{Solution Based Processing}

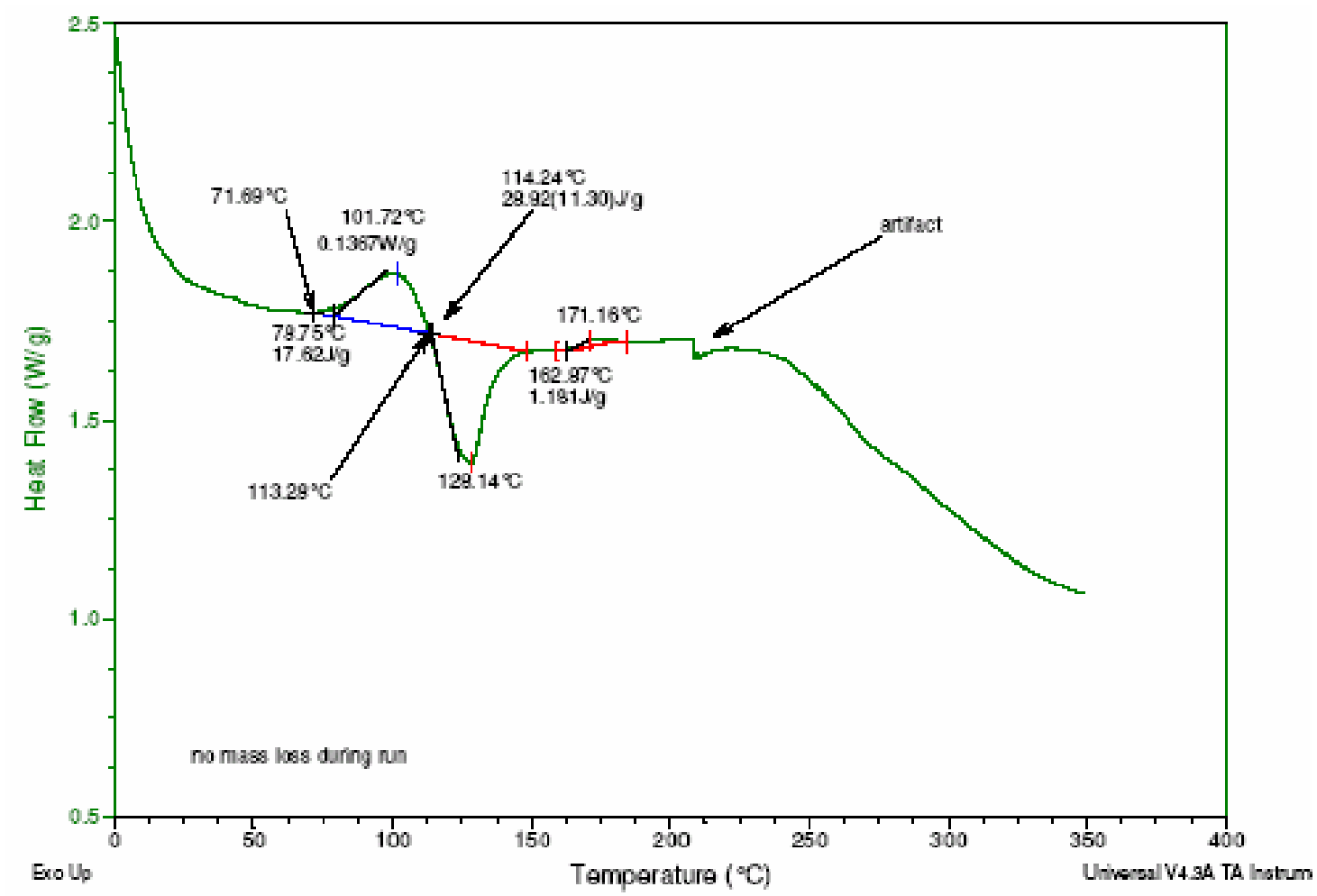

Figure 72: DSC of $\mathrm{Mg}\left(\mathrm{BH}_{4}\right)_{2}\left(\mathrm{NMe}_{3}\right)$.

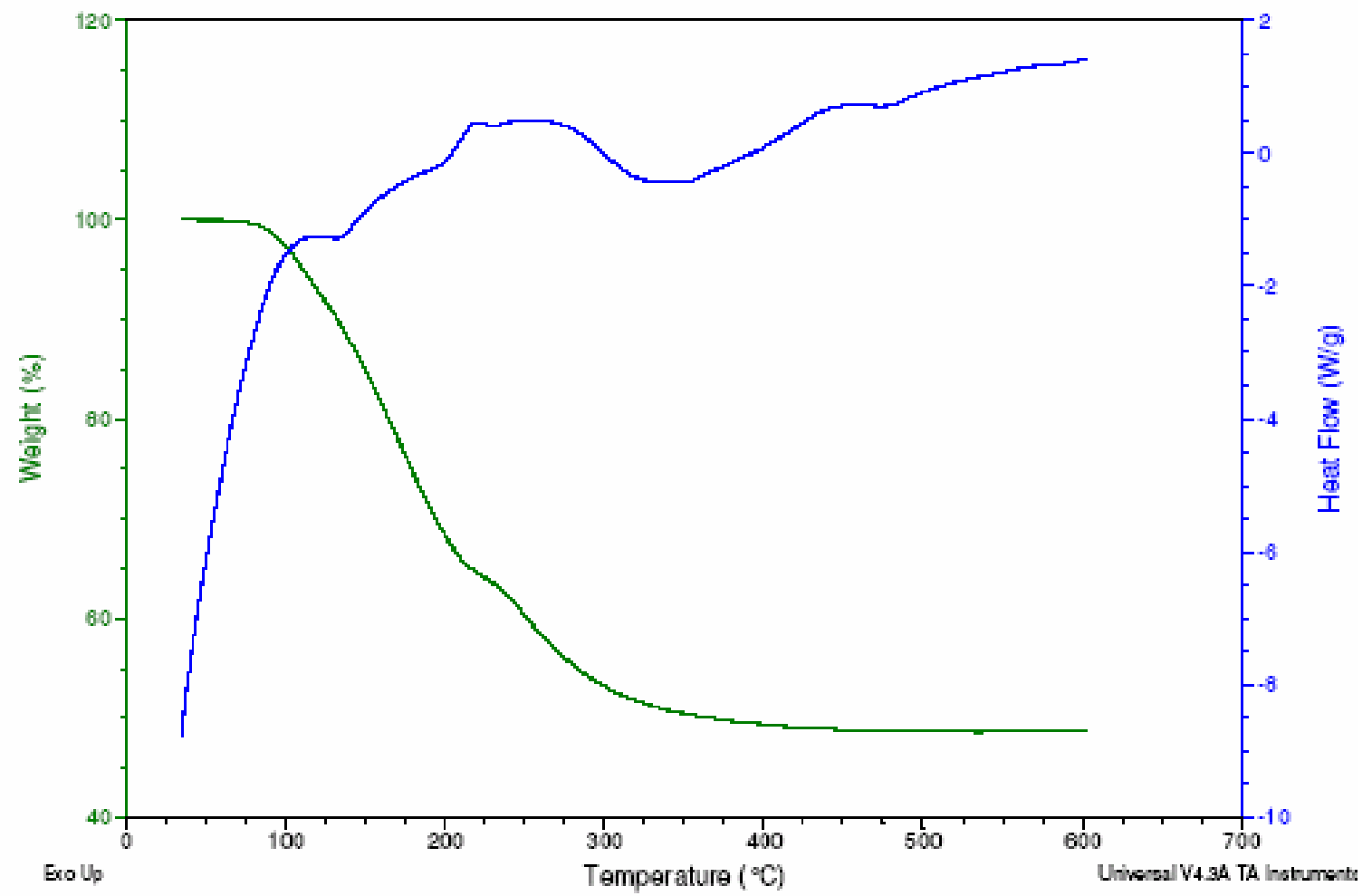

Figure 73: TGA-DSC of $\mathrm{Mg}\left(\mathrm{BH}_{4}\right)_{2}\left(\mathrm{NMe}_{3}\right)$. 


\section{Solution Based Processing}

\subsection{Complex 5: $\mathrm{Zr}\left(\mathrm{BH}_{4}\right)_{4}\left(\mathrm{NH}_{3}\right)_{8}$}

Some group 4 metal complexes of tetrahydroborate are known. They are usually characterized by high theoretical hydrogen content but thermally unstable as shown in Table 16.

Table 16: Group 4 transition metal complexes of tetrahydroborate.

\begin{tabular}{|c|c|c|c|}
\hline Group 4 metal & Known Borate* & H \% & Thermal Stability \\
\hline $\mathrm{Ti}$ & $\mathrm{Ti}\left(\mathrm{BH}_{4}\right)_{3} \cdot \mathrm{Et}_{2} \mathrm{O}$ & $13.1 \%$ (no ether) & unstable at $-20^{\circ} \mathrm{C}$ \\
\hline $\mathrm{Zr}$ & $\mathrm{Zr}\left(\mathrm{BH}_{4}\right)_{4}$ & $10.7 \%$ & unstable at ambient $\mathrm{T}$ \\
\hline $\mathrm{Hf}$ & $\mathrm{Hf}\left(\mathrm{BH}_{4}\right)_{4}$ & $6.8 \%$ & unstable at ambient $\mathrm{T}$ \\
\hline
\end{tabular}

* For Ti, see Ref. 71.

* For $\mathrm{Zr}$ and Hf, see Ref. 72.

Our approach to improve the thermal properties of these materials was to form complexes with polar molecules that could stabilize the dehydrogenation process via filling the open metal coordination sites. A particularly useful polar group is ammonia, which not only provides for this coordination, but also can be a source of hydrogen as well.

We decided to focus our initial efforts on $\mathrm{Zr}\left(\mathrm{BH}_{4}\right)_{4}$ which is typically much more stable than its $\mathrm{Ti}$ analogs and surprisingly volatile, thus easily separable from $\mathrm{LiCl}$ by distillation. The ammonia complex of $\mathrm{Zr}$ borohydride was prepared by a two-step process:

$$
\begin{aligned}
& \mathrm{ZrCl}_{4}+4 \mathrm{LiBH}_{4} \longrightarrow \mathrm{Zr}\left(\mathrm{BH}_{4}\right)_{4} \uparrow+4 \mathrm{LiCl} \\
& \mathrm{Zr}\left(\mathrm{BH}_{4}\right)_{4}+\mathrm{NH}_{3} \text { (excess) } \longrightarrow \mathrm{Zr}\left(\mathrm{BH}_{4}\right)_{4} \bullet 8 \mathrm{NH}_{3}
\end{aligned}
$$

The product from reaction of $\mathrm{Zr}\left(\mathrm{BH}_{4}\right)_{4}$ with ammonia turns out to be an octa-ammonia complex, $\mathrm{Zr}\left(\mathrm{BH}_{4}\right)_{4} \cdot 8 \mathrm{NH}_{3}$, obtained in excellent yield (92\%). This complex is thermally stable at room temperature. Thus, the concept of stabilizing the metal borate complex via ammonia coordination was confirmed.

Confirmation of an octa-ammonia complex was obtained by elemental analysis using ICP (theory: $\mathrm{Zr}$ 31.8\%, B 15.1\%; found: Zr 31.7\%, B 15.4\%) and ${ }^{1} \mathrm{H}-\mathrm{NMR}$. Figure 74 shows the ${ }^{1} \mathrm{H}-\mathrm{NMR}$ spectrum (both ${ }^{11} \mathrm{~B}$-coupled and decoupled) of $\mathrm{Zr}\left(\mathrm{BH}_{4}\right)_{4}=8 \mathrm{NH}_{3}$ in DMSO-D ${ }_{6}$. The integration of the resonances indicated the presence of two types of $\mathrm{BH}_{4}$ groups in a three ( $\delta-0.5$ to $\left.0.3 \mathrm{ppm},\right)$ : one ( $\delta 1$ to $2 \mathrm{ppm}$ ) ratio as well as three types of ammonia $\left(16 \mathrm{BH}_{4}\right.$ protons and $24 \mathrm{NH}_{3}$ protons). 


\section{Solution Based Processing}

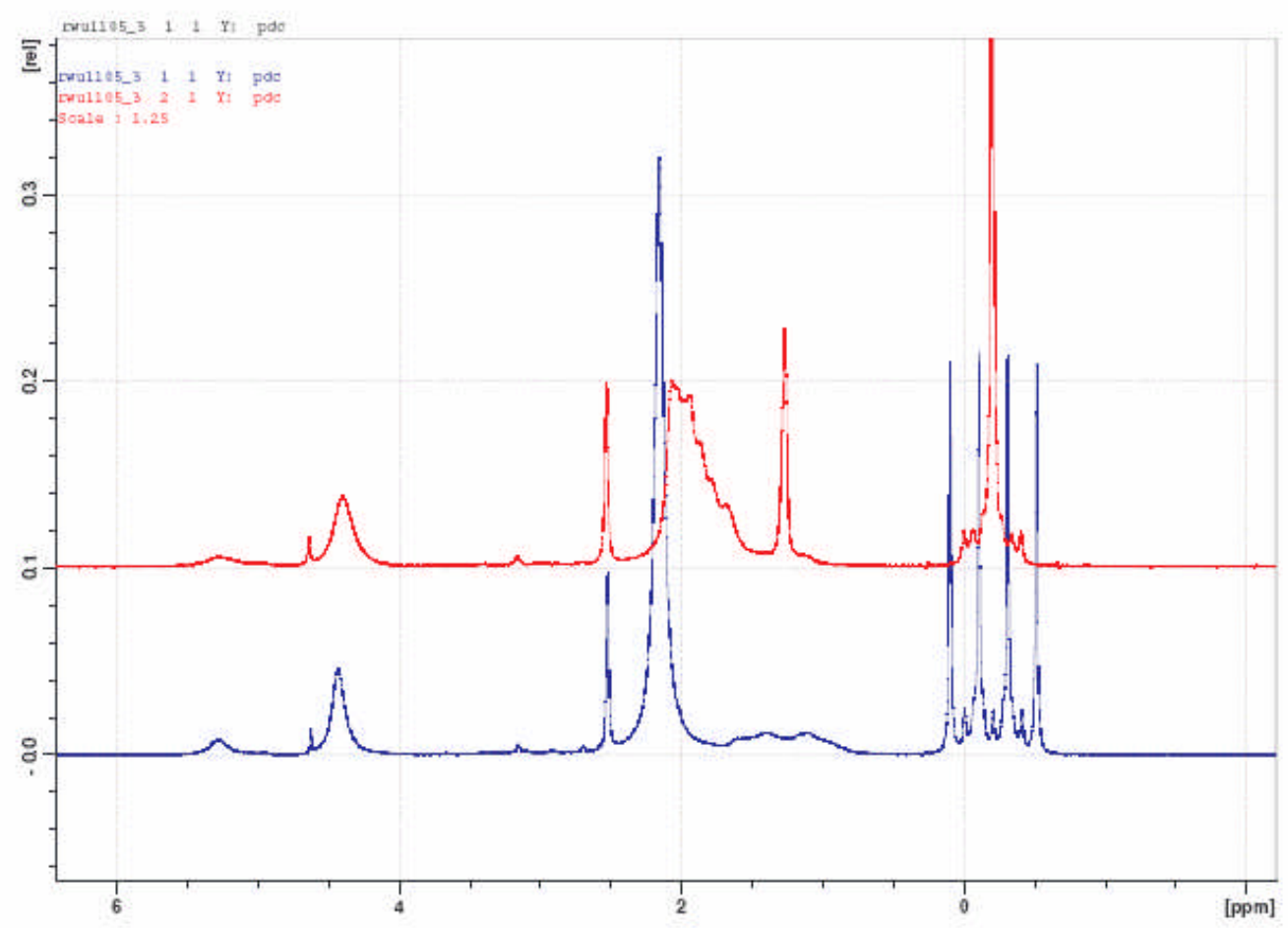

Figure 74: ${ }^{11} \mathrm{~B}$ Decoupled (red / upper) and coupled (blue / lower) spectra of $\mathrm{Zr}\left(\mathrm{BH}_{4}\right)_{4}=8 \mathrm{NH}_{3}$.

The XRD pattern of $\mathrm{Zr}\left(\mathrm{BH}_{4}\right)_{4} \cdot 8 \mathrm{NH}_{3}$ is shown in Figure 75 .

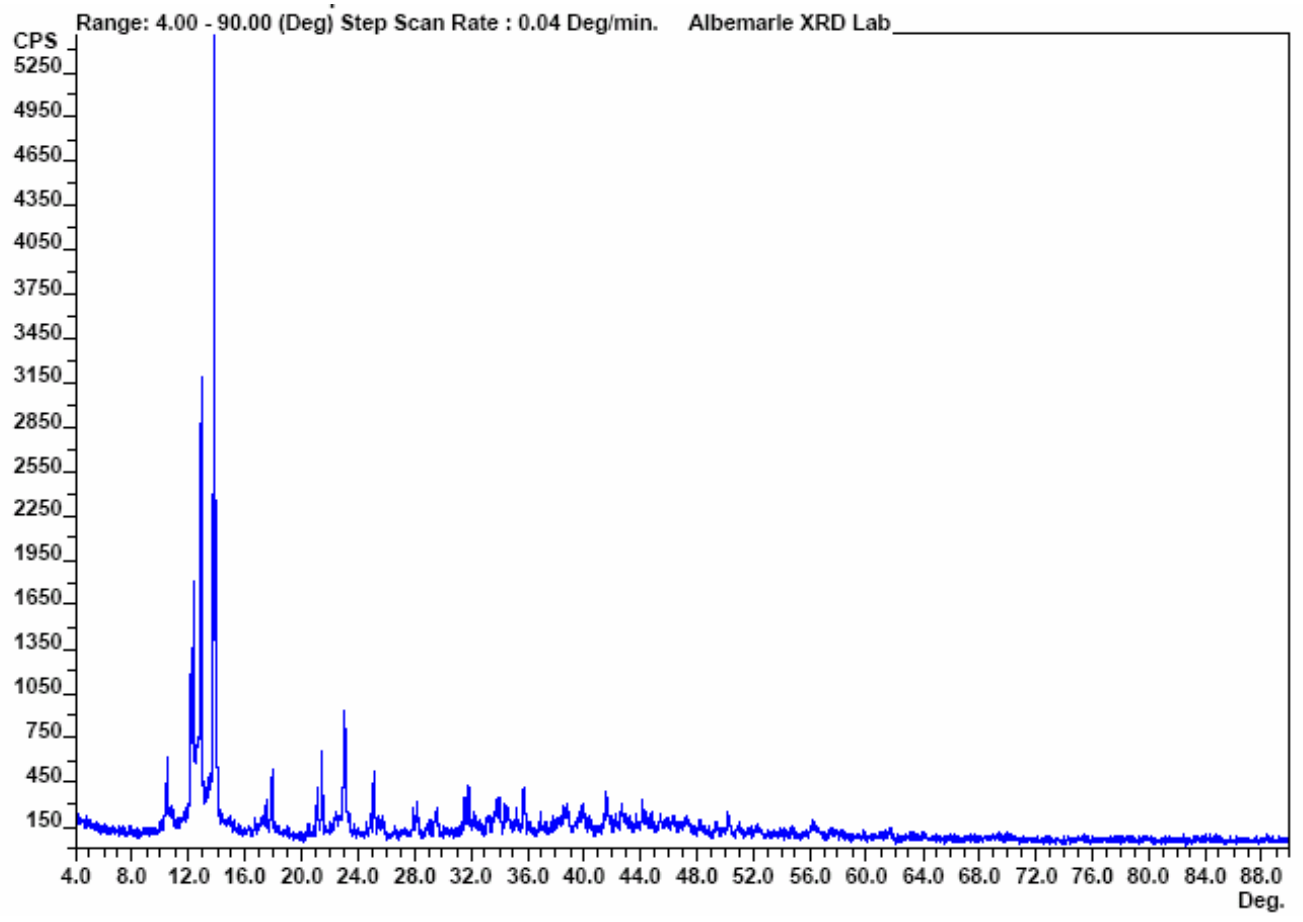

Figure 75: XRD pattern of $\mathrm{Zr}\left(\mathrm{BH}_{4}\right)_{4}=8 \mathrm{NH}_{3}$. 


\section{Solution Based Processing}

The DSC and TGA-DTA of this complex are shown in Figure 76 and Figure 77, respectively. The DSC shows a single exotherm at $147^{\circ} \mathrm{C}$ with a heat release of $286 \mathrm{~kJ} / \mathrm{mol}$. Such a heat release is much larger than the $70.3 \mathrm{~kJ} / \mathrm{mol}$ in $\mathrm{Mg}\left(\mathrm{NH}_{3}\right)_{2}\left(\mathrm{BH}_{4}\right)_{2}$. Assuming both complexes operating via the same $\mathrm{NH}_{3} \bullet \mathrm{BH}_{3}$-like mechanism, the $\mathrm{Zr}$ complex must have a much more complete hydrogen discharge than the $\mathrm{Mg}$ complex. The $34 \%$ weight loss in the TGA at around the same temperature could be accounted for by a combined loss of 4 ammonias (24\%) and 28 hydrogens (10\%). A small endotherm at $100-110^{\circ} \mathrm{C}$ suggests dissociation and evaporation of ammonia.

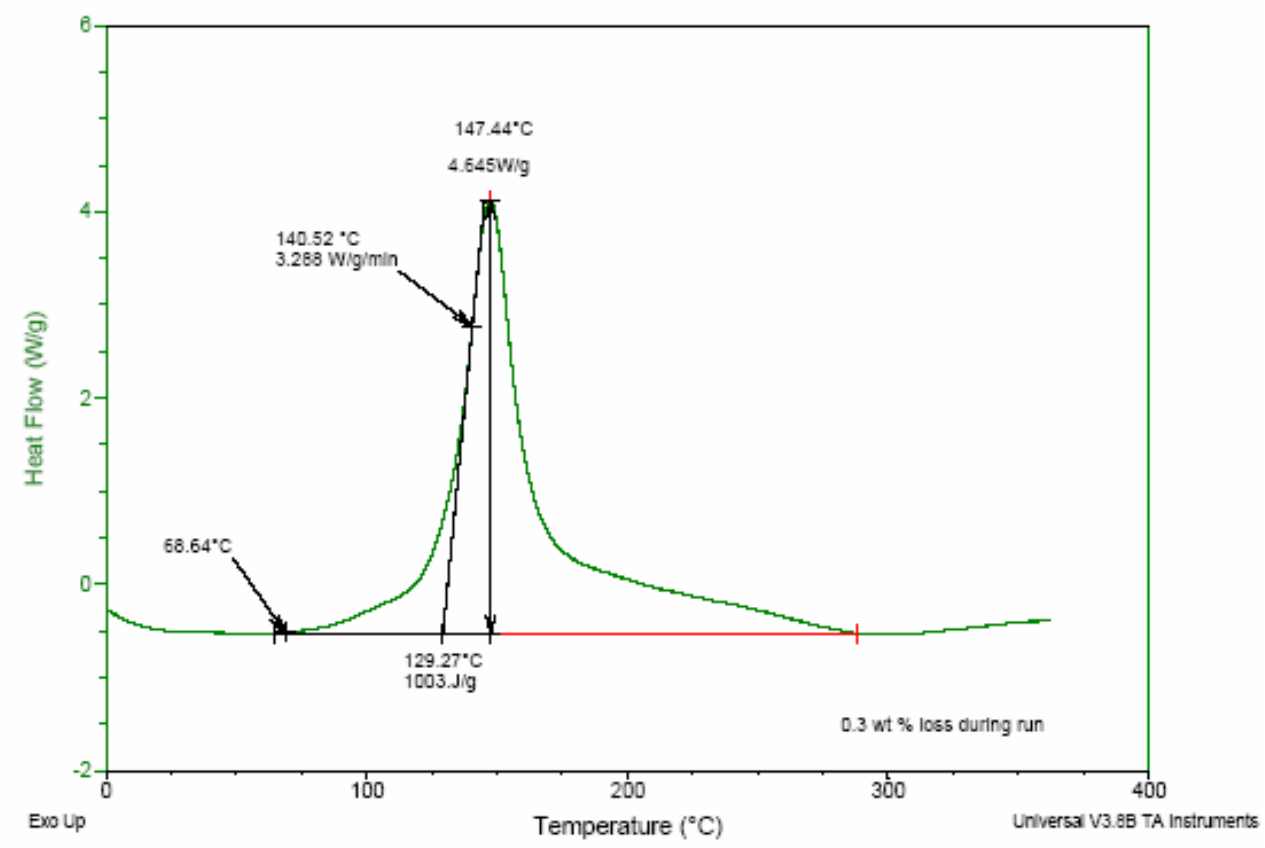

Figure 76: $\mathrm{DSC}$ of of $\mathrm{Zr}\left(\mathrm{BH}_{4}\right)_{4} \bullet 8 \mathrm{NH}_{3}$.

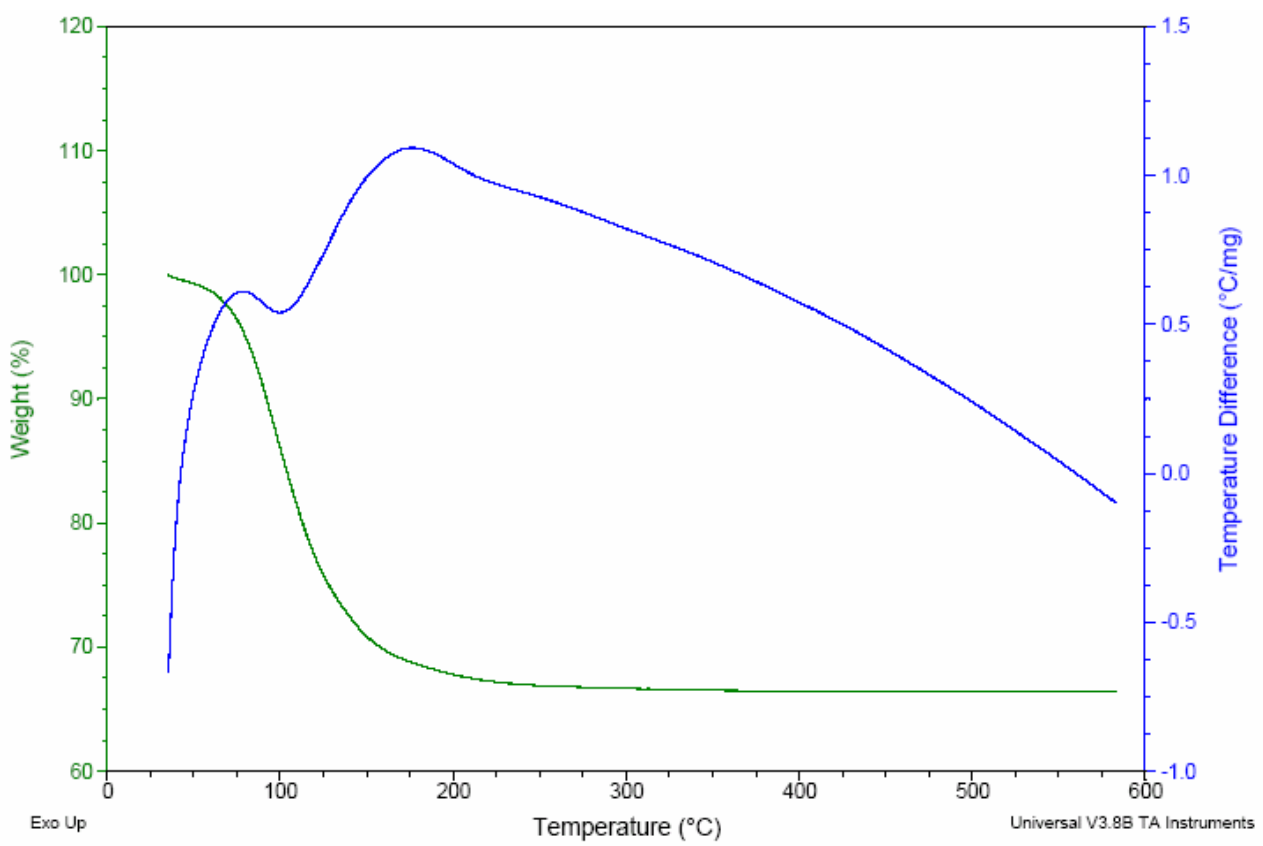

Figure 77: TGA-DTA of $\mathrm{Zr}\left(\mathrm{BH}_{4}\right)_{4} \bullet 8 \mathrm{NH}_{3}$. 


\section{Solution Based Processing}

\subsection{Complex 6: $\mathrm{Zr}\left(\mathrm{BH}_{4}\right)_{4}\left(\mathrm{H}_{2} \mathrm{NC}_{2} \mathrm{H}_{4} \mathrm{NH}_{2}\right)_{2}$}

The TGA analysis of $\mathrm{Zr}\left(\mathrm{BH}_{4}\right)_{4}=8 \mathrm{NH}_{3}$ indicates four out of eight ammonia molecules are "loose", which can present a hazard to the PEM fuel cell. To address this problem, we opted to use the less volatile ethylenediamine $\left(\mathrm{ED}, \mathrm{bp} 118^{\circ} \mathrm{C}\right)$ in place of ammonia. Thus, reaction of $\mathrm{Zr}\left(\mathrm{BH}_{4}\right)_{4}$ with two equivalents of $\mathrm{ED}$ in $\mathrm{Et}_{2} \mathrm{O}$ resulted in an instant precipitation of a white solid with an empirical formula of $\mathrm{Zr}\left(\mathrm{BH}_{4}\right)_{4}(\mathrm{ED})_{2.5}$ (ICP: $\mathrm{Zr}=30.2 \%$; $\left.\mathrm{B}=14.7 \%\right)$. The material is apparently a mixture of coordination complexes $\mathrm{Zr}\left(\mathrm{BH}_{4}\right)_{4}(\mathrm{ED})_{\mathrm{x}}$, where $\mathrm{x}=1$,2,3..etc. The starting complex, $\mathrm{Zr}\left(\mathrm{BH}_{4}\right)_{4}$, is absent since it is highly soluble in $\mathrm{Et}_{2} \mathrm{O}$ and would have been removed by filtration. The $\mathrm{H}^{1}$-NMR of the material in DMSO showed two types of $\mathrm{BH}_{4}{ }^{-}$anion and a myriad of resonances assignable to $\mathrm{N}-\mathrm{H}$. A small amount of solvent $\mathrm{Et}_{2} \mathrm{O}$ was also detected $(<1 \mathrm{wt} \%)$, which cannot be removed by vacuum drying at room temperature. In contrast, there is no coordinated $\mathrm{Et}_{2} \mathrm{O}$ detected in $\mathrm{Zr}\left(\mathrm{BH}_{4}\right)_{4} \cdot 8 \mathrm{NH}_{3}$.

The thermal analyses results of the ethylenediamine complex are shown in Figure 78 and Figure 79. The DSC (Figure 78) shows at least three exothermic peaks at temperatures below $225^{\circ} \mathrm{C}$ with an onset temperature of $86^{\circ} \mathrm{C}$. The size of the total exotherm, $261.5 \mathrm{~J} / \mathrm{g}$, is roughly a quarter of that for $\mathrm{Zr}\left(\mathrm{BH}_{4}\right)_{4} \bullet 8 \mathrm{NH}_{3}$. This reduced exotherm is beneficial in thermal management and should in principle render more favorable thermodynamics. At temperatures of $>225^{\circ} \mathrm{C}$, some additional exothermic events of unknown nature begin to occur.

The ethylenediamine complex, $\mathrm{Zr}\left(\mathrm{BH}_{4}\right)_{4}(\mathrm{ED})_{2.5}$, has a maximum hydrogen content of $8.7 \mathrm{wt} \%$ consistent with the TGA results (Figure 79) which shows a weight loss of about 7.5 wt\% at temperatures up to $238^{\circ} \mathrm{C}$. Further weight loss occurs as the temperature is increased. Again, the nature of this high temperature phenomenon is unknown at this time. Throughout the temperature range, the weight loss follows a gradual profile which is consistent with $\mathrm{Zr}\left(\mathrm{BH}_{4}\right)_{4}(\mathrm{ED})_{2.5}$ being a mixture as discussed earlier.

Ethylenediamine complexes, $\mathrm{Zr}\left(\mathrm{BH}_{4}\right)_{4}(\mathrm{ED})_{\mathrm{x}}$ where $\mathrm{x}$ is 2.1 or 3.7 , have also been synthesized. Unfortunately, none of these complexes show reversible hydrogen discharge/re-charge under practical real-world conditions. 


\section{Solution Based Processing}

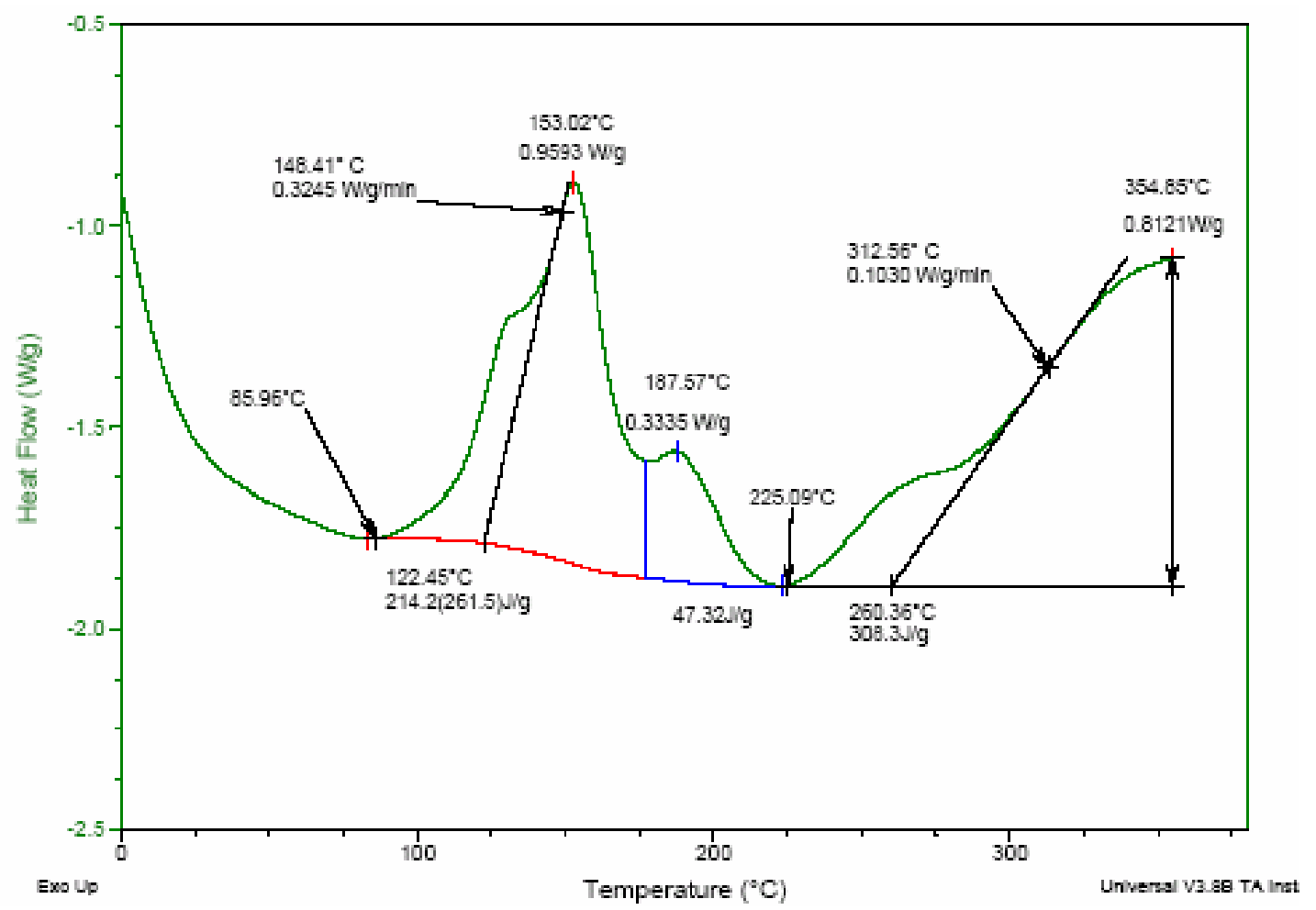

Figure 78: DSC of of $\mathrm{Zr}\left(\mathrm{BH}_{4}\right)_{4}(\mathrm{ED})_{2.5}$.

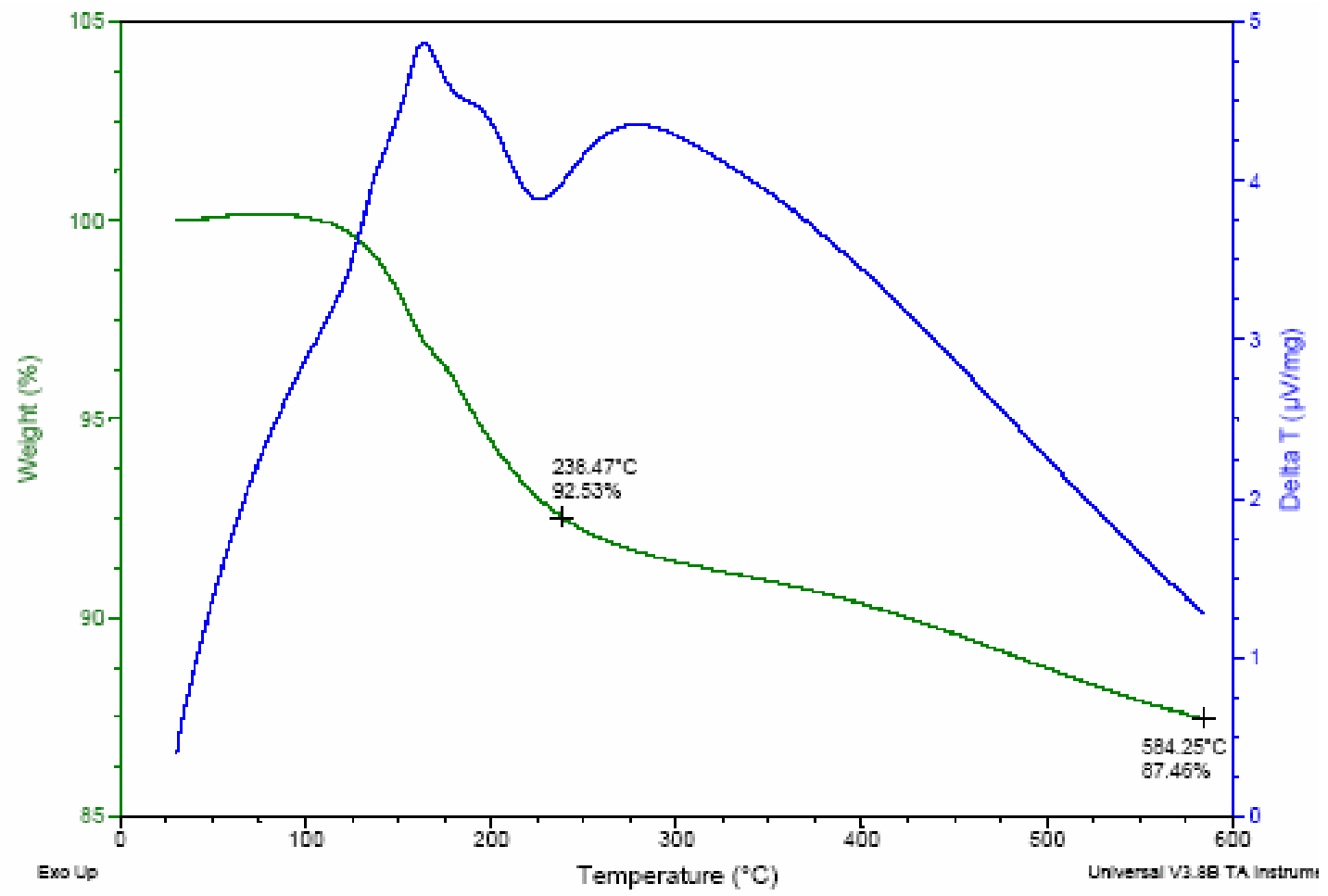

Figure 79: TGA-DTA of $\mathrm{Zr}\left(\mathrm{BH}_{4}\right)_{4}(\mathrm{ED})_{2.5}$. 


\section{Solution Based Processing}

\subsection{Complex 7: $\mathrm{NaTi}\left(\mathrm{BH}_{4}\right)_{4}\left(\mathrm{NH}_{3}\right)_{6}$}

In preparing the titanium analog of $\mathrm{Zr}\left(\mathrm{BH}_{4}\right)_{4}\left(\mathrm{NH}_{3}\right)_{8}$, we encountered a number of obstacles. First, the known precursor complex, $\mathrm{Ti}\left(\mathrm{BH}_{4}\right)_{3} \cdot{ }^{\circ} \mathrm{Et}_{2} \mathrm{O}$, unlike $\mathrm{Zr}\left(\mathrm{BH}_{4}\right)_{4}$, is thermally unstable (at $>-20^{\circ} \mathrm{C}$ ) and appears to be sensitive to nitrogen as well. Additionally, $\mathrm{Ti}\left(\mathrm{BH}_{4}\right)_{3}{ }^{\circ} \mathrm{Et}_{2} \mathrm{O}$ is also much less distillable than $\mathrm{Zr}\left(\mathrm{BH}_{4}\right)_{4}$, thus making the literature preparation method rather impractical. We noticed from the literature that the 1,2-dimethoxyether (DME) complex of $\mathrm{Ti}\left(\mathrm{BH}_{4}\right)_{3}$, prepared by $\mathrm{Ti}\left(\mathrm{BH}_{4}\right)_{3}{ }^{\circ} \mathrm{Et}_{2} \mathrm{O}+$ DME, is much more thermally stable. We have thus designed a modified synthesis of $\mathrm{Ti}\left(\mathrm{BH}_{4}\right)_{3} \cdot \mathrm{DME}$ using $\mathrm{NaBH}_{4}$ instead of $\mathrm{LiBH}_{4}$ and DME as the solvent instead of $\mathrm{Et}_{2} \mathrm{O}$. The modified method requires no distillation of the product, and its product is indeed thermally stable at room temperature for at least a couple of days. We proceeded to prepare its corresponding ammonia complex. The product from the ammonia reaction is a purple solid and appeared to be thermally stable at room temperature as well. Its $\mathrm{H}^{1}$-NMR in DMSO reveals the absence of DME and is strikingly similarly to that of $\mathrm{Zr}\left(\mathrm{BH}_{4}\right)_{4} \bullet 8 \mathrm{NH}_{3}$. Surprisingly, the ICP analysis suggested the isolated purple material was an ionic compound, $\mathrm{NaTi}\left(\mathrm{BH}_{4}\right)_{4} \cdot\left(\mathrm{NH}_{3}\right)_{6}$ (ICP: $\mathrm{Na} 9.81 \%$; Ti $21.1 \%$; B 19.6\%).

Equation $38 \mathrm{TiCl}_{4}(\mathrm{DME})+5 \mathrm{NaBH}_{4} \rightarrow \mathrm{NaTi}\left(\mathrm{BH}_{4}\right)_{4} \cdot \mathrm{DME}+4 \mathrm{NaCl}+\mathrm{BH}_{3} / \mathrm{H}_{2} \uparrow$

Equation $39 \quad \mathrm{NaTi}\left(\mathrm{BH}_{4}\right)_{4} \cdot \mathrm{DME}+\mathrm{NH}_{3}($ excess $) \longrightarrow \mathrm{NaTi}\left(\mathrm{BH}_{4}\right)_{4}\left(\mathrm{NH}_{3}\right)_{6}$

The thermal analyses results of $\mathrm{NaTi}\left(\mathrm{BH}_{4}\right)_{4}\left(\mathrm{NH}_{3}\right)_{6}$ are shown in Figure 80 and Figure 81. The DSC of this titanium compound (Figure 80) is strikingly similar to that of $\mathrm{Zr}\left(\mathrm{BH}_{4}\right)_{4}\left(\mathrm{NH}_{3}\right)_{8}$, showing one single exotherm peaking at $\sim 170^{\circ} \mathrm{C}$. Figure 82 shows the overlay of the two DSC data sets. It is interesting that the titanium complex is slightly more stable thermally than the zirconium complex in the closed DSC system, undoubtedly due to the ionic nature of the Ti complex versus the neutral $\mathrm{Zr}$ complex. The exotherm amounts to $220 \mathrm{~kJ} / \mathrm{mol}$, compared to $286 \mathrm{KJ} / \mathrm{mol}$ for $\mathrm{Zr}\left(\mathrm{BH}_{4}\right)_{4}\left(\mathrm{NH}_{3}\right)_{8}$.

The TGA-DTA for $\mathrm{NaTi}\left(\mathrm{BH}_{4}\right)_{4}\left(\mathrm{NH}_{3}\right)_{6}$ (Figure 81) shows a weight loss of 32\%, indicating about 3 ammonias out of 6 that are loosely bound as has previously been observed in $\mathrm{Zr}\left(\mathrm{BH}_{4}\right)_{4}\left(\mathrm{NH}_{3}\right)_{8}$. Interestingly, the weight loss is accompanied by an endotherm, not exotherm, as shown by the DTA graph. This strongly suggests the hydrogen discharge pathway of $\mathrm{NaTi}\left(\mathrm{BH}_{4}\right)_{4}\left(\mathrm{NH}_{3}\right)_{6}$ in an open system such as TGA is less $\mathrm{NH}_{3} \mathrm{BH}_{3}$-like (known to decompose exothermically) and more like $\mathrm{NaTi}\left(\mathrm{BH}_{4}\right)_{4}$ whose decomposition, like most of the metal hydrides, is endothermic. 


\section{Solution Based Processing}

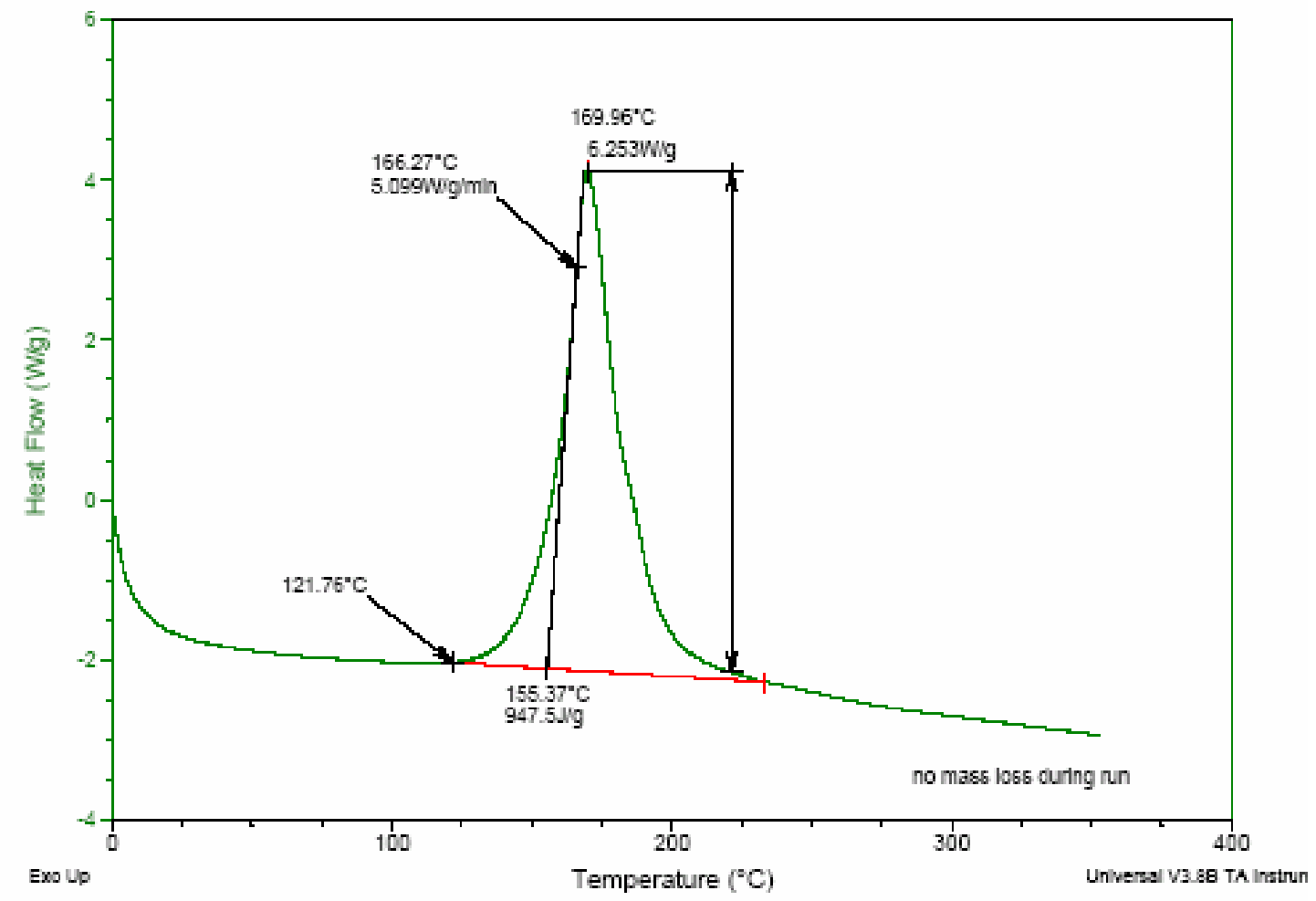

Figure 80: DSC of $\mathrm{NaTi}\left(\mathrm{BH}_{4}\right)_{4}\left(\mathrm{NH}_{3}\right)_{6}$.

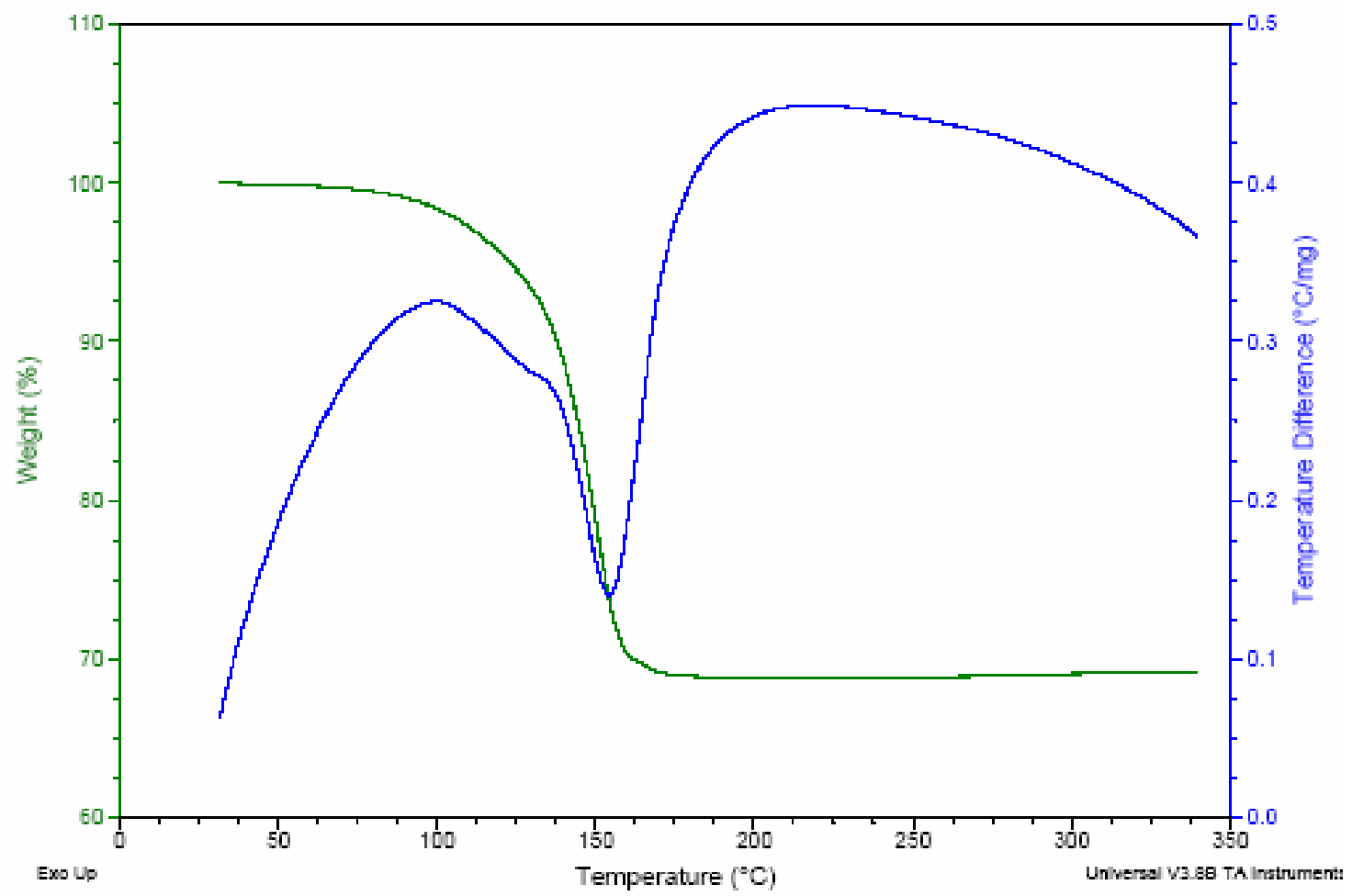

Figure 81: TGA-DTA of $\mathrm{NaTi}\left(\mathrm{BH}_{4}\right)_{4}\left(\mathrm{NH}_{3}\right)_{6}$. 


\section{Solution Based Processing}

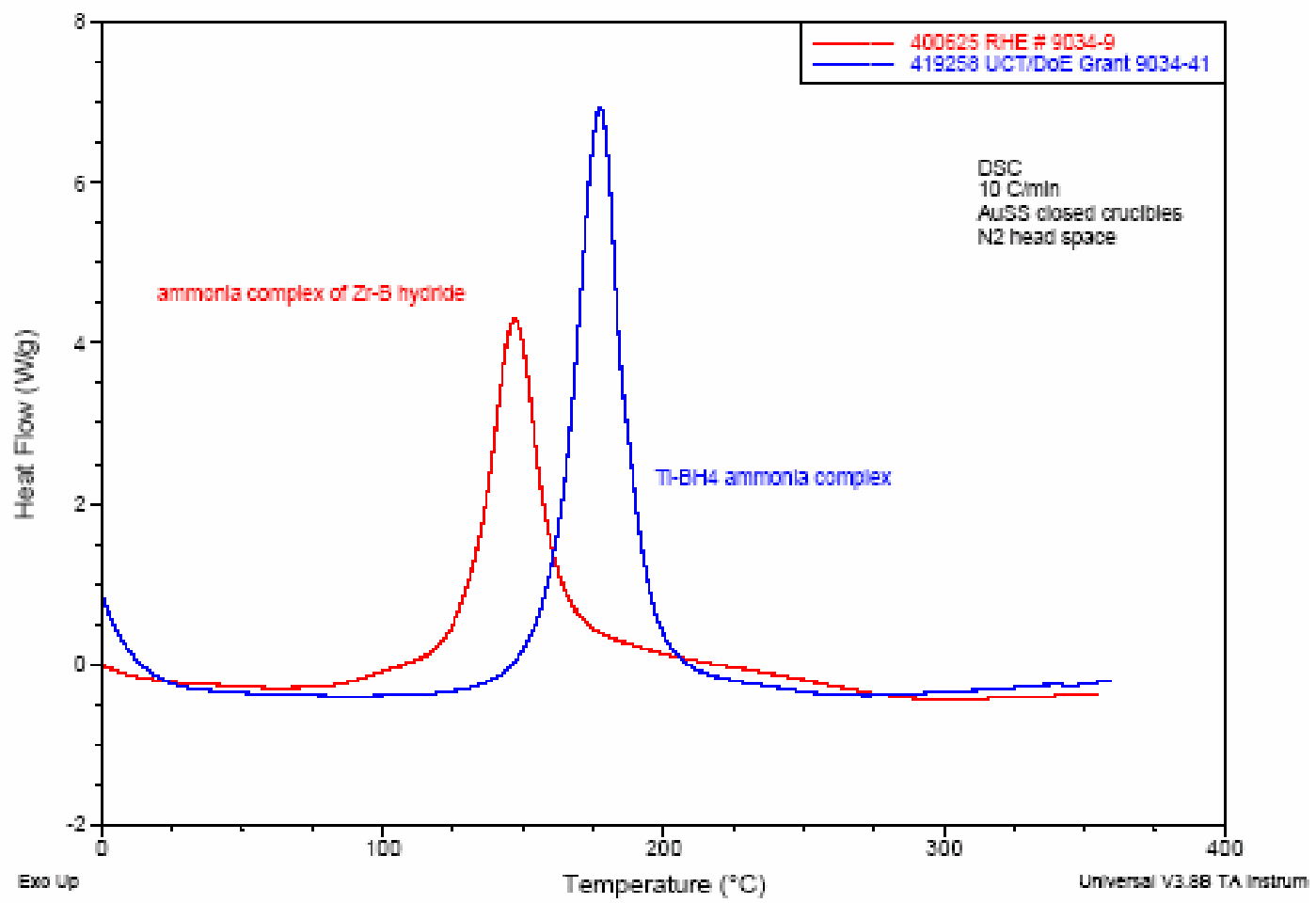

Figure 82: Overlay of DSC data for $\mathrm{Zr}\left(\mathrm{BH}_{4}\right)_{4}\left(\mathrm{NH}_{3}\right)_{8}$ (red / left peak) and $\mathrm{NaTi}\left(\mathrm{BH}_{4}\right)_{4}\left(\mathrm{NH}_{3}\right)_{6}$ (blue / right peak).

\subsection{Complex 8: $\mathrm{NaTi}\left(\mathrm{BH}_{4}\right)_{4} \mathrm{DME}(\mathrm{DME}=1,2$-dimethoxyethane $)$}

The reaction of $\mathrm{TiCl}_{4}$ and $\mathrm{NaBH}_{4}$ in $\mathrm{DME}$ first produces $\mathrm{NaTi}\left(\mathrm{BH}_{4}\right)_{4}(\mathrm{DME})_{3}$ which can be easily converted to $\mathrm{NaTi}\left(\mathrm{BH}_{4}\right)_{4} \mathrm{DME}$ by applying vacuum at room temperature. The yield was nearly quantitative. During the reaction, the titanium center was reduced from an oxidation state of VI to III. The tri-DME complex is known [Ref. 73], whereas the mono-DME complex has not been previously reported. The $\mathrm{NaTi}\left(\mathrm{BH}_{4}\right)_{4} \cdot \mathrm{DME}$ is a blue compound, containing $7.3 \mathrm{wt} \%$ of $\mathrm{B}-\mathrm{H}$ hydrogen. It is unstable at room temperature and slowly decomposes into a dark gray compound.

The thermal analyses of $\mathrm{NaTi}\left(\mathrm{BH}_{4}\right)_{4}{ }^{\circ} \mathrm{DME}$ produced the results of Figure 83 and Figure 84 below. The DSC shows an initial endotherm at $\sim 100^{\circ} \mathrm{C}$ immediately followed by two exotherms at $\sim 110^{\circ} \mathrm{C}$. The endotherm is likely due to evaporation of DME and/or hydrogen discharge. The occurrence of endotherms that immediately follow is interesting. It is speculated that it arises from re-coordination of $\mathrm{DME}$ to the $\mathrm{Ti}$ or $\mathrm{B}$ center after hydrogen discharge. If true, the intermediates have apparently been stabilized (thus, endothermic) by the presence of DME. There is another big exotherm at $>200^{\circ} \mathrm{C}$. The TGA-DTA shows a weight loss of about 44\%, consistent with loss of the DME ligand ( 41\%) and some hydrogen. The DTA curve shows the weight loss being accompanied by an endotherm, typical of a metal hydride. 


\section{Solution Based Processing}

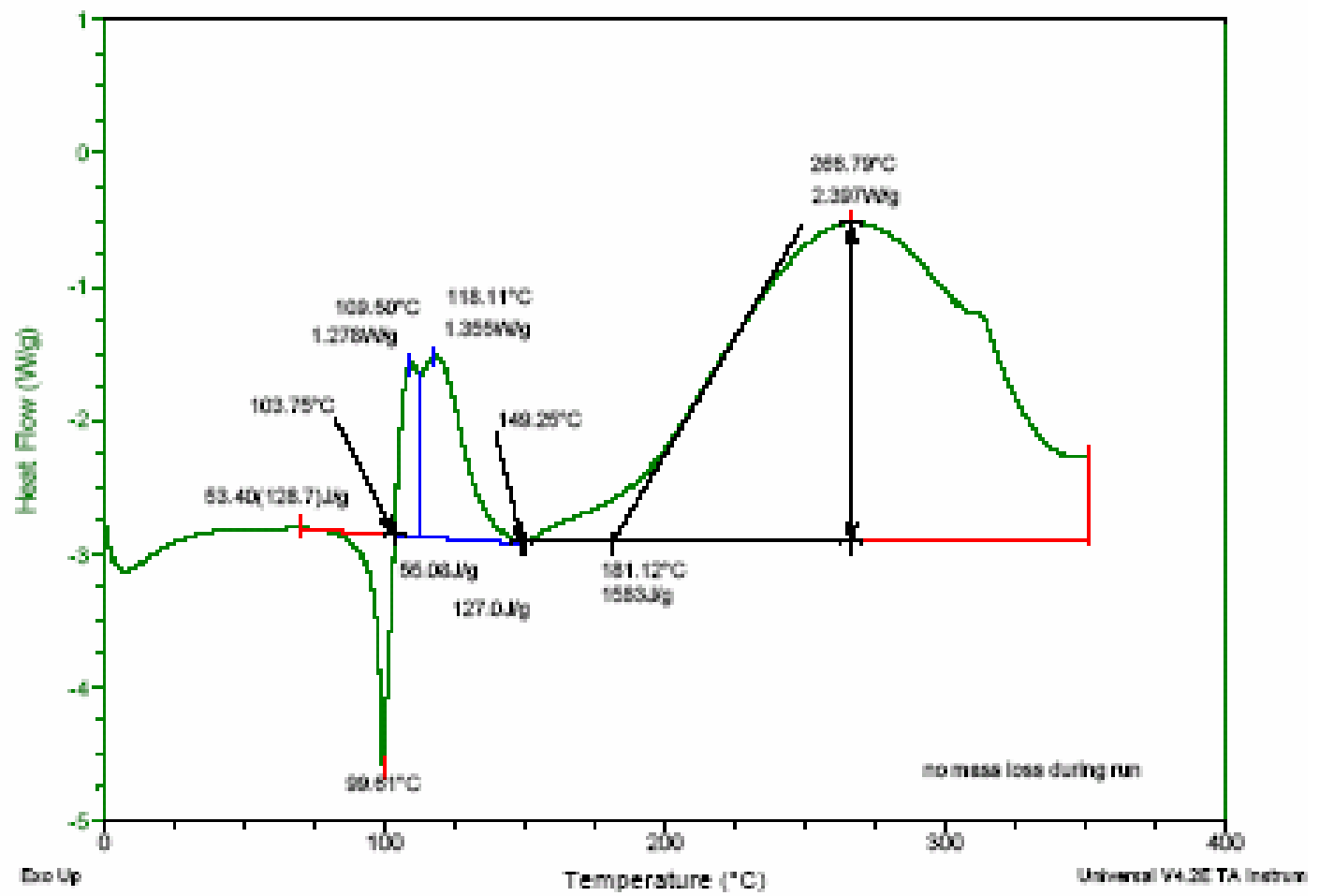

Figure 83: DSC of $\mathrm{NaTi}\left(\mathrm{BH}_{4}\right)_{4} \bullet \mathrm{DME}$.

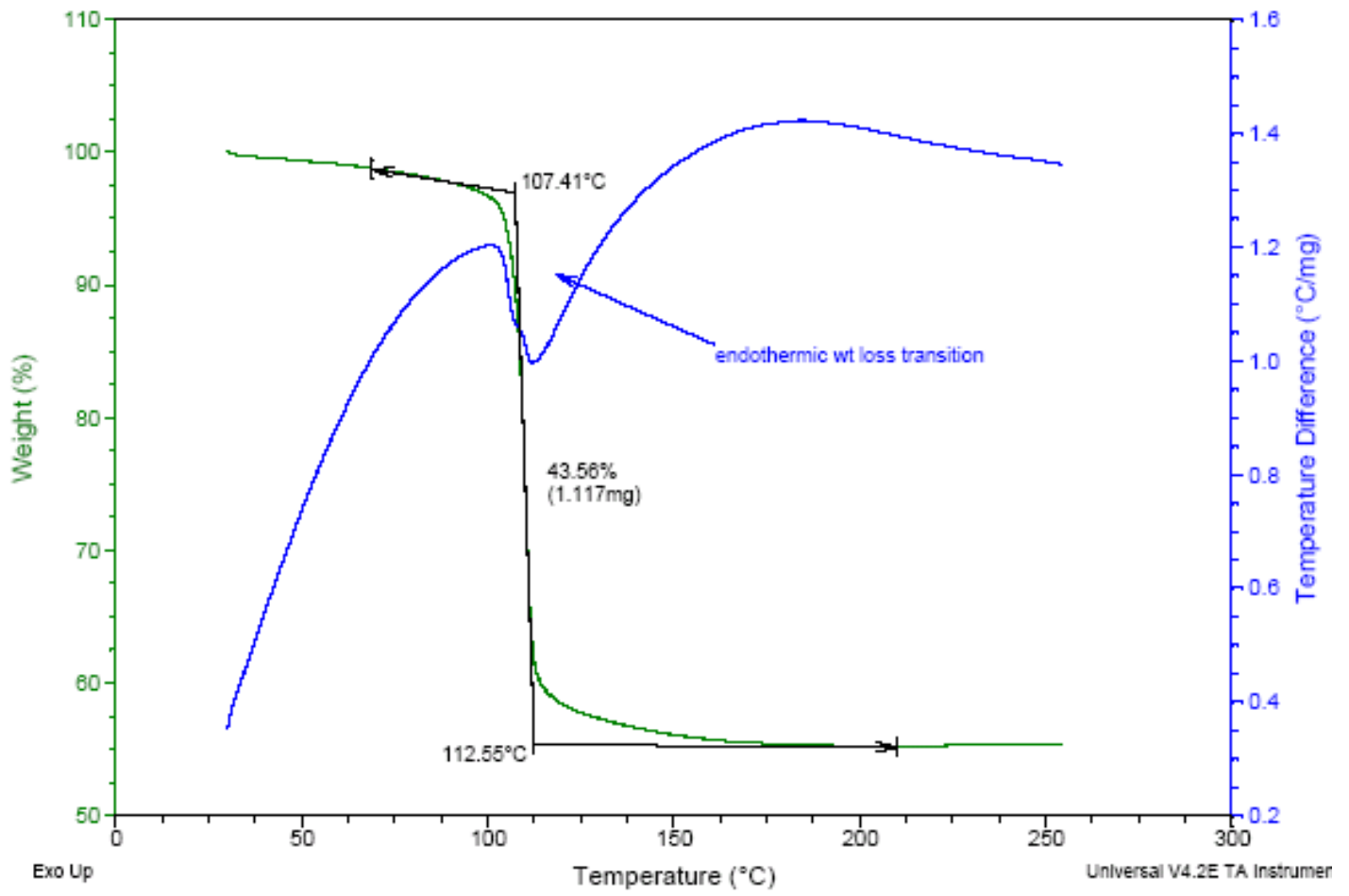

Figure 84: TGA-DTA of $\mathrm{NaTi}\left(\mathrm{BH}_{4}\right)_{4} \bullet \mathrm{DME}$. 


\section{Solution Based Processing}

To study the reversibility of hydrogen charge and discharge of $\mathrm{NaTi}\left(\mathrm{BH}_{4}\right)_{4} \cdot \mathrm{DME}$, we have successfully employed an analytical technique called DRIFTS (Diffuse Reflectance Infrared Fourier Transform Spectroscopy). This technique allows the sample to be mounted in a sealed cell under dry nitrogen. The IR-active frequencies in this complex include: $\mathrm{B}-\mathrm{H}$ frequencies at $2000-2500 \mathrm{~cm}^{-1}$ and $\mathrm{C}-\mathrm{H} / \mathrm{O}-\mathrm{C}$ frequencies at 2800-3000 and $800-1500 \mathrm{~cm}^{-1}$. Figure 85 below shows the three overlay DRIFTS spectra before and after hydrogen charge and discharge conditions. The following observations can be made from the spectra:

- The material after hydrogen discharge at $60^{\circ} \mathrm{C}$ changed color from blue to black but still contain some residual B-H absorbances, suggesting at least one of the four boron-hydrides still remains.

- The reverse reaction did indeed occur at temperatures as low as $20^{\circ} \mathrm{C}$, as evidenced by the increased B-H frequencies. This observed hydrogen recharge, however, is small compared to the original complex and the material remains black.

- The DME ligand is crucial for the reverse hydrogen reaction to occur. $\mathrm{NaTi}\left(\mathrm{BH}_{4}\right)_{4} \cdot \mathrm{DME}$ releases DME after hydrogen discharge. If DME were allowed to escape from the system, then the reverse reaction would not occur. Consistent with this observation, the overlay spectra show a direct correlation between DME and B-H absorbances: the more DME, the higher B-H absorbances.

Thus, the hydrogen sorption/desorption kinetics of $\mathrm{NaTi}\left(\mathrm{BH}_{4}\right)_{4} \cdot \mathrm{DME}$ is rather interesting. The DRIFTS study shows the complex is able to discharge most of its hydrogen at $60^{\circ} \mathrm{C}$, turning from blue to black, and recharge some of hydrogen back at a temperature as low as $20^{\circ} \mathrm{C}$. These observations suggest significant improvement from Ti-doped $\mathrm{LiBH}_{4}$, which requires $>350^{\circ} \mathrm{C}$ and $650^{\circ} \mathrm{C}$ for the respective reactions to occur [Ref. 74].

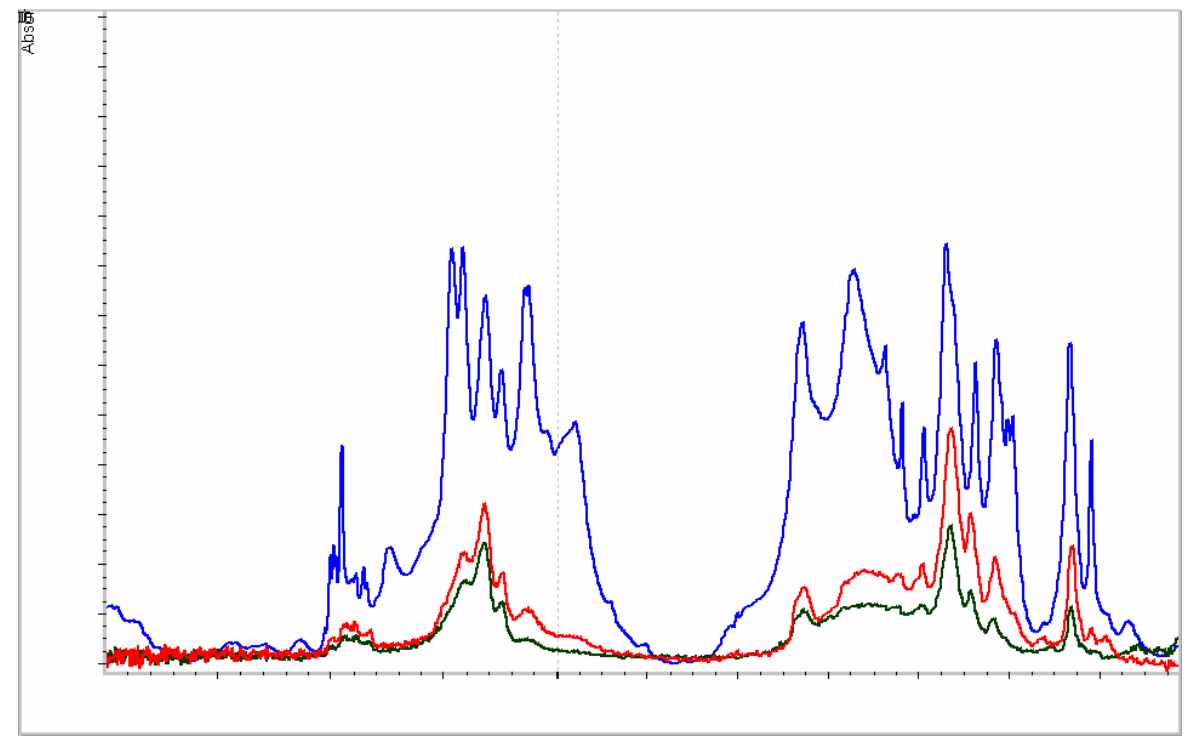

Figure 85: The overlay DRIFTS spectra of $\mathrm{NaTi}\left(\mathrm{BH}_{4}\right)_{4} \cdot \mathrm{DME}$ before and after hydrogen discharge; Top: $\mathrm{NaTi}\left(\mathrm{BH}_{4}\right)_{4} \cdot \mathrm{DME}$ before hydrogen discharge; Middle: after $60^{\circ} \mathrm{C}$ hydrogen discharge and $20^{\circ} \mathrm{C}$ recharge; Bottom: after $60^{\circ} \mathrm{C}$ hydrogen discharge. 


\section{Solution Based Processing}

\subsection{Complexes 9 and 10: $\mathrm{Na}_{2} \mathrm{O}\left[\mathrm{Ti}\left(\mathrm{BH}_{4}\right)_{4} \mathrm{DME}\right]_{2}$ and $\mathrm{NaOTi}\left(\mathrm{BH}_{4}\right)_{3} \mathrm{DME}$}

During the study of its hydrogen sorption/desorption kinetics, we found $\mathrm{NaTi}\left(\mathrm{BH}_{4}\right)_{4} \cdot \mathrm{DME}$ has the three following issues:

1. Thermally unstable at room temperature

2. DME reduces gravimetric $\mathrm{H} \%$

○ $\operatorname{NaTi}\left(\mathrm{BH}_{4}\right)_{4} \cdot \mathrm{DME}, 7.3 \% \mathrm{H}$

○ $\mathrm{NaTi}\left(\mathrm{BH}_{4}\right)_{4}, 12.4 \% \mathrm{H}$

3. $\operatorname{Ti}(\mathrm{III}) \leftrightarrow \operatorname{Ti}(0)$ or $\operatorname{Ti}(\mathrm{II})$ not reversible (a key challenge)

These three issues were addressed in this study, vide infra.

A key challenge of $\mathrm{NaTi}\left(\mathrm{BH}_{4}\right)_{4} \cdot \mathrm{DME}$ is the fact that the redox cycle of the titanium center is not reversible. While a completely reversible hydrogen sorption/desorption cycle dictates that the titanium center has a low barrier between various oxidation states, the current $\mathrm{Na} / \mathrm{Ti} / \mathrm{B} / \mathrm{H}$ system appears to favor the titanium center in the reduced state(s).

One strategy to coerce the titanium center to be more able to re-oxidize is to incorporate an oxide ligand into the $\mathrm{Na} / \mathrm{Ti} / \mathrm{B} / \mathrm{H}$ system. We choose to use water as a source of oxygen. Since a direct hydrolysis of $\mathrm{NaTi}\left(\mathrm{BH}_{4}\right)_{4}-\mathrm{DME}$ failed to yield the right products, we had to carry out a partial hydrolysis of $\mathrm{TiCl}_{4}(\mathrm{DME})$ which gives two oxy titanium chloride intermediates, depending on the hydrolysis ratio, as shown below. Table 17 summarizes the properties of these two intermediates along with $\mathrm{TiCl}_{4}(\mathrm{DME})$.

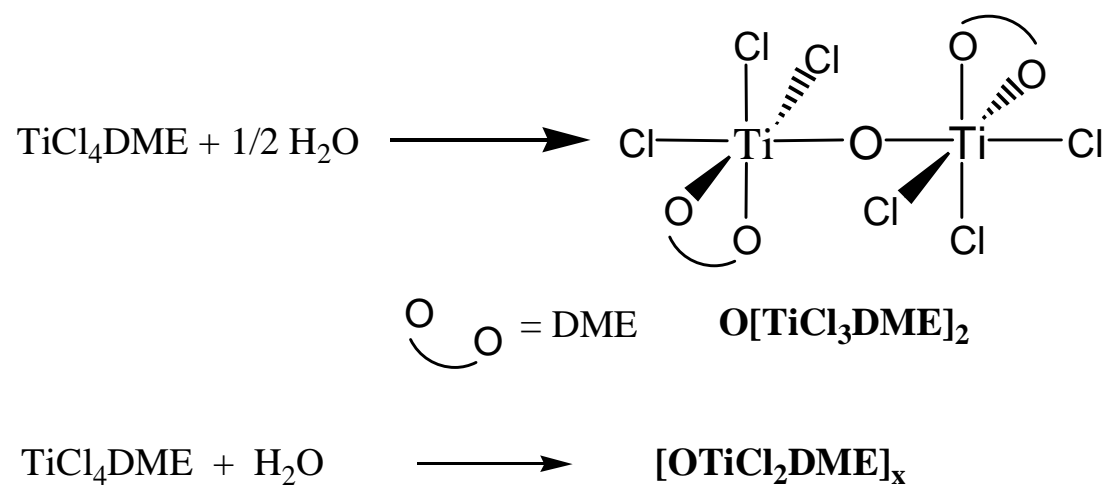

$x=2$ or higher

Table 17: Properties of oxy titanium chloride precursors.

\begin{tabular}{|c|c|c|c|}
\hline & $\mathbf{T i C l}_{\mathbf{4}}$ (DME) & $\left.\mathbf{O}_{\mathbf{T}} \mathbf{T i C l}_{\mathbf{6}} \mathbf{D M E}\right]_{\mathbf{2}}$ & {$\left[\mathbf{O T i C l}_{\mathbf{2}} \mathbf{D M E}\right]_{\mathbf{n}}$} \\
\hline O/Ti ratio & 0 & 0.5 & 1.0 \\
\hline Ti wt\% & $17.1 \%$ & $19.0 \%$ & $21.3 \%$ \\
\hline Color & Orange & Yellow & White \\
\hline Solubility in DME & High & Medium & Very low \\
\hline
\end{tabular}




\section{Solution Based Processing}

This hydrolysis reaction (1) produces the intended product $\mathrm{O}\left(\mathrm{TiCl}_{3} \mathrm{DME}\right)_{2}$ in $>90 \%$ yield (ICP: found $19.3 \% \mathrm{Ti}$; theory $19.0 \%)$. Three analogous compounds of the type, $(\mu-\mathrm{O})\left[\mathrm{TiCl}_{3} \mathrm{~L}\right]_{2}$ have been structurally characterized by single crystal X-ray determination: where $\mathrm{L}=\mathrm{MeSC}_{2} \mathrm{H}_{4} \mathrm{SMe}$ [Ref. 75] or two $\mathrm{Me}_{2} \mathrm{~S}$ [Ref. 76] or two THF [Ref. 77].

Reaction (2) in which one equivalent of water was added, also proceeded quite smoothly giving a white product with the indicated empirical formula in essentially quantitative yield. While being in excellent agreement with the ICP analysis, the $\left[\mathrm{OTiCl}_{2} \cdot \mathrm{DME}\right]_{\mathrm{x}}$ was likely a mixture of dimer, oligomers, or even polymers. The DME ligand in $\left[\mathrm{OTiCl}_{2} \cdot \mathrm{DME}\right]_{\mathrm{x}}$ cannot be removed with high vacuum at room temperature. At elevated temperatures, however, two transformations were observed. One was the anticipated evaporation of DME and the other was sublimation of some small amounts of yellow Ti-containing material. The yellow materials are likely to be low-oxygen, low molecular weight species such as $\mathrm{TiCl}_{4} \cdot \mathrm{DME}$ monomer or $\mathrm{O}\left[\mathrm{TiCl}_{3} \cdot \mathrm{DME}\right]_{2}$ dimer from reaction (1). These yellow species form during heating and are likely generated from some kind of disproportionation. At $100^{\circ} \mathrm{C}$, both transformations start to occur but at a very slow rate. At $130^{\circ} \mathrm{C}$, removal of DME was close to completion after just one and a half hours. The resulting white product lost roughly $8 \%$ of $\mathrm{Ti}$ via sublimation of the yellow species mentioned above. It should be noted that the attempt to remove $\mathrm{DME}$ in $\mathrm{O}\left[\mathrm{TiCl}_{3} \cdot \mathrm{DME}\right]_{2}$ under similar conditions resulted in sublimation of the dimer without loss of DME.

Thus, we have demonstrated that when a sufficient amount of oxide ligand was added to the quaternary $\mathrm{Na} / \mathrm{Ti} / \mathrm{B} / \mathrm{H}$ system, the bonding between the titanium center and the DME ligand was weakened and it is now possible to prepare DME-free $\left[\mathrm{OTiCl}_{2}\right]_{\mathrm{x}}$. The oxy titanium chloride, $\mathrm{OTiCl}_{2}$, is known in the literature. However, it was always made as an aqueous solution. To our knowledge, we have made the $\mathrm{OTiCl}_{2}$ in the anhydrous form for the first time. The anhydrous OTiCl$_{2}$ represents an interesting alternative dopant in the research of Ti-doped metal hydrides.

Table 18 summarizes the use of these oxy precursors for the preparations of their corresponding $\mathrm{BH}_{4}{ }^{-}$ complexes. In the subsequent reactions with $\mathrm{NaBH}_{4}$, these new oxo-bridged precursors immediately exhibit a markedly different behavior from that of $\mathrm{TiCl}_{4} \mathrm{DME}$. There was no reduction of $\mathrm{Ti}(\mathrm{IV})$ when treated with $\mathrm{NaBH}_{4}$. The titanium centers in complexes $\mathbf{9}$ and $\mathbf{1 0}$ remain as Ti(IV). Apparently, the oxo ligand renders the Ti(IV) center to be more resistant to reduction. This modification partially address the issue \#3, vide supra, and represents one step in the right direction in the rational design of the fully reversible hydrogen storage media based on Ti.

Another change that occurs in these oxide containing complexes is that both complexes $\mathbf{9}$ and $\mathbf{1 0}$ are now more thermally robust than $\mathrm{NaTi}\left(\mathrm{BH}_{4}\right)_{4} \cdot \mathrm{DME}$. Clearly, the introduction of the oxide ligand stabilizes the complexes and alleviates the issue \#1, vide supra.

As can be seen from Table 18, the yield of complex 10 was moderate (40-50\%). This is because the reaction in DME produced roughly a 50:50 DME soluble and insoluble composition, as shown in the scheme below. The soluble half was the DME-containing salt, $\mathrm{NaOTi}\left(\mathrm{BH}_{4}\right)_{3} \cdot \mathrm{DME}$. The insoluble part, on the other hand, was DME-free but co-precipitates with the by-product $\mathrm{NaCl}$, which was also insoluble in DME. It is not clear if the DME-free products were neutral $\mathrm{OTi}\left(\mathrm{BH}_{4}\right)_{2}$ or ionic $\mathrm{NaOTi}\left(\mathrm{BH}_{4}\right)_{3}$ or a combination of both. Thus, this was yet another sign of solvate-free yet thermally 


\section{Solution Based Processing}

robust complex being formed as a result of incorporating an oxide ligand. So far, the DME-free products have not been tested since the issue of their separation from $\mathrm{NaCl}$ has not been resolved.

Table 18: Comparison of reaction products $\mathrm{w} / \mathrm{NaBH}_{4}$.

\begin{tabular}{|c|c|c|c|}
\hline & $\mathrm{TiCl}_{4} \mathrm{DME}$ & $\mathrm{O}\left[\mathrm{TiCl}_{3} \mathrm{DME}\right]_{2}$ & {$\left[\mathrm{OTiCl}_{2} \mathrm{DME}\right]_{\mathrm{x}}$} \\
\hline O/Ti ratio & 0 & 0.5 & 1.0 \\
\hline $\begin{array}{c}\text { Isolated } \\
\text { products w/ } \\
\mathrm{NaBH}_{4} \\
\end{array}$ & $\operatorname{NaTi}\left(\mathrm{BH}_{4}\right)_{4} \mathrm{DME}$ & $\begin{array}{c}\mathrm{Na}_{2} \mathrm{O}\left[\mathrm{Ti}\left(\mathrm{BH}_{4}\right)_{4} \mathrm{DME}\right]_{2} \\
9\end{array}$ & $\begin{array}{c}{\left[\mathrm{NaOTi}\left(\mathrm{BH}_{4}\right)_{3} \mathrm{DME}\right]_{\mathrm{x}}} \\
\mathbf{1 0}\end{array}$ \\
\hline Isolated yields & $>95 \%$ & $70-80 \%$ & $40-50 \%$ \\
\hline $\begin{array}{c}\text { Oxidation state } \\
\text { of Ti }\end{array}$ & Ti(III) & $\operatorname{Ti}(\mathrm{IV})$ & $\mathrm{Ti}(\mathrm{IV})$ \\
\hline Stable at ${ }^{\circ} 5^{\circ} \mathrm{C}$ & No & Yes & Yes \\
\hline
\end{tabular}

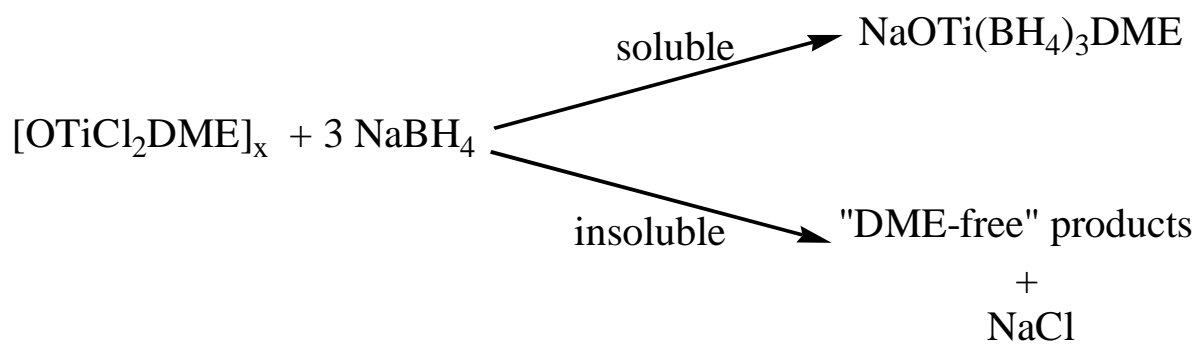

The complexes 9 and $\mathbf{1 0}$ were tested for both hydrogen discharge and recharge reactions. They both discharged hydrogen around $80^{\circ} \mathrm{C}$. Unfortunately, however, we have not found conditions up to $100^{\circ} \mathrm{C} / 1000$ psi in which hydrogen uptake is observed.

\subsection{Solution Based Processing Conclusions}

During the duration of the program we have synthesized seven novel organometallic complexes as possible reversible hydrogen storage candidates. In addition, three new oxy titanium precursors were also synthesized, including the anhydrous $\mathrm{OTiCl}_{2}$ as an interesting alternative dopant to $\mathrm{TiCl}_{3}$ commonly used. All of the new complexes discharge hydrogen at very mild temperatures, although none of them show full reversibility. A number of new concepts have been demonstrated, especially in the use of a coordinating ligand. Thus, ammonia, ethylenediamine, and DME have been used to stabilize the $\mathrm{BH}_{4}{ }^{-}$complexes of $\mathrm{Ti}$ and $\mathrm{Zr}$. On the other hand, $\mathrm{NH}_{3}$ and $\mathrm{NMe}_{3}$ appear to destabilize $\mathrm{Mg}\left(\mathrm{BH}_{4}\right)_{2}$ allowing it to release hydrogen at a much lower temperature. The latter is in our opinion particularly noteworthy and should be pursued further. 


\section{Molten State Processing}

\section{Molten State Processing}

\subsection{Overview}

The unique Molten State Processing (MSP) technique was developed and applied at the Savannah River National Laboratory (SRNL) to provide a wider range of temperatures and pressures in the search for novel storage compounds. These conditions promote high atomic mobility, in some cases enabling liquid state mixing of substitutional species and possible alteration of mixed metal alanate and other hydride stoichiometry. The SRNL MSP approach produces operating conditions that allow materials to interact and combine, leading to a higher potential for successful fusion over traditional ball milling and chemical processing techniques. In addition to the formation of new complexes, the process was found to enhance kinetics.

Structural characterization and physical property analyses were employed to identify newly synthesized complex hydride phases. X-ray diffraction and PCT system testing were the primary methods. The MSP apparatus developed is shown in Figure 86, with the central component being a high pressure, elevated temperature reactor vessel.

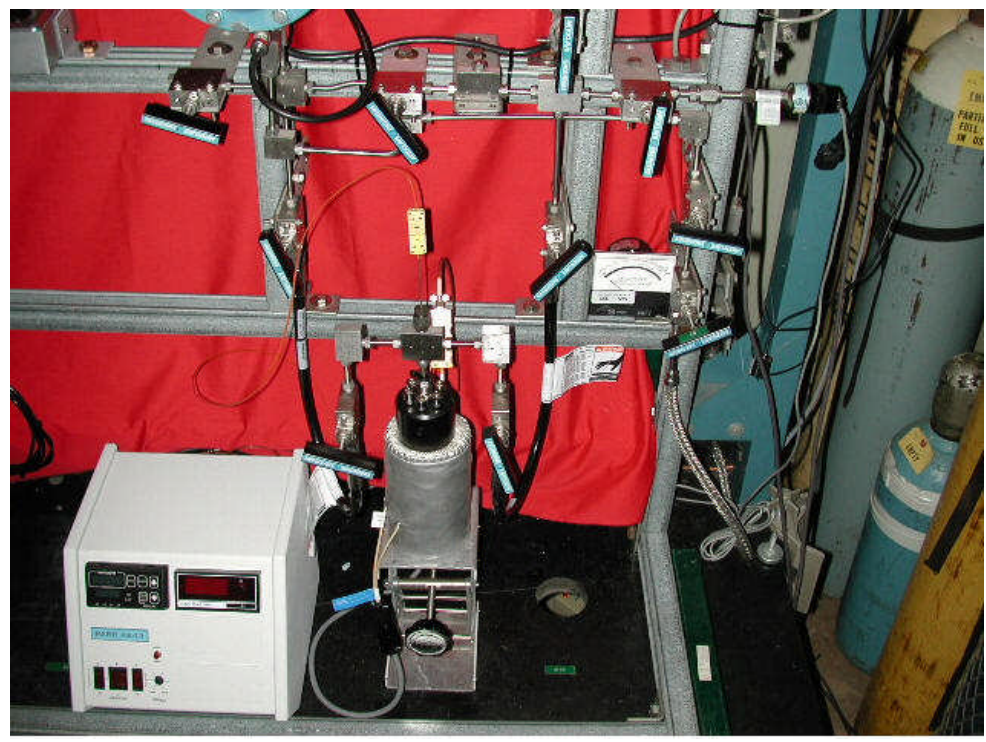

Figure 86: SRNL Molten State Processing apparatus.

Table 19 gives an overview for the majority of novel compositions examined in the effort. As previously discussed, the initial objective was to explore materials of the class, $\mathrm{Na}_{\mathrm{y}} \mathrm{M}_{+\mathrm{ix}}\left(\mathrm{AlH}_{4}\right)_{\mathrm{y}+\mathrm{ix}}$ based on $\mathrm{NaH}, \mathrm{AlH}_{3}$, transition metal or rare earth (M) hydrides. The pure transition metal alanates (e.g. $\mathrm{Ti}, \mathrm{Fe}, \mathrm{Mn}, \mathrm{Cu}, \ldots$...tc.), are only stable at very low temperatures. In the latter stages of the project, novel borohydrides were also examined using both MSP as well as limited solvent assisted synthesis at SRNL. The processing and characterization of the various material systems are described in more detail in the sections below. 


\section{Molten State Processing}

Table 19: Overview composition matrix for majority of MSP.

\begin{tabular}{|c|c|c|c|c|c|}
\hline Compounds & mol ratios & prep cond & MSP cond & BM Results & MSP Results \\
\hline MgCl2:LiBH4 & $1: 2$ & $\begin{array}{l}\text { Spex BM } 60 \text { min } \\
\text { THF }\end{array}$ & & $\mathrm{Mg}\left(\mathrm{BH}_{4}\right)_{2}(\mathrm{THF})_{3}$ & \\
\hline MgB2:LiBH4 & $1: 2$ & $\begin{array}{l}\text { Spex BM } 60 \mathrm{~min} \\
\text { THF }\end{array}$ & & $\begin{array}{l}\text { Extremely hard material stuck } \\
\text { To vial walls }\end{array}$ & \\
\hline MgB2:H2 100 psi & $1: \sim 0.1$ & Frit BM 60 min & & $\begin{array}{l}\mathrm{SM}+\mathrm{Mg}, \mathrm{MgO} \text {,(both in SM) } \\
\mathrm{NiCrFe}(\mathrm{rxn} \text { w/SS vessel) }\end{array}$ & \\
\hline MgB2:LiBH4:H2 100 psi & $3: 1: \sim 0.1$ & Frit BM 114 min & & $\mathrm{SM}+\mathrm{NiCrFe}(\mathrm{rxn}$ w/ss vessel) & \\
\hline MgB2:H2 100 psi & $1: \sim 0.1$ & Frit BM 114 min & & $\mathrm{SM}+\mathrm{NiCrFe}($ rxn w/ss vessel) & \\
\hline NaAlH4:LiAlH4:Cr & $1: 1: 1$ & Spex BM 60 min & $170-4500-2 \mathrm{~h}$ & $\mathrm{SM}+\mathrm{Al}$ & $\begin{array}{l}\text { LiNa2AlH6, NaAlH4, } \\
\text { Al, } \mathrm{Cr}, \mathrm{NaH} \text { ? }\end{array}$ \\
\hline NaAlH4:LiAlH4:Mn & 1:1:1 & Spex BM 60 min & $190-4500-2 h$ & $\mathrm{SM}+\mathrm{Al}$ & $\begin{array}{l}\text { LiNa2AlH6, Al, Mn, } \\
\mathrm{NaH} ?\end{array}$ \\
\hline NaAlH4:LiAlH4:Mn & 1:1:1 & Spex BM 60 min & $170-4500-2 \mathrm{~h}$ & $\mathrm{SM}+\mathrm{Al}$ & $\begin{array}{l}\text { LiNa2AlH6, Al, Mn, } \\
\text { NaH? }\end{array}$ \\
\hline NaAlH4:LiAlH4:MgH2:VHx & 1:1:1:1 & Spex BM 60 min & $170-4500-2 \mathrm{~h}$ & $\mathrm{SM}+\mathrm{Al}$ & $\begin{array}{l}\text { VH0.81, LiAlH4, MgH2, Al, } \\
\text { LiAn2AlH6, NaMgH3 }\end{array}$ \\
\hline NaAlH4:LiAlH4:MgH2:Cr & $1: 1: 1: 1$ & Spex BM 60 min & $170-4500-2 h$ & $\mathrm{SM}+\mathrm{Al}$ & $\begin{array}{l}\mathrm{MgH} 2, \mathrm{Al}, \mathrm{LiAn} 2 \mathrm{AlH} 6 \\
\mathrm{NaMgH} 3, \mathrm{Cr}, \mathrm{Al}, \mathrm{NaH} ?\end{array}$ \\
\hline NaAlH4:LiAlH4:MgH2:Cr & $1: 1: 1: 1$ & Spex BM 60 min & $60-4500-3 \mathrm{~h}$ & $\mathrm{SM}+\mathrm{Al}$ & $\mathrm{SM}+\mathrm{Al}, \mathrm{Li} 3 \mathrm{AlH} 6$ \\
\hline NaAlH4:LiAlH4:MgH2:Cr & $1: 1: 1: 1$ & cold ball mill & $60-4500-3 \mathrm{~h}$ & SM & $\mathrm{SM}+\mathrm{Al}, \mathrm{Li} 3 \mathrm{AlH} 6$ \\
\hline NaAlH4:LiAlH4:MgH2:Cr & 1:1:1:2 & Spex BM 60 min & & $\mathrm{SM}+\mathrm{Al}$ & \\
\hline NaAlH4:LiAlH4:MgH2:Cr & $1: 1: 1: 4$ & Spex BM 60 min & & $\begin{array}{l}\mathrm{NaAlH} 4, \mathrm{MgH} 2, \mathrm{Cr}, \\
\mathrm{Al}, \mathrm{Li} 3 \mathrm{AlH} 6\end{array}$ & \\
\hline NaAlH4:LiAlH4:MgH2:Cr & $1: 1: 2: 2$ & Spex BM 60 min & & $\mathrm{SM}+\mathrm{Al}$ & \\
\hline $\mathrm{NaAlH4}$ :LiAlH4:MgH2:Cr & $1: 1: 2: 1$ & Spex BM 60 min & & $\mathrm{SM}+\mathrm{Al}$ & \\
\hline NaAlH4:LiAlH4:MgH2:Mn & 1:1:1:1 & Spex BM 60 min & $170-4500-2 \mathrm{~h}$ & $\begin{array}{l}\text { MnH0.07!, NaAlH4, } \\
\mathrm{MgH} 2, \mathrm{LiAlH} 4, \mathrm{Al}\end{array}$ & $\begin{array}{l}\mathrm{MgH} 2, \mathrm{Al}, \mathrm{LiAn} 2 \mathrm{AlH} 6 \\
\mathrm{NaMgH} 3, \mathrm{Mn}, \mathrm{Al}, \mathrm{NaH} ?\end{array}$ \\
\hline $\mathrm{NaAlH} 4: \mathrm{VHx}$ & $1: 1$ & Spex BM 60 min & $190-4500-2 \mathrm{~h}$ & $\mathrm{n} / \mathrm{a}$ - outgasses & \\
\hline $\mathrm{NaAlH} 4: \mathrm{Cr}$ & $1: 1$ & Spex BM 60 min & 190-4500-2h & SM & $\mathrm{Na3AIH6,} \mathrm{NaAlH4,} \mathrm{Cr}$ \\
\hline NaAlH4:Mn & $1: 1$ & Spex BM 60 min & 190-4500-2h & SM & $\mathrm{SM}+\mathrm{Na} 3 \mathrm{AlH} 6$ \\
\hline LiAlH4:VHx & $1: 1$ & Spex BM 60 min & & & \\
\hline LiAlH4:Cr & $1: 1$ & Spex BM 60 min & $170 \mathrm{C} 2 \mathrm{~h}$ & $\mathrm{SM}+\mathrm{Al}$ & $\mathrm{SM}+\mathrm{Al}, \mathrm{Li} 3 \mathrm{AlH} 6$ \\
\hline LiAlH4:Mn & $1: 1$ & Spex BM 60 min & & $\mathrm{SM}+\mathrm{Al}$ & $\mathrm{Mn}, \mathrm{Al}$ \\
\hline LiAlH4:KH:TiCl3 & $1: 2: 0.04$ & BM 40 min & & $\begin{array}{l}\text { LiAlH4, KAlH4, } \\
\text { K3AlH6 }\end{array}$ & $\mathrm{KAlH} 4, \mathrm{~K} 3 \mathrm{AlH} 6, \mathrm{KCl}$ \\
\hline LiAlH4:MgH2:TiCl3 & 1:1:0.04 & BM 40 min & & $\begin{array}{l}\mathrm{MgH} 2, \mathrm{Li3AlH6}, \\
\mathrm{Al}, \mathrm{LiCl}, \mathrm{Mg}\end{array}$ & $\mathrm{MgH} 2, \mathrm{Al}, \mathrm{LiCl}$ \\
\hline LiAlH4:CaH2:TiCl3 & $1: 1: 0.04$ & BM 40 min & & SM, Li3AlH6, Al & $\mathrm{CaH} 2, \mathrm{Al}, \mathrm{LiCl}, \mathrm{LiH}$ \\
\hline LiAlH4:Mg2NiH4 & $1: 1$ & & & $\begin{array}{l}\mathrm{MgH} 2, \mathrm{Mg} 2 \mathrm{NiH} \\
\mathrm{Mg} 2 \mathrm{NiH} 0.3, \mathrm{Al} 1.1 \mathrm{Ni} 0.8\end{array}$ & \\
\hline $\mathrm{NaAlH} 4: \mathrm{Mg} 2 \mathrm{NiH} 4$ & $1: 1$ & & & $\begin{array}{l}\mathrm{SM}, \mathrm{NaMgH} 3 \\
\mathrm{Mg} 2 \mathrm{NiH} 0.3\end{array}$ & \\
\hline NaAlH4:Mg2NiH4:TiCl3 & $1: 1: 0.04$ & mortar pestle & & $\begin{array}{l}\mathrm{SM}, \mathrm{MgH} 2 \\
\mathrm{Mg} 2 \mathrm{NiH} 0.3\end{array}$ & \\
\hline NaAlH4:Mg2NiH4:TiCl3 & $1: 1: 0.04$ & BM 40 min & & $\begin{array}{l}\mathrm{SM}, \mathrm{Al}, \mathrm{NaMgH} 3 \\
\mathrm{Mg} 2 \mathrm{NiH} 0.26\end{array}$ & \\
\hline Mg2NiH4: $\mathrm{NaH}$ & $1: 1.2$ & mortar pestle & & $\mathrm{SM}, \mathrm{MgH} 2, \mathrm{Mg} 2 \mathrm{NiH} .26$ & \\
\hline Mg2NiH4:LiH & $1: 9.9$ & BM 40 min & & $\mathrm{SM}, \mathrm{MgH} 2, \mathrm{Mg} 2 \mathrm{NiH} .26$ & \\
\hline
\end{tabular}




\section{Molten State Processing}

\section{$6.2 \mathrm{Na}_{2} \mathrm{LiAlH}_{6}$}

Initial MSP development and application focused on the synthesis of known alanate compounds including $\mathrm{Na}_{2} \mathrm{LiAlH}_{6}$. Temperature Programmed Desorption (TPD) studies were conducted to assess hydrogen desorption kinetics of the MSP synthesized materials.

A stoichiometric mix of $\mathrm{NaAlH}_{4}$ and $\mathrm{LiH}$ designed to produce $\mathrm{Na}_{2} \mathrm{LiAlH}_{6}$ was prepared and placed in the high temperature $\backslash$ pressure cell. After holding at $3000 \mathrm{psi}_{2}$ pressure and $190^{\circ} \mathrm{C}$ for $\sim 1$ hour, XRD analysis was performed on the material, with the pattern shown below in Figure 87. The desired compound, $\mathrm{Na}_{2} \mathrm{LiAlH}_{6}$ was identified by comparison to library spectra (orange lines), along with residual starting materials.

$$
\mathrm{NaH}+\mathrm{LiH}+\mathrm{NaAlH}_{4} \rightarrow \mathrm{Na}_{2} \mathrm{LiAlH}_{6}
$$

The XRD peaks showed slight shifts indicating that perhaps the product was Li-rich.

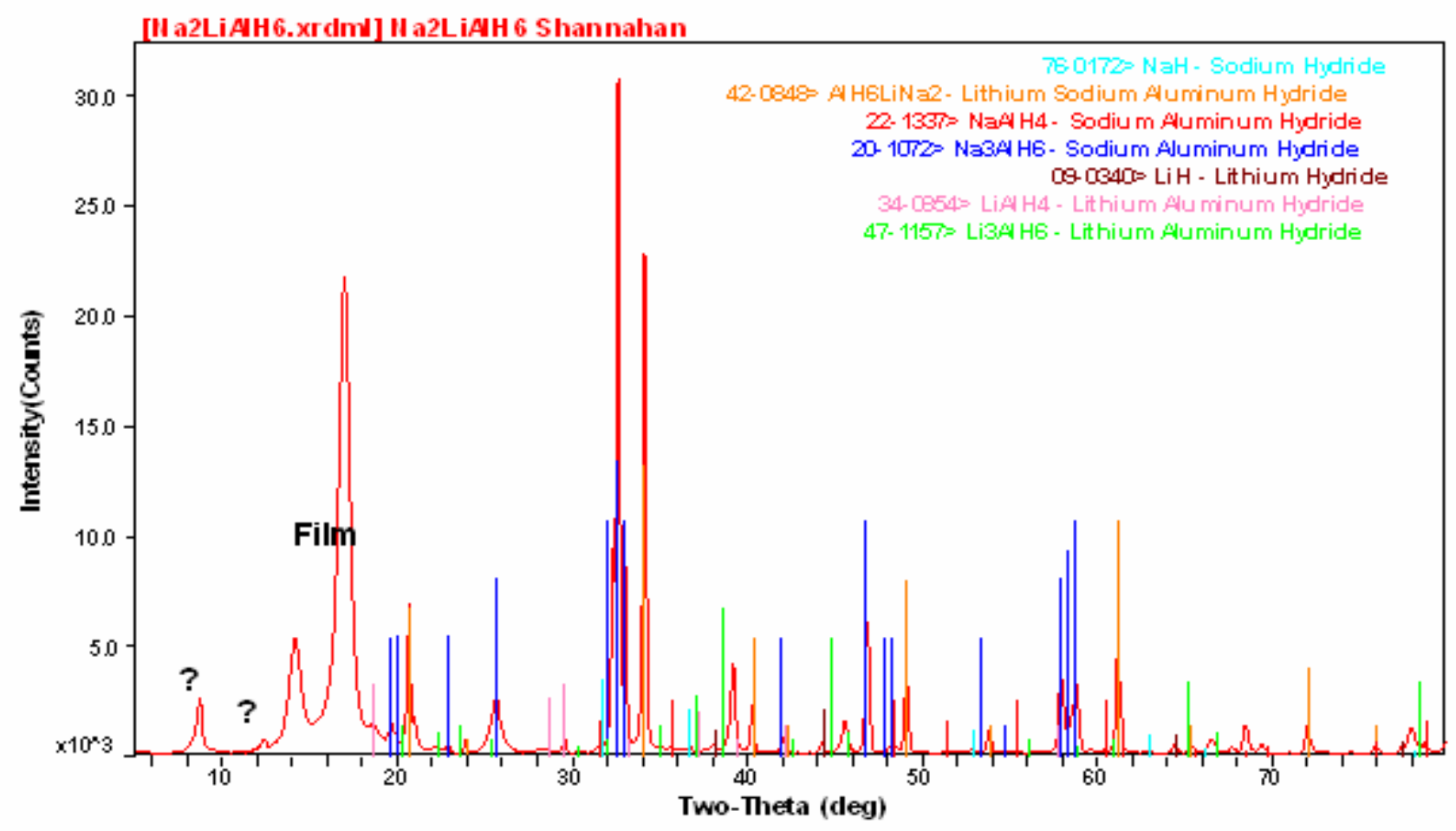

Figure 87: $\mathrm{XRD}$ results of $\mathrm{MSP} \mathrm{NaAlH}_{4} / \mathrm{LiH}$ indicating the presence of $\mathrm{Na}_{2} \mathrm{LiAlH}_{6}$.

A second attempt was made with the melt held at temperature for $\sim 5$ hours. A mixture was obtained which was still only partially enriched in $\mathrm{Na}_{2} \mathrm{LiAlH}_{4}$. A TPD experiment was performed at a temperature ramp rate of $5^{\circ} \mathrm{C} / \mathrm{min}$. As can be seen in Figure 88, the material begins to dehydrogenate at $\sim 175^{\circ} \mathrm{C}$. 
Molten State Processing

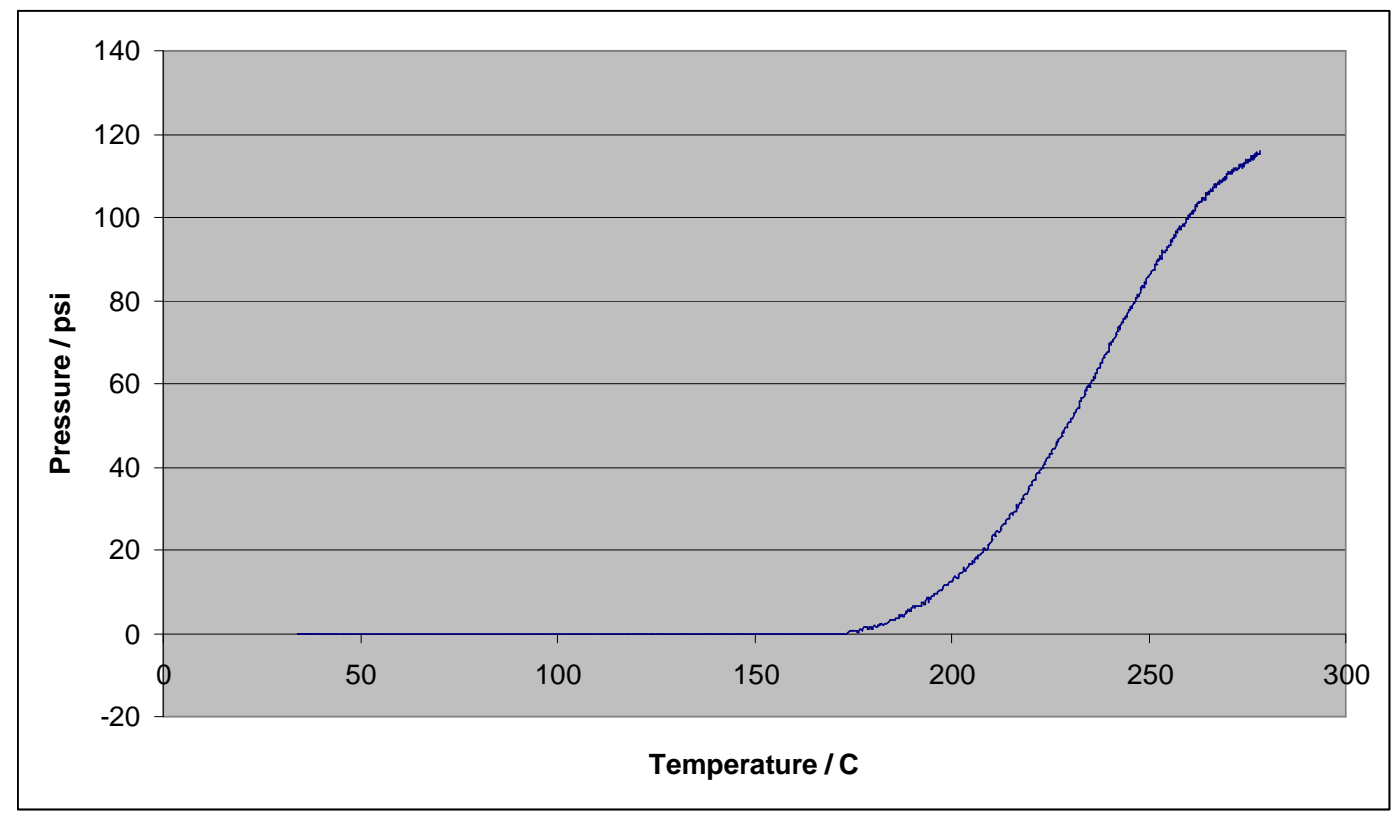

Figure 88: TPD results for $\mathrm{NaAlH}_{4} / \mathrm{LiH}$ MSP material.

\subsection{Catalyzed $\mathrm{NaAlH}_{4}$}

Additional efforts were conducted to produce a composite complex hydride similar to that formed through standard practice with conventional metal hydrides. Titanium hydride $\left(\mathrm{TiH}_{2}\right)$ was mixed with $\mathrm{NaAlH}_{4}$ and melt processed. The first attempt used uncatalysed $\mathrm{NaAlH}_{4}$ and ball-milled $\mathrm{TiH}_{2}$. The chemicals were ball-milled and then processed at $190^{\circ} \mathrm{C}$ and 3,000 psi for 2 hours. A TPD run was made on this material up to $270^{\circ} \mathrm{C}$ which showed that no pressure producing gas evolved, and the $\mathrm{XRD}$ of the desorbed material showed sodium hydride, titanium hydride, traces of $\mathrm{Na}_{3} \mathrm{AlH}_{6}$, aluminum, and possibly traces of aluminum hydride and $\mathrm{Ti}_{2} \mathrm{O}_{3}$ as seen in Figure 89. Thus, the material had desorbed during the melt processing. 


\section{Molten State Processing}

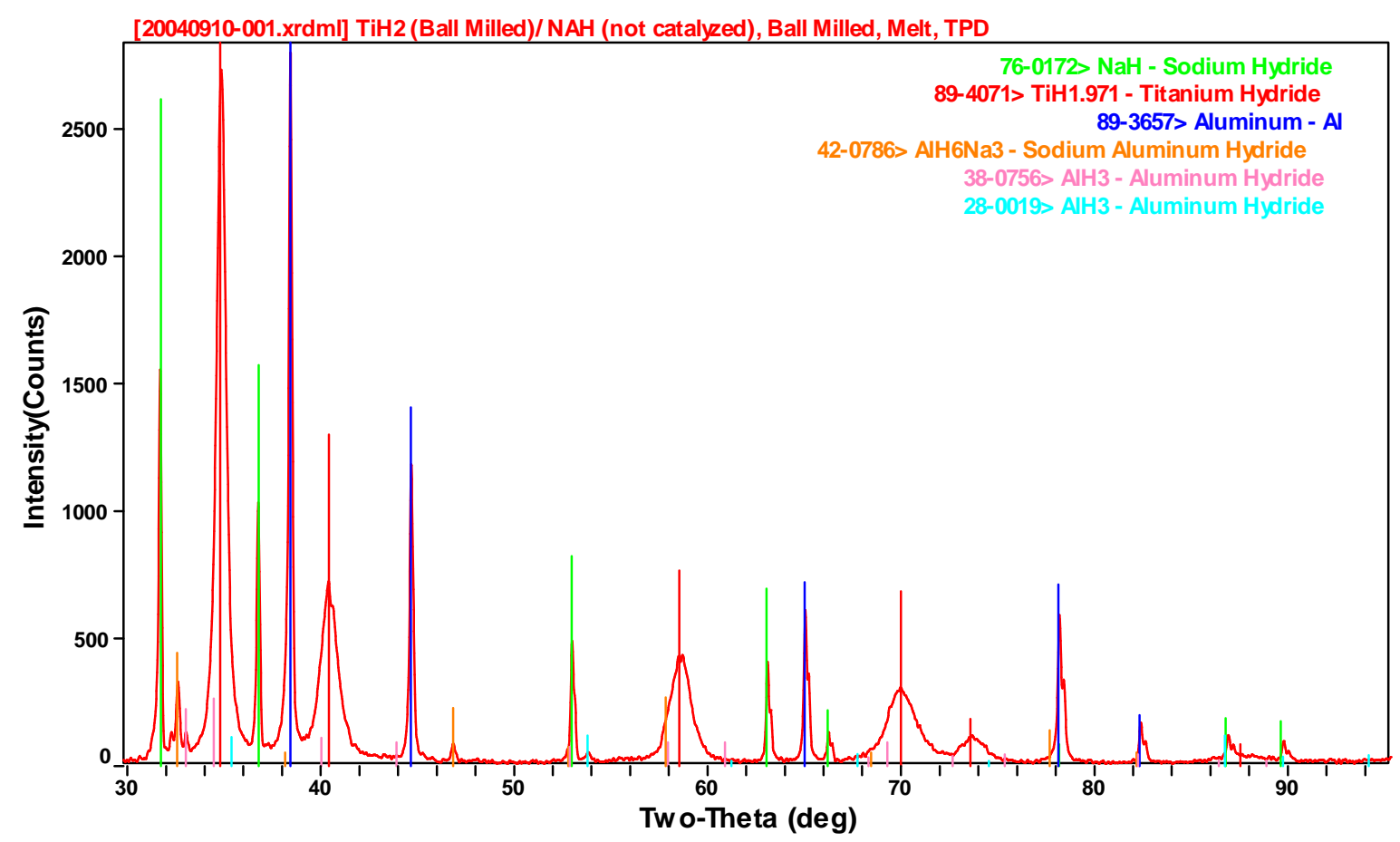

Figure 89: XRD results following processing of $\mathrm{NaAlH} 4 / \mathrm{TiCl} 3$ at $190^{\circ} \mathrm{C} / 3 \mathrm{kpsi} / 2 \mathrm{hrs}$.

A second attempt used a ball-milled mixture of titanium-butoxide catalyzed $\mathrm{NaAlH}_{4}$ and ball-milled $\mathrm{TiH}_{2}$. It also was heated for 2 hours at $190^{\circ} \mathrm{C}$ and 3,000 psi. Initially the sample was cooled to room temperature, with final cooling to $\sim-40^{\circ} \mathrm{C}$ with dry ice while still at 3,000 psi in order to retain any metastable compounds which may have formed. The pressure was removed and the material allowed to return to room temperature. No pressure rise was observed during heating to ambient temperature, indicating that no metastable phases dehydrided. The XRD results of this melt processed material showed $\mathrm{TiH}_{2}, \mathrm{NaH}, \mathrm{Al}$, and traces of $\mathrm{NaAlH}_{4}$ and $\mathrm{Na}_{3} \mathrm{AlH}_{6}$. A subsequent TPD to $\sim 300^{\circ} \mathrm{C}$ showed no pressure increase, similarly indicating that no significant desorption had occurred.

In a third attempt to melt process $\mathrm{TiH}_{2}$ and $\mathrm{NaAlH}_{4}$, excess aluminum was added. All chemicals were hand-milled only in this experiment. The mixture was melted at $190^{\circ} \mathrm{C}$ and 3,000 psi for 2 hours; then the pressure was increased at temperature to 4,900 psi and held for 2 hours. The XRD of this material showed only $\mathrm{NaH}, \mathrm{Al}$, and $\mathrm{TiH}_{2}$. A subsequent TPD produced no pressure.

The conclusion from these experiments is that the $\mathrm{TiH}_{2}$ is a very efficient decomposition catalyst, as the melt processing did not produce substantial quantities of hydrogenated alanates. The possible detection of alane in the first set of experiments (Figure 89, $\approx 52$ deg.) is intriguing.

\section{$6.4 \mathrm{MgH}_{2} / \mathrm{NaAlH}_{4}$ and $\mathrm{Mg}_{2} \mathrm{NiH}_{4} / \mathrm{NaAlH}_{4}$}

Additional MSP synthesis experiments were conducted on combinations of $\mathrm{MgH}_{2}, \mathrm{Mg}_{2} \mathrm{NiH}_{4}$ and $\mathrm{NaAlH}_{4}$. Four mixtures of $\mathrm{MgH}_{2} / \mathrm{NaAlH}_{4}$ and two mixtures of $\mathrm{Mg}_{2} \mathrm{NiH}_{4} / \mathrm{NaAlH}_{4}$ were prepared and examined. The four $\mathrm{MgH}_{2}: \mathrm{NaAlH}_{4}$ mixtures had a mole ratio of $\sim 4.4: 1$ with the addition of $\sim 0.7$ mole $\% \mathrm{TiCl}_{3}$. The two mixtures of $\mathrm{Mg}_{2} \mathrm{NiH}_{4}: \mathrm{NaAlH}_{4}$ were prepared with a mole ratio of 1:1. $\mathrm{TiCl}_{3}$ 


\section{Molten State Processing}

was added in an effort to catalyze the hydrogenation and dehydrogenation steps. Three processing techniques were used to combine the powders: Hand Mixed (HM), Hand Shaken (HS) and Ball Milled (BM). Hand Shaken refers to hand shaking the starting materials in a ball mill vial with no balls, and Ball Milling was conducted in a SPEX mill for one hour. Melt processing was conducted at $150^{\circ} \mathrm{C}$ and 200 bar for 2 hours.

Table 20 and Table 21 give the trial identifiers, the molar ratios of $\mathrm{MgH}_{2} / \mathrm{NaAlH}_{4}$ and $\mathrm{Mg}_{2} \mathrm{NiH}_{4} /$ $\mathrm{NaAlH}_{4}$ respectively, the mole $\%$ of $\mathrm{TiCl}_{3}$, the processing methods and the resulting XRD pattern Figure numbers.

Table 20: Summary of $\mathrm{MgH}_{2} / \mathrm{NaAlH}_{4}$ compositions. $\mathrm{HM}$ = Hand Mixed; HS = Hand Shaken; BM = Ball Milled.

\begin{tabular}{|lcccc|}
\hline Trial & $\mathbf{M g H}_{\mathbf{2}} / \mathbf{N a A l H}_{\mathbf{4}}$ & $\mathbf{m} / \mathbf{\%} \mathbf{T i C l}$ & Processing & XRD \\
\hline 1a & 4.3 & 0.70 & HM & Figure 90 \\
\hline 2a & 4.4 & 0.76 & HS & Figure 91 \\
\hline 3a & 4.4 & 0.83 & HS & Figure 92 \\
\hline 4a & 4.2 & 0.85 & BM & Figure 93 \\
\hline
\end{tabular}

Table 21: Summary of $\mathrm{Mg}_{2} \mathrm{NiH}_{4} / \mathrm{NaAlH}_{4}$ experiments.

\begin{tabular}{|cccccc|}
\hline Trial & $\mathbf{M g}_{\mathbf{2}} \mathbf{N i H}_{\mathbf{4}} / \mathbf{N a A l H}_{\mathbf{4}}$ & $\mathbf{\%} \mathbf{T i C l}_{\mathbf{3}}$ & Milling & XRD(Milled) & XRD(Melt) \\
\hline 1b & 1.0 & 4.2 & HS & Figure 97 & - \\
\hline 2b & 1.0 & 4.2 & BM & Figure 98 & Figure 99 \\
\hline
\end{tabular}

TPD experiments consisted of heating the specimen at a rate of $5^{\circ} \mathrm{C} / \mathrm{min}$ from ambient to $250^{\circ} \mathrm{C}$ with continuous pressure monitoring in a modified Sievert's apparatus.

All four XRD patterns of the $\mathrm{MgH}_{2} / \mathrm{NaAlH}_{4}$ compositions (Figure 90 to Figure 93) show strong reflections for $\mathrm{Al}, \mathrm{MgH}_{2}$, and $\mathrm{NaMgH}_{3}$, and moderately strong reflections for $\mathrm{Mg}$ and $\mathrm{NaCl}$, with the exception of Figure 93 where the $\mathrm{Mg}$ reflection is weak. Semi-quantitative analysis was not available to further analyze the relative proportions of the products.

TPD experiments were conducted on compositions $3 \mathrm{a}$ and $4 \mathrm{a}$ and were followed by rehydrogenation attempts. Mixture 3a had a subsequent TPD run conducted, whereupon it was removed and sampled for XRD (Figure 95). This XRD showed strong reflections for $\mathrm{MgH}_{2}, \mathrm{Al}$, and $\mathrm{NaMgH}_{3}$ and moderate reflections for $\mathrm{Mg}$ and $\mathrm{NaCl}$. The first TPD to $220^{\circ} \mathrm{C}$ produced no noticeable hydrogen release above baseline, and the second TPD to $245^{\circ} \mathrm{C}$ likewise showed no significant $\mathrm{H}_{2}$ release.

The XRD pattern of the ball milled and melted product from mixture 4a in Figure 93 showed traces of $\mathrm{NaAlH}_{4}$. Subsequent TPD gave limited $\mathrm{H}_{2}$ evolution starting at $\sim 80^{\circ} \mathrm{C}$ and continuing up to $280^{\circ} \mathrm{C}$. This limited hydrogen release was most likely due to remaining $\mathrm{NaAlH}_{4}$. This sample was removed, rehydrogenated and analyzed again in the XRD of Figure 96. These results showed strong reflections for $\mathrm{Al}, \mathrm{MgH}_{2}$, and $\mathrm{NaMgH}_{3}$, moderate reflections for $\mathrm{Mg}$ and $\mathrm{NaCl}$, and possibly a trace of $\mathrm{NaAlH}_{4}$. 


\section{Molten State Processing}

Mixture $1 \mathrm{~b}$ had strong $\mathrm{NaAlH}_{4}$ reflections and moderate $\mathrm{Mg}_{2} \mathrm{NiH}_{4}, \mathrm{Mg}_{2} \mathrm{NiH}_{0.3}$, and $\mathrm{MgH}_{2}$ reflections. This material had two TPD-rehydrogenation cycles performed on it, followed by a final XRD as shown in Figure 100. The TPD experiments did not produce any significant hydrogen desorption (the first went to $250^{\circ} \mathrm{C}$, the second to $260^{\circ} \mathrm{C}$ ). The $\mathrm{XRD}$ results showed strong reflections for $\mathrm{Al}$, $\mathrm{NaMgH}_{3}, \mathrm{Mg}_{2} \mathrm{NiH}_{4}, \mathrm{Mg}_{2} \mathrm{NiH}_{0.3}$, and $\mathrm{NaCl}$, with moderate reflections for $\mathrm{NaAlH}_{4}$ and $\mathrm{MgH}_{2}$.

Mixture 2b's XRD taken after ball milling 40 minutes showed strong reflections for $\mathrm{NaAlH}_{4}, \mathrm{Al}$, $\mathrm{MgH}_{2}, \mathrm{Mg}, \mathrm{Mg}_{2} \mathrm{NiH}_{4}$, and $\mathrm{NaCl}$, with moderate peaks for $\mathrm{Na}_{3} \mathrm{AlH}_{6}$. The XRD of the melted product had strong reflections for $\mathrm{NaMgH}_{3}, \mathrm{Mg}_{2} \mathrm{NiH}_{4}$, and $\mathrm{NaCl}$, with moderate peaks for $\mathrm{NiAl}_{3}$ alloy, and possibly a trace of $\mathrm{MgH}_{2}$ present. Mixture 2b also had two TPD experiments conducted on it (separated by a rehydrogenation), but was sampled for XRD after the second TPD. The first TPD (to $230^{\circ} \mathrm{C}$ ) produced an anomalous sharp desorption occurring over the rage $170-190^{\circ} \mathrm{C}$. The second TPD to $240^{\circ} \mathrm{C}$ produced no desorption. The XRD after the second TPD is given in Figure 101 .

In all cases, after the melt processing, the compound $\mathrm{NaMgH}_{3}$ was detected in appreciable quantities. When examining the $\mathrm{MgH}_{2} / \mathrm{NaAlH}_{4}$ mixtures, the other major products were $\mathrm{Al}$ and unreacted $\mathrm{MgH}_{2}$, with moderate peaks observed for $\mathrm{Mg}$ and $\mathrm{NaCl}$ in most cases. When the $\mathrm{Mg}_{2} \mathrm{NiH}_{4} / \mathrm{NaAlH}_{4}$ mixtures were examined, the situation was somewhat more complicated as several $\mathrm{Mg}_{2} \mathrm{NiH}_{\mathrm{x}}$ compounds could be observed, along with $\mathrm{Al}, \mathrm{MgH}_{2}$ and $\mathrm{NaMgH}_{3}$ as major products. In one experiment $\mathrm{NiAl}_{3}$ was also observed.

The compound $\mathrm{NaMgH}_{3}$ seems to be quite easy to form, showing up in almost all the XRDs obtained. However, it does not seem to evolve hydrogen at low temperatures $\left(<\sim 280^{\circ} \mathrm{C}\right)$. The XRDs from the $\mathrm{Mg}_{2} \mathrm{NiH}_{3}$ experiments are quite complicated and might mask several other minor compounds. The Xray cross section of $\mathrm{Mg}$ and $\mathrm{Ni}$ are quite similar for the $\mathrm{Cu} \mathrm{K}$-alpha source in use, and this makes it difficult to distinguish the $\mathrm{Mg}$ compounds from $\mathrm{Mg}-\mathrm{Ni}$ compounds. It is unclear at this point why the $\mathrm{Mg}_{2} \mathrm{NiH}_{3} / \mathrm{NaAlH}_{4}$ mixture $2 \mathrm{~b}$ showed an anomalous TPD. The XRD of the melted mixture did show $\mathrm{NiAl}_{3}$ alloy, which had not been observed before.

The various milling methods (hand, ball, none) do not seem to impact the results strongly. The melt processing step seems to equalize all the possible variations, which is, in part, the benefit of the melt processing method. 


\section{Molten State Processing}

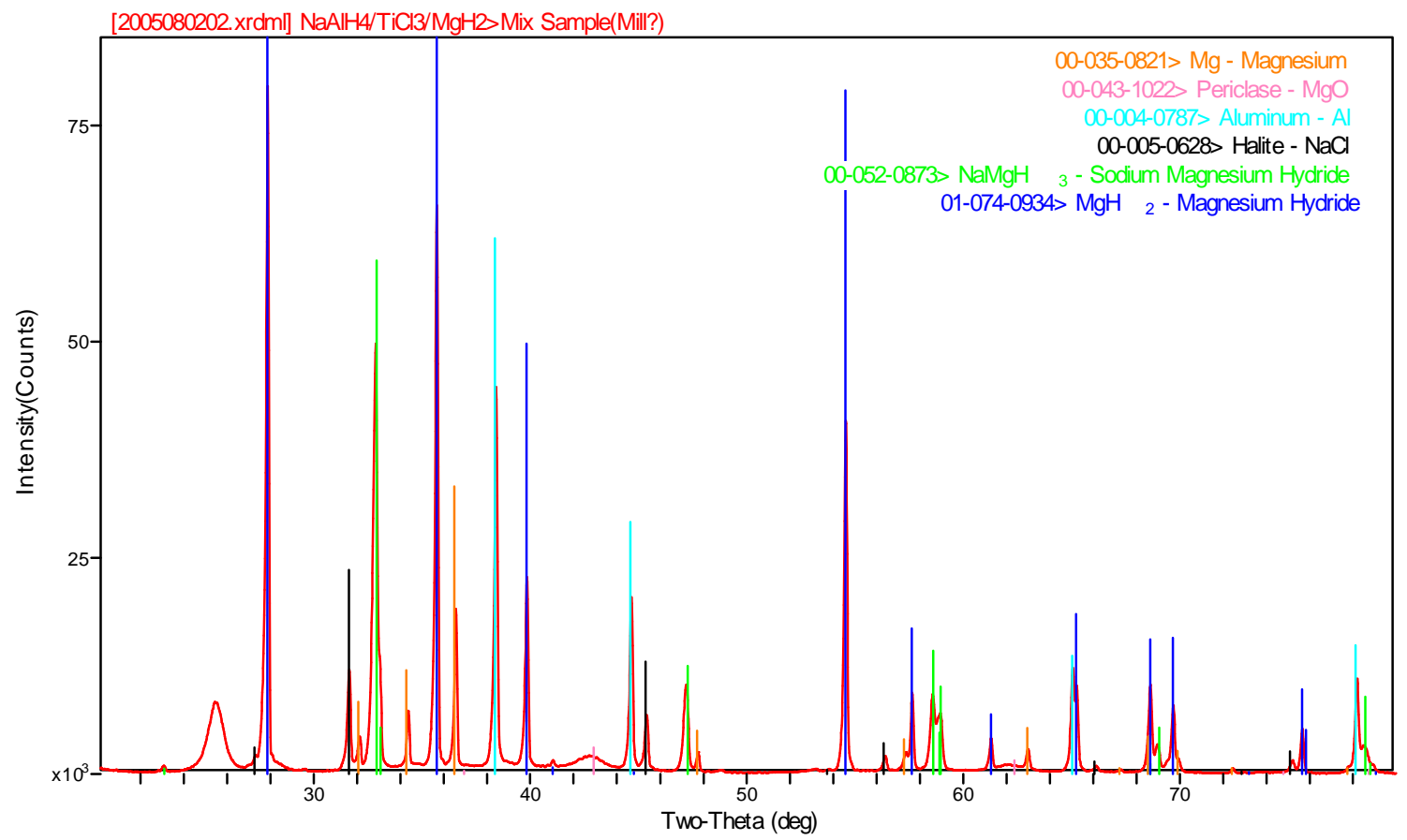

Figure 90: XRD analysis of Hand Mixed/MSP $\mathrm{MgH}_{2} / \mathrm{NaAlH}_{4} / \mathrm{TiCl}_{3}$.

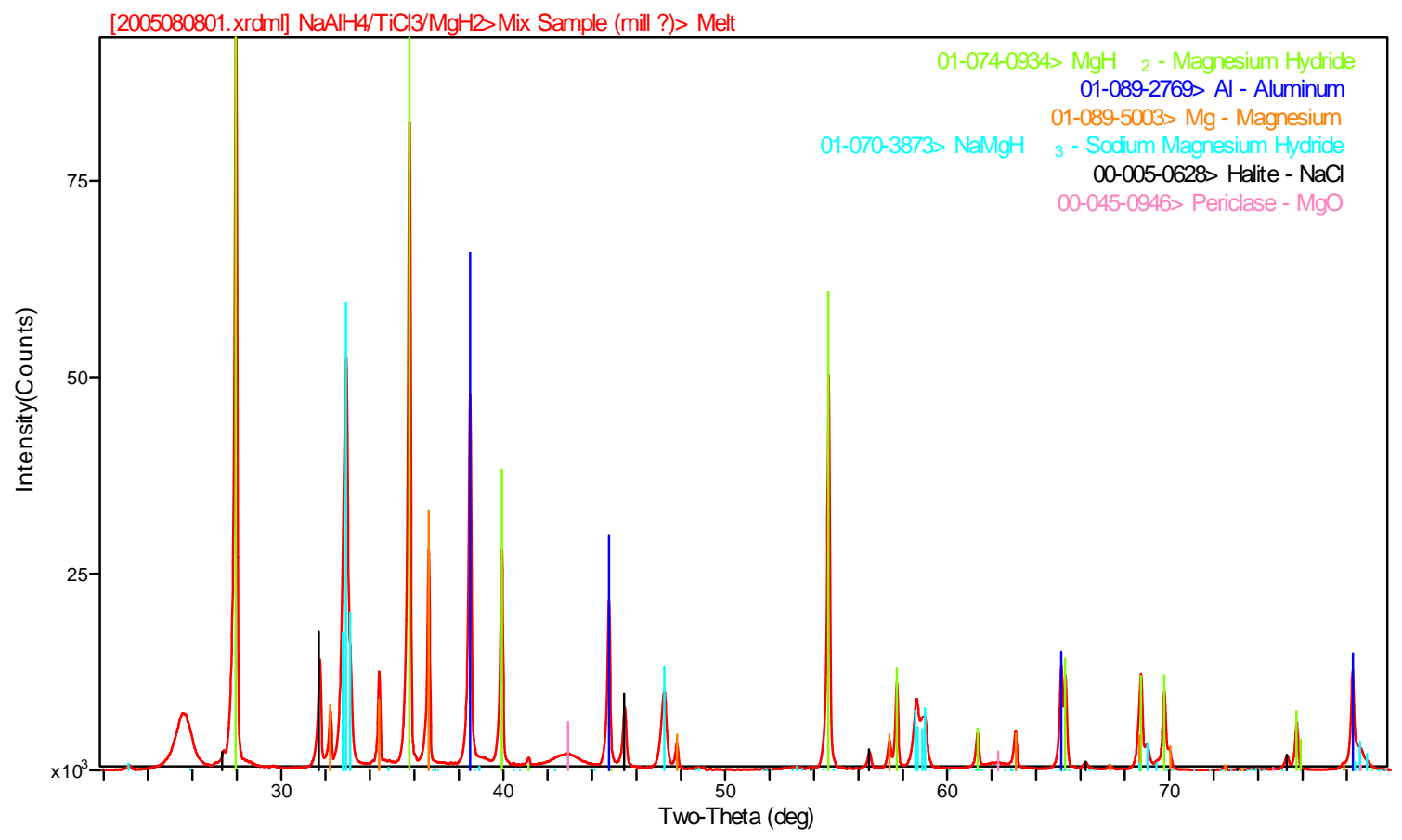

Figure 91: XRD Analysis of Hand Shaken/MSP $\mathrm{MgH}_{2} / \mathrm{NaAlH}_{4} / \mathrm{TiCl}_{3}$. 


\section{Molten State Processing}

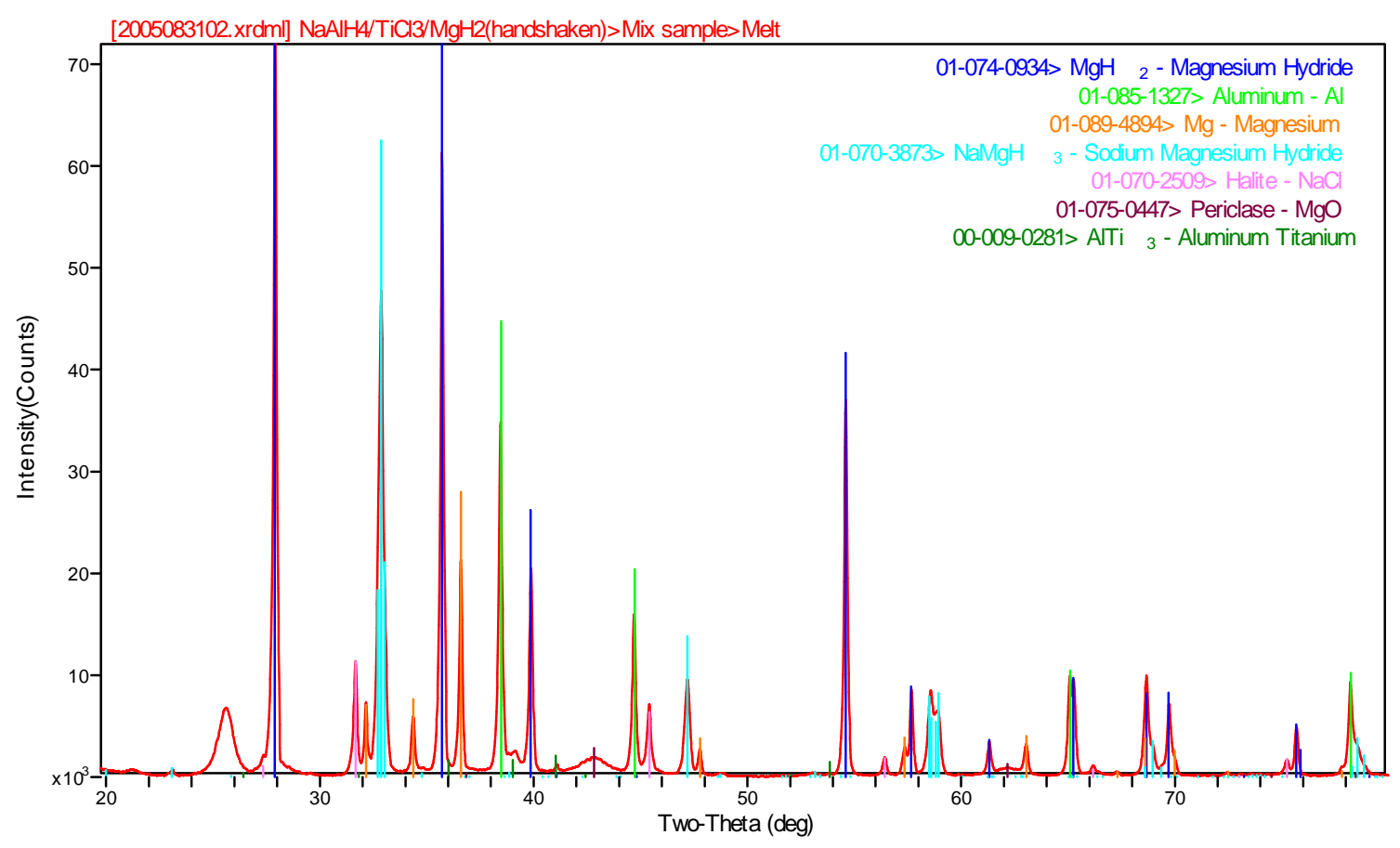

Figure $92 \mathrm{XRD}$ Analysis of Hand Shaken/MSP $\mathrm{MgH}_{2} / \mathrm{NaAlH}_{4} / \mathrm{TiCl}_{3}$.

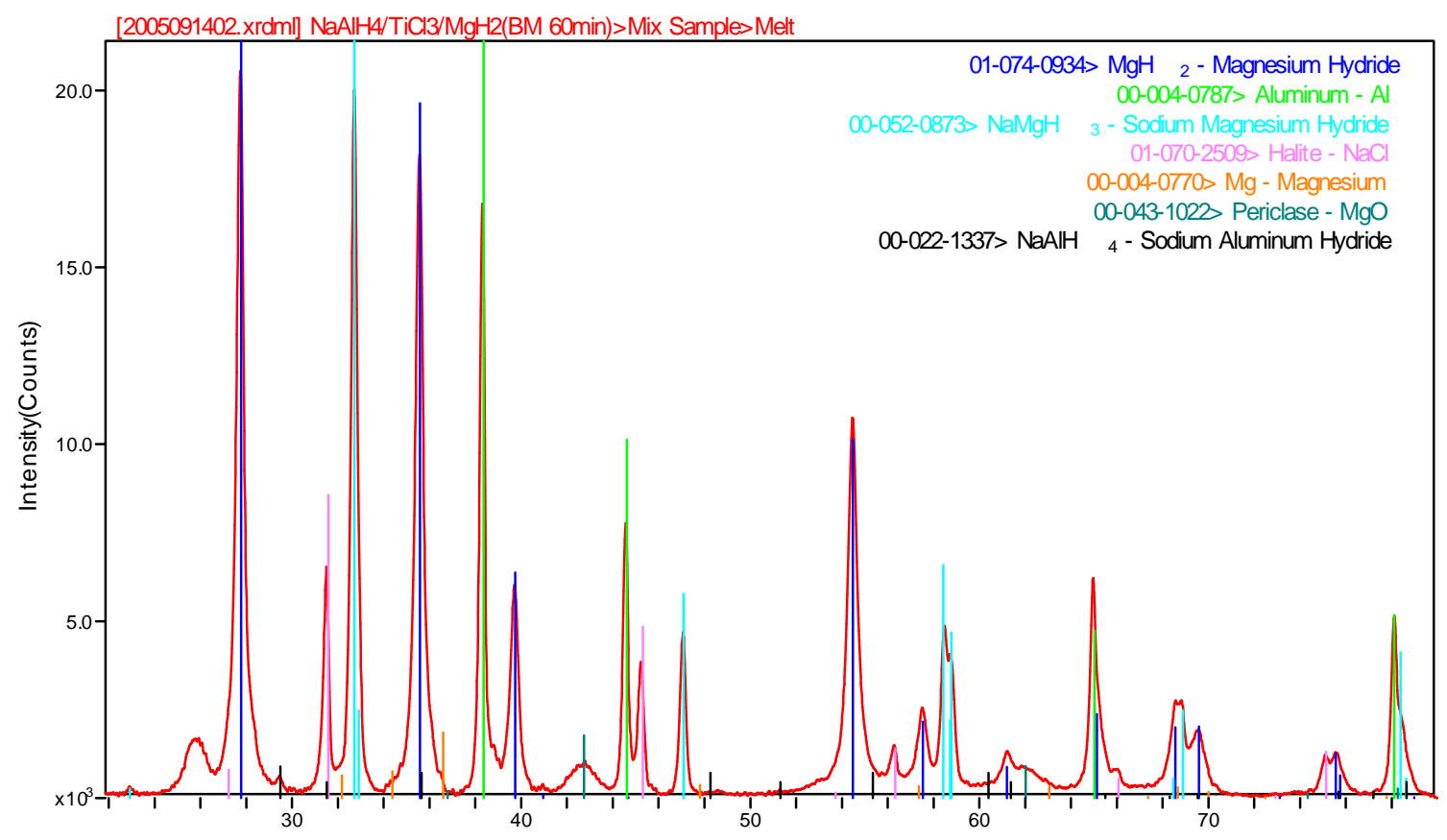

Figure 93 XRD Analysis of Ball Milled/MSP $\mathrm{MgH}_{2} / \mathrm{NaAlH}_{4} / \mathrm{TiCl}_{3}$. 


\section{Molten State Processing}

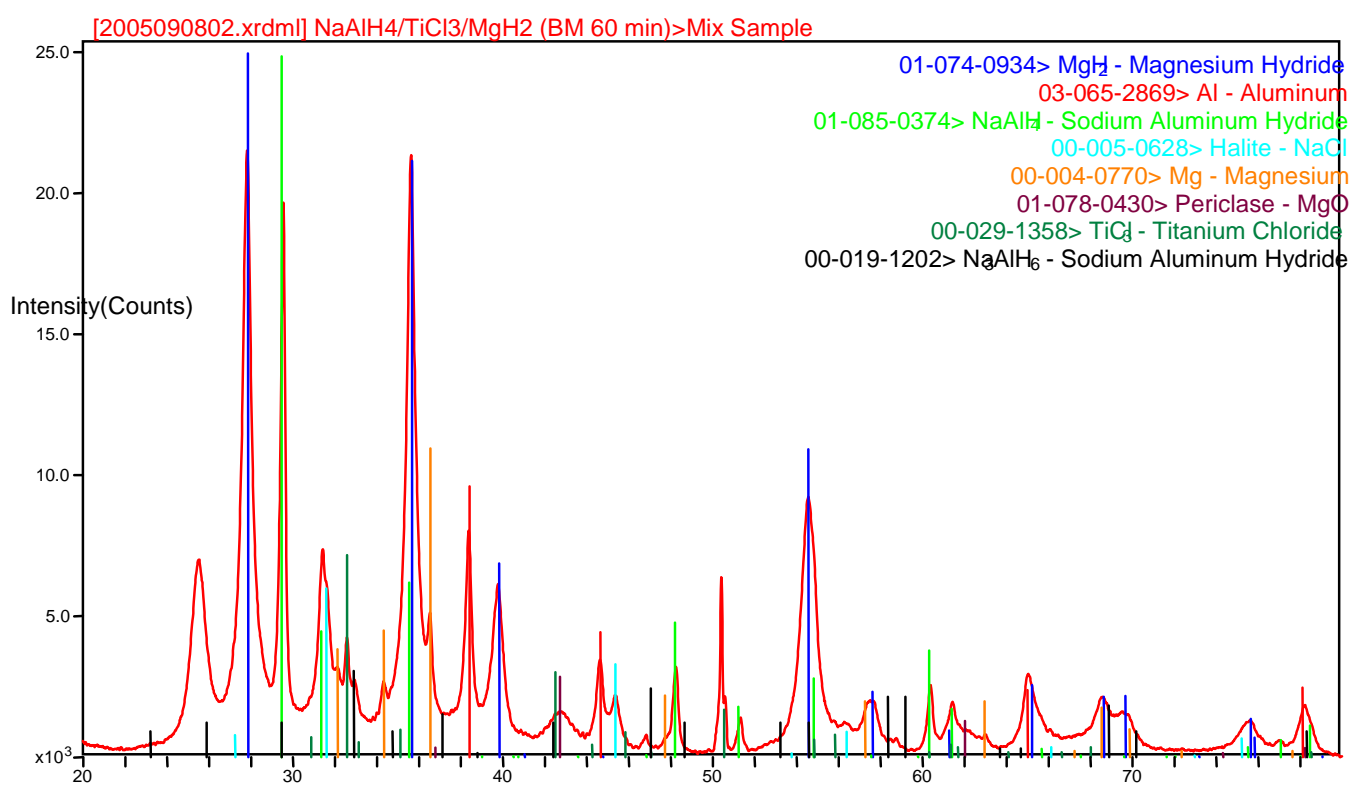

Figure 94: XRD analysis of ball milled only $\mathrm{MgH}_{2}$ / $\mathrm{NaAlH}_{4}$.

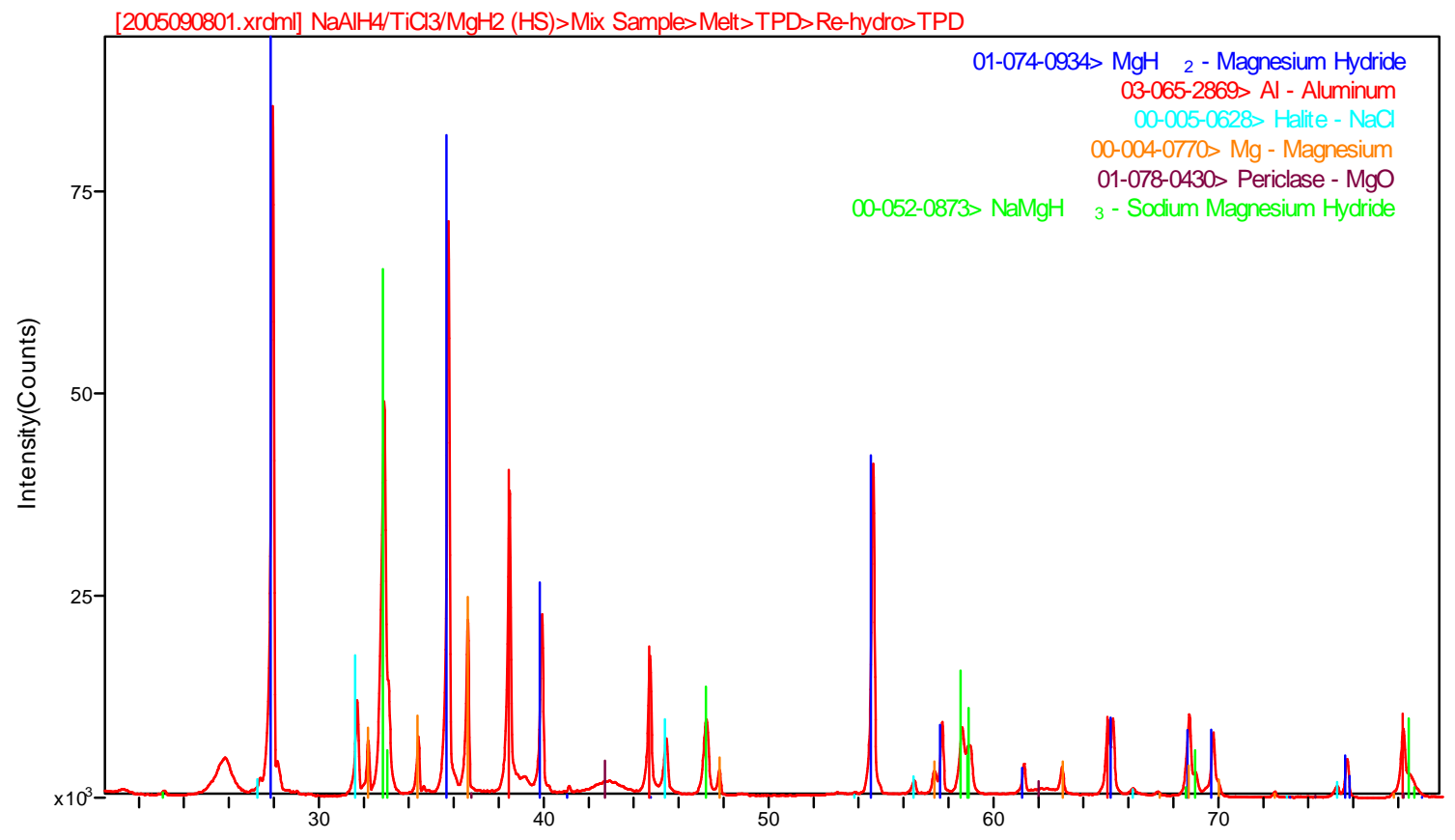

Figure 95 XRD analysis of mixture 3a after TPD run. 


\section{Molten State Processing}

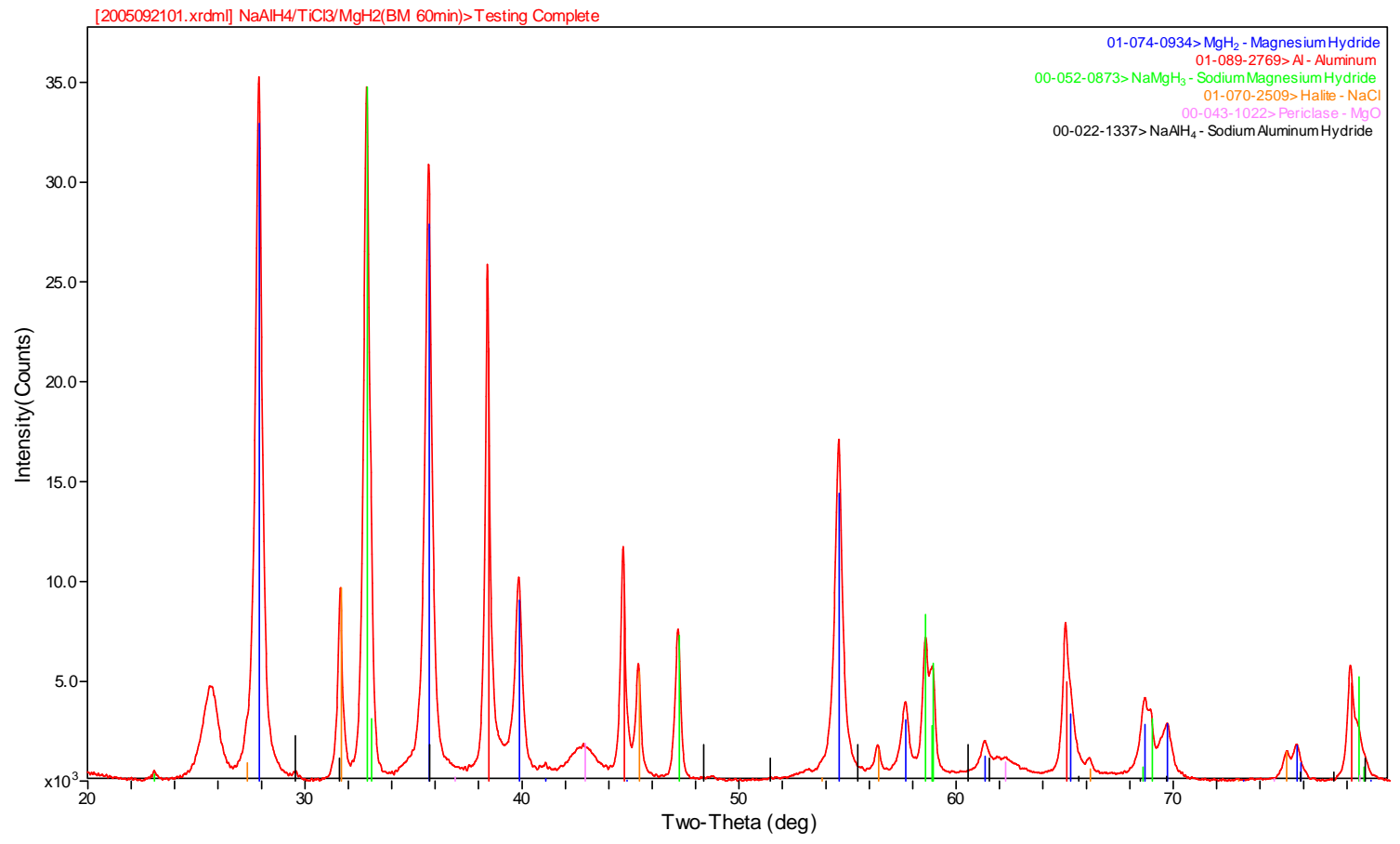

Figure 96: XRD analysis of mixture 4a after MSP, TPD and rehydrogenation.

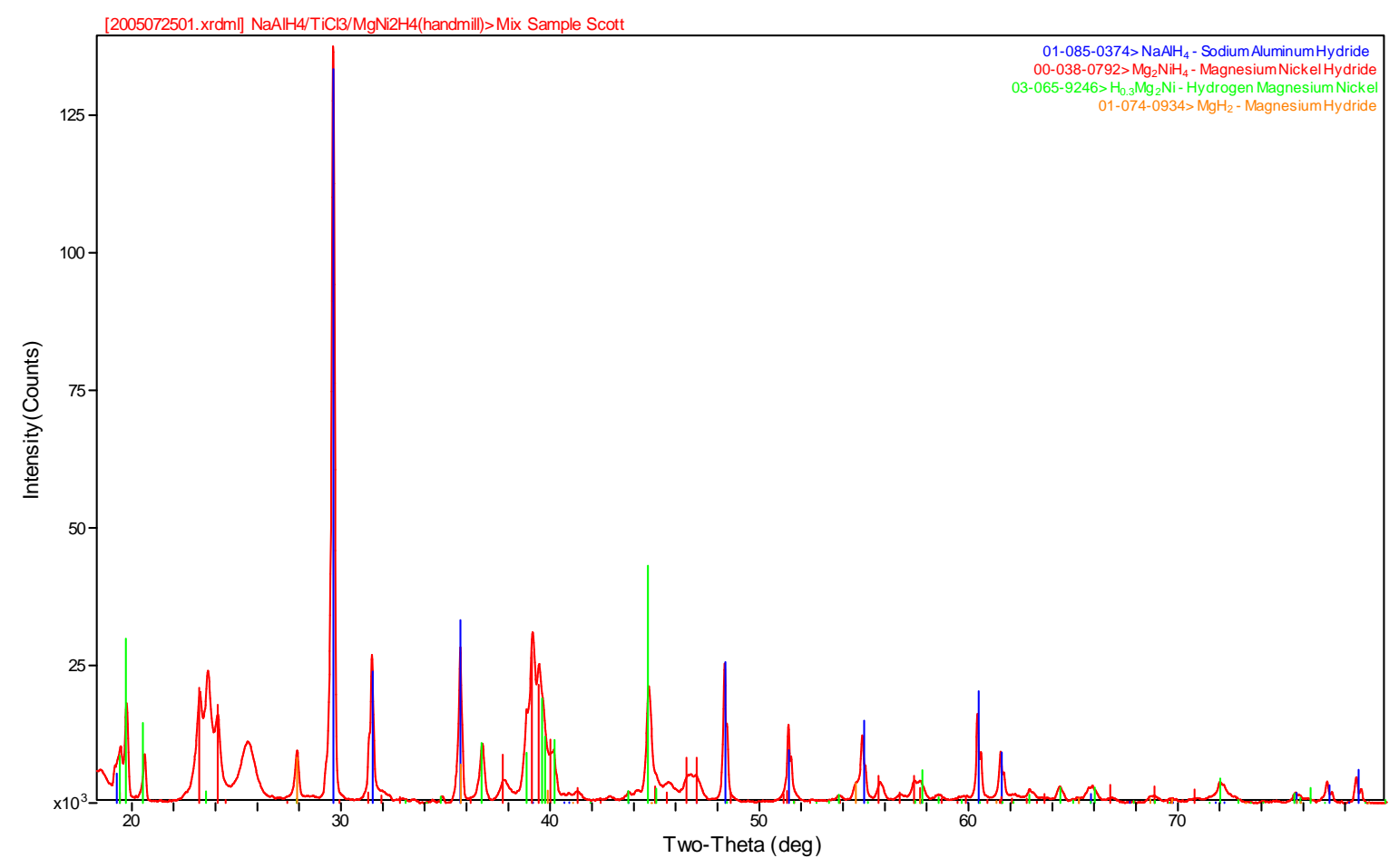

Figure 97: XRD analysis of Hand Mixed $\mathrm{Mg}_{2} \mathrm{NiH}_{4} / \mathrm{NaAlH}_{4}$. 


\section{Molten State Processing}

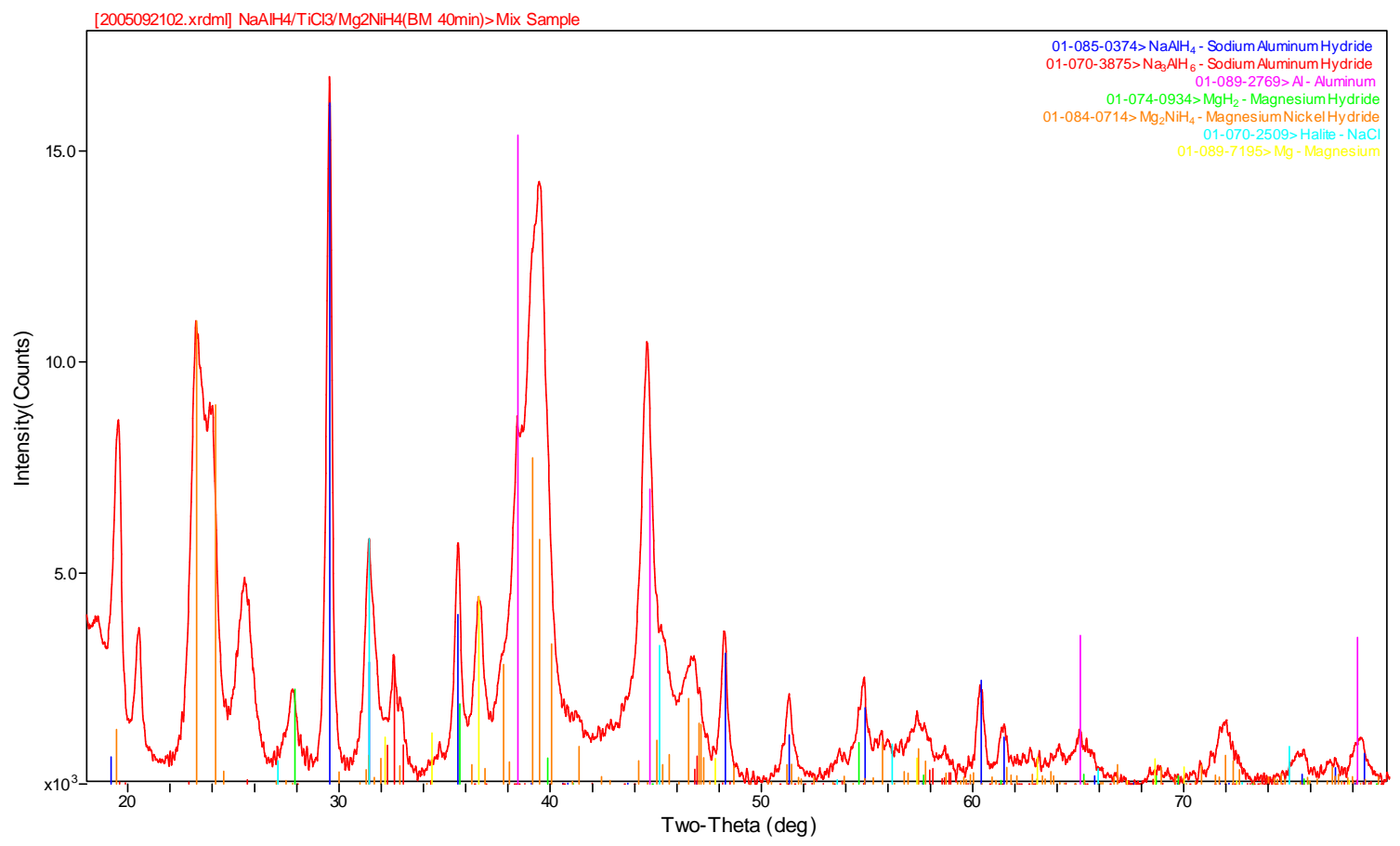

Figure 98: XRD Analysis of Ball Milled $\mathrm{Mg}_{2} \mathrm{NiH}_{4} / \mathrm{NaAlH}_{4}$.

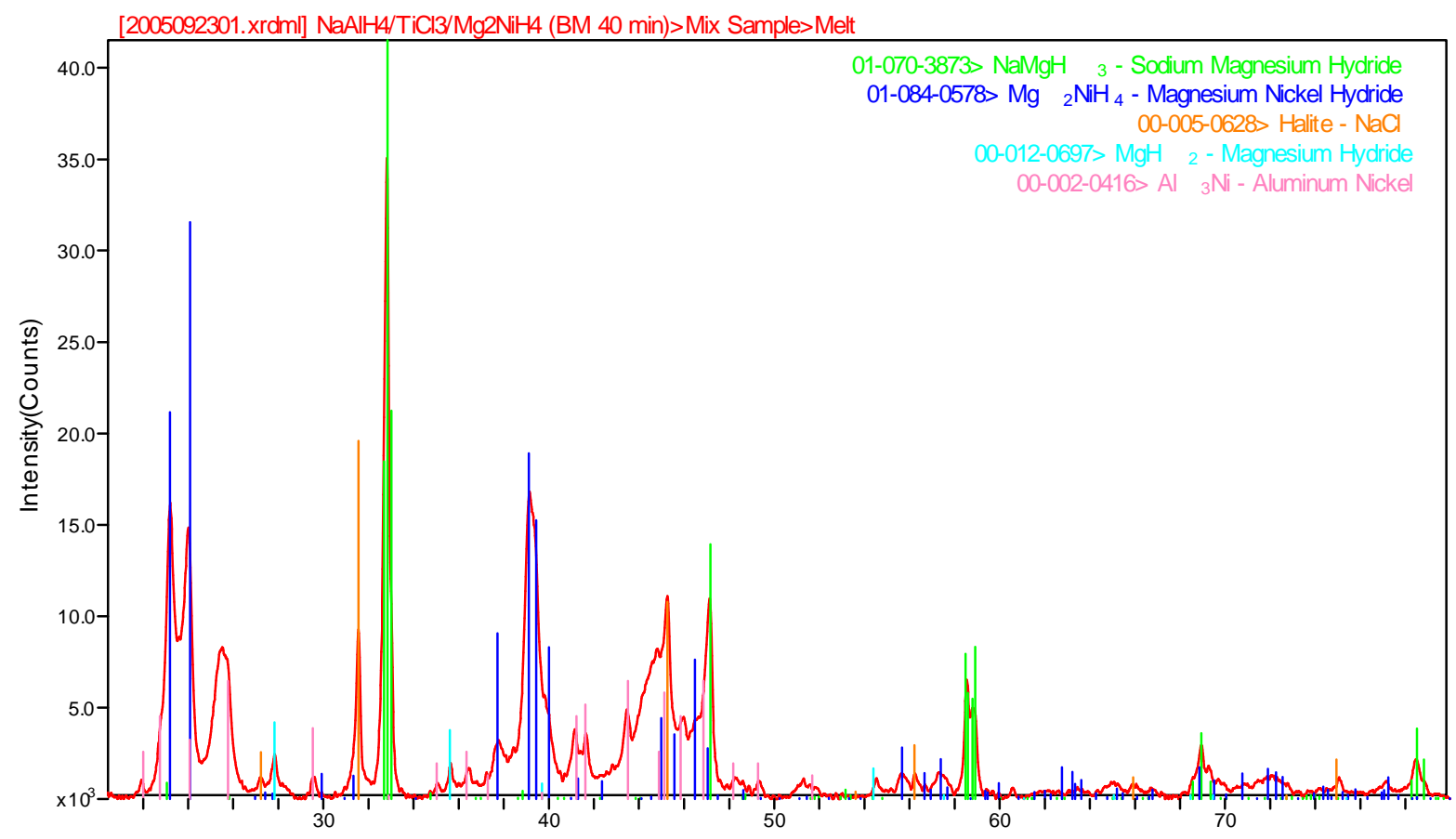

Figure 99: XRD analysis of Ball Milled / $\mathrm{MSP} \mathrm{Mg}_{2} \mathrm{NiH}_{4} / \mathrm{NaAlH}_{4}$. 


\section{Molten State Processing}

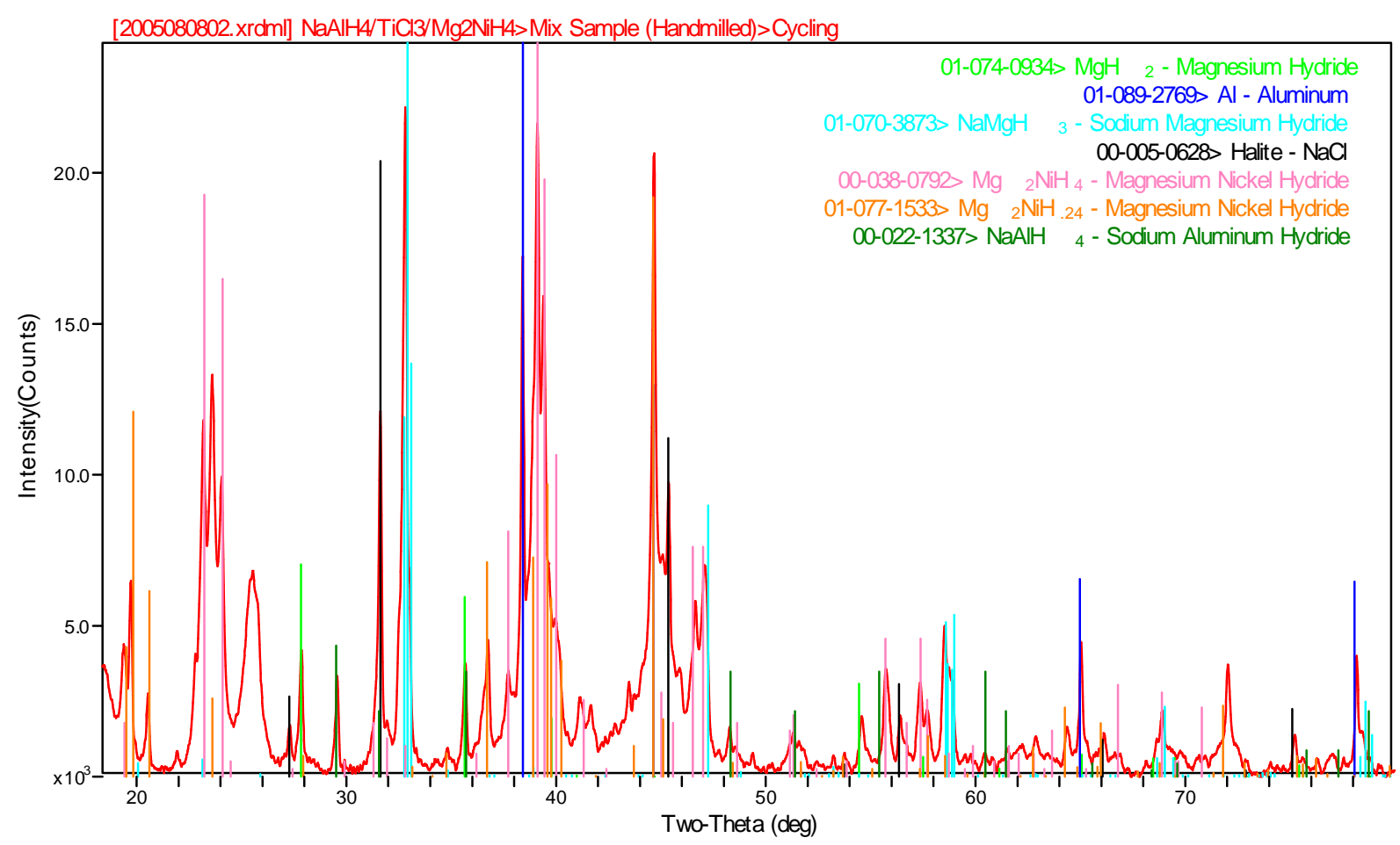

Figure 100: XRD analysis of mixture $1 \mathrm{~b}$ after two dehydride/hydride cycles.

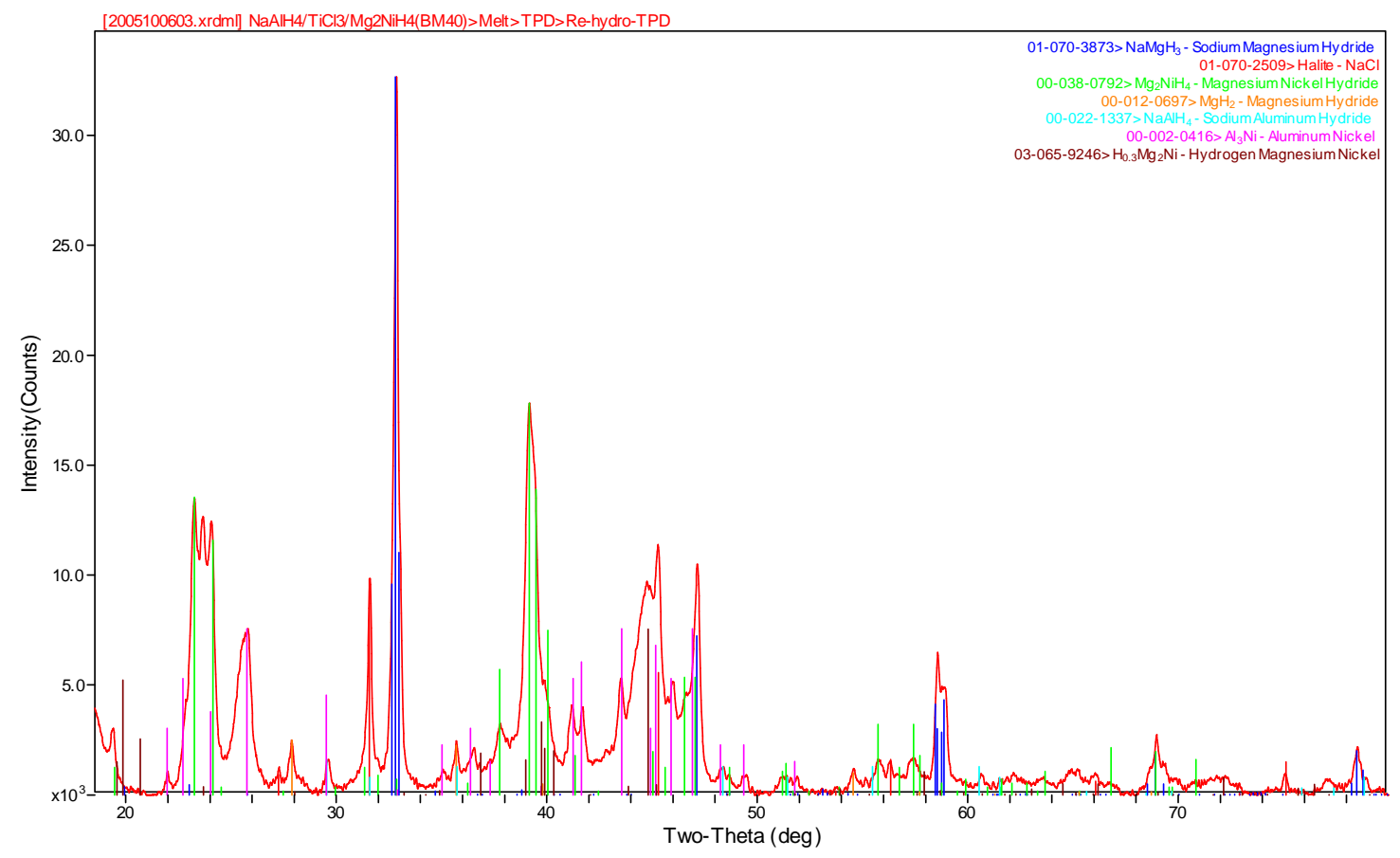

Figure 101: analysis of mixture $2 \mathrm{~b}$ after two dehydride/hydride cycles. 


\section{Molten State Processing}

\section{5 $\mathrm{NaAlH}_{4}+\mathrm{MgH}_{2}+\left(\mathrm{TiH}_{2}\right.$ or Fe $)$}

Sodium aluminum hydride reactions with the mixtures containing $\mathrm{MgH}_{2}+\mathrm{TiH}_{2}$ and $\mathrm{MgH}+\mathrm{Fe}$ were studied. A nominal 1:1 molar mixture of $\mathrm{MgH}_{2}$ and $\mathrm{TiH}_{2}$ was prepared by SPEX milling for 60 minutes. An XRD of the mixture showed no reaction. A quantity of 1.430 grams of this mixture was combined with 1.012 grams of $\mathrm{NaAlH}_{4}$ and 0.114 grams of $\mathrm{TiCl}_{3}$, and ball milled for 40 minutes (Figure 102). The sample was melted and an XRD sample obtained (Figure 103). A 1.042 gram sample of the melt processed material was thermally desorbed with no change in composition observed (Figure 104).

A nominal 1:1 molar mixture of $\mathrm{MgH}_{2}$ and Fe (Sigma-Aldrich 99.99+\%) was prepared by placing 1.605 grams of $\mathrm{MgH}_{2}$ (SRNL prep) and 3.415 grams of Fe into a ball mill vial using in this case only 4 balls ( 2 large, 2 small) vs. the normal 5 (2 large, 3 small) and ball milled for 60 minutes. A quantity of 1.004 grams of $\mathrm{NaAlH}_{4}, 0.114$ grams of $\mathrm{TiCl}_{3}$ and 1.530 grams of the $\mathrm{MgH}_{2}: \mathrm{Fe}$ mixture were placed were ball milled for 40 minutes (Figure 105). The material was melted (Figure 106) and thermally desorbed, similarly showing little change in composition (Figure 107).

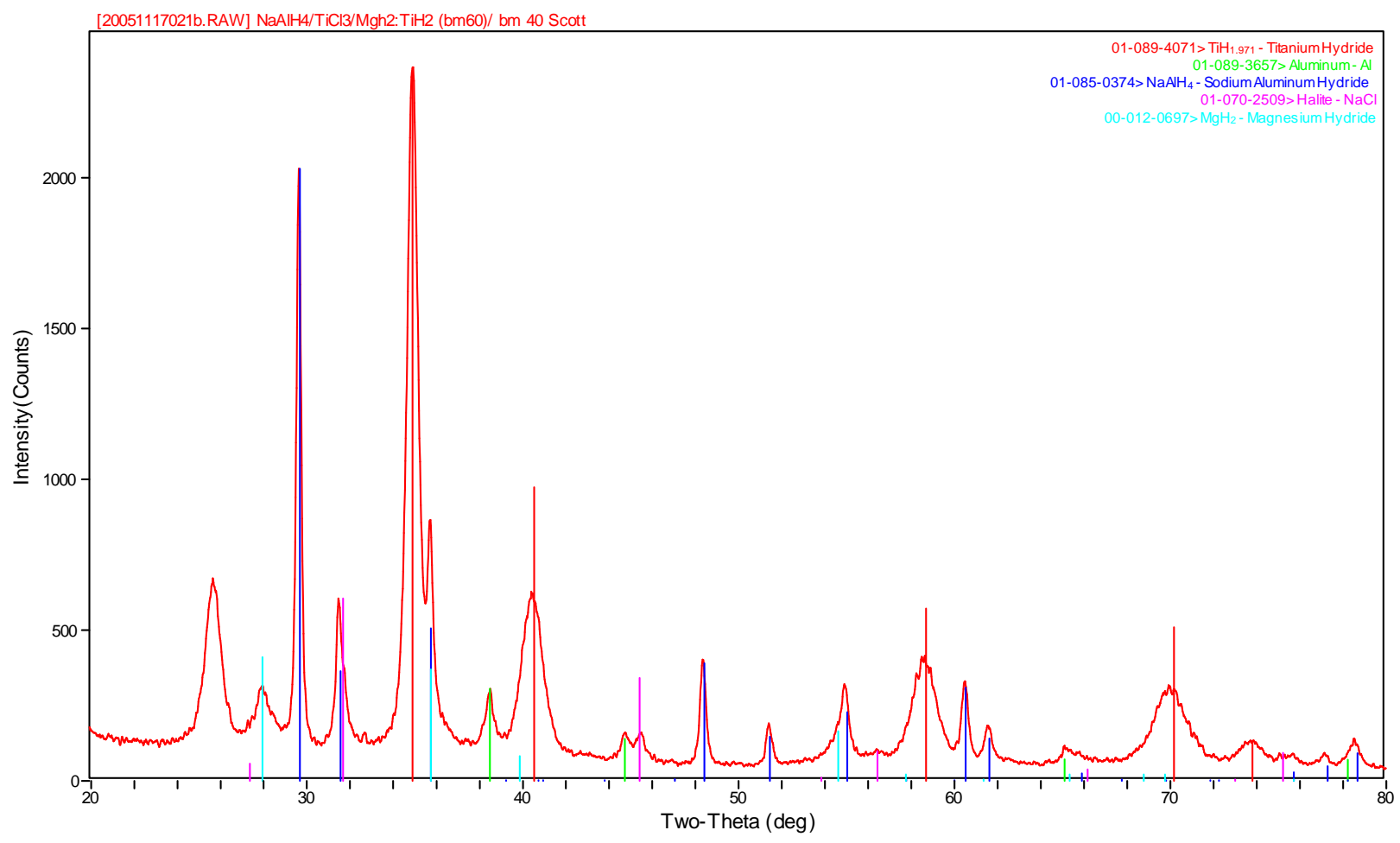

Figure 102: Ball milled $\mathrm{NaAlH}_{4} / \mathrm{TiCl}_{3} / \mathrm{MgH}_{2} / \mathrm{TiH}_{2}$ mixture. 


\section{Molten State Processing}

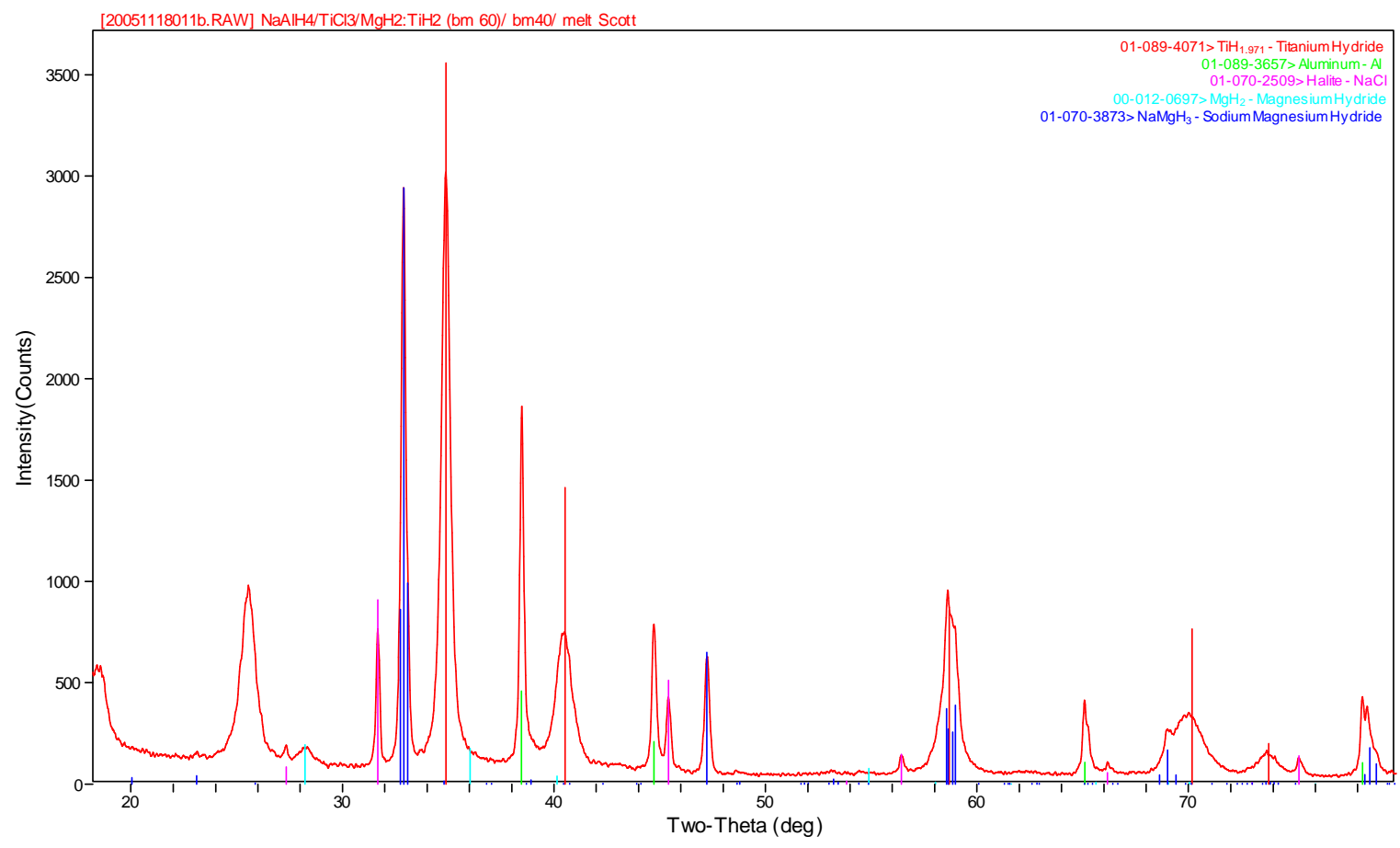

Figure 103: Melt processed $\mathrm{NaAlH}_{4} / \mathrm{TiCl}_{3} / \mathrm{MgH}_{2} / \mathrm{TiH}_{2}$ mixture.

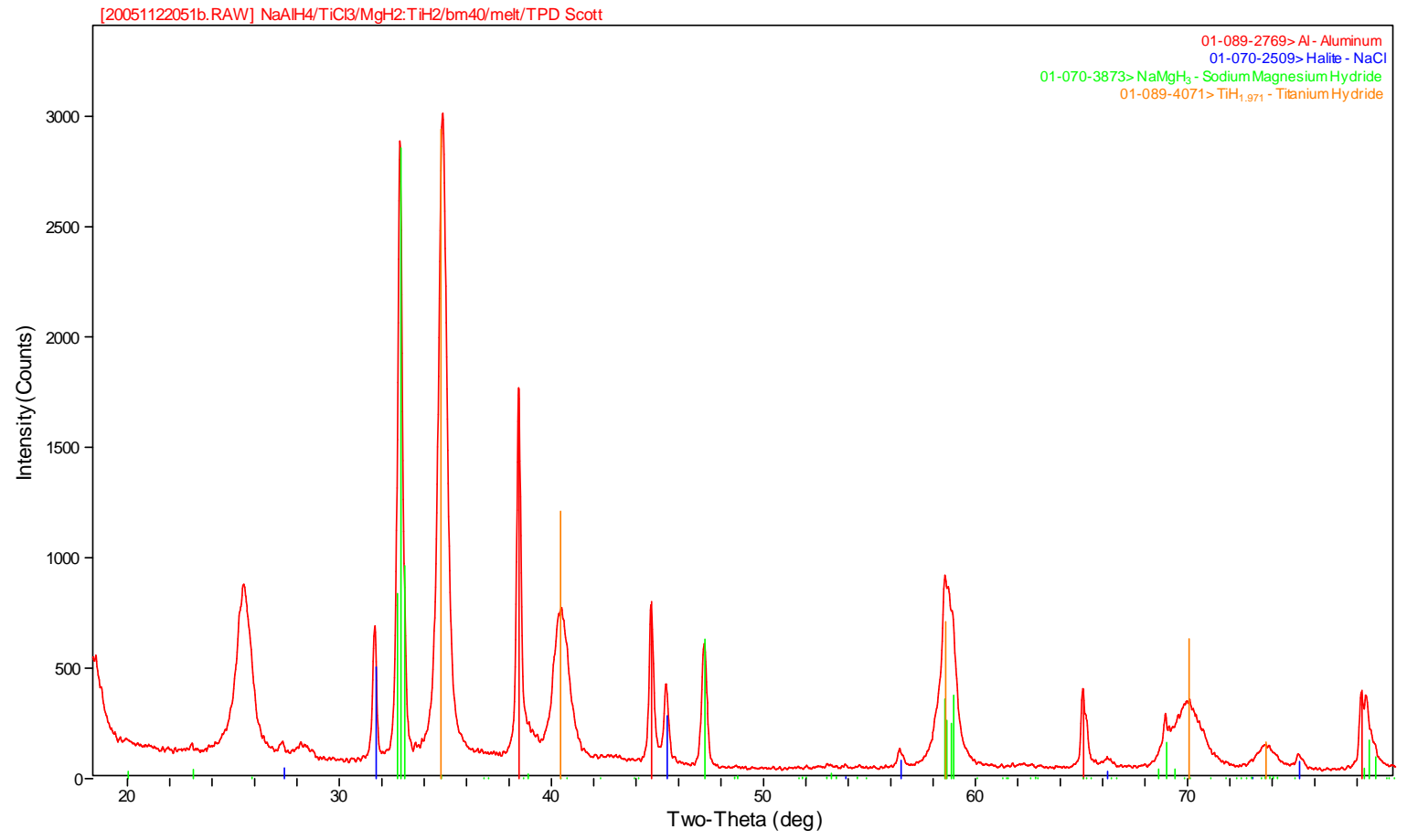

Figure 104: Desorbed melt processed $\mathrm{NaAlH}_{4} / \mathrm{TiCl}_{3} / \mathrm{MgH}_{2} / \mathrm{TiH}_{2}$ mixture. 


\section{Molten State Processing}

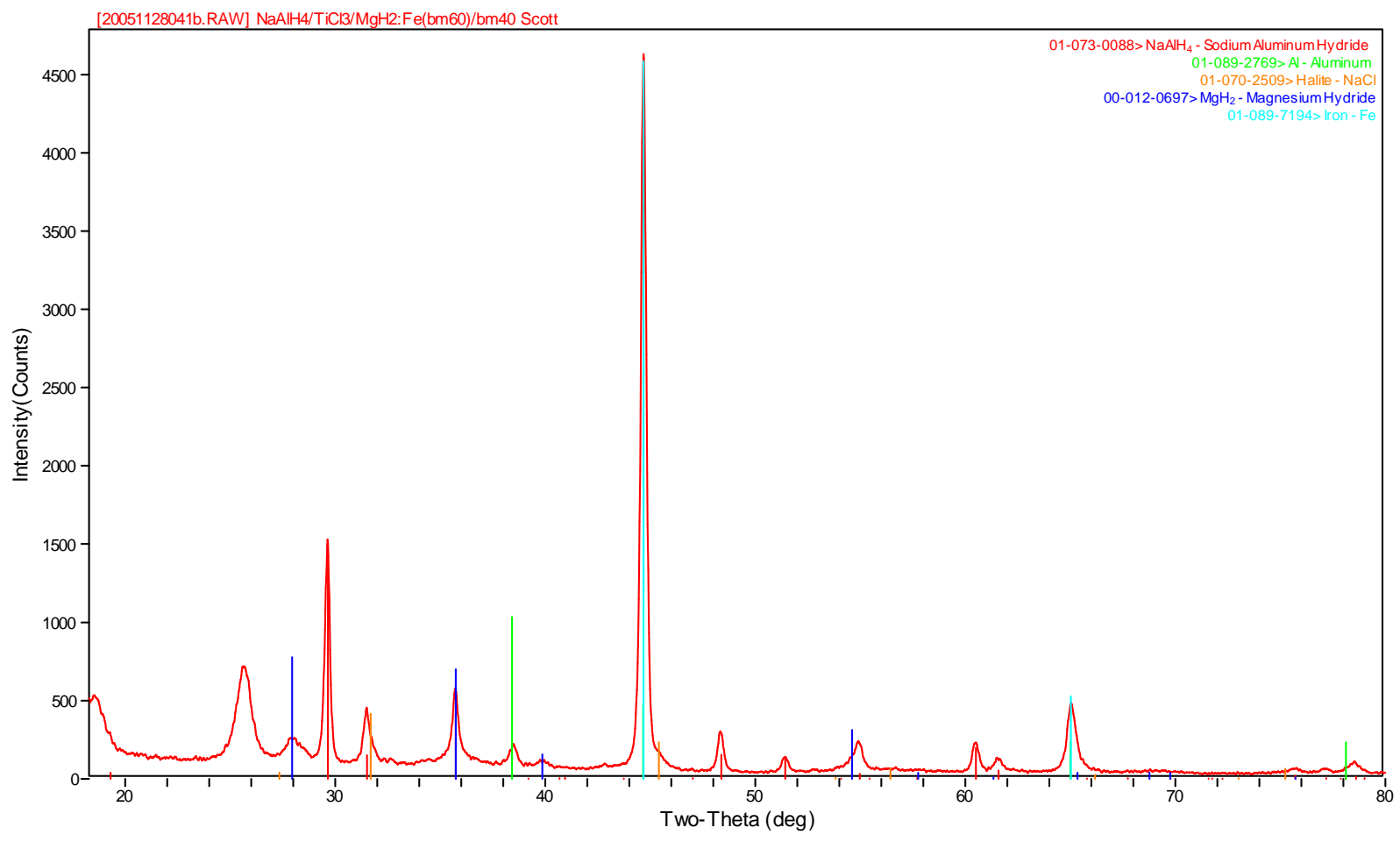

Figure 105: Ball milled $\mathrm{NaAlH}_{4} / \mathrm{TiCl}_{3} / \mathrm{MgH}_{2} / \mathrm{Fe}$ mixture.

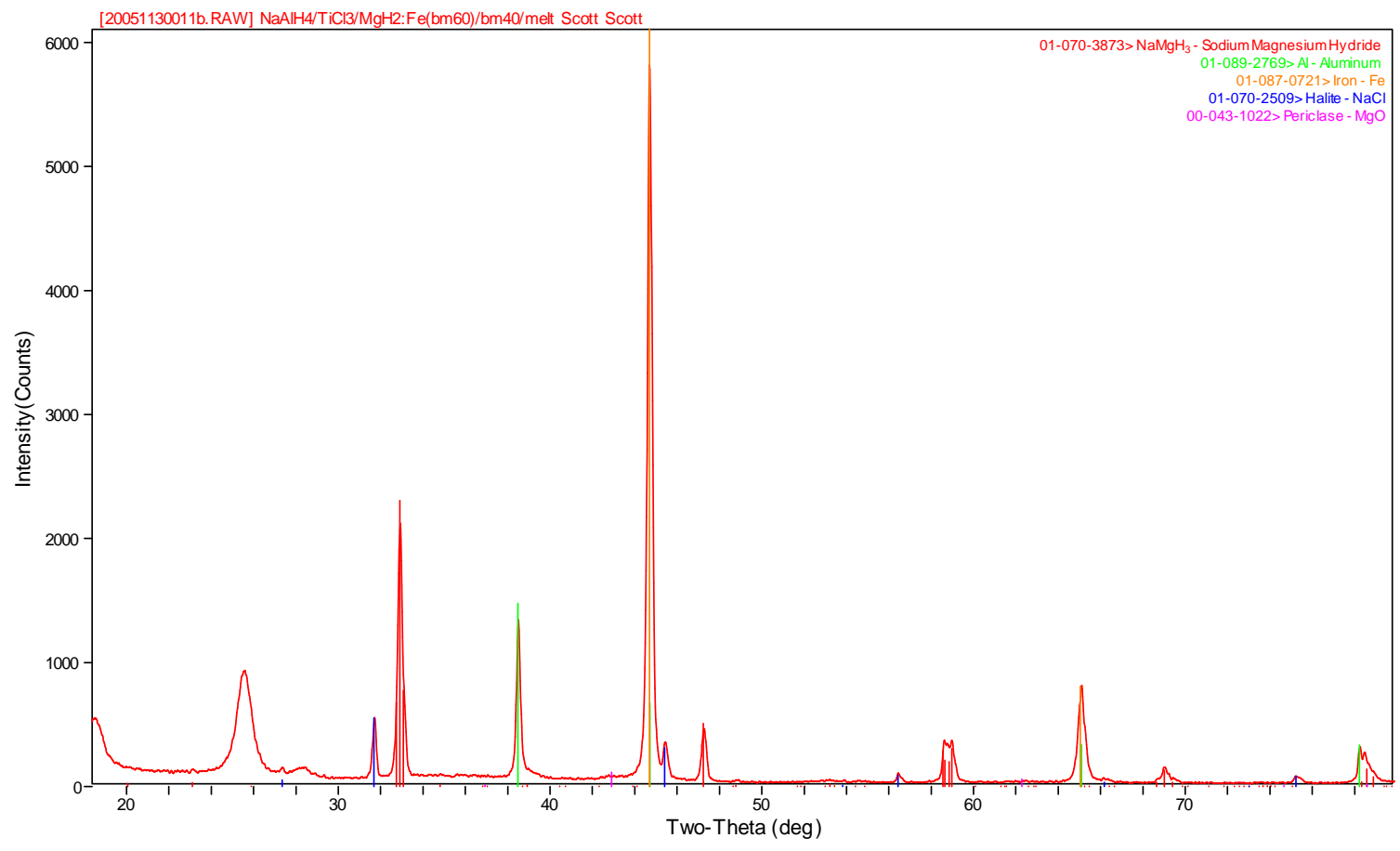

Figure 106: Melt processed $\mathrm{NaAlH}_{4} / \mathrm{TiCl}_{3} / \mathrm{MgH}_{2} / \mathrm{Fe}$ mixture. 


\section{Molten State Processing}

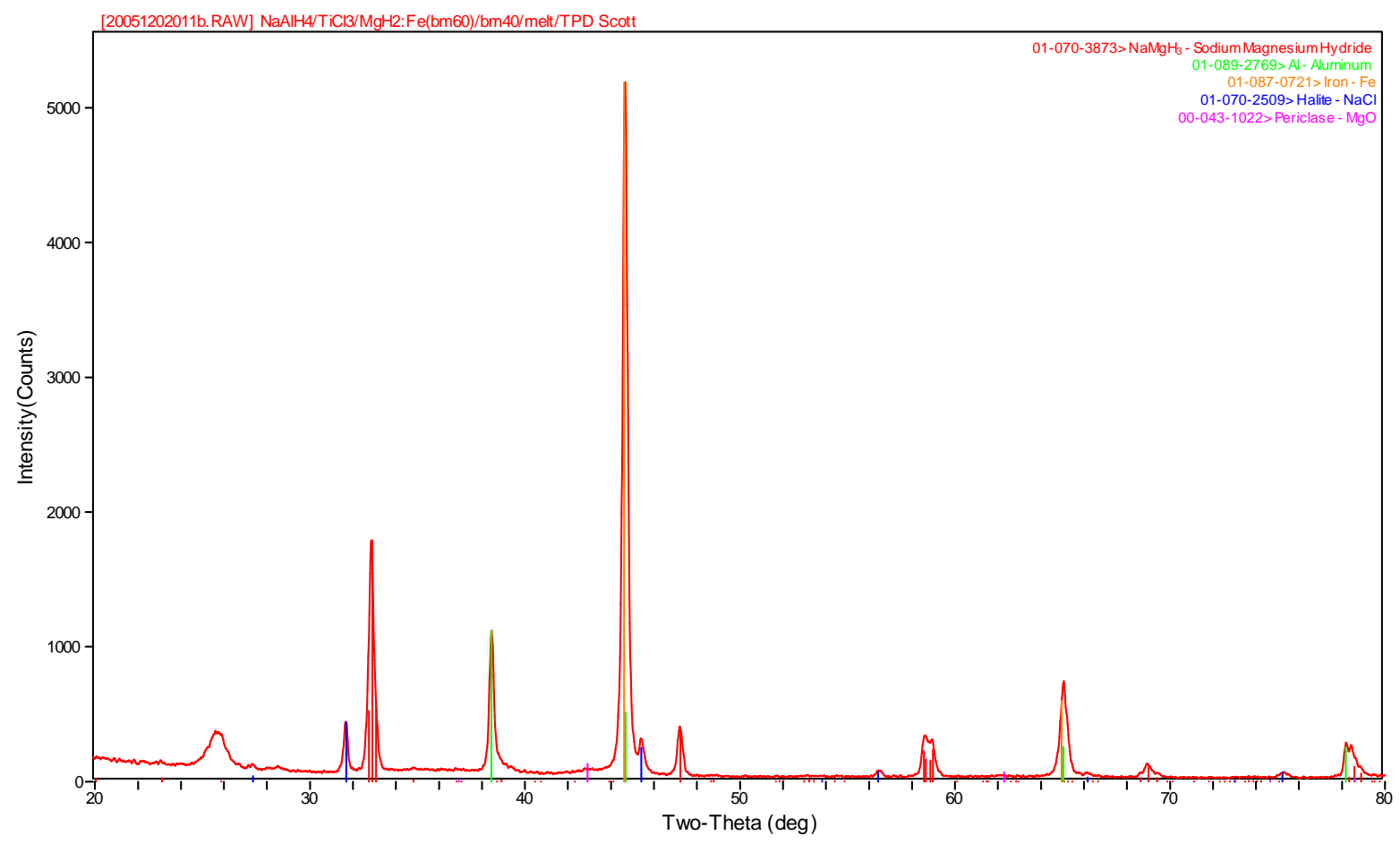

Figure 107: Desorbed melt processed $\mathrm{NaAlH}_{4} / \mathrm{TiCl}_{3} / \mathrm{MgH}_{2} / \mathrm{Fe}$ mixture.

\section{$6.6 \mathrm{NaH}+\left(\mathrm{MgH}_{2} \mathrm{Or} \mathrm{Mg}_{2} \mathrm{NiH}_{4}\right)$}

Quantities of 1.420 grams of $\mathrm{NaH}$ and 1.576 grams of $\mathrm{MgH}_{2}$ were ball milled for 60 minutes, which induced the formation of some $\mathrm{NaMgH}_{3}$. This mixture was not melted and only a thermal desorption was conducted which produced little change in composition (Figure 108).

A mixture containing 0.531 grams of $\mathrm{NaH}$ and 2.046 grams of $\mathrm{Mg}_{2} \mathrm{NiH}_{4}$ (SRNL prep) was ball milled for 40 minutes (Figure 109). This mixture was not melt processed before a thermal desorption was conducted (Figure 110). During this TPD, a pressure of $75 \mathrm{psi}$ developed at $320^{\circ} \mathrm{C}$, which represents a minor desorption from the $\mathrm{Mg}_{2} \mathrm{NiH}_{4}$. 


\section{Molten State Processing}

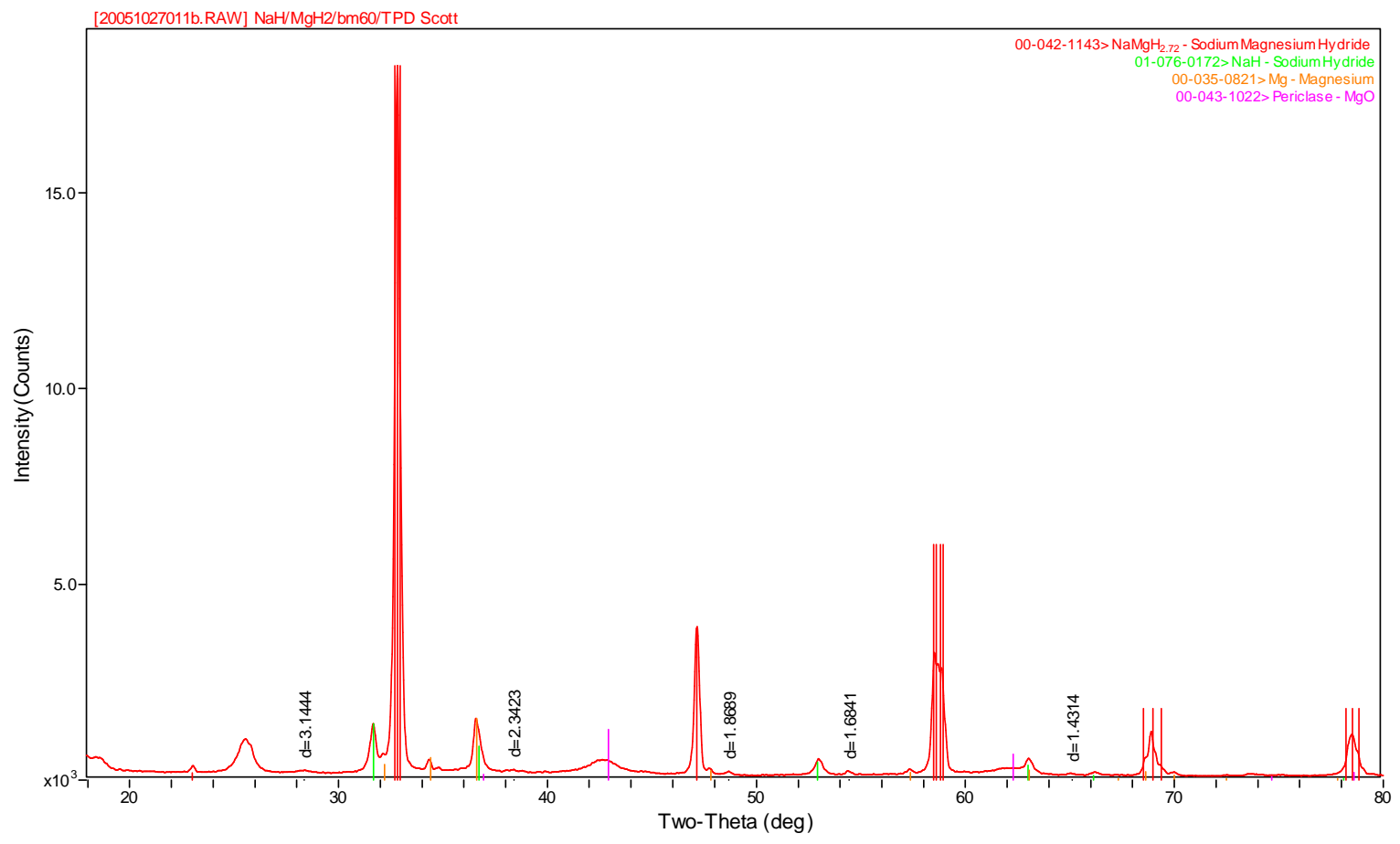

Figure 108: Ball milled and desorbed $\mathrm{NaH} / \mathrm{MgH}_{2}$ mixture.

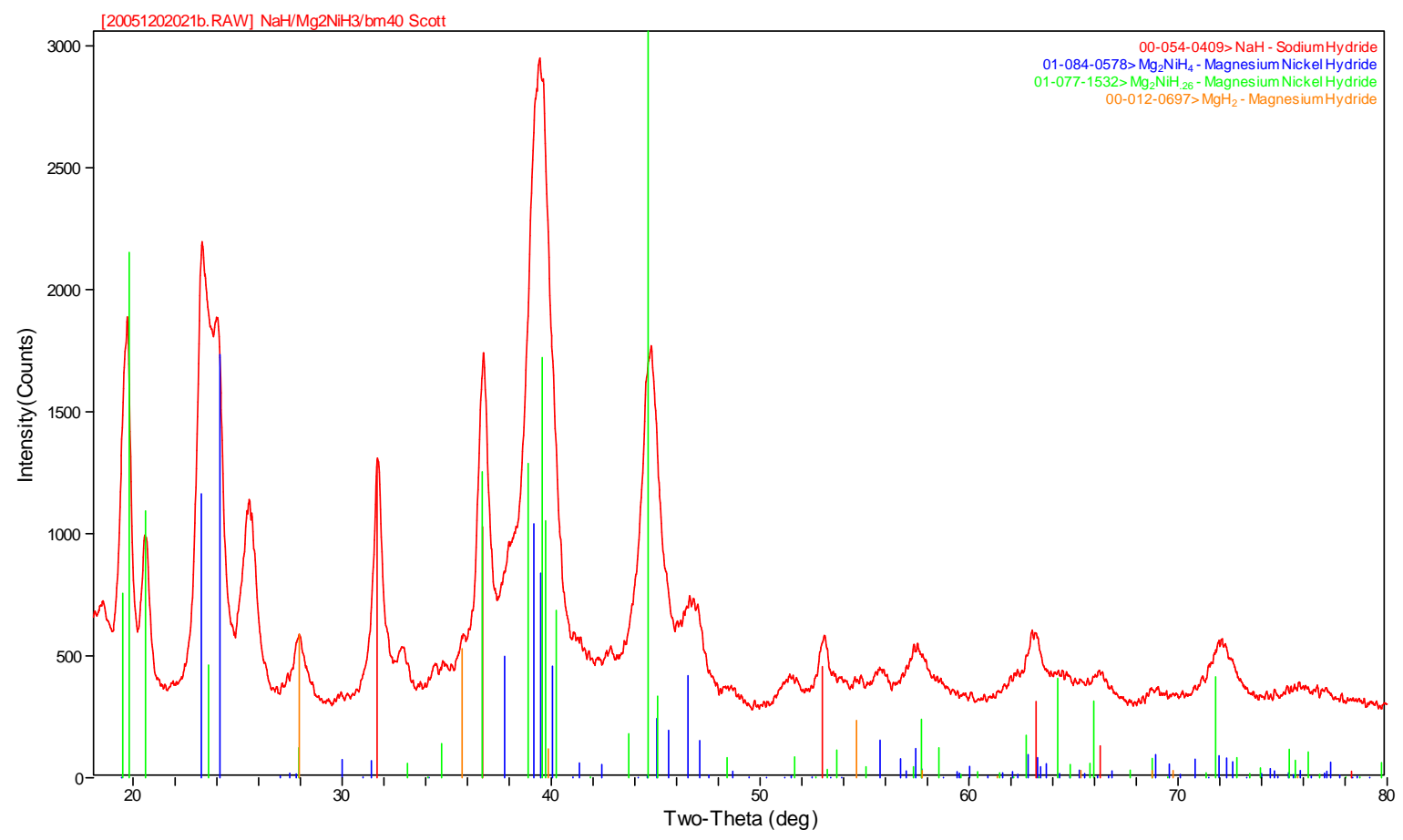

Figure 109: Ball milled $\mathrm{NaH} / \mathrm{Mg}_{2} \mathrm{NH}_{4}$ mixture. 


\section{Molten State Processing}

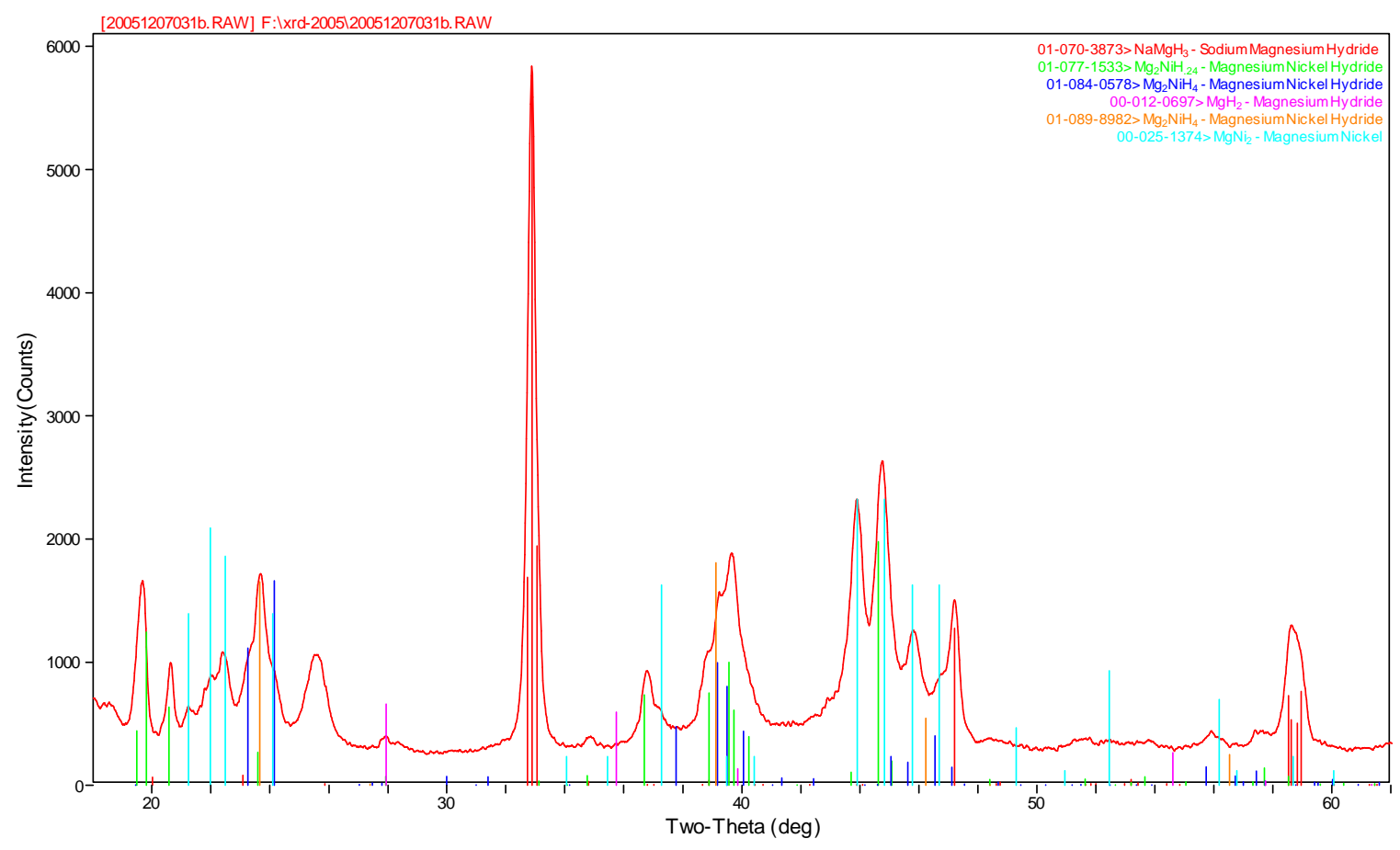

Figure 110: Desorbed $\mathrm{NaH} / \mathrm{Mg}_{2} \mathrm{NH}_{4}$ mixture.

\section{7 $\mathrm{LiAlH} 4+\left(\mathrm{KH}\right.$ or $\mathrm{MgH}_{2}$ or $\left.\mathrm{CaH}_{2}\right)$}

A combination of 0.712 grams of $\mathrm{KH}, 0.344$ grams of $\mathrm{LiAlH}_{4}$, and 0.052 grams of $\mathrm{TiCl}_{3}$ was milled for 40 minutes (Figure 111). The XRD pattern for melt processing of this mixture is shown in Figure 112 , indicating little change in composition from the as-mixed state.

In the first trial involving $\mathrm{MgH}_{2}, 0.684$ grams of $\mathrm{MgH}_{2}, 0.967$ grams of $\mathrm{LiAlH}_{4}$, and 0.155 grams of $\mathrm{TiCl}_{3}$ were milled for 40 minutes resulting in the XRD pattern of Figure 113. The mixture was melt processed, producing the partially altered XRD pattern of Figure 114 indicating decomposition of the lithium aluminum hexahydride.

A second trial involving a reduced proportion of $\mathrm{MgH}_{2}$ contained 0.472 grams of $\mathrm{MgH}_{2}, 2.034$ grams of $\mathrm{LiAlH}_{4}$, and 0.330 grams of $\mathrm{TiCl}_{3}$ which were similarly ball milled for 40 minutes (Figure 115). The mixture was melt processed (Figure 116), producing results similar to trial 1, and a thermal desorption run conducted to $275^{\circ} \mathrm{C}$ with no desorption related pressure rise occurring. This material was cooled under hydrogen pressure, initially at $\sim 750 \mathrm{psi}$, to room temperature with no sign of uptake.

For the experiments involving $\mathrm{CaH}_{2}, 1.069$ grams of $\mathrm{CaH}_{2}$ (Sigma-Aldrich 99.9\%), 0.961 grams of $\mathrm{LiAlH}_{4}$, and 0.152 grams of $\mathrm{TiCl}_{3}$ were ball milled for 40 minutes (Figure 117). The mixture was then melt processed with the resulting XRD pattern of Figure 118, indicating decomposition of the lithium aluminum hexahydride similar to the $\mathrm{MgH}_{2}$ mixtures. 


\section{Molten State Processing}

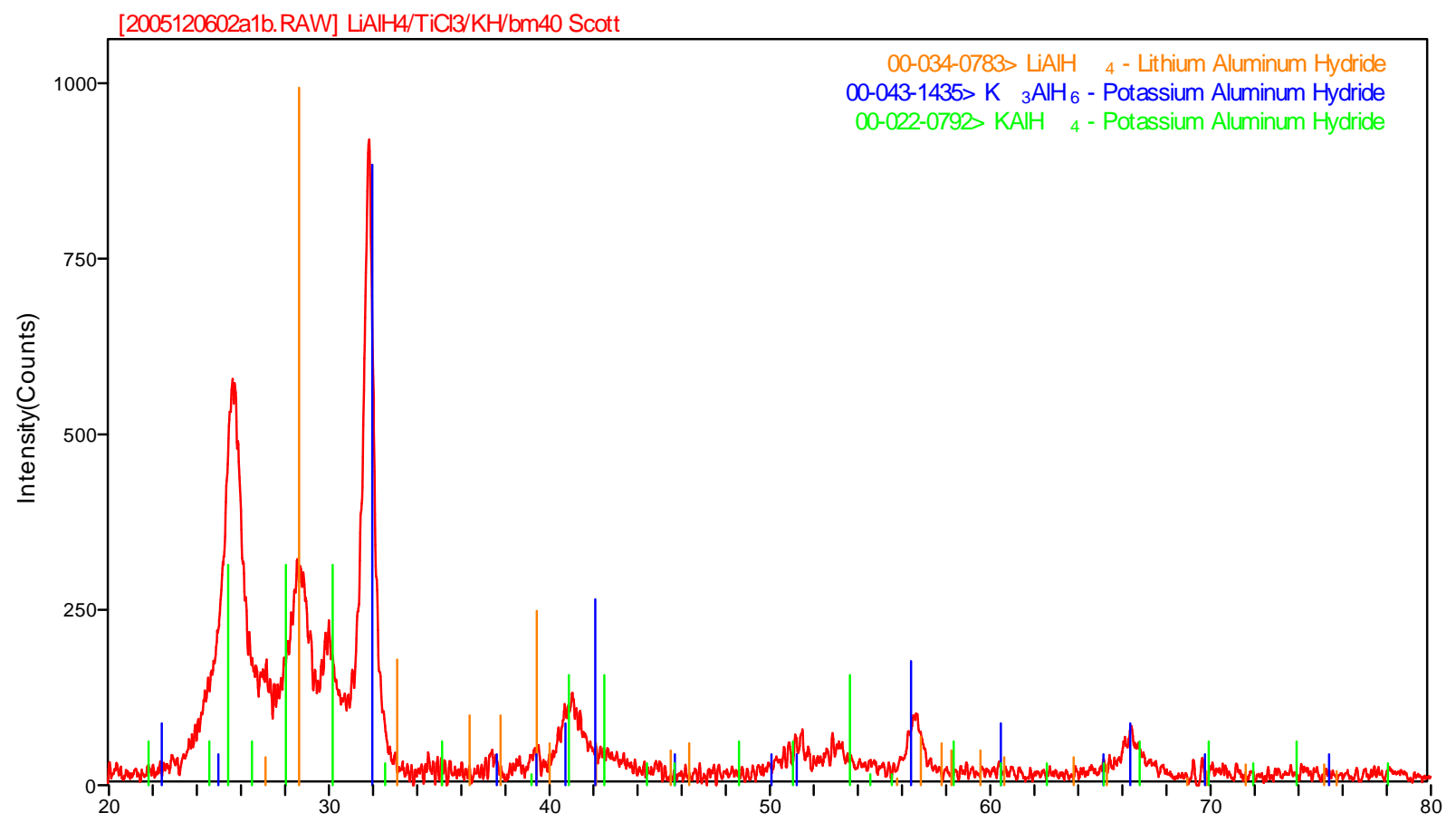

Figure 111: Ball milled $\mathrm{LiAlH}_{4} / \mathrm{TiCl}_{3} / \mathrm{KH}$ mixture.

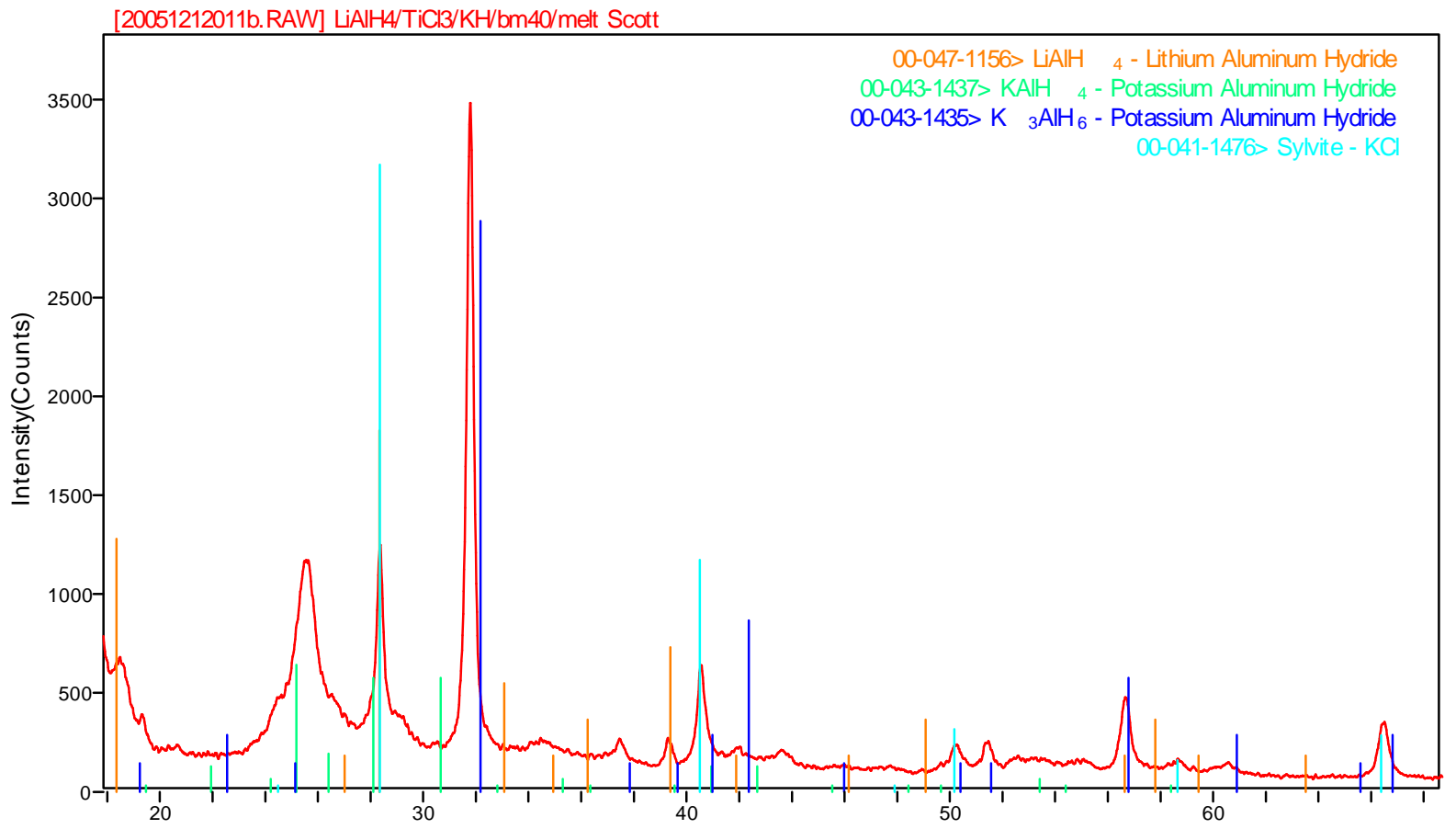

Figure 112: Melt processed $\mathrm{LiAlH}_{4} / \mathrm{TiCl}_{3} / \mathrm{KH}$ mixture. 


\section{Molten State Processing}

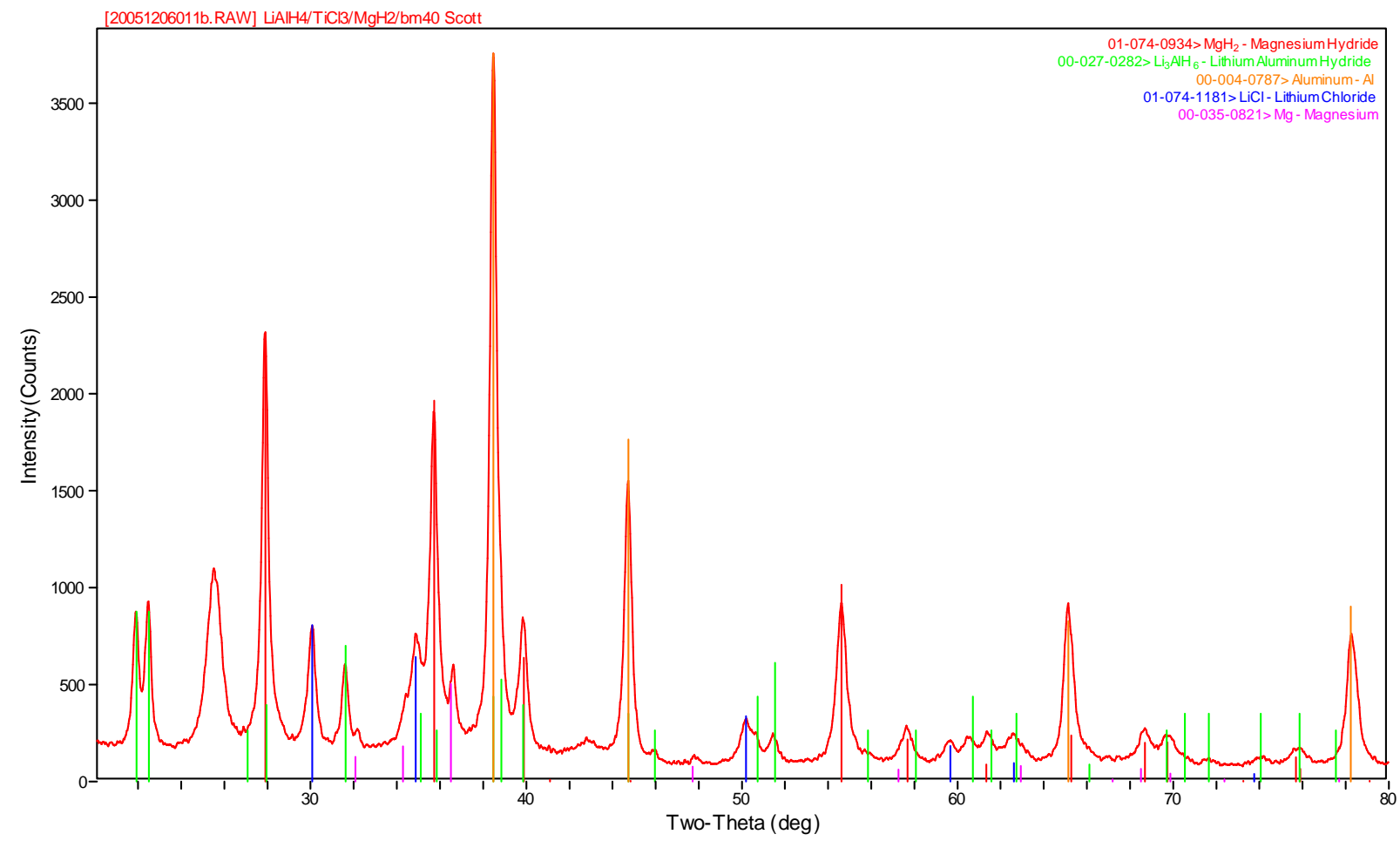

Figure 113: Ball milled $\mathrm{LiAlH}_{4} / \mathrm{TiCl}_{3} / \mathrm{MgH}_{2}$ mixture - trial 1.

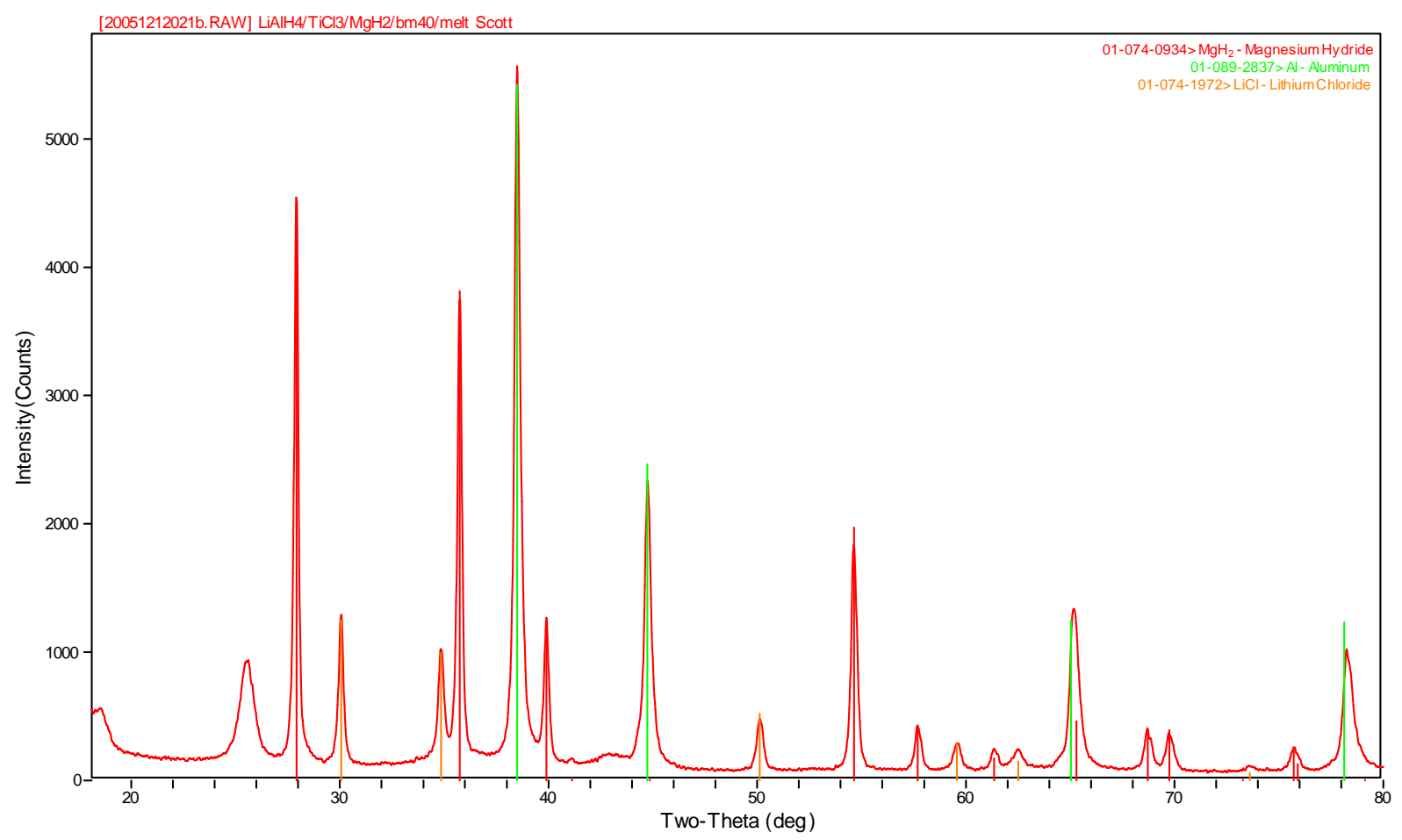

Figure 114: Melt processed $\mathrm{LiAlH}_{4} / \mathrm{TiCl}_{3} / \mathrm{MgH}_{2}$ mixture - trial 1 . 


\section{Molten State Processing}

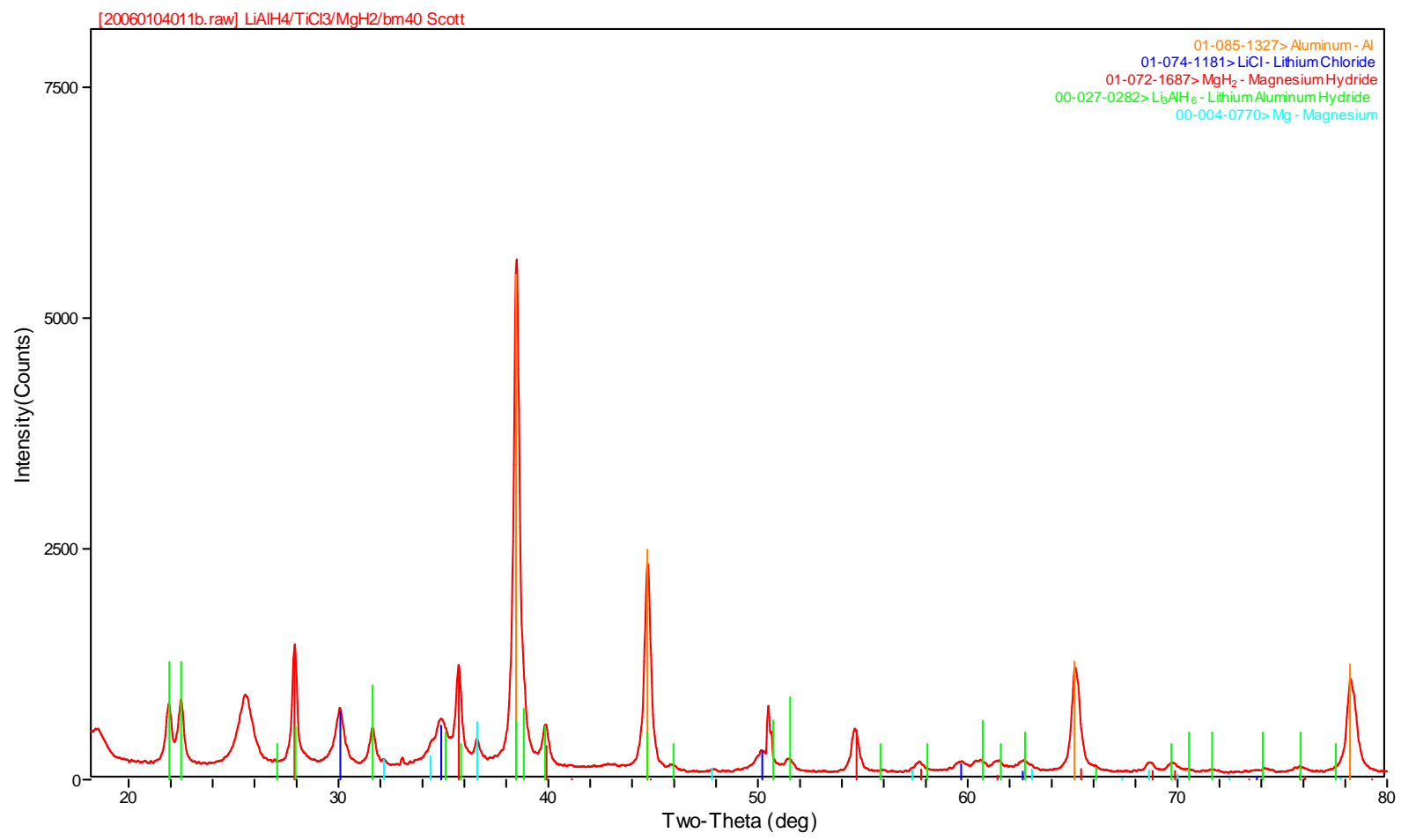

Figure 115: Ball milled $\mathrm{LiAlH}_{4} / \mathrm{TiCl}_{3} / \mathrm{MgH}_{2}$ mixture - trial 2.

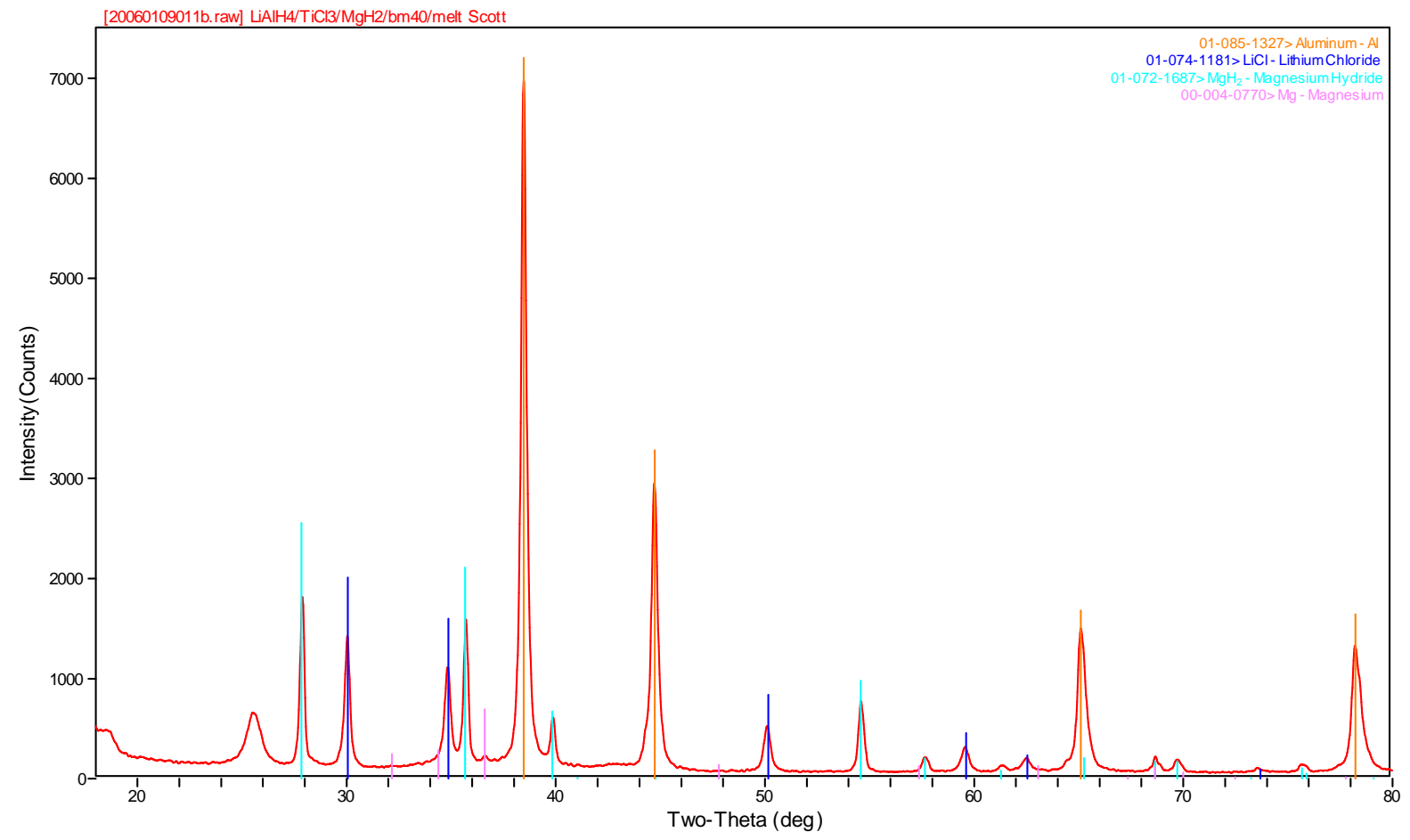

Figure 116: Melt processed $\mathrm{LiAlH}_{4} / \mathrm{TiCl}_{3} / \mathrm{MgH}_{2}$ mixture - trial 2. 


\section{Molten State Processing}

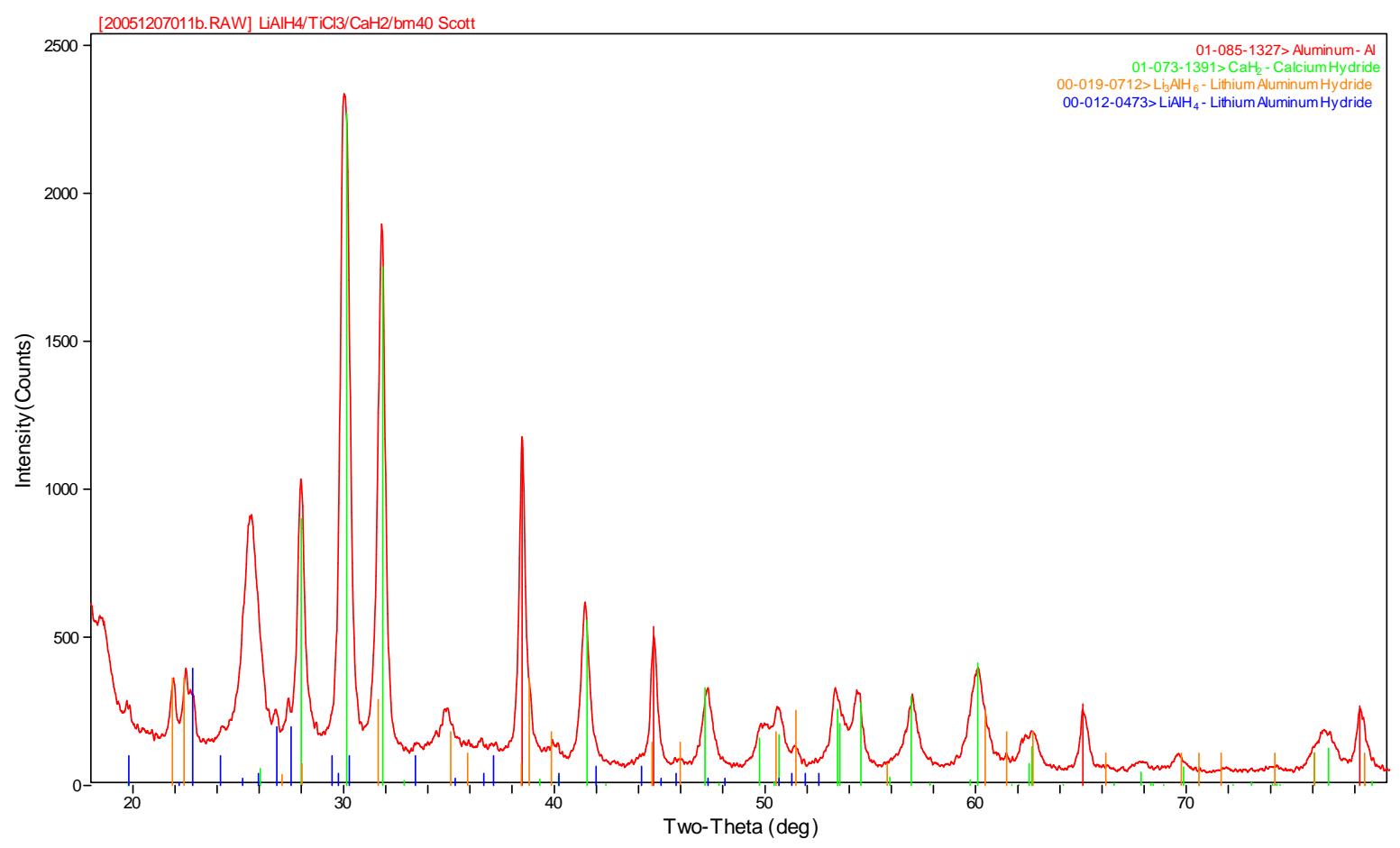

Figure 117: Ball milled $\mathrm{LiAlH}_{4} / \mathrm{TiCl}_{3} / \mathrm{CaH}_{2}$ mixture.

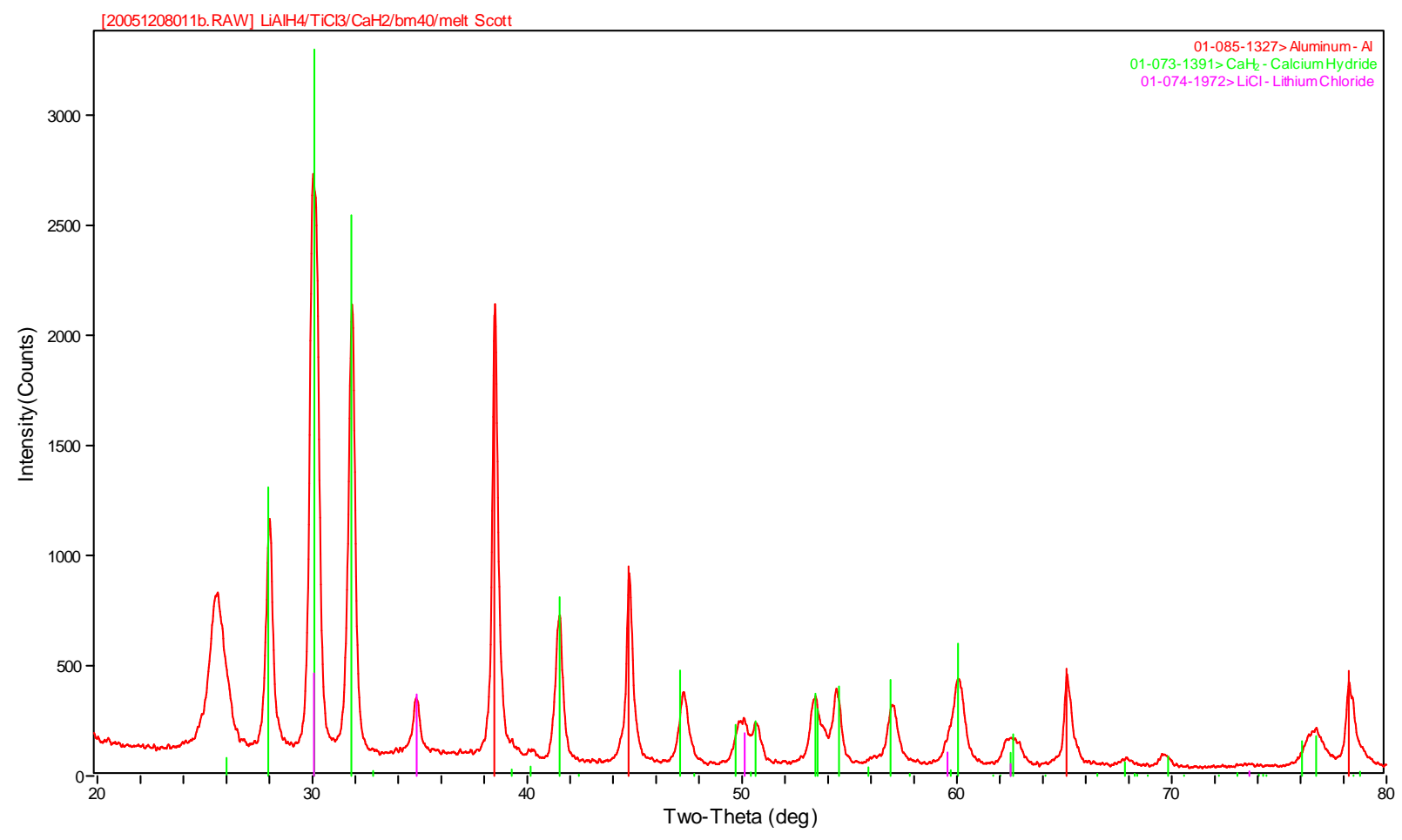

Figure 118: Melt processed $\mathrm{LiAlH}_{4} / \mathrm{TiCl}_{3} / \mathrm{CaH}_{2}$ mixture. 


\section{Molten State Processing}

\subsection{Mixtures Involving $\mathrm{Mn}, \mathrm{Cr}$ or $\mathrm{V}$}

Various binary (e.g. $\mathrm{NaAlH}_{4}: \mathrm{Cr}$ 1:1 mol ratio), ternary (e.g. $\mathrm{NaAlH}_{4}: \mathrm{LiAlH}_{4}: \mathrm{Cr}$ 1:1:1 mol ratio) and quaternary (e.g. $\mathrm{NaAlH}_{4}: \mathrm{LiAlH}_{4}: \mathrm{MgH}_{2}: \mathrm{Cr}$ 1:1:1:1 mol ratio) mixtures involving $\mathrm{Mn}, \mathrm{Cr}$ or $\mathrm{V}$ were examined. For detailed composition descriptions, see Table 19. The mixtures were created by ball milling powders in a SPEX ball mill. These mixtures were then heated under $\sim 4500 \mathrm{psi}_{2}$ pressure in the MSP step. Below are sections for each transition metal element added to the mixture, followed by a general summary.

\subsubsection{Mixtures of Mn:}

The binary mixtures of Mn ball milled with either $\mathrm{NaAlH}_{4}$ or $\mathrm{LiAlH}_{4}$ yielded starting materials, and in the case of $\mathrm{Li}$ alanate, Al metal, presumably from the decomposition of $\mathrm{LiAlH}_{4}$. When heated for MSP, the binary $\mathrm{Na}$ mixture produces $\mathrm{Na}_{3} \mathrm{AlH}_{6}$ in addition to the starting materials. The mixture with $\mathrm{Li}$ produces $\mathrm{Mn}$ and $\mathrm{Al}$, while any $\mathrm{Li}$ species are amorphous as they do not show up in the XRD pattern. The ternary mixture of both alanates with $\mathrm{Mn}$ yields starting materials and $\mathrm{Al}$ with ball milling. Heating this mixture for MSP at $170^{\circ} \mathrm{C}$ or $190^{\circ} \mathrm{C}$ yields $\mathrm{LiNa}_{2} \mathrm{AlH}_{6}, \mathrm{Mn}, \mathrm{Al}$ and possibly $\mathrm{NaH}$. The quaternary mixture of both alanates, $\mathrm{MgH}_{2}$ and $\mathrm{Mn}$ is interesting in that it yields $\mathrm{MnH}_{0.07}$ with just ball milling, in addition to the non-Mn starting materials and $\mathrm{Al}$. The $\mathrm{H}$ is assumed to originate with $\mathrm{LiAlH}_{4}$ that decomposes with ball milling. When this mixture is heated for MSP, the $\mathrm{MnH}_{0.07}$ decomposes leaving $\mathrm{Mn}$, in addition to $\mathrm{MgH}_{2}, \mathrm{Al}, \mathrm{LiNa}_{2} \mathrm{AlH}_{6}, \mathrm{NaMgH}_{3}$, and possibly $\mathrm{NaH}$.

\subsubsection{Mixtures of $\mathrm{Cr}$ :}

The binary mixtures of $\mathrm{Cr}$ ball milled with $\mathrm{NaAlH}_{4}$ or $\mathrm{LiAlH}_{4}$ yield starting materials, and in the case of the $\mathrm{Li}$ alanate $\mathrm{Al}$, suggesting that some of the $\mathrm{LiAlH}_{4}$ has decomposed with ball milling. When heated for MSP, the sodium mixture yields starting materials and $\mathrm{Na}_{3} \mathrm{AlH}_{6}$. The binary mixture with $\mathrm{Li}$ forms starting materials, $\mathrm{Al}$, and $\mathrm{Li}_{3} \mathrm{AlH}_{6}$ with the MSP reaction at $170^{\circ} \mathrm{C}$. The ternary mixture of both alanates with $\mathrm{Cr}$ gives starting materials and $\mathrm{Al}$ with ball milling. The MSP products for this mixture are $\mathrm{LiNa}_{2} \mathrm{AlH}_{6}, \mathrm{NaAlH}_{4}, \mathrm{Al}, \mathrm{Cr}$ and possibly $\mathrm{NaH}$. The quaternary mixture, which has $\mathrm{MgH}_{2}$ in addition to the ternary mixture, forms starting materials and $\mathrm{Al}$ with ball milling. When heated, the mixture forms $\mathrm{NaMgH}_{3}, \mathrm{LiNa}_{2} \mathrm{AlH}_{6}, \mathrm{MgH}_{2}, \mathrm{Cr}, \mathrm{Al}$ and possibly $\mathrm{NaH}$.

For the quaternary mixture, which has $\mathrm{NaAlH}_{4}, \mathrm{LiAlH}_{4}$, and $\mathrm{MgH}_{2}$, the ratio of starting materials away from the simple 1:1:1:1 mixture was explored. The $\mathrm{Cr}$ and the $\mathrm{MgH}_{2}$ were varied to see if this would change the reaction. When the $\mathrm{Cr}$ content was doubled, regardless of the $\mathrm{MgH}_{2}$ content, ball milling formed starting materials and $\mathrm{Al}$. This mixture of products was also seen with the original $\mathrm{Cr}$ ratio of 1 . When the 1:1:1:1 mixture is ball milled "cold" by cooling the vial every 10 minutes for a total of 60 minutes of milling, the decomposition of $\mathrm{LiAlH}_{4}$ was prevented and only the starting materials (no Al) were seen in the XRD pattern as shown in Figure 119 below. This mixture was then melt processed at a low temperature of $60^{\circ} \mathrm{C}$ (usually done at $170^{\circ} \mathrm{C}$ or higher). The low temperature MSP method yields $\mathrm{SM}, \mathrm{Al}$, and $\mathrm{Li}_{3} \mathrm{AlH}_{6}$. The $\mathrm{Na}$ and $\mathrm{Mg}$ compounds do not react as they do with higher temperatures, confirming that the $\mathrm{LiAlH}_{4}$ is the least stable hydride in the mixture. When the ratio of $\mathrm{Cr}$ is increased to 4, ball milling alone causes the $\mathrm{LiAlH}_{4}$ to decompose completely, forming $\mathrm{Al}$ and $\mathrm{Li}_{3} \mathrm{AlH}_{6}$ in addition to the other 3 starting materials. 


\section{Molten State Processing}

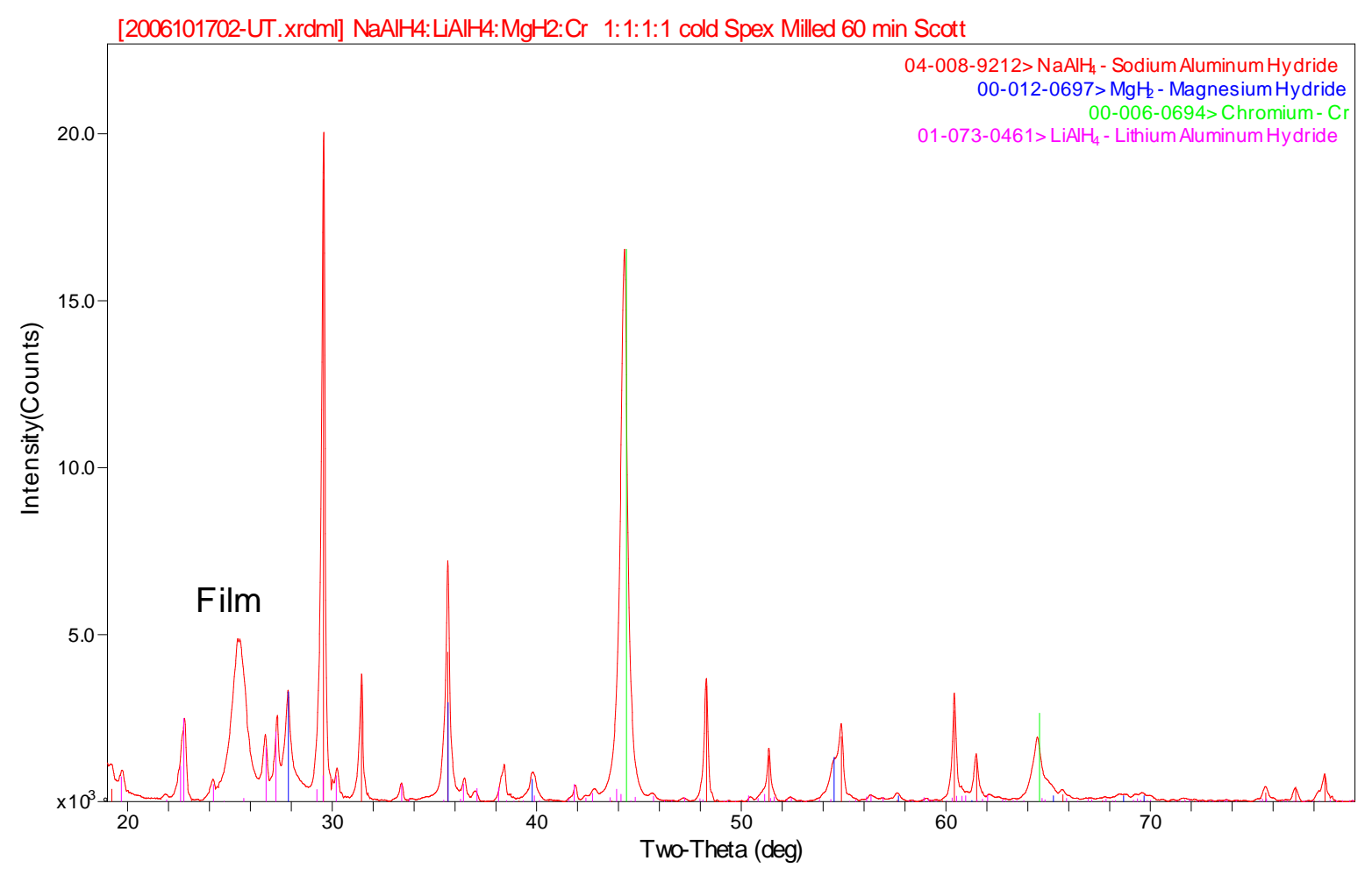

Figure 119: Ball milled $\mathrm{NaAlH}_{4}: \mathrm{LiAlH}_{4}: \mathrm{MgH}_{2}: \mathrm{Cr}$ 1:1:1:4 with cooling.

\subsubsection{Mixtures of $\mathrm{VH}_{\mathrm{x}}$ :}

Vanadium hydride is not commercially available. The hydride was synthesized at SRNL using V metal powder and a high pressure $\mathrm{H}_{2}$ manifold. The powder was heated to $300^{\circ} \mathrm{C}$ with active vacuum, and 30 minute cycles of $\sim 4000 \mathrm{psi}_{2}$ were alternated with active vacuum for a total of 3-5 cycles. The material was cooled to room temperature under $\mathrm{H}_{2}$ pressure. The newly synthesized material dehydrided slightly at room temperature, as seen by a pressure increase with time, so it was evacuated for $\sim 30$ minutes to remove residual gas. The material was evaluated by XRD, shown below in Figure 120.

The binary mixture of $\mathrm{NaAlH}_{4}$ with $\mathrm{VH}_{0.81}$ outgassed after ball milling, so XRD could not be performed. The quaternary mixture of $\mathrm{NaAlH}_{4}: \mathrm{LiAlH}_{4}: \mathrm{MgH}_{2}: \mathrm{VH}_{0.81} 1: 1: 1: 1$ forms starting materials and $\mathrm{Al}$ after ball milling. The MSP reaction of this mixture at $170^{\circ} \mathrm{C}$ results in the formation of starting materials $\mathrm{LiAlH}_{4}, \mathrm{MgH}_{2}$ and $\mathrm{VH}_{0.81}$ in addition to $\mathrm{Al}, \mathrm{LiNa}_{2} \mathrm{AlH}_{6}$ and $\mathrm{NaMgH}_{3}$ as shown in Figure 121. 


\section{Molten State Processing}

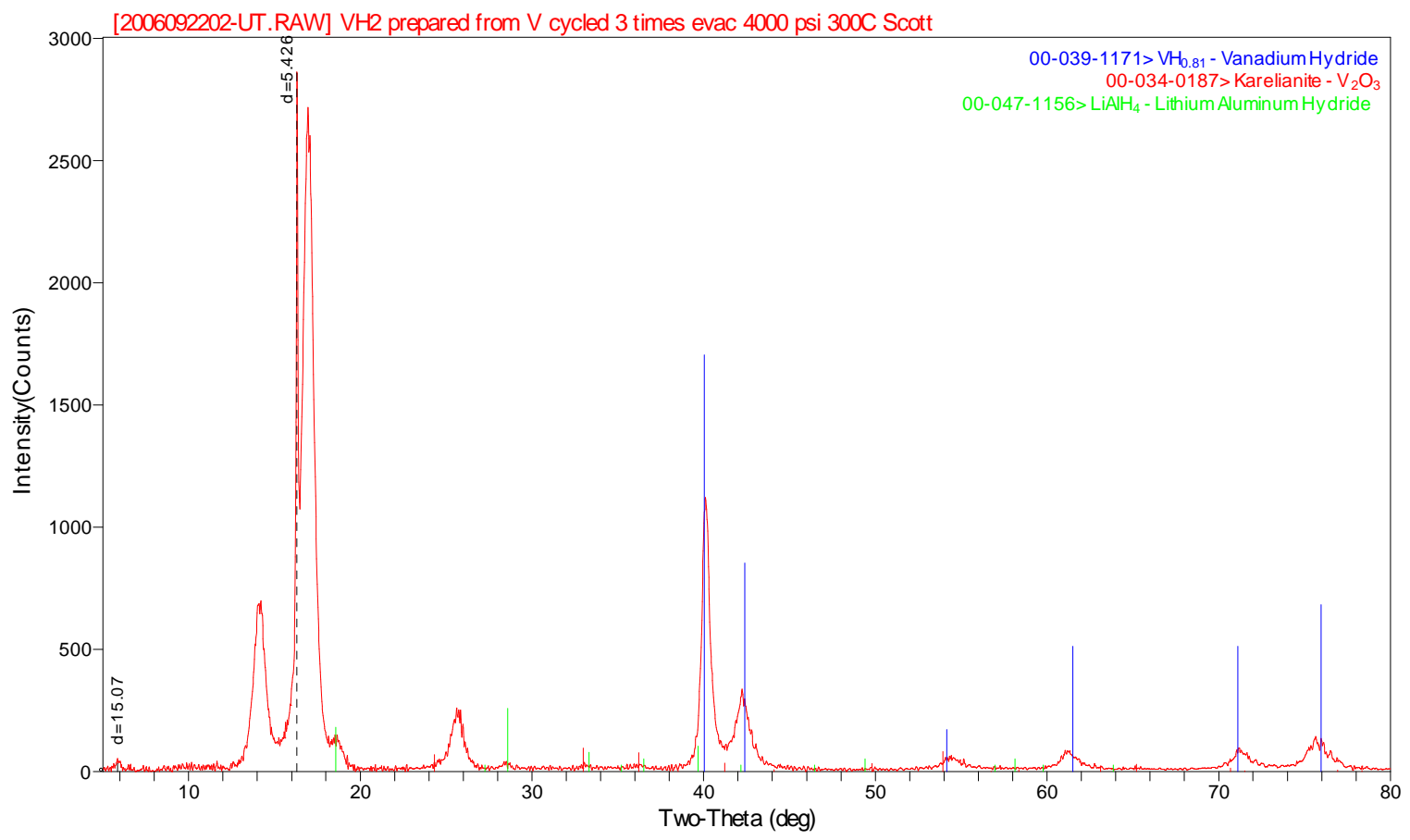

Figure 120: XRD pattern of $\mathrm{VH}_{0.81}$ synthesized at SRNL.

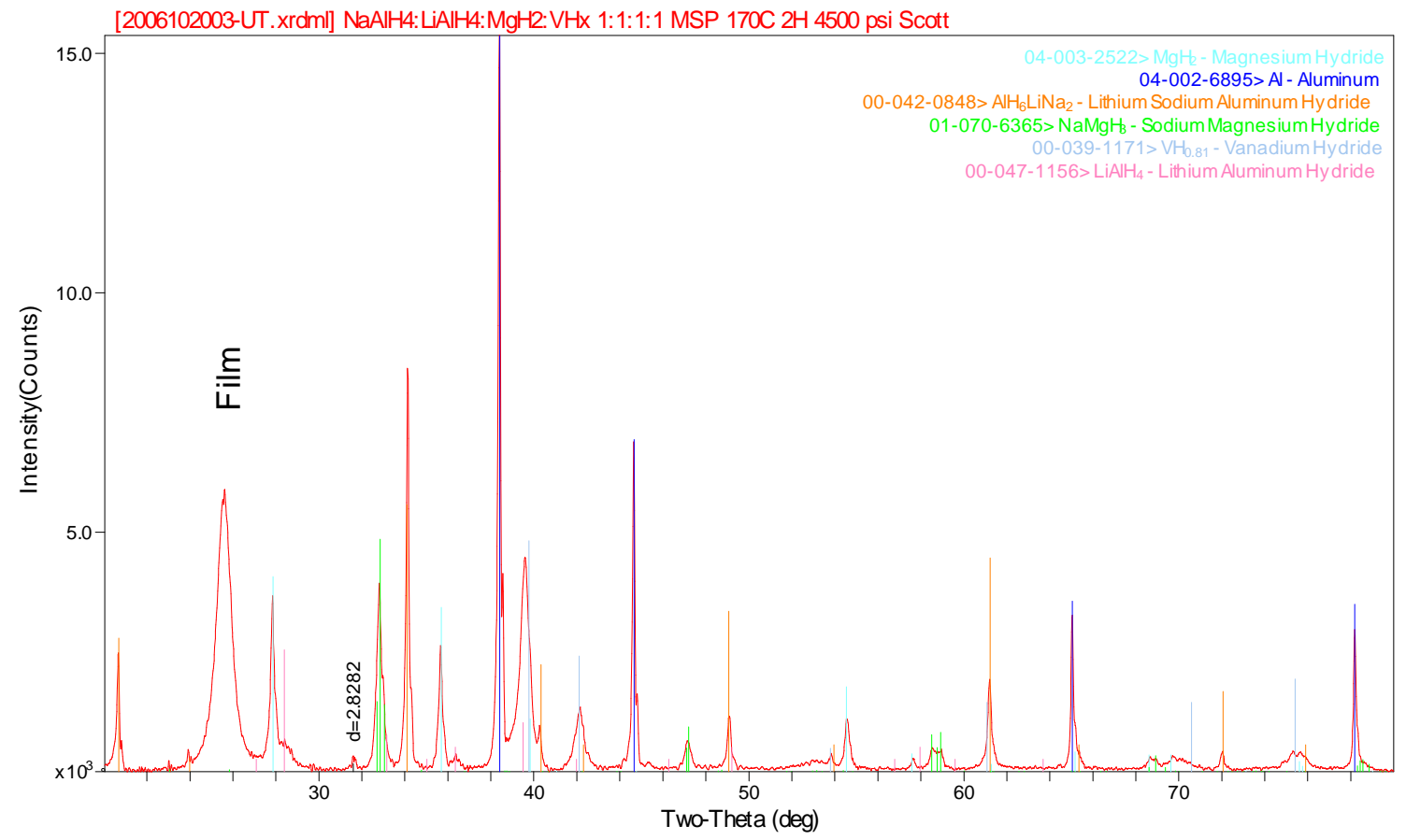

Figure 121: Melt processed $\left(170^{\circ} \mathrm{C}\right) \mathrm{NaAlH}_{4}: \mathrm{LiAlH}_{4}: \mathrm{MgH}_{2}: \mathrm{VH}_{0.81}$ 1:1:1:1.

Summary 


\section{Molten State Processing}

Table 22 below summarizes the results of these experiments, where starting materials are designated SM. The addition of elements or other hydrides destabilizes $\mathrm{LiAlH}_{4}$, while mixtures with binary hydrides produce the hexahydride, $\mathrm{Li}_{3} \mathrm{AlH}_{6} . \mathrm{NaAlH}_{4}$ in combination with $\mathrm{Mg}$ materials produces $\mathrm{NaMgH}_{3}$. As observed in Section 6.4 and consistent with the modeling in Section 3.3.2.2, when the $\mathrm{Mg}$ compound used is $\mathrm{Mg}_{2} \mathrm{NiH}_{4}, \mathrm{NaMgH}_{3}$ forms with just ball milling, while mixtures with $\mathrm{MgH}_{2}$ do not form the mixed metal hydride until heated in the MSP step. Mixtures containing $\mathrm{LiAlH}_{4}$ and $\mathrm{NaAlH}_{4}$ form $\mathrm{LiNa}_{2} \mathrm{AlH}_{6}$ with MSP.

The summary provides a general sense of the reactions seen, and there are occasional exceptions. One is the quaternary mixture mentioned above, $\mathrm{NaAlH}_{4}: \mathrm{LiAlH}_{4}: \mathrm{MgH}_{2}: \mathrm{Mn}$, which formed a $\mathrm{Mn}$ hydride with BM, with the $\mathrm{H}$ most likely supplied by $\mathrm{LiAlH}_{4}$ decomposition. Further reaction under MSP conditions reforms elemental $\mathrm{Mn}$ as well as other products. The XRD patterns for these two reactions are shown below in Figure 122 and Figure 123.

Table 22: High level conclusions for $\mathrm{Na}$ and $\mathrm{Li}$ alanate mixtures $(\mathrm{BM}=\mathrm{Ball}$ Milled; $\mathrm{MSP}=$ Molten State Processed; SM = Starting Materials).

\begin{tabular}{|c|c|c|}
\hline Mixture & $\mathbf{B M}$ & MSP \\
\hline $\mathrm{NaAlH}_{4}+$ elements & No reaction & $\mathrm{Na}_{3} \mathrm{AlH}_{6}$ \\
\hline $\mathrm{LiAlH}_{4}+$ elements & $\mathrm{Al}$ and $\mathrm{SM}$ & $\mathrm{Al}, \mathrm{SM}$ and $\mathrm{Li}_{3} \mathrm{AlH}_{6}$ \\
\hline $\begin{array}{l}\mathrm{NaAlH}_{4}+\mathrm{LiAlH}_{4} \\
\text { mixtures }\end{array}$ & Usually Al and SM. & $\begin{array}{l}\mathrm{LiNa}_{2} \mathrm{AlH}_{6}, \mathrm{NaMgH}_{3} \text { with } \mathrm{Mg} \\
\text { mixtures if } \mathrm{MSP} \text { is at least } 170^{\circ} \mathrm{C} \text {. } \\
\mathrm{SM}, \mathrm{Al} \text { and } \mathrm{Li}_{3} \mathrm{AlH}_{6} \text { if } \mathrm{MSP} \text { is } \\
60^{\circ} \mathrm{C} \text {. }\end{array}$ \\
\hline $\mathrm{NaAlH}_{4}+\mathrm{Mg}_{2} \mathrm{NiH}_{4}$ & $\mathrm{NaMgH}_{3}$ & \\
\hline $\mathrm{NaAlH}_{4}+\mathrm{MgH}_{2}$ & No NaMg compounds & $\mathrm{NaMgH}_{3}$ \\
\hline $\begin{array}{l}\mathrm{LiAlH}_{4}+\text { binary } \\
\text { hydrides }\end{array}$ & $\begin{array}{l}\mathrm{Li}_{3} \mathrm{AlH}_{6} \text { or ion } \\
\text { exchange (with } \mathrm{KH} \text { - } \\
\mathrm{KAlH}_{4} \text { ) }\end{array}$ & \\
\hline
\end{tabular}




\section{Molten State Processing}

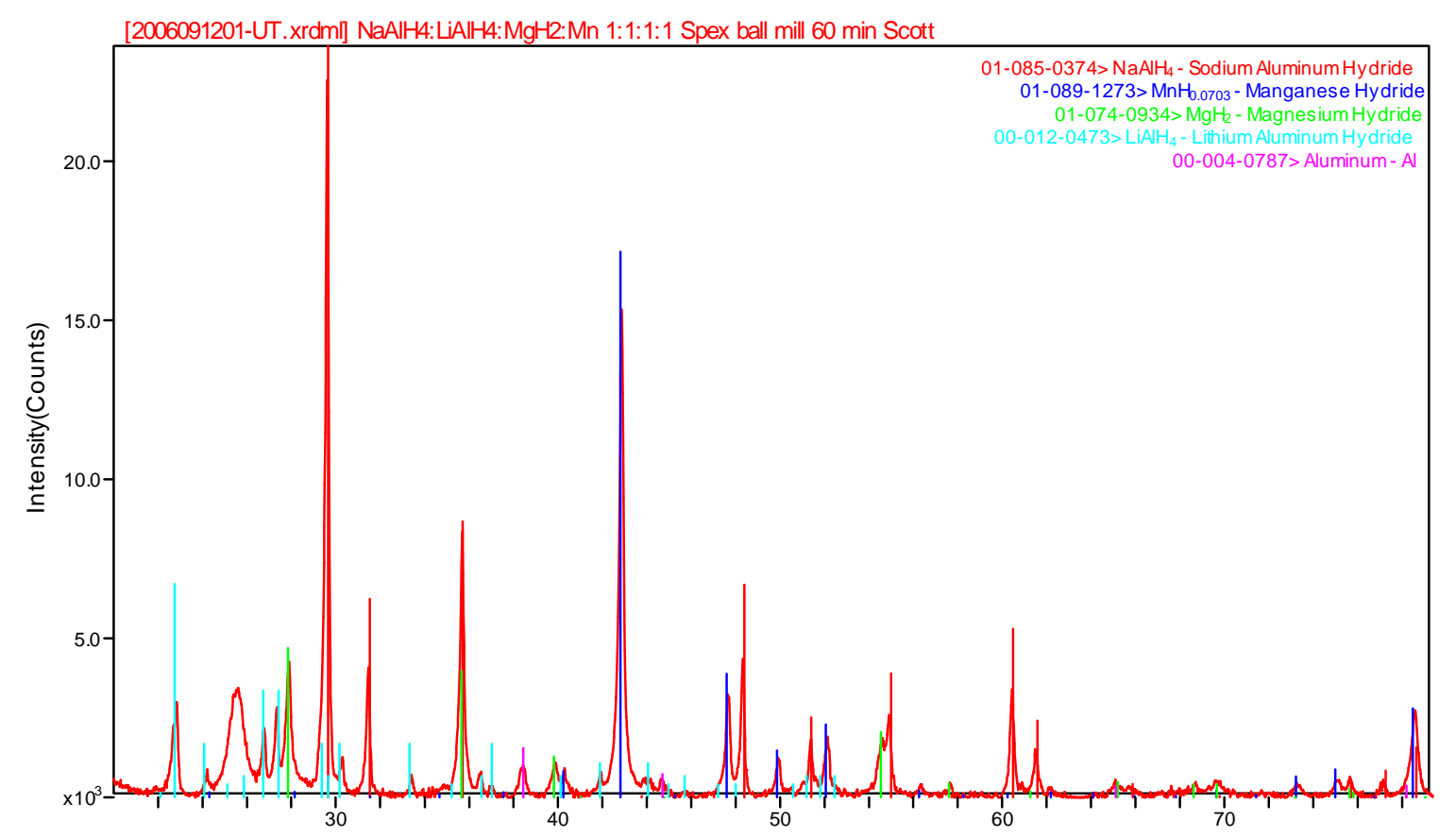

Figure 122: XRD pattern of ball milled 1:1:1:1 mol ratio $\mathrm{NaAlH}_{4}: \mathrm{LiAlH}_{4}: \mathrm{MgH}_{2}: \mathrm{Mn}$.

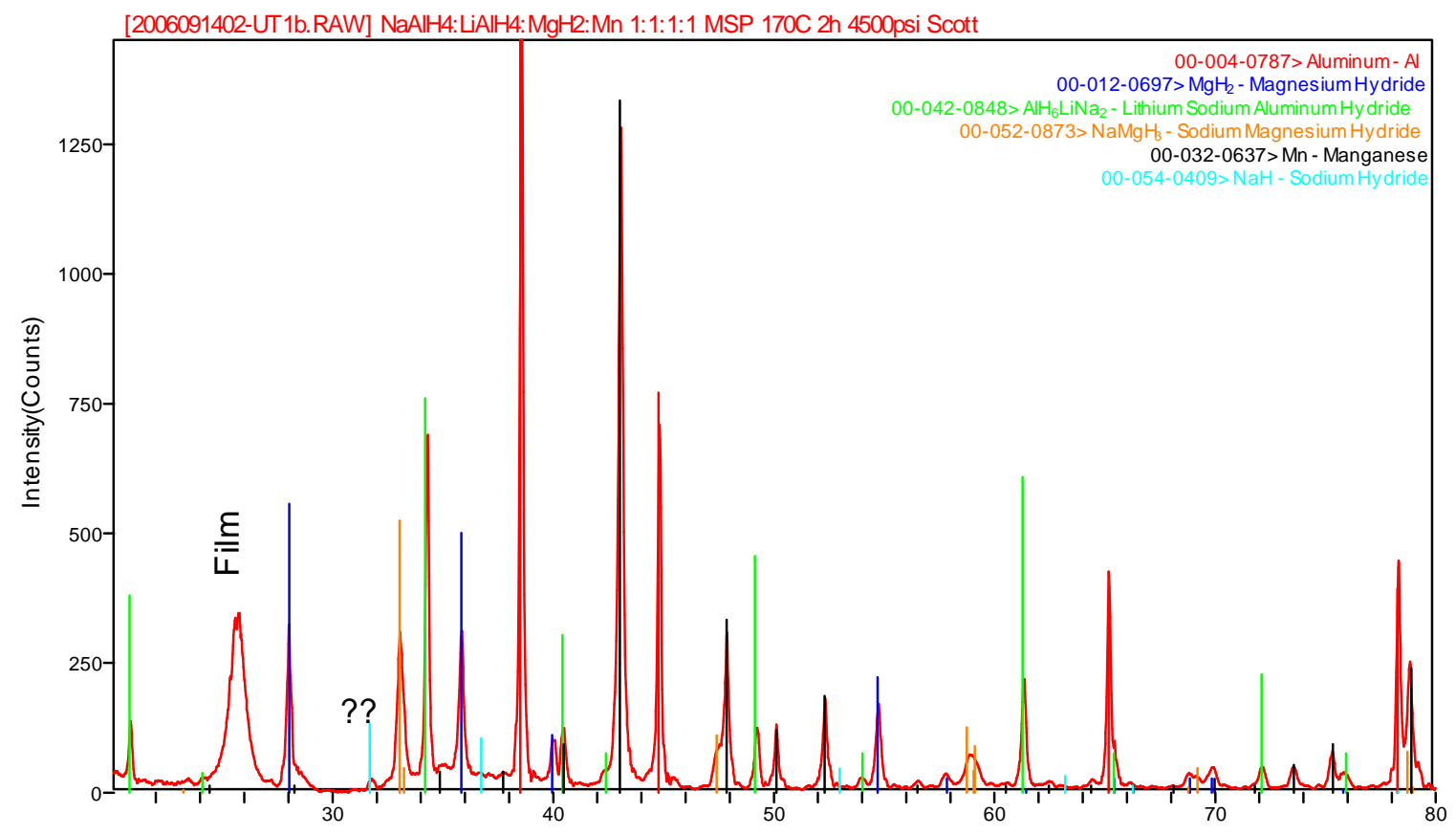

Figure 123: XRD pattern of $170^{\circ} \mathrm{C}$ MSP 1:1:1:1 mol ratio $\mathrm{NaAlH}_{4}: \mathrm{LiAlH}_{4}: \mathrm{MgH}_{2}: \mathrm{Mn}$. 


\section{Molten State Processing}

\subsection{Mixed Metal Borohydrides - MSP}

The production of $\mathrm{Mg}(\mathrm{BH} 4)_{2}$ materials, including mixed metal borohydrides containing $\mathrm{Mg}$ was explored through Fritsch milling of $\mathrm{MgB}_{2}$ alone and $\mathrm{MgB}_{2}$ mixed with $\mathrm{LiBH}_{4}$ under $\sim 100$ psi of $\mathrm{H}_{2}$ pressure, the maximum pressure rating of the milling vials. The resulting products were evaluated by XRD. The processed mixtures resulted in the formation of starting products and $\mathrm{NiCrFe}$, presumably from a reaction with the stainless steel vials as shown below in Figure 124. The vials were limited to 100 psi of gas pressure, which resulted in a less than stoichiometric $\mathrm{H}_{2}$ mole ratio for the quantities milled. We attempted to refill the vials with $\mathrm{H}_{2}$ during the course of ball milling, but found that the valve stem on the vials clogged with powder and therefore were unable to add more hydrogen.

The XRD peaks of the ball milled $\mathrm{MgB}_{2}$ are significantly broader than those of the material as purchased as shown in Figure 125 and Figure 126 below. The peak width analysis shows that the change is due not only to the crystallite size reduction but also the strain induced by ball milling (see Table 23).

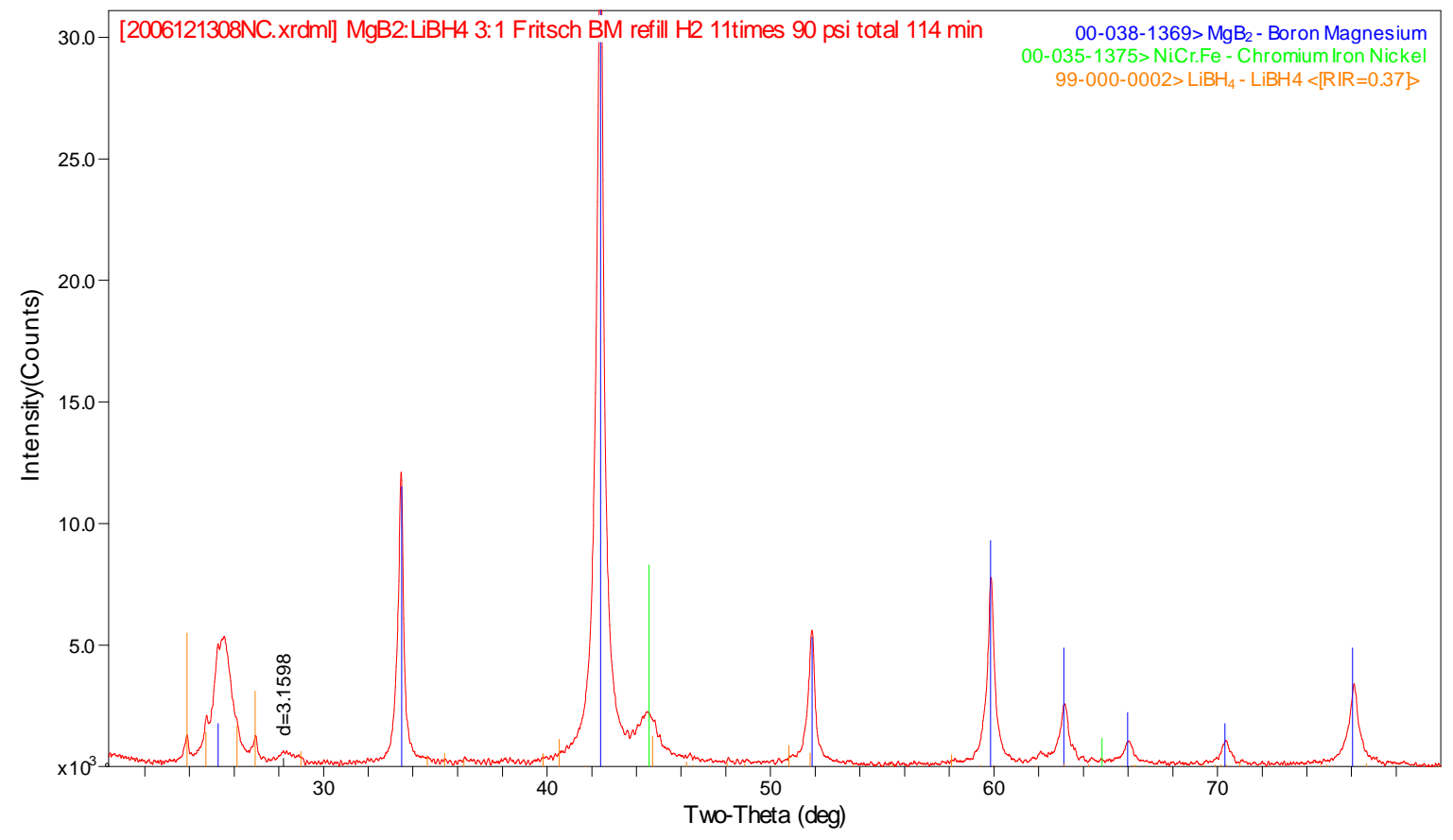

Figure 124: Mixture of $\mathrm{MgB}_{2}$ and $\mathrm{LiBH}_{4}$ ball milled with $\mathrm{H}_{2}$. 


\section{Molten State Processing}

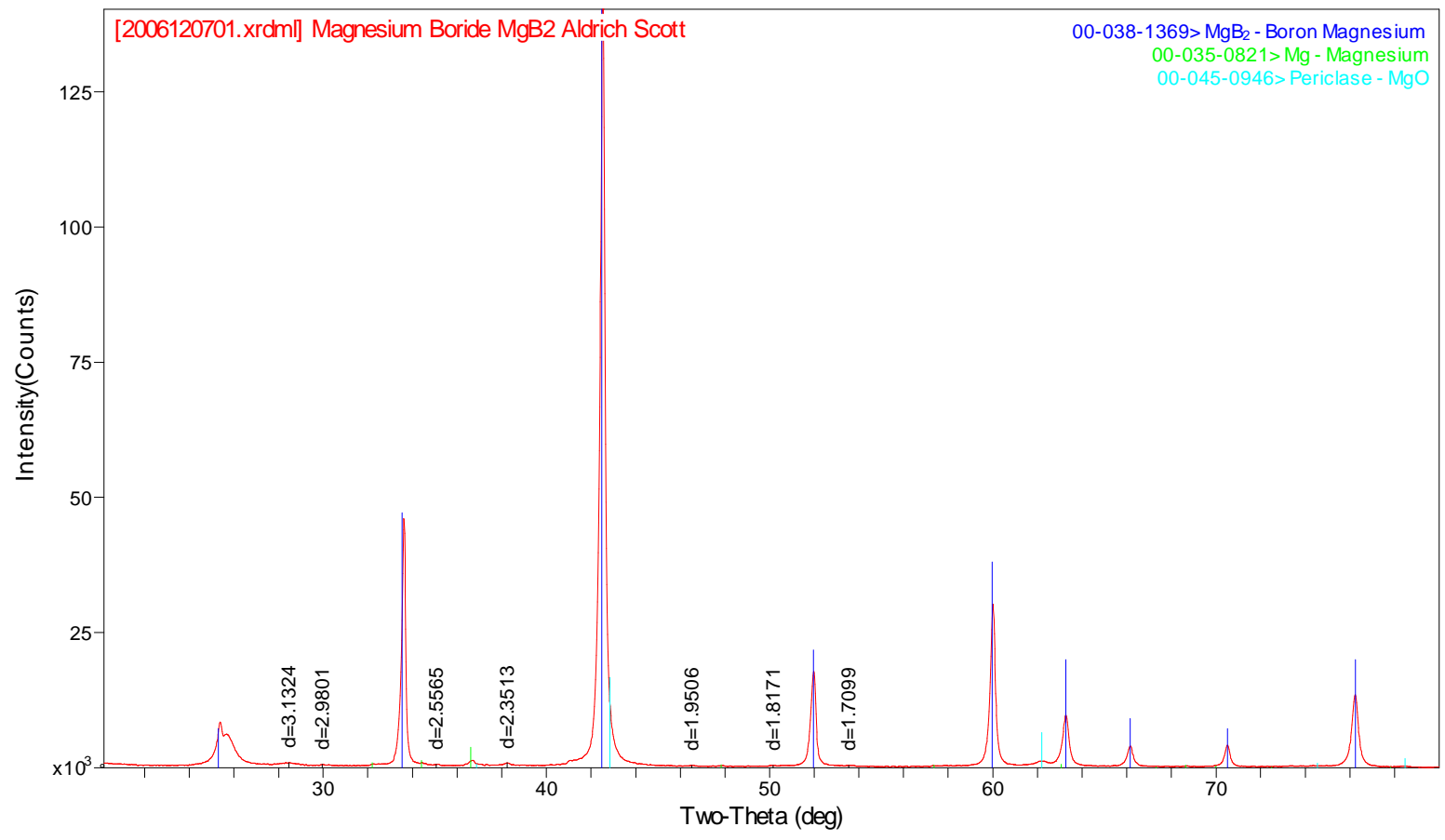

Figure 125: $\mathrm{MgB}_{2}$ as purchased.

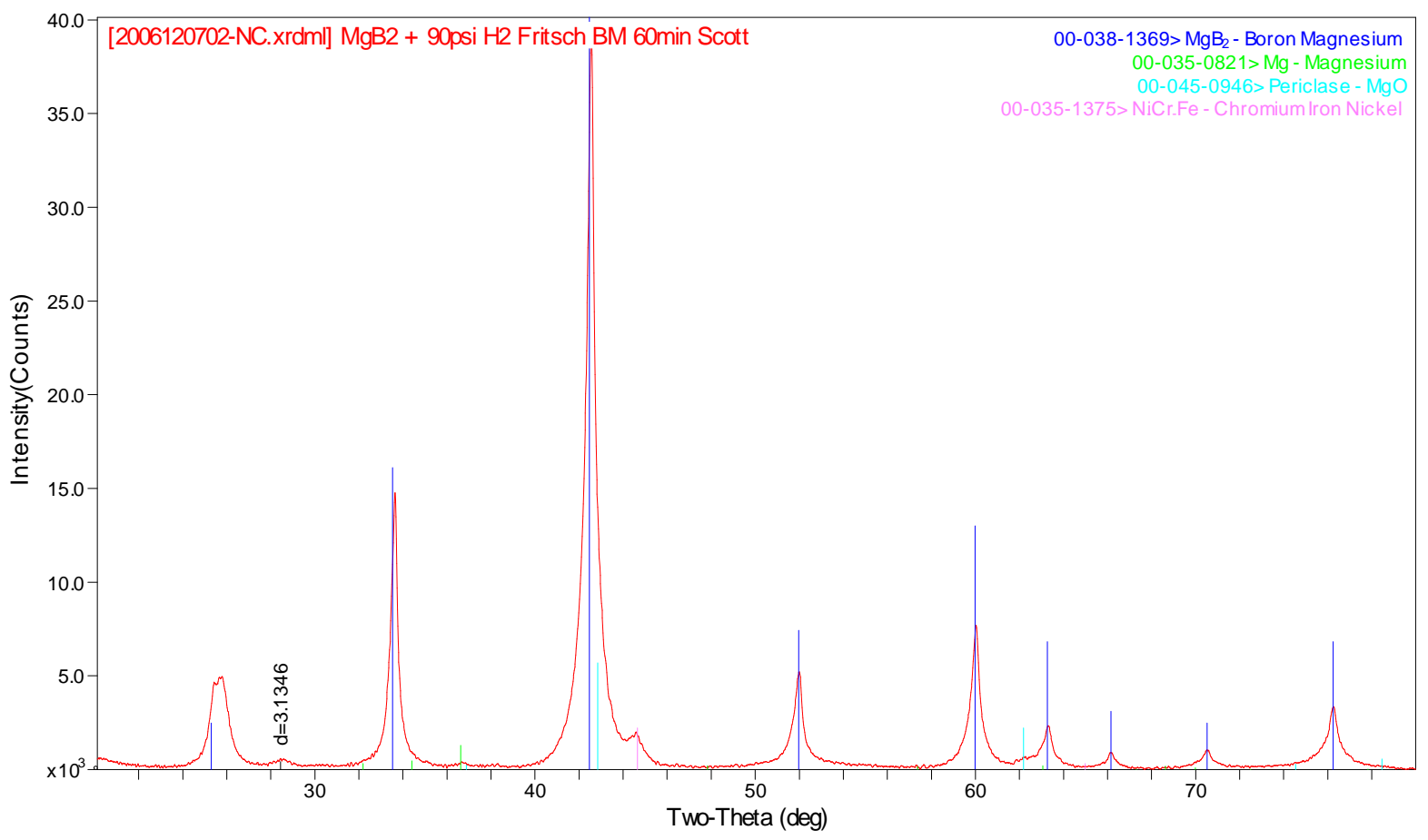

Figure 126: a) $\mathrm{MgB}_{2}$ ball milled for 60 minutes. 


\section{Molten State Processing}

Table 23: $\mathrm{MgB}_{2}$ strain with ball milling

\begin{tabular}{|l|c|l|}
\hline Sample ID & Crystalline Size $(\AA)$ & Strain $(\%)$ \\
\hline Ball milled $\mathrm{MgB}_{2}$ & $597(60)$ & $0.331(0.016)$ \\
\hline As purchased $\mathrm{MgB}_{2}$ & $1051(53)$ & $0.113(0.004)$ \\
\hline
\end{tabular}

\subsection{Mixed Metal Borohydrides - Solvent Mixing}

Two mixtures, $\mathrm{MgCl}_{2}$ combined with $\mathrm{LiBH}_{4}$ and $\mathrm{MgB}_{2}$ combined with $\mathrm{LiBH}_{4}$ were milled with THF. The first sample products were evaluated by XRD. The second mixture formed a very hard coating on the inside of the ball mill vial. The metathesis reaction between $\mathrm{MgCl}_{2}$ and $\mathrm{LiBH}_{4}$ takes place in the presence of THF to form $\mathrm{Mg}\left(\mathrm{BH}_{4}\right)_{2}(\mathrm{THF})_{\mathrm{n}}$ as well as $\mathrm{LiCl}$. The presence of the tri-THF compound was verified by XRD. The XRD pattern is shown below in Figure 127, with the comparison peaks marked. There are unaccounted for peaks associated with minor products which have yet to be identified. To further evaluate this material, UTRC ran TGA-MS analysis, shown in Figure 128. The TGA shows that the material continually loses weight from 30 to $300^{\circ} \mathrm{C}$. The mass spectrometry data show that the $\mathrm{H}_{2}$ evolution begins at $68^{\circ} \mathrm{C}$, which corresponds to the boiling point of THF $\left(66^{\circ} \mathrm{C}\right)$. This confirms that the THF adducts stabilize the material, as $\mathrm{H}_{2}$ is liberated by their release. An increase in the $\mathrm{H}_{2}$ release occurs at $216^{\circ} \mathrm{C}$.

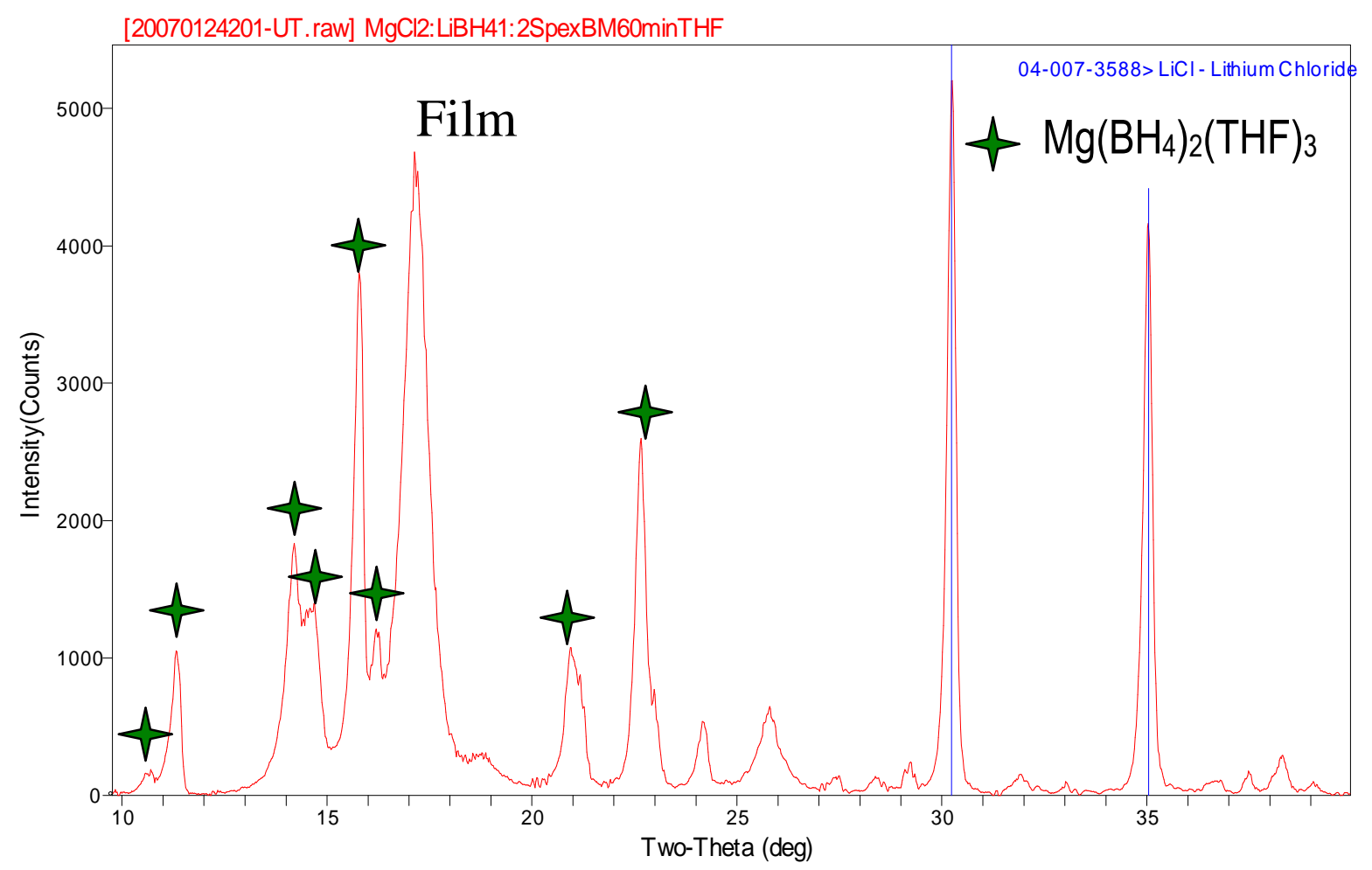

Figure 127: Mixture of $\mathrm{MgCl}_{2}$ and $\mathrm{LiBH}_{4}$ ball milled with THF. 


\section{Molten State Processing}

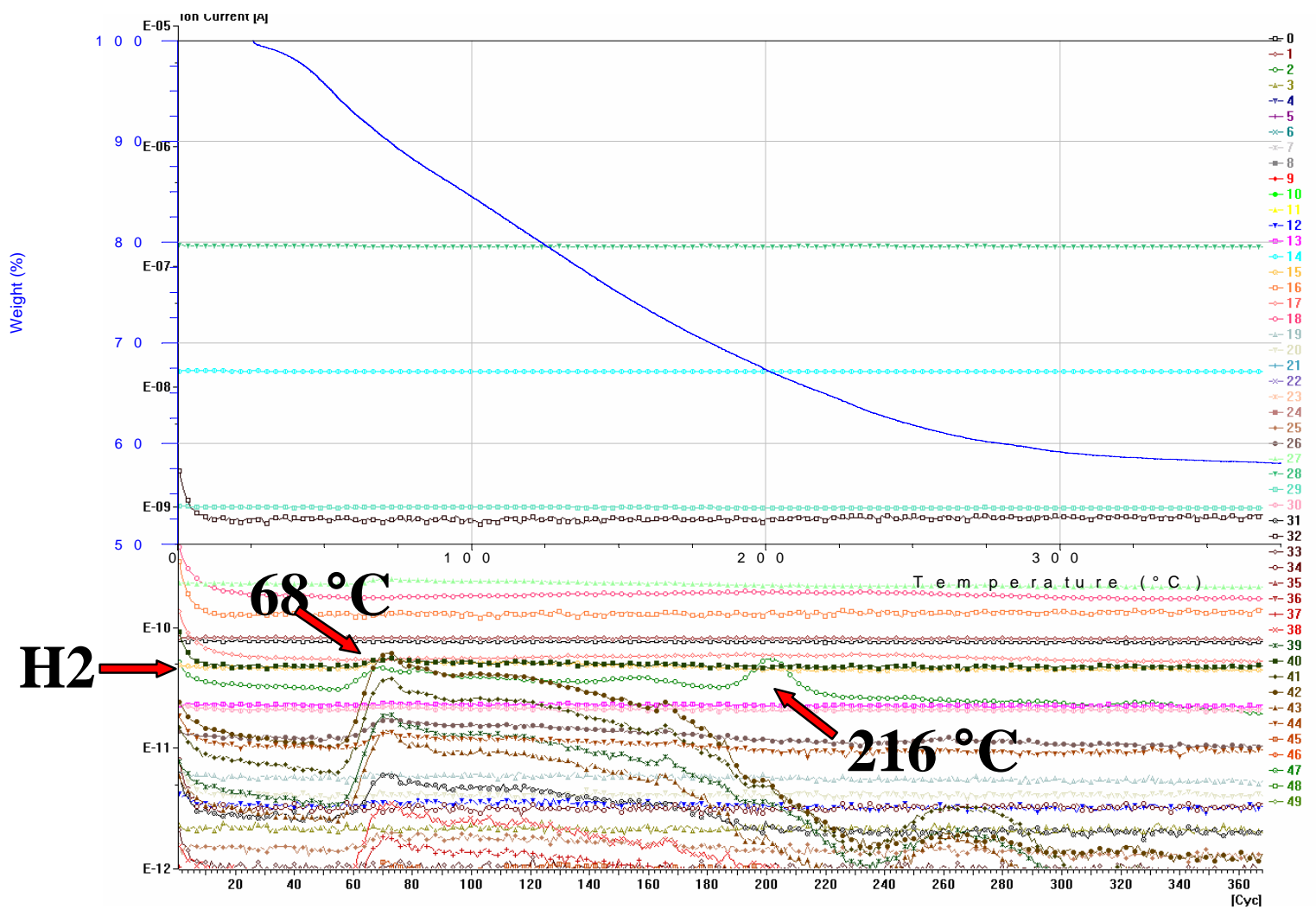

Figure 128: TGA-MS of $\mathrm{Mg}(\mathrm{BH} 4)_{2}(\mathrm{THF})_{3}$ containing product. 


\section{Conclusions}

\section{Conclusions}

\subsection{Summary}

Execution of the program evolved dynamically based upon our results and in response to reviewer recommendations. In the first stage, the team surveyed quaternary systems associated with the alkali alanates, implementing atomic modeling methodologies and parallel syntheses. In the second stage, the original approach was expanded to simultaneously pursue high capacity quaternary complex hydrides leveraged with high capacity coupled reactions, applying a triad of first principles modeling, thermodynamics, and experimental methodologies. These methods were iteratively implemented to enable new high capacity systems to be identified, refined, and evaluated. In the third stage, once new quaternary or ligand-stabilized high capacity systems had been identified, additional characterization methods were employed and modeling was utilized to investigate reaction mechanisms.

The primary activities and key results of the project include the following:

\section{General Synthesis and Characterization}

- A broad range of 9 quaternary systems was explored, including 6 alanate systems and 3 borohydride systems.

- A wide range of characterization techniques was employed to elucidate reaction mechanisms, and evaluate performance characteristics including XRD, DSC, TGA-MS, ICP, PCI / Sievert's, neutron diffraction and DRIFTS.

- Table 1 summarizes the performance of the best alanate and borohydride materials.

\section{First Principles Modeling}

- The implementation of coupled predictive methodologies provided a new capability to survey, simulate, and evaluate new candidate hydrogen storage compounds prior to their identification or preparation in the laboratory.

- These coupled methodologies joined together ground state minimizations using density functional theory, thermodynamic property predictions using direct method lattice dynamics, and phase stability predictions using chemical thermodynamics.

- The tool was extended to optimize the elemental stoichiometry within a compositional space at selected temperature/pressure conditions to obtain the highest theoretical hydrogen storage capacity.

- Significant elements required for implementation of these methodologies included:

- Approaches for proposing input candidate structures,

- Criteria for down-selection and refinement of candidate phases,

- Methods for assessment and incorporation of newly predicted thermodynamic data alongside experimental data,

- Procedures to predict the relative phase stability of the candidates compared to existing known phases over a wide range of temperatures and pressures.

- The predictive framework was used to survey more than 300 proposed phases:

- Over 170 candidate phases in the quaternary spaces encompassing known alanate phases: Na-Ti-Al-H, Li-Ti-Al-H, and Na-Li-Al-H, 


\section{Conclusions}

- Over 50 phases within the Na-Mg-Al-H and $\mathrm{Li}-\mathrm{Mg}-\mathrm{Al}-\mathrm{H}$ quaternary systems. In each system, numerous favorable ground-state minimized candidate structures were identified for the compound stoichiometries $\mathrm{Am}_{2} \mathrm{MgAlH}_{7}$ and $\mathrm{AmMgAlH}$, where $\mathrm{Am}$ represents the alkaline metals $\mathrm{Na}$ or $\mathrm{Li}$,

- Over 60 complex alanate, boronate, and amine phases as well as lower order phases within the Li-Mg-Na-Al-B-N-H septenary system and over 40 co-reactant phases within related quaternary compositional systems.

- Combined atomistic and thermodynamic modeling has been shown to yield accurate predictions of plateau pressures suitable for guidance on in-situ reversibility.

- Reaction design with co-reactants was implemented, improving complex stability by reducing dehydrogenation exotherms up to a factor of four, lowering $\mathrm{H}_{2}$ discharge onset temperatures below $100^{\circ} \mathrm{C}$ and preventing $\mathrm{NH}_{3}$ side-product formation.

- The $\mathrm{Mg}\left(\mathrm{BH}_{4}\right)_{2} * 2 \mathrm{NH}_{3}$ ligand-stabilized borohydride complex synthesized by SBP was found to change behavior with slightly different synthesis conditions and/or aging. One of the two mechanisms was an amine-borane $\left(\mathrm{NH}_{3}-\mathrm{BH}_{3}\right)$ like dissociation reaction, possibly forming $\mathrm{MgH}_{2}$ and $\mathrm{BN}$ which releases $16 \mathrm{wt} \% \mathrm{H}_{2}$. From FPM, the stability of the $\mathrm{Mg}\left(\mathrm{BH}_{4}\right)_{2} * 2 \mathrm{NH}_{3}$ compound was found to increase with inclusion of the $\mathrm{NH}_{3}$ groups in the inner-Mg coordination sphere, which in turn correlated with lowering the dimensionality of the $\mathrm{Mg}\left(\mathrm{BH}_{4}\right)_{2}$ network.

\section{Solid State Processing}

- Solid State Processing has been used to characterize the $\mathrm{Na}_{\mathrm{i}} \mathrm{Li}_{\mathrm{j}} \mathrm{Mg}_{\mathrm{k}} \mathrm{M}_{\mathrm{x}} \mathrm{Al}_{\mathrm{y}} \mathrm{H}_{\mathrm{x}}(\mathrm{M}=\mathrm{Ti}, \mathrm{Ni}, \mathrm{Co}$, $\mathrm{Fe}, \mathrm{Cr}$ ) systems at $200 \mathrm{bar}$ and temperatures ranging from 80 to $120^{\circ} \mathrm{C}$. While no $\geq 7.5 \mathrm{wt} \%$ materials were synthesized, numerous reversible hydrogen storage reactions have been identified via combinations of hydrides and alanates, yielding theoretical capacities of 2.6-5.6 wt \%.

- The $\mathrm{H}_{2}$ desorption measurements for the various Ak-Tm-B-H compounds indicated up to $12 \mathrm{wt} \%$ of $\mathrm{H}_{2}$ was generated at $400^{\circ} \mathrm{C}$, when the removable $\mathrm{LiCl}$ side-reaction product weight was excluded in the capacity calculation. However, the most active material can only be partially recharged up to $2 \mathrm{wt} \% \mathrm{H}_{2}$ at $220-300^{\circ} \mathrm{C}$ and $195 \mathrm{bar}_{2}$ pressure. The reversibility of this system is limited due to stable product formation.

- X-Ray Diffraction analysis indicated that most of the Ak-Tm-B-H compounds studied were amorphous in structure.

- Qualitative evidence of reversibility for amorphous borohydrides was obtained using Diffuse Reflectance Infrared Fourier Transform Spectra (DRIFTS) analyses, which is sensitive to various B-H vibrational frequencies.

\section{Solution Based Processing}

- Doped $\mathrm{NaAlH}_{4}$ having Ti at 2, 4, 10, and 33\% levels were prepared through SBP. Hydrogen storage performance of these compounds was inferior to the corresponding ball-milled materials, presumably due to the larger particle size.

- A novel alanate that was synthesized using $\mathrm{SBP}$ was $\left.\operatorname{LiMg}(\mathrm{AlH})_{3}\right)_{3}$ This material demonstrated a $7.0 \mathrm{wt} \%$ capacity with a desorption temperature of $150^{\circ} \mathrm{C}$.

- $\mathrm{Mg}\left(\mathrm{BH}_{4}\right)_{2}$ was synthesized in a number of ligand stabilized forms. Varying $\mathrm{H}_{2}$ desorption mechanisms of these complexes were identified through integrated experimental analyses, performance testing and first principles atomic-thermodynamic modeling. 


\section{Conclusions}

- In order to reduce the generation of ammonia, a co-reactant was mechanically mixed with $\mathrm{Mg}\left(\mathrm{BH}_{4}\right)_{2} * 2 \mathrm{NH}_{3}$. Only a trace amount of ammonia was detected at temperatures up to $450^{\circ} \mathrm{C}$.

- Another $\mathrm{Mg}\left(\mathrm{BH}_{4}\right)_{2}$ complex was prepared with a less volatile aprotic ligand, in which there is no possibility of the hydrogen release via a $\mathrm{BH}_{3} \mathrm{NH}_{3}$-like mechanism. The hydrogen release kinetics of this $\mathrm{Mg}\left(\mathrm{BH}_{4}\right)_{2}$ system represents unambiguous evidence that the ligand has a significant destabilizing influence which does not require a boron nitride intermediate.

- The compound $\mathrm{NaTi}\left(\mathrm{BH}_{4}\right)_{4} \cdot \mathrm{DME}$ has the potential for up to $7.3 \mathrm{wt} \%$ capacity, including the solvent ligand weight (the capacity would be $\sim 12 \mathrm{wt} \%$ without the ligands). The synthesis has a very high yield using inexpensive starting materials. The complex discharges $\mathrm{H}_{2}$ coupled with ligand release at temperatures as low as $60^{\circ} \mathrm{C}$, and partially recharges as low as $20^{\circ} \mathrm{C}$ in the presence of the released ligand.

\section{Molten State Processing}

- A stoichiometric mix of $\mathrm{NaAlH}_{4}$ and $\mathrm{LiH}$ subjected to the MSP temperature and pressure conditions produced the compound $\mathrm{Na}_{2} \mathrm{LiAlH}_{6}$ with partial conversion.

- Mixtures of $\mathrm{NaAlH}_{4}$ and $\mathrm{TiH}_{2}$ that were melt processed produced $\mathrm{NaH}$ rather than catalyzed $\mathrm{NaAlH}_{4}$, indicating $\mathrm{TiH}_{2}$ is a very efficient decomposition catalyst.

- The addition of the elements $\mathrm{Mn}, \mathrm{Cr}$ and $\mathrm{V}$ or other hydrides destabilize $\mathrm{LiAlH}_{4}$, while mixtures with binary hydrides produce the hexahydride, $\mathrm{Li}_{3} \mathrm{AlH}_{6}$ as summarized in Table 22 . $\mathrm{NaAlH}_{4}$ in combination with $\mathrm{Mg}$ materials produces $\mathrm{NaMgH}_{3}$.

- As observed in Section 6.4 and consistent with the modeling in Section 3.3.2.2, when the $\mathrm{Mg}$ compound used is $\mathrm{Mg}_{2} \mathrm{NiH}_{4}, \mathrm{NaMgH}_{3}$ forms with just ball milling, while mixtures with $\mathrm{MgH}_{2}$ do not form the mixed metal hydride until heated in the MSP step.

- Mixtures containing $\mathrm{LiAlH}_{4}$ and $\mathrm{NaAlH}_{4}$ form $\mathrm{LiNa}_{2} \mathrm{AlH}_{6}$ with MSP.

\subsection{Recommendations}

One of the outcomes of this project was the productive integration of FPM, syntheses and characterization to screen, investigate and evaluate new materials. We have found based on experience that the discovery of new materials from modeling alone is very difficult and that syntheses often precede FPM in materials discovery. FPM yields the greatest value when iteratively coupled with experiments for determination of new material structures, investigation of experimentally observed characteristics and examination of modified chemistries. Therefore, it is important in the execution of such a project to have close collaboration between the modeler(s) and experimentalist(s), with the usual advantages if they are in the same organization or in close proximity.

We also found that there were clear benefits in having multiple organizations with their specific expertise pursue similar, complementary endeavors. The three synthesis methods were distinct and yet were applied on common materials systems, which illuminated the advantages and disadvantages of each. In some cases SSP was superior (catalyzed $\mathrm{NaAlH}_{4}$ ); in other cases SBP was more successful (stabilized $\mathrm{Mg}\left(\mathrm{BH}_{4}\right)_{2}$ ). If the project had focused on interrogating in detail one material system, then down-selection to a single synthesis route might have been appropriate, but given the broad surveying of the current project, retaining the multiple synthesis methods throughout was the better approach. 


\section{Conclusions}

Multiple organizations conducting different characterization techniques is an easier activity to separate, coordinate and execute. A potential drawback is the required shipment of materials. This is not a significant issue for small quantities of stable compounds, but it can be problematic if the materials are unstable, as was the case for a number of SBP borohydride materials. Thus, care should be taken to study aging effects at a single location in a well controlled manner and shipping may demand special requirements for temperature uniformity when sharing potentially unstable materials for multi-organizational characterization.

Similar to the transition in material focus which has occurred in the hydrogen storage community, based on the results in the current project, the apparent potential of alanate based compounds has diminished since the inspiring discovery of $\mathrm{NaAlH}_{4}$ reversibility. Our efforts produced numerous compounds / reactions with capacities greater than conventional metal hydrides but less than that of $\mathrm{NaAlH}_{4}$, and one material with a nominal capacity of $7.0 \mathrm{wt} \%$ was irreversible. Therefore, we concur that the potential of alanates is insufficient to motivate a strong emphasis in future novel materials research.

Borohydrides have and continue to receive a great deal of attention for both chemical and reversible metal hydride systems. Like other efforts, we have found that a key challenge for this material class is reaction design/control to avoid the formation of stable products which inhibit reversibility. To a lesser extent, the formation of volatile $\mathrm{B}_{\mathrm{x}} \mathrm{H}_{\mathrm{y}}$ products is an issue, but there are storage system engineering concepts which could address this. The boron oriented reactions observed and simulated in this effort are complex and have exhibited markedly different behavior with minor modifications in synthesis conditions or simulated structure. While no completely viable storage materials were synthesized in this effort, we feel the potential remains to develop high capacity borohydrides with tailored reactions which have adequate reversibility / regenerability. 


\section{Publications and Presentations}

\section{Publications and Presentations}

\section{$\underline{\text { Publications }}$}

1. C. Qiu, S. M. Opalka, O. M. Løvvik, and G. B. Olson, "Thermodynamic modeling of Tihydride and Ti dissolution in sodium alanates," submitted CALPHAD.

2. S. Sartori, S. M. Opalka, O.M. Løvvik, M. N. Guzik, X. Tang, B. C. Hauback, "Experimental studies of $\alpha-\mathrm{AlD}_{3}$ and $\alpha^{\prime}-\mathrm{AlD}_{3}$ versus first principles modelling of alane isomorphs," accepted J. Mater. Chem.

3. S. Opalka, O.M. Løvvik, H.W. Brinks, P.W. Saxe, B.C. Hauback: "Integrated Experimental -

Theoretical investigations of the Na-Li-Al-H system”. Inorg. Chem. (2007) 46, 1401-1409.

4. H. Grove, H.W. Brinks, R. Heyn, F.-J. Wu, S.M. Opalka, X. Tang, B.L. Laube, B.C. Hauback: "The structure of $\operatorname{LiMg}\left(\mathrm{AlD}_{4}\right)_{3}$ ". J. Alloys and Compounds (in press).

4. X. Tang, S. M. Opalka, B. L. Laube, F. - J. Wu, J. R. Strickler, D. L. Anton, "Hydrogen Storage Properties of Na-Li-Mg-Al-H Complex Hydrides," J. Alloys Compd. (2007) 446-447, 228-231.

5. C. Qiu, S. M. Opalka, G. B. Olson, and D. L. Anton, "Thermodynamic modeling of the sodium alanates and the Na-Al-H System,” Int. J. Mat. Res. 97 (2006) 1484-1494.

6. O. M. Lovvik and S. M. Opalka, "The stability of Ti in $\mathrm{NaAlH}_{4}$," Applied Physics Letters 88, 161917-1-3(2006). Also published in the May 1, 2006 issue of Virtual Journal of Nanoscale Science \& Technology. http://www.vjnano.org

7. C. Qiu, S. M. Opalka, G. B. Olson, and D. L. Anton, "The Na-H System: from First Principles Calculations to Thermodynamic Modeling,” Int. J. Mat. Res. 97845 (2006).

8. O. M. Lovvik, O. Swang, and S. M. Opalka, "Modelling alkali alanates for hydrogen storage by density-functional band-structure calculations" J. Mater. Res., 20(12) 3199-3213 (2005).

9. O. M. Lovvik and S. M. Opalka, "First-principles calculations of Ti-enhanced $\mathrm{NaAlH}_{4}$," Phys. Rev. B 71 054103-1-10 (2005).

10. C. Qiu, G. B. Olson, S. M. Opalka and D. L. Anton, "A Thermodynamic Evaluation of the AlH System," J. of Phase Equilibria and Diffusion 25(6) 520-527 (2004).

11. O. M. Løvvik, S. M. Opalka, H. W. Brinks and B. C. Hauback, "Crystal structure and thermodynamic stability of the lithium alanates $\mathrm{LiAlH}_{4}$ and $\mathrm{Li}_{3} \mathrm{AlH}_{6}$," Phys. Rev. B $\underline{69}$ 134117-134125 (2004).

12. S. M. Opalka and D. L. Anton, "First Principles Study of Sodium-Aluminum-Hydrogen Phases," J. of Alloys and Compounds $\underline{356-357}$ 486-489 (2003). 


\section{Publications and Presentations}

\section{$\underline{\text { Presentations }}$}

1. S. Sartori, H. Grove, M.H. Sørby, S.M. Opalka, B.C. Hauback: "Synthesis, Structure and Properties of Alanates based on Li-Mg and K for Hydrogen Storage". Gordon Research Conference Hydrogen-Metal Systems, USA, July 2007.

2. S. M. Opalka, P. W. Saxe, and O. M. Løvvik, "Atomic simulations of alane phase transformations and dehydrogenation mechanisms," presentation at the American Physical Society Annual Meeting, Denver, Colorado, USA, March 5-9, 2007.

3. H. Grove, H.W. Brinks, R.H. Heyn, A. Klaveness, R.F.-J. Wu, S.M. Opalka, X.T. Tang, B.L. Laube, B.C. Hauback: "Synthesis and properties of lithium magnesium alanate". 19th Nordic Structural Chemistry Meeting, Norway, January 2007.

4. O. M. Lovvik, and S. M. Opalka, "Theory of complex hydrides," invited presentation to be made at the International Symposium on Metal-Hydrogen Systems, Lahaina, HI, October 1-6, 2006.

5. O. M. Løvvik and S. M. Opalka, "Density-functional calculations of new alanates," invited presentation to be made at the International Symposium on Materials Issues in Hydrogen Production and Storage, Santa Barbara, CA, August 20-25, 2006.

6. S. M. Opalka, C. Qiu, and O. M. Løvvik, "First Principles Contributions to the Thermodynamic Assessment of Solid Sate Metal Hydride and Complex Hydride Phases," invited presentation at the DOE Theory Focus Session on Hydrogen Storage Materials, Crystal City, MD, May 18, 2006.

7. S. M. Opalka, T. H. Vanderspurt, S. C. Emerson, D. A. Mosher, Y. She, X. Tang, and D. L. Anton, "Theoretical Contributions Towards the Development of Storage Media and Related Materials for Hydrogen Processing", invited presentation at the 2006 TMS Annual Meeting to be held at San Antonio, Texas, March, 2006.

8. S. M. Opalka, D. A. Mosher, X. Tang, D. L. Anton R. Zidan, K. Shanahan, J. Strickler, F.-J. Wu, O. M. Lovvik, H. Brinks, and B. Hauback, "Complex hydride compounds with enhanced hydrogen storage capacity,'Experts' SemiAnnual Workshop of the IEA Hydrogen Implementing Agreement Task 17 - Solid and Liquid State Hydrogen Storage Materials at Tateshina, Japan, October 23-27, 2005.

9. C.Qiu, G. B. Olson, S. M. Opalka, and D. L. Anton, "Thermodynamic Modeling of Sodium Alanates and the Effect of Ti," presentation at the 2005 Fall MRS Meeting, Boston, MA, November 29-Dec. 3, 2005.

10. O. M. Lovvik, O. Swang, S. M. Opalka, and P. N. Molin, "Alanates for Hydrogen Storage Density Functional Calculations of Structural, Electronic, and Thermodynamical Properties," invited presentation at the 2005 Fall MRS Meeting, Boston, MA, November 29-Dec. 3, 2005. 


\section{Publications and Presentations}

11. S. M. Opalka, O. M. Lovvik, H. W. Brinks, B. C. Hauback, Paul W. Saxe, and D. L. Anton, "Combined Experimental-Theoretical Investigations of the Na-Li-Al-H System," Materials Science \& Technology 2005 Pittsburgh, PA, on September 25-28, 2005.

12. C. Qiu, S. M. Opalka, D. L. Anton, G. B. Olson, "Thermodynamic Modeling of Sodium Alanates,” Materials Science \& Technology 2005 Pittsburgh, PA, on September 25-28, 2005.

13. O. M. Løvvik and S. M. Opalka, "First-principles calculations of Ti-enhanced NaAlH4." Presentation at the International Symposium of Metal Hydrogen Systems (MH2004), Krakow, Poland, September 10, 2004. 


\section{References}

\section{References}

1. E. Wiberg, and R. Uson, Z. Naturforsch.,B, $\underline{6}$ (1951) 392.

2. B. Bogdanovic and M. Schwickardi, J. Alloys Compd., 253 (1997) 1.

3. C. M. Jensen and K. J. Gross, Appl. Phys. A $\underline{72}$ (2001) 213.

4. K. J. Gross, G. Thomas, and C. M. Jensen, J. Alloy Compd. 330-332 (2002) 683.

5. C. Qiu, S. M. Opalka, G. B. Olson, and D. L. Anton, Int. J. Mat. Res.(formerly Z. Metallkd.) 97, (2006) 1484.

6. O. M. Løvvik and S. M. Opalka, Appl. Phys. Lett. $\underline{88}$ (2006) 161917.

7. E. H. Majzoub and K. J. Gross, J. Alloys Compd. 356-357 (2003) 363.

8. K. Hashi, K. Ishikawa, K. Suzuki, and K. Aoki, Mat. Trans., 43(11) (2002) 2734.

9. G. Kresse and J. Hafner, Phys. Rev. B, 47(1) (1993) 558.

10. G. Kresse and J. Fürthmuller, Comput. Mater. Sci., $\underline{6}$ (1996) 15.

11. G. Kresse and J. Fürthmuller, Phys. Rev. B, 54(16) (1996) 11169.

12. W. Kohn and L. J. Sham, Phys. Rev., 140 (1965) 1133.

13. G. Kresse and D. Joubert, Phys. Rev. B, 59(3) (1999) 1758.

14. J.P. Perdew, J.A. Chevary, S.H. Vosko, K.A. Jackson, M.R. Pederson, D.J. Singh, and C. Fiolhais, Phys. Rev. B, 46(11-15) (1992) 6671.

15. S. M. Opalka and D. L. Anton, J. Alloys Compd., 356-357 (2003) 486.

16. C. Qiu, S. M. Opalka, G. B. Olson, and D. L. Anton, Int. J. Mat. Res., 97 (2006) 845.

17. O. M. Løvvik and S. M. Opalka, Phys. Rev. B, 71 (2005) 054103.

18. MedeA-Phonon Version 1.0 using Phonon Software 3.11, Copyright Prof. K. Parlinski.

19. K. Parlinski, Z. Q. Li, Y. Kawazoe, Phys. Rev. Lett. 78, 4063 (1997).

20. Materials Design MedeA Phonon application note.

21. Thermo-Calc Software A.B., Stockholm, Sweden.

22. HSC Chemistry 5, Outokumpu Research Oy, Pori, Finland.

23. C. Qiu, G. B. Olson, S. M. Opalka and D. L. Anton, J. Phase Equil. Dif., 25(6) (2004) 520.

24. O. M. Løvvik, S. M. Opalka, H. W. Brinks and B. C. Hauback, Phys. Rev. B, $\underline{69}$ (2004) 134117.

25. S. M. Opalka and E. Rönnebro, Sandia-UTRC Collaboration Plan, 8/19/2005.

26. Endeavor Version 1.3, Klaus Brandenburg and Holger Putz, () 2000-2005, Crystal Impact GbR.

27. H. Putz, J. C. Schön, and M. Jansen, J. Appl. Cryst., $\underline{32}$ (1999) 864. 


\section{References}

28. TC Matlab Toolbox Version 3.01, (C) 1995-2004, Foundation of computational Thermodynamics, Stockholm, Sweden.

29. H. Kohlmann, "Metal Hydrides," Encylcopedia of Physical Sciences and Technology, (R. A.

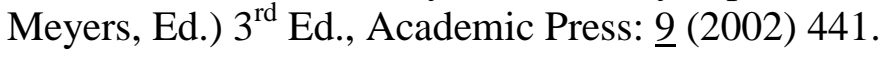

30. K. Yvon, "Hydrides: Solid State Transition Metal Complexes," Encyclopedia of Inorganic Chemistry (Ed. R. B. King), John Wiley and Sons: $\underline{3}$ (1994b) 1401.

31. K. Yvon, Z. Kristallogr., 218 (2003) 108.

32. W. Bronger, J. Alloys and Compd., 229 (1995) 1.

33. W. Bronger and G. Auffermann, Chem. Mater., 10 (1998) 2723.

34. E. C. Ashby, Chem. Ind. (London), (1962) 208.

35. B. Siegel and G. G. Libowitz, "The Covalent Hydrides and Hydrides of the Groups V to VIII Transition Metals," in Metal Hydrides, (Eds. W. M. Mueller, J. P. Blackledge, and G. G. Libowitz) AcademicPress: (1968) 545.

36. T. N. Dymova, Y. M. Dergachev, V. A. Sokolov, and N. A. Grechanaya, Doklady Akademii Nauk SSSR, $\underline{224}$ (1975) 556.

37. G. J. Thomas, S. E. Gunthrie, and K. Gross, Proc. 1999 DOE Hydrogen Program Annual Peer Review, (1999).

38. K. J. Gross, G. J. Thomas, and C. M. Jensen, J. Alloys Compd., 330-332 (2002) 683.

39. B. Bogdanovic, R. A. Brand, A. Marjanovic, M. Schwickardi, and J. Tolle, J. Alloys Compd., $\underline{302}$ (2000) 36.

40. O. M. Løvvik, O. Swang, and S. M. Opalka, J. Mater. Res., 20(12) (2005) 3199.

41. S. M. Opalka, O. M. Løvvik, H. W. Brinks, P.W. Saxe, and B. C. Hauback, Inorg. Chem., $\underline{46}(4)$ (2007) 1401.

42. A. Fossdal, H. W. Brinks, J. E. Fonnelop, B. C. Hauback, J. Alloys Compd., 397 (2005) 135.

43. J. Graetz, Y. Lee, J. J. Reilly, S. Park, T. Vogt, Phys. Rev. B 71 (2005) 1844115.

44. C. Qiu, S. M. Opalka, O. M. Løvvik, and G. B. Olson, submitted CALPHAD.

45. H. W. Brinks, B. C. Hauback, C. M. Jensen, R. Zidan, J. Alloys Compd., 392 (2005) 27.

46. J. Hout, S. Boily, V. Guther, R. Schultz, J. Alloys Compd., $\underline{383}$ (1999) 304.

47. M. Mamatha, B. Bogdanovic, M. Felderhoff, A. Pommerin, W. Schmidt, F. Schuth, and C. Weidenthaler, J. Alloys Compd., 416 (2006) 303.

48. COST507 Light Alloys Database, COST507 Project: Round II, European Commission.

49. Binary Alloy Phase Diagrams CDROM, ASM International, Materials Park, OH.

50. H. Grove, H. W. Brinks, R. H. Heyn, F.-J. Wu, S. M. Opalka, X. Tang, B. L. Laube, B. C. Hauback, J. Alloys Compd., in press, doi:10.1016/j.jallcom.2007.01.150. 


\section{References}

51. X. Tang, S. M. Opalka, B. L. Laube, F.-J. Wu, J. R. Strickler and D. L. Anton, J. Alloys Compd., $\underline{446-447}$ (2007) 228.

52. H. Grove, H. W. Brinks, O. M. Løvvik, R. H. Heyn and B. C. Hauback, J. Alloys Compd., in press, doi:10.1016/j.jallcom.2007.06.029.

53. P. Chen, Z. Xiong, J. Luo, J. Lin, and K. L. Tan, Nature, 420 (2002) 302.

54. J. F. Herbst and L. G. Hector, Phys. Rev. B, 72 (2005) 125120.

55. B. M. Bulychev and A. G. Burlakova, Khimiya, 19(4) (1978), 498.

56. Z. Lodziana and T. Vegge, Phys. Rev. Lett., 93 (2004) 145501.

57. P. Vajeeston, P. Ravindran, A. Kjekshus, and H. Fjellvåg, Appl. Ohys. Let., $\underline{89}$ (2006) 071906.

58. X. Tang, B. L. Laube, D. L. Anton, S.-J. Hwang, and R. C. Bowman, presentation at American Physical Society Meeting, Denver, Co, March 5-9, 2007.

59. B. Bogdanovic, M. Schwickardi, J. Alloys Comp. 253-254 (1997)

60. P. Claudy, B. Bonnetot, J. P. Bastide, J. M. Letoffe, Mater. Res. Bull. 17 (1982) 1499.

61. E. Ronnebro, D. Noreus, K. Kadir, A. Reiser, B. Bogdanovic, J Alloys Comp. 299 (2000), 101.

62. M. Mamatha, B. Bogdanovic, M. Felderhoff, A. Pommerin, W. Schmidt, F. Schueth, C. Weidenthaler, J Alloys Comp. 407 (2006) 78.

63. Y. Nakamori, H.-W. Li, K. Kikuchi, M. Aoki, K. Miwa, S. Towata and S. Orimo, J Alloys Comp. 446-447 (2007) 296.

B. Bogdanovic, M. Schwickardi, J. Alloys Comp. 253-254 (1997) 1.

64. J. R. Strickler, U.S. patent 5,264,590, 1993.

65. B. Bogdanovic and M. Schwickardi, J. Alloys Compds. 1997, 253, 1.

66. Graetz et al., Applied Physics. Let. 2004, 85, 3, 500.

67. B. M.Bulychev, K. N. Semenenko, K. B. Bitcoev, Koord. Khim, 4 (1978), 374-380.

68. Bogdanovic et al., J. Alloys compd. (2006), 407 (1-2), 78-86.

69. Adriaan Sachtler, 2005 Hydrogen Program Annual Review, Washington D.C., Project ST-5.

70. V. N. Konoplev, Zh. Neorg. Khim. 25 (1980) 1737-1740.

71. K. Franz and H. Noth, Z. Anorg. Allg. Chem. 397, 247 (1973).

72. B. D. James and B. E. Smith, Synth. React. Inorg. Met.-Org. Chem. 4, 461 (1974).

73. Borisov et al., Zhurnal Neorgnicheskoi Khimii (1986), 31(1), 86-92.

74. U.S. patent 0046930, 2006.

75. Levason et al., J. Chem. Soc. Dalton Trans, 2000, 3001-3006.

76. Schormann et al., Acta Cryst, 2003, E59, 674-675. 


\section{References}

77. Streltsova et al., Koord. Khim, 1988, 14, 421-429. 


\section{Appendix}

\section{Appendix}

\subsection{Semi-Quantitative XRD Analysis of Alanate Phases}

Results from semi-quantitative X-Ray Diffraction analysis for the majority of the alanate materials synthesized via Solid State Processing are given in the current appendix. The bar graphs display the composition evolution from starting materials, as-milled and thermal/hydrogen pressure processing.

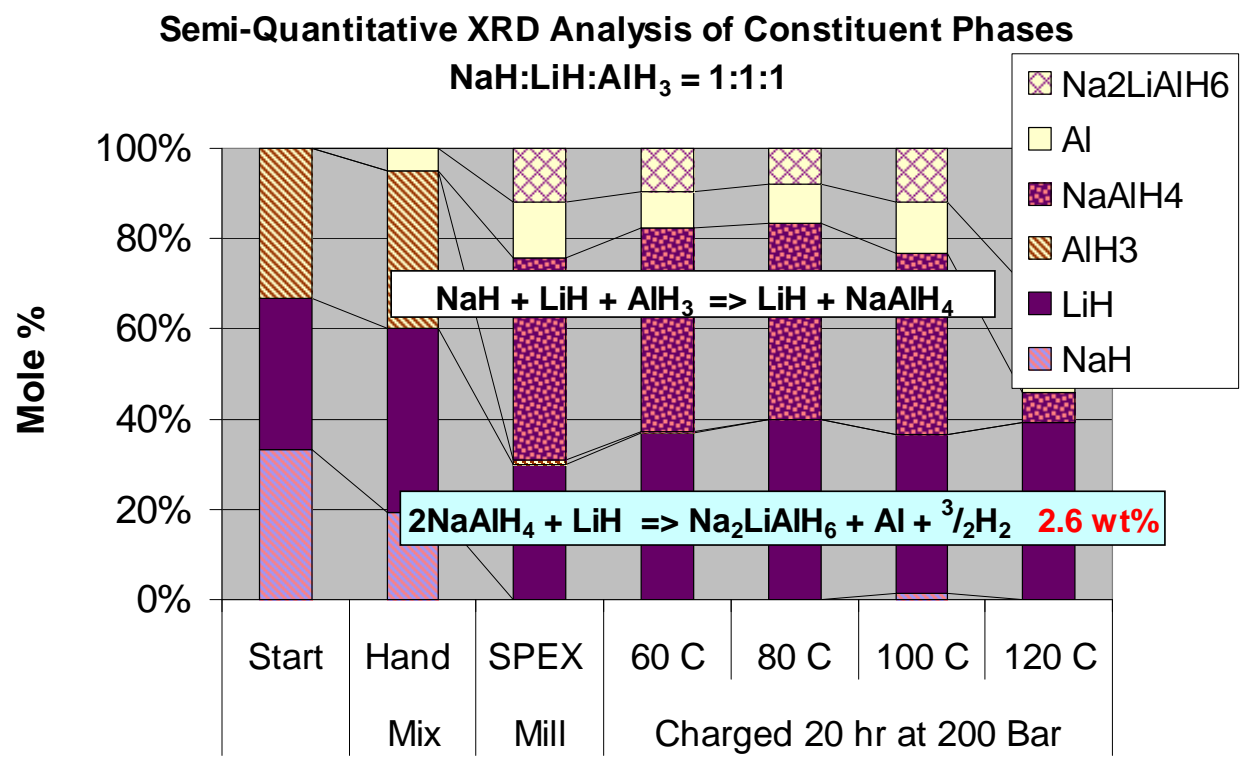

Figure 129: NaH:LiH:AlH $=1: 1: 1$.

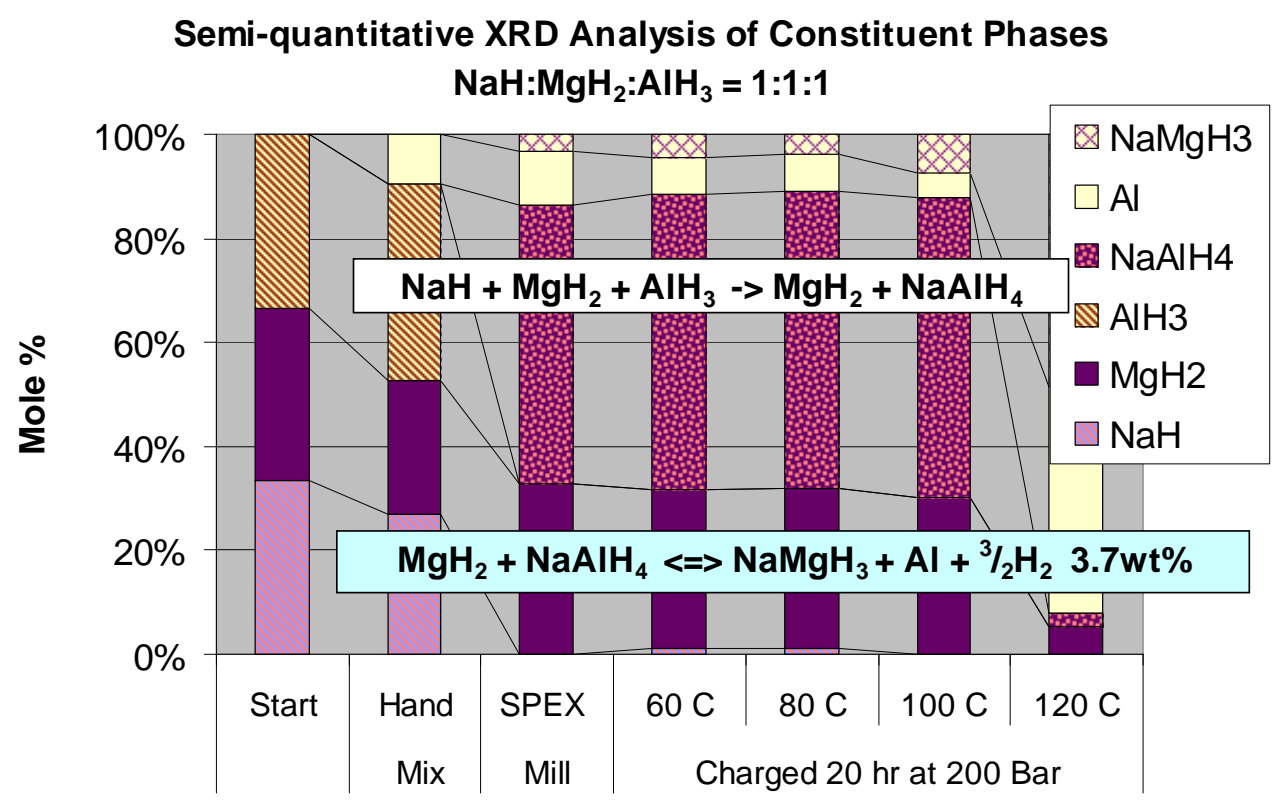

Figure 130: $\mathrm{NaH}: \mathrm{MgH}_{2}: \mathrm{AlH}_{3}=1: 1: 1$. 


\section{Appendix}

XRD Analysis of Constituent Phases

$\mathrm{LiH}: \mathrm{MgH} 2: \mathrm{AlH} 3=1: 1: 1$

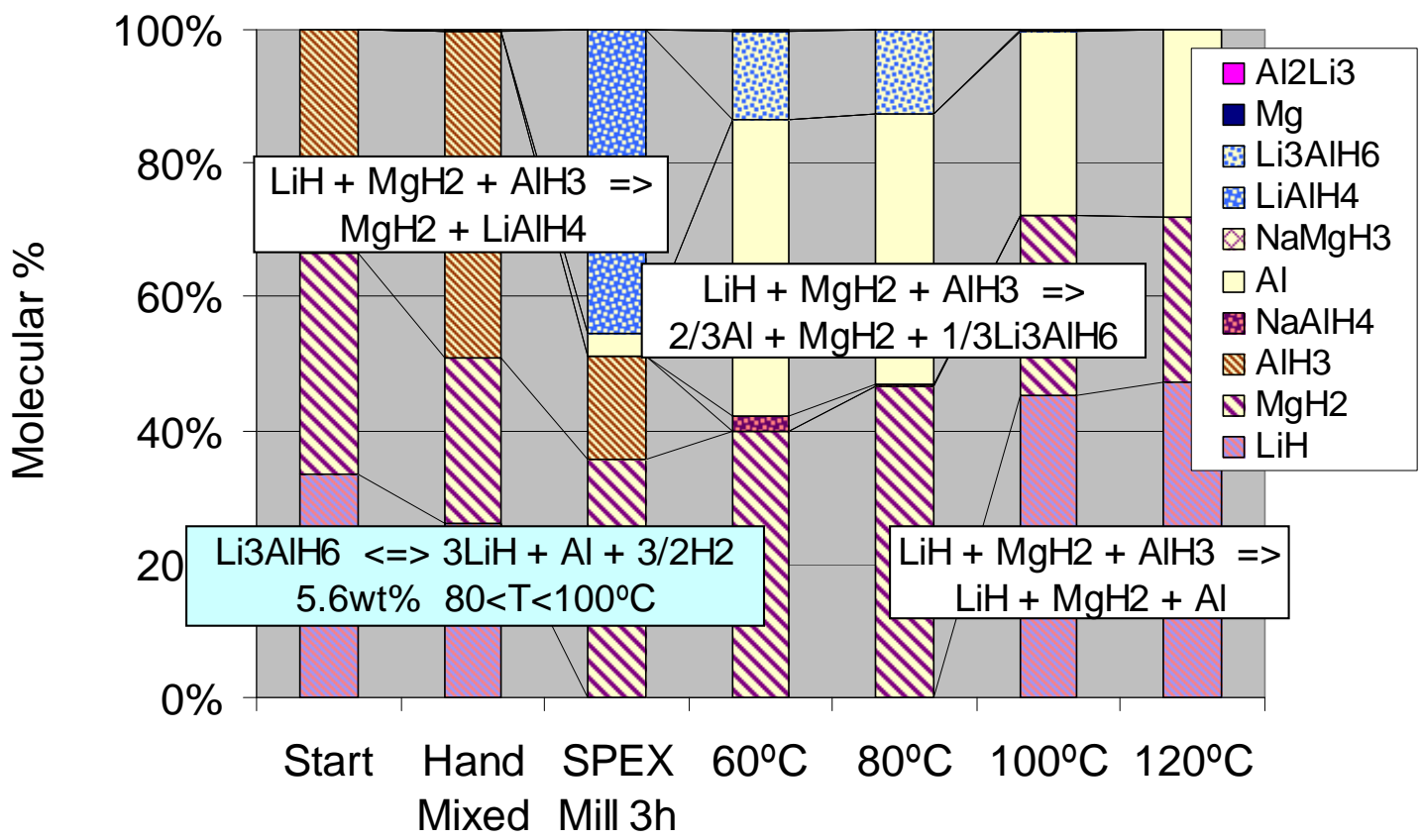

Figure 131: $\mathrm{LiH}: \mathrm{MgH}_{2}: \mathrm{AlH}_{3}=1: 1: 1$.

$\mathrm{NaH}: \mathrm{LiH}: \mathrm{MgH}_{2}: \mathrm{AlH}_{3}$

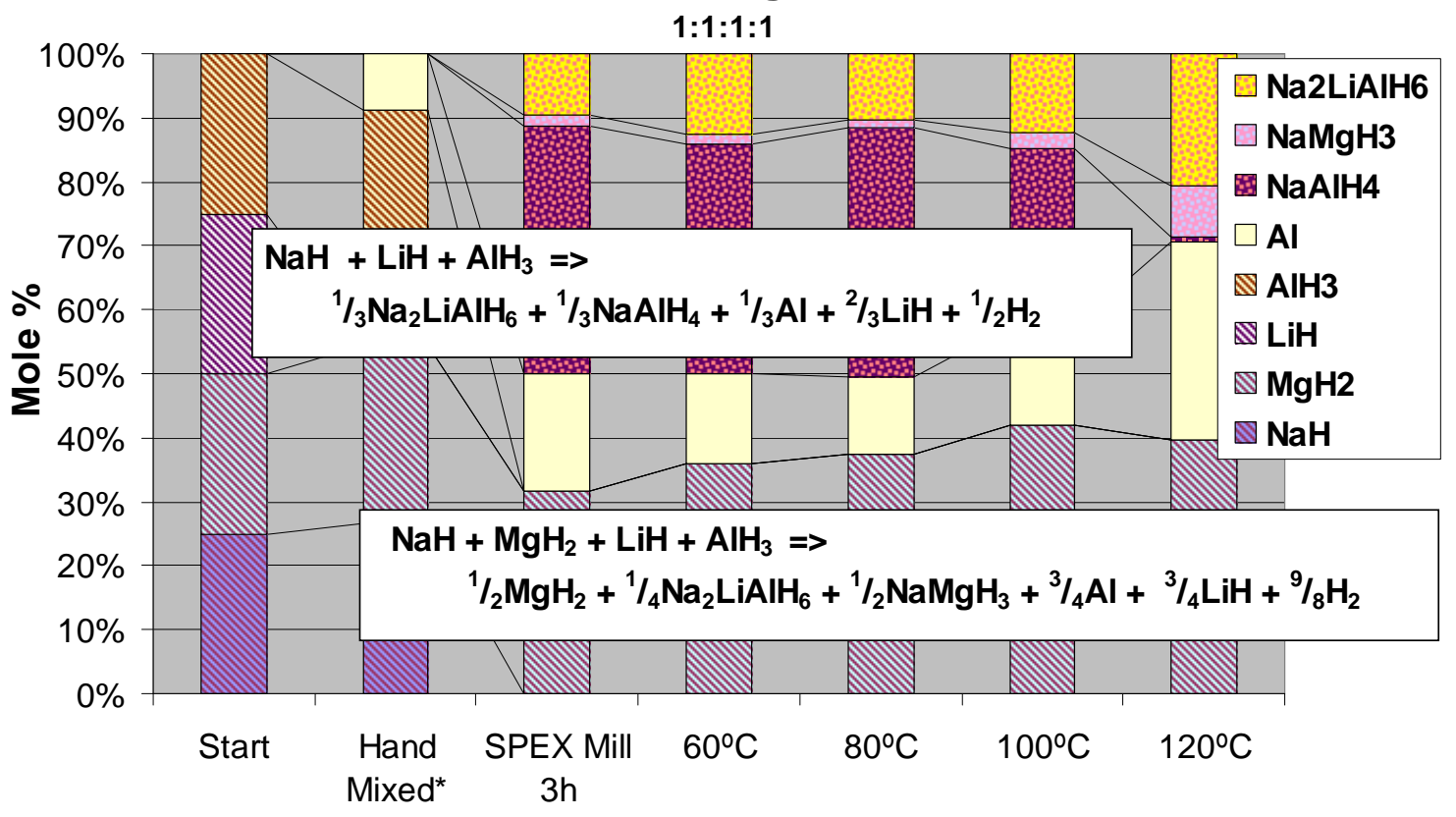

Processing + Temperature for Charging 20 Hours at 200 Bar

Figure 132: $\mathrm{NaH}: \mathrm{LiH}: \mathrm{MgH}_{2}: \mathrm{AlH}_{3}=1: 1: 1: 1$. 


\section{Appendix}

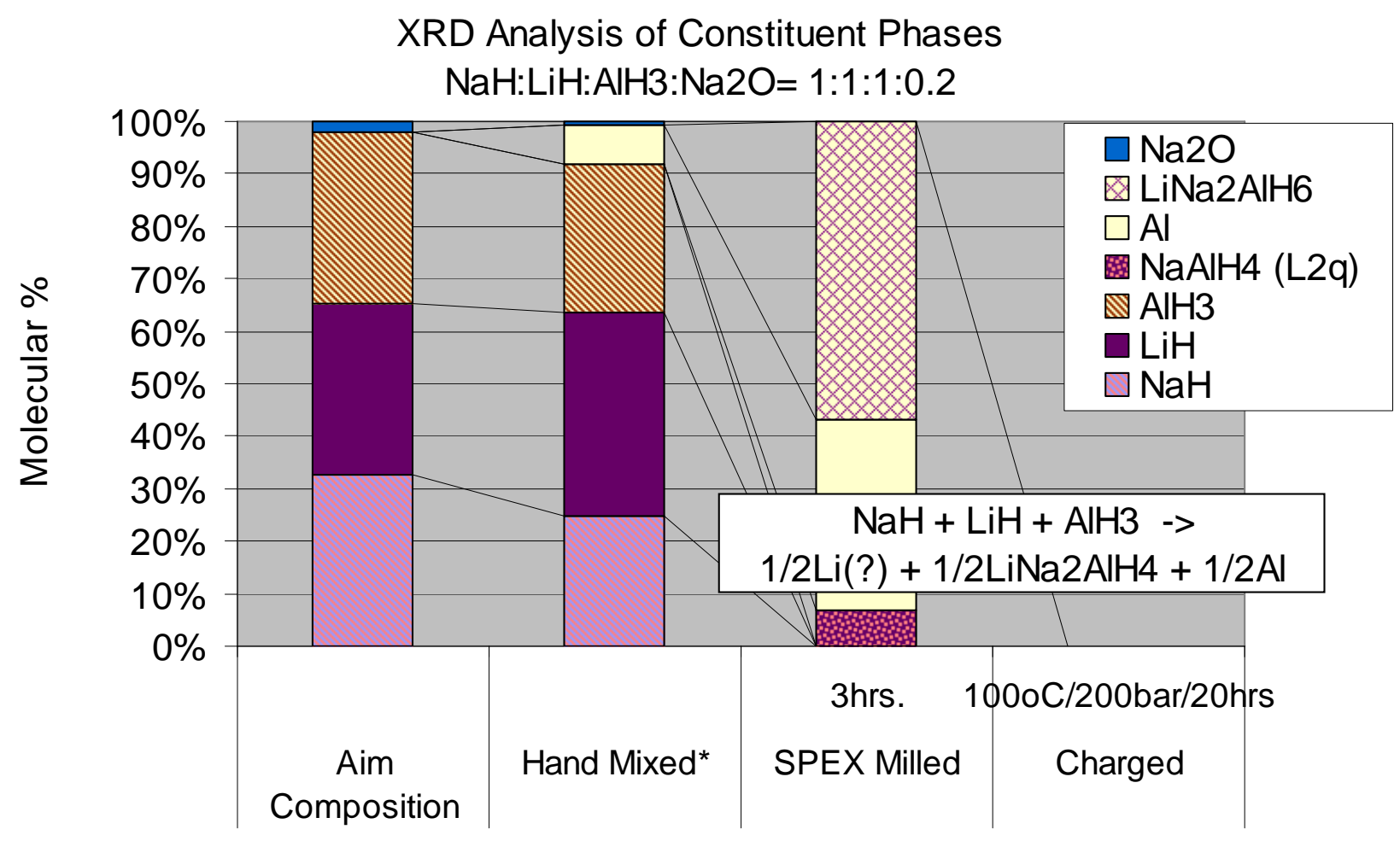

Figure 133: $\mathrm{NaH}: \mathrm{LiH}: \mathrm{AlH}_{3}: \mathrm{Na}_{2} \mathrm{O}=1$ :1:1:0.2.

XRD Analysis of Constituent Phases

$\mathrm{NaH}: \mathrm{LiH}: \mathrm{AlH} 3: \mathrm{NaOH}=1: 1: 1: 0.2$

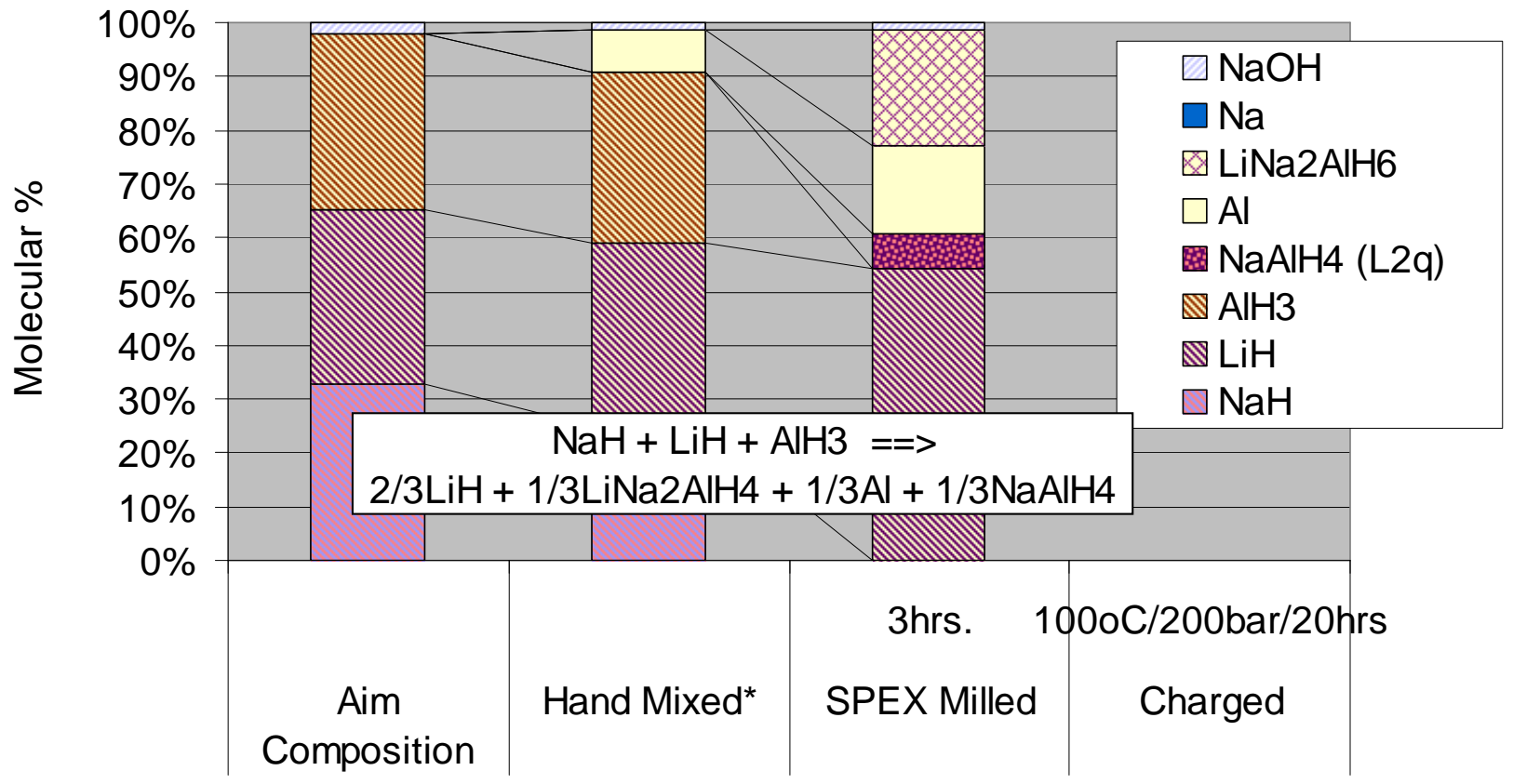

Figure 134: $\mathrm{NaH}: \mathrm{LiH}^{\mathrm{AlH}} 3 \mathrm{HaOH}=1 \mathrm{~N}: 1: 1: 0.02$. 


\section{Appendix}

XRD Analysis of Constituent Phases

$\mathrm{NaH}: \mathrm{Ti}: \mathrm{Al}=1: 1: 1$

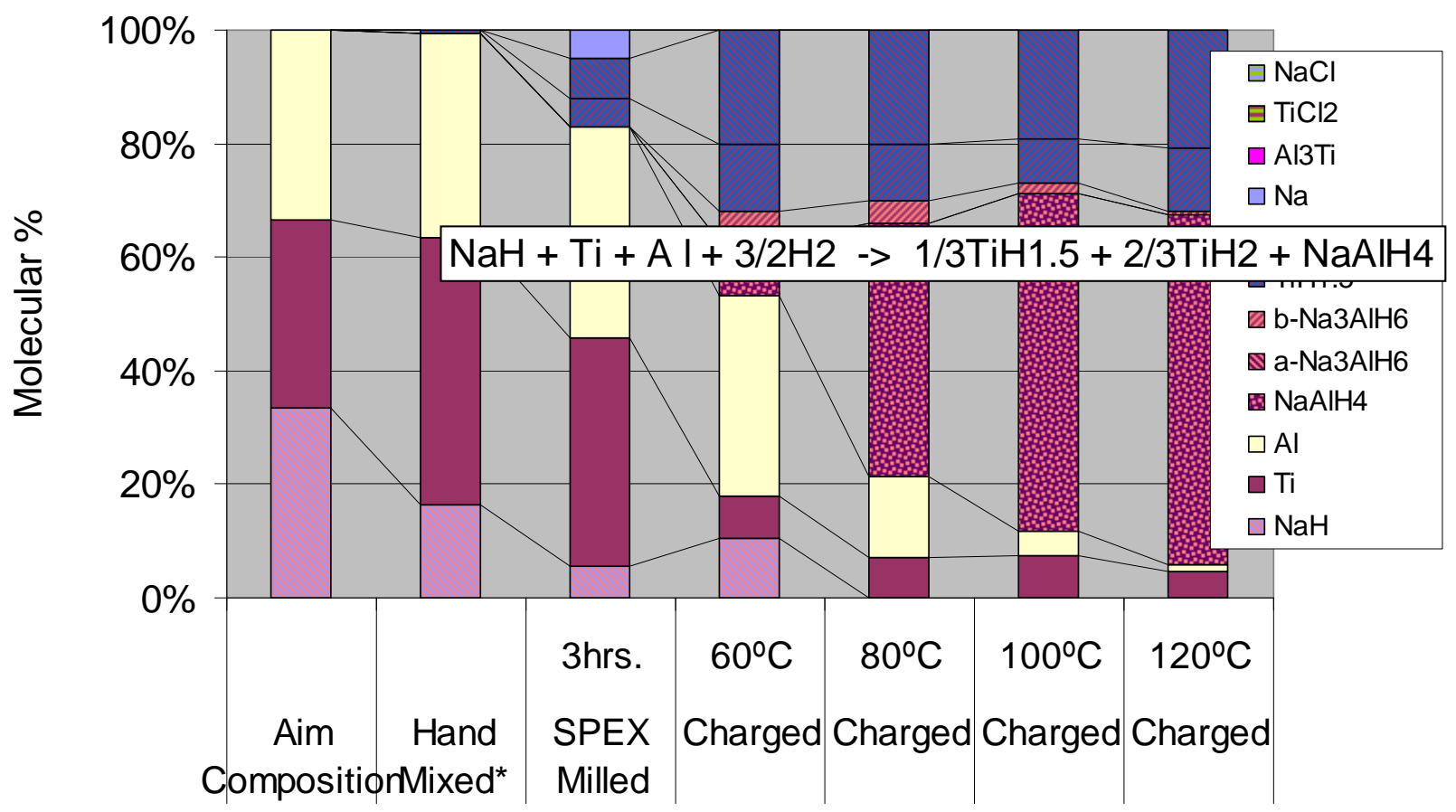

Figure 135: NaH:Ti:Al=1:1:1.

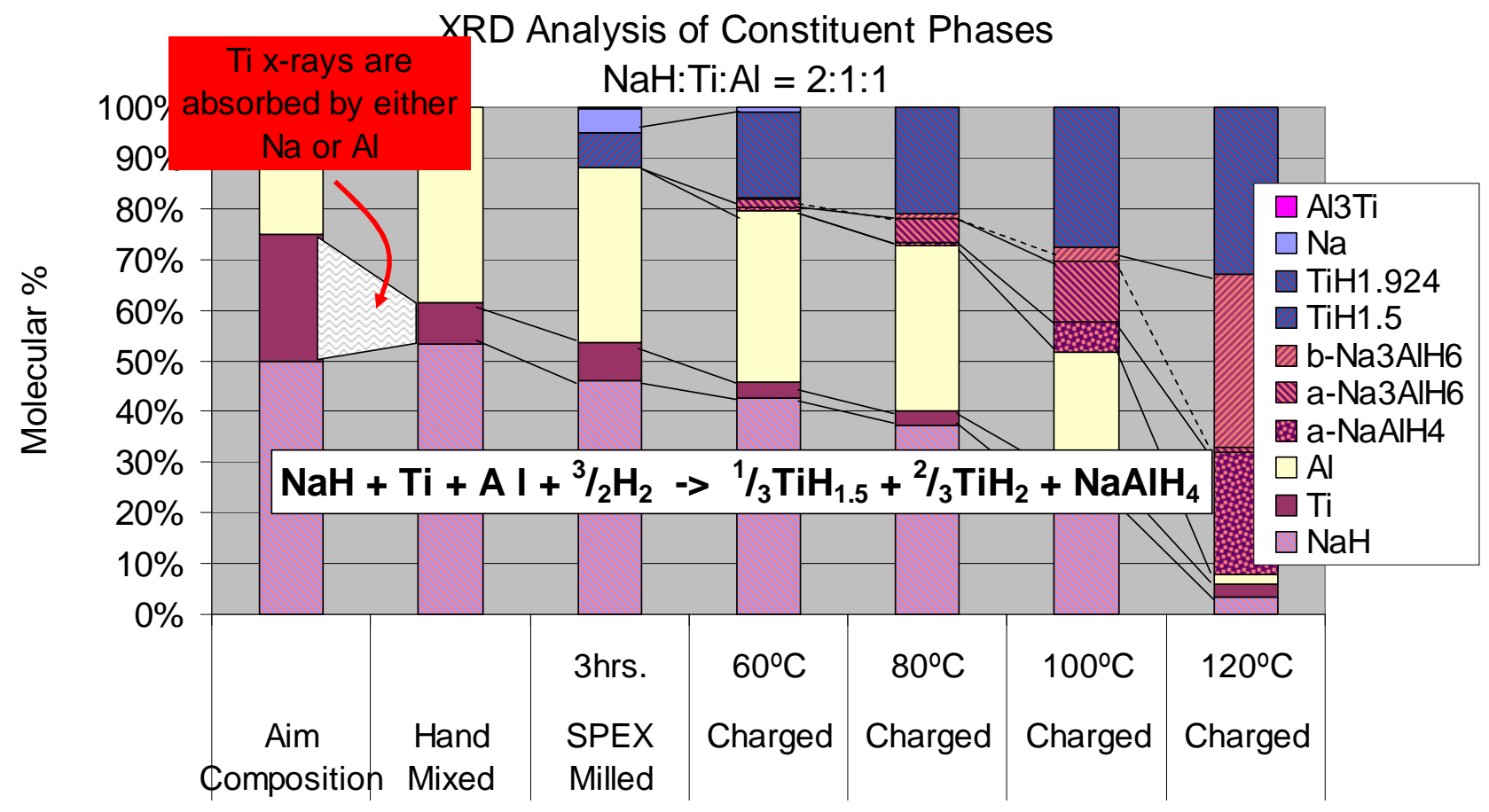

Figure 136: NaH:Ti:Al=2:1:1. 


\section{Appendix}

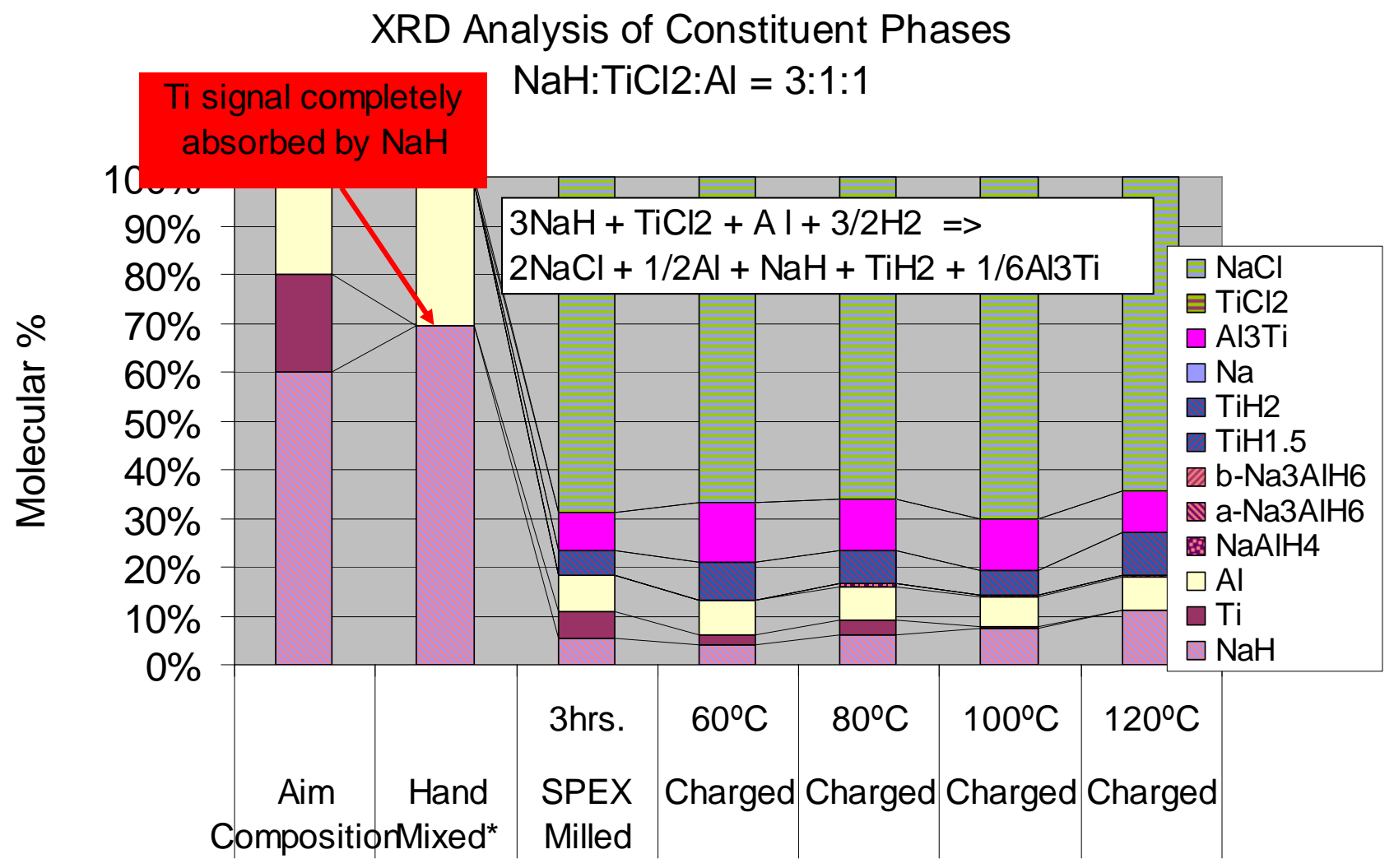

Figure 137: NaH:TiCl2:Al=3:1:1.

XRD Analysis of Constituent Phases $\mathrm{NaH}: \mathrm{TiCl} 2: \mathrm{AlH} 3=3: 1: 1$

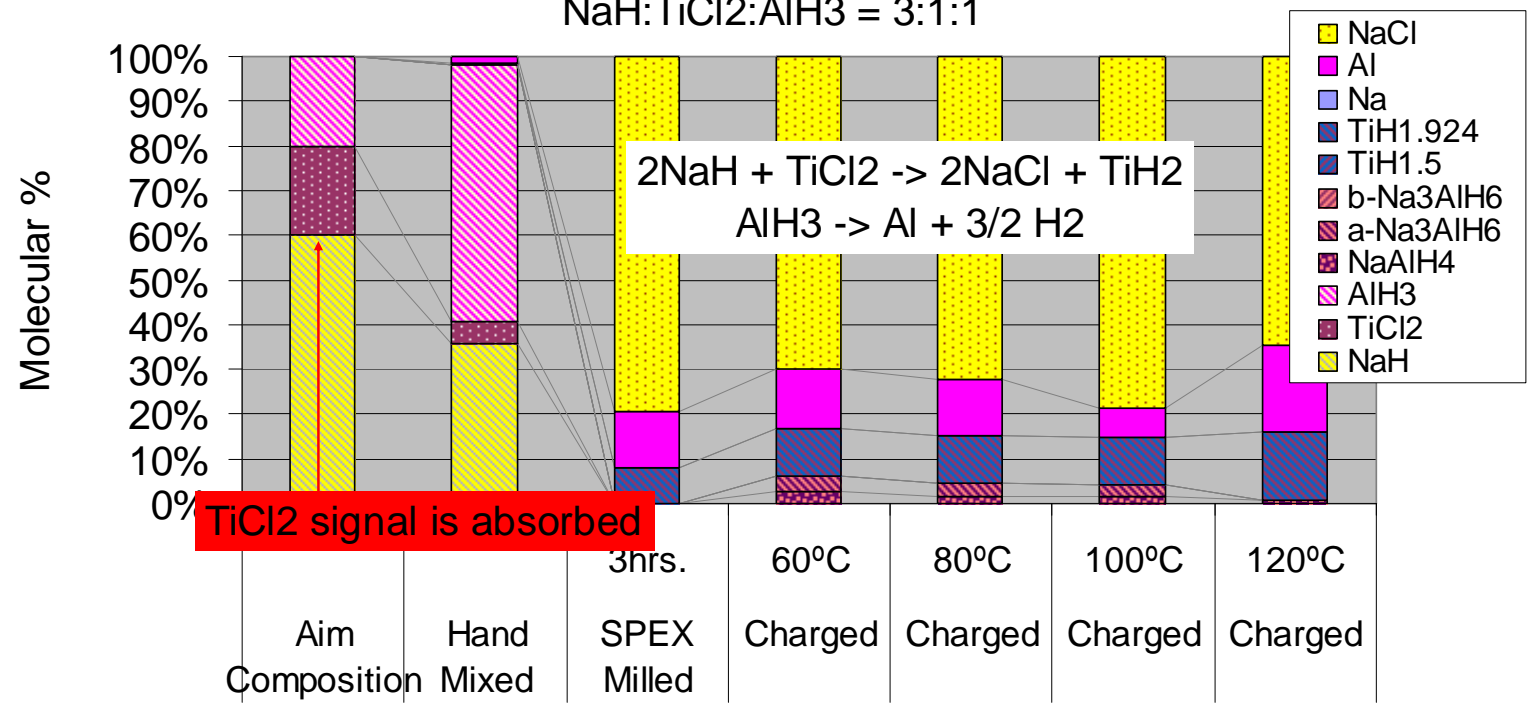

Figure 138: $\mathrm{NaH}_{\mathrm{TiCl}}: \mathrm{Al}=$ 3:1:1 . 


\section{Appendix}

XRD Analysis of Constituent Phases

$\mathrm{NaH}: \mathrm{TiH} 2: \mathrm{AlH} 3=1: 1: 1$

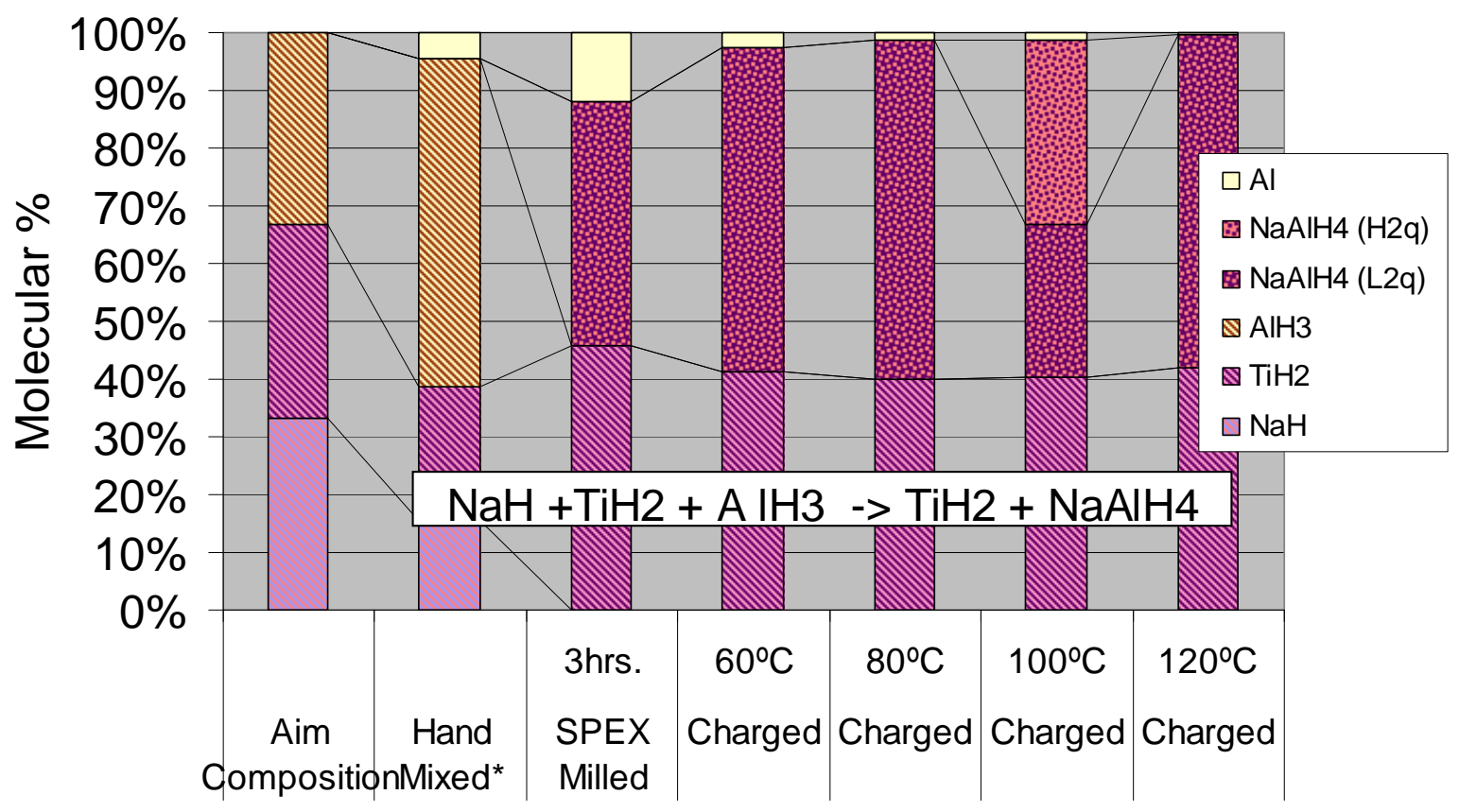

Figure 139: $\mathrm{NaH}: \mathrm{TiH}_{2}: \mathrm{AlH}_{3}=1: 1: 1$.

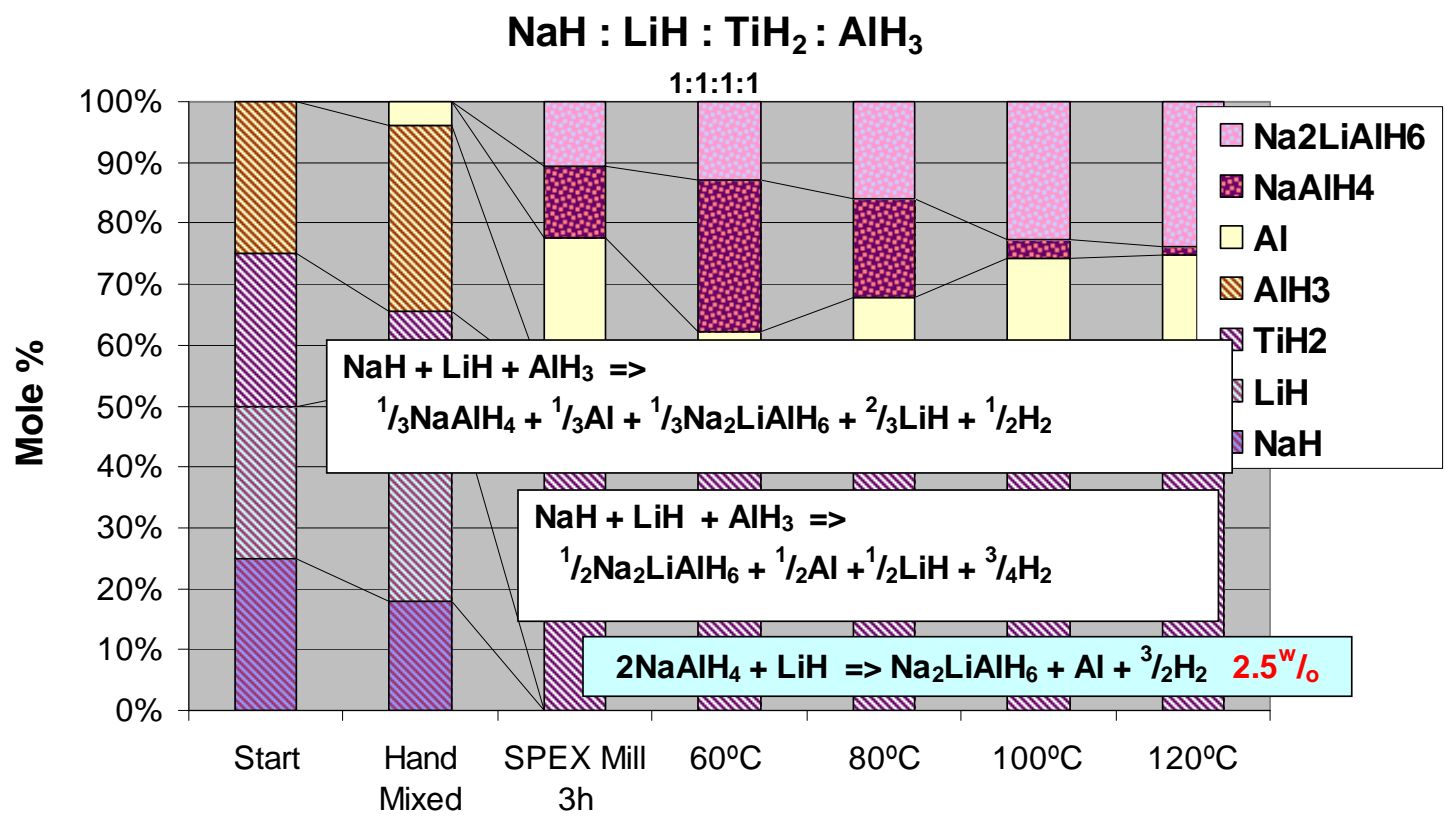

Processing + Temperature for Charging 20 Hours at 200 Bar

Figure 140: NaH:LiH:TiH $2: \mathrm{AlH}_{3}=1: 1: 1: 1$. 


\section{Appendix}

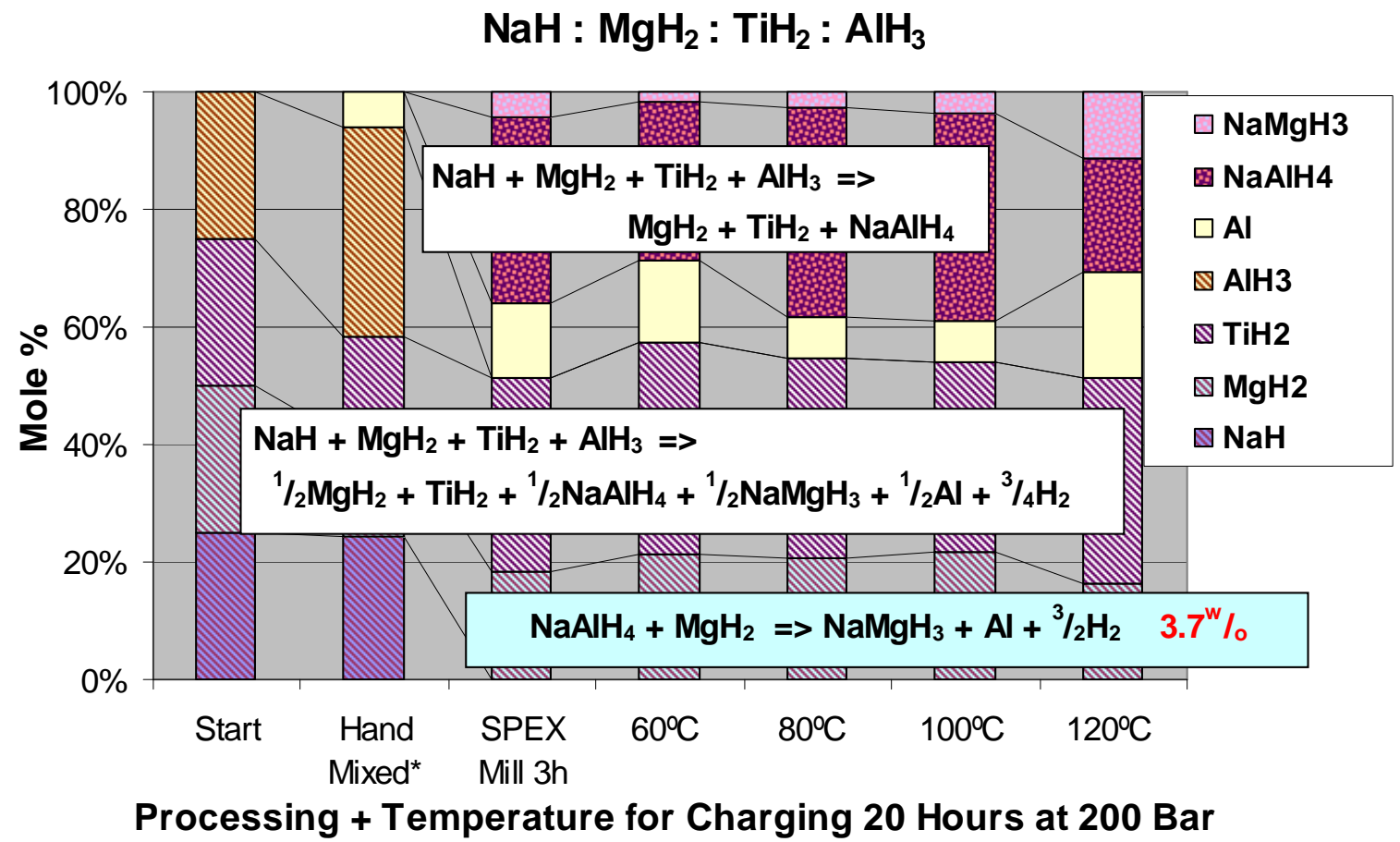

Figure 141: $\mathrm{NaH}: \mathrm{MgH}_{2}: \mathrm{TiH}_{2}: \mathrm{AlH}_{3}=1: 1: 1: 1$.

XRD Analysis of Constituent Phases

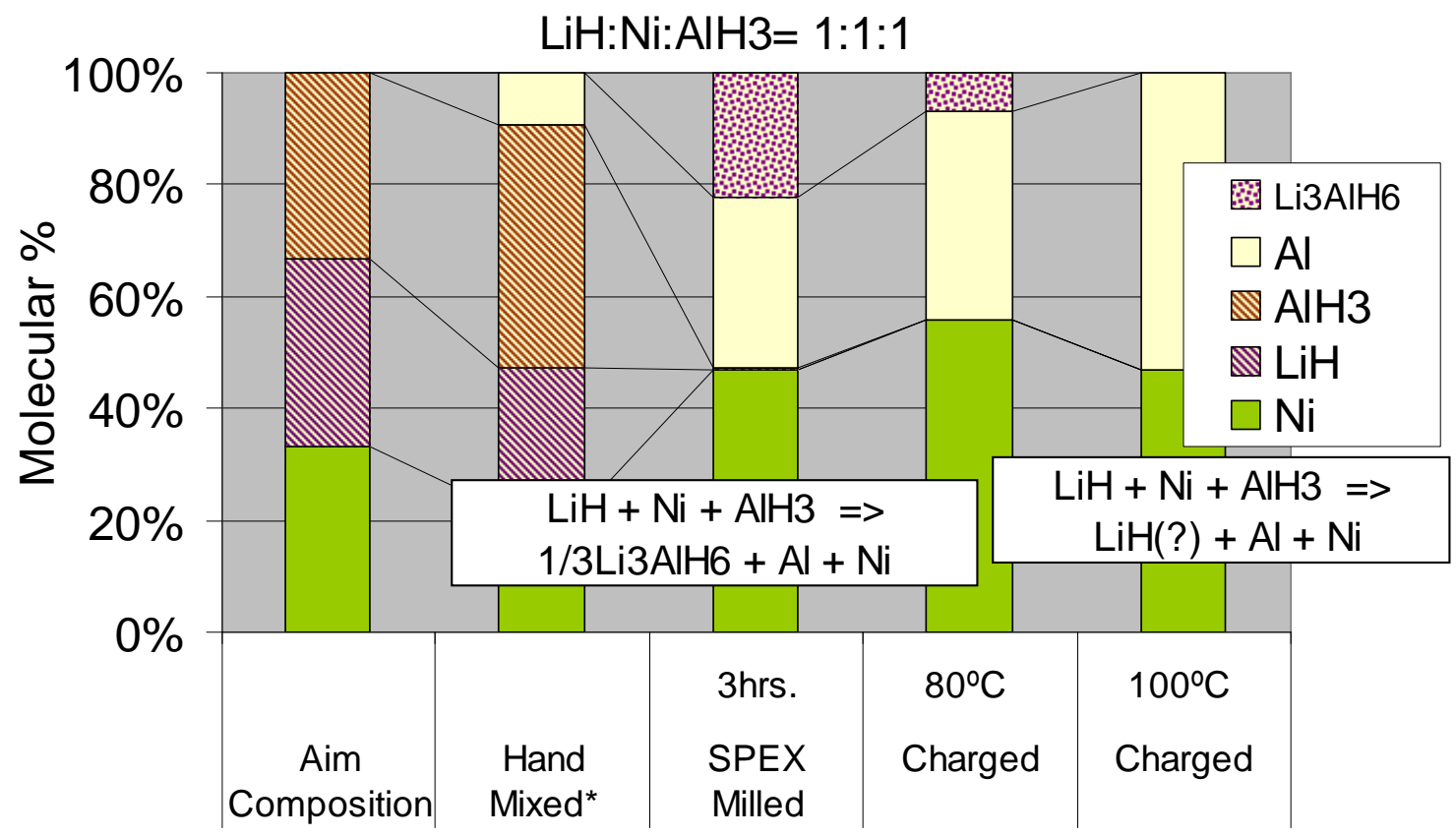

Figure 142: LiH:Ni:AlH $3=1: 1: 1$. 


\section{Appendix}

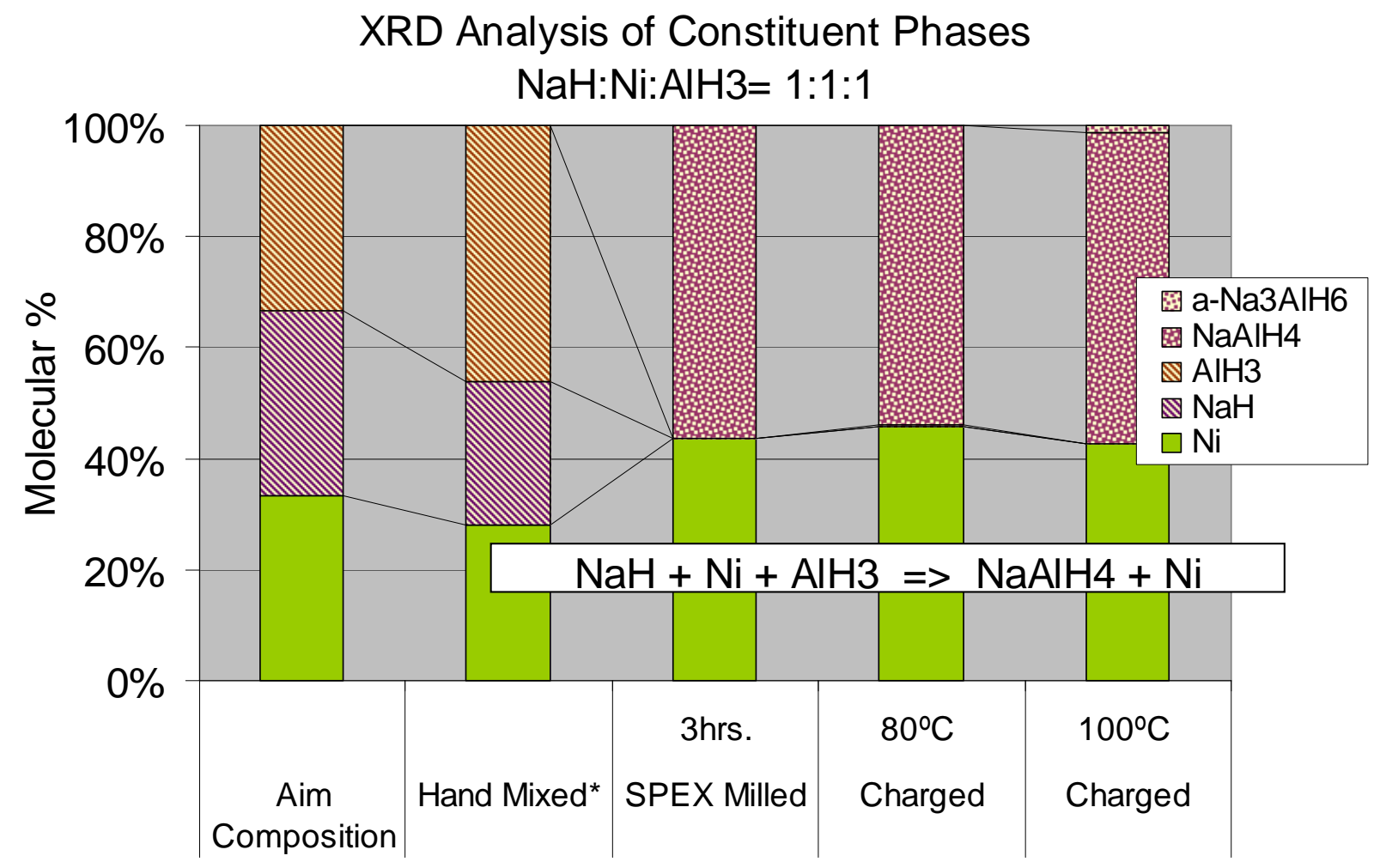

Figure 143: NaH:Ni:AlH $=1: 1: 1$.

XRD Analysis of Constituent Phases

$\mathrm{MgH} 2: \mathrm{Ni}: \mathrm{AlH} 3=1: 1: 1$

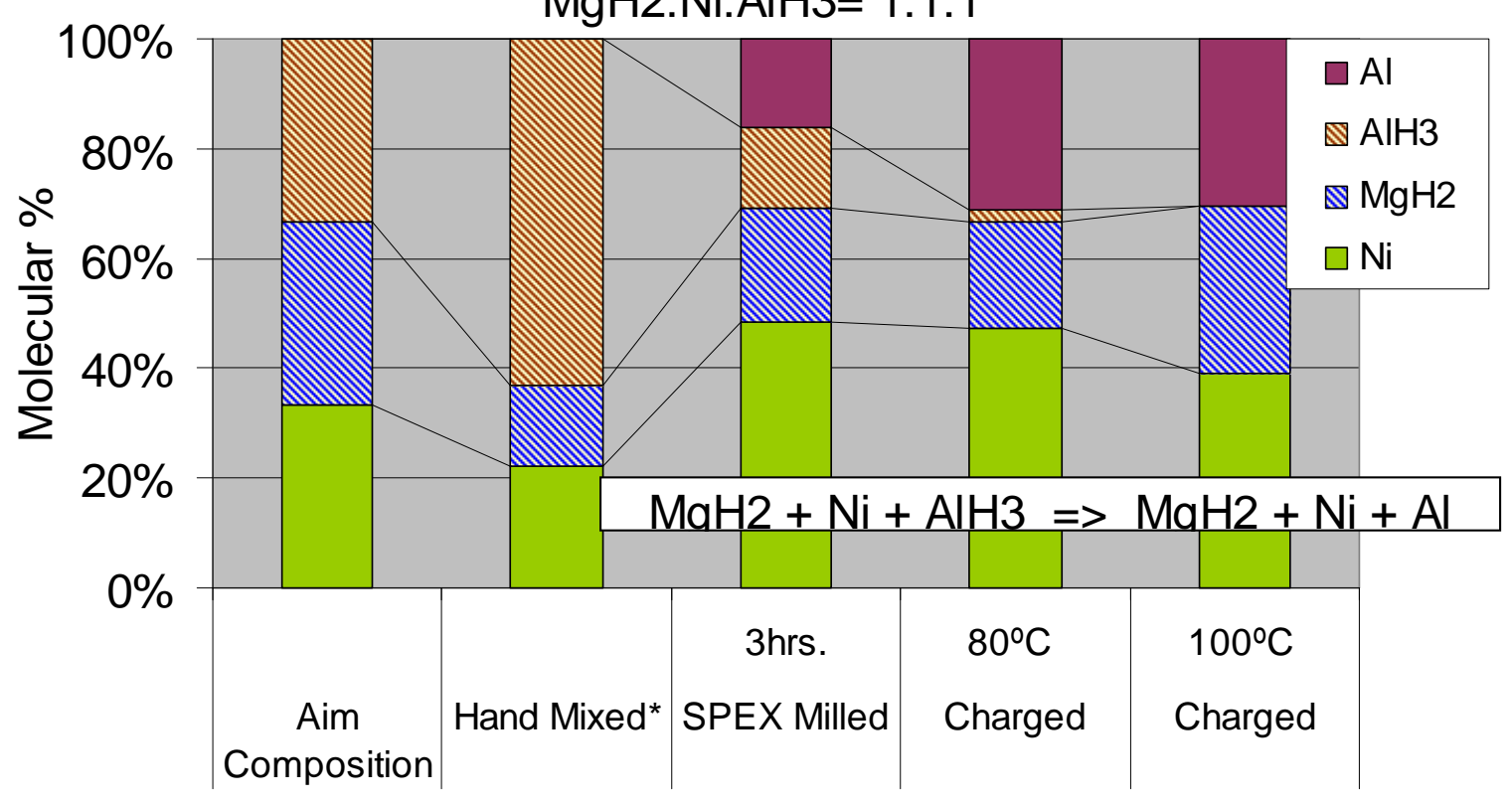

Figure 144: $\mathrm{MgH}_{2}: \mathrm{Ni} \mathrm{AlH}_{3}=$ 1:1:1. 


\section{Appendix}

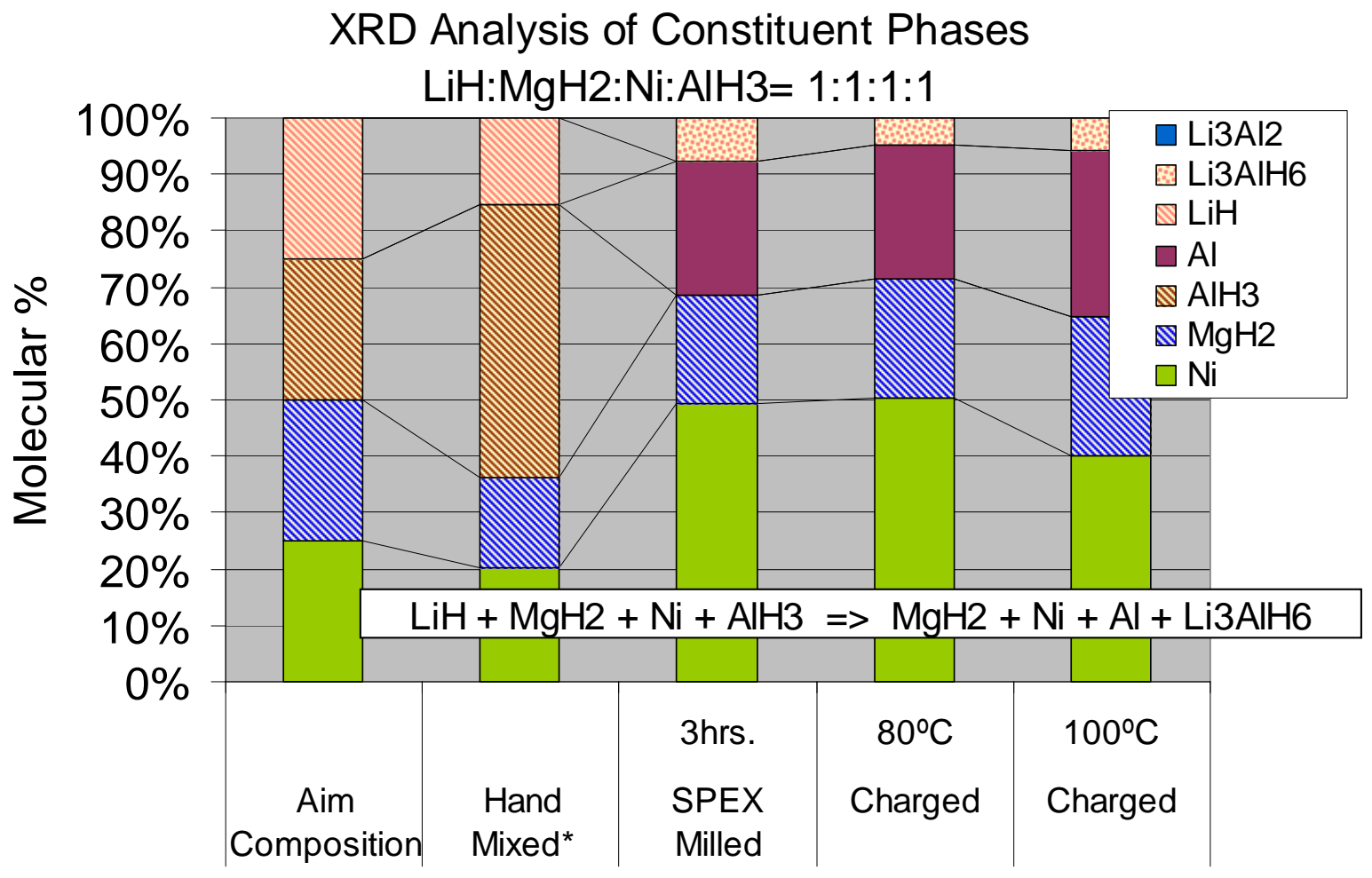

Figure 145: $\mathrm{LiHMgH}_{2}: \mathrm{Ni} \mathrm{AlH}_{3}=1: 1: 1: 1$.

XRD Analysis of Constituent Phases

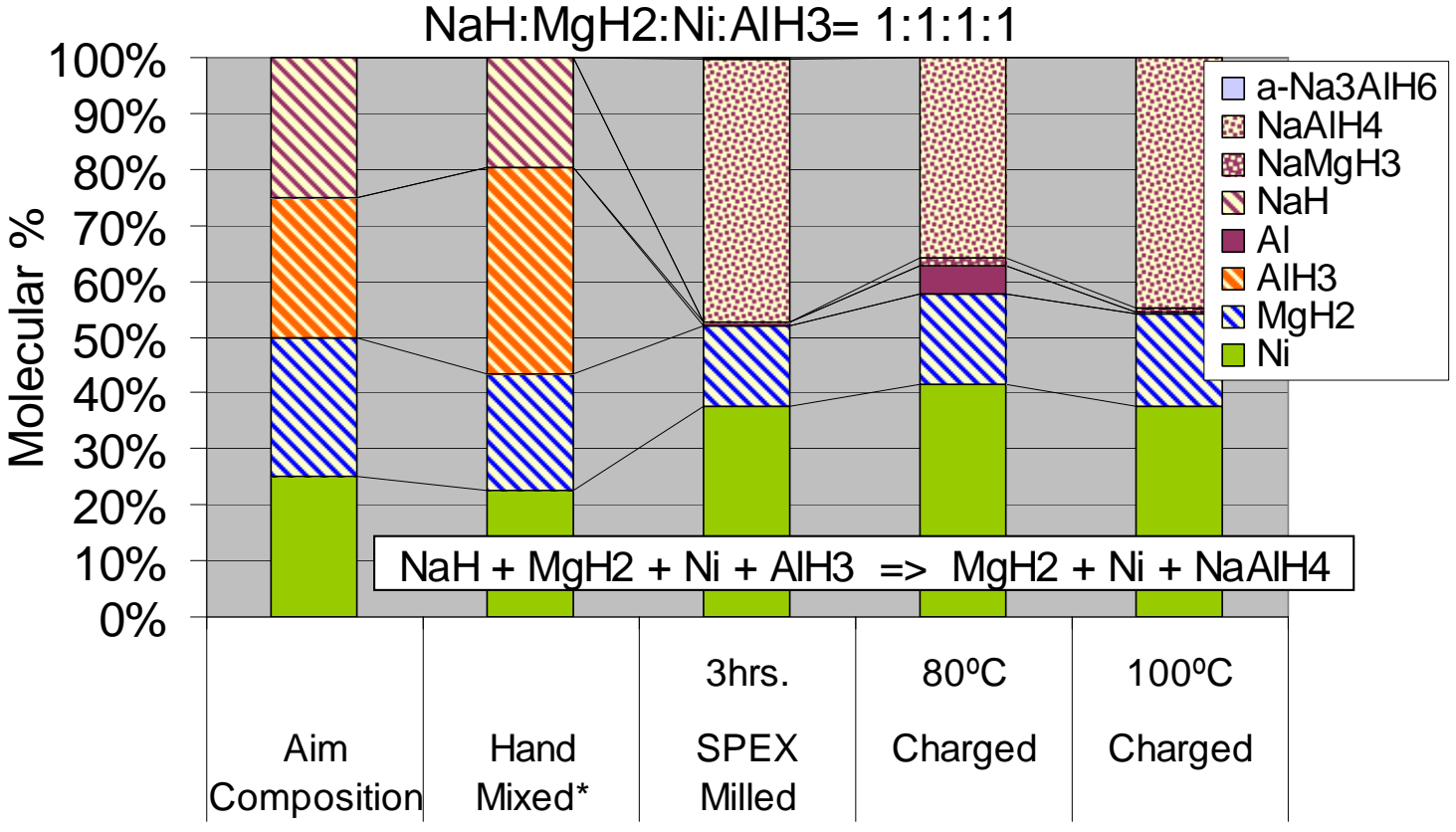

Figure 146: $\mathrm{NaH}: \mathrm{MgH}_{2}: \mathrm{Ni}: \mathrm{AlH}_{3}=1: 1: 1: 1$. 


\section{Appendix}

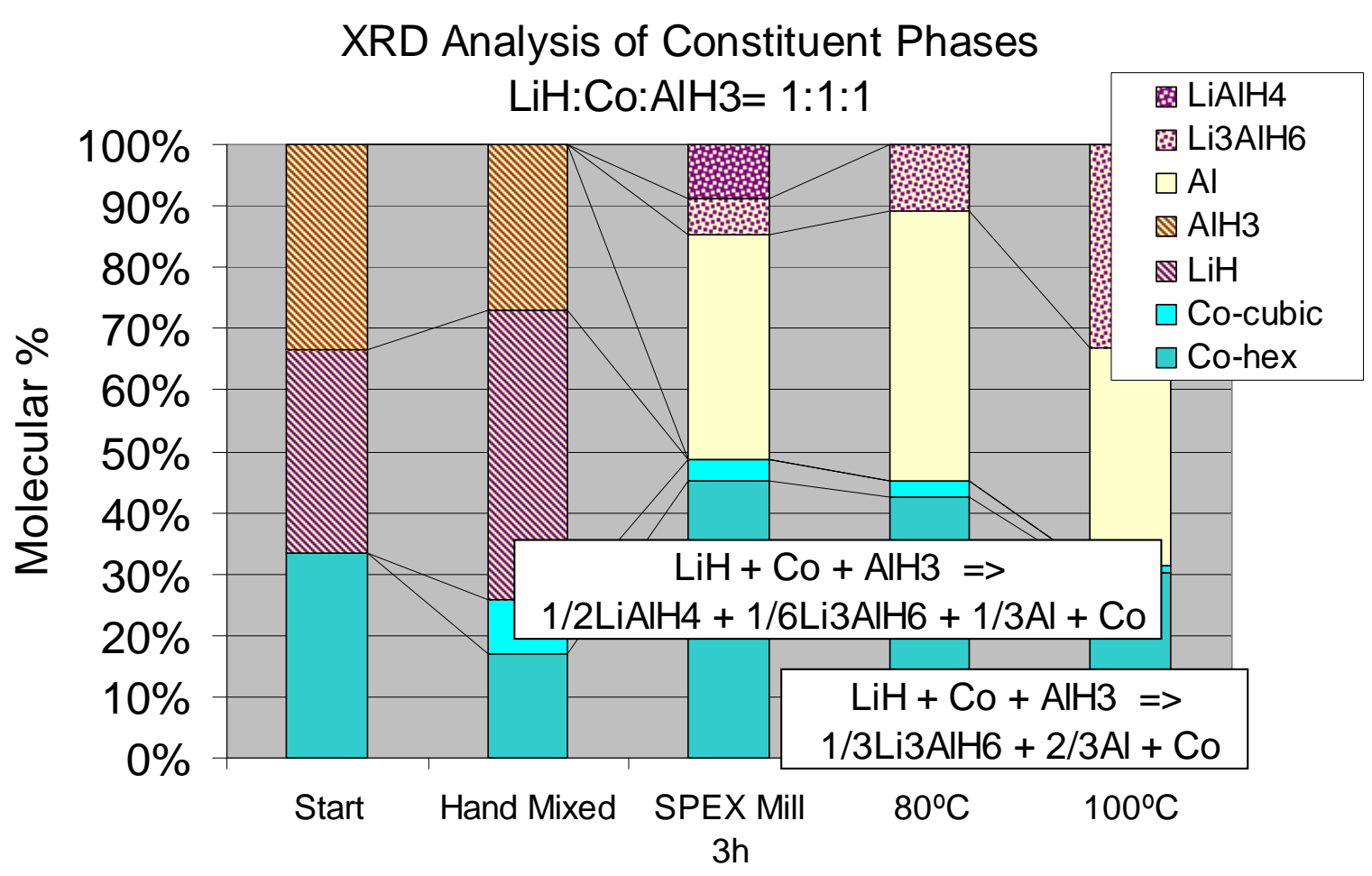

Figure 147: LiH:Co: $\mathrm{AlH}_{3}=$ 1:1:1.

XRD Analysis of Constituent Phases

$\mathrm{Na}: \mathrm{Co}: \mathrm{AlH} 3=1: 1: 1$

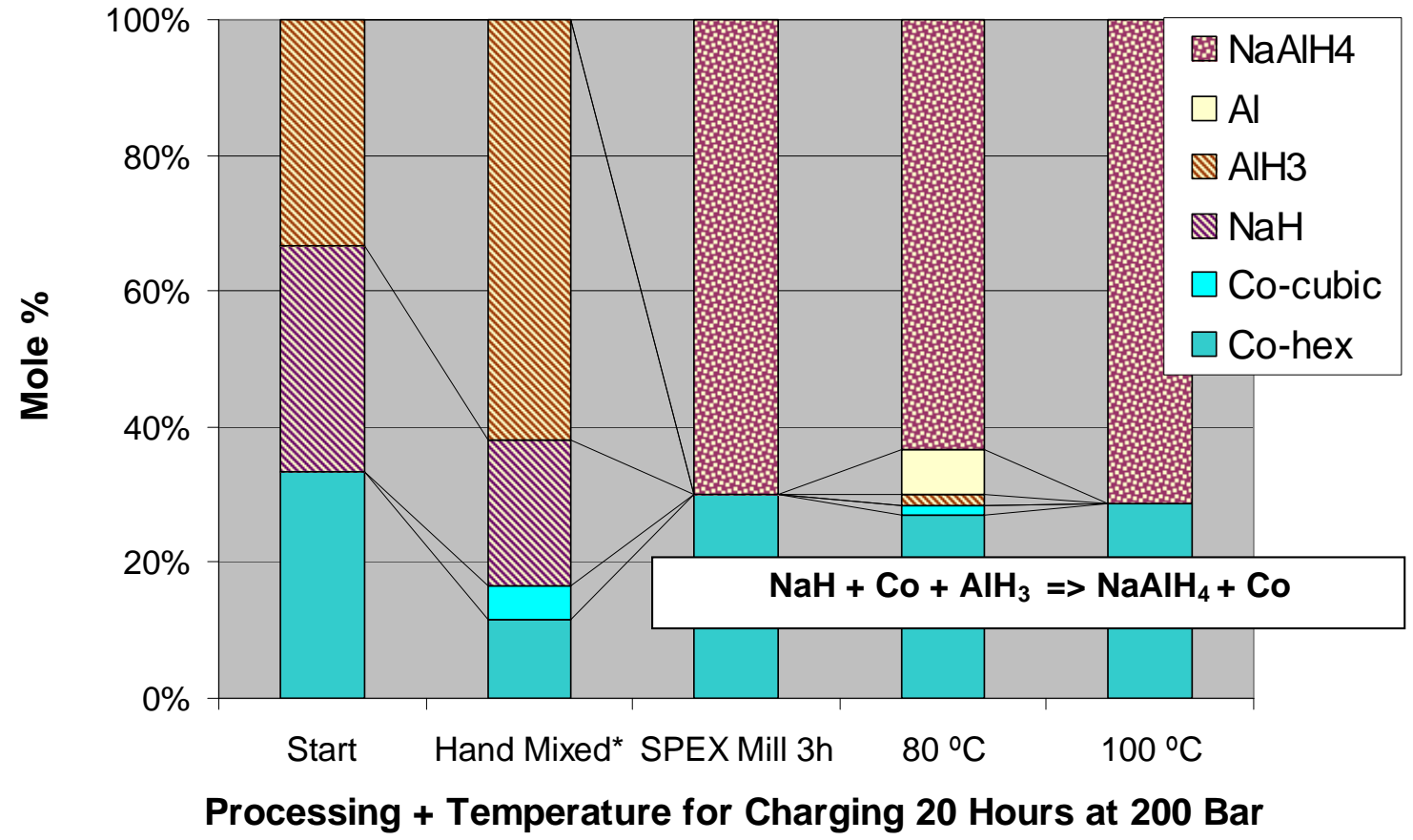

Figure 148: Na:Co: $\mathrm{AlH}_{3}=1: 1: 1$. 


\section{Appendix}

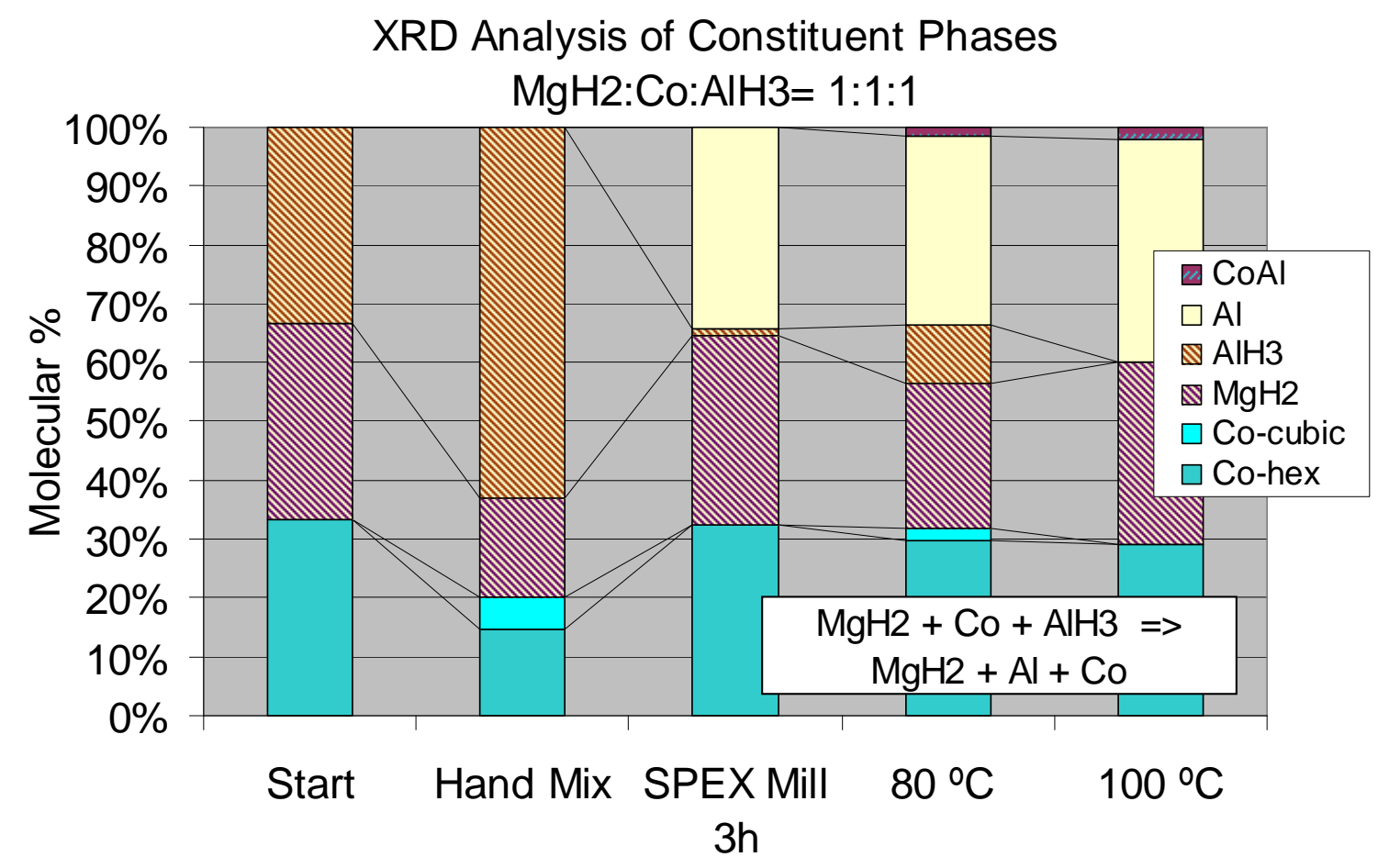

Figure 149: $\mathrm{MgH}_{2}: \mathrm{Co}: \mathrm{AlH}_{3}=1: 1: 1$.

XRD Analysis of Constituent Phases

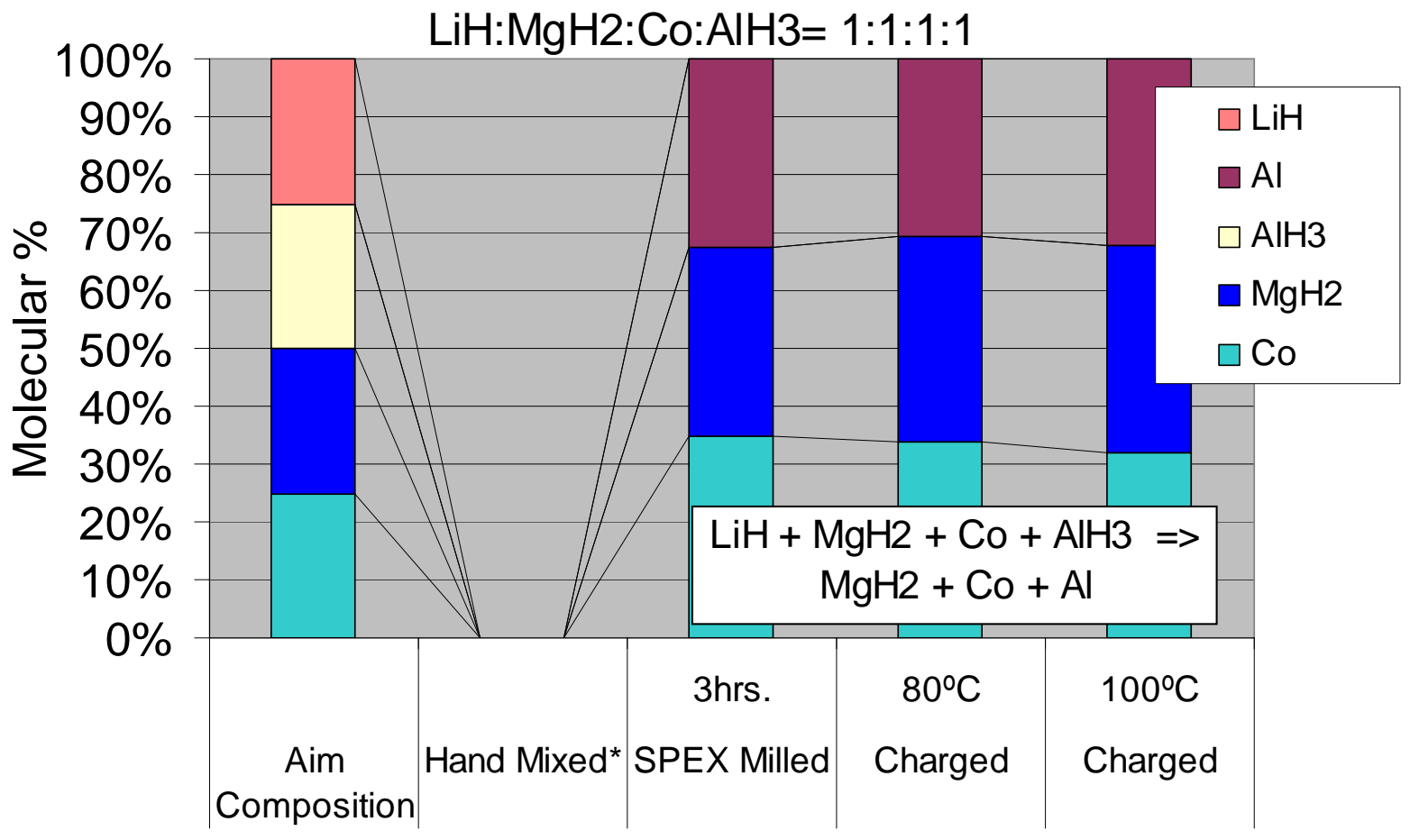

Figure 150: LiH:MgH $: \mathrm{Co}_{2} \mathrm{AlH}_{3}=$ 1:1:1:1. 


\section{Appendix}

XRD Analysis of Constituent Phases

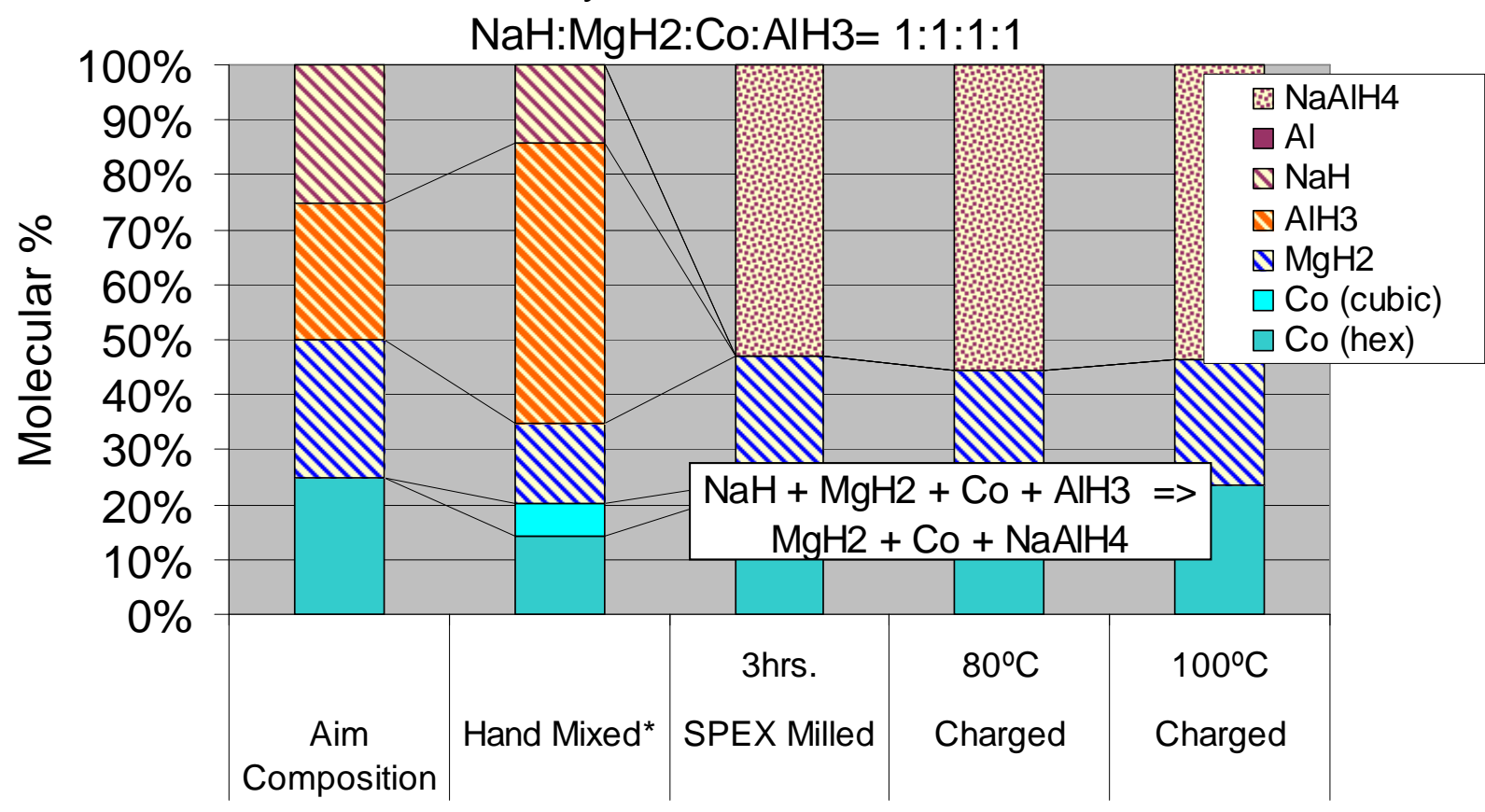

Figure 151: $\mathrm{NaH}: \mathrm{MgH}_{2}: \mathrm{Co}^{\mathrm{AlH}} 3 \mathrm{3}=1: 1: 1$.

XRD Analysis of Constituent Phases

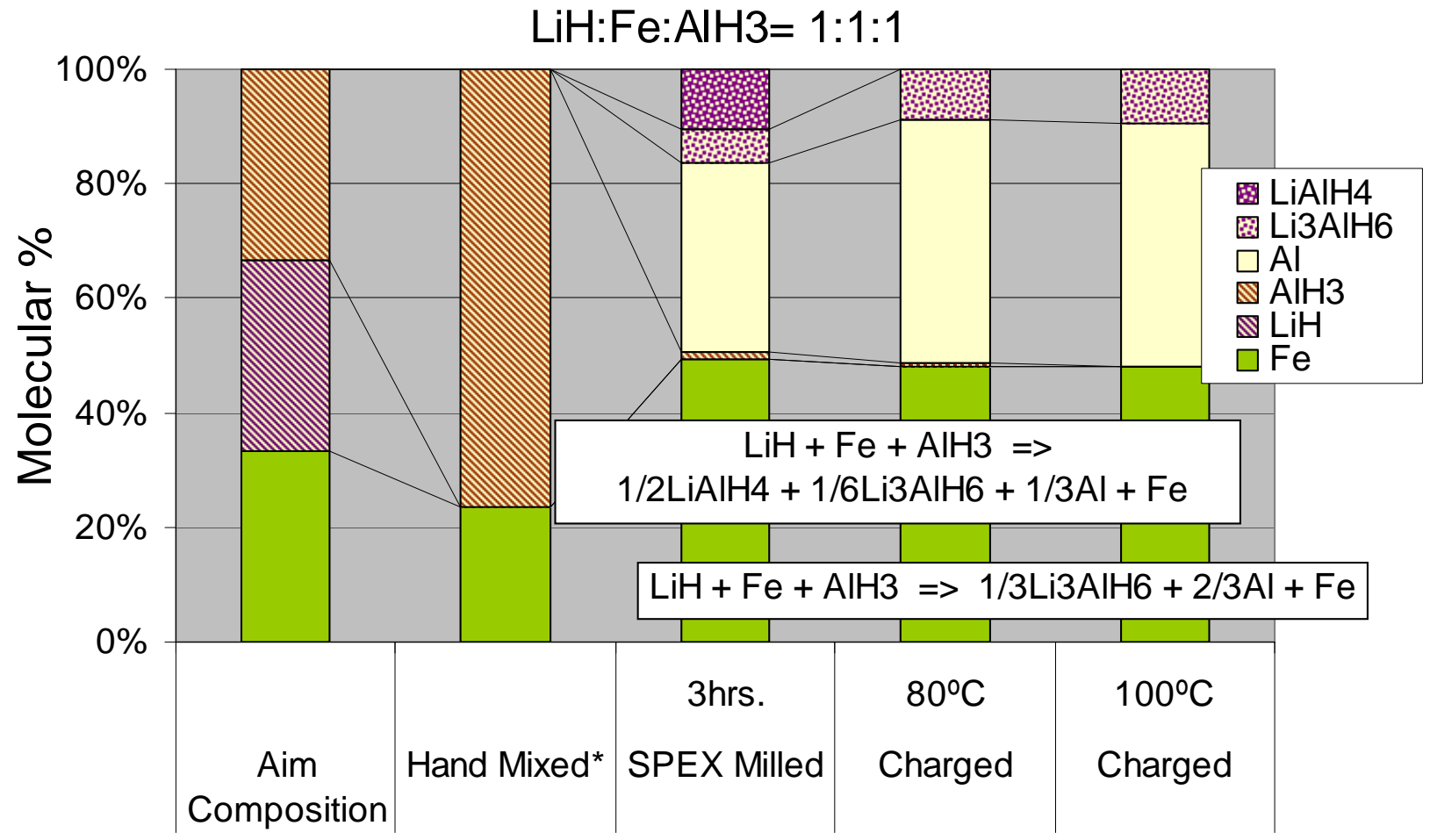

Figure 152: $\mathrm{LiH}: \mathrm{Fe}: \mathrm{AlH}_{3}=1: 1: 1$. 


\section{Appendix}

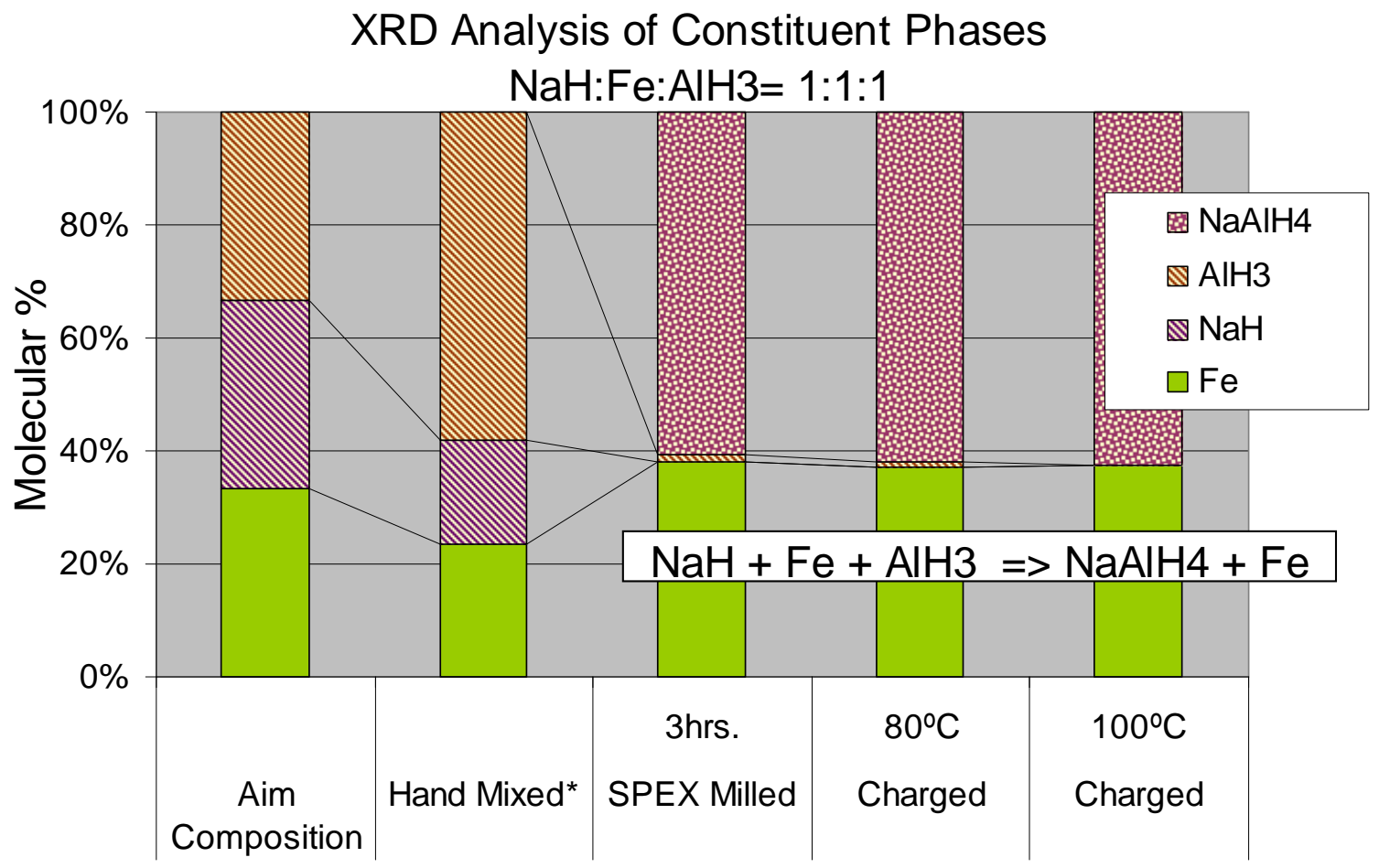

Figure 153: NaH:Fe:AlH $=1$ :1:1.

XRD Analysis of Constituent Phases

$\mathrm{MgH} 2: \mathrm{Fe}: \mathrm{AlH} 3=1: 1: 1$

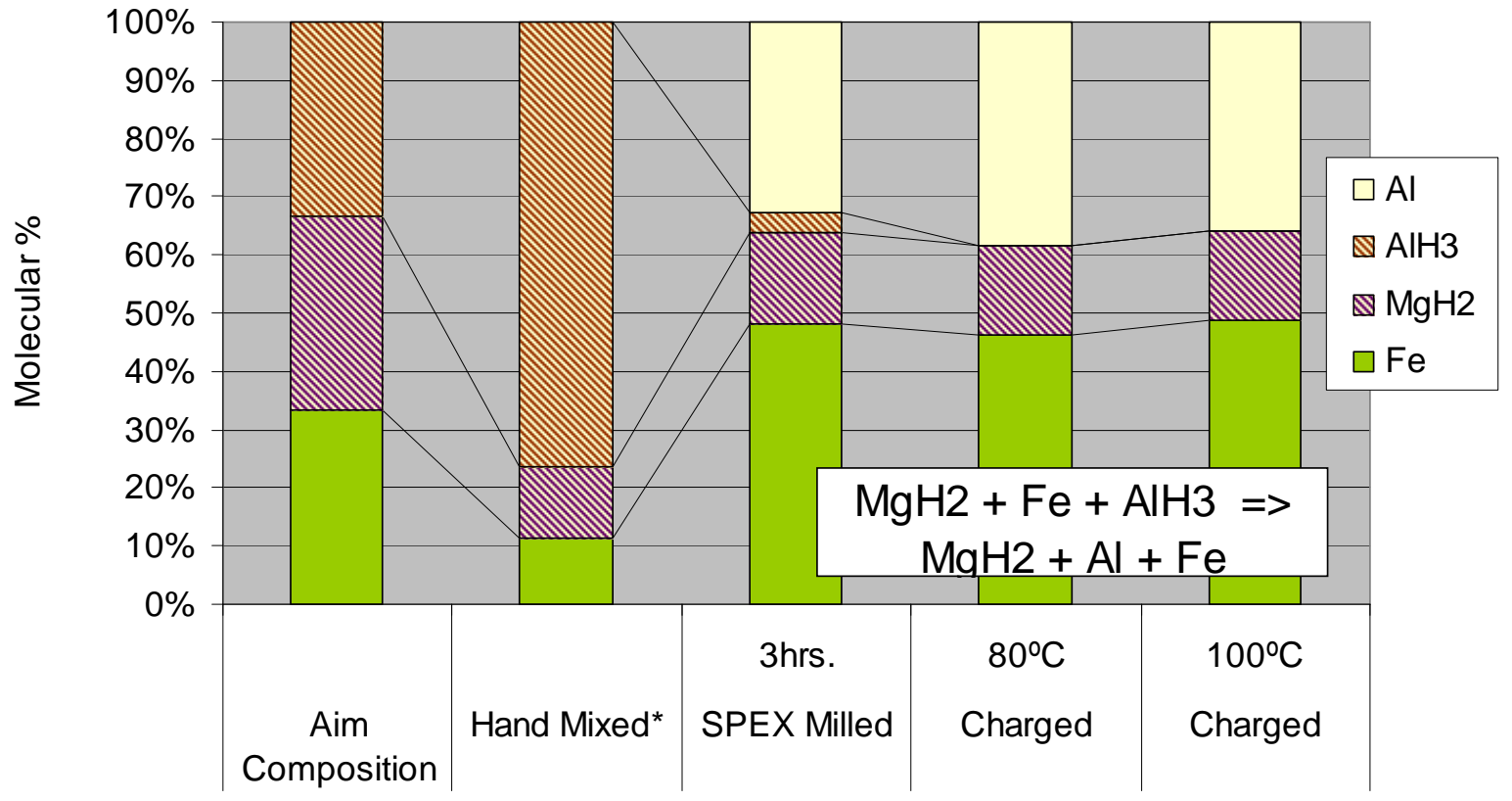

Figure 154: $\mathrm{MgH}_{2}: \mathrm{Fe}: \mathrm{AlH}_{3}=$ 1:1:1. 


\section{Appendix}

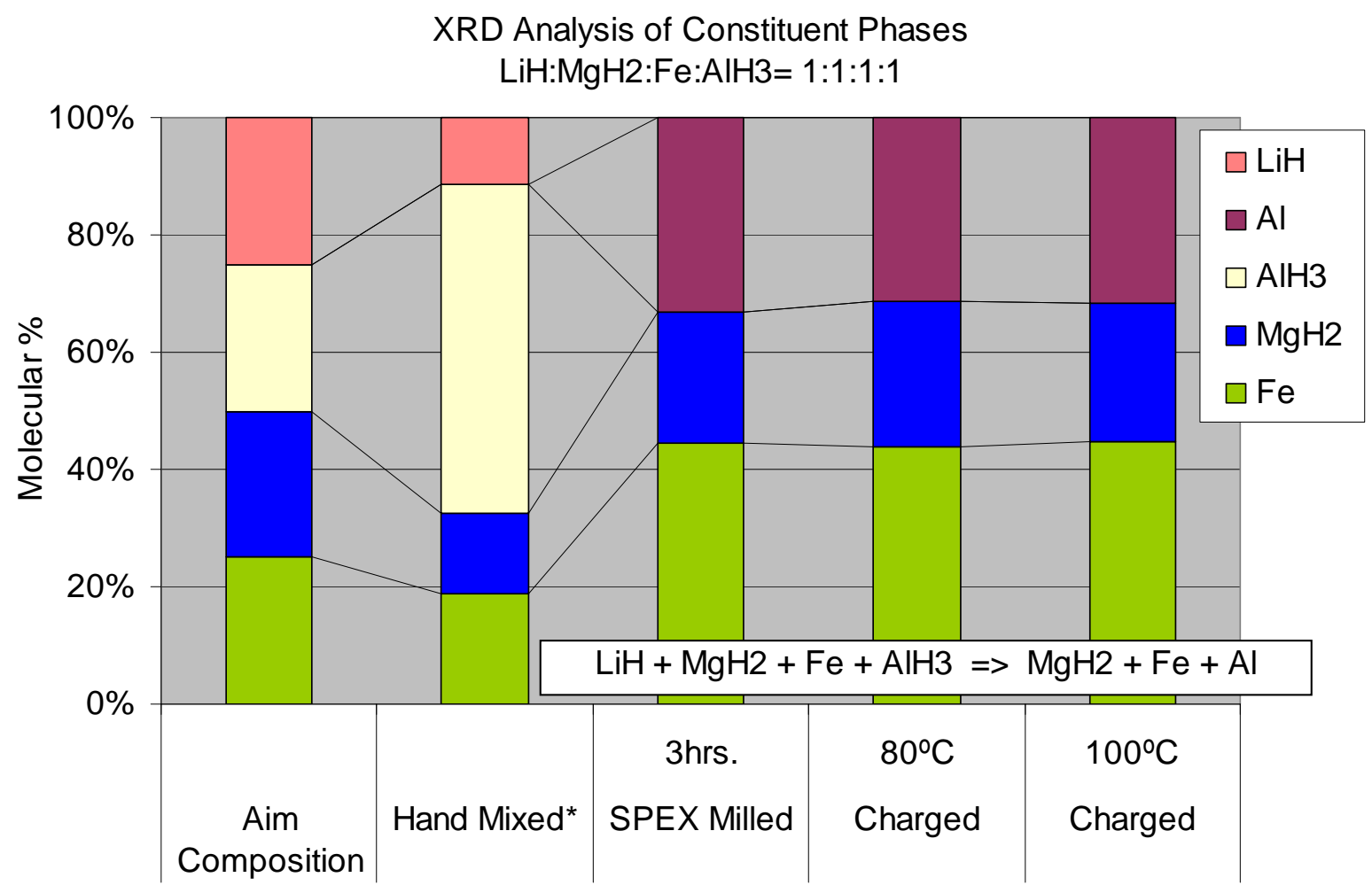

Figure 155: $\mathrm{LiH}_{\mathrm{MgH}}: \mathrm{Fe}: \mathrm{AlH}_{3}=1: 1: 1: 1$.

XRD Analysis of Constituent Phases

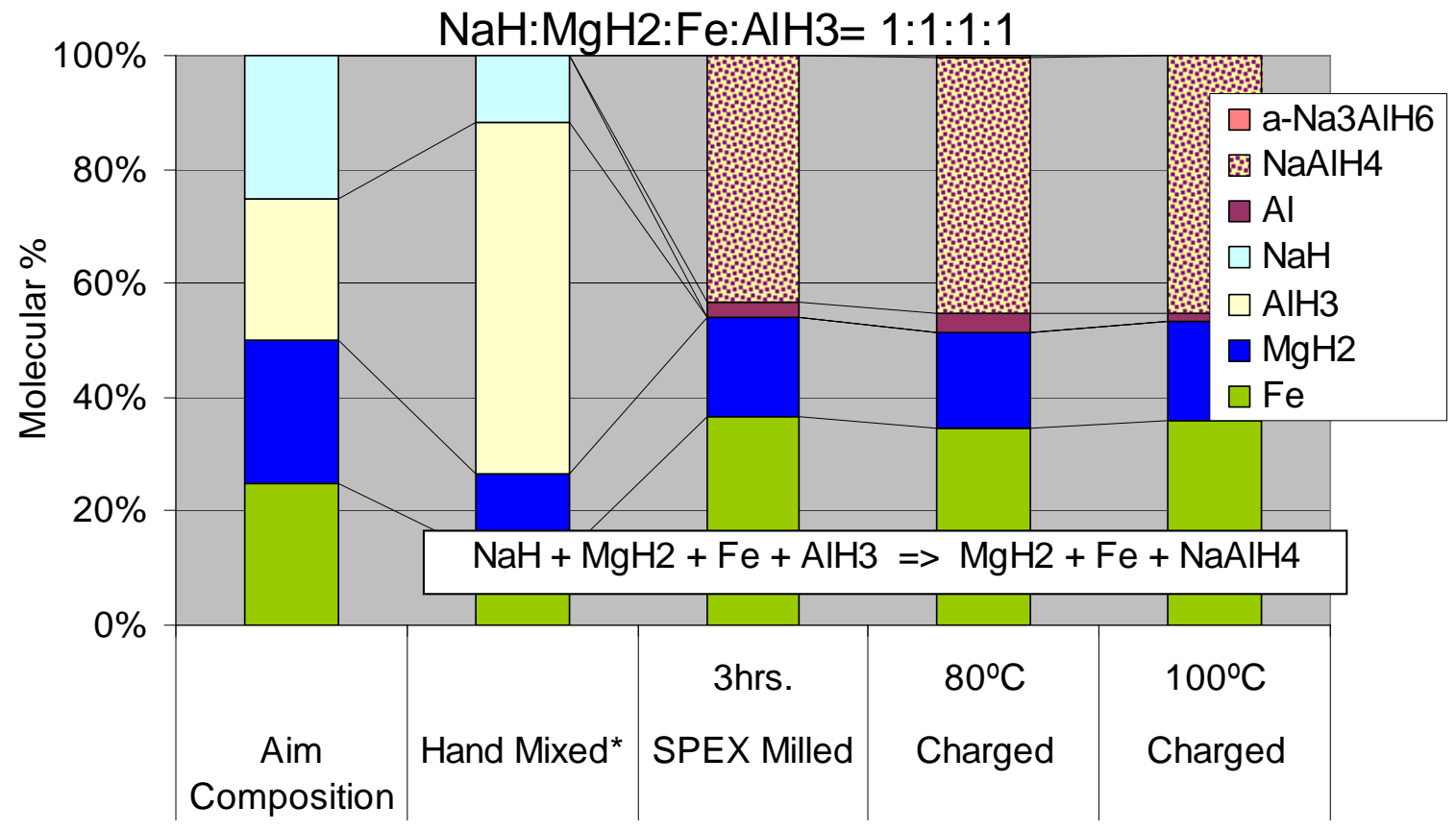

Figure 156: $\mathrm{NaH}: \mathrm{MgH}_{2}: \mathrm{Fe}: \mathrm{AlH}_{3}=1: 1: 1: 1$. 


\section{Appendix}

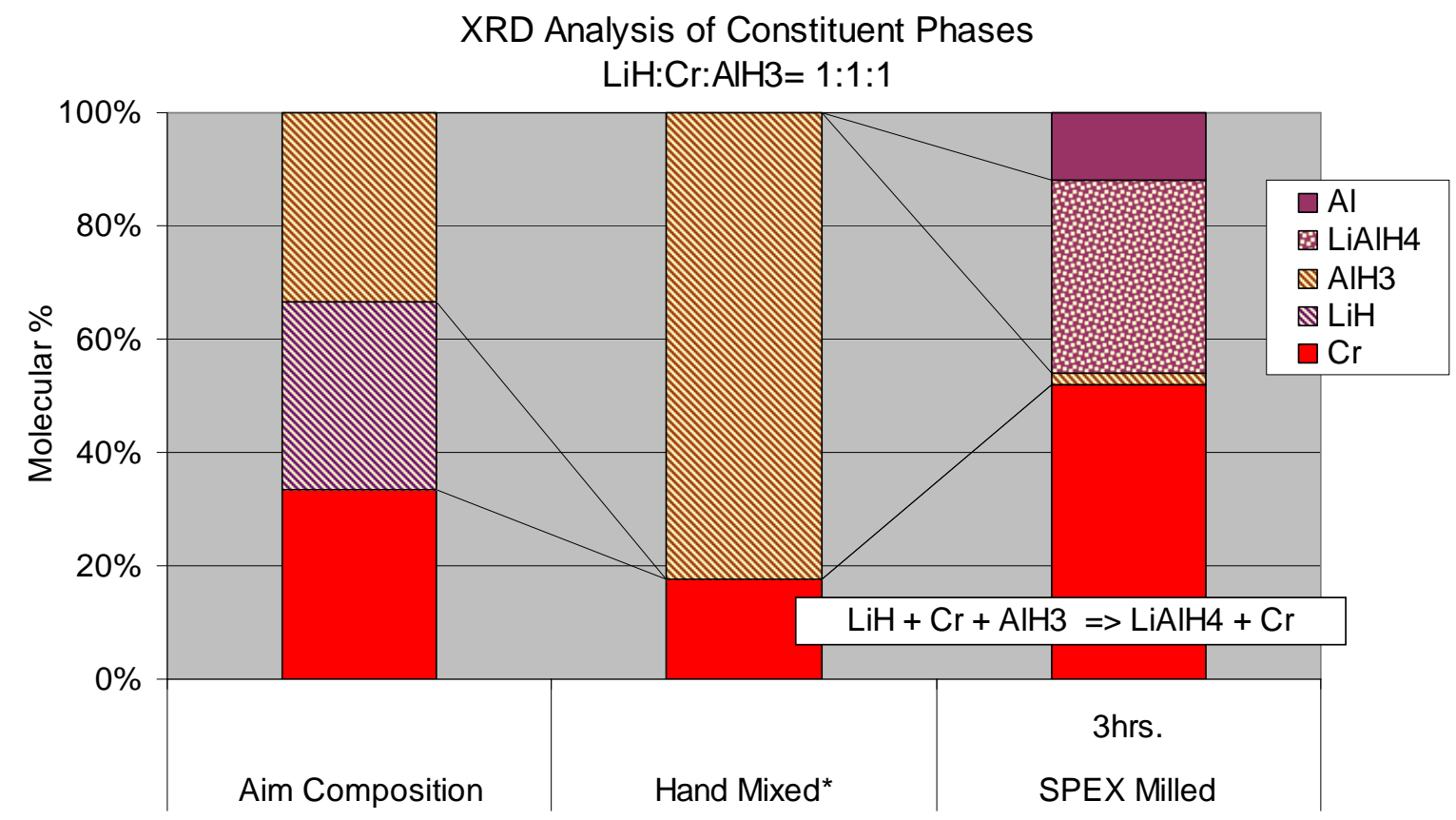

Figure 157: LiH:Cr: $\mathrm{AlH}_{3}=1: 1: 1: 1$.

\section{XRD Analysis of Constituent Phases}

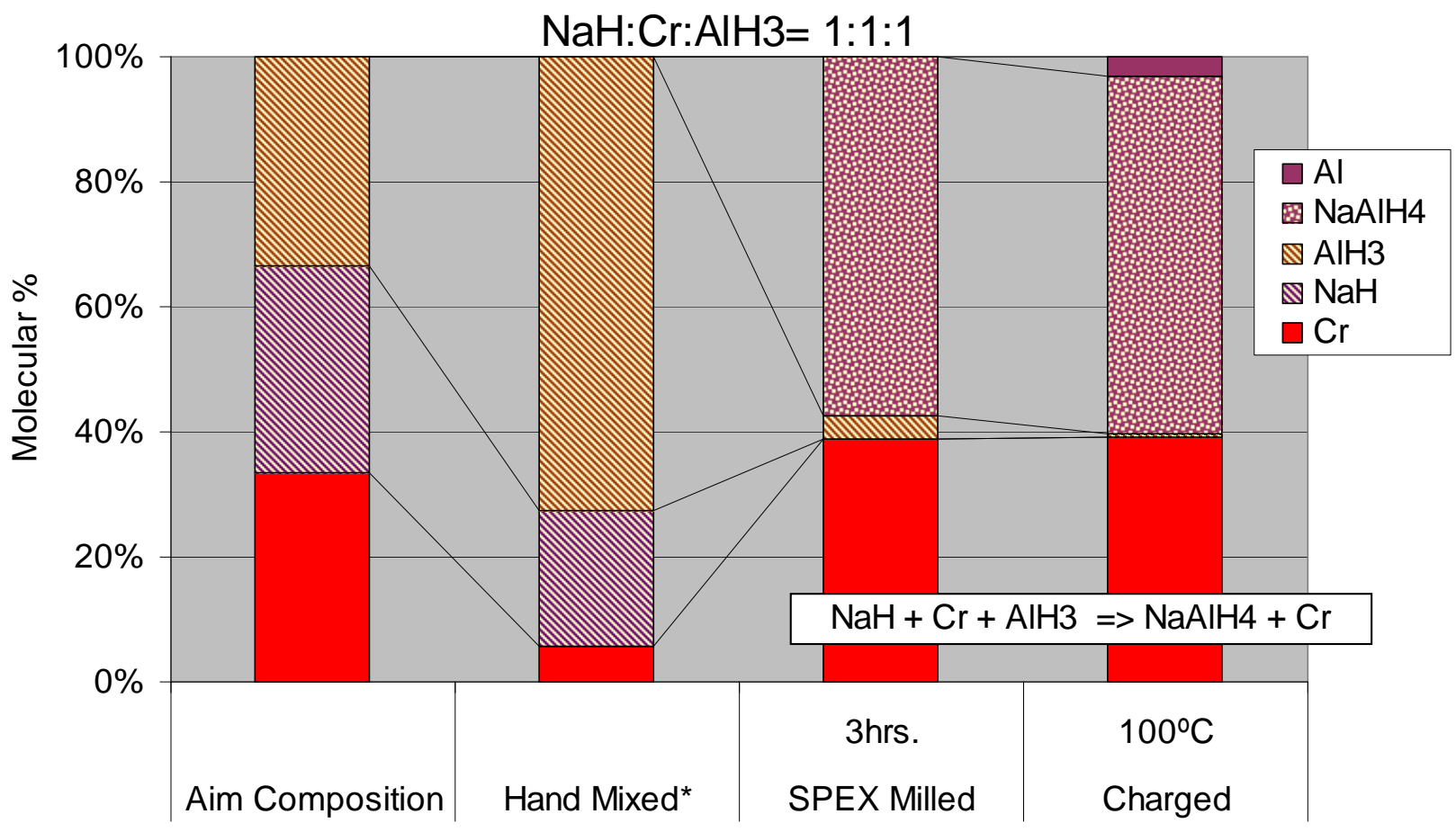

Figure 158: NaH:Cr: $\mathrm{AlH}_{3}=$ 1:1:1. 


\section{Appendix}

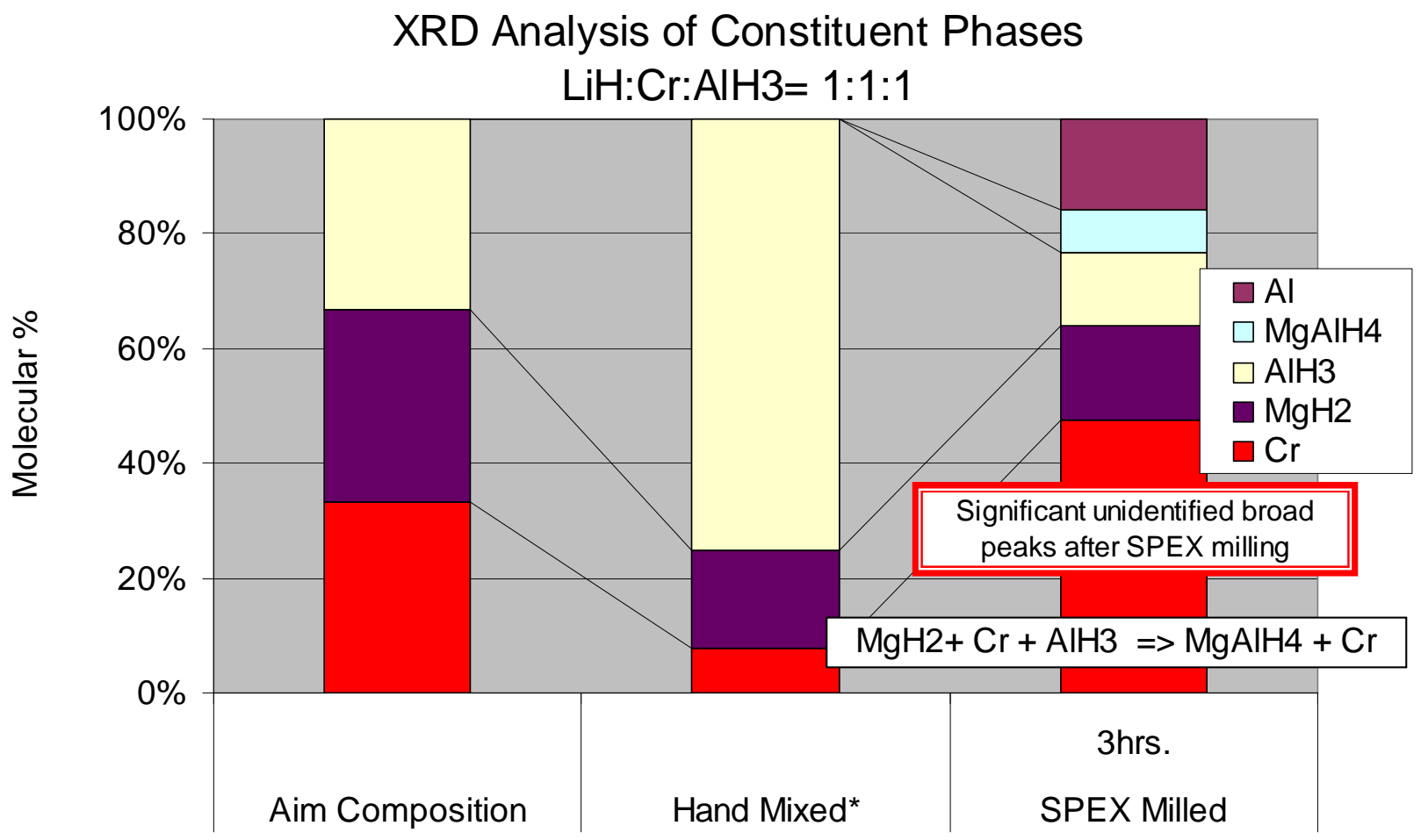

Figure 159: $\mathrm{MgH}_{2}: \mathrm{Cr}: \mathrm{AlH}_{3}=1: 1: 1$. 